\title{
abbreviatio - Historische Perspektiven auf ein rhetorisch-poetisches Prinzip
}

Edited by: Frick, Julia ; Grütter, Oliver

\begin{abstract}
Dieser Band versteht das literarische Verfahren der abbreviatio als einen bewussten Vorgang der Reduktion und als eine sinnstiftende Tätigkeit des Verdichtens umfangreicherer Bezugstexte. Er führt interdisziplinäre sowie komparatistische Perspektiven auf das rhetorisch-poetische Prinzip zusammen und arbeitet so über einzelne Textsorten hinausgehende Formen und Funktionen heraus. Anhand der Analyse antiker, mittelalterlicher und frühneuzeitlicher Texte profilieren die Beiträge systematische und historische Aspekte der literarischen Kürzung im Spannungsfeld von Latinität und Volkssprache.
\end{abstract}

Posted at the Zurich Open Repository and Archive, University of Zurich

ZORA URL: https://doi.org/10.5167/uzh-204331

Edited Scientific Work

Published Version

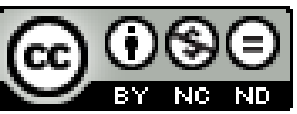

The following work is licensed under a Creative Commons: Attribution-NonCommercial-NoDerivatives 4.0 International (CC BY-NC-ND 4.0) License.

Originally published at:

abbreviatio - Historische Perspektiven auf ein rhetorisch-poetisches Prinzip. Edited by: Frick, Julia; Grütter, Oliver (2021). Basel: Schwabe Verlag. 
Julia Frick Oliver Grütter (Hg.)

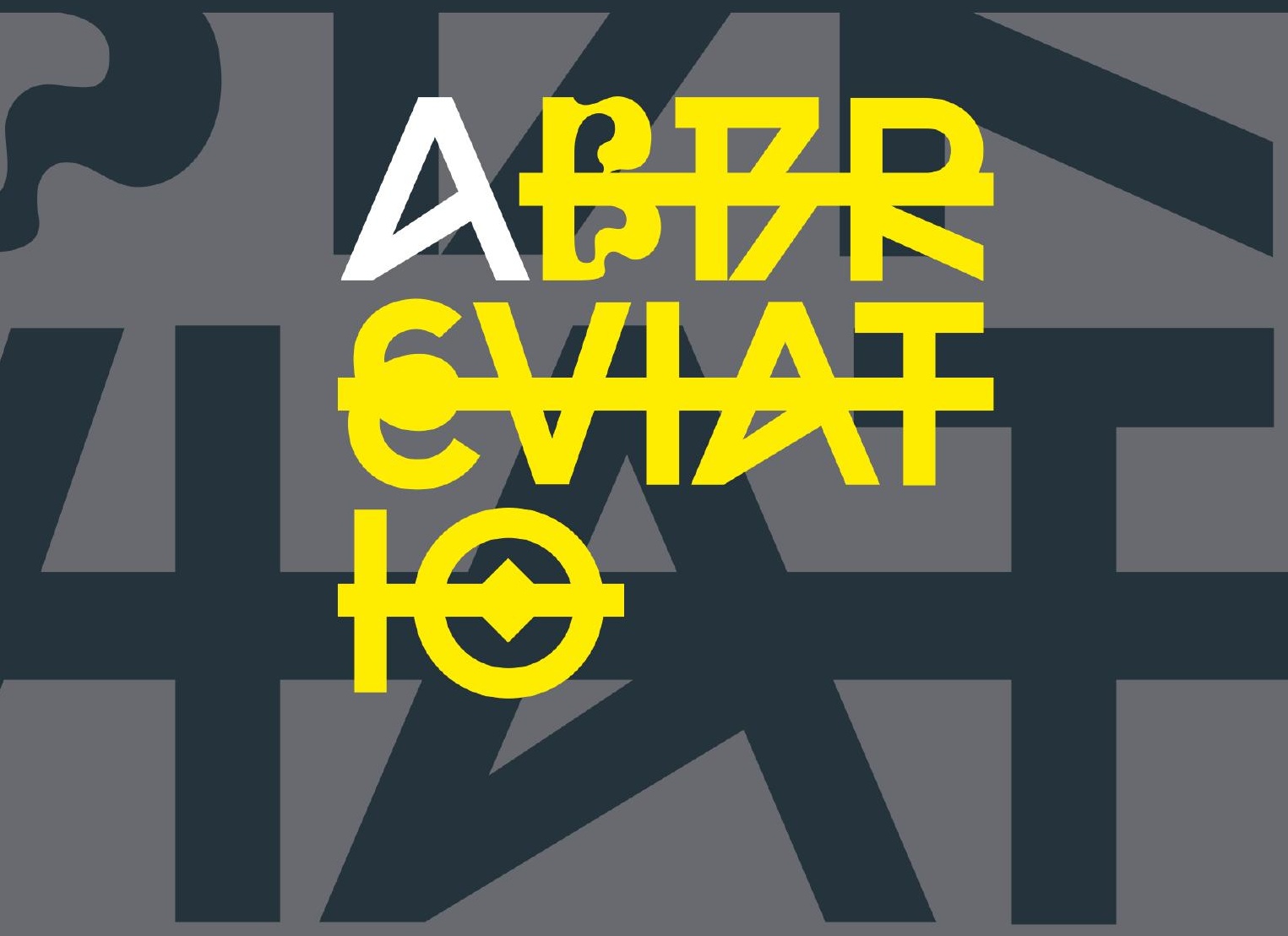

Historische

풀

Perspektiven auf ein rhetorischpoetisches Prinzip 


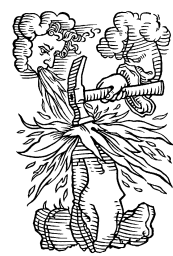



Julia Frick, Oliver Grütter (Hg.)

\section{abbreviatio}

Historische Perspektiven auf ein rhetorisch-poetisches Prinzip 


\section{Die Druckvorstufe dieser Publikation wurde vom Schweizerischen National- fonds zur Förderung der wissenschaftlichen Forschung unterstützt.}

Erschienen 2021 im Schwabe Verlag Basel

Bibliografische Information der Deutschen Nationalbibliothek

Die Deutsche Nationalbibliothek verzeichnet diese Publikation in der Deutschen Nationalbibliografie; detaillierte bibliografische Daten sind im Internet über http://dnb.dnb.de abrufbar.

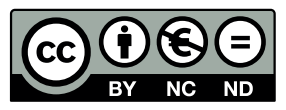

Dieses Werk ist lizenziert unter einer Creative Commons Attribution-NonCommercial-NoDerivatives 4.0 International (CC BY-NC-ND 4.0)

(C) 2021 Schwabe Verlag, Schwabe Verlagsgruppe AG, Basel, Schweiz

Dieses Werk ist urheberrechtlich geschützt. Das Werk einschliesslich seiner Teile darf ohne schriftliche Genehmigung des Verlages in keiner Form reproduziert oder elektronisch verarbeitet, vervielfältigt, zugänglich gemacht oder verbreitet werden.

Abbildung Umschlag: Mihaly Varga (https://ateliervarga.ch/)

Korrektorat: Monika Paff, Langenfeld

Umschlaggestaltung: icona basel gmbh, Basel

Satz: $3 w+p$, Rimpar

Printed in Germany

ISBN Printausgabe 978-3-7965-4111-7

ISBN eBook (PDF) 978-3-7965-4217-6

DOI 10.24894/978-3-7965-4217-6

Das eBook ist seitenidentisch mit der gedruckten Ausgabe und erlaubt Volltextsuche. Zudem sind Inhaltsverzeichnis und Überschriften verlinkt.

rights@schwabe.ch

www.schwabe.ch 


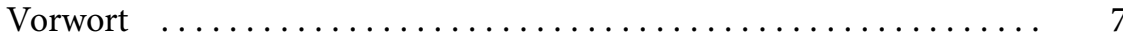

Julia Frick (Zürich): Literarische Kürzung. Konzepte der abbreviatio in historischer Perspektive ..........................

\section{Formsemantiken : Quantitative und qualitative Relationierung}

Christiane Reitz (Berlin / Rostock): Homer in Kürze. Zu

Handhabbarkeit und Ästhetik antiker Epitomai ..............

Richard Trachsler (Zürich): Wie lang ist kürzer? Überlegungen zum brevitas-Topos der französischen mises en prose ................

Susanne Köbele (Zürich): Immer schneller kürzer oder:

Wenn die Form den Text verzehrt. Das Schlussgedicht in Hartmanns von Aue Klage . . . . . . . . . . . . . . . . . . . . . . . . . . . . . . . .

Raphael Schwitter (Bonn / Zürich): Das «versefüllende Asyndeton〉 in der spätlateinischen Dichtung. Zur Ambivalenz eines poetischen Stilmittels . . . . . . . . . . . . . . . . . . . . . . . . .

Jörg Wesche (Göttingen): Bühnenrede, kurz. Kürzetechniken im Dramenwerk von Andreas Gryphius

\section{Kürzung im Kontext kulturhistorischer Diskurse}

Ricarda Bauschke (Düsseldorf): Diskursive Evaluation der histoire. Herborts Liet von Troye im Spannungsfeld von brevitas, adaptatio und aemulatio

Almut Suerbaum (Oxford): Geistliche Lieder als theologische Ver-Dichtung mystischer Theologie ... 
Hans Jürgen Scheuer (Berlin): Das Heilige im Gebrauch. Zur kompilatorischen Form der Legende

Thomas Haye (Göttingen): Zeitsparende Epik. Die Inhaltsangaben (argumenta) zur Laurentias des Giovanni Mario Filelfo (1426-1480). . 261 Oliver Grütter (Zürich): Johann Spangenbergs Epitome der Victoria Christi ab inferis (Helius Eobanus Hessus) im reformatorischen und kontroverstheologischen Zusammenhang $\ldots \ldots \ldots \ldots \ldots \ldots \ldots$

\section{Fassungsdivergenz und Formen redaktioneller Kürzung}

Martin Baisch (Hamburg): Bedingungen und Formen der Fassungenbildung im höfischen Roman $\ldots \ldots \ldots \ldots \ldots \ldots \ldots$

Michael Stolz (Bern) und Richard F. Fasching (Bern / Zürich): Original und Kopie des Rappoltsteiner Parzifal. Kürzungsverfahren in der Abschrift Roma, Biblioteca Casanatense, Ms. 1409

Cordula Kropik (Basel): So vil unnútzer wort man list! Kürzung und Zusammenfassung in der Heidelberger und der Dresdener Virginal ....

Sandra Linden (Tübingen): abbreviatio als Beschleunigung. Einige Beobachtungen zu Redaktionen und Überlieferungsvarianz in der Versnovellistik 407

Pia Selmayr (Zürich): In der Kürze liegt die Würze.

Kürzungsphänomene in lateinischen und deutschen

Fleischpfanderzählungen des (Spät-)Mittelalters 433

Beiträgerinnen und Beiträger 463

Verzeichnis der Autoren und Werke 465 


\section{Vorwort}

Der vorliegende Band versammelt die Beiträge der internationalen Konferenz «abbreviatio. Formen - Funktionen - Konzepte», die vom 20. bis 22. Februar 2019 an der Universität Zürich stattfand.

Wir danken den Vortragenden für ihre intensive Auseinandersetzung mit dem Tagungsthema sowie den Moderatorinnen und Moderatoren für die produktive und anregende Diskussionsatmosphäre (Carmen Cardelle de Hartmann, Ulrich Eigler, Nikolaus Henkel, Paul Michel, Andrea Möckli, Coralie Rippl, Cornelia Ritter-Schmalz, Sarina Tschachtli, Christoph Uiting). Das Konzept des Bandes hat davon reich profitiert. Allen Beiträgerinnen und Beiträgern sind wir für die zügige schriftliche Ausarbeitung ihrer Vorträge und das damit verbundene Engagement zu Dank verpflichtet, für fachlichen Rat Claudia Schindler und Michael Waltenberger.

Wir danken den Zürcher Mitarbeiterinnen und Mitarbeitern für ihre Mithilfe bei der Vorbereitung und Durchführung der Konferenz: im Sekretariat Brigitte Königs und Kathrin Rabe, Raoul DuBois, Tim Gallusser, Julia Sjöberg und Anina Steinmann für ihre organisatorische Unterstützung, Sarah Möller und Tim Huber für das Verfassen des Tagungsberichts (ZfdPh 138 [2019], S. 448-456). Die graphische Gestaltung des abbreviatio-Logos übernahm Mihaly Varga (https://ateliervarga.ch/).

Großer Dank gebührt dem Schweizerischen Nationalfonds sowie dem Graduate Campus der Universität Zürich für die großzügige finanzielle Unterstützung, ohne die die Realisierung der Konferenz nicht möglich gewesen wäre. Den UZH Alumni, dem Kompetenzzentrum Zürcher Mediävistik sowie dem Mittelbaufonds des Deutschen Seminars danken wir für die Bereitstellung zusätzlicher Fördergelder. Dem Schweizerischen Nationalfonds gebührt darüber hinaus Dank für die Finanzierung der Publikation.

Dass der Band in dieser Form erscheinen konnte, ist dem Schwabe Verlag Basel zu danken, insbesondere Nina Brennecke, Annina Clavadet- 
scher, Harald S. Liehr und Sebastian Schmitt, die die Veröffentlichung so umsichtig wie professionell betreut haben.

Zürich, im Januar 2021

J. F. / O. G. 


\title{
Literarische Kürzung
}

\section{Konzepte der abbreviatio in historischer Perspektive}

von

Julia Frick (Zürich)

\section{Literarische Kürzung: Produktionsnorm und / oder Rezeptionsphänomen?}

\begin{abstract}
Mes révérends pères, mes lettres n'avaient pas accoutumé de se suivre de si près, ni d'être si étendues. Le peu de temps que j'ai eu a été cause de l'un et de l'autre. Je n'ai fait celle-ci plus longue que parce que je n'ai pas eu le loisir de la faire plus courte. La raison qui m’a oblige de me hâter vous est mieux connue qu'a moi.

«Meine Briefe, ehrwürdige Väter, pflegten sonst nicht so lang zu seyn und auch nicht so schnell aufeinanderzufolgen; an beiden ist die Kürze der Zeit Schuld, denn daß dieser Brief so lang ist, hat darin seinen Grund, daß ich nicht Muße hatte, ihn kürzer zu machen, und der Grund, mich so sehr zu beeilen, ist Euch eben so gut bekannt als mir. ${ }^{1}$
\end{abstract}

Dieses bekannte Dictum des Philosophen Blaise Pascal illustriert ein für das Phänomen der Kürzung charakteristisches Spannungsmoment, das sich in einem ambivalenten Verhältnis der prozessualen Kategorien Textlänge und Zeit konstituiert: So korreliert der schriftliche Umfang des brieflich niedergelegten Sachverhalts mit der Verfügbarkeit der temporalen Dimension eines 〈Mußeraumes〉 (le loisir), der die formale Ausgestaltung des zu Vermittelnden grundlegend bestimmt. Dabei erweist sich der 〈lange` Text - paradoxerweise - als zeitsparend in der Produktion (Stichwort: Eile, hâte) und damit auch im Hinblick auf die Lektüre, weil ihm aufgrund der mangelnden Möglichkeit zu stilistischer Vervollkommnung ein formales Raffinement abgehe. Die 〈Kürzung〉 erscheint hier insofern - das dokumentiert die apologetische Haltung - als das erstrebenswertere Ideal. Denn das «schnelle-

1 Blaise Pascal, Les Provinciales (1656/57), hier: 16. Brief (an die Jesuiten), 4. Dez. 1656, S. 313. Deutsche Übersetzung nach Hartmann (1830), S. $316 \mathrm{f}$. 
re> Schreiben garantiert - entgegen der vielleicht nächstliegenden Vermutung - keineswegs einen 〈guten〉 Text, ganz im Gegenteil: cito scribendo non fit ut bene scribatur, bene scribendo fit ut cito (Inst. or. X,3,10; «schnelles Schreiben geschieht nicht, um gut zu schreiben, [sondern] gutes, um schnell zu schreiben $>$ ). ${ }^{2}$ So bezeichnet schon der antike Rhetoriklehrer Quintilian die emendatio eines bereits entworfenen längeren Textes als die bei weitem wichtigste, da nützlichste Aufgabe (longe utilissima, Inst. or. X,4,1). In den Bereich einer Revision der sprachlichen Ausdrucksformen gehören u. a. die Modi des Hinzufügens und Tilgens (adicere, detrahere, ebd.), um eine möglichst präzise Diktion zu erreichen, die freilich nur um den Preis eines hohen (Zeit-)Aufwands und der Übung zu gewinnen ist (Inst. or. X,3,9).

Dieser Dialektik auf der Ebene der Textherstellung entspricht eine ambivalente Dynamik auf der Ebene der Rezeption: Die Lektüre der elaborierten Reduktion eines Textes erweist sich zwar einerseits aufgrund ihres effektiven Umfangs vordergründig als «schneller», das heißt in temporaler Hinsicht: kürzer als die des umfangreicheren Originals; andererseits führt die Dichte der Darstellung und der damit verbundene Anspielungsreichtum tendenziell zur Ambiguisierung und damit zur Verunklärung von Sinn, die eine intensivere Auseinandersetzung mit dem Text erfordert, um die darin enthaltenen Bedeutungsdimensionen vollständig zu erfassen. Bedenkt man zudem den Faktor der Performativität, der die Lektüreprozesse nach beiden Seiten hin «temporalisiert), sodass die Kategorien Textlänge und Rezeptionsdauer in ein reziprokes Verhältnis treten, ${ }^{3}$ ergeben sich komplexe Verschränkungen differierender Zeit-Ebenen, deren Zusammenspiel je nach historischem Kontext unterschiedlichen Normen und kulturellen Bedingtheiten unterliegt - ein Phänomen, das die Formel «Länge des Textes - Länge der Lektüren» konzis auf den Punkt bringt. ${ }^{4}$

Mit dieser ambivalenten Konfiguration gehen divergierende Strategien literarischer Kürzung einher: zwischen bewusster Komplexitätsreduktion und Wissensverengung beziehungsweise -verkürzung, aus der gar Wissensverlust

2 Hg. Winterbottom (1970).

3 «In the reality of reading, and even more so of listening, the factors of length and duration tend at times even to reciprocally neutralize one another [...]. [T] he pronounced brevity of a poem [...] neutralizes the effects of its duration». Zumthor (2016), S. $75 \mathrm{f}$. $4 \quad$ Ich danke Marc-Aeilko Aris, München, für diese Anregung. 
resultieren kann, und, konträr dazu, der gelehrt-kompetitiven Dimension der aemulatio, durch prononcierte brevitas in einen 〈Dialog〉 mit dem Bezugstext zu treten, um das Anspruchsniveau der kürzenden Darstellung selbst zu erhöhen. ${ }^{5}$ Die Kultivierung extremer Kürze als Redetugend birgt zugleich die Gefahr der obscuritas, die das Gesagte durch eine artifizielle Ausdrucksweise 'verdunkelt〉 und damit unmittelbar einsichtiger Sinnzuweisung entzieht. ${ }^{6}$ Ein solcher Stil kann eine hohe intellektuelle Leistung erfordern, um die Hüllen «dunkler Kürze` zu beseitigen. ${ }^{7}$

Gerade infolge des engen Nexus von literarischer Kürze und dadurch bedingter 〈Dunkelheit〉 - symptomatisch im bekannten Ausspruch des Horaz: brevis esse laboro, obscurus fio (Ars poetica, vv. $25 \mathrm{f}$.; <ich bemühe mich, kurz zu sein, und werde dabei dunkel $>)^{8}$ - changieren die historisch fassbaren Einschätzungen von Kürzungsphänomenen «zwischen pragmatisch bedingter Ablehnung und bereichsspezifischer Akzeptanz».9 Als Eingriff in die Integrität des Werkes werden nicht-autorisierte kürzende Versionen in den praefationes, Widmungsbriefen und anderen Paratexten griechischer, lateinischer, aber auch volkssprachiger Texte scharf verurteilt und als Verfälschungen der Autorintention untersagt. ${ }^{10}$ Im Rahmen institutioneller Bildungsvermittlung hingegen erleichtern beispielsweise knappe argumenta als didaktische Instrumentarien des Wissenserwerbs das Memorieren umfangreicherer Narrative. ${ }^{11}$ Funktional gebunden als Hinführung zu

$5 \mathrm{Zu}$ beiden Formen der Funktionalisierung literarischer Kürzungsverfahren Dusil / Schwedler / Schwitter (2016b), S. $11 \mathrm{f}$.

6 Eine solche in der zeitgenössischen Schuldeklamation praktizierte brevitas wird von Quintilian in der Institutio oratoria kritisiert. Vgl. Schwitter (2015), S. 93-103. Zur obscuritas vgl. den Überblick von Walde (2003); Fuhrmann (1966), bes. S. 50-53. In Bezug auf die Verbindung von obscuritas und ihrem nur teilweise kongruenten volkssprachigen Äquivalent wildekeit siehe Köbele / Frick (2018).

7 Vgl. Haug (1998), bes. S. 204.

8 Hg. Rudd (1989).

9 Köbele (2018), S. 13.

10 Zur Wahrnehmung der Kürzung zwischen Originalitätsverdacht und Verfälschung Mülke (2010), bes. S. 69.

11 Die argumenta bilden zusammen mit den accessus ad auctores sowie der wortbezogenen Glossierung wie auch der sach- und kontextorientierten Kommentierung ein differenziertes Instrumentarium der Texterschließung. Für den lateinischen Bereich, mit 
den Originalschriften eines Autors erscheinen auch kompakte Kompendien als probates Mittel, die copia librorum zu bewältigen. ${ }^{12}$ Ziel ist jeweils die auf zentrale Aspekte eines Werkes fokussierte Lektüre, unterstützt durch eine kürzende und gliedernde Anordnung seiner Elemente, wie dies das prominente Beispiel des Breviculum zu der in 155 Büchern niedergelegten Lehre des Raimundus Lullus demonstriert. ${ }^{13}$

Die hohe Zahl überlieferter antiker Epitomai und mittelalterlicher Breviarien spiegelt eine ungebrochene Nachfrage nach abbreviationes umfangreicherer Werke. Insofern gehört das Phänomen, Kurzfassungen bekannter Texte und Stoffe zu bieten, in der Antike, im lateinischen Mittelalter und innerhalb der neulateinischen, humanistisch geprägten Literaturproduktion als Prozess des Ordnens, Klassifizierens und Abstrahierens zum grundlegenden Umgang mit den tradierten Wissensbeständen. ${ }^{14}$ Als produktiv erweist sich die Kürzung insbesondere in literarhistorischer Hinsicht als spezifische Konstante innerhalb der Textproduktion, vor allem der im Schulkontext ubiquitären Neugestaltung der materia exsecuta: ${ }^{15}$ Neben dem Parameter der Erweiterung (amplificatio beziehungsweise dilatatio) erscheint die Kürzung (abbreviatio) eines Stoffes als komplementäre Technik der tractatio materiae und repräsentiert damit eine alternative Option narrativer Entwürfe, die von den mittelalterlichen Autoren nicht nur praktiziert, sondern auch in den zeitgenössischen lateinischen Poetiken kodifiziert wird. ${ }^{16}$ Sie bietet «hinsichtlich Konzeption und praktischer Handhabung den

Angabe weiterführender Literatur, Munk Olsen (2009); in germanistisch-mediävistischer Perspektive Henkel (1988); Henkel (2000); Frick (2017).

12 Vgl. Mülke (2010), bes. S. 81. Die Problematik der Beherrschbarkeit von Wissen in der Frühen Neuzeit diskutiert Werle (2007).

13 In der bildlichen Inszenierung der feierlichen Überreichung des Breviculum durch Raimundus Lullus' Schüler Thomas Migerius an die Königin von Frankreich und Navarra in der Handschrift, Karlsruhe, Badische Landesbibliothek, Hs. St. Peter perg. 92, fol. 11 ${ }^{\mathrm{v}}$, wird der Kürzungsvorgang durch die Feststellung legitimiert, dass Thomas den textus des Originals nicht verändert habe. Vgl. Heinzer (1988); Lutz (2006), bes. S. 9-11. Zur Symbolisierung des Textes im Bild Meier (2006), bes. S. 359-365.

$14 \mathrm{Zu}$ Techniken und Formen der Verkürzung in der antiken Literatur Reitz (2007); Horster / Reitz (2010); Horster / Reitz (2018).

15 Vgl. Knapp (2014), S. 220.

16 Vgl. u. a. Klopsch (1980); Worstbrock (1985); Knapp (2014). 
Hintergrund für eine Technik», ${ }^{17}$ die sich auch an volkssprachigen Texten des Mittelalters und der Frühen Neuzeit beobachten lässt. ${ }^{18}$ Quantitätsphänomene gehören hierbei zum Spektrum der durch Variantenbildung und Fassungsdivergenz geprägten spezifischen Überlieferungsbedingungen volkssprachiger Literatur und manifestieren sich in der synchronen Existenz kürzender Redaktionen neben den jeweiligen «Langversionen` eines Textes. ${ }^{19}$ Erstere bilden - als Repräsentationsform eines eigenständigen Typus des Erzählens - je nach Gattungszusammenhang charakteristische Merkmale aus, die sich auf einer abstrakteren Beobachtungsebene an gemeinsame «Grundkonstanten〉 rückbinden lassen.

Die Erscheinungsformen und Funktionalisierungen literarischer Kürzung (abbreviatio) im kulturellen Kontinuum sind so vielfältig wie unübersehbar. Obwohl das Mittelalter «in nahezu allen Gattungsbereichen der lateinischen Literatur solche Abbreviationes» entwickelt, ${ }^{20}$ blieb das Phänomenen der Kürzung als Organisationsform literarischen Wissens bisher allenfalls ein randständiger Ort im wissenschaftlichen Diskurs vorbehalten: «Die Forschung hat sich bisher weder mit dem Vergleich von Kurz- und Langfassungen befasst, noch das Stilideal der brevitas mit seinen Auswirkungen auf die mittelalterliche Literatur untersucht.» ${ }^{21}$ Diesem Desiderat abzuhelfen, indem die historisch rekonstruierbaren literarischen Kürzungspraktiken in einem interdisziplinären, komparatistischen Zugriff, genauer: in einem Dialog zwischen Latinistik, Romanistik und germanistischer Mediävis-

\footnotetext{
17 Henkel (1993), S. 40.

18 Die Tatsache, dass die im Schulunterricht anhand der lateinischen Sprache und Literatur vermittelten Techniken der primär poetischen Arbeit an vorgängigen Stoffen als «sprachenunabhängig[]» verstanden wurden und daher auch in der volkssprachigen Textproduktion Anwendung fanden, sieht Knapp (2014), S. 231 f., als grundsätzlich denkbare Konstellation des Wissenstransfers im 12. und 13. Jahrhundert an. Vgl. dazu auch Murphy (2005); zum Dichten als Schulfach Stotz (2008).

19 Zur Fassungsdivergenz innerhalb der mittelhochdeutschen Epik exemplarisch Bumke (1996); Strohschneider (1991); Henkel (1993); zur Lyrik Holznagel (1995); zur Versnovellistik Eichenberger (2017) sowie jetzt Dahm-Kruse (2018) und bes. die mehrbändige Ausgabe der deutschen Versnovellistik von Ridder / Ziegeler (2020). Zum Phänomen der «Retextualisierung B Bumke / Peters (2005).
}

20 Henkel (1993), S. 40.

21 Schmidt (2008), S. 36. 
tik, auf gemeinsame Perspektiven hin befragt werden, ist das Ziel des vorliegenden Bandes.

Der Fokus liegt auf rhetorisch-poetischen Verfahren der abbreviatio als eines bewussten Vorgangs der Reduktion und als einer sinnstiftenden Tätigkeit des Verdichtens längerer Narrative. Dabei kann dieser Vorgang der Textkonstitution von dem durchaus kontingenten Faktum 〈bloßer> Kürze (im Sinne des Stilideals der brevitas) geschieden werden: Denn die abbreviierten Versionen eines Textes verhalten sich relational zur jeweiligen Bezugsgröße - sei es hinsichtlich eines konkret existierenden längeren Vorlagenmaterials, sei es hinsichtlich eines 〈Prätextes〉, der auch jenseits einer expliziten schriftlichen Realisierung ein kulturell tradiertes Sinngefüge repräsentiert, dessen Identität «nicht an die Identität seines Wortlautes» gebunden ist. ${ }^{22}$ Die Charakteristika der Kürzungskategorien ergeben sich also erst aus der Zusammenschau mit den umfangreicheren Bezugstexten der jeweiligen Gattung. ${ }^{23}$ Denn die aus dem Vorgang der abbreviatio resultierende kürzere, mitunter auch «kurze` Form ist als solche kein Absolutum, sondern Ergebnis kultureller Sinnbildungs- und Literarisierungsprozesse. Ihre prägenden Spezifika formieren sich erst vor dem Hintergrund der Referentialisierung mit den umfangreicheren Narrativen und deren 〈Bauformen〉. ${ }^{24}$ Damit hebt sich der dezidiert dem rhetorisch-poetischen Verfahren der abbreviatio verpflichtete, mit der Relation von Text und Prätext operierende Ansatz von rezenten Diskussionen insbesondere der germanistischen Forschung zu kleinen Formen $>{ }^{25}$ aber auch von Arbeiten zur (primär technischen`) Wissensverarbeitung und -vermittlung

22 Strohschneider (1998), S. 108. Zur strukturellen Offenheit mittelalterlicher Texte Lutz (2006), S. 11.

$23 \mathrm{Zu}$ diesem Aspekt in Bezug auf Formen des antiken Epyllions Baumbach / Bär (2012).

24 Für die 〈Bauform〉 des Epos siehe jetzt in latinistischer Perspektive umfassend Reitz / Finkmann (2019).

25 Vgl. das Forschungsprogramm des Berliner Graduiertenkollegs 2190 〈Wissensgeschichte kleiner Formen`, das mit den Praxisfeldern Literatur, Wissenschaft und Populärkultur Kleinformen des Schreibens (v. a. Kurzprosa, aber auch moderne Medien) fokussiert: [http://www.kleine-formen.de/forschungsprogramm/] 15.07.2020. Zum Konzept der «einfachen Form〉 einschlägig schon Jolles (1930). Zu kleinen literarischen Formen des deutschsprachigen Mittelalters (Gebete, Fabeln, Sprichwörter, Verserzählungen u. a.) Holznagel / Cölln (2017); zu Bildern als〈Kurzformen kultureller Kontexte` eingehend Griese (2011). 
durch Exzerpte, Florilegien etc. in Spätantike und Frühmittelter ab. ${ }^{26}$ Auch der aktuell in die germanistisch-mediävistische Debatte eingeführte Begriff des 〈prägnanten Erzählens ${ }^{27}$ für das die narrativen Spezifika der Versnovellistik als Formkonstanten der 〈Kürze〉 in Anschlag gebracht werden, verfolgt ein gegenüber dem vorliegenden Ansatz grundsätzlich anders gerichtetes Frageinteresse: Die im Rekurs auf interdisziplinäre Arbeiten bewusst «facettenreich[] $\rangle^{28}$ vorgenommene Konzeptualisierung der 〈Prägnanz ${ }^{29}$ fokussiert einen "Wahrnehmungsmodus» als (historisches beziehungsweise literaturwissenschaftliches) Rezeptionsphänomen, ${ }^{30}$ in dessen Rahmen 〈Prägnanz〉 auf unterschiedlichen Ebenen als narrative Modellierung und Strukturierung von Textsinn wirksam werde.

Der vorliegende Schwerpunkt basiert demgegenüber auf dem rhetorisch-poetischen Konzept der Kürzung, wie es in den Schriften antiker Rhetoriker methodisch reflektiert und in den Epitomai auch praktiziert wird und - vielfach auf produktive Weise modifiziert - als konstitutives Element der Arbeit am Text in Mittelalter und Früher Neuzeit beobachtbar wird. Damit stehen sowohl die im engeren Sinne rhetorisch-formalen und stilistischen Aspekte als auch narrative und epistemische Logiken, inhaltliche Gesichtspunkte sowie pragmatische Faktoren im Zentrum des Erkenntnisinteresses, sodass neben den auf der Rezeptionsebene zu lokalisierenden Textstrategien und -effekten spezifisch konturierte Produktionsparameter in den Blick kommen. In diesem Zusammenhang fungiert 〈Prägnanz〉 durchaus als Beschreibungskategorie spezifischer Texteigenschaften (jedoch nicht des Erzählens als solchen), und auch dies im Sinne eines historischen Verständnisses, demgemäß die Reduktion der Worte mit einer semantischen Dichte

26 Mit je unterschiedlicher Schwerpunktsetzung McGill / Watts (2018); Dusil/ Schwedler / Schwitter (2016); Eigler (2003); Elm (2000).

27 Dimpel / Wagner (2019).

28 Wagner / Dimpel (2019), S. 8.

29 Als nicht unproblematisch erweist sich der 〈Prägnanz〉-Begriff sowohl aufgrund seiner konzeptuellen Offenheit als auch der Verpflichtung des ‘prägnanten Erzählens` auf eine a priori festgelegte Formsemantik. Auf diesen Aspekt verweist auch Waltenberger (2019), S. 29.

30 «Prägnanz ist nicht als Entität explizit in einem Text vorhanden, sondern sie wird einem Text vom (historischen wie rezenten) Interpreten zugeschrieben - aufgrund spezifischer Texteigenschaften.» Wagner / Dimpel (2019), S. 3. 
korreliert, die unterschiedliche implizite, narrativ nicht realisierte Deutungsoptionen auf engstem Raum bindet. ${ }^{31}$

In einer über engere Fachgrenzen und einzelne Textsorten hinausweisenden Perspektive sollen die Formen, Funktionen und Konzepte der abbreviatio profiliert werden, um die historische Signifikanz der Kürzungsfunktionen im Spannungsfeld von Latinität und Volkssprache zu erschließen. Denn gerade die Gleichzeitigkeit unterschiedlicher Konzepte von Lang- und Kurzfassungen dokumentiert, dass ein knapperes, stringenteres Erzählen schon immer zu den Möglichkeiten literarischer Produktion gehört hat. Welche Strategien der Kürzung lassen sich jeweils beobachten? Welche spezifischen Mechanismen und Verfahrensweisen kommen dabei zum Einsatz - mit welchen Auswirkungen sowohl im Hinblick auf die Poetiken und Epistemologien der Texte als auch im Hinblick auf Sprach- und Diskursdifferenzen? Welchen Stellenwert haben in diesem Kontext die relationalen Differenzkategorien Kürzung beziehungsweise Erweiterung? Welche Rolle spielen dabei Fragen der Medialität und Materialität? - Die von einer textsortenimmanenten Typologie der Kürzungen abstrahierende, epochenübergreifend angelegte Beschreibung kann dazu beitragen, grundsätzliche Spezifika der abbreviatio zu konturieren, um Einsichten in basale Prozesse literarischer Sinnbildungsmechanismen zu gewinnen. Inwiefern diese wiederum texttypenspezifische Poetiken der Reduktion bedingen und dabei auf ein jeweils dominantes historisches Interesse reagieren, arbeiten die exemplarischen Fallstudien zur Verbindung von kultureller Praxis, tradierter Norm und zeitgenössischem Formbewusstsein heraus.

\section{Historische Differenzierung: brevitas und abbreviatio}

In seinem Werk über die Auffindung des Stoffes (De inventione) nennt Cicero die brevitas neben der Klarheit und Glaubwürdigkeit als «Leitprinzip für die Komposition der Redeteile»:32

31 Waltenberger (2019), S. 30: «Die Verknappung der Worte geht dabei nicht mit semantischer Reduktion einher; vielmehr soll das Gesagte möglichst viele Sinnaspekte im Ungesagten mit sich führen.»

32 Dazu Kallendorf (1994), Sp. 53 f. 
Oportet igitur eam tres habere res: ut brevis, ut aperta, ut probabilis sit. Brevis erit, si, unde necesse est, inde initium sumetur et non ab ultimo reperetur; et si, cuius rei satis erit summam dixisse, eius partes non dicentur - nam saepe satis est, quid factum sit, dicere, ut ne narres, quemadmodum sit factum -; et si non longius, quam quo opus est, in narrando procederetur; et si nullam in rem aliquam transibitur, et si ita dicetur, ut nonnumquam ex eo, quod dictum est, id, quod non est dictum, intellegatur; et si non modo id, quod obest, verum etiam id, quod nec obest nec adiuvat, praeteribitur; et si semel unum quidque dicetur; et si non ab eo, quo in proxime desitum erit, deinceps incipietur. (De inv. 1,28)

«Sie [sc. die narratio] soll aber drei Eigenschaften besitzen: sie möge kurz klar und glaubwürdig sein. Kurz ist sie, wenn man von da, wo es nötig ist, den Anfang nimmt und nicht bei dem Entferntesten beginnt, und wenn man, wo es genügt, den Hauptpunkt genannt zu haben, nicht dessen Teile nennt - denn oft genügt es zu sagen, was geschehen ist, und man braucht nicht zu berichten, auf welche Weise es geschehen ist - und man nicht weiter fortschreitet beim Erzählen, als nötig ist, und wenn man zu keiner anderen Sache abschweift; und wenn man so spricht, daß man bisweilen aus dem, was gesagt wurde, auch das, was nicht gesagt wurde, erschließt; und wenn man nicht nur das, was schadet, sondern auch das, was weder schadet noch hilft, übergeht; und wenn man jeden einzelnen Punkt nur einmal nennt; und wenn man nicht mit dem, womit man eben erst aufgehört hat, wieder aufs neue beginnt. ${ }^{33}$

Als konstitutive Merkmale rhetorischer Kürze erscheinen hier zunächst inhaltlich-formale Charakteristika (eine klare, stringent ausgerichtete Struktur ohne Wiederholungsmomente und Gedankensprünge; das Weglassen von Details, die sich zum Sachverhalt indifferent verhalten, sodass sie dessen Darlegung über das angemessene Maß hinaus in die Länge ziehen); diese werden durch stärker stilistisch orientierte Maßgaben ergänzt (z. B. ein gewisser Anspielungsreichtum, der es erlaubt, nicht Gesagtes zu erschließen, das Vermeiden von Weitschweifigkeit und Redundanz). Der brevitas eignet eine doppelte Dimension: Sie fungiert einerseits als sprachliche Verdichtung mit qualitativer Tendenz, die andererseits und zugleich quantitative Aspekte der Rede bedingt. Denn der fundamentale Fehler, den die Orientierung am Axiom der brevitas häufig mit sich bringe, liegt - so Cicero weiter - in der defizitären Wahrnehmung 〈absoluter Kürze, das heißt: gerade in der Vernachlässigung quantitativer Gesichtspunkte: 
Ac multos imitatio brevitatis decipit, ut, cum se breves putent esse, longissimi sunt; cum dent operam, ut res multas brevi dicant, non ut omnino paucas res dicant et non plures, quam necesse sit. (De inv. 1,28)

২Viele aber führt das Nachahmen der Kürze (imitatio brevitatis) in die Irre, sodass sie, während sie glauben kurz zu sein, allzu weitschweifig sind; und wenn sie sich Mühe geben, viele Dinge kurz zu sagen, und nicht, überhaupt nur wenige Dinge zu sagen und nicht mehr, als nötig ist.>

Die Kategorie der brevitas zielt - zusammen mit den Leitprinzipien perspicuitas und verisimile ${ }^{34}$ - auf eine effektive Präsentation durch eine knappe, eindeutigpräzise Ausdrucksweise und ermöglicht es dem Zuhörer, die Struktur der Darlegung zu durchschauen und auf diese Weise dem Gesagten genau zu folgen. Das Ideal erscheint allerdings nur dann optimal realisiert, wenn die auf Kürze abgestellte Rhetorik nicht durch eine ausufernde Fülle der erzählten Details überwuchert wird: Hier dokumentiert sich in Ciceros mahnender Äußerung ein Konzept der brevitas, das den Prozess stilistischer Formgebung ganz wesentlich an eine hinreichende Reduktion inhaltlicher Elemente bindet.

Das der brevitas bisweilen inhärente Möglichkeitsspektrum unausgesprochenen Wissens (et si ita dicetur, ut nonnumquam ex eo, quod dictum est, id, quod non est dictum, intellegatur, De inv. 1,20,28) rückt die Stilkategorie aufgrund der Neigung zu extremer Kürze in ein Spannungsfeld von virtus und vitium dicendi. ${ }^{35}$ Auf der konkreten Ebene der Textproduktion ist die brevitas als figura elocutionis Teil des rhetorischen ornatus und kann sowohl in den einzelnen Wörtern (in verbis singulis) als auch in den Wortfiguren (in verbis coniunctis) wirksam werden, ${ }^{36}$ insbesondere durch

34 Die drei Kategorien Klarheit (perspicuitas), Kürze (brevitas) und Wahrscheinlichkeit (verisimile) gelten schon seit Isokrates als Tugenden der narratio. Der Begriff für

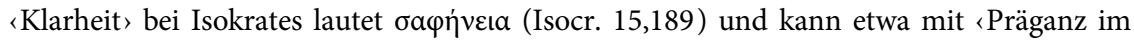
Ausdruck (wörtl.: des Mundes)> übersetzt werden. Die genannten drei Tugenden sind in der Rhetorica ad Herennium übernommen: Tres res convenit habere narrationem, ut brevis, ut dilucida, ut verisimilis sit (Rhet. Her. 1,9,14; «Drei Eigenschaften sollten in der narratio zusammenkommen, [nämlich] dass sie kurz, klar und wahrscheinlich ist `).

35 Vgl. Lausberg (1960), S. $169 \mathrm{f}$.

36 Vgl. Kallendorf (1994). Der Bezugsautor ist Cicero: Brevitas autem conficitur simplicibus verbis semel una quaque re dicenda, nulli rei nisi ut dilucide dicas serviendo (De partitione oratoria VI,19). 
Figuren der detractio wie der Ellipse oder des Asyndeton. ${ }^{37}$ Von besonderer Relevanz ist in unserem Zusammenhang, dass aus der Perspektive der antiken Rhetorik der funktionale Aspekt der mit der brevitas zu erzielenden Effekte entscheidend auf einer qualitativen Komponente im Sinne einer hervorhebenden, intensivierenden, gleichermaßen aber auch abschwächenden Darstellung basiert, sich darin jedoch keineswegs erschöpft. Vielmehr erweist sich die inhaltlich-quantitative Dimension der Kürze als gleichgewichtiges Korrelat zur sprachlich-formalen Verdichtung.

Die Forderung nach Kürze ist dem Mittelalter durch die rhetorischen Schriften des Cicero, Quintilian und des Auctor ad Herennium bekannt. ${ }^{38}$ Die mittellateinischen Poetiken des 12. Jahrhunderts wie die des Matthäus von Vendôme und Galfred von Vinsauf, die hieran in wesentlichen Punkten anschließen, transformieren das antike Postulat jeweils für ihre eigenen Zusammenhänge. Sie kodifizieren, was insbesondere im Schulkontext «geübter und anerkannter Standard literarischer Praxis und sprachlich-formaler Gestaltung in der Literatur ihrer Zeit ist ${ }^{39}$ und können insofern als Reflex einer «lebendigen Dichtungspraxis [gelten], die auch ohne sie Bestand hatte.$^{40}$ Es geht dabei in erster Linie um dichtungspraktische, nicht erzähltheoretische Gesichtspunkte, ${ }^{41}$ nämlich um die Vermittlung einer literarischen Technik, die sich in der Formgestaltung kleinerer Einheiten (z. B. descriptiones) konstituiert, kaum aber «das Werkganze und dessen Makrostruktur» im Blick hat. ${ }^{22}$ Dass gerade Galfreds Poetria nova in diesem Bereich $\mathrm{zu}$ den ausgesprochen wirkmächtigen Werken gehört, dokumentiert ihre Überlieferung mit rund 200 erhaltenen Handschriften, in denen der Text vielfach mit Glossen oder sogar umfangreicherer Kommentierung versehen ist. ${ }^{43}$ Der Laborintus Eberhard des Deutschen, ${ }^{44}$ der zentrale Parameter der

37 Zu den figurae detractionis Lausberg (1960), S. 346.

38 Vgl. Schmidt (2008), S. 29.

39 Henkel (2017), S. 28.

$40 \quad$ Linden (2017), S. 5.

41 Hübner (2003), S. 80: «Denn es gab [...] im 12. und 13. Jahrhundert zwar eine entwickelte, differenzierte und trotz ihrer technischen Ausrichtung durchaus niveauvolle Dichtungstheorie, aber nur eine sehr elementare Erzähltheorie.»

42 Knapp (2014), S. 220.

43 Vgl. ebd., S. 223. Dazu auch Woods (1985).

44 Vgl. die kommentierte Ausgabe von Vollmann (2020). 
aus dem französischen Raum stammenden Artes poeticae reproduziert, markiert ein signifikantes Zeugnis der «Reichweite` intellektueller Transferprozesse, ${ }^{45}$ wie sie in dieser Zeit für die Kultur der Germania und Romania charakteristisch sind. ${ }^{46}$ Insofern berechtigt die Existenz dieser «literarischen Infrastruktur ${ }^{47} \mathrm{zu}$ der These, dass die in den zeitgenössischen Poetiken vermittelten Prinzipien dichterischer Praxis auch zum literarischen Erfahrungsraum der in der Volkssprache schreibenden, an der lateinischen Kulturtradition partizipierenden Autoren gehören, deren produktiven Umgang mit «Sujets der auctores-Lektüre» prägen ${ }^{48}$ und leitende Kategorien bilden für das sich etablierende volkssprachige Erzählen in der schriftliterarisch gestützten (epischen) (Groß-)Form. ${ }^{49}$

Die mittellateinischen Poetiken sind grundsätzlich rückgebunden an die antike theoretische Reflexion und praktische Handhabe des rhetorischen Instrumentariums (bes. Donat, Cicero, Pseudo-Cicero, Horaz). ${ }^{50}$ Das Stil-

45 Zum «Reichweiten >-Begriff Henkel / Noll / Rexroth (2020).

46 Die Dynamiken der intellektuellen Netzwerke im 12. Jahrhundert untersucht Bezner (2005).

$47 \quad$ Knapp (2014), S. 231.

48 Henkel (2011), S. 143.

49 Am Beispiel des Literaturexkurses im Tristan Gottfrieds von Straßburg führt Knapp (2014), S. 232f., die (auch terminologischen) Anleihen bei den mittellateinischen Artes poeticae aus. Dazu am Beispiel des Eneasromans Heinrichs von Veldeke Schmitz (2007); in germanistisch-komparatistischer Perspektive Masse / Seidl (2016). Lieb (2005), S. 362, hinterfragt $\mathrm{zu}$ Recht eine statische Veranschlagung der historisch-poetischen Kategorien auf mittelhochdeutsche Texte im Sinne eines rein «mechanistische[n] Modell[s]». Freilich zielt die eigentliche Intention der rhetorisch grundierten mittellateinischen Poetiken gerade nicht auf das ‘Ganze` der materia, sondern gibt lediglich einzelne Gestaltungsmöglichkeiten an die Hand und repräsentiert insofern keine ausgebildete (Erzähl-)Theorie. «Der Unterschied zwischen dem Niveau von Schullehrbüchern und Chrétiens oder Hartmanns Erzählkunst stellt zweifellos ein grundsätzliches Problem dar. Ein noch grundsätzlicheres entsteht aber durch die Differenz zwischen den epistemischen Systemen der Rhetorik und der Erzähltheorie. Denn die rhetorische Theorie der Dichtkunst, wie sie in den Poetiken des 12. und 13. Jahrhunderts kristallisiert, vermittelte einen Begriff etwa von der descriptio, und zu diesem Begriff hatte die Rhetorik praktische Übungen zu bieten. Gleiches gilt für die Amplifikationstechniken oder für die in der Ornatuslehre vermittelten Formulierungstechniken. All dies gehört jedoch nicht zu den Gegenständen der Erzähltheorie.» Hübner (2003), S. 81.

50 Dazu Knapp (2014), S. 227. 
prinzip der Kürze erscheint darin zur Kategorie der abbreviatio transformiert, die als Gegenbegriff zur amplificatio beziehungsweise dilatatio materiae fungiert. ${ }^{51}$ Die Techniken der Kürzung und Ausweitung eines Stoffes werden als zwei mögliche Bearbeitungsmodi beschrieben, zu deren Exemplifizierung jeweils unterschiedliche (formal-stilistische) Arbeitsschritte genannt und an zum Teil umfangreicherem Beispielmaterial illustriert werden. ${ }^{52}$ Mit dieser Neu-Konfiguration geht zwar eine programmatische Verschiebung von einer qualitativen Dimension, wie sie in der antiken Rhetorik dominiert, zu einem quantitativen Prinzip der Erweiterung beziehungsweise Kürzung des Umfangs einher. Insofern aber die inhaltliche Reduktion im Modus der abbreviatio nicht ohne sprachlich-formale brevitas zu denken ist, ${ }^{53}$ die den komprimierten Wortlaut auf eine implizite semantische Mehrschichtigkeit hin transparent hält, ${ }^{54}$ erscheinen beide Kategorien obwohl auf unterschiedlichen Ebenen lokalisiert - als sich wechselseitig bedingende Konstituenten einer auf die Inhalts- wie Formseite zielenden Verdichtung: Erst in der Spezifik der formalen und stilistischen Elemente

51 Vgl. Worstbrock (1985).

52 Matthäus von Vendôme (Ars versificatoria, vor 1175) setzt Kürze besonders für die Handlungsschilderung an (IV 17-19: utendum est breviloquio, ut materia clausulatim explanetur, Faral [1982], S. 185). Vgl. Galfred von Vinsauf (Poetria nova, um 1200) zur amplificatio und abbreviatio als zwei möglichen Parametern im Prozess des poetischen Schaffens: Curritur in bivio: via namque vel ampla vel arta, / Vel fluvius vel rivus erit; vel tractius ibis, / Vel cursim salies; vel rem brevitate notabis, / Vel longo sermone trahes. Non absque labore / Sunt passus utriusque viae [...] (vv. 206-210; Faral [1982], S. 203; «Man kommt an einen Scheideweg: Denn der Weg wird entweder breit oder schmal, ein Fluss oder Rinnsal sein; entweder wirst du ausladender gehen oder im Eilschritt springen; entweder den Gegenstand in Kürze beschreiben oder in langer Rede ausfalten. Nicht ohne Mühe sind die Schritte auf beiden Wegen`).

53 Hac brevitate potes longum succingere thema, / Hac cymba transire fretum. Narratio facti / Eligit hanc formam verbi, quae facta modeste / Non superinfundat nubem, sed nube remota / Inducet solem. [...] (vv. 702-706; Faral [1982], S. 219; «Mit dieser [sc. der beschriebenen] Kürze kannst du ein langes Thema umschließen, mit diesem Kahn über das Meer fahren. Die Erzählung des Geschehens wählt die Gestalt des Wortes, die - wenn dies auf angemessene Weise geschieht - keine Wolke darüberlegen soll, sondern die Sonne herbeiführen wird)).

54 Dazu Waltenberger (2019), S. 30. 
kann sich das implizite Sinnpotential der «vom Inhaltlich-Erzählenden absehende[n] Qualität» ${ }^{55}$ der Reduktion vollständig entfalten.

Die abbreviatio, wie sie die mittellateinischen Poetiken um 1200 präsentieren, besitzt also eine doppelte Ausrichtung, die zwar der eingangs zitierten Maßgabe der antiken Rhetorik vergleichbar ist, gleichwohl mit einer dazu asymmetrischen Gewichtung operiert: Sie kennzeichnet vorrangig eine konzeptuelle, die Quantität betreffende Komponente, ebenso wie sie auch als Stilkategorie im engeren Sinne (Stichwort: brevitas) fungiert, die sich in der Modellierung des einzelnen sprachlichen Ausdrucks äußert.56 «Der Modus der Kürze und das Verfahren des Kürzens dienen dabei synergetisch dem einen Ziel: Qualitäten durch Quantifizierung wahrnehmbar, beurteilbar und erinnerbar zu machen.» ${ }^{57}$

\section{Formen, Funktionen, Konzepte der abbreviatio in historischer Perspektive}

Diese unterschiedlichen Referenzebenen der abbreviatio gilt es zusammenzusehen, um die historisch variablen Erscheinungsformen, Funktionskontexte und die sich in ihnen herauskristallisierenden textsorten- und sprachenunabhängigen Charakteristika der Kürzung herauszuarbeiten. Obschon die literarische Kürzung - das dokumentieren die Beiträge des Bandes - als kulturelle Konstante auf dem Feld der Textproduktion über Sprach- und Diskursdifferenzen hinweg fungiert, prägen sich die Verfahren und Mechanismen der

56 Sic breve splendet opus: nihil exprimit aut magis aequo / aut minus (vv. 730 f.; Faral [1982 ], S. 219 f.; ‘So glänzt das kurze Werk: Es drückt nichts aus, das dem Angemessenen etwas hinzufügt oder wegnimmt $)$.

57 Scheuer, in diesem Band, S. 239. Vgl. auch Galfreds Exempel für die Verwendung der Kürzungstechnik, in dem der Themenkomplex zum «Schneekind` in zwei Hexametern verdichtet wird: De nive conceptum quem mater adultera fingit / Sponsus eum vendens liquefactum sole refingit (vv. 733 f.; Faral [1982], S. 220). Vgl. zu Technik und Funktionsweise der das Sujet abbreviierenden lateinischen Verse im Vergleich mit den deutschen Fassungen des Stoffes Henkel (2017), S. 38-42. Galfreds «Schneekind -Version als «narratives Musterbeispiel» und «Paradefall gesteigerter struktureller Prägnanz» behandelt Waltenberger (2019), S. $30 \mathrm{f}$. 
abbreviatio jeweils kontextspezifisch aus. Auf einer abstrakteren Beobachtungsebene lassen sich freilich gemeinsame Perspektiven konturieren:

1) Auf der Ebene des Zusammenspiels von abbreviatio, brevitas und ¿Zeit) ist eine ambivalente Dynamik zu beobachten. Der temporale Aspekt wird nicht nur ganz grundlegend im Hinblick auf die Textproduktion bedeutsam (etwa als Zeitdruck bei der Verfertigung, als ökonomische Erwägung im Umgang mit dem möglicherweise knappen Material), sondern auch auf der Ebene der Narration selbst: Denn aus Eingriffen in die Makrostruktur eines Textes, z. B. Kürzungen nicht primär handlungstragender Elemente wie descriptiones, Mono- und Dialoge, können auf der narrativen Ebene eine veränderte Erzähltechnik oder modifizierte Figurenkonzeption resultieren. ${ }^{58}$ Deren jeweilige Differenzqualität gegenüber dem vorgängigen Bezugshorizont wird aber erst durch eine spezifische poetische Faktur, ${ }^{59}$ z. B. die semantisch-syntaktische oder lexikalische Verdichtung auf der Ebene der Wortfiguren, ${ }^{60}$ sprachlich modelliert. So ist es die mit dem abbreviierenden Zugriff auf das Vorlagenmaterial korrelierende formal-stilistische Kategorie der Kürze (brevitas), die ein erhöhtes Tempo (velocitas) der Erzählung bewirkt und zugleich Verschiebungen hinsichtlich der Zeitstrukturen und -semantiken innerhalb des Erzählens selbst generiert.61 Dass den dabei entstehenden «unsicheren Zeitbilanzen [...] unsichere Axiologien [entsprechen]»,62 dokumentiert die jeweils relational gebundene Spannung zwischen Kürzung / Kürze und ihrer Prozessualität jenseits reiner Formaspekte: So können intertextuelle Allusionen die Kurzfassung auf den Ausgangstext hin transparent halten ${ }^{63}$ oder das vorliegende Kürzungsverfahren in expliziten oder impliziten Verweisen exponieren, die das produktionsästhetische Prinzip der abbreviatio reflektieren, ${ }^{64}$ zugleich aber kompetente Rezipienten voraussetzen, die imstande sind, die «Verschiebungen und Akzentsetzungen

\footnotetext{
58 Hierzu Baisch, in diesem Band.

59 Vgl. Zacke u. a. (2020).

60 Vgl. Lausberg, Rhetorik, S. 346-353.

61 Mit jeweils unterschiedlichem Fokus Grütter; Köbele; Linden; Reitz; Wesche, in diesem Band.

62 Köbele, in diesem Band, S. 91.

63 Vgl. Dusil / Schwedler / Schwitter (2016b), S. 12.

64 So z. B. in den Inhaltsangaben (argumenta) zu den einzelnen Büchern lateinischer Epen. Dazu Haye, in diesem Band.
} 
zu erkennen».65 Im Gegenteil können diese Bezüge auch bewusst kaschiert werden, um dem «neuen〉 Text ein Distinktionsmerkmal gegenüber dem (alten〉 zu verschaffen. ${ }^{66}$

2) Die Parameter Kürzung und Erweiterung repräsentieren keineswegs ein Modell von «attraktive[r] dichotomische[r] Schlichtheit», ${ }^{67}$ sondern bedingen einander in komplexer Weise und eignen sich damit - auch oder gerade angesichts unterschiedlicher Fachtraditionen - zur methodisch kontrollierten und theoretisch reflektierten Textanalyse. Die Beiträge des Bandes spiegeln eindrücklich die zentrale Beobachtung, dass sich abbreviatio und amplificatio nicht als antagonistische Kategorien denken lassen, sondern vielmehr in ihrer gegenseitigen Interdependenz paradoxe $\left\langle\right.$ Kippfiguren ${ }^{68} \mathrm{mit}$ ambivalenten Implikationen erzeugen.69 Als Grundkonstanten der literarischen Produktion werden sie auf unterschiedlichen Ebenen wirksam: in der rhetorischen Formgebung wie der narratologischen Gestaltung eines Textes. $^{70}$ Kürzende Eingriffe in die syntagmatische Abfolge der Erzählung bedingen nämlich Irritationen der paradigmatischen Sinnkonstitution, die wiederum explizierend-amplifizierende Einschübe erfordern, um die durch den Vorgang des abbreviare entstandenen Motivationsdefizite auszugleichen. ${ }^{71}$ «Dass Texte sich nicht immer an das halten, was sie programmatisch zu tun vorgeben $»{ }^{72}$ zeigt sich anhand der in Erzählerkommentaren vielfach anzutreffenden (Selbst-)Verpflichtung auf das Stilideal der Kürze, sog. «Kürze-Topoi ${ }^{73}$ deren Kalkül, indem es die Kürzung selbst unterläuft, jeweils ganz eigene Spielräume alternativer, mitunter spannungsvoller Sinnentfal-

$65 \quad$ Reitz (2007), S. 346.

66 Vgl. Mülke (2010), S. 74 f.

67 Lieb (2005), S. 362.

68 Unter medialen Aspekten Kiening (2016).

69 Zur Frage nach historischen Form-Semantiken der Kürzung Köbele, in diesem Band.

70 Zum «versefüllenden Asyndeton`Schwitter, in diesem Band; zur narrativen Sinnkonstitution durch Kürzung und Zusammenfassung Kropik, in diesem Band; zum Zusammenfall formaler und quantitativer Phänomene bei Herbort von Fritzlar Bauschke, in diesem Band.

71 Vgl. Selmayr, in diesem Band. Mit Bezug auf die mittelhochdeutsche Epik Frick (2018), S. 23-50.

72 Köbele (2018), S. 12.

73 Zum mittelhochdeutschen Antikenroman Frick (2020c). 
tung eröffnet. abbreviatio und amplificatio erscheinen damit als dynamische Verfahren mit vielfältigen Synergieeffekten, ${ }^{74}$ deren Verhältnis je nach Text und Kontext neu zu bestimmen ist, sodass eine möglichst enge Zusammenführung verschiedener Ebenen geboten scheint, um die Phänomene der abbreviatio in ihrer ganzen historischen Breite zu erfassen.

3) Diese Überlegungen führen zur zentralen Frage nach dem Verhältnis von quantitativen und qualitativen Gesichtspunkten. Denn Kürzung entsteht in der Regel nicht zufällig, sondern ist Ergebnis diffiziler Strukturierungsund Formgebungsprozesse und insofern Teil literarischer Diskurse. ${ }^{75}$ Weil «[f]ormale Modellierung [...] immer auch die Sinnproduktion von Texten [tangiert]», ${ }^{76}$ tendieren quantitative Modalitäten wie abbreviatio und amplificatio dazu, in qualitative, das meint, «inhaltlich relevante, axiologisch besetzte Prozesse» umzuschlagen. ${ }^{77}$ Wann sind Kürzungen im historischen Kontext als Prägnanzgewinne zu verbuchen, wann als 〈bloße〉 Redundanzvermeidung ${ }^{? 78}$ Welche rhetorisch-poetischen Effekte werden durch die Kürzung verstärkt beziehungsweise gemildert, welche allererst evoziert? Lassen sich bestimmte Funktionstypen unterscheiden - z. B. im Hinblick auf narrative Aspekte im Kontext differierender Zeitsemantiken (brevitas / velocitas)? ${ }^{79}$ Wie ist die gegenläufige Tendenz zu Wiederholungsfiguren einzuschätzen, etwa im Rahmen inserierter Kataloge ${ }^{80}$ oder durativ prozessierter Kürzungsprogramme?81 Heißt Kürzung allein Fokussierung auf handlungsrelevante und -motivierende Inhalte, mithin: die summa facti?82 Und sind damit

\footnotetext{
74 Dazu Scheuer, in diesem Band.

75 Mit Bezug auf Diskursinterferenzen bei Herbort von Fritzlar Bauschke, in diesem Band. - «[B]revity is never random but constitutes a structuring model. This is doubtless why Latin rhetoric had recourse to the term brevitas (sermo brevis, 〈brief discourse〉) to designate not a model per se, but a virtus (capacity or virtue), a modality, and (in the scholastic sense) a qualitas (quality or property) of formal structure.» Zumthor (2016), S. 74.

76 Frick / Rippl (2020), S. 8.

77 Köbele, in diesem Band, S. 93.

$78 \quad \mathrm{Zu}$ dieser Frage Frick (2020b).

79 Am Beispiel antiker Epitomai Reitz (2007), bes. S. 338; Reitz (2010). Für die mittelhochdeutsche Dichtung am Beispiel der Nibelungenklage Frick (2020a).

80 Dazu Reitz (2017).

81 Dazu Köbele, in diesem Band.

82 Am Beispiel der Prosaauflösungen mittelhochdeutscher Versepen Schnell (1984).
} 
wertende Implikationen wie die vom Komplexitätsabbau oder Kohärenzverlust kürzender Redaktionen als folgerichtig zu erweisen?

Die Erscheinungsformen kürzender Bearbeitungen von längeren Narrativen bewegen sich in einem Spektrum unterschiedlicher Realisierungsmöglichkeiten. Ihre historische Signifikanz dokumentiert sich in einem eigenständigen Profil der Texte, das ein bestimmtes Rezeptionsinteresse hervortreten lässt. Aber auch dort, wo die den Kurzfassungen zugrunde liegenden Tendenzen sich nur ansatzweise fassen lassen, stellt die Frage nach intendierter versus kontingenter Kürzung ein besonders heikles Problemfeld dar; denn selbst hinter einer Kürzung «ohne erkennbare spezifische Zielsetzung ${ }^{83}$ kann - ebenso wie bei der planvollen Kurzredaktion - im Hinblick auf die rhetorische Ausgestaltung das Prinzip und Verfahren der abbreviatio aufscheinen. Gerade für volkssprachige Texte ist dabei - im Gegensatz zur lateinischen Literatur der Antike, des Mittelalters und der Frühen Neuzeit der besondere Status der Texte im Spannungsfeld von Mündlichkeit und Schriftlichkeit sowie deren Überlieferung in Mehrfachfassungen zu berücksichtigen, die sich an das Konzept des Wiedererzählens rückbinden lassen. ${ }^{84}$ Von dieser speziellen historischen Konstellation ausgehend können Fragen nach der Funktionalisierung der Kurzfassungen in ihren Überlieferungskontexten entscheidende Hinweise auf die durch die abbreviatio modellierten «neuen〉 Akzentuierungen der Texte bieten. ${ }^{85}$

Die Frage nach der abbreviatio muss immer auch als Frage nach der Perspektive verstanden werden. Denn mitnichten konstituiert sie eine «einfach abzählbare Reduktion der Erzählmasse einer Bearbeitung gegenüber ihrer Vorlage».86 So wie sich ihre quantitativen Charakteristika erst aus einem Vergleich der Kürzung mit dem Prätext beziehungsweise den Bezugstexten der entsprechenden Gattung ergeben, ${ }^{87}$ erfordert die Veranschlagung von qualitativ orientierten Kohärenz- oder Komplexitätskriterien eine Lektüre, die die situativ gebundenen Funktionskontexte stets mitreflektiert.

Henkel (1993), S. 58.

84 Einschlägig Worstbrock (1999). Vgl. auch Bumke / Peters (2005); Zacke u. a. (2020).

85 Vgl. Baisch (2005); in kulturwissenschaftlicher Perspektive Baisch (2006).

86 Scheuer (2017), S. 61.

87 Zur Relation von Text und Prätext Stolz / Fasching, in diesem Band; zur Frage «Wie lang ist kürzer?» Trachsler, in diesem Band. 
Dass etwa dem Postulat der im Rahmen der abbreviatio praktizierten stilistischen brevitas in der Latinität ganz andere formale Möglichkeiten als in der Volkssprache zur Verfügung stehen, bedingt einen grundsätzlich verschiedenen quantitativen wie qualitativen Charakter der Kürzung, der in weit höherem Maße auf die intellektuelle Potenz der Rezipienten abgestellt ist. Das von Nikolaus Henkel für diesen Zusammenhang implementierte Konzept des «intellektuellen Kontrakt $[s] »{ }^{88}$ der unter veränderten Bedingungen auch in der Volkssprache realisierbar ist, zielt auf die Instrumentalisierung kulturellen Wissens, das die Wirkungspotentiale literarischer Kürzung maßgeblich bestimmt.

Die in diesem Modell fokussierten Komponenten der Produktion (Formvermögen) und Rezeption (literarische Kennerschaft als Erfordernis für das Verständnis) erscheinen als anschlussfähig für die Frage nach einem historischen poetischen Konzept der abbreviatio. Die Produktionsprinzipien und Wirkungskalküle evozieren eine typologische Vielfalt der mit der literarischen Kürzung verbundenen Phänomene: Zwar vermittelt sich die Kurzfassung genau genommen als (relational gesehen) «kurzer` Text, der sich allenfalls durch einen beim angezielten Publikum dominanten Erfahrungshorizont von einem intertextuell präsenten 〈Langtext〉 als Kürzung sinnstiftend abheben kann; dennoch gehen die Verfahren der abbreviatio «nicht darin auf, einen vorgefundenen Erzählstoff subtraktiv zu kürzen oder ihn mithilfe bestimmter Stilmittel kompendiöser wiederzuerzählen».89 Die Grundoperationen erschöpfen sich also nicht in quantitativen und qualitativen Modifikationen, die sich zwischen eindeutig identifizierbaren Relationen von Vorlage und Bearbeitung bewegen, sondern umfassen zugleich Rezeptionssignale im Sinne narrativ verdichteter, allusiv auf die Bildung der Leser rekurrierender topischer Schemata ${ }^{90}$ sowie Bezugnahmen auf ein gattungstypisches beziehungsweise im weiteren Sinne kulturelles Wissen, ${ }^{91}$ vor dessen

\footnotetext{
88 Henkel (2017), S. 41.

89 Scheuer (2017), S. 58.

90 Von abbreviatio-bedingten «narrative[n] Leerstellen», die von den Rezipienten in einem intellektuellen Spiel erst aufzufüllen und «in ihrer sinnstiftenden Funktion zu erkennen» sind, spricht Henkel (2017), S. 41.

91 Am Beispiel mystischer Lieder Suerbaum, in diesem Band; im Hinblick auf die mittelalterliche Versnovellistik Linden; Selmayr, in diesem Band.
} 
Hintergrund sich die Charakteristika der abbreviatio als epochen- und genrespezifischer Technik formieren. Weil dabei Fragen nach Produktion und Rezeption unmittelbar zusammenhängen, lässt sich die historische Signifikanz der Kürzungsfunktionen nur über eine Differenzierung unterschiedlicher Beobachtungsebenen, die «Zusammenschau überlieferungshistorischer, text- und gattungspoetischer, wirkungsästhetischer und diskursgeschichtlicher Aspekte» erschließen. ${ }^{92}$ Diese methodische Herausforderung ist zugleich eine Chance: Es ist das Verdienst der Beiträge, die dynamischen und komplexen Prozesse der aktualisierenden Sinnstiftung durch abbreviativ verdichtete tradierte Sujets und Narrative historisch kontextualisierend herauspräpariert zu haben.

\section{Formsemantiken : Quantitative und qualitative Relationierung}

Literarische Kürzung besitzt eo ipso keinen Modellcharakter im Sinne festgelegter Strukturmechanismen, sondern repräsentiert eine Modalität des Umgangs mit vorgängigen Texten und Stoffen, die zwar durch in der Bildungssphäre gelehrter Latinität formulierte rhetorisch-poetische Maßgaben grundiert ist, diese aber adaptierend und modifizierend in unterschiedliche Kontexte einspeist, wo sie als Formkonstante mit spezifischen semantischen, d. h. qualitativen Implikationen fungiert. Weil die Wahrnehmung dessen, was lang oder kurz ist, je nach kulturellen, sprachlichen, diskurs- und gattungshistorischen Kontexten variiert, lässt sich eine Relationierung quantitativer und qualitativer Prozesse sowie Momente ihres wechselseitigen Umschlagens nur über die Frage nach historischen Formsemantiken bestimmen. Eine grundlegende methodische Annäherung, die über die Asymmetrie formalistisch vs. funktionsanalytisch hinausweist, bieten die Beiträge dieser Sektion.

Christiane Reitz untersucht am Beispiel der Ilias Latina die literarischen Techniken des Verkürzens «als ästhetisches und intellektuelles Phänomen» (S. 46). Sie beobachtet, dass die Bauelemente epischen Erzählens auch im Modus der abbreviatio, die durch Auslassungen und Raffungen narrative Beschleunigung bewirke, bewusst beibehalten beziehungsweise anzitiert würden und damit eine gattungsspezifische Semantik aktualisierten. Sie seien als 
«Fingerzeig in Richtung des epitomistischen Verfahrens»(S. 57) zu verstehen, der die Rezipienten dazu auffordere, das nur knapp Tangierte aus eigener Kenntnis zu ergänzen. Der Vergleich mit der «spezifische[n] ästhetische[n] und ikonographische[n] Sprache»(S. 47) der Tabulae Iliacae als einer Art «Zwischentext»(S.60) thematisiert Aspekte der Medialität und Materialität der Kürzung als Konstante in der Auseinandersetzung mit der literarischen Tradition, deren Ästhetik darin bestehe, die Leser beziehungsweise Betrachter zur Reflexion über die «Möglichkeiten der Wiedergabe eines so komplexen Textes wie der homerischen Ilias» (S. 60) anzuleiten.

Der grundsätzlichen Frage nach der Referenzialisierbarkeit von Textumfang und performativer Dauer (‘Wie lang ist kürzer?〉) ist der Beitrag von Richard Trachsler gewidmet. Gegenstand ist der brevitas-Topos in den Bearbeitungen älterer französischer Versromane, der neben dem Anspruch nach sprachlicher Modernisierung zum gängigen Inventar der Prologe spätmittelalterlicher mises en prose gehöre. Ausgehend vom mittelfranzösischen Fachterminus für die Operation der Prosaauflösung (réduire en prose) geht es um die Frage, inwiefern diese «Reduktion〉 der Form auch im Hinblick auf die tatsächliche Zeit der Lektüre zu Buche schlage. Mit Bezug auf Ergebnisse der Performance Studies setzt Trachsler eine «approximative Kalkulation der Rezitationszeiten»(S. 77) für die jeweiligen Fassungen an, die dokumentiere, dass die abbreviatio darauf abziele, "gefühlte Längen zu eliminieren» (S. 80), und in diesem Sinne immer auch eine qualitative Implikation besitze.

Daran anschließend analysiert Susanne Köbele mit der Frage «Wie lang ist immer kürzer?» (S. 91) die Interpretationsmöglichkeiten historischer Formsemantiken am Beispiel des textinternen Verfahrens systematischer Kürzung im Schlussgedicht der Klage Hartmanns von Aue. Dieses «Kürzungsexperiment»(S.96) zeichne sich durch eine ambivalente Spannung aus, indem die «schrumpfende Form〉 zugleich mittels eines versifikatorischen Prinzips amplifiziert werde. Die Beobachtung dieses paradoxen Phänomens führt zur übergreifenden methodischen Überlegung nach der Bewertung von Kürzungsfunktionen in literarischen Texten: Diese könnten nur über eine Differenzierung der Perspektiven und die Zusammenführung unterschiedlicher Beobachtungsebenen sichtbar werden. Als konstitutiv im Hinblick auf Hartmanns Klage erweist sich eine spezifische, im Modus von Kürzung und Erweiterung modellierte Zeit-Poetik des Textes, die eine "prägnante wie 
innovative Umsetzung des pragmatischen Paradox der hohen Minne» (S. 96) repräsentiere.

Ambivalente Form-Inhalt-Relationen im Spannungsfeld von abbreviatio und amplificatio, von «maximale[r] Kondensierung der [...] Referenzstoffe und -werke bei gleichzeitiger formaler Aufschwellung» (S. 155) verhandelt Raphael Schwitter anhand unterschiedlicher Textgruppen der spätlateinischen Dichtung (hexametrische und lyrische Dichtung, Epigrammatik, Katalogdichtung). Das (versefüllende Asyndeton` erweise sich dabei als dominantes, aufgrund seines raffend-kumulierenden Verfahrens schillerndes Stilmittel, das eine spezifische narrative Logik ausstelle: In Form einer «elliptischen Verdichtung» (S. 126) würden die Wissensbestände des «klassischen Literaturkanons» (S. 138) in einer Weise aufgerufen, dass der «Eindruck absoluter Vollständigkeit» (S. 155) entstehe. Die literarischen Funktionsweisen der abbreviatio nähmen eine soziale Dimension an, indem der narrativ-abbreviierende Modus auf intellektuelle Inklusions- beziehungsweise Exklusionsmechanismen berechnet sei.

Um verstechnisch erzeugte Kürze geht es auch Jörg Wesche am Beispiel des Dramenwerks von Andreas Gryphius. Im Mittelpunkt steht die Frage nach der historischen Stilisierung von «Nähesprachlichkeit» (S. 165) im Kontext der literarisch modellierten «dramaturgischen Dynamik mündlicher Strukturen» (166): «Ziel ist somit die Engführung von dramenanalytischen und interaktionslinguistischen Perspektiven im Hinblick auf Kürze im dramatischen Dialog» (S. 165). Stilistisch-poetische Kürzemechanismen exponierten eine «rhetorische in situ-Technik» (S. 170), die Spielarten konzeptioneller Mündlichkeit durch Verfahren artifizieller Versifikation konsequent verdichte. Quantitative und qualitative Relationen bedingten einander insofern, als die «interaktionale Kürze» (S. 171) eingelassen sei in die große Form» des Dramas, sodass die «Textsortenspezifik von Kürze [...] auf theatralische Performanz und Transitorik hin angelegt zu sein» scheine (S. 177).

\section{Kürzung im Kontext kulturhistorischer Diskurse}

Das Beispiel der Kürzetechniken in Gryphius' Dramenwerk dokumentiert, dass die Funktionsweisen der abbreviatio sich nicht nur jeweils gattungsspe- 
zifisch distinkt ausprägen, sondern zugleich kultur- und diskursgeschichtlichen Konstanten unterliegen. Im engeren Sinne rhetorische Formaspekte stehen dabei im Dienste spezifischer Semantiken, deren Sinnpotential sich in einem Kontinuum von poetischer Technik, literarischer Tradition, aber auch kultur- und sozialhistorischer Situierung der Texte entfaltet. Der Verflechtung von Produktions- und Wirkungskalkül abbreviierender Poetiken vor dem Horizont historischer Diskurse sind die Beiträge dieser Sektion gewidmet.

Ricarda Bauschke fokussiert Herbort von Friztlar als «Grenzgänger» (S. 206) zwischen der Praxis des höfischen Amplifizierens und dem «abbreviatorische[n] Erzählen von Troja» (S. 189) in der zeitgenössischen lateinischen Literatur. Die «Verquickung beider Paradigmen» (S. 206) im Liet von Troye interpretiert Bauschke als "bewusst vollzogene[ ] Diskursmischung» (S. 188), die sowohl am Ideal der volkssprachigen adaptation courtoise als auch der lateinischen rhetorischen Tradition partizipiere. Das Oszillieren zwischen unterschiedlichen Referenzebenen dokumentiere den relationalen Charakter der abbreviatio, die zwischen texttypen- und diskursspezifischen Kürze-Länge-Parametern changiere. Herborts «Novitätsanspruch» (S. 200) bestehe damit in einer aemulatio «konkurrierende[r] Erzählverfahren» (S. 188), deren Kontextgebundenheit sich auch in der gemeinsamen handschriftlichen Überlieferung der Texte abzeichne.

Den Umgang mit Texten, Kontexten und Konzepten als «habitualisierte Praxis» (S. 226) in spezifischen kultur- und diskurshistorischen Konstellationen (hier: der spätmittelalterlichen Reformbewegung) verhandelt Almut Suerbaum am Beispiel mystischer Lieder. Als Teil von kulturellen Netzwerken schließe sich das analysierte lyrische Textmaterial an historische Diskurse an, die zugleich im Modus abbreviierender 〈Verdichtung〉 der Bezugstexte mit den für das mystische Sprechen charakteristischen Formen inzitativer Rede ${ }^{93}$ aktualisiert würden: Die kreativen Adaptationsprozesse der im Umfeld der Dominikanerinnenkonvente kursierenden Predigten und Traktate etablierten eine «Sprachform, welche unter Verzicht auf syntagmatische und syntaktische Kohärenzen eine neue, andere Form der Kohärenz stiftet, welche zentral über die Klanglichkeit bestimmt ist und affektiv wirkt» (S. 225). 
Das legendarische Erzählen als textsortenspezifische und diskurs- wie kontextorientierte Form «exemplarischer religiöser Kommunikation» (S. 230) ist Gegenstand des Beitrags von Hans Jürgen Scheuer. Er zielt auf die Herauspräparierung eines «intrinsische[n] Momentum[s]» (S. 235), das die Legende innerhalb der historischen praxeologischen Konstellationen des hagiographischen Feldes als «distinkte Literaturform» (ebd.) exponiere. Grundlegendes Merkmal sei ihre «Entstehung durch das Verfahren der compilatio» (ebd.), das im Akt einer selektierenden Neu-Akzentuierung durch quantitative abbreviatio und qualitative brevitas das jeweilige Grundmotiv zu einer «wiedererkennbaren Pathosformel verdichtet» (S. 236): «Sie erlaubt es, Heiligkeit aus dem Kontext ihrer vormodernen, genauer: vorreformatorischen Praxis und Überlieferung heraus als konzentrierte formative Energie zu beschreiben» (S. 255).

Am Beispiel der Laurentias des Giovanni Mario Filelfo (1426-1480) untersucht Thomas Haye die Möglichkeiten der Bewältigung umfangreichen Textmaterials im historischen Kontext des italienischen Renaissance-Humanismus. Der monumentale Umfang des lateinischen Epos stehe in spannungsvollem Kontrast zum Faktor der offensichtlich knappen (Rezeptions-) Zeit des hochstehenden Widmungsträgers Lorenzo de' Medici. Als spezifische Strategie für den Erfolg der poetischen Leistung als «kulturelle Investition» (S. 265) bediene sich Giovanni Mario daher der «Tradition der paratextuellen argumenta» (S. 276), knapper Inhaltsangaben, die er jedoch durch ihre Positionierung am Werkende neu funktionalisiere: Nicht mehr nur als Anschluss an antike Konventionen repräsentierten sie «die Schlüsselpartie des Gesamtwerkes» (S. 277), die «eine Lektüre des vollständigen Epos sogar weitgehend überflüssig machte[ ]» (S. 278).

Reformatorische und kontroverstheologische Diskurse um die Deutung der Höllenfahrt Christi rekonstruiert Oliver Grütter anhand von Johann Spangenbergs Triumphus Christi heroicus, einer Kurzfassung der Victoria Christi ab inferis des Helius Eobanus Hessus. In seiner Analyse des syntaktischen und versifikatorischen Verfahrens der abbreviatio kann Grütter zeigen, dass auch in diesem Fall die «quantitative Reduktion des Bezugstextes [...] mit einer qualitativen einher[geht]» (S. 283), die mittels des Stilideals der brevitas realisiert werde. Dabei offeriere der Schluss des Textes eine exegetisch prägnante «reformatorische Kodierung der Kurzfassung» (S. 297), die den Triumphus vor dem Hintergrund der (widersprüchlichen) lutheri- 
schen Deutung der Höllenfahrt profiliere und die historische Rezeption im Kontext der zeitgenössischen innerreformatorischen Kontroversen um die Höllenfahrt maßgeblich bestimme.

\section{Fassungsdivergenz und Formen redaktioneller Kürzung}

Dass die Tradierung mittelalterlicher Texte in der Volkssprache in sehr viel stärkerem Maße als die der in der gelehrten Bildungssprache Latein verfassten Werke der mouvance unterliegt, gehört zu den überlieferungshistorischen Grundtatsachen. Infolge der Ausbildung eines charakteristischen Variantenprofils lassen sich «gleichwertige Parallelversionen` unterscheiden, ${ }^{94}$ die einerseits Einblicke in die Relationen zwischen Vorlage und Bearbeitung erlauben; andererseits zeichnet sich an ihnen die Aktualisierung von Rezipientenwissen, etwa bezüglich textsortenspezifischer Erzählmuster, ab, sodass sich auch unabhängig voneinander entstandene, divergente Fassungen eines Textes über im Gattungskontinuum präsente Referenztypen jenseits konkret schriftlich fassbarer Prätexte in Bezug setzen lassen. Die produktive Aneignung vorgängigen literarischen Materials im Modus der abbreviatio analysieren die Beiträge dieser Sektion ausgehend von der mittelhochdeutschen Epik und Versnovellistik.

Martin Baisch nimmt eine Revision des Forschungsdiskurses zu Bewertung und Umgang mit Fassungsdivergenz im höfischen Roman vor. Die Annahme, dass die Parameter Streichung und Vermehrung als komplementäre Formen der Ausdifferenzierung von Sinn zu verstehen seien, grundiert die Leitfragen nach der «textproduktive[n] Perspektive» (S. 331), den «Phänomene[n] und Effekte[n]» auf der Textebene (ebd.) sowie nach dem «historischen Index» der Varianz (S. 332). Wie die jeweils unterschiedlich gelagerten Transformationsphänomene unter Zugrundelegung des rhetorisch-poetischen Ansatzes historisch beobachtbar werden, demonstriert ein Vergleich der Kürzungsoperationen in der Nibelungenklage ${ }^{\star} \mathrm{J}$ sowie dem Tristan Gottfrieds von Straßburg im Cgm 51, der die «je unterschiedlich kohärente[n] (Gegen-)Entwürfe zu den bearbeiteten Textwelten» (S. 339) aufzeigt. 
Den singulären Fall, 〈Original〉 und 〈Kopie〉 (S. 348) eines Textes miteinander konfrontieren zu können, präsentieren Michael Stolz und Richard Fasching anhand des Rappoltsteiner Parzifal. Dabei arbeiten die Autoren mit einer «skripturalen Begrifflichkeit»(S. 347), welche das Verhältnis von Text und Prätext als das einer «Transkription» (ebd.) bestimmt. In der kopierten Version des umfangreichen Werkes (Roma, Biblioteca Casanatense, Ms. 1409) «lassen sich [...] auffällige Kürzungsvorgänge beobachten» (S. 346), die offenbar direkt «während des Kopierprozesses» (S. 349) vorgenommen worden seien: Die im Akt der Abschrift entstandene quantitative Varianz konstituiere dabei keine neue 〈Fassung〉 des Textes, sondern dokumentiere vielmehr eine kommunikative Handlung, indem die Eigenart der Kurzversion «Verstehensakte im Überlieferungsprozess nachvollziehen lässt» (S. 370).

Die «Frage nach dem rechten Maß der Worte» (S. 378) untersucht Cordula Kropik am Beispiel der Heidelberger und der Dresdener Virginal. In den jeweiligen Kurzversionen der Texte ließen sich zwar verschieden ausgeprägte abbreviatio-Konzepte beobachten, denen gleichwohl ein gemeinsamer Fluchtpunkt im Hinblick auf ein spezifisches Wirkungskalkül eigne: im einen Fall realisiert durch die Formulierung einer "praktische[n] Erzähllehre» (S. 387) im Sinne einer «rhetorische[n] Narratologie» (S. 394), während Kürzungen im anderen Fall als Instrument mündlichkeitsnaher Textproduktion fungierten, wobei die Rezipienten angehalten seien, «Darstellungslücken aus alltagsweltlichem oder literarischem Schemawissen zu füllen» (S. 402). Der Beitrag dokumentiert nachdrücklich, dass die Entscheidung, "[w]elche Worte unnütz sind und welche nicht» (S. 403), nur mittels einer Vervielfältigung der Beobachtungsebenen und methodischen Zugänge zu erschließen ist.

Ein synchrones Nebeneinander gleichwertiger Textfassungen, ohne dass sich ein gemeinsamer schriftlich fixierter Referenzpunkt rekonstruieren ließe, ist auch für die Überlieferung der Versnovellistik charakteristisch. Sandra Linden nimmt «unterschiedliche[] Aggregatzustände[ ]» (S. 408) mittelhochdeutscher Mären in den Blick, die sie auf die literarischen Kürzungsstrategien und den damit evozierten «ästhetische[n] Reiz» (S. 407) des Erzählens hin befragt. Dieser basiere statt auf einem «Vergleich mit einem konkreten längeren Ausgangstext» (S. 425) auf einem «Gattungswissen» (ebd.) der Rezipienten, das die jeweils ein- beziehungsweise ausgefalteten 
Erzählmuster vor dem Hintergrund des literarischen Kontinuums evaluiert. An ausgewählten Fallstudien zeigt Linden, dass die abbreviatio im Dienste einer spezifischen narrativen «Dynamisierung und Beschleunigung der Handlungsabläufe» (S. 429) stehe, sodass das Publikum eine «intellektuelle[]Freude» (ebd.) primär über die «erhöhte[] Erzählgeschwindigkeit» (ebd.) im eigenständigen Rückgriff auf die «Bezugsmatrix der Gattung» (S. 425) beziehe.

Unterschiedlich akzentuierte Realisierungen des «Fleischpfand $〉$-Motivs im Kontext einer «umfassende[n] narrative[n] Tradition» (S. 434) behandelt Pia Selmayr am Beispiel lateinischer und deutscher Versionen der CreditorErzählung. Das Verfahren erweiternder und kürzender «Retextualisierung» (S. 436) des primären Bezugspunktes 〈Fleischpfand` eröffne Gestaltungsspielräume, die die Sinnkonstitution der Texte tangierten und - vergleichbar mit Lindens Beobachtung - ein Vorwissen auf der Seite der Rezipienten aktivierten, das «die jeweilige Version als kulturelles Produkt aus[weist]» (S. 437). Das zur pointierten (Um-)Akzentuierung des Erzählkerns genutzte Gestaltungsprinzip der abbreviatio treibe «eine Aushandlung von Liebe und Begehren, Recht und Gerechtigkeit, Ökonomie, Kommunikation und Wissen voran[ ]» (S. 436) und gehe "zugleich mit einer Umorganisation von Wissen» (S. 457) einher, die Bekanntes und Neues changieren lasse und so «Formen der Rezeption mit textueller Reproduktion» (ebd.) verbinde.

\section{Bibliographie}

\section{Primärliteratur}

M. Tullius Cicero: De inventione. Über die Auffindung des Stoffes. De optimo genere oratorum. Über die beste Gattung von Rednern. Lateinisch-deutsch, hg. und übers. v. Theodor Nüßlein, Darmstadt 1998.

Deutsche Versnovellistik des 13. bis 15. Jahrhunderts (DVN), hg.v. Klaus Ridder / HansJoachim Ziegeler, 6 Bde., Basel / Berlin 2020.

Eberhard der Deutsche. Laborintus. Nach dem Text von Edmond Faral hg., übers. und kommentiert v. Justin Vollmann 2020, Basel 2020.

Faral, Edmond: Les Arts poétiques du XIIe et du XIIIe siècle. Recherches et documents sur la technique littéraire du moyen âge, Genf 1982 (Nachdr. Paris 1924).

Quintus Horatius Flaccus. Epistles, Book II. And Epistle to the Pisones, hg.v. Niall Rudd, Cambridge 1989. 
Pascal, Blaise: Les Provinciales ou les lettres écrites par Louis de Montalte a un provincial de ses amis et aux RR. PP. Jesuites sur le sujet de la morale et de la politique, Paris 1656/57.

Blaise Pascal's Provinzialbriefe über die Moral und Politik der Jesuiten. Übersetzt von J. J. G. Hartmann, Berlin 1830.

M. Fabi Quintiliani Institutiones oratoriae libri duodecim, 2 Bde., hg.v. Michael Winterbottom, Oxford 1970.

Woods, Marjorie C. (Hg.): An Early Commentary on the Poetria nova of Geoffrey of Vinsauf, New York 1985.

\section{Forschungsliteratur}

Baisch, Martin: abbreviatio im Spannungsfeld von Textkritik und Hermeneutik. Zur Kurzfassung der höfischen Erzähltexte Gottfrieds von Straßburg und Ulrichs von Türheim im Cgm 51, in: Elizabeth Andersen / Manfred Eikelmann / Anne Simon (Hgg.): Texttyp und Textproduktion in der deutschen Literatur des Mittelalters, Berlin / New York 2005 (Trends in Medieval Philology 7), S. 101-120.

Baisch, Martin: Textkritik als Herausforderung der Kulturwissenschaft. Tristan-Lektüren, Berlin / New York 2006 (Trends in Medieval Philology 9).

Baumbach, Manuel / Bär, Silvio: A Short Introduction to the Ancient Epyllion, in: dies. (Hgg.): Brill's Companion to Greek and Latin Epyllion and Its Reception, Leiden / Boston 2012, S. ix-xvi.

Bezner, Frank: Vela veritatis. Hermeneutik, Wissen und Sprache in der Intellectual History des 12. Jahrhunderts, Leiden / Boston 2005.

Bumke, Joachim: Die vier Fassungen der Nibelungenklage. Untersuchungen zur Überlieferungsgeschichte und Textkritik der höfischen Epik im 13. Jahrhundert, Berlin u. a. 1996 (Quellen und Forschungen zur Literatur- und Kulturgeschichte 8 [242]).

Bumke, Joachim / Peters, Ursula (Hgg.): Retextualisierung in der mittelalterlichen Literatur, Berlin 2005 (ZfdPh Sonderheft 124).

Dahm-Kruse, Margit: Versnovellen im Kontext. Formen der Retextualisierung in kleinepischen Sammelhandschriften, Tübingen 2018 (Bibliotheca Germanica 68).

Dimpel, Friedrich Michael / Wagner, Silvan (Hgg.): Prägnantes Erzählen, Oldenburg 2019 (Brevitas 1 - BmE Sonderheft).

Dusil, Stephan / Schwedler, Gerald / Schwitter, Raphael (Hgg.): Exzerpieren - Kompilieren - Tradieren. Transformationen des Wissens zwischen Spätantike und Frühmittelalter, Berlin / Boston 2016 (Millennium-Studien 64). [= 2016a ]

Dusil, Stephan / Schwedler, Gerald / Schwitter, Raphael: Transformationen des Wissens zwischen Spätantike und Frühmittelalter. Zur Einführung, in: dies. (2016), S. 1-22. $[=2016 b]$ 
Eichenberger, Nicole: Variationen eines Themas. Zur Korrelation von Umfang und literarisch-konzeptioneller Gestaltung bei stoffverwandten geistlichen Verserzählungen, in: Holznagel / Cölln (2017), S. 155-175.

Eigler, Ulrich: Lectiones vetustatis. Römische Literatur und Geschichte in der lateinischen Literatur der Spätantike, München 2003 (Zetemata 115).

Elm, Kaspar (Hg.): Literarische Formen des Mittelalters. Florilegien, Kompilationen, Kollektionen, Wiesbaden 2000 (Wolfenbütteler Mittelalter-Studien 15).

Frick, Julia: Schriftliche und visuelle argumenta im Nachdruck von Thomas Murners Aeneis-Übersetzung (Worms 1543), in: Mittellateinisches Jahrbuch 52 (2017), S. 231-260.

Frick, Julia: abbreviatio. Zur historischen Signifikanz von Kürzungsfunktionen in der mittelhochdeutschen höfischen Epik des 13. Jahrhunderts. Eine Projektskizze, in: PBB 140 (2018), S. 23-50.

Frick, Julia: Reflexionen des Untergangs. Erzählen vom Ende in den Fassungen der Nibelungenklage, in: Julia Weitbrecht / Andreas Bihrer / Timo Felber (Hgg.): Die Zeit der letzten Dinge. Deutungsmuster und Erzählformen des Umgangs mit Vergänglichkeit in Mittelalter und Früher Neuzeit, Göttingen 2020 (Encomia Deutsch 6), S. 125-142. [= 2020a]

Frick, Julia: Zwischen Sinnreduktion und Prägnanz. Kürzung als Instrument der Sinnbildung in historischer Poetik und literarischer Reflexion, in: Zacke u. a. (2020), S. 219-244. [=2020b]

Frick, Julia: ez wâre ze sagene al ze lank. Zum Stellenwert der 〈Kürze-Topoi〉 im mittelhochdeutschen Antikenroman, in: ZfdPh 139 (2020), S. 353-378. [=2020c]

Frick, Julia / Rippl, Coralie (Hgg.): Dynamiken literarischer Form im Mittelalter, Zürich 2020 (Mediävistische Perspektiven 10).

Fuhrmann, Manfred: Obscuritas. Das Problem der Dunkelheit in der rhetorischen und literarästhetischen Theorie der Antike, in: Wolfgang Iser (Hg.): Immanente Ästhetik - Ästhetische Reflexion. Lyrik als Paradigma der Moderne, München 1966 (Poetik und Hermeneutik 2), S. 47-72.

Goeinng, Anja-Silvia / Grafton, Anthony T. / Michel, Paul (Hgg.): Collectors' Knowledge: What Is Kept, What Is Discarded / Aufbewahren oder wegwerfen - Wie Sammler entscheiden, Leiden / Boston 2013.

Griese, Sabine: Text-Bilder und ihre Kontexte. Medialität und Materialität von Einblatt-, Holz- und Metallschnitten des 15. Jahrhunderts, Zürich 2011 (Medienwandel Medienwechsel - Medienwissen 7).

Hasebrink, Burkhard: Formen inzitativer Rede bei Eckhart. Untersuchungen zur literarischen Konzeption der deutschen Predigt, München 1992 (Texte und Textgeschichte 32). 
Haug, Walter: Geheimnis und dunkler Stil, in: Aleida Assmann / Jan Assmann / Theo Sundermeier (Hgg.): Schleier und Schwelle, Bd. 2: Geheimnis und Offenbarung, München 1998 (Archäologie der literarischen Kommunikation 5,2), S. $203-217$.

Heinzer, Felix: Zur Bedeutung und Geschichte des Breviculums. Vortrag anlässlich der Präsentation des vollst. Faksimile der Handschrift der Badischen Landesbibliothek St. Peter perg. 92 am 13. Sept. 1988 in der Badischen Landesbibliothek Karlsruhe, Karlsruhe 1988 (Vorträge Badische Landesbibliothek 19).

Henkel, Nikolaus: Deutsche Übersetzungen lateinischer Schultexte. Ihre Verbreitung und Funktion im Mittelalter und in der frühen Neuzeit. Mit einem Verzeichnis der Texte, München 1988 (MTU 90).

Henkel, Nikolaus: Kurzfassungen höfischer Erzähldichtung im 13./14. Jahrhundert. Überlegungen zum Verhältnis von Textgeschichte und literarischer Interessenbildung, in: Joachim Heinzle (Hg.): Literarische Interessenbildung im Mittelalter. DFG-Symposion 1991, Stuttgart / Weimar 1993, S. 39-59.

Henkel, Nikolaus: Deutsche Glossen. Zum Stellenwert der Volkssprache bei der Erschließung lateinischer Klassiker, in: Wolfgang Haubrichs / Ernst Hellgardt (Hgg.): Theodisca. Beiträge zur althochdeutschen und altniederdeutschen Sprache und Literatur in der Kultur des frühen Mittelalters, Berlin 2000 (Ergänzungsbände zum Reallexikon für Germanische Altertumskunde 22), S. 387-413.

Henkel, Nikolaus: Dialoggestaltung in deutschen und französischen Romanen des 12. Jahrhunderts. Das Modell der Dramen des Terenz und Seneca, in: Monika Unzeitig / Nine Miedema / Franz Hundsnurscher (Hgg.): Redeszenen in der mittelalterlichen Großepik. Komparatistische Perspektiven, Berlin 2011, S. 139-164. Henkel, Nikolaus: Reduktion als poetologisches Prinzip. Verdichtung von Erzählungen im lateinischen und deutschen Hochmittelalter, in: Holznagel / Cölln (2017), S. 2755.

Henkel, Nikolaus / Noll, Thomas / Rexroth, Frank (Hgg.): Reichweiten. Dynamiken und Grenzen kultureller Transferprozesse in Europa, 1400-1520. Bd. 1: Internationale Stile - Voraussetzungen, soziale Verankerungen, Fallstudien, Berlin 2020 (Abhandlungen der Akademie der Wissenschaften zu Göttingen. N. F. 49/1).

Holznagel, Franz-Josef: Wege in die Schriftlichkeit. Untersuchungen und Materialien zur Überlieferung der mittelhochdeutschen Lyrik, Tübingen 1995 (Bibliotheca Germanica 32 ).

Holznagel, Franz-Josef / Cölln, Jan (Hgg.): Die Kunst der brevitas. Kleine literarische Formen des deutschsprachigen Mittelalters, Berlin 2017 (Wolfram-Studien XXIV). Horster, Marietta / Reitz, Christiane (Hgg.): Condensing texts - condensed texts, Stuttgart 2010 (Palingenesia 98).

Horster, Marietta / Reitz, Christiane: Handbooks, Epitomes, and Florilegia, in: Scott McGill / Edward J. Watts (Hgg.): A Companion to Late Antique Literature, New York 2018 (Blackwell Companions to the Ancient World), S. 431-450. 
Hübner, Gert: Erzählform im höfischen Roman. Studien zur Fokalisierung im Eneas, im Iwein und im Tristan, Tübingen 2003 (Bibliotheca Germanica 44).

Jolles, André: Einfache Formen. Legende, Sage, Mythe, Rätsel, Spruch, Kasus, Memorabile, Märchen, Witz, Halle a. S. 1930.

Kallendorf, Craig / Gondos, Lisa (Übers.): Art. Brevitas, in: HWRh Bd. 2 (1994), Sp. $53-$ 60.

Kiening, Christian: Fülle und Mangel. Medialität im Mittelalter, Zürich 2016.

Klopsch, Paul: Einführung in die Dichtungslehren des lateinischen Mittelalters, Darmstadt 1980.

Knapp, Fritz Peter: Poetik, in: ders. (Hg.): Die Rezeption lateinischer Wissenschaft, Spiritualität, Bildung und Dichtung aus Frankreich, Berlin / Boston 2014 (Germania Litteraria Medievalis Francigena [GLMF] 1), S. 217-242.

Köbele, Susanne: Einleitung, in: Köbele / Frick (2018), S. 9-25.

Köbele, Susanne / Frick, Julia (Hgg.): wildekeit. Spielräume literarischer obscuritas im Mittelalter, Berlin 2018 (Wolfram-Studien XXV).

Lausberg, Heinrich: Handbuch der literarischen Rhetorik, München 1960.

Lieb, Ludger: Die Potenz des Stoffes. Eine kleine Metaphysik des «Wiedererzählens`, in: Bumke / Peters (2005), S. 356-379.

Linden, Sandra: Exkurse im höfischen Roman, Wiesbaden 2017 (MTU 147).

Lutz, Eckart Conrad: Text und 〈Text〉 - Wortgewebe und Sinngefüge. Zur Einleitung, in: Eckart Conrad Lutz / Wolfgang Haubrichs / Klaus Ridder (Hgg.): Text und Text in lateinischer und volkssprachiger Überlieferung des Mittelalters. Freiburger Kolloquium 2004, Berlin 2006 (Wolfram-Studien XIX), S. 9-31.

Masse, Marie-Sophie / Seidl, Stephanie (Hgg.): 〈Texte dritter Stufe〉. Deutschsprachige Antikenromane in ihrem lateinisch-romanischem Kontext, Münster 2016 (Kultur und Technik 31).

McGill, Scott / Watts, Ed (Hgg.): A Companion to Late Antique Literature, New York 2018 (Blackwell Companions to the Ancient World).

Meier, Christel: Konkretisierung und Symbolisierung des Textes im Bild. Eine Skizze. Zugleich ein Versuch über das textus-Konzept von Raimundus Lullus, in: Ludolf Kuchenbuch / Uta Kleine (Hgg.): 〈Textus〉 im Mittelalter. Komponenten und Situationen des Wortgebrauchs im schriftsemantischen Feld, Göttingen 2006 (Veröffentlichungen des Max-Planck-Instituts für Geschichte 216), S. 337-373.

Mülke, Markus: Die Epitome - das bessere Original? In: Horster / Reitz (2010), S. 6989.

Murphy, James J.: The Arts of Poetry and Prose, in: Alastair Minnis / Ian Johnson (Hgg.): The Cambridge History of Literary Criticism. Bd. 2: The Middle Ages, Cambridge 2005, S. $42-67$. 
Munk Olsen, Birger: L'étude des auteurs classiques latins aux $\mathrm{XI}^{\text {e }}$ et $\mathrm{XII}^{\mathrm{e}}$ siècles. 6 Bde., Paris 1982/85/87/89/2009/2014, bes. Bd. 4,1: La réception de la littérature classique. Travaux philologiques, Paris 2009.

Posselt, Bernd: Konzeption und Kompilation der Schedelschen Weltchronik, Wiesbaden 2015 (Monumenta Germaniae Historica. Schriften 71).

Reitz, Christiane: Verkürzen und erweitern - literarische Techniken für eilige Leser? Die Ilias Latina als poetische Epitome, in: Hermes 135 (2007), S. 334-351.

Reitz, Christiane: Homer kürzen? Verkürzung und Paraphrase homerischer Epik in der antiken Kritik, in: Horster / Reitz (2010), S. 289-305.

Reitz, Christiane: Das Unendliche beginnen und sein Ende finden - Strukturen des Aufzählens in epischer Dichtung, in: Christine Schmitz / Angela Jöne / Jan Kortmann (Hgg.): Anfänge und Enden. Narrative Potentiale des antiken und nachantiken Epos, Heidelberg 2017, S. 105-118.

Reitz, Christiane / Finkmann, Simone (Hgg.): Structures of Epic Poetry. 3 Bde., Berlin / Boston 2019.

Scheuer, Hans Jürgen: Faltungen. Brevitas, Allegorie und Exemplarität in mittelalterlichen Transformationen Ovids, in: Holznagel / Cölln (2017), S. 57-75.

Schmidt, Paul Gerhard: Die Kunst der Kürze, in: Stotz (2008), S. 23-40.

Schmitz, Silvia: Die Poetik der Adaptation. Literarische inventio im Eneas Heinrichs von Veldeke, Tübingen 2007 (Hermaea N. F. 113).

Schnell, Rüdiger: Prosaauflösung und Geschichtsschreibung im deutschen Spätmittelalter. Zum Entstehen des frühneuhochdeutschen Prosaromans, in: Ludger Grenzmann / Karl Stackmann (Hgg.): Literatur und Laienbildung im Spätmittelalter, Stuttgart 1984 (Germanistische Symposien-Berichtsbände 5), S. 214-248.

Schwitter, Raphael: Umbrosa lux. Obscuritas in der lateinischen Epistolographie der Spätantike, Stuttgart 2015 (Hermes Einzelschriften 107).

Stackmann, Karl: Mittelalterliche Texte als Aufgabe, in: Werner Foerste / Karl Heinz Borck (Hgg.): Festschrift für Jost Trier zum 70. Geburtstag, Köln / Graz 1964, S. $240-267$.

Stotz, Peter (Hg.): Dichten als Stoff-Vermittlung. Formen, Ziele, Wirkungen. Beiträge zur Praxis der Versifikation lateinischer Texte im Mittelalter, Zürich 2008 (Medienwandel - Medienwechsel - Medienwissen 5).

Strohschneider, Peter: Höfische Romane in Kurzfassungen. Stichworte zu einem unbeachteten Aufgabenfeld, in: ZfdA 120 (1991), S. 419-439.

Strohschneider, Peter: Rezension zu: Joachim Bumke: Die vier Fassunngen der Nibelungenklage. Untersuchungen zur Überlieferungsgeschichte und Textkritik der höfischen Epik im 13. Jahrhundert, Berlin / New York 1996, in: ZfdA 127 (1998), S. $102-117$.

Wagner, Silvan / Dimpel, Friedrich Michael: Prägnante Kleinepik, in: Dimpel / Wagner (2019), S. 1-13. 
Walde, Christine: Art. Obscuritas, in: HWRh Bd. 6 (2003), Sp. 358-368.

Waltenberger, Michael: 〈Bedeutungsschwangerschaften〉. Überlegungen zu Prägnanz und Pointierung mit Lessing und Galfred von Vinsauf, in: Dimpel / Wagner (2019), S. $21-43$.

Werle, Dirk: Copia librorum. Problemgeschichte imaginierter Bibliotheken 1580-1630, Tübingen 2007 (Frühe Neuzeit 119).

Worstbrock, Franz Josef: Rhetorische Formtypen der mittelalterlichen Lyrik $\left({ }^{1} 1975\right)$, in: ders.: Ausgewählte Schriften. Bd. 1: Schriften zur Literatur des Mittelalters, hg.v. Susanne Köbele / Andreas Kraß, Stuttgart 2004, S. 17-38.

Worstbrock, Franz Josef: Dilatatio materiae. Zur Poetik des Erec Hartmanns von Aue, in: Frühmittelalterliche Studien 19 (1985), S. 1-30.

Worstbrock, Franz Josef: Wiedererzählen und Übersetzen, in: Walter Haug (Hg.): Mittelalter und Frühe Neuzeit. Übergänge, Umbrüche und Neuansätze, Tübingen 1999 (Fortuna vitrea 16), S. 128-142.

Zacke, Birgit u. a. (Hgg.): Text und Textur. WeiterDichten und AndersErzählen im Mittelalter, Oldenburg 2020 (BmE Themenheft 5).

Zumthor, Paul: Brevity as form (trans. by Laurence T. Moscato and William Nelles), in: Narrative 24 (2016), S. 73-81 (ursprüngl. erschienen als: La Brièveté comme Forme, in: Michelangelo Picone / Giuseppe Di Stefano / Pamela D. Steward (Hgg.): La Nouvelle. Formation, codification et rayonnement d'un genre médiéval. Actes du colloque international de Montréal 1982, Montréal 1983, S. 3-8). 

Formsemantiken: Quantitative und qualitative Relationierung 



\title{
Homer in Kürze
}

\section{Zu Handhabbarkeit und Ästhetik antiker Epitomai}

von

Christiane Reitz (Berlin / Rostock)

\begin{abstract}
I.
cuiauis oratio insimulari potest, si ea quae ex prioribus nexa sunt principio sui defrudentur, si quaedam ex ordine scriptorum ad lubidinem supprimantur, si quae simulationis causa dicta sunt adseuerantis pronuntiatione quam exprobrantis legantur. (Apul. Ap. 82)

\Jede Äußerung kann verfälscht werden, wenn das, was aus dem Vorhergehenden entwickelt ist, seines Anfangs beraubt wird, wenn etwas aus der Abfolge des Geschriebenen nach Belieben unterdrückt wird, wenn das, was zum Zwecke der Ironie gesagt worden ist, mit dem Tonfall des Ernstes wie eine Schmähung vorgetragen wird.>
\end{abstract}

Mit diesen Worten warnt Apuleius in seiner Verteidigungsrede davor, Zitaten und Ausschnitten und grundsätzlich Bearbeitungen von Texten Glauben zu schenken. Zu leicht könne man davon in die Irre geführt werden. Hier artikuliert sich in nuce ein großes Misstrauen gegenüber der Technik des Verkürzens; das Zitat führt uns ein in das weite Spektrum verkürzender Gattungen.

Warum werden Texte verkürzt und zusammengefasst? Auf diese Frage gibt es viele Antworten. Eine zwar einfache, aber doch grundlegende Unterscheidung lautet: Wir können verkürzte Texte unter gattungstypischen Gesichtspunkten betrachten: Epitomai, Periochai, Blütenlesen, Hypotheseis. ${ }^{1}$ Insbesondere, wenn der Ausgangstext nicht mehr existiert, kommen wir dann rasch in ein der Quellenforschung verwandtes Gebiet. Auf der anderen

1 Der grundlegende Überblick ist nach wie vor Opelt (1962). Vgl. auch Horster / Reitz (2010) und Horster / Reitz (2018). 
Seite stellen die Techniken des Verkürzens ein ästhetisches und intellektuelles Phänomen dar.

Vor wenigen Jahren war durchaus noch die Ansicht anzutreffen, das Kürzen und Verkürzen sei ein Anzeichen für die nachlassende intellektuelle Potenz einer ganzen Epoche, Indiz dafür, dass breite Schichten der spätantiken Gesellschaft(en) nicht mehr in der Lage oder willens waren, größere Corpora und längere Texte $\mathrm{zu}$ lesen und $\mathrm{zu}$ durchdringen: Verkürzung wurde als Degenerationssignal aufgefasst. Auch das Buch von Markus Sehlmeyer, in dem in schöner Übersichtlichkeit Breviarien und ähnliche Texte vorgestellt werden, ist von dieser Grundannahme nicht ganz frei. ${ }^{2}$ Gegenwärtig haben das zunehmende forscherische Interesse an der Spätantike und daher das tiefere Eindringen in die neu entstehenden oder sich entschiedener etablierenden literarischen Gattungen die Sicht verändert; und vor allem artikuliert sich ein vermehrtes Eingehen auf intellektuelle Prozesse, auf Fragen, wie Wissen gespeichert, organisiert und verwahrt wird. ${ }^{3}$ Nicht nur die materiellen Voraussetzungen spielen hierfür eine Rolle. ${ }^{4}$ In diesem Kontext wird auch Gattungsspezifika verkürzender Genres mehr Aufmerksamkeit gewidmet. Ein Beispiel könnte die blühende Forschung $\mathrm{zu}$ den Centones $\operatorname{sein}^{5}$ oder überhaupt $\mathrm{zu}$ Zitaten im weiteren Sinne. ${ }^{6}$ Ein anderes ist die Ilias Latina, die noch vor gut zehn Jahren allenfalls als Anfängerlektüre für angehende Lateinstudenten diente. Am Erscheinen einer neuen Ausgabe, der Vorbereitung eines englischsprachigen Kommentars und eines Tagungsbandes ist zu sehen, ${ }^{7}$ dass dieser Text nunmehr, nach den abgeschlossen geglaubten Diskussionen über die Autorschaft, ${ }^{8}$ Gegenstand literaturwissenschaftlicher Forschung geworden ist.

\footnotetext{
2 Vgl. Sehlmeyer (2009).

3 Wegweisend hier die Arbeiten von Moatti, besonders Moatti (1997).

4 Ein Beispiel dafür, wie materielle Voraussetzungen und Verkürzungspraxis zusammenhängen, führt Werner Suerbaum (1992) aus, der plausibel argumentiert, die lateinische Zusammenfassung / Übersetzung der Odyssee von Livius Andronicus habe die Länge gehabt, um auf einer Papyrusrolle untergebracht zu werden.
}

5 Vgl. Bažil (2007); Schottenius Cullhed (2015).

6 Vgl. Binternagel / Tischer (2010) und Tischer (2021, im Druck).

7 Green (in Vorbereitung); Falcone / Schubert (2021, im Druck).

8 Zum Akrostichon fasst Scaffai (1997), S. 11-14, die vorangegangene Forschungsliteratur zusammen. 
Eine parallele Entwicklung kann man in Bezug auf die Tabulae Iliacae feststellen. Diese eher unscheinbaren Bildtafeln, rückseitig oder auch zwischen den Bildfeldern mit Inschriften versehen und an verschiedenen Orten aufbewahrt, wurden in der Forschungsgeschichte periodisch immer einmal hervorgeholt. Inzwischen muss man nicht mehr auf die, wie sich gezeigt hat, nicht vollständige Edition von Sadurska (1964) zurückgreifen. Nahezu hundert Jahre zuvor hatte Otto Jahn sich mit 'griechischen Bilderchroniken〉 befasst; seine Arbeiten wurden 1873 postum herausgegeben. Neuerdings haben Altertumswissenschaftler wie Valenzuela Montenegro, Petrain und Squire diese Zeugnisse endgültig von dem Werturteil befreit, es handele sich um schlichte Hilfsmittel für Schüler oder ungebildete Rezipienten, wie man sie in der Gestalt des neureichen Freigelassenen Trimalchio in Petrons Roman Satyricon karikiert findet. Stattdessen wurde zunehmend die spezifische ästhetische und ikonographische Sprache dieser Marmorreliefs untersucht.

Bevor ich mich einigen Passagen der Ilias Latina zuwende, um an ihnen zu zeigen, wie Grundkonstanten epischen Erzählens in dieser Sonderform von epischem Gedicht bewahrt sind und doch dem Zweck der Kürze und Prägnanz gehorchen, möchte ich kurz und beispielhaft auf einige andere Texte und Textsorten hinweisen, in denen die Inhalte der großen Epen (Homers und Vergils) in raffender und resümierender Form konserviert und tradiert werden. Dadurch wird die Bandbreite der Möglichkeiten etwas klarer, und es erweist sich das kulturelle Bedürfnis nach solchen Resümees und auch die Freude an der Variation, mit diesen Möglichkeiten umzugehen.

In einem Aufsatz von 2010 bin ich der Frage nachgegangen, welche Verfahren die antike Homerkritik, soweit sie uns greifbar ist, zum Epitomieren verwendet. ${ }^{9}$ Ich bin zu dem Schluss gekommen, dass die alexandrinische Homer-Kommentierung in der Regel davon ausgeht, dass der Leser mit dem Text so gut vertraut ist oder doch jedenfalls mit einem Text in der Weise versorgt ist, dass er auf inhaltliche Zusammenfassungen nicht angewiesen ist. Inzwischen habe ich mit einem gewissen Bedauern feststellen müssen, dass wir auch für die deutlich spätere Vergil-Kommentierung (Servius und Servius auctus) nicht mit Inhaltszusammenfassungen zu rechnen haben. Der Kommentar dient dem ganzen Text; zusammenfassende notes zu Beginn eines 
Lemmas sind eine neuzeitliche Erfindung, die dem sprachlich nicht ganz firmen Benutzer Orientierung bieten sollen. In der Antike scheint das nicht vorzukommen. Was der antike Kommentator jedoch vermerkt, ist ein epitomierendes Verfahren des Dichters selbst. Im 16. Gesang der Ilias charakterisiert der Scholiast zu Vers 123-3 bT den dort angebrachten

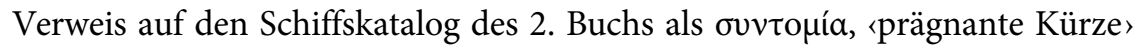

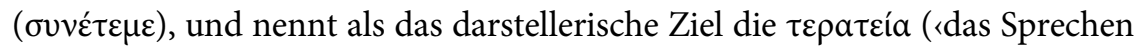
von Wunderdingen`). Innerhalb von Reden wird von den Scholiasten vielfach die verkürzende Darstellungsweise angemerkt.

Nicht zuletzt durch die Arbeiten von Markus Dubischar ${ }^{10}$ und in jüngerer Zeit vor allem von Eleanor Dickey ${ }^{11}$ sind «Schultexte〉 in den Blick gerückt, in denen zum Memorieren Inhaltsangaben der homerischen Gesänge erhalten sind, ganz offensichtlich auch für Schüler, die jedenfalls nicht muttersprachlich Latein sprachen, vielleicht auch nicht unbedingt Griechisch. Hypotheseis, die knappen Zusammenfassungen, die in der handschriftlichen Überlieferung den Dramentexten vorangestellt sind, können ebenfalls der Gedächtnisstütze oder auch, wie Peter von Möllendorff für Komödien gezeigt hat, ${ }^{12}$ als Paratexte sehr wahrscheinlich kommerziellen Zwecken, also dem Buchhandel gedient haben. Die Gattungszugehörigkeit der Verae Historiae des Aelian ist problematisch, und ich möchte sie hier nicht diskutieren, aber auch dieser Text des 2. Jahrhunderts n. Chr. enthält Beispiele für handhabbare Zusammenfassungen. $\mathrm{Ob}$ wir die kurzen Resümees der Aeneis, die unter dem Namen des Ausonius erhalten sind, als Kunststückchen zu verstehen haben, kann ich hier ebenfalls nicht ausführen, aber auch diese Textsorte rückt im Augenblick in den Fokus der Forschung. ${ }^{13}$

Wichtig ist also festzuhalten, dass die Ilias Latina für uns zwar der einzige derartige Text ist, dass er sich aber in eine ganze Reihe von Textsorten einfügt, die alle zu verschiedenen Zwecken und für verschiedene Adressaten eine Raffung eines kanonischen Textes bereitstellen. Es ist ferner wichtig, nochmals darauf hinzuweisen, dass solche Zusammenfassungen

10

11 Dickey (2018), S. 184, listet ihre zahlreichen Arbeiten zu diesem Thema auf.

12 von Möllendorff (2010).

13 Vgl. das Forschungsprojekt von Markus Kersten zum Thema «Ausonius. Dichtung und Deminution` (Universität Basel). 
keineswegs nur in einem Umbruchzeitalter angefertigt wurden. Wenn wir lesen, dass Antiochus von Palaestina vor der drohenden Zerstörung von Ancyra und seines Klosters auf Geheiß seines Abtes Eustathius alle wichtigen Texte der Bibliothek in den Pandekten zusammenschreiben musste, können wir das als eindringliche Metapher lesen, dass Menschen zu bestimmten Zeiten sehr bewusst war, wie bedroht ihre Texte und deren Inhalt durch die Zeitumstände waren. Aber von einer ideologischen Tendenz zur Epitomierung auszugehen, wäre verfehlt. ${ }^{14}$

\section{II.}

Epitomierungen ‘ür den Hausgebrauch haben zu allen Zeiten stattgefunden, wie schon Ilona Opelt in ihrem immer noch maßgeblichen Artikel im RAC (1962) festgestellt hat. Verkürzung und Kondensieren von Texten lässt sich schon für das 4. Jahrhundert v. Chr. nachweisen (nicht zuletzt auch durch die Bemerkungen von Martial 14, 184: Homer; 186: Vergil; 188: Cicero; 190: Livius; 192: Ovid). Für Historiker wie Theopomp und Philochoros oder Philosophen wie Theophrast und Epikur wird berichtet, sie hätten selbst Epitomai veröffentlicht. Zusammenfassungen von historischen, Inhaltsangaben von dramatischen Texten, die Praxis des Exzerpierens philosophischer Werke für den weiteren Gebrauch (Cicero Brutus 15), Sulpicius Apollinaris' Zusammenfassungen des Terenz (2. Jahrhundert) und Kurzfassungen von Livius' Ab urbe condita ${ }^{15}$ bezeugen derartige Praktiken, die auch methodisch verwandt sind mit dem Vorgehen und der Verbreitung von wissensgefüllten Texten wie denen der immer noch sogenannten Buntschriftsteller.

Doch nimmt die Verkürzung und Kondensierung literarischer, zumal poetischer Texte eine Sonderstellung ein. Aber auch hier zeigt sich, dass die

\footnotetext{
14 Vgl. Horster / Reitz (2018).

15 Florus, den man zwar nicht unbestritten, aber plausibel ins 1. Jahrhundert n. Chr. zu datieren pflegt, und die sogenannten «Periochai`. Obwohl die uns erhaltenen Kurzfassungen, die auch für die Rekonstruktion der verlorenen Bücher von Ab urbe condita wichtig sind, aus dem 4. Jahrhundert stammen, ist die Existenz solcher Zusammenfassungen schon für das 1. Jahrhundert, also kurz nach der Entstehung des Geschichtswerkes, bezeugt; vgl. z. B. Martial, ep. 14.190. Zu diesen Fragen vgl. Chaplin (2010).
} 
Periochae Homeri, dem Ausonius zugeschrieben (4. Jahrhundert), eben nicht nur ein spät auftretendes Phänomen spätantiker Dekadenz oder auch konservativen Traditionsbewusstseins sind. Mögen diese Prosatexte einer Leserschaft, die des Griechischen nicht mehr in derselben Weise kundig war wie noch wenige Jahrhunderte zuvor, auch als Leitfaden durch den langen Text der homerischen Gedichte gedient haben, liegen die Dinge für poetische Texte anders. Das Beispiel der Ilias Latina belegt das. Der Text wird heute weitgehend unbestritten in die neronische Zeit datiert, eine Zeit, in der die lesende Gesellschaft in Rom zweisprachig war. ${ }^{16}$ Wir wissen leider nichts Genaues über das Iliacon des Lucan, das Statius in Silv. 2.7 erwähnt vielleicht war es eine Zusammenfassung des 24. Gesanges der Ilias? Die Ilias Latina ist also der einzige ganz erhaltene Text, an dem man verkürzende poetische Praktiken überprüfen kann. Dieser Text ist in Hunderten von Handschriften überliefert, diente er doch dem Mittelalter als Ersatz für das angesichts der fehlenden Kenntnisse des Griechischen nicht mehr gelesene homerische Epos. Obwohl der Text anonym oder unter der Überschrift 〈Homerus Latinus〉 überkommen ist, macht das Akronym des Verfassernamens (ITALICVS [...] SCRIPSIT, IL 1-8 und 1.063-1.070) die Zuschreibung einigermaßen präzise. Wenn es sich um P. Baebius Italicus handelt, dann ist es recht plausibel, dass wir es mit dem späteren Volkstribun (unter Vespasian) zu tun haben, nachmalig Statthalter von Lykien und Pamphylien und Suffektkonsul unter Domitian im Jahr 90, also eine Persönlichkeit mit militärischen, politischen und, wie zu zeigen sein wird, literarischen Ambitionen - insofern, wenn auch in der Reihenfolge genau andersherum, gar nicht so verschieden von Silius Italicus. ${ }^{17}$

Der Text beginnt mit einer fast wörtlichen Übersetzung des IliasProöms. Das Tempo zieht im Verlauf des Textes merklich an und schwankt auch erheblich. Die handschriftlich überlieferte Buchunterteilung - gleichviel, ob sie, was man heute eher für unplausibel hält, dem Autor zugeschrieben wird ${ }^{18}$ oder einem Bearbeiter, durch den die Aufteilung dann Eingang in

16 Dazu vgl. unten S. 59.

17 Scaffai (1997), S. 11-22, diskutiert die verschiedenen Vorschläge ausführlich und weist auch auf die plausible Identifikation des Epitomators mit dem inschriftlich nachweisbaren Politiker P. Baebius Italicus hin.

18 Vgl. Bott (1920); frühere Arbeiten sind z. B. Baehrens (1881), Birt (1913). 
einen Teil der handschriftlichen Überlieferung fand - belegt das. Man muss freilich bedenken, dass diese Übersicht es nicht erfasst, wenn der Autor die Reihenfolge der Ereignisse bisweilen umstellt oder Begebenheiten auslässt.

\begin{tabular}{ll} 
Homer, Ilias & Ilias Latina (IL) ${ }^{19}$ \\
1 & $1-110$ \\
2 & $111-251$ \\
3 & $252-343$ \\
4 & $344-388$ \\
5 & $389-537$ \\
6 & $538-563$ \\
7 & $564-649$ \\
8 & $650-685$ \\
9 & $686-695$ \\
10 & $696-740$ \\
11 & $741-757$ \\
12 & $758-771$ \\
13 & $772-778$ \\
14 & $779-789$ \\
15 & $790-804$ \\
16 & $805-835$ \\
17 & $836-838$ \\
18 & $839-891$ \\
19 & $892-910$ \\
20 & $911-930$ \\
21 & $931-943$ \\
22 & $944-1.003$ \\
23 & $1.004-1.014$ \\
24 & $1.015-1.070$ \\
& \\
\hline 1 &
\end{tabular}

19 Die Übersicht folgt Scaffai 1997, S. 47 f. Scaffai argumentiert plausibel, dass der Text schon vor dem Einsetzen der uns greifbaren mittelalterlichen handschriftlichen Überlieferung in Bücher unterteilt wurde. 
Im Jahr 2007 habe ich einige der raffenden Verfahren in Kategorien gefasst ${ }^{20}$ und habe betont, dass - anders als fast immer in Epitomai historiographischer Schriften - der Epitomator des Ilias-Textes keineswegs strikt auf wörtliche Rede verzichtet. Der Wechsel von direkter und indirekter Rede erzeugt Wechsel im Erzähltempo, ohne allzu referierend $\mathrm{zu}$ wirken. In referierte Rede können in besonderer Weise Werturteile mit dem Ziel der Leserlenkung integriert werden. Ebenso kann direkte Rede so erweitert werden, dass an anderer Stelle Szenen verknappt oder ganz eingespart werden können, weil sie schon vorgetragen worden sind. ${ }^{21}$ Die Zusammenfassung von Handlungselementen, die sich in der Vorlage zeitlich nacheinander abspielen, ist ein ähnliches Verfahren. Die These, dass an manchen der Stellen, an denen zusammengefasst oder ausgelassen wird, vom Epitomator Verweise auf dieses aussparende Verfahren angebracht sind, scheint Bestand zu haben. Ein Beispiel ist die Auslassung der Teichoskopie. Diese Szene, in der Helena auf Weisung der Göttin Aphrodite die Mauern von Troja aufsucht und dort den anwesenden Älteren Trojas die griechischen Kämpfer vorstellt, fehlt in der Ilias Latina. Jedoch wird in der anschließenden Szene, in der Paris und Helena sich im Schlafgemach wiederfinden, auf die Mauerschau verwiesen und sie ist inhaltlich vorausgesetzt, denn in IL 317 und 321 spricht Helena davon, dass sie auf den Mauern war. Die Bedeutung der Teichoskopie für die Epizität eines Textes wird zudem dadurch betont, dass der Dichter an einer anderen Stelle einen Hinweis auf Zuschauer von

20 Im Folgenden beziehe ich mich auf Reitz (2007); vgl. auch Horster / Reitz (2018) und Reitz (2021, im Druck).

21 Beispiel für eine Wertung in der indirekten Rede ist die Eingangsszene zwischen Chryses und Agamemnon, in der ein negatives Urteil über Agamemnon formuliert wird: Sed negat Atrides Chrysenque excedere castris / despecta pietate iubet: ferus ossibus imis / haeret amor spernitque preces damnosa libido (IL 24-26; «Aber der Atride lehnt ab und befiehlt, Chryses möge das Lager verlassen, unter Missachtung des Gebots der Frömmigkeit: Tief im Mark sitzt die wilde Liebe und es verachtet die Bitten die schädliche Begierde`). Es können aber auch in Reden Erweiterungen untergebracht werden, die dann an anderer Stelle wieder Einsparungen ermöglichen. So enthält die Rede des sterbenden Hektor (Hom. Il. 22.338-22.343 - IL 979/87) schon Elemente, die in der homerischen Ilias erst in der Szene des letzten Buchs berichtet werden, als Priamos bei Achill den Leichnam seines Sohnes auslöst. 
der Mauer aus neu einführt. Hecuba und Priamus beobachten den Zweikampf ihres Sohnes Hector mit Achill (IL 944f). Abgesehen davon, dass dadurch das Pathos der Szene gesteigert wird, ${ }^{22}$ kann so auf die Bedeutung dieser funktional so wichtigen epischen und vor allem auch tragischen Bauform verwiesen werden. ${ }^{23}$

Andere Beispiele, wie der lateinische Dichter trotz der gedrängten Form traditionelle epische Bauformen und Erzählelemente aufnimmt, seien angefügt. Obwohl der ausführliche Katalog der griechischen Schiffe, der bei Homer das zweite Buch der Ilias weitgehend einnimmt, in der Kurzversion nur wenig Platz findet (immerhin IL 167-221), wird an ihn durch eine auffällige Inkonsistenz in der Zahlangabe gemahnt. Zunächst wird die exakte Zahlangabe etwas umständlich umschrieben (IL 220f: his ducibus Graiae Troiana ad litora puppes / bis septem venere minus quam mille ducentae, $\mathrm{d}$. h. 1186 Schiffe. Die nachfolgende Liste ergibt allerdings nur die Summe von 1126). In IL 801 hingegen benutzt der Autor eine bereits zur Chiffre erstarrte Angabe, mille carinas (1000 Schiffe). ${ }^{24}$ Der Katalog wird durch eine besonders breit gestaltete Inspirationsbitte, in der zwei Instanzen um Beistand gebeten werden, eingeleitet. Dieser Umstand berechtigt dazu anzunehmen, dass der Rezipient sich durchaus mit den poetologischen Problemen dieser Bauform auseinandersetzen soll. Ein Pendant zu der doppelten Inspirationsbitte an Calliope und an Apoll bildet am Ende des Textes eine in der epischen Literatur einmalige Form der Sphragis, nämlich die Aufforderung an die Muse, den Schritt anzuhalten (IL 1.063: siste gradum). In der elegischen Dichtung ist die Vorstellung vom Schiff des Dichters vertraut. In der Ilias Latina wird diese Metapher neben den Anruf der Calliope, die Erwähnung des Quelltextes (potentis Homeri), alle Musen, Pallas und Phoebus platziert. Es ist nicht unwahrscheinlich, dass nach tausend Versen erkennbaren Bemühens um Kürze diese auffällige und füllige Schlusswendung eine gewisse Ironie enthält.

22 So Scaffai (1997), z. St. S. 406.

23 Vgl. Fucecchi (2019) zur Teichoskopie als episch-elegischem Erzählelement in Strukturen epischer Dichtung.

24 Vgl. mille rates. Dazu ausführlicher Reitz (2017). 
Ebenso sind die Zeitangaben für den Leser ein Fingerzeig auf das, was in der Kürzung des epischen Textes geschieht. Dienen die Tagzeiten, die hereinbrechende Nacht und der aufziehende Morgen, in der Ilias traditionell als typisches Ende und als Neuanfang des (Schlacht-)Geschehens und markieren - für uns zumindest seit alexandrinischer Zeit greifbar - den Beginn eines neuen Gesanges, also in der Regel einer neuen Papyrusrolle, ${ }^{25}$ so hat der lateinische Dichter die Tagzeitangaben durchaus nicht konsistent über den Text verteilt. Die zunehmende Geschwindigkeit des Textes würde das ja auch gar nicht erlauben. Zwischen den beiden Tagesanbrüchen IL 130 und 157 f. z.B. wird keine Nacht erwähnt. In IL 632 beginnt der Tag mit einer Heeresversammlung, ein Ereignis, dessen genaue Terminierung in der homerischen Ilias unklar bleibt. In IL 650 und 741 folgen weitere Zeitangaben, die ebenfalls keine Entsprechung in der homerischen Ilias haben. Auf diese Weise wird der Eindruck eines regelmäßigen Zeitablaufs vermittelt, ohne dass die Buchabfolge des griechischen Textes exakt nachvollzogen wird.

Wappnungsszenen gehören zum spezifischen Repertoire des Heldenepos. Den vier ausgedehnten Rüstungsszenen der Ilias Homers steht in der Ilias Latina, an auffällige Stelle gesetzt, die Rüstung Hectors gegenüber. Ich habe schon darauf hingewiesen, ${ }^{26}$ dass die spezifische Reihenfolge traditioneller Wappnungen hier durchbrochen ist, und zwar in der Weise, dass Hector - als trojanischem Helden und damit auch Ahnherrn der Römer eine besondere ästhetische Qualität zukommt. Er wird nahezu wie eine gewappnete Panzerstatue geschildert, in der der Blick des Betrachters von oben, also vom Helm, nach unten bis zu den Beinschienen wandert. Die Illusion des Aktes der Rüstung ist also durchbrochen.

Patroklos' Rüstung vor dem Aufbruch in den Kampf, in dem er Achill vertritt und der für ihn mit dem Tode enden wird, nimmt in der homerischen Ilias viel Raum ein, und das nahende Unheil zeichnet sich ab, weil Achills Lanze - ein väterliches Erbstück von Pelias - ihm zu schwer ist. In der Ilias Latina liegt der Schwerpunkt indessen darauf, dass sich der junge griechische Krieger regelrecht verkleidet: falsa imagine (IL 813), horrendi sub imagine Achillis (IL 813), mentitos vultus simulati [...] Achillis (IL 832). Erst 
als er am Boden liegt, wird diese Verkleidung enthüllt, denn Apoll greift ein: pandit (IL 831), denudatque virum (IL 832). Möglicherweise ist das betonte Verkleiden und Enthüllen ein weiterer Fingerzeig auf die epische Konvention, in diesem Falle eben die der Rüstungsszene.

Epische Kampfszenen enthalten traditionell verschiedene Elemente, vom Auftakt des Massenkampfes über die Kettenkämpfe, die Sterbeszenen einzelner Krieger, jeweils mit den entsprechenden, oft topischen Gleichnissen. Alle diese Elemente sind auch in der Ilias Latina vorhanden, jedoch wird die vollständige Topik nie gänzlich ausgeführt, sondern je einzelne Elemente in je unterschiedlichen Kampfgeschehnissen. So wird der Leser aufgefordert, aus diesen Mosaikteilen das komplette, erwartbare Bild der Schlacht zusammenzufügen, quer zur Chronologie.

Götterversammlungen dienen in epischen Texten dazu, dass die Götter - in der Regel auf Geheiß des obersten Gottes Zeus / Jupiter - über den Fortgang des Geschehens beraten oder über eine Klage einer beleidigten Gottheit befinden. Dies ist ein dramaturgisches Mittel, um auf das kommende Geschehen vorauszublicken oder um Ursachen des aktuellen Konfliktes nachzuholen. In der Illias Latina wird die erste Götterversammlung mit der Bitte der Thetis an Jupiter um Rache für ihren beleidigten Sohn Achill ausgelöst (IL 83). In der homerischen Ilias verstreicht zwischen dem Gespräch zwischen Mutter und Sohn (bis Hom. Il. 1.428) und dem Beginn des Göttergesprächs und der Götterversammlung (Il. 1.493 beziehungsweise Il. 1.533 in Zeus' Haus) ein Zeitraum von zwölf Tagen, in dem die Olympier bei den Äthiopern verweilen, also ein längeres Intervall. In diesem 〈Intervall〉 wird von der Rückgabe der Chryseis durch Odysseus berichtet. Diese Ereignisse sind im lateinischen Text vorverlegt (IL 62-67: Odysseus bringt Chryseis zu ihrem Vater und kehrt ins Lager zurück). Es fehlt am Ablauf der Handlung nichts, nur die Erzählchronologie ist verändert. Dass auf das zeitliche Intervall verzichtet wird, bezeichne ich als Pseudo-Raffung. Dadurch, dass im Text nicht explizit Zeit vergeht, die Götter plötzlich und ohne besonderen Zeitverlust durch Einberufung oder zurückzulegende Wegstrecke anwesend sind, entsteht der Eindruck von Tempo und schnell aufeinander folgenden Ereignissen.

Auch die anderen Götterversammlungen werden gerafft. Es fehlen die Referate der Debatten, es fehlen die Aufzählungen der anwesenden Götter. Die Götterszene vor Priamos' Bittgang zu Achill gegen Ende des Textes ist 
entsprechend dem gegen Ende des Textes immer mehr anziehenden Tempo ganz fortgelassen.

Konventionelle Bestandteile heroischer Epen sind auch die Beweinung und Bestattung. Auch hier sehen wir die Eingriffe des kürzenden Autors deutlich. Bei Patroclus' Tod werden Achills Trauer beim Eintreffen der Nachricht und sein Weinen bei der Aufbahrung zusammengezogen. Auch sind die Parallelen zwischen den Bestattungen des Patroclus und Hector näher aneinandergerückt; auch die Beweinung Hectors (durch Andromache und Hecuba) ist in die eigentliche Bestattung eingebunden. Die in der Ilias auf die Bücher 22 und 24 verteilten Ereignisse um die beiden toten Helden sind im verkürzten Text aneinandergerückt, thematisch verwandte Erzählteile - Sterben, Sorge um den Toten, Bestattung - stehen nebeneinander anstelle der homerischen Fernbezüge.

Ein episches Erzählelement, auf das der Dichter der Ilias Latina nicht verzichtet, sind die Beinahe-Episoden, wie sie Heinz Günther Nesselrath genannt hat. ${ }^{27}$ In das Geschehen sind solche Episoden in der Ilias vor allem durch die Entrückungen eingebunden. Der Krieger wird in einem kritischen Augenblick aus der Schlacht entfernt, um ihn für das folgende Geschehen aufzusparen. Vier solcher Entrückungen hat auch der Ilias Latina-Autor inkorporiert, ${ }^{28}$ obwohl man denken könnte, dass gerade solches NichtGeschehen sich besonders für eine Kürzung anbiete. Aber diese plötzlichen Eingriffe in das Schlachtgeschehen sind dramatisch besonders effektvoll, und sie bieten auch Anlass für über den Handlungskontext hinausgehende Überlegungen. Dies nutzt der Autor für Paris an der oben erwähnten auffälligen Stelle der Auslassung der Teichoskopie. Die zweite Entrückungsszene des Aeneas nutzt Baebius, um eine Prophezeiung der künftigen Bedeutung des Aeneas für Rom anzufügen. Es wäre zu überlegen, ob gerade diese Beinahe-Episoden für den Leser auch ein Fingerzeig in Richtung des epitomistischen Verfahrens sind, denn der spätere Autor verfügt gerade hier über das Potenzial, seinen Stoff zu kürzen oder aber zu erweitern.

27 Nesselrath (1992) und (2019). Vgl. die Zusammenstellung der von ihr so bezeichneten if not scenes> bei de Jong (1987).

28 IL 308: Paris im Zweikampf mit Menelaos; IL 423: In der Aristie des Diomedes; IL 463: Aeneas wird beinahe von Diomedes getötet; IL 899-902: Aeneas wird von Neptun vor Achill gerettet. 
Wie kann dieser Text zeitlich eingeordnet werden? Viel hat man vorgeschlagen, um die Datierung in die neronische Zeit plausibel zu machen. Nicht nur die möglichen Hinweise auf Neros Herrschaft - dass der Gott Apollo herausgestellt wird, dass die Schildbeschreibung mit einem Blick auf die künstlerischen Leistungen und die herrschende Gerechtigkeit in der friedlichen Stadt abschließt und dass das julisch-claudische Geschlecht in der Passage über seinen Ahnherrn Aeneas IL 899-902 (clarae gentis origo) besonders gewürdigt werde - werden herangezogen, sondern auch panegyrische Tendenzen der Epoche überhaupt. Zum Vergleich bieten sich die panegyrisch eingefärbte Bukolik des Calpurnius Siculus und der Carmina Einsidlensia an und auch der Eingang von Senecas Apocolocyntosis, wie auch immer man zu der Frage steht, ob dieser Text als Parodie zu verstehen sei. ${ }^{29}$ Insbesondere sprachliche Ähnlichkeiten, der deutliche und häufige Rekurs auf Vergil und Ovid, aber auch auf Wendungen, die auf spätere Epik vorausweisen, werden für eine Datierung in die 60er-Jahre des 1. Jahrhunderts n. Chr. ins Feld geführt; ob es plausibel ist, dafür auch Einflüsse aus der elegischen Dichtung heranzuziehen, also eine Akzentuierung des Liebesthemas und der daraus erwachsenden Leidenschaften geltend zu machen, kann hier nicht Gegenstand der Erörterung sein. Stattdessen sei abschließend ein Blick auf mögliche Parallelen aus der Welt der Bilder geworfen.

III.

Im Jahre 1663 publizierte Raffaele Fabretti eine Marmortafel mit Inschrift, die fortan in der Forschung Tabula Iliaca genannt wurde. Es handelt sich, wie man nach und nach hat zeigen können, um ein Stück von mittlerweile 22 bekannten, mehr oder weniger gut erhaltenen Tafeln aus dem 1. Jahrhunderts n. Chr., auf denen Inschriften und bildliche Darstellungen eine Kombination eingegangen sind. In der Forschung haben sie im 19. Jahrhundert erneut Interesse erregt. 1964 hat Anna Sadurska die zu diesem Zeitpunkt bekannten 19 Exemplare neu publiziert. In der philologischen Forschung sind sie, zumal seit dem Verdikt von Nicolas Horsfall (1995), der sie als aufwen-

29 Zum ganzen Komplex übersichtlich Scaffai (1997), S. 19-26. Zu Calpurnius und den Carmina Einsidlensia vgl. Merfeld (1999); zu Seneca Holzberg (2016). 
digeren Spickzettel für ungebildete römische Zeitgenossen im Stile des petronischen Trimalchio abtat, ${ }^{30}$ wenig beachtet worden. Wie gesagt hat die heutige Forschung sich dieser Denkmalgruppe erneut angenommen und besonders zur Ikonographie und zum Text-Bild-Verhältnis Erhellendes erarbeitet. ${ }^{31}$ Die meisten Tafeln greifen Themen aus den homerischen Gedichten auf, vor allem aus der Ilias. Zwei der Tafeln sind von der homerischen Schildbeschreibung inspiriert, es gibt aber auch eine Tafel mit thebanischem Thema und eine andere zum Herakles-Mythos.

Die mit etwa $25-42 \mathrm{~cm}$ größte und am besten erhaltene dieser Tafeln ist die sogenannte Tabula Iliaca Capitolina. ${ }^{32}$ Die figurenreiche Tafel trägt Bilder aus dem trojanischen Sagenkreis vom Beginn der Ilias bis zur Abfahrt des Aeneas nach Hesperien. Zwei Pfeiler zu den Seiten des Mittelbildes (die linke Hälfte ist verloren) bilden die architektonische Gliederung des Bildes. Unter dem zentralen Bild des Aeneas lesen wir folgenden Text:

\author{
TPSIKO $\Sigma$ \\ I $A$ IA $\Sigma$ KATA OMHPON

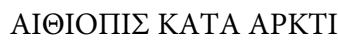 \\ NON TON MI $\Lambda$ $\Sigma I O N$ \\ I $\Lambda$ IA $\Sigma$ H MIKPA $\Lambda$ E \\ ГOMENH KATA \\ $\Lambda$ E $\Sigma$ XHN ПYPPAION
}

I $A$ IOY ПЕP $\Sigma$ I $\Sigma$ KATA $\Sigma T H \Sigma I X O P O N$

Zerstörung Trojas nach Stesichoros

Trojanisch (sc. Tafel / Dichtung?)

Ilias nach Homer

Aithiopis nach Arkti/nos aus Milet

Die kleine Ilias ge/lesen nach / Lesches von Pyrrhaia ${ }^{33}$

30 Vgl. zum literarischen Geschmack und dessen Karikierung bei Petron jetzt Schindler (2019).

31 Valenzuela Montenegro (2004); Squire (2011); Petrain (2014).

32 Mus. Cap. Inv. Scu 316 [http://capitolini.info/scu00316/?lang=en] 05.03.2020.

33 Vgl. Squire (2011), S. 253, zu den verschiedenen Deutungsmöglichkeiten und Problemen. 
Der ohne Weiteres erkennbare Unterschied zum bloßen Plot der Ilias hat dazu geführt, dass die altphilologische Forschung sich vor allem darum gekümmert hat, wie man aus diesen Zeilen Rückschlüsse auf den uns ja verlorenen homerischen Kyklos ziehen könne. ${ }^{34}$ Die längere Inschrift auf dem Pfeiler hat dagegen weniger interessiert. ${ }^{35}$ Dabei ist sie aufschlussreich, ebenso wie es aufschlussreich ist, sich die Verteilung der Bilder im Vergleich zum Ilias-Text anzusehen. Es liegt nicht in meiner Kompetenz, das Relief im Einzelnen $\mathrm{zu}$ beschreiben. Dazu ist in der Literatur, insbesondere bei Valenzuela Montezuela und Michael Squire, das Nötige gesagt. ${ }^{36}$ Aber es ist für unseren Kontext von Bedeutung, dass die Illustration des ersten Buchs der Ilias auf der Tabula Capitolina mehr Raum einnimmt als die anderen. Es trifft über dem Pfeiler mit den Bildern des 24. Gesanges zusammen. Fast alle Hauptereignisse sind dargestellt: die Ankunft des Chryses im Lager der Achaiaer, sein Gebet zu Apoll, die daraufhin unter den Griechen ausbrechende Pest, die Versammlung der Achaier mit dem Konflikt zwischen Achill und Agamemnon, die Rückgabe der Chryseis und schließlich der Bittgang der Thetis zu Zeus. Die linke Seite der Tafel mit den Büchern 2-12 ist nicht erhalten, es geht also mit Buch 13 weiter. Im 13. Gesang der Ilias nutzt Poseidon die Abwesenheit des Zeus, um die in Bedrängnis geratenen Griechen zum Kampf anzuspornen. Der Homer-Leser oder -Hörer erfährt von den besonderen Leistungen der beiden Aias und der Krieger Idomeneus und Meriones. Auf den Bildern ist viel Schlachtgetümmel zu sehen, und vor allem ist das Bemühen erkennbar, in die Menge der Kämpfer durch Namensbeischriften Ordnung zu bringen.

Ebenfalls bezeichnend ist es, dass die Troja-Bilderzählung bis hin zur literarisch vor allem aus Vergils Aeneis bekannten Abreise des Aeneas aus seiner Heimatstadt weitergeführt ist. Es ist also festzuhalten, dass im 1. Jahrhundert n. Chr. solche Bildwerke mit inschriftlichen Erläuterungen existierten und eine gewisse Verbreitung hatten, eine eigene Ikonographie entwickel-

34 Zum epischen Kyklos sind die Forschungsmeinungen und -fragen zugänglich zusammengefasst in Fantuzzi / Tsagalis (2016).

35 Der Text ist im Anhang beigegeben.

36 Vgl. Montezuela (2004); Squire (2011). 
ten, dass sie Themen spezifizierten und kombinierten und ein eigenständiges Erzähltempo anschlugen.

In der Forschungsgeschichte ist ein Vergleich zwischen der Ilias Latina und den Tabulae Iliacae weitgehend ad acta gelegt worden, seit man auch die These einer Zwischenstufe zwischen der homerischen Ilias und unserem Text nicht mehr favorisierte. Ein solcher Zwischentext, also eine Art Breviarium in Prosa oder aber auch ein Bilderzyklus, wurde z. B. von Müller angenommen, die These des Bilderzyklus hat zuerst Brüning aufgestellt. ${ }^{37}$ Weber führte diese Deutung mit den Tabulae Iliacae zusammen, und noch Sadurska schloss sich dem an. ${ }^{38}$ Dahinter steht ebenfalls, wie für die epitomierte lateinische Ilias, die Vorstellung von einfachem Material, seien es Texte oder eben Bilder, als Schulmaterial oder als Anschauungsunterricht für weniger gebildete Personen. Weiter führt aber ein Ansatz, diese Produkte in ihrer eigenen Ästhetik zu bewerten und einzuordnen. Squire führt in seiner Studie aus, dass die Ilias-Tafeln Zeugnisse einer Auseinandersetzung mit der literarischen und zugleich mit der materiellen Tradition sind. ${ }^{39}$ Die Dichotomie von Text und Bild wird durch das kleine Format beider Medien in besonderer Weise herausgestellt. Es geht nicht nur um Kunststücke, wie den gesamten Text der Ilias auf einem winzigen Textträger, z. B. dem sprichwörtlichen Sesamkorn, unterzubringen, sondern um das Zusammenspiel von Bild und Text, beide scheinbar leicht zugänglich, beide jedoch verknappt und ohne zusätzliche Informiertheit und geistige Offenheit kaum entschlüsselbar. Die Linearität des Textes und die Synchronizität der Bilder treten in einen Dialog und fordern den Betrachter heraus, über die Möglichkeiten der Wiedergabe eines so komplexen Textes wie der homerischen Ilias nachzusinnen..$^{40}$ Um uns also mit der Pragmatik der verkürzenden Gattungen zu befassen, ist es unabdingbar, sich zugleich gewissenhaft auf deren kulturellen und intellektuellen Kontext einzulassen.

\footnotetext{
37 Vgl. Müller (1860); Brüning (1894).

38 Vgl. Weber (1902); Sadurska (1964).

39 Vgl. Squire (2011), S. 303.

40 Vgl. dazu das von Squire (2009), S. 139, treffend angeführte Zitat von Roland Barthes: «We read on, we skip, we look up, we dip in again» (Roland Barthes: The Pleasure of the Text, transl. by Richard Miller, New York 1989, S. 11 f.).
} 


\section{Bibliographie}

\section{Primärliteratur}

Baebii Italici Ilias Latina, hg.v. M. Scaffai, Bologna ${ }^{2} 1997$ (Edizioni e saggi universitari di filologia classica 28).

Baehrens, Emil: Poetae Latini Minores, Bd. III, Leipzig 1881, S. 3 -7.

Green, Steven James: Ilias Latina. Text, translation, and commentary, Oxford (Pseudepigrapha Latina) [in Vorbereitung].

\section{Forschungsliteratur}

Bažil, Martin: Centones Christiani. Métamorphoses d'une forme intertextuelle dans la poésie latine chrétienne de l'Antiquité tardive, Paris 2007.

Binternagel, Alexandra / Tischer, Ute (Hgg.): Fremde Rede - Eigene Rede. Zitieren und verwandte Strategien in antiker Prosa, Frankfurt a. M. 2010.

Birt, Theodor: Kritik und Hermeneutik nebst Abriß des antiken Buchwesens, in: Iwan Müller (Hg.): Handbuch der Altertumswissenschaften 1,3, München 1913, S. 222 242.

Bitto, Gregor: Alexandrian book division and its reception in Greek and Roman epic, in: Christiane Reitz / Simone Finkmann (Hgg.), Structures of Epic Poetry, vol. I, Berlin / Boston 2019, S. 133-163.

Bott, Heinrich: De epitomis antiquis, Diss., Marburg 1920.

Brüning, Adolf: Über die bildlichen Vorlagen der ilischen Tafeln, in: Jahrbuch des deutschen archäologischen Instituts 9 (1894), S. 136-164.

Chaplin, Jane: The Livian Periochae and the Last Republican Writer, in: Horster / Reitz (2010), S. 451-467.

de Jong, Irene: Narrators and focalizers. The presentation of the story in the Iliad, Amsterdam 1987.

Dickey, Eleanor: Learning Latin the Ancient Way. Latin Textbooks from the Ancient World, Cambridge 2018.

Dubischar, Markus: Survival of the Most Condensed? Auxiliary Texts, Communications Theory, and Condensation of Knowledge, in: Horster / Reitz (2010), S. 39-67.

Fabretti, Raphaelis: De Columna Traiani Syntagma. Accesserunt explicatio veteris tabellae anaglyphae Homeri Iliadem atque ex Stesichoro Arctino et Lesche Ilii excidium continentis, et Emissarii Lacus Fucini Descriptio, Rom 1683.

Falcone, Maria Jennifer / Schubert, Christoph (Hgg.): Ilias Latina. Text, Interpretation, Reception, Leiden / Boston (Mnemosyne Supplements) [2021, im Druck].

Fantuzzi, Marco / Tsagalis, Christos (Hgg.): The Greek Epic Cycle and Its Ancient Reception: A Companion, Cambridge 2015. 
Fucecchi, Marco: Teichoscopies in classical and late antique epic, in: Christiane Reitz / Simone Finkmann (Hgg.), Structures of epic poetry, vol. II.1, Berlin / Boston 2019, S. 207-244.

Holzberg, Nikolas: Racheakt und «negativer Fürstenspiegel` oder literarische Maskerade? Neuansatz zu einer Interpretation der Apocolocyntosis, in: Gymnasium 123 (2016), S. 321-339.

Horsfall, Nicholas: Virgil's impact at Rome: The non-literary evidence, in: Nicholas Horsfall (Hg.): A companion to the study of Virgil, Leiden / New York 1995, S. 249-256.

Horster, Marietta / Reitz, Christiane (Hgg.): Condensing Texts - Condensed Texts, Stuttgart 2010 (Palingenesia 98).

Horster, Marietta / Reitz, Christiane: Handbooks, Epitomes and Florilegia. Late antique variations on the short form, in: Scott McGill / Ed Watts (Hgg.): Blackwell Companion to Late Antique Literature, Chichester 2018, S. 431-450.

Merfeld, Beate: Panegyrik - Paränese - Parodie? Die Einsiedler Gedichte und Herrscherlob in neronischer Zeit, Trier 1999.

Moatti, Claudia: La raison de Rome. Naissance de l'esprit critique à la fin de la République, Paris 1997.

von Möllendorff, Peter: Werbende Dichtung? Die hypotheseis emmetroi der Komödien des Aristophanes, in: Horster / Reitz (2010), S. 269-287.

Müller, Lucian: Homerus Latinus, in: Philologus 15 (1860), S. 475-50.

Nesselrath, Heinz-Günther: Almost-episodes' in Greek and Roman epic, in: Christiane Reitz / Simone Finkmann: Structures of Epic Poetry, vol. I, Berlin / Boston 2019, S. $565-608$.

Nesselrath, Heinz-Günther: Ungeschehenes Geschehen. «Beinahe-Episoden` im griechischen und römischen Epos von Homer bis zur Spätantike, Stuttgart 1992.

Petrain, David: Homer in Stone. The Tabulae Iliacae in their Roman context, Cambridge 2014.

Opelt, Ilona: Epitome, in: RAC (1962), Sp. 944-973.

Reitz, Christiane: Verkürzen und Erweitern. Literarische Techniken für eilige Leser? Die Ilias latina als poetische Epitome, in: Hermes 135 (2007), S. 334-351.

Reitz, Christiane: Homer kürzen? Verkürzung und Paraphrase homerischer Epik in der antiken Kritik, in: Horster / Reitz (2010), S. 289-305.

Reitz, Christiane: Das Unendliche beginnen und sein Ende finden - Strukturen des Aufzählens in epischer Dichtung, in: Christine Schmitz / Angela Jöne / Jan Kortmann (Hgg.): Anfänge und Enden. Narrative Potentiale des antiken und nachantiken Epos, Heidelberg 2017, S. 105-118.

Reitz, Christiane: Bauform in der Kürze. Zum Umgang mit epischen Strukturen in der Ilias Latina, in: Maria Jennifer Falcone / Christoph Schubert (Hgg.): Ilias Latina. 
Text, Interpretation, Reception, Leiden / Boston (Mnemosyne Supplements) [2021, im Druck].

Sadurska, Anna: Les tables iliaques, Warschau 1964.

Schindler, Claudia: Genial daneben? Überlegungen zu Eumolpus' Troiae Halosis, in: Gymnasium 126 (2019), S. 167-190.

Schottenius Cullhed, Sigrid: Proba the Prophet. The Christian Virgilian Cento of Faltonia Betitia Proba, Leiden / Boston 2015.

Sehlmeyer, Markus: Geschichtsbilder für Pagane und Christen. Res Romanae in den spätantiken Breviarien, Berlin 2009.

Squire, Michael: Image and Text in Graeco-Roman Antiquity, Cambridge 2009.

Squire, Michael: The Iliad in a Nutshell. Visualizing Epic on the Tabulae Iliacae, Oxford 2011.

Suerbaum, Werner: Zum Umfang der Bücher in der archaischen lateinischen Dichtung: Naevius, Ennius, Lukrez und Livius Andronicus auf Papyrus-Rollen, in: Zeitschrift für Papyrologie und Epigraphik 92 (1992), S. 153-173.

Tischer, Ute: Zitat und Markierung. Signalisieren und Erfassen von Zitaten in römischer Prosa, Göttingen 2021 [im Druck].

Valenzuela Montenegro, Nina: Die Tabulae Iliacae. Mythos und Geschichte im Spiegel einer Gruppe frühkaiserzeitlicher Miniaturreliefs, Berlin 2004.

Weber, Ernst: Über den Homerus Latinus, in: Philologus 61 (1902), S. 528-539. 


\section{Anhang}

Übersetzung der Inschrift auf der Tabula Iliaca Capitolina (nach Valenzuela Montenegro 2004).

(Paraphrase der Ereignisse Homer, Ilias 13-24).

Die Achaier bauen eine Mauer und einen Graben um die Schiffe. Nachdem sich beide Parteien bewaffnet und die Schlacht auf dem Feld begonnen haben, verfolgen die Troer die Achaier bis zur Mauer und schlagen in jener Nacht ihr Lager bei den Schiffen auf. Die Ersten der Achaier beratschlagen sich und beschließen daraufhin, jemanden zu Achill zu senden. Agamemnon aber gibt viele Geschenke und die Briseis. Odysseus, Phoinix und zusätzlich Aias, die zu ihm geschickt worden sind, melden Achill die Worte von Seiten des Agamemnon. Der aber nimmt weder die Geschenke an noch gibt er darin nach, sich zu versöhnen und ihnen zu helfen. Nachdem die Vornehmsten das gehört haben, schicken sie Odysseus und Diomedes als Späher aus. Diese aber begegnen Dolon, der von Hektor als Späher gesandt worden ist, und erfahren vom ihm die Aufstellung der Wächter des Heerlagers. Daraufhin töten sie diesen sowie Rhesos aus dem Volk der Thraker, mit ihm auch noch andere. Sie nehmen die Pferde an sich und führen sie zu den Schiffen. Als es Tag geworden ist, beginnen sie die Schlacht und in der Folge ziehen sich Agamemnon, Diomedes, Odysseus, Machaon und Eurypylos verletzt zu den Schiffen zurück. Patroklos, der von Achill geschickt worden ist, erkundigt sich bei Nestor nach der Schlacht. Hektor, nachdem er die Tore ins Lager eingebrochen hat, greift die Mauern der Hellenen an und beginnt die Schlacht vor den Schiffen. Als der Kampf entbrannt ist, hört Achill den Stand der Schlacht von Patroklos, der ihn darum bittet, zu helfen und ihn zu den Gefährten bei den Schiffen zu schicken; weil er gesehen hat, dass das Schiff des Protesilaos brennt, schickt er Patroklos zusammen mit den Myrmidonen los, nachdem er ihm seine Pferde gegeben und mit seinen Waffen ausgerüstet hat; als die Trojaner das sehen, fliehen sie alle sofort. Im Laufe dieser Wendung tötet Patroklos unter vielen anderen auch Sarpedon, den Sohn des Zeus, die Übrigen verfolgt er bis zur Mauer. Hektor aber erwartet ihn und trifft ihn tödlich und kommt so in den Besitz der Waffen. Als der Kampf um die Leiche entbrannt ist, bringt Antilochos betrübt die Nachricht in das Zelt des Achill. Thetis aber geht zu Hephaistos, um von ihm eine Rüstung zu 
erbitten. Bereitwillig kommt er ihrem Wunsch nach. Die Griechen aber bringen die Leiche des Patroklos zu den Schiffen. Nachdem Thetis die Waffen übergeben hat, gibt Agamemnon Achill die Briseis. Achill verfolgt den Asteropaios bis in den Skamander und tötet ihn. Achill, der Gefahr im Fluss entflohen, begegnet Hektor im Zweikampf, tötet ihn, nimmt seine Waffen an sich, bindet den Leichnam am Wagen an und schleift ihn über das Feld zu den Schiffen. Und nach der Bestattung des Patroklos veranstaltet er für ihn Spiele unter den Anführern. Priamos gelangt zu den Schiffen und kauft Hektor von Achill los. Nachdem Priamos wieder in die Stadt gekommen ist, begraben jenen die Trojaner und errichten sein Grab. 



\section{Wie lang ist kürzer?}

\section{Überlegungen zum brevitas-Topos der französischen mises en prose}

von

Richard Trachsler (Zürich)

Wer immer in akademischen Kreisen verkehrt, weiß, dass immer dann Vorsicht geboten ist, wenn ein Redner zu Wendungen wie <ich will es kurz machen〉 oder 〈kurz gesagt〉 greift. 〈Kurz gesagt〉 ist nämlich meist nichts anderes als eine Formel, eine mehr oder minder leere Floskel, die bemüht wird, wenn es darum geht, die Lizenz auszuhandeln, es eben nicht kürzer, sondern länger machen zu dürfen, und sich über die versprochene brevitas dennoch die benevolentia des Hörers zu sichern. Benevolentia, die es zu erhaschen gilt, und brevitas sind Indizien dafür, dass man sich hier in einer Tradition bewegt, die bereits von den Rhetoren der Antike abgesteckt worden ist und eine längere Geschichte mit sich trägt. ${ }^{1}$ Auch die Autoren des lateinischen Mittelalters haben die Begriffe und die entsprechenden Konzepte verwendet und zur brevitas einiges zu sagen gewusst, und wie nicht anders zu erwarten, haben auch die volkssprachlichen Schriftsteller reichlich von der brevitas oder genauer vom brevitas-Topos Gebrauch gemacht: ${ }^{2}$ Die alt- und mittelfranzösische Literatur, um die es hier gehen wird, wimmelt jedenfalls von Formulierungen wie pour faire bref, pour abregier, pour cause de brieveté oder, kurz und bündig, briefment, ein Adverb, dessen Gebrauch wegen seiner Häufigkeit etwa bei Evrard de Conty, der sich eben alles andere als kurzfasst, als idiosynkratischer tic bezeichnet worden ist. ${ }^{3} \mathrm{Ob}$ erfolgreich oder nicht, all

1 Das Register von Lausberg (1990) bietet einen schnellen und bequemen Zugang zu den einschlägigen Passagen der klassischen auctoritates.

2 Siehe dazu Badel (2011). Zum brevitas-Topos grundlegend Curtius (1954), S. 479485. Mit Fokus auf den mittelhochdeutschen Antikenroman Frick (2020), mit Bibliographie.

3 Ducos (2006), S. 222, zitiert von Jeay (2011), S. 105. 
diese Ausdrücke wollen dasselbe erreichen: Es geht darum zu signalisieren, dass man den Leser oder Hörer nicht mit langen Ausschweifungen langweilen will.

Es gibt viele Gründe, sich kurzfassen zu wollen - oder das zumindest vorzugeben: Ein Kompilator z. B. kann sich selektiv bei der Auswahl seiner Materie geben, ein Kommentator kann geltend machen, dass er seine Auslegungen einschränkt, und ein Chronist kann beanspruchen, Ereignisse zu überspringen oder zu kondensieren. Jede Textsorte kultiviert brevitas und setzt den Topos entsprechend ein.

Hier soll es nun um eine ganz bestimme Gattung und eine ganz bestimmte Art von brevitas gehen, nämlich die abbreviatio, wie sie, als Gegenstück zur amplificatio verstanden, in den spätmittelalterlichen mises en prose anzutreffen ist.

Obwohl vereinzelt Texte bereits im frühen 13. Jahrhundert aus der Versin die Prosaform transponiert worden sind, sind die sogenannten mises en prose ein Phänomen, das in der französischen Literatur im späteren 14. Jahrhundert einsetzt und sich über das Ende des Mittelalters hinaus bis ins 16. Jahrhundert hineinzieht. ${ }^{4}$ Diese mises en prose, früher etwas despektierlich dérimages, «Entreimungen`, genannt, sind per definitionem nie Originalschöpfungen, sondern immer Überführungen älterer Verstexte in Prosa. Bei großzügiger Zählung umfasst das erhaltene Corpus heute knapp 80 Texte, wobei die Fluktuation in der Zählung sich vor allem daraus erklärt, dass es manchmal schwerfällt zu entscheiden, ob zwei solcher Prosafassungen eines älteren Werkes wirklich zwei verschiedene Fassungen darstellen oder eine nichts weiter als eine Variante der andern ist. ${ }^{5}$

Nicht immer ist die Versfassung, auf welcher die mise en prose beruht, vollständig erhalten, aber für diese rund 80 Werke dürfen mit ziemlicher Sicherheit Versvorlagen angenommen werden. Die Beharrlichkeit, mit der während fast zwei Jahrhunderten Reime in Prosa überführt worden sind und sich dieses quantitativ beachtliche Corpus gebildet hat, erklärt sich zum Teil

4 Es handelt sich im letzteren Fall vor allem um Graalsprosa, der offenbar ein Sonderstatus zukam.

5 Siehe das ausgezeichnete Verzeichnis Nouveau répertoire de mises en prose (XIV ${ }^{\text {e }}$

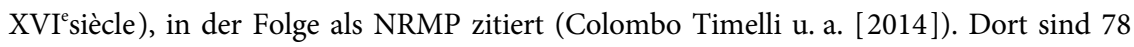
Werke verzeichnet. Die Standardstudie zu den mises en prose ist Doutrepont (1939). 
durch die Notwendigkeit, die Drucker und Verleger mit Texten zu versorgen. Es bestand eine starke Nachfrage nach Geschichten aller Art, und die alten strophischen chansons de geste, genau wie die alten Versromane, waren buchstäblich das nächstbeste vorhandene Erzählmaterial. Der Bedarf an Material war derart groß, dass bisweilen ein gereimtes Werk gleich zweimal und auf völlig unabhängige Weise in Prosa umgeformt worden ist. So beispielsweise der Cleomadés des Spielmanns Adenet le Roi, der die orientalische Geschichte des fliegenden Holzpferds im Abendland bekannt macht. ${ }^{6}$ Wie dem Cleomadés ist es auch der Belle Hélène de Constantinople ergangen, die erst von einem anonymen Autor, dann von Jean Wauquelin, einem Berufsschreiber und Schriftsteller im burgundischen Milieu, «entreimt〉 worden ist.7 Doch nicht nur die Gattung des alten Versromans ist betroffen, auch in der Epik sind ein paar Doubletten zu verzeichnen, z. B. Galien le Restoré und vor allem der Cycle des Lorrains, von dem gar drei Prosafassungen angefertigt wurden. ${ }^{8}$

Warum die Autoren im Spätmittelalter einen derartigen Aufwand trieben, ist leicht verständlich: In der ursprünglichen Form waren die Verstexte des 12. und 13. Jahrhunderts nicht mehr zu konsumieren und noch viel weniger zu verkaufen. Die dominante Form für eine moderne Erzählung war mittlerweile die Prosa, und die Sprache der Versvorlagen war so sehr veraltet, dass man sie kaum mehr verstand. Die Autoren mussten also eine doppelte Arbeit auf sich nehmen: Sie mussten sich einerseits der unseligen Verse entledigen und andererseits das sprachliche Gewand so weit modernisieren, dass die Texte nicht nur wieder verständlich, sondern auch den mittlerweile veränderten Publikumsgeschmack treffen würden. Diese NeuPräsentation begann bei den Titeln, spiegelt sich dann aber auch in der Angleichung an die neuen Gattungsdominanten all jener inhaltlichen Aspek-

$6 \quad \mathrm{Zu}$ den Details siehe die Ausgabe Le Cheval volant en bois, ed. Maillet / Trachsler (2010), S. 50.

7 Die Ausgabe der anonymen Prosafassung der Belle Hélène ist von Barbara Ferrari in ihrer noch nicht publizierten Mailänder Dissertation erstellt worden. Diejenige von Wauquelin ist greifbar: La Belle Hélène, ed. de Crécy (2002).

$8 \quad \mathrm{Zu}$ Galien siehe die Ausgabe von Keller / Kaltenbach (1998), für die anderen Werke sei auf das NRMP verwiesen. 
te, die dem veränderten ästhetischen Kanon zuwiderliefen. ${ }^{9}$ Die betreffenden Punkte werden systematisch in beinahe allen Prologen der mises en prose erwähnt, an recht prominenter Stelle findet in der Regel auch die Tatsache Erwähnung, dass der Autor der Prosa die Versvorlage gekürzt habe.

Der Prolog des Erstdrucks von Guillaume de Palerme, der auf einen Versroman aus dem späten 13. Jahrhundert zurückgeht, thematisiert z. B. die erwähnten Aspekte wie folgt:

\section{Guillaume de Palerne von Pierre Durand}

Et je, considerant le langaige qui estoit rommant antique rymoié en sorte non intelligible ne lisible à plusieurs, $[\ldots]$ ay traduit et transferé le langage de ceste dicte histoire en langage moderne françoys pour à chascun qui lire le vouldra estre plus intelligible. [...] Soit doncques leue l'hystoire attentivement et soit chascun adverty que comme l'on fait de la bonne vigne, je n’ay seullement taillé et resecqué les choses au premier livre contenue[s] qui m’ont semblé estre absurdes et moins que raisonnables.

〈Und ich, der ich die Sprache [des Buches] in Betracht zog, die altes «Romanisch〉 war, in Reimen und von einer Art, die für die Meisten [heute] weder verständlich noch lesbar ist, habe die Sprache dieser Geschichte in modernes Französisch übersetzt und transponiert, damit es für die, die es zu lesen wünschen, besser verständlich sei. [...] Man lese nun diese Geschichte mit Sorgfalt, und es sei jeder gewahr, dass ich, wie man guten Wein macht, lediglich diejenigen Dinge aus dem ersten Buch herausgeschnitten und zurückgestutzt habe, die mir absurd und inkohärent vorkamen. $>^{10}$

Jetzt fragt man sich natürlich, welche 〈Absurditäten〉 der Autor eliminiert hat. Ein systematischer Vergleich zeigt eigentlich nur einen einzigen Eingriff: Guillaume de Palerme ist eine Werwolf-Geschichte, die in der Versvorlage in medias res mit der Entführung eines Kindes durch einen Wolf beginnt. Erst

9 Zu den Titeln siehe Roccati (2016).

10 Pierre Durand, L'hystoire du noble et vaillant chevalier Guillaume de Palerne et de la belle Melior, lequel Guillaume de Palerne fut filz du roy de Cecille et par fortune et merveilleuse adventure devint vacher, et finablement fut empereur de Romme soubz la conduicte d'ung loup garoux, filz au roy d'Espaigne, Olivier Arnoullet, Rouen, 1552, fol. aiv. Die Übersetzung, wie auch die folgenden, stammt von mir. $\mathrm{Zu}$ den verschiedenen Ausgaben des Guillaume de Palerne siehe jetzt Cappello (2014), der eine unbekannte Fassung entdeckt hat, die Williams (1952) nicht kannte. 
später wird enthüllt, dass der Wolf in Wirklichkeit gar kein Wolf ist, sondern ein verwandelter Königssohn, der das Kind nicht fressen, sondern im Gegenteil beschützen wollte, und dass somit die Welt in Ordnung ist oder genauer durch die Werwolf-Figur, die ja eigentlich der Weltordnung zuwiderläuft, wiederhergestellt wird. Die Prosafassung hat hier den in der Versvorlage umgestellten ordo naturalis der Erzählung korrigiert und liefert somit von vornherein die Erklärung für die dramatische Eingangsszene. Eigentliche Tilgungen lassen sich nicht ausmachen. ${ }^{11}$

Dennoch ist der Anspruch der abbreviatio derjenige, der zusammen mit dem Argument der sprachlichen Modernisierung in der Topik der Prologe dieser mises en prose am häufigsten vorkommt. Häufig wird einfach das factum formuliert, ohne dass eine ausführliche Begründung oder ein ästhetisches Programm geliefert würde. Auch hier ist es nicht schwierig, Beispiele anzuführen.

\section{Theseus de Cologne}

Et est ladicte hystoire redigee et mise en escript es croniques des roys de Coulongne en bel et aorné latin et moult au long, si n'en ay extrait que la principale et plus seure et vraye substance, sans rien laisser sinon aucun langage superflu, et ce pour cause de briefveté et atediacion ou ennuy. ${ }^{12}$

«Und besagte Geschichte ist verfasst und niedergeschrieben in den Chroniken der Könige von Köln in schönem und ausgeschmücktem Latein und sehr ausführlich; so habe ich daraus lediglich die wichtigsten und gesicherten und wahrhaftigen Elemente exzerpiert, ohne irgendwelche überflüssigen Ausdrücke stehenzulassen, um der Kürze, des Verdrusses oder der Langweile willen.>

\section{Anseïs de Carthage \\ Prologue:}

Et dist pour entrer en matere, qu'aprez ce qu'il a veu et leu en pluseurs croniques, qu'il a eu son intencion d'exposer brief les fais d'Espaigne [...]. Soubz laquelle exposition non prolixe et bonne doctrine rois, ducz, princes et chevaliers se poront rigler en leur vie $[. .$.$] .$

11 Siehe dazu Trachsler (2012), mit Bibliographie. Hier und im Folgenden: Hervorhebungen des Verfassers.

12 Paris, BnF, fr. 15096, zitiert nach dem NRMP, S. 857. Zu den zahlreichen allesamt nicht edierten Prosafassungen der Theseus-Tradition siehe Bacquin (2018). 
Epilogue:

$[\ldots]$ je dis ainsi que les haulz fais abreviés en cel cronique $[\ldots] \cdot{ }^{13}$

Prolog:

«Und [der Autor] sagt eingangs, dass er nach dem, was er in verschiedenen Chroniken gesehen und gelesen hat, die Absicht gefasst habe, die Ereignisse in Spanien kurz darzulegen. Nach dieser Darstellung, die nicht ausufert, und der guten Lehre können sich Könige, Herzöge, Prinzen und Ritter in ihrem Leben ausrichten.>

Epilog:

[...] und so sage ich, dass die in dieser Chronik gekürzten Heldentaten [...].

Bertrand du Guesclin, Versionen A und $\mathrm{AC}^{14}$

Lequel Romant, sans addiction ou diminucion aucune, sera cy-aprés traictié en prose pour cause de briefté, et extrait d'un autre Romant compilé en paroles rymées; excepté mutacion de paroles pour autres, pour abregier le langage, et euader prolixité.

«Besagter Roman, ohne etwas hinzuzufügen oder wegzulassen, soll in der Folge hier in Prosa abgefasst werden, um der Kürze willen, und aus einem anderen Roman, der aus gereimten Wörtern zusammengesetzt ist, extrahiert werden; es sollen lediglich Ausdrücke ausgetauscht werden, um die Rede zu kürzen und Weitschweifigkeit zu vermeiden.>

Es geht also darum, bref $\mathrm{zu}$ sein; was $\mathrm{zu}$ vermeiden ist, heißt prolixité, «Weitschweifigkeit〉. Was damit genau gemeint ist, wird in der Regel - brevitas verpflichtet? - nicht ausgeführt. Manchmal finden sich dennoch etwas längere Erklärungen, die die Arbeitsweise in einen weiteren Kontext einbinden und die Eingriffe rechtfertigen.

So erklärt etwa der Lothringer Philippe de Vigneulles, er habe seinen Stoff in zweierlei Hinsicht neu ausgerichtet. Einerseits habe er alles gekürzt, was sich nur irgendwie habe kürzen lassen, und andererseits habe er die Materie in Kapitel unterteilt, eine Praxis, die sich gegen Ende des Mittelalters

13 Paris, BnF, Arsenal, 3324, zitiert nach dem NRMP, S. 36.

14 Histoire de messire Bertrand du Guesclin (ed. Ménard [1618]), zitiert nach dem NRMP, S. 93. 
und insbesondere mit dem Aufkommen der Prosaform immer stärker durchsetzt. ${ }^{15}$

Geste des Lorrains von Philippe de Vigneulles

Et pour ce, je, Philippe de Vignuelle le marchamps, a l'honneur de Dieu et de la cité, ay heu deliberé de meistre ladicte histoire de ancyenne rime et chansson de geste en prose, par chapitre et au plus brief que j'é peu ne sceu. Et la cause pour quoy que l'istoire est de grant excellance et merveilleux fait d'armes, laquelle se lessoit du tout a lire et n'estoit quasy plus memoire d'icelle par ce que moult de gens n'entendoient pas bien le langaige de quoy l'on soulloit huser, ne ne prenoient plaisir a le lire pour l'anciennetey d'icelluy. ${ }^{16}$

«Und deswegen habe ich, Philippe de Vigneulles, Kaufmann, zu Ehren Gottes und der Stadt mich entschlossen, besagte Geschichte und chanson de geste aus alten Reimen in Prosa zu überführen, in Kapitel gegliedert und so kurz ich es konnte und vermochte. Und der Grund, weswegen die Geschichte, die ganz hervorragend ist und eine wundersame Heldentat erzählt, immer weniger gelesen wird und die Erinnerung daran beinahe verschwunden ist, ist, dass viele Leute der Sprache, die man früher verwendete, nicht mehr kundig waren und dass sie der Lektüre kein Vergnügen abgewinnen konnten, weil die Sprache so veraltet ist.)

Weiter führt er aus, dass der Zeitgeschmack sich geändert habe und dass «die Leute von heute> lieber kurze und gefällige Erzählungen hätten, dass er aber überall, wo er unnütze Wortfluten weggelassen habe, dies mit der Formel pour abregiér kenntlich gemacht habe.

Et weullent les gens de maintenant avoir chose abregee et plaisante, car les esprit deviegne tout les jours plus agus et soubtille. Pour ce advertis a tous les liseurs et auditeurs d'icelle histoire que moy, l'acripvains, l'ais abregees, et que partout la ou vous trovaireis ainsy escript 〈pour abregiés [sic]), quant ainsy trovereis lisant, c'est a dire qu'il y ait en l'ancienne histoire quelque grant procés de parolles inutille lesquelles j'ay lessié pour eviter prolixitey. ${ }^{17}$

15 Siehe dazu die Untersuchungen zu Cligès, Le roman du Chastelain de Coucy et de la dame de Fayel, La Manekine, Jehan d'Avennes, La Fille du comte de Pontieu, Saladin, Érec und La Belle Hélène de Constantinople von Colombo Timelli (2004) und Marchal (2010). 16 NRMP, S. 550. Zum Autor Philippe de Vigneulles siehe Yonnet de Metz, ed. Herbin (2011). Dazu auch Jones (1998) und (2001).

17 NRMP, S. 550. 
«Und die Leute von heute wollen gekürzte und gefällige Dinge lesen, denn unser Intellekt wird täglich schärfer und feinsinniger. So informiere ich alle Leser und Hörer dieser Geschichte, dass ich, der Schreiber, die Geschichte gekürzt habe und dass überall, wo ihr beim Lesen die Angabe «um es kurz zu machen` findet, in der ursprünglichen Geschichte eine große Menge von nutzlosen Wörtern steht, die ich weggelassen habe, um Weitschweifigkeit zu vermeiden.>

Jean Wauquelin, der Autor der Belle Hélène de Constantinople, der im Umfeld der Herzöge von Burgund mehrere mises en prose verfasst hat, spricht davon, die unnützen Reimwörter herauszuschneiden und zu überspringen:

Belle Hélène de Constantinople von Jean Wauquelin

[...] selon le contenu d'un livret rimé à moy delivré par le commandement de mondit tresredoubté seigneur, et ce pour retrenchier et sincoper les prolongacions et motz inutiles qui souvent sont mis et boutez en telles rimes. ${ }^{18}$

‘...] gemäß dem Inhalt eines gereimten Büchleins, das mir auf Befehl meines hochwürdigen Herrn ausgehändigt worden war, damit ich die Längen und nutzlosen Wörter herausschneiden und entfernen solle, die sich häufig in solchen Reimerzählungen finden.>

Eine ähnliche Ansicht vertreten auch der Autor der Prosafassung von Godefroi de Bouillon oder der Pseudo-Turpin:

\section{Godefroi de Buillon}

[...] et l'ai commenchie sans rime pour l'estore avoir plus abregie et si me sanle que le rime est mout plaisans et mout bele mais mout est longue. ${ }^{19}$

‘...] und ich habe sie ohne Reim in Angriff genommen, damit die Geschichte kürzer werde; es will mir nämlich scheinen, dass die Reimerzählung sehr gefällig und schön sei, aber sehr lang.>

Pseudo-Turpin

Chi commenche l'estoire de Torpins [...]. Et por che que l'estoire traitie par rime samble menchonge, est ceste sans rime mise en romans selonc le raison del latin (fol. $208^{\text {ra }}$ ).

18 La Belle Hélène, ed. de Crécy (2002), S. 14 = NRMP, S. 56. Zu Wauquelin siehe den Sammelband von de Crécy / Parussa / Hériché-Pradeau (2006).

19 Godefroi de Buillon, ed. Roberts (1996), S. 1 = NRMP, S. 420. 
«Hier beginnt die Geschichte von Turpin. Und weil die in Reimen abgehandelte Geschichte erlogen wirkt, ist diese hier ohne Reime in die romanische Sprache übersetzt, gemäß der lateinischen Vorlage.>

[...] et ne demora gaires que Pinabiaus fu recreans par Tierri, car jo, Torpins archevesques, je le vi et $\mathrm{i}$ fui et mis en estoire le bataille sans rime et a briés mos (fol. $\left.219^{\mathrm{vb}}\right) .^{20}$

‘...] und bald darauf wurde Pinabaus von Thierry besiegt, denn ich, Erzbischof Turpin, habe es gesehen und war dabei und habe die Schlacht in eine Geschichte ohne Reime und mit wenigen Worten geformt.>

Was hier anklingt, ist natürlich der altbekannte Vorwurf, dass der Reim nicht nur unnötig, sondern auch schädlich sei. Das überflüssige Reimwort sei quasi dazuerfunden, anorganisch und auf jeden Fall unauthentisch und folglich unwahr. Es kombinieren sich also hier zwei Faktoren: «Gereimte Erzählungen sind lang und falsch, Prosaerzählung folglich kurz und wahrhaftig», ${ }^{21}$ und die Operation der mise en prose ermöglicht es, beide Probleme im selben Durchgang zu korrigieren.

Bezeichnenderweise heißt die Operation, aus Versen Prosa zu machen, mit dem mittelfranzösischen Fachterminus reduire en prose. Jetzt stellt sich natürlich die Frage, ob diese Reduktion quantitativ auch zu Buche schlägt und, wenn ja, in welchem Umfang. Wie lange dauerte die Lektüre der Versvorlage im Vergleich zur derart reduzierten Prosafassung?

Erstaunlicherweise liegt auf diese recht simple Frage auch nach mehreren Jahrzehnten von Performance Studies keine Antwort vor. Es scheint sogar, dass sie innerhalb des eher angelsächsisch dominierten Kreises der Spezialisten der mittelalterlichen Performance gar nicht gestellt worden sei, genau wie konkrete Quantifizierungen überhaupt fehlen. ${ }^{22}$

$20 \quad$ Palumbo (2008), S. 153-54.

21 Die Formel stammt von Palumbo (2008), S. 153.

22 Das Epizentrum für mittelalterliche Performance Studies liegt in New York, siehe die Sammelbände Vitz / Freeman Regalado / Lawrence (2005); Doss-Quinby / Krueger / Burns (2007); Gertsman (2008); Duys / Emery / Postlewate (2015). - Das New Yorker Team ist auch an verschiedenen Websites beteiligt, insbesondere dem YouTube-Channel $\mathrm{zu}$ «Medieval Tales in Performance»: [https://www.youtube.com/channel/UC2wz1u R1Sl93vNMWML2Ieyw] 16.01.2020, mit dem showcase "Performing Medieval Narrative Today: A Video Showcase» oder «Arthurian Legend Performed»: [http://vimeo.com/Art hurPerform] 16.01.2020. 
Haben sich Forscher, die sich mit mündlicher Dichtung und der chanson de geste beschäftigten, immerhin schon in den 1960er-Jahren gefragt, inwieweit gewisse Formeln Einschnitte und Reprisen in einer Rezitation markieren könnten und inwieweit unsere geschriebenen Texte überhaupt als Reflex von konkreten Vortragssituationen anzusehen sind, ist die überwiegende Zahl von Performance-Studien vor allem close readings gewidmet. ${ }^{23}$ Zahlenangaben zu effektiven Vortragsdauern sind immer noch ein Desiderat. Empirisch ermittelte Größen, die zum Teil aus der Theaterforschung kommen, legen einen Leserhythmus von 1200 bis 1500 Achtsilbern pro Stunde nahe. Somit kann man wohl für Alexandriner eine entsprechend niedrigere Zahl von 800 bis 1000 ansetzen. ${ }^{24}$

Für die mittelalterliche Prosa fehlt nach meinem Kenntnisstand jede Art von Vorstudie. Untersuchungen $\mathrm{zu}$ Sprechtempo und Wortausstoß pro Minute, die für die Prosa in den modernen Medien durchgeführt worden sind, geben Anhaltspunkte, weisen aber gleichzeitig auf eine beträchtliche Bandbreite hin, die verschiedenen Parametern zu unterliegen scheint. Einerseits spielt der persönliche Duktus des einzelnen Sprechers eine Rolle, andererseits fällt aber auch die konkrete Sprech-Situation ins Gewicht: Liegt der durchschnittliche Wortausstoß in den modernen französischen Medien bei ca. 200 Wörtern pro Minute, kann er unter gewissen Bedingungen, insbesondere bei feierlich-offiziellen Reden, auf beinahe die Hälfte sinken oder umgekehrt bei Kurzreportagen von 60 bis 90 Sekunden auf 230 Wörter pro Minute steigen, eine Proportion, die bereits Gefahr läuft, die Verständlichkeit zu beeinträchtigen. ${ }^{25}$ Wir gehen hier von mittleren Werten von rund 130 bis 140 Wörtern pro Minute aus, einer Größenordnung, die dem Umstand Rechnung tragen will, dass es sich um Kunstprosa handelt, die nicht mit der Alltagssprache gleichzusetzen ist und deren Verständnis und

24 Ich danke Darwin Smith, ausgesprochener Kenner des mittelalterlichen Theaters, für diese Angaben.

25 So war z.B. der frühere französische Präsident Jacques Chirac als eher langsamer Redner bekannt, der mit knapp 100 Wörtern pro Minute gemessen wird. Zahlen nach Rist (1999). DOI: [https://doi.org/10.3406/colan.1999.2909] 06.03.2020. 
Vermittlung vom Publikum wie auch vom Vortragenden eine gewisse Anstrengung erfordern. ${ }^{26}$

Der Vergleich zwischen Versvorlage und Prosafassung ist ebenfalls ein ziemlich heikles Unterfangen, da wir nicht immer mit Sicherheit wissen, ob es tatsächlich die uns bekannte Versfassung ist, die der mise en prose zugrunde liegt, denn schließlich heißt es in den Prologen der Bearbeitung jeweils nur, dass der Verfasser von einer Reimfassung ausgegangen ist. Manchmal sind untereinander divergierende Versionen solcher Werke erhalten, und vereinzelt haben die Versfassungen mit den Prosafassungen nicht viel zu tun, sodass die Filiation nicht gesichert ist, da man theoretisch auch ein verschollenes Modell postulieren kann. Im Folgenden haben wir uns auf einigermaßen unproblematische Fälle beschränkt, z. B. auf den bereits erwähnten Cleomadés von Adenet le Roi, der zu den Versromanen gehört, die gleich zweimal in Prosa überführt worden sind. ${ }^{27}$

Auf den ersten Blick bestätigt die wie auch immer approximative Kalkulation der Rezitationszeiten vollauf die Absichtserklärungen der zahlreichen Prologe der mises en prose, die sämtlich ihre Tendenz zur Kürzung verkünden: Für die fast 19.000 Verse von Adenets Originalfassung dürfte eine Rezitationsdauer von ca. 16 Stunden zu veranschlagen sein; für die eine mise en prose, die wohl im burgundischen Umfeld entstanden ist und nur in der einen Handschrift Bnf f. fr. 12561 überliefert ist, findet der Text auf knapp 80 eher kleinen Blättern von 295 x 210 mm Platz, wo zusätzlich Kapitelüberschriften- und Nummern eingeführt werden. Bei der zweiten mise en prose, die in der Handschrift Oxford, Bodleian Library, Lyell 48, erhalten ist, die jedoch auf den Lyoner Druck des Guillaume Leroy aus den 1480er-Jahren zurückgeht, liegt der Fall noch krasser: Der Text ist auf 34 Blätter im Kleinfolio-Format ohne Inhaltsverzeichnis und Kapitelüberschriften gedruckt. Für die erste Prosafassung sind somit rund drei Stunden für eine Rezitation zu veranschlagen, bei der zweiten dürfte der ganze Text in

26 Zu Dank verpflichtet bin ich meinen Mitarbeiterinnen Claudia Tassone und Stephanie Wittwer, die auf dieser Basis die approximativen Rezitationszeiten für alle hier aufgeführten Werke ermittelt haben. Für die Prosatexte sind die Zahlen aufgrund der Anzahl von Wörtern pro Blatt oder Seite hochgerechnet worden.

27 Siehe Anm. 6. Dazu die Einträge von Fanny Maillet zu Cléomadés und Clamadés im NRMP, S. 171-181. 
knapp 90 Minuten zu lesen sein. Der Sprung von der Versfassung, für deren Lektüre ganz sicher mehrere Tage eingeplant werden mussten, da ja die berechneten 16 Stunden wohl nicht an einem einzigen Tag zu bewältigen waren, ist beachtlich. Es ist auch klar, dass man einen Sprung dieser Größenordnung nicht allein mit der Elimination der Reimwörter meistern kann. Der Vergleich des plots der Versfassung mit den beiden voneinander unabhängigen Prosafassungen zeigt, dass die Reduktion auf ganz andere Weise zustande gekommen ist, nämlich durch die Auslassung ganzer Episoden, welche, hastig ausgeführt, im Druck sogar dazu führt, dass eine Passage getilgt wird, auf die später angespielt wird. ${ }^{28}$ Es finden sich jedoch in beiden Prosafassungen auch Stellen - und dieser Punkt ist methodologisch wichtig -, die in der Versfassung keine Entsprechung haben und somit von den Verfassern hinzugefügt worden sind. Trotz aller Eile, trotz allen Kürzungsdrangs, haben die Autoren der beiden Prosafassungen es sich nicht nehmen lassen, jeder auf seine Art einige Details hinzuzufügen. Man kann sogar auf ein Paradox hinweisen: «le texte le plus concis étant celui qui nomme davantage ${ }^{29}$

Eine derart drastische Form von abbreviatio, wie sie der Cleomadés erfährt, ist jedoch im von uns untersuchten Corpus die Ausnahme. Zwar lassen sich auch bei anderen Texten Reduktionen feststellen, die de facto zu einer Verringerung der Rezitationsdauer und somit $\mathrm{zu}$ einer schnelleren Abwicklung der Intrige führen können, doch lässt sich aus den Zahlen auch klar ablesen, dass die abbreviatio-Ratio nicht überall identisch ist. Immerhin führt sie bei folgenden Titeln jedes Mal zu einem kürzeren Text.

\author{
Vers-Cligés \\ ca. 6.800 Achtsilber $=$ ca. $5 \mathrm{~h}$ \\ Prosa-Cligés \\ ca. 4 h $30 \mathrm{~min}$
}

Vers-Erec

ca. 6.900 Achtsilber $=$ ca. $5 \mathrm{~h}$

Für einen Vergleich siehe Bohler (2010) und Trachsler (2015).

29 «Der kompaktere Text ist derjenige, der mehr Details benennt.» Die schöne Formel stammt von Fanny Maillet, Le Cheval volant en bois, ed. Maillet / Trachsler (2010), S. 50. 
Prosa-Erec

ca. $3 \mathrm{~h}$

Vers-Floriant et Florette

ca. 7.300 Achtsilber $=$ ca. 5 h $30 \mathrm{~min}$

Prosa-Floriant et Florette

ca. $5 \mathrm{~h}$

Vers-Belle Hélène

ca. 18.700 Achtsilber $=\mathrm{ca} .17 \mathrm{~h} 30 \mathrm{~min}$

Prosa-Belle Hélène

ca. $13 \mathrm{~h}$

Bei anderen Texten ist bei derselben Kalkulationsmethode allerdings quasi kein Unterschied festzustellen, und bei einigen fällt die Prosafassung gar länger aus als die Versfassung.

Vers-Gilles de Chin

ca. 5.550 Achtsilber $=$ ca. $4 \mathrm{~h}$

Prosa-Gilles de Chin

ca. 6 h $30 \mathrm{~min}$

Vers-Gérard de Nevers

ca. 6.650 Achtsilber $=$ ca. $5 \mathrm{~h}$

Prosa-Gérard de Nevers

ca. 5 h $30 \mathrm{~min}$

Vers-Reine Berte

3.500 Zwölfsilber $=\mathrm{ca} .4 \mathrm{~h}$

Prosa-Reine Berte

ca. $5 \mathrm{~h}$

Bei allen Schwankungen und Unsicherheiten, welche unsere empirische Kalkulationsmethode vielleicht mit sich bringt, wird hier ersichtlich, dass - der Kürzungs-Bekundungen der Prologe sehr zum Trotz - die abbreviatio keineswegs ein linearer Vorgang ist, weil offenbar die Tilgungen einhergehen mit Konzessionen an die Publikumserwartung, wo eine Ritterbiographie mit einigen Liebes- und Turnierszenen angereichert werden kann, auch wenn die 
Vorlage keine enthielt. ${ }^{30}$ Es geht schließlich darum, den Geschmack der Zeit zu treffen. Dazu gehören gewisse literarische Ingredienzen wie die Gewandtheit des Protagonisten im Liebesdialog und auf dem Schlachtfeld, genauso wie heute der shootout zum Western.

Es ist unbestritten, dass einige mises en prose so stark kürzen, dass die narrative Kohärenz nicht nur gefährdet, sondern eindeutig kompromittiert ist, doch scheint es keine allgemeine Tendenz zu geben, die Werke auf ein bestimmtes Kaliber reduzieren zu wollen. Die abbreviatio zielt also darauf ab, gefühlte Längen $\mathrm{zu}$ eliminieren und müsste deshalb nicht nur quantitativ, sondern auch qualitativ großflächig untersucht werden. Wahrscheinlich wäre es auch klug, sich nicht auf eine einzige Antwort einzustellen, sondern zu akzeptieren, dass innerhalb dieses technischen und ästhetischen Prozesses der Umformung der Reimfassungen in Prosa verschiedene Szenarien existieren. Die einen Autoren eliminieren mehr und schneller als andere, und alle versuchen im Laufe der Operation, dem veränderten Publikumsgeschmack Rechnung zu tragen, indem sie hinzufügen, was fehlt, und eliminieren, was nunmehr zu viel ist. Manchmal ist abbreviatio ein «Null-Summen-Spiel».

\section{Bibliographie}

\section{Primärliteratur}

Le Cheval volant en bois. Édition des deux mises en prose du Cleomadès d'après le manuscrit Paris, BnF fr. 12561 et l'imprimé de Guillaume Leroy (Lyon, ca. 1480), hg.v. Fanny Maillet / Richard Trachsler, Paris 2010 (Textes du Moyen Age 14).

Galien le Restoré en prose, hg.v. Hans-Erich Keller / Nikki L. Kaltenbach, Paris 1998 (Nouvelle bibliothèque du Moyen âge 43).

Godefroi de Buillon. The Old French Crusade Cycle, Bd. 10, hg.v. Jan Boyd Roberts, Tuscaloosa 1996.

Jehan Wauquelin, La Belle Hélène de Constantinople. Mise en prose d’une chanson de geste, hg.v. Marie-Claude de Crécy, Genève 2002 (Textes littéraires français 547).

Pierre Durand, L'hystoire du noble et vaillant chevalier Guillaume de Palerne et de la belle Melior, lequel Guillaume de Palerne fut filz du roy de Cecille et par fortune et

Dies hat Maura Felice (2014) am Beispiel des Richard sans Peur gezeigt. Die ProsaBiographie wird umgeschrieben und umfasst mehr Liebschaften, aber auch mehr Kämpfe im Vergleich zur Versfassung. 
merveilleuse adventure devint vacher, et finablement fut empereur de Romme soubz la conduicte d'ung loup garoux, filz au roy d'Espaigne, Rouen: Olivier Arnoullet 1552.

Yonnet de Metz. Mise en prose de Philippe de Vigneulles (1515-1528) d'après le manuscrit $h$, avec en regard la version remaniée en vers du manuscrit $\mathrm{N}$ (Arsenal 3143-XIV siècle), hg.v. Jean-Charles Herbin, Paris 2011.

\section{Forschungsliteratur}

Bacquin, Mari: Théséus de Cologne. En route vers la prose, in: Cahiers de recherches médiévales et humanistes 35 (2018), S. 283-329.

Badel, Pierre-Yves: La brièveté au risque de l'obscurité. Poétique médio-latine et comique, in: Catherine Croizy-Naquet / Laurence Harf-Lancner / Michelle Szkilnik (Hgg.): Faire court. L'esthétique de la brièveté dans la littérature du Moyen Âge, Paris 2011, S. 19-33.

Bohler, Danielle: Du roman au récit 〈light`. La mise en prose de Cleomadès au $\mathrm{XV}^{\mathrm{e}}$ siècle. Réflexions sur le remaniement par abrégement, in: Maria Colombo Timelli / Barbara Ferrari / Anne Schoysman (Hgg.): Mettre en prose aux $\mathrm{XIV}^{\mathrm{e}}-\mathrm{XVI}^{\mathrm{e}}$ siècles, Turnhout 2010, S. 77-86.

Cappello, Sergio: Le passage à l'imprimé des mises en prose des romans. Giglan et Guillaume de Palerne ‘a l'enseigne de l'escu de France`, in: Maria Colombo Timelli / Barbara Ferrari / Anne Schoysman (Hgg.): Pour un nouveau répertoire des mises en prose. Roman, chanson de geste, autres genres, Paris 2014, S. 69-84.

Colombo Timelli, Maria: Pour une «défense et illustration〉 des titres de chapitres. Analyse d'un corpus de romans mis en prose au $\mathrm{XV}^{\mathrm{e}}$ siècle, in: Emmanuel Bury / Francine Mora (Hgg.): Du roman courtois au roman baroque, Paris 2004, S. 209-232.

Colombo Timelli, Maria u. a. (Hgg.): Nouveau répertoire de mises en prose $\left(\mathrm{XIV}^{\mathrm{e}}-\mathrm{XVI}^{\mathrm{e}}\right.$ siècle), Paris 2014 (Textes littéraires du Moyen Âge 30; Mises en prose 4).

Curtius, Ernst Robert: Europäische Literatur und lateinisches Mittelalter, Bern 1954.

De Crécy, Marie-Claude / Parussa, Gabriella / Hériché-Pradeau, Sandrine (Hgg.): Jean Wauquelin. De Mons à la cour de Bourgogne, Turnhout 2006 (Burgundica XI).

Doss-Quinby, Eglal / Krueger, Roberta L. / Burns, E. Jane (Hgg.): Cultural Performances in Medieval France. Essays in Honor of Nancy Freeman Regalado, Cambridge 2007.

Doutrepont, Georges: Les Mises en prose des épopées et des romans chevaleresques du $\mathrm{XIV}^{\mathrm{e}}$ au XVIe siècle, Bruxelles 1939 (Académie royale de Belgique. Classe des Lettres. Mémoires. Collection in- $\left.8^{\circ} 40\right)$.

Ducos, Joëlle: Lectures et vulgarisation du savoir aristotélicien. Les gloses d'Évrart de Conty (sections XXV-XXVI), in: Pieter de Leemans / Michèle Goyens (Hgg.): Aristotle's Problemata in different Times and Tongues, Louvain 2006, S. 199-225. 
Duys, Kathryn A. / Emery, Elizabeth / Postlewate, Laurie (Hgg.): Telling the story in the Middle Ages. Essays in honor of Evelyn Birge Vitz, Cambridge / WoodbridgeRochester 2015.

Felice, Maura: Des vers à la mise en prose, in: Maria Colombo Timelli / Barbara Ferrari / Anne Schoysman (Hgg.): Pour un nouveau répertoire des mises en prose. Roman, chanson de geste, autres genres, Paris 2014, S. 139-150.

Frick, Julia: Ez wâre ze sagene al ze lank. Zum Stellenwert der 〈Kürze-Topoi〉im mittelhochdeutschen Antikenroman, in: ZfdPh 139 (2020), S. 353-378.

Gertsman, Elina (Hg.): Visualizing Medieval Performance: Perspectives, Histories, Contexts, Aldershot, Eng. / Burlington, Vt. 2008.

Jeay, Madeleine: 〈Pour cause de briefté〉. Les formes d'abrègement dans la narration longue, in: Catherine Croizy-Naquet / Laurence Harf-Lancner / Michelle Szkilnik (Hgg.): Faire court. L'esthétique de la brièveté dans la littérature du Moyen Âge, Paris 2011, S. 105-120.

Jones, Catherine M.: «Modernizing〉 the epic. Philippe de Vigneulles, in: David P. Schenck / Mary Jane Schenck (Hgg.): Echoes of the Epic. Studies in Honor of Gerard J. Brault, Birmingham 1998, S. 115-132.

Jones, Catherine M.: Autour du «nouveau langage`. La Geste des Loherains aux $\mathrm{XVI}^{\mathrm{e}}$ et $\mathrm{XIX}^{\mathrm{e}}$ siècles, in: Salvatore Luongo (Hg.): L'épopée romane au Moyen Âge et aux temps modernes. Actes du XIV ${ }^{e}$ Congrès international Rencesvals, Bd. 2, Napoli 2001, S. 693-704.

Lausberg, Heinrich: Handbuch der literarischen Rhetorik, Stuttgart ${ }^{3} 1990$.

Marchal, Matthieu: Mises en chapitres, rubriques et miniatures dans Gérard de Nevers, in: Maria Colombo Timelli / Barbara Ferrari / Anne Schoysman (Hgg.): Mettre en prose aux XIV ${ }^{\mathrm{e}}-\mathrm{XVI}^{\mathrm{e}}$ siècles, Turnhout 2010, S. 187-195.

Palumbo, Giovanni: Une mise en prose de la mort de la Belle Aude au XIII ${ }^{e}$ siècle, in: Tania Van Hemelryck / Maria Colombo Timelli (Hgg.): Quant l'ung amy pour l'autre veille. Mélanges de moyen français offerts à Claude Thiry, Turnhout 2008, S. 147-162.

Rist, Colas: 200 mots à la minute. Le débit oral des médias, in: Communication et langages $119,1^{\text {er }}$ trimestre 1999. Dossier: Les nouvelles technologies de la communication, S. 66-75.

Roccati, Giovanni Matteo: Le roman dans les incunables. L'impact des stratégies éditoriales dans le choix des titres imprimés, in: Anne Schoysman / Maria Colombo Timelli (Hgg.): Le roman français dans les premiers imprimés, Paris 2016 (Rencontres. Série Civilisation médiévale 17), S. 95-126.

Trachsler, Richard: Du nouveau sur le Garou ? Observations sur le roman de Guillaume de Palerne médiéval et sa mise en prose, in: Laurent Brun u. a. (Hgg.): Le Moyen Age par le Moyen Age, même. Réception, relectures et réécritures des textes 
médiévaux dans la littérature française des $\mathrm{XIV}^{\mathrm{e}}$ et $\mathrm{XV}^{\mathrm{e}}$ siècles, Paris 2012 (Colloques, congrès et conférences sur le Moyen Age 13), S. 211-221.

Trachsler, Richard: Du Cleomadés au Clamadés. Les mises en prose du roman d'Adenet le Roi, in: Dorothea Kullmann / Shaun Lalonde (Hgg.): Réécritures. Regards nouveaux sur la reprise et le remaniement de textes, dans la littérature française et au-delà, du Moyen Age à la Renaissance, Toronto 2015 (Toronto Studies in Romance Philology 2), S. $73-82$.

Vitz, Evelyn Birge / Freeman Regalado, Nancy / Lawrence, Marilyn (Hgg.): Performing Medieval Narrative, Cambridge 2005.

Williams, Harry F.: Les versions de Guillaume de Palerne, in: Romania 73 (1952), S. $64-$ 77. 



\section{Immer schneller kürzer oder: Wenn die Form den Text verzehrt}

Das Schlussgedicht in Hartmanns von Aue Klage

von

Susanne Köbele (Zürich)

Für Franz Josef Worstbrock

\section{I. «Schrumpfende Form». Kürzung und Zeitregie}

Kürzung wird im Folgenden nicht als zentrales Paradigma der Bearbeitung vorgängiger Materie verhandelt. Nicht um kürzende Aneignung fremder Stoffe im Horizont «habituelle[r] Vorlagenbindung ${ }^{1}$ soll es gehen, sondern um ein textinternes Verfahren: den Sonderfall systematischer Kürzung durch ein versifikatorisches Prinzip, das den Umfang des Textes kontinuierlich schrumpfen lässt. Die Funktion solcher Kürzung scheint auf der Hand zu liegen: Der Text hat es eilig, zum Ende zu kommen. Doch er lässt sich dabei Zeit, und das ist nicht die einzige widersprüchliche Implikation seiner Kürzungsregie. Will er sich möglichst schnell überflüssig machen? Oder im Gegenteil möglichst lang und umfassend seine Kunst demonstrieren? Hinzu kommt: Die einfache Maßnahme mechanischer Kürzung steuert auf ein unkalkulierbares Ende zu. Als beschleunigte Kurzfassung seiner selbst wird der Text immer länger, zugleich immer schneller kürzer, bis am Schluss die Zeit stillsteht - oder ist sie nur zerronnen?

Mein Thema ist das sogenannte «Schlussgedicht ` aus Hartmanns Klage, ein kunstvolles Kürzungsexperiment, das in der deutschen Literaturgeschichte des Mittelalters ohne Parallele ist. Kurz ist es nicht, sondern nach Bauschema 270 Verse lang (überliefert sind 264 Verse), und es beschließt

2 Hg. v. Gärtner (2015) (= zit.). 
einen Text, der als ganzer gleichfalls historisch neu wirkt. Die Klage ist ein performativ gerahmtes Streitgespräch zwischen den personifizierten IchInstanzen Herz und Leib, das heterogene Gattungs- und Wissenstraditionen zusammenführt (romanische Lyrik, Minnesang, allegorische Minnelehren, lateinische Leib-Seele-Streitdialoge), ohne dass konkrete Prätexte aus der Literatur der Zeit nachgewiesen werden können. ${ }^{3}$ Bereits der Prolog spielt mit Gattungsinterferenzen, ${ }^{4}$ die auch den Gesamttext prägen. Als Hauptthema wird der Widerspruch zwischen stetem Dienst eines jungelinc und steter Dienstverweigerung der Dame angekündigt. Das variiert eine hochminnesängerische Konstellation (vv. 14-17), freilich im Erzählgestus und Erzählmetrum vierhebiger Reimpaarverse. Zur Verschwiegenheit verpflichtet, klagt der von der Dame nicht Gewürdigte, in autobiographischer Inszenierung Hartmann von Aue selbst, den Konflikt zunächst seinem Inneren:

disen kumberlîchen strît

entorste er nieman gesagen;

[...] er klagete sîne swære

in sînem muote [...].

daz waz von Ouwe her Hartman,

der ouch dirre klage began

durch sus verswigen ungemach.

(vv. 18f., 24f. u. 29-31)

Die angekündigte klage erweist sich dabei von Anfang an als vieldeutiger Sprechakt, der zwischen Liebes- und Rechtsdiskurs schillert und, wiederum minnesangkonform, in diesem Doppelsinn von planctus (〈Wehklage〉) und accusatio (‘Anklage〉) auch Selbstanklage einschließt. Der Textfortgang setzt die Klage dann mit vielen zusätzlichen religiösen Anspielungen nicht «ly-

3 Inhalt und Argumentationsstruktur der Klage sind prägnant zusammengefasst bei Cormeau / Störmer ( $\left.{ }^{3} 2007\right)$.

$4 \mathrm{Zu}$ Überschneidungen geistlich-weltlicher Diskurse in der Klage Mertens (1988), Philipowski (2006), Köbele (2006). Parallelen zur lateinisch-romanischen Gattungstradition des Streitgedichts bei Kasten (1973), zu romanisch-deutschen Intertextualitätseffekten Masse (2012). Zur Tradition des «selbstbetrachtenden Dialogs〉 Hess (2016), zu inhaltlichen Berührungen mit Hartmanns Liedern Haustein (2021). Nahe liegen außerdem die Tradition des Liebesbriefs (saluts d'amour, «Büchlein`-Tradition) und der Minnerede. Glier (1971), S. 20, fasst die Klage als in ihrer Zeit isolierten Minnereden-〈Vorläufer `. 
risch als monologische Ich-Klage um, sondern als umfänglichen Streitdialog zwischen Herz und Leib, der für das Ich das Risiko potentieller Unendlichkeit hat: ein êwiger strît (v. 900). Im Schlussgedicht findet er trotzdem ein Ende.

Nachdem es rund 1.600 Reimpaarverse lang mit sich gestritten hat, überbringt das Ich als sein eigener Bote der Dame einen strophenartig präsentierten Liebesgruß, der beständige Dienstbereitschaft beschwört, aber als Text bedenklich schrumpft. Er wendet sich an die Dame in 15 kreuzgereimten 'Strophen`, deren Umfang sich sukzessive jeweils um ein Verspaar reduziert: von üppigen 32 Versen zu Beginn bis zu vier Versen am Schluss (v. 1.645-1.914), wobei je zwei Verse zusammengenommen einen Langzeilentypus ergeben, der als 〈Vagantenzeile〉 in mittellateinischen und mittelhochdeutschen Texten der Zeit weit verbreitet ist. Diese 15 immer schneller immer kürzeren 〈Strophen〉 können mit ihrer formalen (quantitativen) Variabilität nicht als Lied-Strophen im strikten Sinn gelten, sie sind umgekehrt durch die formkonstante Maßnahme kalkulierter Kürzung aber auch keine Leich-Versikel. ${ }^{5}$ Kein Wunder, dass die Forschung, die den Gesamttext der Klage als 〈Frühwerk〉 des Autors in die 〈Frühphase〉 der Gattung Minnerede einsortiert, für die Bestimmung des Schlussabschnitts keine idealtypischen Abstraktionen oder, in diachroner Perspektive, reinen Prototypen ansetzt, sondern sich geeinigt hat auf die texttypologisch neutrale Bezeichnung des «sogenannten Schlussgedichts : nicht Fisch noch Fleisch.

Die ältere Klage-Forschung hat den Schluss, der also durch systematische Verwendung versifikatorischer Abbreviation eine historisch neue Form kreiert, als 〈bloßes〉 Formspiel unter Manierismus-Verdacht gestellt und die Frage nach einer Signifikanz der Kürzung kategorisch verneint. Der Schluss der Klage sei nicht mehr als ein Anhängsel ohne «ästhetischen Wert», ohne «Intensivierung» und «Verdichtung», ja ohne «Sinn», so die Extremposition 1997 bei Heinz Kischkel, ${ }^{6}$ der es dem Autor absprechen und erst im 13. Jahrhundert entstanden sehen möchte. Schon Friedrich Heinrich von der

Im Folgenden ist «Strophe〉 daher immer in distanzierenden Anführungszeichen zu denken. Dieser Vorbehalt mehrfach eingeklammerter Nomenklaturen (das «sogenannte Schlussgedicht〉, 〈Strophen〉, 〈Frühphase〉) verweist auf ein grundsätzliches Dilemma historischer Abstraktion, für das letztlich nur kontrollierte Anachronismen übrig bleiben.

$6 \quad$ Kischkel (1997), S. 94. 
Hagen hatte 1838 in seinen Minnesängern den Klage-Schluss, vom überlieferten Kontext isoliert, als «Leich» abgedruckt.7 Valeska Lembke moniert nach wie vor die «manierierte, strenge Form» des Schlussgedichts, ${ }^{8}$ die aber, so die These, im Textverlauf zu passablen Form-Inhalts-Entsprechungen fortschreite, sodass «mit zunehmender Reife und Einsicht des Ich die optimale Entsprechung von Inhalt und Form» entstehe, die zu Beginn des Schlussgedichts noch "gestört» sei. ${ }^{9}$ Auf ihre Weise hat bereits die Überlieferung des Textes auf das formal ungewöhnliche, gattungshybride Kürzungskunstwerk reagiert: Das Ambraser Heldenbuch, mehr als drei Jahrhunderte nach der Textentstehung, scheint die kalkulierte Systematik der schrumpfenden Form nämlich nicht konsequent umzusetzen. Wurde sie übersehen oder aktiv verdeckt ?10 Die Systematik der Versreduktion zeigt sich bei der Rezeption des Textes ja erst nach und nach, und sie ist deswegen leicht übersehbar beziehungsweise überhörbar, weil die Kürzung um je ein Verspaar an einem mit 32 Versen ungewöhnlich amplifizierten Strophenformat ansetzt. Aus dieser Sicht wäre es zwar kein Zufall, dass das Ambraser Heldenbuch (Hans Ried oder bereits seine Vorlagen) in das Formexperiment gewissermaßen hineinstolperte, wenn es den Beginn des Schlussgedichts nicht, wie im Fall der meisten anderen Strophen, mit abwechselnd roten und blauen Lombarden und Zeilenabstand markiert. Doch hat sich im Blick auf die Gesamtinszenierung des Textes in der Handschrift die Frage damit nicht erledigt, ob die Überlieferung die textkonstitutive Kürzungssystematik gezielt unsichtbar macht. Wie ist die Mise en page des Schlussgedichts in A zu deuten? In A sei für den Übergang von Dialog zu Schlussgedicht keine Initiale gesetzt worden, «damit der Schluß nicht als eine selbständige Dichtung vom Hauptteil

7 HMS III (1838), S. 468 ff-hh. Schon Zutt (1968), S. 361, hat darauf hingewiesen, dass die frühen Klage-Editionen durch Moriz Haupt $\left({ }^{2} 1881\right)$ und Fedor Bech (1867) die Form des Schlussgedichts weitgehend verdecken. Ihr eigener Versuch, den Text als «Zahlenkomposition» zu (re-)konstruieren, hat in der Forschung kaum Resonanz gefunden. Die Ausgabe von Gärtner (2015), die für die Textpräsentation möglichst weit zur Überlieferung zurückkehrt, setzt die Strophenform des Schlussgedichts vollständig um, markiert aber die in A jeweils fehlenden Initialen (und evidente Fehlverse).

8 Lembke (2013), S. 123.

9 Ebd., S. 126.

10 Vgl. unten S. 96-98. 
getrennt würde». ${ }^{11}$ Diese Erklärung - die Kürzung als Maßnahme zur Sicherung der Textkohärenz - wurde in der Klage-Forschung immer wieder weitergereicht, doch scheint sie mir den Befund zu unterbieten. Anders gesagt: Die Überlieferung hilft nicht weiter beim Versuch der Klärung der Kürzungsfunktion, sondern sie ist selbst klärungsbedürftig.

Die jüngste Forschung hat den Gesamttext der Klage mittlerweile beeindruckend komplex erschlossen, ${ }^{12}$ jedoch die Frage nach der Kürzungsfunktion des Schlussgedichts entweder ganz ausgespart oder nur gestreift und nach wie vor nicht ausgeschöpft. Daher greife ich sie hier erneut auf: Wie ist es zu verstehen, dass der Text am Schluss übergeht in eine lange, zunächst kaum wahrnehmbare, dann immer schnellere Kürzung seiner selbst?

Diese Frage lässt sich nur in der Zusammenschau mehrerer Ebenen bewältigen. Andernfalls findet man nur schwer einen Weg zwischen dem Risiko pauschaler Unterschätzung der Form einerseits und ihrer interpretativen Überlastung anderseits. ${ }^{13}$ Zweifellos wirkt die systematische Kürzung, weil als Form unumkehrbar und auf interne Vollständigkeit angelegt, als «effektives formales Mittel, den Textschluss zu sichern».14 Doch Hanno Rüther legt nicht nur für den Übergang zwischen Dialog und Strophen, sondern für das Schlussgedicht als Ganzes die Kürzung in diesem Sinn auf eine formale Maßnahme der Textsicherung fest. Trotzdem bleiben offene Fragen, denn er forciert für seine ausdrückliche «Poetologie des Textendes` auch inhaltliche Kohärenz: Der formalen Reduktion der Klage entspreche eine Reduktion von konfliktträchtigen Asymmetrien, weswegen das Schlussgedicht als affirmative Schließung des Gesamttextes zu verstehen sei. Hier soll diese These, mit der Rüther nicht allein steht, zunächst nur als Symptom für ein methodisches Hintergrundproblem der übergreifenden Frage nach Kürzungsfunktionen in Texten interessieren: Wie lassen sich schwierige, weil ästhetisch überdeterminierte, historisch ferne Formsemantiken angemessen

\footnotetext{
11 Zutt (1968), S. 362.

12 Zuletzt ausführlich Gebert (2019), Hess (2016), Lembke (2013) und Strittmatter (2013), jeweils mit sorgfältiger Diskussion vorausgehender Forschung.

13 Methodologisch weiterführend zur Frage: «[W]elche Semantik kann die Form mitteilen?» März (1999), S. 324.
}

14 Rüther (2018), S. 243. 
interpretieren, jenseits der Alternative «rein funktionsanalytischer (funktionalistischer) und formalistischer Reduktion hier, bloßer Formspekulation dort? Wie entgeht man Kurzschlüssen zwischen quantitativen Prozessen (dem Abbau von Versen) und qualitativen Prozessen (dem Abbau inhaltlicher Voraussetzungen), ohne die Frage nach Kürzungssignifikanz ganz preiszugeben? Fungiert die Kürzung im Schlussgedicht der Klage als affirmatives Mittel der Positivierung von Negativität? Im Folgenden möchte ich zeigen, dass eine Zusammenschau überlieferungshistorischer, text- und gattungspoetischer, wirkungsästhetischer und diskursgeschichtlicher Aspekte das Schlussgedicht im Gegenteil als spannungsvolles (nicht: Spannung reduzierendes) Kürzungsexperiment in seiner spezifischen Faktur erschließen kann. Es erscheint dann als genuine Pointe der Klage und gewinnt nicht nur einiges literarästhetisches Gewicht, sondern auch historische Signifikanz.

Ausgangspunkt meiner Überlegungen sind widersprüchliche Zeitimplikationen der «schrumpfenden Form〉 des Schlussgedichts, die die Forschung zur Frage der Kürzungsfunktion des Textes bislang nicht einbezogen hat. Auf den ersten Blick bleibt unklar, was von einer Minnewerbung zu halten ist, die sich durch stete Versreduktion selbst ans Ziel bringt - ans glückliche Ziel der Werbung? Oder bloß an ihr unseliges Ende? Ans Ende der tugendhaften Ablehnung der Dame oder ans Ende des tugendhaften Ausharrens ihres Minnedieners? Ich schlage, um in diesen Fragen weiterzukommen, für Hartmanns Schlussgedicht eine Differenzierung vor: Als doppelt paradoxes Phänomen gedehnter Beschleunigung und amplifizierter Kürzung kostet die artifizielle Form den Text einerseits Zeit, die sie anderseits - der Text wird ja immer schneller kürzer - auch gewinnt. Schon deswegen ist die Frage nicht leicht zu entscheiden, ob in diesem Kürzungskunstwerk die Reduktion aus einem Mangel geboren ist - temporal: aus Zeitnot, moralisch: aus einem Defizit an stoete - oder im Gegenteil aus der Fülle unendlicher Dienstbeständigkeit? ${ }^{15}$ Vielleicht ist es gar nicht dieselbe Zeit, die verstreicht. Wenn sich

15 Vgl. neuerdings Gerok-Reiter / Lahr / Leidinger (2020), hier v. a. die Beiträge von Sonja Glauch (mit reicher Dokumentation älterer einschlägiger Forschung) und Christoph Huber. Zur unabschließbaren pragmatischen Paradoxie konstitutiv vergeblichen Dienstes im hohen Sang Müller (1999). Zur performativen Funktion von «Freude〉-Inszenierung im Minnesang Hausmann (2004). Noch in Johanns von Konstanz Minnelehre (um 1300), hg.v. Huschenbett (2001), verifizieren Goldbuchstaben im exklusiven Latein 
der Schluss bis zur Selbstaufhebung des Textes abkürzt, weil längst alles gesagt ist, dann beseitigt die Kürzung überflüssige Zeit. Wenn sich der Schluss abkürzt, weil es im Gegenteil nichts zu sagen und zu erwarten gibt, verstreicht kostbare Zeit. Den unsicheren Zeitbilanzen entsprechen unsichere Axiologien, weil das Ich sein Dauerleiden permanent umdeutet zu Dauerfreude, und umgekehrt. Die «Überwindung» und «Umwandlung» von swere in hôhen muot kann, wie Wolfgang Monecke formuliert hat, als «eine Kardinalaufgabe höfischer Kultur» gelten. ${ }^{16}$ Weil im Hohe-Minne-Diskurs aber offenbleibt, wie berechtigt oder im Gegenteil illusionär solche Umdeutung jeweils ist, schlagen mit den Zeitachsen auch die Sprechakte Klage und Preis beständig ineinander um - in Hartmanns Schlussgedicht immer schneller und auf immer engerem Raum. Die Zeitbilanz ist axiologisch mehrdeutig, und so muss die Antwort auf die Frage «Wie lang ist immer kürzer?,17 für das Schlussgedicht und seine verstechnische abbreviatio zwangsläufig ambivalent ausfallen: Immer kürzer war nicht zu lang, wenn der Augenblick, den die Kürzung am Ende übrig lässt, sich als Moment zeitloser Gegenwart «erfüllt). Bleibt hingegen nur ein flüchtiger Augenblick, der im $\mathrm{Nu}$ vorbei ist - und die Dame hat nichts gesagt -, dann war immer kürzer immer noch zu wenig lang.

Kompliziert wird der Fall dadurch, dass die verstechnische abbreviatio des Schlussgedichts weder mit einer analogen abbreviativen Poetik einhergeht noch mit einer durchgängig amplifikatorischen. Vielmehr wird Vielfalt durch abundante Wiederholungsrhetorik im Modus von amplificatio reduziert. Iterative Figuren, emphatische Leitworttechniken, Metaphernserien, wiederkehrende Sprechakte blenden Differenz gewissermaßen ab. Der Effekt ist also auch auf poetologisch-performativer Ebene eine, wie ich meine,

die Ewigkeit der Minne (daz der iemer minnet, / die wil er lebet, eweclich, vv. 358 f.; ignis hic mitissimus / sed durat primo longius, vv. 849 f., vgl. auch $871 \mathrm{f}$.); zugleich wird die schnelle Vergänglichkeit der kurzen Nacht beklagt (v. 460), auch auf Lateinisch: sed velocissime transit (v. 862), und für die im Nu entzündete Liebesglut entsprechend Heilung in kurzen stvnt erhofft (v. 951). Dauernder Dienst um des Dienstes willen steht der auf persuasio <jetzt> angelegten Liebesrhetorik gegenüber, die unendliche Dauer des Liebesaffekts seiner je neu verlorenen oder wiederzugewinnenden Aktualität.

16 Monecke (1968), S. 37.

17 Vgl. den Beitrag von Richard Trachsler, in diesem Band. 
durchgängige und textkonstitutive Spannung zwischen Sequenzierung und Paradigmatisierung, wohingegen die jüngere Forschung ${ }^{18}$ für die «Entwicklung» eines literarischen «Fortschritts» im Verlauf des Schlussgedichts selbst plädiert und mit abnehmender Verszahl die Abnahme «formalen Prunks und pathetischer Rhetorik» erkennen will. ${ }^{19}$ Doch nicht nur in rhetorischer, auch in metrischer Hinsicht lässt sich für den wohl okzitanisch inspirierten Typus durchgereimter Strophen eine spannungsvolle Reduktion im Modus von amplificatio beobachten: Durch die Wiederholung identischer Reimklänge, also durch serielle Reduktion auf jeweils nur einen einzigen Kreuzreimklang pro Strophe, z. T. in Kombination mit grammatischem Reim, verschränken sich auch in dieser Hinsicht Simultan- und Verlaufsdimension des Textes. Und schließlich werden (affekt-)ambivalente Zeit- und Wertimplikationen von Kürzung auch auf der Textebene umfassend thematisch: als je neu artikulierte Spannung zwischen Zeitverlust und Zeitgewinn, Dauer und Prozess, Verheißung und Erfüllung 〈jetzt〉.

Es zeichnet sich vor diesem Hintergrund ab, wie heikel die Frage nach der Signifikanz von Kürzungsfunktionen ist, jenseits der bloßen Feststellung der Form abbreviativer Selbstaufhebung des Textes. Wie weit reichen die Folgen des Prinzips kontinuierlicher Versreduktion für die Poetik und produktive Rezeption des Textes? Wenn nicht ein «bloßer` Formmechanismus die Kürzung regiert, worin läge dann die historische (ästhetische, strukturelle, diskursive) Signifikanz dieses Kunstgriffs? Nomenklaturen sind, hier wie auch sonst, nie unschuldig. So scheint die Frage nach Kürzungs〈Funktionen` oder Kürzungs-〈Implikationen`zwar unverfänglicher als die Frage nach Kürzungs- $\$ Intentionen`, bleibt aber umso unverbindlicher, je funktionalistischer argumentiert wird. Und auch für die heuristisch durchaus angebrachte Rede von Kürzungs-〈Effekten` öffnen sich schneller, als uns lieb sein kann, die bekannten hermeneutischen Fallen der Rezeptionsästhetik.

Die Einleitung in diesem Band sucht methodisch Ordnung zu schaffen und erinnert an drei zentrale Aspekte, die bei Kürzungsverfahren in Texten zu bedenken sind. Ich reformuliere sie hier abschließend für den Sonderfall des höfischen Minnediskurses des hohen Mittelalters und beziehe sie jeweils 
auf Hartmanns Klage. Der erste Punkt: Kürzungsprozeduren in Texten hängen mit Zeit zusammen. ${ }^{20}$ Im Kontext höfischer (hoher) Minne entfaltet sich eine ganz eigene Zeitregie, eine "Zeit-Poetik», die auch in den Texten selbst reflektiert und performativ wirksam wird, wie zuletzt Sonja Glauch dokumentiert und sehr genau durchdacht hat. ${ }^{21}$ Für das hartmannsche Kürzungskunstwerk der Klage spielt der Faktor Zeit wie bereits angedeutet eine spezifische Rolle. Das kann nicht überraschen bei einem Autor, der gattungsübergreifend auf Schritt und Tritt Zeitdilemmata bespricht und generiert, sei es in seinen Liedern durch abbreviierte, «nicht erzählte» Geschichten, ${ }^{22}$ sei es in seinen Erzähltexten, die immer wieder ihre Helden mehrdeutig aus der Zeit herausfallen lassen. ${ }^{23}$ Zweitens: Quantitative Maßnahmen von Kürzung und Amplifikation können unübersichtlich in qualitative, d. h. inhaltlich relevante, axiologisch besetzte Prozesse übergehen. ${ }^{24}$ Auch dieser Punkt hat besondere Relevanz im Kontext höfischer Minnedichtung, die geradezu programmatisch Zeit- und Wertimplikationen ihrer Leitbegriffe (stcete, triuwe) verschränkt: «Wenn die Rede von ewiger Treue ist, verschiebt sich der Wunsch nach Dauer auf die Ebene des Wertes, der Tugend.» ${ }^{25}$ Insbesondere bei Hartmann transportiert der Schlüsselbegriff stoete mit seiner zwischen Dauer und Verlauf, Prozess- und Zielorientierung angesiedelten Konfliktsemantik zentrale Systemaporien der höfischen Minnekultur. Dabei sollte nicht vergessen werden, dass solche mehrdeutigen Zeit- und Wertbilanzen angesichts der minnesangtypischen Doppelreferenz der Ich-Rolle als Sänger und Liebender immer auch metapoetisch zu Buche schlagen: Wenn Singen von stetem Minnedienst seinerseits als steter Minnedienst gilt, Minnekommunikation immer zugleich als Metakommunikation fungiert, dann sind alle Zeitverläufe - Kürzen, Längen, Anfangen und vor allem auch Aufhören - im Kontext hoher Minne ein Problem von eminenter Reichweite. Entsprechend kompliziert sind in der Regel die Auflagen für den

Zur entsprechenden rhetorischen Kategorie der velocitas (Quintilian) vgl. Grütter, in diesem Band.

21 Vgl. Glauch (2020).

22 Haustein (2011); Egidi (2020).

23 Störmer-Caysa (2007).

24 Vgl. die Einleitung von Frick, in diesem Band.

25 Huber (2020), S. 155. 
Minnediener: nicht zu viel und zu breit, nicht zu wenig und zu kurz reden und schon gar nicht damit aufhören. ${ }^{26}$ Für das Schlussgedicht der Klage scheint mir genau dieser Aspekt zentral: Wer den Text - die Zeit seines Verlaufs - kürzt, bringt sich immer auch in Verdacht, die «Eigenzeit der

26 Die höfische Minnedichtung hat, je näher am pragmatischen Paradox der hohen Minne, ein umso größeres Problem damit, das Ende zu erreichen oder abzukürzen. Insbesondere Texte, die unter dem Eindruck von Hartmanns Klage stehen, übernehmen zwar nicht das Kürzungsmodell, kreieren aber je eigene Lösungsmodelle: Strickers Frauenehre, in A zusammen mit Hartmanns Klage überliefert, kompensiert das Aufhörenmüssen mit einer Anspielung auf Emanationsmetaphysik (der Dichter als volles Gefäß, das unendlich Frauenpreis ausströme, ohne je leer zu werden [hg. Hofmann (1976), vv. 1.867-1.872]; durchaus naheliegend, wenn die Dame als «anderer Gott der Welt» gilt, vgl. v. 1.894) und schließt damit an die hochfrequenten religiösen Allusionen in Hartmanns Schlussgedicht an (die Dame als Göttin, stcete des Ich bis ans Ende der Welt). Die religiöse Hyperbolik ist auch aufgenommen in Ulrichs von Liechtenstein Frauendienst (hg. Spechtler [1987]), der eingangs auffällig breit über die Unmöglichkeit, zum Ende zu kommen, räsoniert (Wie sol man des wol ze ende komen, / des ende nimmer wirt vernomen / und daz für war niht endes hat?, 4,1-3) angesichts des unendlich sich verbreitenden Glanzes der Frauen (ir lop sich breitet als der tac - / wa endet sich der sunne schin?, 2,4f.) und das Problem des Textendes mit dem Modell «Anschlusskommunikation` löst. Johann von Konstanz in seiner Minnelehre (um 1300, hg. Huschenbett [2001]), in der das Ich auch auf «schnelle〉 Erlösung hofft (in kurtzen stunden, v. 2.541), inszeniert den Schluss (in A) als ironische Fürbitte ( $₫$ Möge ihr roter Mund mir schnell helfen. Numquam Amen.`), ähnlich auch in C; oder schließt alternativ mit dezisionistischen Formeln wie «Hier soll der Text ein Ende haben', die sich auch verdoppeln können, weil der Text eben doch so schnell kein Ende findet. Anfang des 15. Jahrhunderts empfiehlt sich Eberhard von Cersne in Der Minne Regel (hg. Wöber [1861/1981], vv. 4.800-4.830) selbst als Dichter (und Liebhaber) durch eine abschließende strophische Kunstdemonstration mit Autorsignatur (Binnenreime, Fremdwörter, hoher Stil); zu schweigen von einem Text wie Hadamars Jagd, der in üppiger Breite über 600 Strophen lang immer wieder übers Längen, Kürzen, Anfangen, Enden und Dauern des Jagdverlaufs spricht, bis hin zu fiktionsironischen Textkürzungsprozeduren des Typs «Der Schluss wäre auch anders möglich, wenn die Dame es wünscht〉. Zu Schlussstrophen in der Lyrik des deutschen Mittelalters und den epochenübergreifend verschiedenen Arten der Schlussmarkierung Zotz (2005), die unter dem Vorbehalt grundsätzlicher Fassungsvariabilität u. a. festhält: Wiederholungsemphase, Tempuswechsel ins Präsens, appellative Sprechakte, Wendung zu Gott, metafiktionale Äußerungen, gnomische und generische Formulierungen. 
Minne» riskant abzukürzen, die «jede Denkmöglichkeit eines Endes» aussetzt. ${ }^{27}$

Auch und gerade Hartmann, keineswegs erst auf argumentationslogisch komplizierte Weise Reinmar, hat in seinen Liedern immer wieder Zeit diskursiviert und Zeitreflexion dabei auch formal umgesetzt. So beklagt das Ich im Abgesang der Eingangsstrophe von MF 209,5ff. (Mîn dienest der ist alze lanc), dass sich aufgrund ungelohnten Dienstes die Zeit unendlich dehne, und umgesetzt ist diese Zeitklage mit einer Kyklos-Figur in Form raffender und zugleich zeitdehnender Akkumulation: ein stunde ein tac, ein tac ein woche, ein woche ein ganzez jâr $(209,14){ }^{28}$ Das Schlussgedicht von Hartmanns Klage setzt Zeitdehnung nicht nur in dieser Form punktuell und auf engstem Raum um, sondern systematisch breit und spannungsreich durch «langes Kürzen >. Die Wirkung seines Kürzungskunstwerks ist entsprechend widersprüchlich: Das Schlussgedicht scheint zwar mit immer denselben Formulierungen, Argumenten, Reimklängen auf der Stelle zu treten und bringt sich so prompt unter Redundanzverdacht. Doch zugleich beschleunigt es kontinuierlich seinen Verlauf, den Verlauf von Text- und Minnezeit, und generiert schon deswegen eine gewisse Spannung, wie die Sache ausgehen wird.

Kern des Kürzungskonzepts im Schlussgedicht der Klage scheint eine auf mehreren Ebenen realisierte, spannungsvolle Gleichzeitigkeit von Dauer (dauernd kürzer) und unumkehrbar zielgerichtetem Prozess (gleichmäßig immer schneller kürzer), wobei die Wiederholungsvorgänge sich jeweils rekursiv schließen. Die Zeit «verrinnt» (v. 1.834) und mit ihr die Hoffnung, je öfter das Ich beschwört, sie «verrinne» keineswegs (v. 1.755). Noch kurz vor Schluss, in der elften Strophe (vv. 1.875-1.886), mahnt das Ich Tempo an und gibt der Dame in einem hyperbolisch amplifizierten Vergleich zu bedenken, dass Zeit umso langsamer dahinschleiche, je länger der strît sich hinziehe, für den auf Leben und Tod im Leid Gefangenen. Doch der Schluss des Schlussgedichts führt dann nur zum Ausgangspunkt des Textes zurück,

27 Lieb (2001), S. 187.

28 Dazu Egidi (2020), S. 380 f.; zur langen klage bei Reinmar als konzeptuelle Zeitdehnung Bleumer (2012), S. 80, zur «Zeit-Poetik» und topischen Zeitsemantiken zwischen Entzeitlichung und Verzeitlichung Glauch (2020). 
ohne mit ihm zusammenzufallen. In diesem Sinn einer rekursiv «schrumpfenden Form〉 wäre das Schlussgedicht die so prägnante wie innovative Umsetzung des pragmatischen Paradox der hohen Minne.

\section{II. kurze wîle, langer wân. Das Schlussgedicht in Hartmanns Klage als rekursives Kürzungskunstwerk}

Zwischen Textentstehung (Ende 12. Jahrhundert) und uns einzig greifbarer Textüberlieferung der Klage (Anfang des 16. Jahrhunderts im Ambraser Heldenbuch) liegen rund dreihundert Jahre. Die Materialität der Texteinrichtung ist nicht nur, wie die Forschung ausführlich diskutiert hat, für die Überlieferungsstabilität des Textes und den Übergang des Streitgesprächs zum Schlussgedicht aufschlussreich, sondern, wie mir scheint, auch und vor allem für das Kürzungsexperiment selbst.

Unstrittig ist, dass angesichts der in der Handschrift sonst verwendeten Gliederungselemente (Überschrift, Zeilenabstand, Initialen, Randverzierung) die Überlieferung «den Text als Ganzes wahrgenommen hat und wahrgenommen haben wollte».29 Spätere Versuche der Forschung, das Schlussgedicht als autor- und epochenfremdes Anhängsel vom Dialogteil abzuspalten, haben die Überlieferung gegen sich. Am strikten Formanspruch des Schlussgedichts gemessen, der auch durch das Reimschema zwingend ist, fehlt in A die Strophenmarkierung durch Lombarden dreimal: zu Beginn (wenn Strophe 1 übergangslos an den Dialog anschließt), dann wieder in der siebten Strophe (die mit der sechsten Strophe. verschmilzt) und noch ein weiteres Mal am Schluss (wenn Strophe 14 und 15 in eins zusammengezogen werden).$^{30}$ Doch was heißt das? Meint «Fehlen〉 eine intendierte Lücke? Lässt sich über die gängige These der Klage-Forschung hinauskommen, der verwischte Übergang zwischen Dialog- und Schlussteil intendiere Gesamt-

29 Hess (2016), S. 27, auch bereits Gärtner (2015), S. IX. Allerdings lässt in der Ambraser Handschrift der Übergang von vierhebigen Paarreimversen in die fünfzehn kontinuierlich verkürzten Kreuzreimstrophen Inkonsistenzen im Interpunktionsprinzip erkennen, die man als Symptom eines «unorganischen` Übergangs zwischen Dialog- und Strophenteil gedeutet hat (Hess 2016, S. 45 f.).

30 Zusammenfassend Hess (2016) zur Mise en page des Schlussgedichts, S. 46-56. 
textkohärenz? Ein Blick in die Handschrift könnte die Vermutung nahelegen, dass die Art und Weise der Textpräsentation das Formexperiment systematischer Kürzung tendenziell unkenntlich macht. Denn nicht nur Lombarden fehlen in A an kürzungssensiblen Stellen, es fehlen zwischendurch auch Verse, und zwar ausgerechnet jeweils in Strophe 6 und 7, die in A wie beschrieben als eine einzige Strophe erscheinen; als Überlieferungslücke (Fehlverse) sind diese kurzen Passagen in der kritischen Ausgabe von Gärtner entsprechend ausgewiesen. ${ }^{31}$ Vor allem dann, wenn das Schrumpfen der «schrumpfenden Form» besonders wahrnehmbar ist, am Schluss, wird sie unsichtbar gemacht: Nach dem Blattwechsel, also ohne direkt möglichen Vergleich zu den vorausgehenden, etwas umfangreicheren Strophen, geben die Strophen 12 und 13 sowie die zusammengezogenen letzten Strophen 14 und 15, was den Strophenumfang betrifft, ein recht gleichmäßiges Bild ab. ${ }^{32}$

Natürlich ist das Eis dünn, auf das man sich mit der Interpretation von Überlieferungsbefunden begibt. Trotzdem stellt sich der Eindruck ein, dass in A zumindest eine Tendenz zu möglichst gleichförmigen, und das heißt hier vor allem: gleichlangen Strophen begegnet. Es scheint mir eine Überlegung wert, ob das vor dem Hintergrund spätmittelalterlich gängiger Überlieferungssymbiosen von Reimpaar-Dichtung und Strophen geschieht. Die Überlieferung würde Hartmanns Kürzungsexperiment dann auf ein historisch näherliegendes Muster verpflichten. Für die so erfolgreichen spätmittelalterlichen Minnereden sind Formatwechsel beziehungsweise synchrone Formverschränkungen ja gattungstypisch ${ }^{33}$ - freilich wird man gerade den Kanzlisten Hans Ried kaum für einen Literaturkenner halten können, also aus der Textpräsentation des Schlussgedichts in A schwerlich ein formästhetisches Kalkül ableiten wollen. ${ }^{34}$ Das historisch neue Kürzungsexperiment Hartmanns, das am hohen literarästhetischen und diskursiven Prestige der Leich-Form partizipiert, ohne im strengen Sinn als Leich gelten zu können (und trotzdem als «Leich〉 in von der Hagens Minnesinger-Ausgabe wandert,

\footnotetext{
31 Vgl. Gärtner (2015).

32 Vgl. fol $26^{\mathrm{v}}$ des Ambraser Heldenbuchs [http://hvauep.uni-trier.de/kb_klage.php? $\mathrm{q}=$ manuscripts\#] 18.07.2020.

33 Dazu exemplarisch Klingner (2013).

34 Darauf macht mich (brieflich) Sonja Glauch aufmerksam, der ich für die sorgfältige Durchsicht und gemeinsame Diskussion dieses Beitrags herzlich danke.
} 
s. o. S. 87 f.), scheint gleichwohl in der Überlieferung «zurückgenommen`was ich in distanzierende Anführungszeichen setze, weil hier im Ganzen nur vermutet werden kann, erst recht für die schwierige Frage, inwiefern die Tendenz zur 'gekürzten Kürzung) in der Klage-Überlieferung das Ergebnis eines vorausschauenden Plans oder aber sukzessiver Assimilierung ist.

Makrostrukturell ergibt sich für die Klage ein auch lateinischen Seelenkampftexten geläufiger dreiteiliger Aufbau, ${ }^{35}$ der sich wie folgt zusammenfassen lässt:

1) vv. 1-32: Prolog und Erzählrahmen;

2) vv. 33-1.644: Dialogteil (mehrfach wechselnde Anklagen und Gegenklagen jeweils durch Herz und Körper, Kooperationsbereitschaft, Stichomythie in vv. 1.168-1.268, Situationsklärung mit zweimaligem Redewechsel);

3) vv. 1.645-1.914: Schlussgedicht.

Das stote-Dilemma scheint dabei die entscheidende Klammer zwischen Dialogteil und Schlussgedicht zu bilden. Der lîp lässt am Ende des Streitgesprächs seine Rolle als Gegenspieler des gespaltenen Ichs hinter sich und tritt im Auftrag des Herzens als ihrer beider Vermittler (fürspreche, v. 1.643; mit mehrdeutiger Semantik als Anwalt und Bote) $)^{36}$ vor die Dame. Sein Sprechakt ist eine hyperbolische Klage, die bereits der Prolog erzählend vorweggenommen hatte. Die erste Schlussstrophe beginnt erneut in der Retrospektive:

Swaz kumbers ich unz her erleit

sît ich sorgen begunde,

daz was ein senftiu arebeit

unz an dise stunde.

(vv. $1.645-1.648)$

35 Differenzierte Gliederungsvorschläge bereits bei Zutt (1968; Zahlenstrukturen etwas überfordernd), Cormeau / Störmer $\left({ }^{3} 2007\right)$, S. 99-105, neben Hess (2016) auch Strittmatter (2013), S. 149 f. Die erste Strophe mit 32 Versen ist genauso lang wie der einleitende Prolog des Textes; auch zur vergleichbar hohen Frequenz von Sentenzen in beiden Rahmenteilen sowie lexikalischen Wiederaufnahmen zusammenfassend Strittmatter (2013), S. 200-204.

36 Zur hohen Minne mit ihren religiösen, metaphysischen und rechtlichen Konnotationen vgl. Cormeau / Störmer ( $\left.{ }^{3} 2007\right)$, S. 108. 
Damit ist gleich zu Beginn des Schlussgedichts der hohe Stellenwert des 〈Jetzt〉 (dise stunde) markiert. Die Schlüsselrolle, die die Zeit - auch im Folgenden - spielt, war bereits angekündigt worden in einem vorausgehenden Redebeitrag des Herzens, das dem Körper als «beste Lehre» (v. 1.614) Zuversicht nahegelegt hatte mit dem Sprichwort «Steter Tropfen höhlt den Stein ${ }^{37}$ :

und merke, swie herte ist ein stein, ob er eteswâ lît daz ein tropfe ze aller zît emziclîchen dar ûf gât, swie kleine kraft ein tropfe hât, er machet durch den stein ein loch. lîp, daz enkumet doch von des trophen krefte niht; von der emzikeit ez geschiht daz er dicke vellet dar.

Die Schlussgedichtstrophen reformulieren nun ebendiesen stoete-Appell des Herzens, aber sie deuten ihn schon zu Beginn um in Zeitdruck (Strophe 1: 〈Möge meine endlose swore ein Ende finden〉, vv. 1.667f.), und dabei kommen, wie auch im Folgenden, in beträchtlichem Ausmaß Konjunktiv und Konditional zum Einsatz. Strophe 2 ist besonders aufschlussreich für diese Tendenz. Sie beginnt erneut im Rückblick und beklagt verlorene Freude ( als ich die Wunde erlitt), dô nam mîn freude ein ende, vv. 1.677f.) und schließt nach einer Reihe hyperbolischer Vergleiche einen Appell an, der die Brisanz des 〈Jetzt〉 $(n \hat{u})$ mit dem Argument beklagt, es könnte zu spät sein und der stete Zweifel den Tod bringen:

nû dîner gnâden wis gemant,

daz ich mich der gemende

ê mir der zwîvel neme ein phant

und mich des lîbes phende.

(vv. 1.699-1.702)

$37 \mathrm{Zu}$ Parallelen bezüglich dieses Sprichworts in der romanischen Lyrik Mertens (1988), S. 19; auch hier mit der Tendenz, Sprichwörter zu zitieren, um sie im nächsten Atemzug zu widerlegen. 
Für das Folgende gilt dann, was Christoph Huber unter dem Titel «Zeitachsen im Minnelied» für Reinmar formuliert hat: «Rückblicke und Ausblicke kollabieren in einem labilen Jetzt.» ${ }^{38}$ Für die Relation von 〈Jetzt - einst immer ergeben sich in der Klage unsichere Sequenzierungen, weil das Ich mit seinen permanenten Rückblicken und Projektionen «auch in seiner Gegenwart nicht stabil verankert ist».39 Dass dabei Hoffnung und Zweifel immer wieder ineinander umschlagen, macht den Zeitverlauf (und ersehnten Augenblick) erst recht unsicher. Die folgende Strophe wiederholt den Kontrast der Zeitstufen (ie - nû - noch nie) im charakteristischen Modus hypothetischer Fallsetzung:

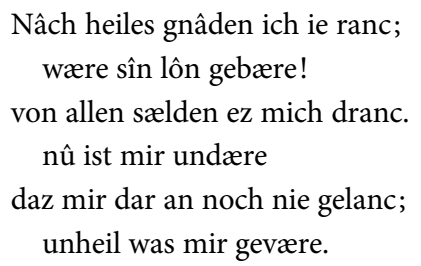

(vv. 1.707-1.712)

Diese Strophe schließt mit dreifachem Konditional und bespricht Zeitdehnung: 〈Wenn du mich umarmtest, könnte ich genesen〉 (vv. 1.720-1.726);40 〈wenn dich mein Leid nicht bewegen würde $[\ldots]$, 〈wenn meine Not mir selbst leidvoll vorkäme, würde mir das Leben zu lang`: sô würde mir daz leben ze lanc (vv. 1.730-1.734).41 Auch Strophe 4 beginnt mit einem temporalen Kontrast (Sît - nû, vv. 1.735 u. 1.738) und klagt trôst ein, 〈jetzt), es erbarmte einen Stein (v. 1.752). Die fünfte Strophe kann als amplifizierte stoete-Bekundung gelten (daz mîn triuwe niht zergât, v. 1771), wieder mit

Huber (2020), S. 159.

39 Ebd., S. 158.

40 Die Übersetzung bei Hess (2016), S. 271, ist hier irreführend (vgl. zu v. 1.723 umbevanc).

41 wan ich noch wol genore, / ob dî mirs woldest wizzen danc / durch dînen schepfore, / daz mir ein süezer umbevanc / vor kumber fride bore / von dînen armen, die sint blanc; / sô würde ich sorgen loere. / und habe ich des deheinen wanc, / sô sî ich gote unmore! / dich meint mit triuwen mîn gedanc. / und bewegte dich niht mîn swoere, / mîner nôt wore ein berc ze kranc; / ob sî mich diuhte swore, / sô würde mir daz leben ze lanc / daz ich sin gerner enbore (vv. 1.720-1.734). 
iterativen Bedingungssätzen im Irrealis («Wenn mir mein Dienst keinen Erfolg einbringt $[\ldots]$ ), v. 1.769; ‘wenn mich dein Trost unerlöst läßt $[\ldots]$, vv. $1.781 \mathrm{f}$.). Die sechste und siebte Strophe führen das Hin und Her von Hoffnung und Illusionsbereitschaft fort. Das Ich wendet sich wieder an die Dame: 〈Hilf, eh ich (ver-) zweifele! Wenn du nicht Gnade zeigst, sterbe ich〉 (Strophe 7). Ausdrücklich wird die Erwartung auf eine positive Antwort der Dame ausgesprochen, und das zeigt auch: Das formale Kürzungsprogramm der Klage läuft zwangsläufig auf diesen heiklen kurzen Moment zu, in dem das Ich verstummt und die Rede an die Dame abgibt, in der Hoffnung auf ihre Geneigtheit und seine «schnelle» Erlösung: gebiutet ez aber dîn rôter munt, / sô genise ich swinde (vv. 1.819f.).

Strophe 8 demonstriert eingangs mit einem Schwur das Schwanken zwischen Hoffen und Zweifel:

Gedinge tuot mich dicke balt;

als ich des beginne,

zwîvel tuot mîn herze kalt

dâ wider ze ungewinne.

(vv. 1.827-1.830)

Daran schließt eine erneute stæte-Übertreibung an, hier im bibelsprachlichen Register: Bevor ich von dir lasse, meine Göttin, verbrennt die ganze Welt, zerrinnen alle Tage, ist das Ende der Welt da, und werde ich in deinem Dienst noch so alt (vgl. vv. 1.831-1.844):

ich wæne ê wazzer unde walt und diu erde verbrinne

- daz ist zuo dem suontage gezalt und uns der tage zerinne, möhte ich werden alsô alt, ê ich von dir die sinne benim, swie lützel ez noch galt, ich diene umb dîne minne. frouwe, durch daz sô behalt, als ich an dich gesinne, an mir dîn tugent manicvalt. ich enweiz war ich entrinne; des nim mîn sorge in dînen gewalt, wan dû bist mîn gotinne. 
Die neunte Strophe greift das Zeitthema - den Zeitdruck - wieder im Konjunktiv auf («noch wäre Zeit, dass du mir meine stcete lohntest`) und appelliert an die Dame:

Frouwe, nû bedenke daz ê sich dîn trôst verspæte, daz ich dîn noch nie vergaz ze frümiclîcher stæte.

In Strophe 10, 11 und 12, die immer ausdrücklicher die "ausdauernde» Liebeshoffnung (mînen langen wân, v. 1861) mit der religiösen Hoffnung auf Erlösung parallelisieren, wird über das spekuliert, was die Dame endlich 〈jetzt〉 gleich sagen könnte - mit Binnenreim-markierter Deixis: $\boldsymbol{n} \hat{\boldsymbol{u}}$ solt d $\hat{\boldsymbol{u}}$ daz an mir begân (v. 1871; Hervorhebung: S. K.). In Strophe 10 ist mittlerweile der Strophenumfang auf 14 Verse geschrumpft. Sie beginnt mit einer Zeitreflexion, die in Form eines Vergleichs wiederum religiöse Zusammenhänge aufgreift:

Ist daz ich mînen langen wân nâch heile volbringe den ich nach dînen minnen hân als ich an got gedinge, sô hât er wol ze mir getân an gnædiclîchem dinge [...]. $(\text { vv. } 1.861-1.866)^{42}$

Das Ich spekuliert im irrealen Konditional: «Wenn meine Beharrlichkeit, meine lange Erlösungshoffnung, Erfolg hätte, mit der ich an deine Liebe glaube wie an Gott, dann hätte er das bewirkt.> Strophe 11, die eingangs der

42 Die Übersetzung dieser Strophe (auch von Str. 11) durch Hess (2016), S. 274 f., ist nicht immer verständlich und bleibt z. T. gegen die kritische Edition bei A, auch bei offenbar agrammatisch verderbten Stellen (etwa bei v. 1.872 u. 1.882). Mein Übersetzungsvorschlag von Strophe 10: «Wenn sich mein langes Hoffen glücklich erfüllen würde, mit dem ich auf deine Minne vertraue, wie ich auf Gott hoffe, dann hat er gut an mir gehandelt mit seiner Gnade und verdiente mein ganzes Lob, mit allem meinem Reden und Singen. Aber umgekehrt werde/würde ich immer leiden, wenn ich damit scheitere. Nun sollst du bei mir bewirken, was dich nur wenig kosten würde, und dein Herz erbarmen lassen, dass ich mit Leid kämpfe.> 
Dame vorwirft, sie habe sich durch ihre Feindseligkeit am Ich «versündigt> (vv. 1.875-1.878), macht die Relativität von Zeitwahrnehmung thematisch, erneut im Sprichwortregister: Dem Glücklichen schlage keine Stunde, doch für Unglückliche schleiche die Zeit noch quälend langsamer dahin als für auf Leben und Tod Eingekerkerte (vv. 1.879-1.884):

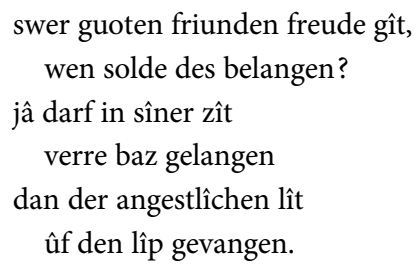

(vv. $1.879-1.884$ )

Gärtner führt im Kommentar zur Stelle ein einschlägiges Freidank-Sprichwort an: swer ûf den lîp gevangen lît, / den dunket lanc ein kurziu zît. ${ }^{43}$ In Strophe 12, die erneut im Konjunktiv Glück irrealisiert (‘Wäre ich fürs Glück geboren $[\ldots]$, v. 1.886), verspricht das Ich der Dame, es würde «schnell〉 restlos alles umsetzen, was sie - vielleicht - sagen würde: swaz der wort mich hiezen, / daz würde unlange verborn (vv. 1.891f.). Auch Strophe 13 beschwört den Augenblick (Nû), der immer näher rückt: Nî ger ich daz diu güete dîn / ir namen an mir êre (vv. 1.897 f.). Noch kurz vor Schluss ist alles offen. Es gebe nur eine mit ungewissem Ausgang verbundene Alternative (Str. 14: Dîn spil [...] geteilet, v. 1.905) von Erlösung oder Verderben. Strophe 14:

$$
\begin{aligned}
& \text { Dîn }{ }^{44} \text { spil ist mir geteilet sô } \\
& \text { daz ich noch erwerbe } \\
& \text { des mîn herze wirdet frô, } \\
& \text { oder gar an freude ersterbe. }
\end{aligned}
$$

43 Gärtner (2015), S. 79, zu vv. $1.883 \mathrm{f}$.

44 Ich folge - anders als Hess (2016), S. 275: «Sein [sc. des Herzens] Spiel hat zwei Optionen für mich» - der Konjektur von Gärtner (gegen A: Sein, wie schon Zutt; dagegen Wolff: Diz). Die Verwirrung der Bezüge ist ein Symptom der permanenten pronominalen Wechsel (v. a. in Str. 13 u. 14). Zum epistemischen Status von Überlieferungs- $\prec F e h-$ lern > in A vgl. die subtilen Überlegungen von Glauch (2019). 
daz ist mir ein swæriu drô,

wilt dû daz ich verderbe.

$(\text { vv. } 1.905-1.910)^{45}$

Hier zeigt sich: Der Kunstgriff systematischer Kürzung impliziert für den Auftritt des Ich einerseits - als Formkalkül - kommunikative Kontrolle, anderseits Kontrollverlust, denn die Kürzung läuft unvermeidlich auf den unsicheren Moment zu, in dem das Ich alles, Gelingen oder Scheitern, aus der Hand geben muss. Ganz zum Ende des Schlussgedichts bleiben vier Verse übrig, die die dauerhafte exklusive Dienstbereitschaft des Ich formulieren. Strophe 15:

\section{Ich hân in dînen gewalt ergeben} die sêle zuo dem lîbe.

die emphâch! jâ müezen sî dir leben und mê deheinem wîbe.

Auch diese umfassende Selbsthingabe von Seele und Leib in der letzten Strophe ist auf der Schwelle von Vergangenheit (vv. 1 f.), Gegenwart (v. 3a) und Zukunft (vv. 3b u. 4) formuliert, und sie ist nichts anderes als die Rückkehr zur Ausgangslage (vgl. etwa die Formulierungsdublette im Prolog v. 9: in ir gewalt ergeben).

Vier Verse, kürzer geht es nicht, unter der Bedingung kreuzgereimter Verse. Und damit zeigt sich die Spezifik des Zusammenhangs von Kürzung und Zeitregie in der Klage: Die Form kontinuierlicher Kürzung, die sich auf verschiedenen Ebenen unterschiedlich auswirkt, bringt für die minnediskurstypische Spannung von Dauer (Ewigkeit, negativ: versäumte Zeit) und Prozess (Veränderlichkeit, negativ: Vergänglichkeit) eine zentrale Relation hinzu: die Spannung von Irreversibilität und Rekursivität. Denn einerseits vollzieht und garantiert Hartmanns Kürzungskunstwerk die Unumkehrbarkeit der Zeit (und sichert so in der Tat formal auch Textstabilität, s. o. S. 88 f.). Doch es führt anderseits - durch parallele Formmaßnahmen wie die noch erreiche, was mein Herz froh macht, oder vor lauter Freudlosigkeit sterbe. Das ist mir eine leidvolle Drohung, wenn du willst, dass ich zugrunde gehe.> In v. 1.908 leuchtet mir Gärtners Entscheidung für mhd. an statt $\hat{a} n$ nur bedingt ein; allenfalls idiomatisch: «was Freude betrifft». 
Angleichung des Textumfangs (32 Verse im Prolog und in der ersten Schlussstrophe), Wiederaufnahmen von Formulierungen, Sprechakten und Argumenten - wieder an den Anfang zurück. Rüther ${ }^{46}$ hat daran erinnert, dass gerade die letzten vier Verse des Schlussgedichts Formulierungen aus dem Dialogteil wiederholen (vgl. vv. 637-640), doch er interpretiert diese Wiederholungsstruktur als affirmative Schließung und Wiederherstellung der Ordnung, «indem der im Prolog eröffnete Rahmen geschlossen und das Verhältnis von Dame und Ich als ein dauerhaftes imaginiert wird».47 Rüther sieht durch das Finale des Schlussgedichts «das Schweigen zwischen Hartmann und Dame aufgehoben.$^{48}$ Das ist sehr zuversichtlich.

Die Hartmann-Forschung tut sich schwer mit der Deutung des Kürzungsvorgangs. Kischkel wertet, wie eingangs erwähnt, den Schluss als ästhetisch minderwertig:

Eine solche Form hätte wohl nur dann einen eigenständigen ästhetischen Wert, wenn der Verkürzung eine Intensivierung des Ausdrucks und eine Verdichtung der Aussage korrespondierte. Da dies nicht der Fall ist, kann man dem ganzen auch keinen Sinn abgewinnen. ${ }^{49}$

Dem Schlussgedicht spricht Kischkel «wegen der formalen und qualitativen Differenzen» nicht nur die Kohärenz zum vorausgehenden Dialog kategorisch $a b,{ }^{50}$ sondern auch die Zuschreibung an Hartmann von Aue; beides findet in der Forschung, die den überlieferten Text historisch ernst nimmt, keine Resonanz mehr. ${ }^{51}$

Im Blick auf die drei Textteile (Prolog, Wechselrede, Schlussgedicht) stellte sich in der Forschung von Anfang an die Frage nach der Kohärenz des Textes und der «Emergenz ${ }^{\mathbf{5}}{ }^{\mathbf{2}}$ seiner Form. Die jüngere Forschung diskutiert vor allem die Frage nach dem integrativen oder ambivalenten Status der Schlussstrophen. Sie stellt dabei Formfragen, zumal die Frage nach der

47 Ebd., S. 244.

48 Ebd.

49 Kischkel (1997), S. 94.

50 Ebd., S. 98.

51 Vgl. die ausführliche Forschungsdiskussion bei Hess (2016), S. 46-56.

52 Ebd., S. 12. 
Funktion der Kürzung, hinter dem Kohärenzproblem zurück. Hess, die sich mit dem Schlussgedicht am ausführlichsten befasst hat, ${ }^{53}$ versteht die Schlussstrophen als redundanzverdächtiges «Zurücktreten des Inhalts hinter die Form», ${ }^{54}$ das zu einem "stark begrenzten inhaltlichen Ausdruck» führe. ${ }^{55}$ Das Schlussgedicht diene "dem ästhetischen Ausdruck», gemeint: der Demonstration des artificium. ${ }^{56}$ Wie dann auch Rüther deutet Hess die Kürzungsmaßnahmen des Textes als Reduktion von Asymmetrie, als Zeichen der erreichten Harmonie zwischen Herz und Leib und vollständiger Restituierung personaler Einheit, insofern «sich die Asymmetrie zwischen den Dialogpartnern Leib und Herz sukzessive verringert und damit zum einen die vollständige Hingabe der ganzen Person, zum andern ihre vollständige Betroffenheit von der Liebe gezeigt» werde. ${ }^{57}$ Bei gleichzeitig unterstellter Formdominanz und inhaltlicher Redundanz soll die schrumpfende Form des Schlussgedichts als sukzessive Verringerung der Asymmetrie gelten. Geht die Formmaßnahme steter Kürzung in der Herstellung von Symmetrie auf?

Auch Lembke berücksichtigt für das Schlussgedicht zwar möglichst viele Beobachtungsebenen (Form, «Stil〉, Argumentation) im Blick auf rekursive Textvorgänge. ${ }^{58}$ Das Modell systematischer Kürzung bezieht sie jedoch nur unspezifisch als allmähliche «Veränderung» der Verszahlen mit in ihre Überlegungen ein: Die «Veränderung» des Umfangs reagiere auf eine allmähliche «Veränderung» des Ich - nämlich: rhetorische «Entwicklung»

53 Vgl. Hess (2016), Kap. 8: Inhaltsparaphrase S. 78-86, zum hohen Kunstanspruch S. 247 (Klangrhetorisierung, Wiederholungsstrukturen); zur nicht fehlerfreien nhd. Übersetzung des Schlussgedichts im Anhang (S. 269-276) Köbele (2018).

54 Hess (2016), S. 58.

55 Ebd., S. 249.

56 Ebd., S. 247.

57 Ebd., S. 265 f. Auch die religiösen Allusionen des Textes werden bei Hess sehr direkt angegangen: Unaufgelöst bleibe am Ende des Schlussgedichts die «eschatologische Hoffnung» auf göttliche Gnade (S. 257) und damit ein «ontologisches Grundproblem» (ebd.). Die Klage-Forschung klammert überhaupt das Spiel von Ernst und Unernst weitgehend aus - obwohl gerade Hartmann für seine «freundliche[ ] Ironie» (Worstbrock [2004/ ${ }^{1}$ 1985], S. 223) bekannt ist (vgl. dazu auch Rippl [2020]). Hess nimmt das Angebot externer Problemlösung (göttliche Gnade) im Schlussgedicht zu wörtlich.

$58 \quad$ Lembke (2013), S. 121 mit Anm. 22. 
und «Reifung» von opulenter Fülle hin zu maßvoller Schlichtheit -, wobei als Tertium comparationis und «Reife»-Kriterium ausgerechnet ein Schlichtheitsgebot geltend gemacht wird, das im Text, auch im Textschluss mit seiner emphatischen Hyperbolik von Gnade, Sünde und Erlösung, nicht greift und dort, wie mir scheint, weder vorrangig thematisiert (in perspektivischer Brechung etwa v. 1514) noch rhetorisch umgesetzt wird.

Auf der Hand liegt, dass die Frage nach der Einschätzung der Kürzungsfunktion steht und fällt mit der Frage danach, ob der Schluss als eine Positivierung von Negativität (von swore) zu lesen ist. Zu diesem Aspekt, ob Hartmanns Streitgespräch mit seiner charakteristischen Vervielfältigung von Sprechakten und Perspektiven auf Konfliktlösung oder Konfliktentfaltung ziele, schwanken die Urteile der Forschung erheblich. ${ }^{59}$ Ich habe andernorts für einen offenen Schluss plädiert ${ }^{60}$ und muss hier die Argumente nicht wiederholen.

Zuletzt hat Gebert ein grundsätzliches, bis zum Schluss unaufgelöstes Konfliktpotential des Textes herausgearbeitet, je neue Glaubwürdigkeitsaporien. ${ }^{61}$ Gebert, der subtil für verschiedene Ebenen Ein- und Ausfaltungsdynamiken des Textes beschreibt, deutet dabei auch die auffällige Leitworttechnik nicht als rhetorisch affirmative Restitution von Einheit, sondern, sehr überzeugend, als raffinierte Abblendungsdynamik. Doch die Frage nach der Funktion der systematischen Versreduktion im Schlussgedicht hat auch er nur gestreift. Allenfalls dessen metrische Form (Kreuzreim mit identischem Reimklang und regelmäßig wechselnden Kadenztypen) wird von ihm semantisiert: Sie bestätige ein «Konsistenzinteresse», das Gebert gerade nicht als abgeschlossenen Zustand von Harmonie und Gleichsinnigkeit fasst, sondern als unabschließbares Wechselspiel von Differenz und Kongruenz: Perspektive Philipowski (2006), Köbele (2006), Strittmatter (2013). Hess (2016) interpretiert die komplexe Dialogstruktur des Textes als widersprüchliche Minnekommunikation, Gebert (2019) deutet die auf verschiedenen Ebenen gelagerten Strukturparadoxien des Textes als paradoxe 〈Wettkampf $>$-Dynamik.

60 Köbele (2006).

61 Gebert (2019). 
«Die Strophenstruktur der Schlussrede hebt in ihren identischen Kreuzreimen dieses Konsistenzinteresse auch formalästhetisch hervor.» ${ }^{62}$

Parallel zur Kürzung ist also auch die Semantisierung der Reime ein methodisches Problem: Inwiefern ist der Übergang von Paarreim in durchgereimte Kreuzreimstrophen interpretativ belastbar? Wo verläuft die Grenze zwischen unverbindlicher Spekulation und selbstgenügsamer Deskription (mit Christoph März «zwischen Zählen und Schwärmen»63)? Ist der Paarreim ein idealer Kandidat für Minne-Symmetrie oder eher der Kreuzreim, insofern er Reziprozität herstellt? Und wäre der Schlagreim sowohl dem Paar- wie Kreuzreim überlegen, weil er Reimdistanzen kürzt? Das sind heikle Fragen, die nur kontextbezogen von Fall zu Fall lösbar sind. Die Grenze zwischen belastbarer Interpretation und freier Assoziation ist für die Rekonstruktion von Reimsemantiken fließend. Wenn in nahezu allen Strophen des Schlussgedichts jeweils nur ein einziger Kreuzreim zum Zuge kommt, der exklusiv durchgehalten wird, ${ }^{64}$ entspricht diese strophenweise umgesetzte Identität nur eines Reimklangs dann der Liebeseinheit von Ich und Dame? Diese in der Klage-Forschung wiederholt anzutreffende These auch metrisch erreichter «Harmonie» und «Einheit» muss freilich alle unaufgelösten Spannungen zwischen Hoffnung und Illusion, die das Schlussgedicht durchgängig kennzeichnen, ausklammern. Auch wenn mir die These von Gebert, dass der identische Reimklang, über Kreuz gestellt, die Spannung von Einheit und Differenz abbilde, mehr einleuchtet als die These erreichter Gleichsinnigkeit durch Gleichklangreime, bleibt die Semantisierung von Reimen ein zwar lohnendes, aber methodisch heikles Unterfangen. ${ }^{65}$ Wird die Lage noch unsicherer, wenn man versuchen würde, auch für die Reimkunst ZeitImplikationen in Anschlag zu bringen und mit der Kürzung zusammenzudenken? Zwischendurch, in der zweiten und sechsten Schlussstrophe, potenzieren ja grammatische Reime und iterative Rhetorik zusätzlich das Äquivalenzprinzip in den jeweils durchgereimten Kreuzreimstrophen. Das erzeugt

62 Ebd., S. 165.

63 März (1999), S. 324.

64 Ausgenommen Str. 3 und 13 im Abvers, dazu Hess (2016), S. 247 f., hier auch Analyse der Kadenzen und Reimbrechung.

65 Vgl. zuletzt die subtilen Überlegungen zu Reimsemantik und Raumsemantik von Störmer-Caysa (2020). 
immerhin einen gleichmäßigen (und gleichklingenden) Zeit- und Textfluss, innerhalb der blockhaften, durch je neuen Reimklang voneinander abgegrenzten Strophen.

Gebert formuliert zur Funktion des Kürzungsexperiments nur einen Satz, bei dem ich nicht sicher bin, wie er zu verstehen ist. Bezogen auf den Übergang von Dialog und Schlussgedicht (nun spreche der Körper, der «die Latenzform», gemeint: die latente Spaltung von Herz und Körper, «zu einer Stimme verdichtet») heißt es zur abbreviatio: «Poetisch wird diese Sprecherreferenz durch einen Strophenbau verdichtet, der kontinuierlich mit jeder Strophe um ein Verspaar schrumpft.» ${ }^{66}$ Wie ist das gemeint? Inwiefern genau hängt die schrumpfende Form mit der 〈Verdichtung〉 der Latenzform von Herz-Körper zu einer einzigen Ich-Stimme zusammen?67 Auch Gebert bezieht in jedem Fall die Kürzung nur auf die Ich-Rolle (ihre abbreviative 〈Verdichtung〉 zu einer einzigen Stimme), nicht auf Zeit-Implikationen der Kürzung, die doch den brisanten Augenblick erhoffter Interaktion von Ich und Dame genau erzeugt, auf den die Kürzung zuläuft.

Mir lag daran zu prüfen, was man für die Funktion der Kürzung gewinnt, wenn man sie zum einen auf die Interaktion zwischen Ich und Dame bezieht, zum andern mit den Zeit-Aporien enger zusammenbringt, die die Forschung zwar für den Gesamttext immer wieder diskutiert, aber nicht mit dem Formanspruch des Textes verbunden hat. In dieser Perspektive scheint dann auf der Hand zu liegen, dass die Maßnahme systematischer

66 Gebert (2019), S. 161 mit Anm. 201. Zur These eines internen Sprecherwechsels bei Lieb / Klingner kritisch auch Hess (2016), S. 251.

67 Ich danke Bent Gebert für seine genaue Durchsicht meines Beitrags, besonders für die hilfreiche Erläuterung (Selbstauslegung, brieflich) seines oben zitierten Satzes zur Kürzungsfunktion, die ich wie folgt zusammenfassen möchte: Verdeckte Komplexität, z. B. im Ich oder in der Semantik von staete, bleibe durch rekursive Operationen (unabschließbare (Redundanzen〉) im Schlussgedicht reproduzierbar erhalten. Das Schlussgedicht kürze, so Gebert, ohne ganz wegzunehmen. Die Kürzungsprozedur (Vers-Reduktion) sei nicht als Wegnahme, Annihilation oder Verlust zu verstehen, sondern als «operative Speicherung». Trotz unterschiedlicher «Form〉-Begriffe: Auch in Geberts differenz- und systemtheoretisch inspirierter Perspektive wird "sowohl die exuberante Anfangs- wie die absolute Schrumpfform» des Schlussgedichts als «Form-Zusammenhang» verstanden. 
Versreduktion in Hartmanns Schlussgedicht mehr als «bloßes〉 Formspiel ist, auch nicht aufgeht in der Funktion als textstabilisierender Faktor (beide Thesen unterstellen, die Form bliebe dem Inhalt gegenüber äußerlich). Und auch Forschungsbeiträge, die die Versreduktion als formale Umsetzung reduzierter Asymmetrien sehen, haben den Text ebenso gegen sich wie die (oben S. 88 bereits zitierte) These, mit der Kürzung sei der Dichter auf dem Weg zu Schlichtheit (gereift). Rhetorische Emphase zieht sich doch durch den Text bis zum Schluss, und warum sollte außerdem nicht gerade auch Kürze zum Pathos neigen dürfen statt nur zu 〈Schlichtheit〉? Die systematische Kürzung des Klage-Schlusses scheint vielmehr als selbstwidersprüchliche stcete-Demonstration zu fungieren, die mit der Zeit nicht nur den Dauerzweifel, sondern, unseligerweise, auch die dauernde Hoffnung abkürzen könnte (mit ebendieser Doppelsemantik: langen wân). In der letzten kreuzgereimten Viererstrophe erreicht sie ihr natürliches Ende als Minimalform, in der sich der Kreuzreim noch umsetzen lässt. So kommt mit Strophe 15 der Text an sein Ende, aber das Ich nicht schon an sein Ziel.

Ein letzter Punkt: Ich verstehe Hartmanns Kürzungsexperiment als Teil und Symptom eines umfassenden Strukturmusters der Klage, die mit auffälligen Zeitsemantiken auf allen Ebenen rekursive Wiederholungen vermehrt darauf hat eindringlich Gebert hingewiesen ${ }^{68}$-, aber gleichzeitig zielgerichtet kürzt. Achtet man auf diese Dynamik in beiden Richtungen, zeigt sich das Kürzungskunstwerk als auf seine Weise 〈kürzungsdilatorisches〉 Gegenstück zu derjenigen Passage, die - mit hundert Versen auffällig umfangreich - im vorausgehenden Dialog stichomythisch, also durch gleichmäßige Kürze der Redebeiträge, den Konflikt verdichtet (vv. 1.168-1.268) und an die riskante Schwelle der Kommunikation mit der Dame führt. ${ }^{69}$ Beide Maßnahmen, so

68 Vgl. Gebert (2019).

69 «Der Dialog von herze und lipp bringt [...] zu keinem Moment der Rede zwei klar trennbare, miteinander konkurrierende Standpunkte hervor, sondern immer eine Verschränkung der Positionen» (Strittmatter [2013], S. 195f.). Herz und Leib bleiben in instabiler Asymmetrie und rekursiven Verschränkungen verbunden, was der Text auch metaphorisch durchspielt über wechselnde Formen von Koordination (z. B. «Partner» und «Freunde», z. B. vv. 121, 421, 978) und gleichzeitiger Subordination (etwa «Richter-Rächer», z. B. v. 417; «Herr-Diener», vv. 1.961-1.074); glänzend ausgeführt bei Gebert (2019), S. $158 \mathrm{f}$. 
verschieden sie sind, bewirken im Modus konsequenter Kürzung eine Beschleunigung des Textverlaufs und schieben zugleich durch auffällige Verbreiterung der Maßnahme amplifikatorisch das Ende auf, das bei aller stoete-Beschwörung jeweils ungewiss bleibt: nach innen (das Herz in Interaktion mit dem Leib) in der Stichomythie und nach außen (das Ich in Interaktion mit der Dame) im Schlussgedicht.

Rekursiv verdoppelt sich im Schlussgedicht auch die Rolle des Boten, der hier nicht als externe Figur des Dritten (und sei es als personifiziertes Büchlein) auftritt. Vielmehr macht das Ich sich ausdrücklich zu seinem eigenen Boten (fürspreche, vgl. vv. 1.643f.): wieder ein rekursiver Vorgang. Und es war bereits davon die Rede, dass auch der Umfang der 32-versigen ersten Strophe an den seinerseits 32-versigen Prolog formal anknüpft und der Sprechakt 〈Klage〉 zu Beginn des Schlussgedichts in einer großen Wiederholungsschleife wieder an den Anfang des Gesamttextes zurückführt. Dazwischen liegt eine doppelte Herstellung von Distanz. Das Ich - trotz provisorischer Konsensbildung in der Stichomythie - bleibt sich selbst so undurchsichtig und unerreichbar wie - trotz beschleunigter Präsenzsuggestion im Schlussgedicht - dem Ich die Dame. Ist das nicht eine eher finstere Reprise?

Versteht man die Klage als Medium einer komplexen Diskursivierung paradoxer Affekte (mhd. wân zwischen 〈Hoffnung〉 und 〈Illusion〉) und grundsätzlich gestörten Innen-Außen-Kommunikation des Ich, erweisen sich die stichomythische Kürzung im Dialog und die systematische Kürzung im Schlussgedicht als kontrastparallel: Beide Kürzungsmaßnahmen führen jeweils dazu, dass rekursive Verdoppelungen die angestrebte Affekt-Transparenz und Glaubwürdigkeit (vgl. v. 1.397; auch v. 1.263: ernest) nicht stabilisieren, sondern im Gegenteil durchgängig stören, und zwar sowohl nach innen im Modus des Selbstgesprächs wie nach außen in Form minnesängerischer Interaktion zwischen Ich und Dame. Und hier wie dort führt die Kürzung auf den heiklen Moment (die gemeinsame Entscheidung) zu, vor die Dame zu treten, 〈jetzt». «Ab der stichomythischen Mittelachse beginnt die Klage, ihre Paradoxien zu restabilisieren.» ${ }^{70}$ Ein nach innen und nach außen vil ungewisser wân (v. 1.077) lässt das Ich am Erfolg seines 
Dienstes kategorisch zweifeln. Dass umgekehrt, retrospektiv und prospektiv, auch der Dame zur Auflösung ihres Zweifels wiederum nichts als Worte bleiben, formuliert der lîp, kurz bevor er vor die Dame tritt, ausdrücklich:

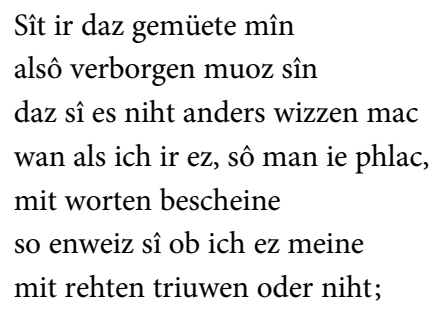

(vv. 1.397-1.403)

Genau diese Evidenzherstellung versucht - unter Zeitdruck - das Schlussgedicht. Alle temporalen Implikationen des Begriffs stcete (Dauer, Verlauf, Geschwindigkeit) werden widersprüchlich ausgefaltet. Unermüdlich, nicht erst in den Schlussstrophen, geht es in der Klage um Zeitregie, um die Kunst des rechten Augenblicks (nu ensûme ez ouch ze deheiner frist, v. 1.540; Unrehtez gâhen sûmet dich, v. 1.551 u. ö.). Schon zu Beginn des Streits musste der Leib sich anhören: Du bist ein rechter Schleicher, trödelst dauernd herum (v. 814), suchst nur kurzwîle (v. 673) und verschläfst das halbe Jahr (v. 678). Am Ende des Streits, als das Herz zugeben muss, es wisse auch nicht, warum Damen ihre Liebhaber immer so lang hinhalten (vv. 1.585-1.587), bleibt dem Leib nur der bittere Kommentar: Du sprichst vom Leid der Glücklichen (der soeligen ungemach, v. 1.601); uns ist nicht einmal Ungeduld gegönnt. Das Herz hilft aus mit dem Argument, ewiges Warten könne auch schon glücklich machen, außerdem: Steter Tropfen höhle den Stein (vv. 1.616-1.625). Aber die Evidenz des Sprichworts, von dem oben schon die Rede war, bleibt nur unsichere Hypothese: ist sî danne ein guot wîp, / sich, sô lônet sî dir, lîp (vv. $1.631 \mathrm{f}$.).

Alle rekursiven Verdopplungen führen also ins Ungewisse. ${ }^{71} \mathrm{Zu}$ Beginn des Dialogs wird geredet «um des Schweigens willen ${ }^{72}$ - es darf kein Schatten auf die Dame fallen. Also klagt das Ich lang und breit gegen sich selbst, bis das Selbstgespräch sich stichomythisch verkürzt und den Konflikt

71 Zur Instanz des muot als schillernden psychophysischen Dachbegriffs vgl. Strittmatter (2013), S. 161-168.

72 Gebert (2019), S. 147. 
beschleunigt. Am Schluss ist es umgekehrt: Das Ich will endlich vor der Dame seine Klage vortragen, aber wird dabei, in aller Breite, immer schneller kürzer. Ganz am Ende, wenn die «Ich jetzt`-Deixis des Sängers an die Dame übergehen soll (‘nun du`), bleibt trotz Kürzungskalkül die reine Kontingenz übrig. Was könnte jetzt noch kommen? Im schlechtesten Fall weder nein noch jâ der Dame - aber das erzählt erst Ulrich von Liechtenstein: dâ wirt uns lang gar kurziu zît (Frauenbuch, vv. 128 u. 132). Wäre es schon genug, wenn die Dame sagen würde: «Sing weiter»?73 Womöglich wirkt der Ritter, indem er immer kürzer und dann gar nicht mehr redet, genau so, wie er nicht sein soll und will: ohne dauerhafte Dienstbereitschaft. Und die Dame bleibt, was sie schon zu Beginn dauernd war: stumm.

\section{Steter Tropfen höhlt den Stein ? Fazit und Ausblick}

Wenn im höfischen Minnediskurs des 12. und 13. Jahrhunderts Minnedienst durch den epochalen Programmbegriff stcete (〈Beständigkeit〉, 〈Dauer〉) ausgezeichnet ist, liegt für den Akt des dienstlich dichten ${ }^{74}$ nicht nur ein moralisches, sondern immer auch ein rhetorisches Zeitdilemma nahe: Redselige Breite ist ebenso verpönt wie allzu zielstrebige Kürze. Sag schnell, was Du willst (ebd., v. 1.684), aber nicht zu schnell, denn übereiltes Abkürzen kann den Liebes- und Dichtererfolg ebenso ruinieren wie Trödeln. Tu ihr Deine Beständigkeit beständig kund, aber langweile nicht durch Länge und Dauernd-Reden. Wer allerdings aufhört mit stetem Reden von stoete, hat den Dienst schon verloren (swer abelat / der het den dienst sin verlorn). ${ }^{75}$ Lohn kann durch falsche Zeitregie also auf vielfältige Weise verspielt werden. Für den Akt des dienstlich dichten bleibt streng genommen nur eine einzige Lösung: mit den Texten eine 〈Verstetigung〉 anzusteuern, und zwar durch Formen der Aufhebung ihrer selbst. ${ }^{76}$

Die systematische versifikatorische abbreviatio am Schluss der Klage ist nichts dem Text Äußerliches, sondern ein genuiner Kunstgriff. Meine

73 Vgl. MF 164,10f.

74 Johann von Konstanz, v. 2.533; programmatisch auch Ulrich von Liechtenstein.

75 Ebd., vv. $984 \mathrm{f}$.

76 Gebert (2019), S. 163, und Glauch (2020). 
Überlegungen zielten auf das (ästhetische, strukturelle, diskursive) Potential dieser systematischen Kürzung, das die Forschung trotz eines aktuellen Interesses an der Klage nicht ausgeschöpft hat. Ich war ausgegangen vom Zusammenhang von Kürzung und Zeitregie: Neben iterativen (je neu kürzen), durativen (dauernd, kontinuierlich kürzen) und relationalen (kürzer als) Zeitdimensionen spielte auch die Geschwindigkeit von (verzögernden, beschleunigenden) Kürzungsvorgängen eine Rolle. Dass die elementaren Textoperationen abbreviatio und amplificatio sich dabei komplex verschränken können, ist per se nicht auffällig. So treten immer wieder Kürzungsprogrammatik und Kürzungspraxis selbstwidersprüchlich auseinander. ${ }^{77}$ Was macht demgegenüber Hartmanns kontinuierliche Kürzung zu einem Sonderfall?

(1) Ein erster Punkt war, dass das abbreviierende Prinzip hier einerseits strikt sukzessionslogisch funktioniert (was uns die eher seltene Sicherheit gibt, in der Überlieferung eindeutig Defekte dingfest machen zu können: Fehlverse, Inkonsequenzen in der Verteilung von Lombarden, die ihrerseits signifikant scheinen). Gleichzeitig wirken im Text rekursive, in sich selbst zurücklaufende (metrische, rhetorische, kompositorische, argumentative) Verdopplungsstrukturen. Im Ganzen ergibt sich eine charakteristische Spannung von Irreversibilität und rekursiver Wiederholung, mit dem Effekt je neu blockierter Endlosschleifen. (2) Zweitens führt ausgerechnet das Formkalkül «Kürzung um jeweils ein Verspaar`, mit dem das Ich eine Entscheidung erzwingen will, am Textschluss in eine unkalkulierbare, offene Situation. (3) Hinzu kommt drittens die Spannung zwischen Dauer und zielorientiertem Prozess, die im Schlussgedicht auch in bemerkenswerter Dichte thematisiert wird, durch das Zeit und in der Zeit wahrnehmende Ich. 〈Lange Hoffnung〉 (v. 1.661): Ist sie dem «langen Zweifel〉 (v. 1.587) an Dauer

77 Daher ist gerade bei ausdrücklicher abbreviatio (iich bin nicht lang〉) mit performativ widersprüchlich umgesetzten dilatorischen Dynamiken zu rechnen (zuletzt, mit Diskussion der älteren Literatur, Frick [2020]) sowie im umgekehrten Fall expliziter dilatatio-Ansprüche (ich bringe Neues`) mit Weiterungs- und Novationsfiktionen; dazu das Teilprojekt «Ich bin niht niuwe -? Neuerung als paradoxer Effekt ihrer Infragestellung im Liebesdiskurs des Mittelalters und der Frühen Neuzeit〉 der Berliner DFG-Forschungsgruppe 2305 «iskursivierungen von Neuem. Tradition und Novation in Texten und Bildern des Mittelalters und der Frühen Neuzeit». 
und Beständigkeit überlegen? Die Doppelsemantik von mhd. wân («Hoffnung〉, 〈Illusion〉) ermöglicht dabei unmerklich neue Sprechaktwechsel und auch Zeitsprünge ( $s \hat{\imath} t-n \hat{u}-i e$ ). Dass quantitative Prozesse des Kürzens und Längens unübersichtlich in qualitative Prozesse umschlagen, lässt sich dem Schlussgedicht daher in fast jedem Vers ablesen. (4) Für die Frage nach Kürzungsimplikationen lohnt es, auf intratextuelle Strukturäquivalenzen zu achten. Schon im vorausgehenden Dialog wird mit Tempounterschieden gespielt, wenn sich die sehr langen Redebeiträge der Kontrahenten am Ende des Dialogs stichomythisch verkürzen, was wiederum auffällig viel Raum bekommt (100 Verse), also seinerseits «dauert». (5) Keinesfalls lässt sich das Hartmannsche Kürzungsmodell mit forma-materia-Dichotomien (Formzwang, Formdominanz) erklären. Ansprüche der Form und solche des Stoffs sind nicht 〈rein〉 zu trennen. Weiter führt die Aufmerksamkeit für eine Form- und Inhaltsaspekte übergreifende Diskursivierung der umstrittenen Ansprüche formvollendeter stoete, die zu den Grundbedingungen höfischer Interaktion im Zeichen von Minnesang gehört. Die mediävistische «Wiedererzählen >-Debatte hat gezeigt, wie schwierig es im Einzelfall ist festzulegen, welche Neuerungen auf der Seite der forma (artificium), welche auf der der materia zu verbuchen sind. Das Schlussgedicht der Klage demonstriert auf seine Weise, dass es nicht ausreicht zu sagen: formal neu und ambitioniert, inhaltlich konventionell.

Die zugegeben heikle Frage nach historischen Form-Semantiken ist mit dem Hinweis auf 〈Formzwang〉 und 〈Formdominanz〉 nicht erledigt. Die Form so weitgehend vom Inhalt zu isolieren, wird mittelalterlichen Texten generell, erst recht dem Klage-Text, nicht gerecht, der mit hohem Differenzierungsaufwand auf allen Ebenen propositionale, ästhetische und performative Gegenläufigkeiten inszeniert. Nicht die Form systematischer Kürzung durchgereimter, wiederholungsrhetorisch progredierender Verse führt $\mathrm{zu}$ einem «stark begrenzten inhaltlichen Ausdruck», ${ }^{78}$ sondern Hartmanns Form der Kürzung ist selbst eine signifikante, spannungsreiche simultanund sukzessionslogische «Ausdrucksform `. Sie überführt den auch inhaltlich relevanten Zeitdruck in akute Gegenwart, immer wieder, in nahezu jeder Strophe, und immer schneller. 
Die Antwort auf unsere Ausgangsfrage «Wie lang ist immer kürzer?〉 fällt aus den genannten Gründen ambivalent aus. Aus der Perspektive des hohen Minnesang-Ethos ist Warten kostbare Qualifikationszeit (‘[...] macht selig`): Immer kürzer wäre dann vielleicht voreilig schnell $\mathrm{zu}$ Ende. Aus der Perspektive eines erfolgs- beziehungsweise lösungsorientierten Pragmatismus, der im Text gleichfalls zu Wort kommt (‘[... höhlt den Stein`), ist es lästige Wartezeit: Hier wäre immer kürzer womöglich doch längst zu spät. Die beiden in Sprichwort-Kürze, aber zugleich wortreich ${ }^{79}$ formulierten Argumente «steter Tropfen höhlt den Stein〉 und seine Passiv-Variante 〈Warten macht selig〉 sind ironischerweise nach beiden Seiten auslegbar. Auch die Relativität von Geschwindigkeit wird im Schlussgedicht sprichworthaft kurz und zugleich redselig nach zwei Seiten ausgefaltet: Dem Glücklichen schlägt keine Stunde, dem Unglücklichen schleicht die Zeit dahin (vv. 1.881-1.884). Beides lässt sich nicht nur auf die Minnezeit beziehen, sondern auch auf die Textverlaufszeit, die mit abnehmender Verszahl schnell-langsam vergeht. Und auch die Minnezeit, als 〈Heilszeit〉 durchgängig religiös konnotiert, spaltet sich, wie immer wieder sichtbar wurde, ihrerseits auf in «zeitlose Zeit` und - angesichts endlicher Lebenszeit - drängende, ja verlorene Zeit.

Die Form der Kürzung in Hartmanns Schlussgedicht ist nicht schwer zu beschreiben, doch ihre Funktionen liegen weniger auf der Hand. Sie sind nur im Plural zu bestimmen und schließen sich durchaus, wie ich meine, zu einem Kürzungs- $\langle$ Konzept $〉$ zusammen, aber ohne dass dieses Konzept auf einen Begriff $\mathrm{zu}$ bringen wäre. Als Konzept komplexer Reduktion oder langsamer Beschleunigung oder raffender Kumulierung bleibt es jeweils in sich spannungsreich. ${ }^{80}$ Entkoppelt dagegen die Interpretation von vornherein

79 Benz (2018), S. 77-80 («Redseligkeit`): «Die Hypertrophie der Werbung überspielt die Konflikte, deren Ausbreitung ihre Voraussetzung war» (ebd., S. 80, mit Bezug auf die Klage).

80 In gewisser Weise ist Hartmanns Schlussgedicht eine Art versifikatorisches Kürzungspendant zum raffend kumulierenden Rapportschema als einem rhetorischen «Sonderidiom der brevitas» (Worstbrock [2004/11975], S. 20; hier auch S. 26 zur lusorischen Seite solcher Kunstformen; zum ‘versefüllenden Asyndeton` vgl. den Beitrag von Raphael Schwitter, in diesem Band). 
solche Verschränkungen von Form und Inhalt, ${ }^{81}$ bleibt nur die Enttäuschung vorgefundener Redundanz, Inhaltsarmut, Inkohärenz oder auch die, wie ich zeigen wollte, zu einseitige These von Kürzung als Medium fortschreitender Symmetrisierung. Das Zeitparadox (das stoete-Dilemma) der hohen Minne verhindert dauernde Positivierung von Negativität. Die unumkehrbare und zugleich rekursive Kürzung bringt den Text, indem sie ihn in die Länge zieht, formvollendet an sein Ende, das so offen ist wie der Anfang.

So wie der Streitdialog trotz stichomythisch beschleunigtem 〈Konsens〉 auf seine unendliche Fortsetzung zielt, manövriert auch der Schluss sich qua Kürzung in ein weiteres Dilemma und ist nicht dessen Auflösung. So wie in der Stichomythie Paradoxien durch Kompromisse nicht beizukommen ist, lässt sich im Schlussgedicht der Dauerzweifel nicht systematisch, dauernd und dauerhaft, wegkürzen, zumal es vielleicht doch Hoffnung ist, die winkt. Der Text bricht aber auch nicht einfach ab, wie viele Minnereden ( Hier sei das Büchlein aus`), sondern erzwingt durch systematische Kürzung dasselbe immer wieder, aber immer kürzer sagend - sein eigenes Verstummen. Wie die Sache ausgeht, ist eine von Hartmanns vielen abbreviierten, «nicht erzählten Geschichten», die auch die Lieder prägen, «auf der Schwelle von früher, jetzt, immer ${ }^{82}$ Sprich jetzt Du, roter Mund, und sag - ganz kurz - ja.

Wie steht es um die historische Signifikanz dieses in seiner Zeit isolierten Kürzungsexperiments? Das Prinzip systematischer Kürzung stellt das schillernde Zeitparadox, das das Schlussgedicht bespricht, auch formal aus. Ein wichtiger Effekt der Kürzungsmaßnahme betrifft daher die Gattung: die historisch neue hybride «Strophen >-Form als prestigeträchtiges Formzitat genau zwischen Leich und Minnesang. ${ }^{83}$ Betroffen sind aber auch Medialität und Überlieferung (Mise en page), Metrik, Struktur, Sprechakt und Argumentationslogik des Textes. Manfred Kern hat, unter anderen Vorzeichen, die spätmittelalterliche Minnerede mit einem glücklichen Begriff als «kom-

\footnotetext{
81 Zuletzt Frick / Rippl (2020).

82 Haustein (2011), S. 91; auch Huber (2020).

83 Oder richtiger: "Genauso weit an Leich und Minnesang vorbei? Denn zwischen Leich und Minnesang könnte keine Form liegen, die so rein stichisch (oder distichisch) ist wie dieses Formexperiment» (Sonja Glauch, brieflich).
} 
plexe Reduktionsform» bezeichnet. ${ }^{84}$ Minnereden können als widersprüchlich «komplexe Reduktionsformen» gelten, weil sie die narrative Unmöglichkeit des Hohen Sangs qua allegorischer Erzählung ins epische Format übersetzen, 〈alte〉 Minnesang-Psychodynamik mit zeitgenössisch aktueller gelehrter Wahrnehmungs- und Liebestheologie «neu〉 reformulieren, dabei Stilhaltungen und episch-lyrische Sprechakte in Texten wie der Minneburg oder Hadamars Jagd in unübersichtlich verschachtelten Binnen- und Rahmenhandlungen mischen. Das macht ihre «transgressive Produktivität» aus. ${ }^{85}$ In solcher Retrospektive würde die literarästhetische Signifikanz der Klage mit ihrem so einfachen wie mehrdeutigen Kürzungsmodell im allgemeinsten Sinn einer «komplexe[n] Reduktionsform» auch literarhistorisch relevant; umgekehrt könnte sich das, was Kerns paradoxe Kategorie für die späten Minnereden sucht, im Blick auf den früheren Text der Klage, die bis in wörtliche Zitate hinein so reiche Resonanz im Spätmittelalter findet,, ${ }^{86}$ noch prägnanter zeigen. Über eine Differenzierung verschiedener Beobachtungsebenen kann also einerseits das komplexe Kürzungskonzept der Klage hinter der verstechnisch simplen Kürzungs- «Mechanik〉sichtbar werden: als Spannung zwischen Irreversibilität und Rekursion, Kalkül und Kontingenz, unseligem Reden und redseligem Schweigen. Gleichzeitig kann sich auch zeigen, wie die Textrezeption die Kürzungsambivalenz immer wieder purifiziert: Schon die Überlieferung in A mit ihrer an spätmittelalterlichen Minnereden orientierten Stropheneinrichtung, die frühe Editorik mit ihrem separaten Abdruck des Schlussgedichts als «Leich〉 oder auch die dezisionistische Haltung, das Problem damit aus der Welt zu schaffen, dass das Schlussgedicht dem Autor und der Epoche abgesprochen wird.

«Steter Tropfen höhlt den Stein`? Auch das Sprichwort löst in der Klage nicht das doppelte Evidenzproblem nach innen und nach außen. Denn nicht dass, sondern wann endlich steter Tropfen den Stein gehöhlt haben wird,

84 Kern (2006), S. 58. Erst recht des Strickers Frauenehre, gleichfalls in A überliefert, würde vor diesem Hintergrund 〈komplexer Reduktion` als vielschichtige MinnesangTransformation erscheinen, die wie Hartmanns Klage die Perspektivität verschiedener Ansprüche auch dialogisch vorführt und dabei verschiedene Zeitlogiken durchspielt. Das pragmatische Paradox des Hohen Sangs wird beim Stricker freilich weitgehend aufgelöst.

85 Kern (2006), S. 60.

86 Ein erster Versuch der Zusammenschau bei Rudorfer (2008). 
steht auf dem Spiel: als künftig vergangene Gegenwart im Irrealis, eingebaut in höchst unsichere Bedingungssätze: ‘Wenn ich zum Glück geboren worden wäre, würde ich, wenn sie mich tröstete, das genießen〉 (vv. 1.887f.). Am Schluss bleiben vier kurze Verse übrig, immer noch zu lang für die unendliche Distanz zwischen Ich und Dame.

\section{Bibliographie}

\section{Primärliteratur}

Hartmann von Aue. Die Klage. Das (zweite) Büchlein aus dem Ambraser Heldenbuch, hg.v. Herta Zutt, Berlin 1968.

Hartmann von Aue. Das Klagebüchlein Hartmanns von Aue und das zweite Büchlein, hg.v. Ludwig Wolff, München 1972 (Altdeutsche Texte in kritischen Ausgaben 4). Hartmann von Aue: Das Büchlein. Nach den Vorarbeiten von Arno Schirokauer zu Ende geführt und hg.v. Petrus W. Tax, Berlin 1979 (Philologische Studien und Quellen 75).

Hartmann von Aue. Die Klage, hg.v. Kurt Gärtner, Berlin u. a. 2015 (Altdeutsche Textbibliothek 123).

[HMS III] Minnesinger. Deutsche Liederdichter des zwölften, dreizehnten und vierzehnten Jahrhunderts, aus allen bekannten Handschriften und früheren Drucken gesammelt und berichtigt, mit den Lesarten derselben, Geschichte des Lebens der Dichter und ihrer Werke, Sangweisen der Lieder, Reimverzeichnis der Anfänge, und Abbildungen sämmtlicher Handschriften, hg.v. Friedrich Heinrich von der Hagen. Bd. 3,1: Minnesinger aus den Jenaer, Heidelberger und Weingartner Sammlungen und den übrigen Handschriften und früheren Drucken, Leipzig 1838.

[Johann von Konstanz] Die Minnelehre des Johann von Konstanz. Nach der Weingartner Liederhandschrift unter Berücksichtigung der übrigen Überlieferung hg.v. Dietrich Huschenbett, Wiesbaden 2001.

Eberhard von Cersne. Der Minne Regel, hg.v. Franz Xaver Wöber. In musikalischer Hinsicht von August Wilhelm Ambros, Hildesheim / New York 1981 (Nachdruck der Ausgabe Wien 1861).

[MF] Des Minnesangs Frühling, unter Benutzung der Ausgaben v. Karl Lachmann und Moriz Haupt, Friedrich Vogt und Carl von Kraus bearbeitet v. Hugo Moser und Helmut Tervooren. Bd. 1: Texte, 38., erneut revidierte Auflage, Stuttgart 1988.

Strickers Frauenehre. Überlieferung - Textkritik - Edition - literaturgeschichtliche Einordnung v. Klaus Hofmann, Marburg 1976 S. 43-164. 
Ulrich von Liechtenstein. Frauendienst, hg.v. Franz Viktor Spechtler, Göppingen 1987 (GAG 485).

Ulrich von Liechtenstein: Das Frauenbuch. Mittelhochdeutsch / neuhochdeutsch, hg., übersetzt u. kommentiert v. Christopher Young, Stuttgart 2003(RUB 18290).

\section{Forschungsliteratur}

Benz, Maximilian: Fragmente einer Sprache der Liebe um 1200, Zürich 2018 (Mediävistische Perspektiven 6).

Bleumer, Hartmut: Ritual, Fiktion und ästhetische Erfahrung. Wandlungen des höfischen Diskurses zwischen Roman und Minnesang, in: Ruth Florack / Rüdiger Singer (Hgg.): Die Kunst der Galanterie. Facetten eines Verhaltensmodells in der Literatur der Frühen Neuzeit, Berlin / New York 2012, S. 51-92.

Cormeau, Christoph / Wilhelm Störmer: Hartmann von Aue. Epoche - Werk - Wirkung. Mit bibliographischen Ergänzungen (1992/93 bis 2006) v. Thomas Bein, München, ${ }^{3} 2007$.

Egidi, Margreth: Zeit, Raum und Subjektivität bei Hartmann von Aue und Burkhard von Hohenfels, in: Annette Gerok-Reiter / Anna Sara Lahr / Simone Leidinger (2020), S. 377-393.

Frick, Julia: abbreviatio. Zur historischen Signifikanz von Kürzungsfunktionen in der mittelhochdeutschen höfischen Epik des 13. Jahrhunderts. Eine Projektskizze, in: PBB 140 (2018), S. 23-50.

Frick, Julia: ez wâre ze sagene al ze lank. Zum Stellenwert der 〈Kürze-Topoi〉im mittelhochdeutschen Antikenroman, in: ZfdPh 139 (2020), S. 353-378.

Frick, Julia / Rippl, Coralie (Hgg.): Dynamiken literarischer Form im Mittelalter, Zürich 2020 (Mediävistische Perspektiven 10).

Gebert, Bent: Der Streit in mir. Zur Klage Hartmanns von Aue, in: ders.: Wettkampfkulturen. Erzählformen der Pluralisierung in der deutschen Literatur des Mittelalters, Tübingen 2019 (Bibliotheca Germanica 71), S. 146-166.

Gerok-Reiter, Annette / Lahr, Anna Sara / Leidinger, Simone (Hgg.): Raum und Zeit im Minnesang. Ansätze - Spielarten - Funktionen, Heidelberg 2020 (Studien zur historischen Poetik 29).

Gewehr, Wolf: Hartmanns〈Klage-Büchlein〉 als Gattungsproblem, in: ZfdPh 91 (1972), S. $1-16$.

Glauch, Sonja / Philipowski, Katharina: Vorarbeiten zur Literaturgeschichte und Systematik vormodernen Ich-Erzählens, in: dies. (Hgg.): Von sich selbst erzählen. Historische Dimensionen des Ich-Erzählens, Heidelberg 2017 (Studien zur historischen Poetik 26), S. 1-61. 
Glauch, Sonja: Rezension zu: Andreas Hammer / Victor Millet / Timo Reuvekamp-Felber (Hgg.): Ereck. Textgeschichtliche Ausgabe mit Abdruck sämtlicher Fragmente und der Bruchstücke des mitteldeutschen Erek, in: PBB 141 (2019), S. 112-127.

Glauch, Sonja: niht langer wan die wîle ich lebe. Zur Zeit-Poetik Reinmars, in: GerokReiter, Annette / Lahr, Anna Sara / Leidinger, Simone (2020), S. 171-199.

Glier, Ingeborg: Artes amandi. Untersuchung zu Geschichte, Überlieferung und Typologie der deutschen Minnereden, München 1971 (MTU 34).

Hausmann, Albrecht: Die vröide und ihre Zeit. Zur performativen Funktion der Inszenierung von Gegenwart im hohen Minnesang, in: ders. (Hg.): Text und Handeln. Zum kommunikativen Ort von Minnesang und antiker Lyrik, Heidelberg 2004 (Beihefte zum Euphorion 46), S. 165-184.

Haustein, Jens: Nichterzählte Geschichten. Zur Minnelyrik Hartmanns von Aue, in: Ralf Plate / Martin Schubert (Hgg.): Mittelhochdeutsch. Beiträge zur Überlieferung, Sprache und Literatur. Festschrift Kurt Gärtner, Berlin / Boston 2011, S. 83-93.

Haustein, Jens: Gesungene Geschichten? Hartmanns Lyrik, in: Cordula Kropik (Hg.): Hartmann von Aue. Eine literaturwissenschaftliche Einführung, Tübingen 2021 (UTB 5562), S. 85-120.

Hess, Ineke: Selbstbetrachtung im Kontext höfischer Liebe. Dialogstruktur und IchKonstitution in Hartmanns von Aue Klage, Berlin 2016 (Philologische Studien und Quellen 255).

Huber, Christoph: Jetzt - einst - immer. Zeitachsen im Minnelied (Reinmar und Heinrich von Mügeln), in: Gerok-Reiter, Annette / Lahr, Anna Sara / Leidinger Simone (2020), S. 155-169.

Kasten, Ingrid: Studien zur Thematik und Form des mittelhochdeutschen Streitgedichts, Hamburg 1973.

Kern, Manfred: 〈Parlando〉. Trivialisierte Bildlichkeit, transgressive Produktivität und europäischer Kontext der Minnerede, in: Ludger Lieb / Otto Neudeck (Hgg.): Triviale Minne? Konventionalität und Trivialisierung in spätmittelalterlichen Minnereden, Berlin/ Boston 2006 (Quellen und Forschungen zur Literatur- und Kutlurgeschichte 40 [274]), S. 55-76.

Kischkel, Heinz: Kritisches zum Schlussgedicht der Klage Hartmanns von Aue, in: ZfdPh 116 (1997), S. $94-100$.

Klingner, Jacob / Lieb, Ludger (Hgg.): Handbuch Minnereden. Mit Beiträgen von IuliaEmilia Dorobantu u. a., 2 Bde., Berlin / Boston 2013.

Klingner, Jacob: ‘Gegenspiele`. Zur Überlieferung von Minnesang und Minnerede in der 〈Weingartner Liederhandschrift〉, in: Susanne Köbele (Hg.): Transformationen der Lyrik im 13. Jahrhundert, Berlin 2013 (Wolfram-Studien XXI), S. 267-286.

Köbele, Susanne: Der paradoxe Fall des Ich. Zur Klage Hartmanns von Aue, in: Katharina Philipowski / Anne Prior (Hgg.): Anima und sêle. Darstellungen und Systematisie- 
rungen von Seele im Mittelalter, Berlin 2006 (Philologische Studien und Quellen 197), S. 265-283.

Köbele, Susanne: Ein Streitgespräch im Schnittpunkt der Diskurse. Die Klage, in: Cordula Kropik (Hg.): Hartmann von Aue. Eine literaturwissenschaftliche Einführung, Stuttgart 2020 (UTB) [im Druck].

Köbele, Susanne: Rezension zu: Ineke Hesse: Selbstbetrachtung im Kontext höfischer Liebe. Dialogstruktur und Ich-Konstitution in Hartmanns von Aue Klage, Berlin 2016, in: PBB 140 (2018), S. 417-424.

Lembke, Valeska: So lerne einen zouberlist. Hartmanns von Aue Klage, in: dies.: Minnekommunikation. Sprechen über Minne als Sprechen über Dichtung in Epik und Minnesang um 1200, Heidelberg 2013, S. 109-129.

Lieb, Ludger: Die Eigenzeit der Minne. Zur Funktion des Jahreszeitentopos im Hohen Minnesang, in: Beate Kellner / Ludger Lieb / Peter Strohschneider (Hgg.): Literarische Kommunikation und soziale Interaktion. Studien zur Institutionalität mittelalterlicher Literatur Frankfurt a. M. u. a. 2001 (Mikrokosmos 64), S. 183-206.

Masse, Marie-Sophie: Der rehte zouberlist aus Karlingen. Ältere und neuere Überlegungen zu Hartmanns Klage, in: Monika Costard / Jacob Klingner / Carmen Stange (Hgg.): Mertens lesen. Exemplarische Lektüren für Volker Mertens zum 75. Geburtstag, Göttingen 2012, S. 89-106.

März, Christoph: Metrik, eine Wissenschaft zwischen Zählen und Schwärmen? Überlegungen zu einer Semantik der Formen mittelhochdeutscher gebundener Rede, in: Jan-Dirk Müller / Horst Wenzel (Hgg.): Mittelalter. Neue Wege durch einen alten Kontinent, Stuttgart / Leipzig 1999, S. 317-332.

Mertens, Volker: Factus est per clericum miles cythereus. Überlegungen zu Entstehungsund Wirkungsbedingungen von Hartmanns «Klage-Büchlein〉, in: Timothy McFarland / Silvia Ranawake (Hgg.): Hartmann von Aue. Changing Perspectives. London Hartmann Symposion 1985, Göppingen 1988 (GAG 486), S. 1-19.

Monecke, Wolfgang: Studien zur epischen Technik Konrads von Würzburg. Das Erzählprinzip der wildekeit, Stuttgart 1968 (Germanistische Abhandlungen 24).

Müller, Jan-Dirk: Performativer Selbstwiderspruch. Zu einer Redefigur bei Reinmar, in: PBB 121 (1999), S. 379-405.

Philipowski, Katharina: Bild und Begriff. sêle und herz in geistlichen und höfischen Dialoggedichten des Mittelalters, in: Katharina Philipowski / Anne Prior (Hgg.): Anima und sêle. Darstellungen und Systematisierungen von Seele im Mittelalter, Berlin 2006 (Philologische Studien und Quellen 197), S. 299-319.

Rippl, Coralie: Die Litotes bei Hartmann von Aue: ironisch? Annäherungen an eine Poetik des Kontrasts, in: Julia Frick / Coralie Rippl (Hg.): Dynamiken literarischer Form im Mittelalter, Zürich 2020 (Mediävistische Perspektiven 10), S. 107-120. 
Rudorfer, Silke Andrea: Die Minne bei Ulrich von Liechtenstein, dem Stricker und Hartmann von Aue. Eine Gegenüberstellung von Frauenbuch, Frauenehre und Klagebüchlein, Neuried 2008 (Deutsche Hochschuledition 147).

Rüther, Hanno: Grundzüge einer Poetologie des Textendes in der deutschen Literatur des Mittelalters, Heidelberg 2018 (Studien zur historischen Poetik 19).

Störmer-Caysa, Uta: Grundstrukturen mittelalterlicher Erzählungen. Raum und Zeit im höfischen Roman, Berlin / New York 2007.

Störmer-Caysa, Uta: Reimsemantik und Raumsemantik, in: Gerok-Reiter, Annette / Lahr, Anna Sara / Leidinger, Simone (2020), S. 61-83.

Strittmatter, Ellen: Poetik des Phantasmas. Eine imaginationstheoretische Lektüre der Werke Hartmanns von Aue, Heidelberg 2013 (Studien zur historischen Poetik 15).

Worstbrock, Franz Josef: Rhetorische Formtypen der mittelalterlichen Lyrik $\left({ }^{1} 1975\right)$, in: Ders.: Ausgewählte Schriften. Bd. 1: Schriften zur Literatur des Mittelalters, hg.v. Susanne Köbele / Andreas Kraß, Stuttgart 2004, S. 17-38.

Worstbrock, Franz Josef: Dilatatio materiae. Zur Poetik des Erec Hartmanns von Aue (1985), in: ders.: Ausgewählte Schriften. Bd. 1: Schriften zur Literatur des Mittelalters, hg.v. Susanne Köbele / Andreas Kraß, Stuttgart 2004, S. 197-228.

Zotz, Nicola: Die Schlußstrophe im mittelalterlichen deutschen Liebeslied, in: Gert Hübner (Hg.): Deutsche Liebeslyrik im 15. und 16. Jahrhundert, Amsterdam / New York 2005, S. 147-168 (Chloe 37).

Zutt, Herta: Die formale Struktur von Hartmanns Klage, in: ZfdPh 87 (1968), S. 359372. 



\section{Das «versefüllende Asyndeton > in der spätlateinischen Dichtung}

\section{Zur Ambivalenz eines poetischen Stilmittels}

von

Raphael Schwitter (Bonn / Zürich)

\section{Einführung}

Bei seiner Behandlung des formalen Manierismus, den er dem natürlichen, das heißt dem klassischen Sprachausdruck als dessen Verkünstelung konträr gegenüberstellte, kam Ernst Robert Curtius auf eine «Entartung» zu sprechen, die darin bestehe, "dass möglichst viele Wörter in einen Vers hineingestopft werden. Man muss zu diesem Zweck entbehrliches «und fortlassen.» Curtius benannte das Phänomen - in Anlehnung an eine Wortprägung des Münchner Philologen Carl Weyman - «versefüllendes Asyndeton». ${ }^{1}$ Weyman selbst war während seiner Arbeit an der «Geschichte der christlichlateinischen Poesie> auf das Stilmittel der aufschwellenden Worthäufung gestoßen. ${ }^{2}$ Curtius erweiterte nun Weymans Perspektive um die mittellateinische Lyrik und um die deutsche Barockdichtung, wobei er letztere als die eigentliche Blütezeit der unverbundenen mehrgliedrigen Reihung ansah. ${ }^{3}$ Im Bannkreis manieristischer Abundanz und barocker Üppigkeit wurde als Wirkungsweise des versefüllenden Asyndetons die "pathetisch-vereindringlichende Steigerung» bestimmt: Indem es eine unbestimmte Vielheit vertritt, suggeriert es den Eindruck von Fülle, wirkt also zugleich emphatischaufschwellend und retardierend. ${ }^{4}$ In diesem Sinn spiegeln die oft virtuosen Worthäufungen der Barockdichtung «die Fülle des Seins und [halten]

1 Curtius ( $\left.{ }^{5} 1965\right)$, S. 289.

2 Weyman (1926), S. 126-127 u. 154 Anm. 1.

3 Curtius ( $\left.{ }^{5} 1965\right)$, S. 289 f., und Curtius (1940/1941), Blasberg (1992), Sp. 1155.

$4 \quad$ Lausberg $\left({ }^{3} 1990\right), \S 709$. 
dennoch die Unmöglichkeit des adäquaten sprachlichen Ausdrucks bewusst».5 Bei genauerer Betrachtung vermag ein derartiger formalistischer Zugriff indes nur die eine Kehrseite des versefüllenden Asyndetons zu offenbaren. Eine andere, scheinbar konträre Wirkungsweise erschließt sich einer mehr narratologisch ausgerichteten Perspektive, welche die asyndetische Reihung nicht primär als eine Vollzugsform der sprachstilistischen Ausgestaltung eines Textes, sondern als spezifisches Erzählverfahren, das heißt als Strategie der Darstellung und Vermittlung von Inhalten, ins Auge fasst. In dieser Sichtweise erweist sich Curtius' versefüllendes Asyndeton als Anwendungsform der brevitas, als Verfahren einer elliptischen Verdichtung der kommunizierten Inhalte, indem schlagwortartig eine Vielzahl von Gegenständen, ja ganze Erzählkomplexe in äußerster Kürze kursorisch abgehandelt werden können. ${ }^{6}$ Aus der Perspektive der Klassischen Philologie ist das Erscheinungsbild des versefüllenden Asyndetons in der hier postulierten Ambivalenz gerade für die spätlateinische Dichtung kennzeichnend. Wie die

$5 \quad$ Blasberg (1992), Sp. 1155; zur Worthäufung im Barock Pliester (1930). Die asyndetische Häufung wird als Stilmittel der accumulatio auch in der mittelhochdeutschen Dichtung eingesetzt, z. B. im Tristan Gottfrieds von Straßburg: ir hâr, ir stirne, ir tinne, / ir wange, ir munt, ir kinne (vv. 925 f., ed. Ranke / Krohn [1980]). Vgl. Arbusow ( ${ }^{2} 1963$ ), S. 65.

6 Ein anschauliches Beispiel aus der römischen Kunstprosa ist Cicero, Pro L. Flacco 62: Adsunt Athenienses, unde humanitas, doctrina, religio, fruges, iura, leges ortae atque in omnes terras distributae putantur. (Zugegen sind auch die Männer aus Athen, wo, wie man glaubt, die feine Bildung, die Wissenschaft, die Religion, die Landwirtschaft, die Rechtsordnungen, die Gesetze ihren Ursprung hatten und sich von dort über alle Länder verbreiteten.> Die Aufzählung wirkt gerade in ihrer enormen inhaltlichen Verdichtung emphatisch-eindringlich. Die klassische Rhetorik kennt diesen Erzählmodus in erster Linie in der Form der praktischen Übungsleistung (praeexercitamen), die einen Bestandteil der exercitatio darstellt. Hier wird neben anderen Modi die narratio per dissolutum empfohlen, in der die Erzählung in kurze, asyndetisch aufeinanderfolgende Satzteile zerlegt wird, vgl. Priscian, Praeexercitamina 2 (ed. Halm [1863], S. 552): Medea, Aeetae filia, prodidit aureum vellus, Absyrtum interfecit fratrem. «Medea, die Tochter des Aeetes, lieferte das Goldene Vlies aus, tötete ihren Bruder Absyrtus.> Vgl. Lausberg ( $\left.{ }^{3} 1990\right)$, \$ 1112. Im Gegensatz zur klassischen Rhetorik behandelt die mittelalterliche Poetik das dissolutum auch als Anwendungsform der abbreviatio, vgl. Arbusow $\left({ }^{2} 1963\right)$, S. 28. Sämtliche Übersetzungen sind die des Verfassers. 
beachtliche Fülle der in den letzten Jahren erschienenen Publikationen dokumentiert, ist die Spätantike nicht nur als eine Periode aufzufassen, die sich stilistisch (in Literatur, Architektur, Malerei und Plastik) am überkommenen Kulturkanon abarbeitete, indem sie ihn überformte, übersteigerte und brach, ihn gerade dadurch aber immer wieder bestätigte und erneuerte, ${ }^{7}$ sondern auch eine Epoche der Epitome, der Cento-Dichtung und der Florilegiensammlung, das heißt der kreativ-selektiven Wissensverdichtung. ${ }^{8}$ Dieses der spätantiken Literatur eigentümliche Changieren zwischen Überladen und Verdichten, zwischen Abbreviation und Amplifikation (im doppelten Sinne als quantitative «Erweiterung» und als «Intensitätssteigerung» ${ }^{9}$ ) lässt sich, wie ich meine, am Phänomen des versefüllenden Asyndetons beispielhaft aufzeigen.

Im Folgenden wird nach einigen einführenden Präliminarien die Anwendungs- und Wirkungsweise des versefüllenden Asyndetons in der spätlateinischen Dichtung fallweise anhand von zwei komplementären Textgruppen analysiert, deren divergente materiale Präsentationsmodi eine isolierte Betrachtung methodisch sinnvoll erscheinen ließ: Den Anfang macht die hexametrische und lyrische Buchdichtung der Spätantike; auf sie folgt die spätantike Epigrammatik unter Berücksichtigung epigraphischer Zeugnisse. Am Schluss steht eine die Ergebnisse zusammenführende Vertiefung, in der die ambivalente Wirkungsweise des versefüllenden Asyndetons noch einmal exemplarisch anhand der spätantiken Katalogdichtung verdeutlicht wird.

7 Aus der stetig wachsenden Forschung zur spätantiken Ästhetik sei hier nur eine knappe Auswahl mit literaturwissenschaftlichem Fokus gegeben: Roberts (1989), Formisano (2007), Hernández Lobato (2012), Schwitter (2015), Elsner / Hernández Lobato (2017).

8 Einen summarischen Überblick bieten Horster / Reitz (2018). Zum Phänomen der Wissensverdichtung und -verkürzung in Spätantike und Frühmittelalter vgl. Dusil / Schwedler / Schwitter (2016); zur Antike allgemein Horster / Reitz (2010).

9 Beim Begriff der amplificatio gilt es grundsätzlich zwischen der «Breitenamplifizierung〉 und der 〈Höhenamplifizierung〉 zu unterscheiden. Während die antike Rhetorik klar zwischen der Steigerung durch Umfangserweiterung (congeries) und der Intensitäts-

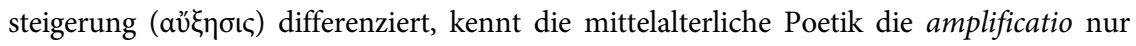
mehr als quantitative «Erweiterung〉. Vgl. Arbusow ( $\left.{ }^{2} 1963\right)$, S. 21; Curtius ( $\left.{ }^{5} 1965\right)$, S. 483; Lausberg $\left({ }^{3} 1990\right), \S \$ 259 ; 406 ; 1246$. 


\section{Grundlegung: Das Asyndeton als Stilfigur in der rhetorischen Theorie und als Gestaltungsmittel in der römischen Dichtung}

Das zeitliche und logisch-semantische Verhältnis koordinierter Glieder von Sätzen oder Satzfolgen (Gedanken) kann mit oder ohne gleichordnende Bindeworte ausgedrückt werden. Erfolgt die Aufreihung durchgängig ohne Konjunktion, definiert die rhetorische Figurenlehre dieses $\sigma \chi \tilde{\eta} \mu \alpha$ als Asyndeton; zusammen mit seinem Gegenstück, dem Polysyndeton, bildet es die syntaktische Realisierung der koordinierenden und (seltener) der subordinierenden Häufung. ${ }^{10}$ Die in der Brachylogie gewonnene Kürze empfiehlt die Aufzählung für die Redeteile der partitio (als dispositio) und der peroratio (als recapitulatio). ${ }^{11}$ Schwieriger zu bestimmen ist die intendierte Wirkungsweise der Stilfigur außerhalb dieser Redeteile, zumal die antike rhetorische Artigraphie zwar den pathossteigernden Effekt des Asyndetons in hoher Rede betont, zugleich aber dessen Anwendung in der einfachen Rede vorsieht. ${ }^{12}$ Diese Ambivalenz liegt darin begründet, dass die Asyndese nicht

10 In der Kontaktform als enumeratio, in der Distanzform als distributio, vgl. Lausberg $\left({ }^{3} 1990\right)$, $\$ \$ 406,668-675,650$. Die koordinierende Häufung ist die congeries; die subordinierende Häufung liegt beim aneinandergereihten Epitheton vor, z. B. Cicero, In Verrem 5,45,118: aderat ianitor carceris, carnifex praetoris, mors terrorque sociorum et civium Romanorum, lictor Sextius. «Da war er, der Pförtner des Kerkers, der Henker des Prätors, Tod und Schrecken der Bundesgenossen und der römischen Bürger, der Liktor Sextius.> 11 Lausberg ( $\left.{ }^{3} 1990\right), \$ \$ 434-435$ u. 671. Beispielhaft für die Prägnanz der peroratio ist

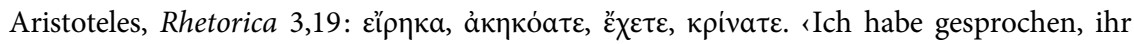
habt es gehört, ihr wisst Bescheid, entscheidet!) Vgl. ferner Cicero, Partitiones oratoriae 53.

12 Puttfarken (1920), S. 3. Vgl. u. a. Ps.-Longinus, De sublimitate 19-21; Cicero, Partitiones oratoriae 21 u. 52-53; Aquila Romanus, De figuris 41 (ed. Halm [1863], S. 35); zu Aristoteles Blettner (1983). Emphase und Kürze des Stilmittels (in einfacher Rede) betonen der Auctor ad Herennium 4,41 (des Satzasyndetons): hoc genus [dissolutum] et acrimoniam habet in se et vehementissimum est et ad brevitatem adcommodatum «diese Figur hat Schärfe, ist äußerst kraftvoll und zur Kürze geeignet); 4,26 (des Wortasyndetons) und Quintilian, Institutio oratoria 9,3,50: figuram, quae, quia coniunctionibus caret, dissolutio vocatur, apta, cum quid instantius dicimus: nam et singula inculcantur et quasi plura fiunt <eine Figur, die, weil sie ohne Bindungen ist, Auflösung heißt, passend, wenn wir etwas mit größerem Nachdruck sagen, denn die Wörter werden einzeln eingebläut und wirken dadurch so, als wären es mehr ’. 
auf den manipulativ-künstlichen Anwendungsbereich der präskriptiven rhetorischen $\tau \dot{\varepsilon} \chi \vee \eta$ restringiert war, sondern zugleich auch ein Phänomen der Umgangssprache darstellte. ${ }^{13}$ Asyndetische Reihungen sind - gerade in der Parataxe - grundsätzlich ubiquitär und in den meisten Sprachen präsent. Idiosynkrasien sind gleichwohl erkennbar, so tritt im Deutschen die Asyndese gegenüber der Monosyndese zurück, während im Lateinischen und Griechischen eine Reihe von Wörtern oder Sätzen entweder durchweg oder gar nicht verbunden wird. ${ }^{14}$ Die moderne rhetorische Theorie und Linguistik kennt zwei Differenzierungsarten unverbundener Reihung:15 Man unterscheidet einerseits nach Wortarten, das heißt zwischen nominalem und verbalem Asyndeton (asv), andererseits nach Länge der Glieder, also zwischen Einzelwort- und Wortgruppen- beziehungsweise Satzasyndeton (ass). Die Anordnung und Abfolge der Glieder kann beim Wortasyndeton nach Bedeutung oder Form, also enumerativ, synonymisch, alliterierend usw. erfolgen; beim Satzasyndeton wird zuerst logisch zwischen koordinierender und subordinierender Stellung, dann nach Bedeutung geschieden. ${ }^{16}$

13 Im Lateinischen erhalten in formelhaften Wendungen wie hinc inde, hac illac, plus minus usw. Zur Satzasyndese als Merkmal der lateinischen Umgangssprache vgl. Hofmann ( $\left.{ }^{4} 1978\right), \S 104$; Scherer (1975), S. 106. Mit Fokus auf die Poesie Maurach $\left({ }^{2} 1989\right)$, $\$ 215$. Eine Miszelle zur ‘volkstümlichen` Wendung assem semiassem bietet Delz (1977). 14 Staab (2003), Sp. 1538.

15 Entsprechende Ansätze finden sich in der antiken Theorie, vgl. Iulius Rufinianus, De schematibus lexeos 20 (ed. Halm [1863], S. 53); Aquila Romanus, De figuris sententiarum et elocutionis 41 (ed. Halm [1863], S. 35); Quintilian, Institutio oratoria 9,3,50: utimur hac figura non in singulis modo verbis, sed sententiis etiam «wir verwenden diese Figur nicht nur bei einzelnen Wörtern, sondern auch bei ganzen Sätzen`. Vgl. Puttfarken (1920), S. 3; Lausberg $\left({ }^{3} 1990\right)$, \$\$ 709-711.

$16 \mathrm{Zu}$ den einzelnen Typen vgl. Puttfarken (1920), S. 4-6; Hofmann / Szantyr (1965), S. 830-831. Einige Beispiele: asv ${ }^{2}$ synonymisch: contemptus, spretus «verachtet, verschmäht> (Terenz, Andria 248); asv ${ }^{4}$ synonymisch mit Klimax: abiit, excessit, evasit, erupit ser entfernte sich, ging weg, entkam, brach aus〉 (Cicero, In Catilinam 2,1); asv $^{3}$ mit $^{2}$ Alliteration und Klimax: veni, vidi, vici «ich kam, sah, siegte〉 (Sueton, Divus Iulius 37,2); asv $^{3}$ summativ: aqua, terra, spiritus, omnia ista 〈Wasser, Erde, Luft, all das〉 (Seneca, Epistulae 117,23); ass adversativ: quaesivi, nusquam repperi ich suchte, fand nie> (Plautus, Persa 44); ass kausal: odi ego aurum, multa multis saepe suasit perperam iich verabscheue Gold, oft rät es vielen Falsches`(Plautus, Captivi 328). Da im Folgenden der Fokus auf 
Das Asyndeton gehört seit Beginn der literarischen Tradierung zu den Gestaltungselementen der römischen Dichtung. Da die klassische Rhetorik prinzipiell auf die Kunstprosa ausgerichtet war, fand die Stilfigur erst in den mittelalterlichen Poetiken eine artigraphische Begründung. ${ }^{17}$ Als klassische Realisierung der asyndetischen Aneinanderreihung kann in der römischen Dichtung die Dreierfigur gelten, z. B. (als Einzelwortasyndeton) Vergil, Aeneis 11,329: aera, manus, navalia «Metall, Arbeitskräfte, Werft), und (als Satzasyndeton) Vergil, Aeneis 4,594: ferte citi flammas, date tela, impellite remos «tragt schnell Fackeln herbei, teilt Waffen aus, treibt die Ruder an.$^{18}$ Demgegenüber besitzen zwei- und viergliedrige Wortreihungen $\left(\mathrm{asv}^{2}\right.$ und asv $^{4}$ ) potenziell einen «umgangssprachlichen > beziehungsweise einen «archaischen> Anstrich, ${ }^{19}$ z. B. Lucilius, Saturae frg. 62 Charpin: durum molle voras

dem versefüllenden Einzelwortasyndeton liegt, ist das Wortgruppen- und Satzasyndeton nicht Gegenstand der Analyse; aus demselben Grund wird auch die Kunstprosa nicht berücksichtigt.

17 Stellen nennen Curtius ( $(1965)$, S. 289, und Arbusow ( $\left.{ }^{2} 1963\right)$, S. 28.

18 Ferner Vergil, Aeneis 12,197: haec eadem, Aenea, terram, mare, sidera iuro «dasselbe schwöre ich, Aeneas, bei Erde, Meer, Sternen;; Vergil, Aeneis 9,37: ferte citi ferrum, date tela, ascendite muros stragt schnell Waffen herbei, teilt Speere aus, besteigt die Mauern', und Ovid, Fasti 3,81 f.: Pallada Cecropidae, Minoia Creta Dianam, / Volcanum tellus Hypsipylea colit «die Cecropiden verehren Pallas, das minoische Kreta Diana, das hypsipyleische Land Vulkan`. Dreigliedrige Asyndeta sind schon in der archaischen Dichtung verbreitet, z. B. Naevius, Bellum Punicum frg. 37 Blänsdorf: urit, populatur, vastat er brennt nieder, verheert, verödet`; Plautus, Amphitruo 196: probri, stupri, dedecoris `Unrecht, Laster, Schande>. Bei den zitierten Fällen mit Einzelwortasyndeta kann technisch nicht von einem Trikolon gesprochen werden, da dort die einzelnen Kola aus mindestens zwei Wörtern bestehen müssen, vgl. Winter-Froemel (2009), Sp. 781.

19 In seiner Kieler Dissertation von 1914 hat Puttfarken den Gebrauch der Figur in der archaischen, klassischen und kaiserzeitlichen lateinischen Dichtung im Einzelnen untersucht, doch sind seiner achtseitigen Publikation von 1920 nur Statistiken, keine Stellen zu entnehmen. Einen knappen historischen Überblick mit Fokus auf die Kunstprosa bieten Hofmann / Szantyr (1965), S. 828-831. Deutlich wird, dass in der archaischen Poesie gerade der Gebrauch von asv ${ }^{2}$ sehr viel ausgeprägter war als in den darauffolgenden Epochen. Sie finden sich (isoliert als militärisch-formelhafte Wendung?) noch bei Vergil: z. B. Aeneis 2,358: per tela, per hostis «durch Waffen, durch Feinde; 2,664: per tela, per ignis «durch Waffen, durch Feuer`; 11,497: per colla, per armos «über Hals, über Bug»; 12,682. Aelius Donat (Commentum Adelphoe Terenti V 9,33, ed. Wessner, Bd. 2, S. 184) erklärt 
¿Zähes, Zartes schlingst du runter〉 (asv ${ }^{2}$ adversativ); Ennius, Annales frg. 498 Skutsch: flentes, plorantes, lacrumantes, obtestantes ijammernd, weinend, schluchzend, flehend > (asv ${ }^{4}$ synonymisch). Synchrone Differenzen lassen sich im Hinblick auf das versefüllende Einzelwortasyndeton in der klassischen Dichtung nur im Ansatz erkennen: So fehlt es im hochsprachlichen Epos der augusteischen Klassik gänzlich, ${ }^{20}$ während es im nähesprachlichen Register der horazischen Episteln zur Bezeichnung affektierter Indignation sporadisch auftritt. ${ }^{21}$ In der nachklassischen Poesie, besonders in hochsprachlichen Gattungen wie Epos und Tragödie, nimmt die Verwendung analog zur zeitgenössischen Kunstprosa zwar zu, ${ }^{22}$ doch sind vielglied-

Formeln wie fanda, nefanda «erlaubt, unerlaubt und digna, indigna «ziemend, ungeziemend als archaisch (fuit veteribus usitatum) und sprichwörtlich (proverbialis elocutio). 20 Bezeichnenderweise findet es sich aber bei Lukrez: De natura deorum 1,685: concursus, motus, ordo, positura, figurae «Begegnungen, Bewegungen, Ordnung, Lage, Gestalten ; 2,669: ossa, cruor, venae, calor, umor, viscera, nervi «Knochen, Blut, Adern, Wärme, Feuchte, Fleisch, Sehnen〉; 5,1192: nubila, sol, imbres, nix, venti, fulmina, grando ‘Wolken, Sonne, Regen, Schnee, Winde, Gewitter, Hagel> (mit Alternanz Singular-Plural).

21 Horaz, Epistulae 2,2,180-181: gemmas, marmor, ebur, Tyrrhena sigilla, tabellas, / argentum, vestis Gaetulo murice tinctas «Gemmen, Marmor, Elfenbein, tyrennische Standbildchen, Gemälde, Silber, in gätulischen Purpur getauchte Gewänder`; Epistulae 2,208209: somnia, terrores magicos, miracula, sagas, / nocturnos lemures portentaque Thessala ‘Träume, schreckenerregende Zauberei, Wunder, Hexen, Nachtgespenster und thessalische Phantastereien); zur Affektwirkung vgl. Aquila Romanus 41 (ed. Halm [1863], S. 35): facit autem figura haec et ad celeritatem et ad vim doloris aliquam significandam, in qua plerumque, cum commoti sumus, hoc modo incidere solemus «die Figur lässt Geschwindigkeit und Intensität der Empfindung hervortreten; auf sie fallen wir meistens zurück, wenn wir erregt sind. Ein asv (über die Versgrenze) zeigt Horaz, Saturae 1,9,2627: est tibi mater, / cognati, quis te salvo est opus? «Hast du Mutter, Verwandte, die von deinem Wohlergehen abhängen?

22 Curtius ( $\left.{ }^{5} 1965\right)$, S. 289 übertreibt, wenn er behauptet, dass sich der Gebrauch bei Statius verallgemeinert habe; versfüllende asv ${ }^{x}$ haben Seneca, Phoenissae 34: semper cruente, saeve, crudelis, ferox «du stets grausamer, wilder, harter, unbändiger ; Hercules furens 32; Hercules furens 1260; Statius, Thebais 10,768-769: At Tyriis templa, arva, domos, conubia, natos / reddite morte mea «Doch den Tyrern gebt durch meinen Tod zurück Tempel, Land, Häuser, Ehepartner, Kinder'; Silvae 1,6,43-44: una vescitur omnis ordo mensa, / parvi, femina, plebs, eques, senatus «Jeder Stand isst an seinem Tisch: die Kinder, die Frauen, das gemeine Volk, die Ritter, die Senatoren`. Zum Gebrauch des Asyndetons in 
rige Wortasyndeta $\left(\operatorname{asv}^{\mathrm{x}}\right)$ erst im literarischen Gebrauch der lateinischen Spätantike in allen poetischen Gattungen anzutreffen.

\section{Fallanalysen}

\section{III.1. Anwendungs- und Wirkungsweisen von asv ${ }^{x}$ in der hexametrischen und lyrischen Buchdichtung der lateinischen Spätantike}

Als Carl Weyman sich in den 20er-Jahren des letzten Jahrhunderts zum versefüllenden Asyndeton äußerte, tat er dies mit Blick auf eine Textpassage aus dem Carmen paschale des christlich-lateinischen Dichters Sedulius (frühes 5. Jahrhundert n.Chr.). Die Stelle steht im Kontext der Gefangennahme Christi im Ölgarten und stellt eine flammende Apostrophe an Judas dar:

Tune cruente, ferox, audax, insane, rebellis, perfide, crudelis, fallax, venalis, inique, traditor inmitis, fere proditor, impie latro, praevius horribiles comitaris signifer enses? (Sedulius, Carmen paschale 5,59-62)

«Gingst nicht du den schrecklichen Schwertern als Weggeleiter voraus, du grausamer, unbändiger, vermessener, toller, widerspenstiger, treuloser, schonungslo-

den Tragödien Senecas vgl. Canter (1925), S. 169-172, zur späteren Kunstprosa (Arnobius u. a.) Hagendahl (1937), S. 207-231. Eingängig ist Plinius, Epistulae 4,14,1-3: Accipies cum hac epistula hendecasyllabos nostros, quibus nos in vehiculo, in balineo, inter cenam oblectamus otium temporis. His iocamur, ludimus, amamus, dolemus, querimur, irascimur, describimus aliquid modo pressius, modo elatius [...]. «Ich schicke dir mit diesem Brief meine Hendecasyllabi, mit denen ich mir im Reisewagen, im Bad, beim Essen die Zeit vertrieben habe. In ihnen scherze, spiele, liebe, weine, klage, zürne ich, beschreibe einiges mal kürzer, mal länger [...] ); aus einem (apokryphen?) Brief des Augustus (= epist. frg. 32 Malcovati) zitiert Macrobius, Saturnalia 2,4,12: vale mel gentium, †meculle $\dagger$, ebur ex Etruria, lasar Arretinum, adamas Supernas, Tiberinum margaritum, Cilniorum smaragde, iaspi figulorum, berulle Porsenae, carbunculum [...] «Ich grüße dich, Honig der Völkerschaften, †, etrurisches Elfenbein, Lasersaft aus Arretium, adriatischer Stahl, Perle des Tiber, cilnischer Smaragd, Jaspis der Töpferer, Beryll des Porsenna, Karbunkel [...]. 
ser, ränkevoller, bestechlicher, ungerechter, unbarmherziger Auslieferer, grausamer Verräter, gottloser Schurke?>

Der dichte Hagel pleonastischer Schmähungen, die Sedulius in ermüdend unermüdlichem Stakkato auf Judas niederprasseln lässt, ist ebenso eindrücklich wie effekterregend. In vergleichbaren affektiert-emotionalen Situationen sind asyndetische Akkumulierungen zwar wie oben vermerkt auch in der früheren römischen Dichtung vereinzelt belegt, doch in Anzahl Glieder und Länge nie derart exzessiv ausgestaltet; erst der zügellose, antiklassische Gebrauch des Stilmittels führte Curtius zu seiner Konzeption der manieristischen Entartung. Beispiele dieser Art sind in der lateinischen Dichtung der Spätantike in der Tat allgegenwärtig. Besonders eindrücklich ist der Auftakt des hexametrischen Hauptwerks des afrikanischen Poeten Dracontius (spätes 5. Jahrhundert n. Chr.), der hier der Anschaulichkeit willen in voller Länge zitiert wird:

Qui cupit iratum placidumve scire Tonantem, hoc carmen, sed mente legat, dum voce recenset. Agnoscet quem templa poli, quem moenia caeli auctorem confessa suum veneranter adorent. Quinque plagae septemque poli, sol, luna, triones, sidera, signa, noti, nix, imber, grando, pruinae, fulmina, nimbus, hiems, tonitrus, lux, flamma, procellae, caelum, terra, iubar, chaos, axis, flumina, pontus, vel quicquid natura dedit praecepta creare, hoc agit et sequitur variis sub casibus iras et pia vota Dei. Miseris hinc atque beatis pro meritis morum, pro certo tramite vitae paupertas, mors, vita, salus, opulentia, languor, taedia, tristitiae, splendor, compendia, damnum, gaudia, nobilitas, virtus, prudentia, laudes, affectus, maeror, gemitus, successus, egestas, ira potestatum, trux indignatio regum. (Dracontius, De laudibus Dei 1,1-17)

‘Wer den Donnerer in seinem Zorn oder seiner Milde kennenzulernen begehrt, möge dieses Gedicht im Herzen lesen, während er es mit der Zunge vorträgt. Erkennen wird er Ihn, den das Firmament des himmlischen Tempels und die Mauern des Himmels als ihren Erschaffer bekennen und feierlich verehren. Die fünf 
Zonen und die sieben Himmel, die Sonne, der Mond, die beiden Bären, die Sterne, die Gestirne, die Winde, der Schnee, der Regen, der Hagel, der Reif, die Blitze, der Nebel, der Winter, der Donner, das Licht, das Feuer, der Sturm, der Himmel, die Erde, der Glanz des Himmels, die Dunkelheit, die Himmelsachse, die Flüsse, das Meer und all das, was die Natur hervorbringt, wenn sie dazu aufgefordert wird, tut dies und fügt sich je nach Umständen dem Zorn und dem Wohlwollen Gottes. Von ihm her rührt für die Elenden wie für die Glückseligen je nach Verdiensten auf ihrem Lebensweg Armut, Tod, Leben, Heil, Reichtum, Krankheit, Überdruss, Traurigkeit, Ansehen, Vorteile, Schaden, Freude, Ehre, Tugend, Weisheit, Lob, Leidenschaft, Kummer, Klagen, Erfolg, Dürftigkeit, Zorn der Mächtigen, furchtbarer Unmut der Könige.>

In zwei virtuosen Aufzählungen wird dem Leser die Unfassbarkeit Gottes als Urheber der Naturgewalten und der menschlichen Fügung in vereindringlichender Worthäufung gleichsam bildhaft vor Augen geführt. Kaum weniger eindrucksvoll, jedoch ganz ohne die Legitimation religiöser Verzückung, präsentiert sich die Beschreibung der Stadt Narbonne, die der gelehrte gallische Aristokrat Sidonius Apollinaris (429/32 - um 468 n.Chr.) in der detaillierenden Form der Leptologie, das heißt der Aufteilung eines Ganzen in kleinste Gegenstandseinheiten, anhand von vierundzwanzig Einzelteilen dem Leser mosaikartig vor Augen stellt:

Salve, Narbo potens salubritate, urbe et rure simul bonus videri, muris, civibus, ambitu, tabernis, portis, porticibus, foro, theatro, delubris, capitoliis, monetis, thermis, arcubus, horreis, macellis, pratis, fontibus, insulis, salinis, stagnis, flumine, merce, ponte, ponto; unus qui venerere iure divos Lenaeum, Cererem, Palem, Minervam spicis, palmite, pascuis, trapetis.

(Sidonius Apollinaris, Carmina 23,37-47)

«Ich grüße Dich, Gesundheit förderndes Narbonne, schön anzusehen sind in gleichen Maßen deine Stadt und dein Land, deine Mauern, Bürger, dein Umlauf, deine Gastschenken, deine Tore, Galerien, dein Forum, dein Theater, deine Tempel, Hügel, Münzstätten, Thermen, Triumphbögen, Kornkammern, Fleischmärkte, Wei- 
den, Quellen, Inseln, Salzgruben, Teiche, Flüsse, Handelswaren, Brücken, deine Meeresflut; allein du verehrst mit Recht von den Göttern Bacchus, Ceres, Pales, Minerva, wegen deiner Ähren, Weinbergen, Futterweiden, Olivenpressen.>

Ein vergleichbares Beispiel eines aufsummierenden asv $v^{x}$ liegt auch in Sidonius' Anrede an den Widmungsträger seiner Kleingedichtsammlung vor: Der Adressat, Magnus Felix, wird hier (mittels eines Wortspiels mit seinem Eigennamen) als vom Glück begünstigter Mann emphatisch hervorgehoben, was durch eine asyndetische Nominalhäufung zum Ausdruck gebracht wird:

Dic, dic quod peto, Magne, dic, amabo

Felix nomine, mente, honore, forma

natis, coniuge, fratribus, parente,

germanis genitoris atque matris

et summo patruelium Camillo.

(Sidonius Apollinaris, Carmina 9,4-8)

«Sag es mir, sag es mir, Magnus, was ich wissen will, sag es mir, ich bitte dich, Felix, glücklich, bist du wegen deines Namens, deines Gemüts, deiner Würde, deiner Schönheit, deiner Kinder, deiner Frau, deiner Brüder, deiner Eltern, wegen des Vaters und auch der Mutter Brüder, und wegen Camillus, des bedeutendsten aller Vettern.>

Sucht man im Durchgang durch die einschlägigen Stellen innerhalb von Sidonius' poetischem Euvre nach Mustern hinsichtlich seiner Verwendung des versefüllenden Asyndetons, springt einem seine Neigung für Aufzählungen, Listen und Kataloge ins Auge, die er mit Dichtern wie Decimus Magnus Ausonius (um 310-393/394 n. Chr.) teilt. ${ }^{23}$ Ein anschauliches Beispiel findet sich im Panegyricus auf den Kaiser Maiorian (reg. 457-461 n. Chr.):

[...] fert Indus ebur, Chaldaeus amomum, Assyrius gemmas, Ser vellera, tura Sabaeus, Atthis mel, Phoenix palmas, Lacedaemon olivum, Arcas equos, Epirus equas, pecuaria Gallus, arma Chalybs, frumenta Libys, Campanus Iacchum, aurum Lydus, Arabs guttam, Panchaia myrrham, Pontus castorea, blattam Tyrus, aera Corinthus; 
Sardinia argentum, naves Hispania defert [...].

(Sidonius Apollinaris, Carmina 5,42-49)

‘...] der Inder bringt Elfenbein, der Chaldäer Amomum, der Assyrer Edelsteine, der Serer Seide, Weihrauch der Sabäer, Attika Honig, der Phönizier Datteln, Sparta Oliven, der Arkadier Streitrosse, Epirus Stuten, der Gallier Viehherden, Waffen der Chalyber, Getreide der Libyer, der Kampaner Wein, Gold der Lyder, der Araber Bernstein, Panchaia Myrrhe, Pontus Bibergeil, Purpur Tyrus, Bronze Korinth; Sardinien bringt Silber herbei, Spanien Schiffe [... .)

Die Szenerie beschreibt zweiundzwanzig Regionen aus allen Teilen des bekannten Erdkreises, die der Göttin Roma ein jeweils landestypisches Produkt darbringen. Das enumerative Wortgruppenasyndeton wirkt auch hier pathetisch steigernd und veranschaulicht hyperbolisch den immensen Machtbereich des Kaisers. Denselben pathossteigernden Effekt nimmt das versefüllende Asyndeton regelmäßig auch in ekphrastischen Passagen ein. ${ }^{24}$ Das folgende Beispiel stammt ebenfalls aus einem Panegyricus, diesmal jedoch auf Kaiser Anthemius (reg. 467-472 n. Chr.). Die Passage ist Teil von Sidonius' Beschreibung der Wohnstätte der Göttin Aurora, wo ewiger Frühling herrscht - hier versinnbildlicht durch einen Katalog von fünfzehn wohlriechenden Pflanzen:

24 Dasselbe Phänomen lässt sich auch in seiner Prosa aufzeigen, vgl. z. B. Sidonius Apollinaris, Epistulae 1,8,2: In qua palude indesinenter rerum omnium lege perversa muri cadunt, aquae stant, turres fluunt, naves sedent, aegri deambulant, medici iacent, algent balnea, domicilia conflagrant, sitiunt vivi, natant sepulti, vigilant fures, dormiunt potestates, faenerantur clerici, Syri psallunt, negotiatores militant, monachi negotiantur, student pilae senes, aleae iuvenes, armis eunuchi, litteris foederati. «In diesem Sumpf werden die Gesetze der Natur unaufhörlich auf den Kopf gestellt: Die Mauern fallen, das Wasser steht, die Türme schwanken, die Schiffe sitzen fest, die Kranken spazieren umher, die Ärzte liegen darnieder, die Bäder sind kalt, die Wohnhäuser brennen, die Lebenden dursten, die Bestatteten schwimmen im Wasser, die Diebe halten Wache, die Behörden schlafen, die Kleriker leihen gegen Zins, die Syrer singen die Psalmen, die Händler dienen Christus, die Mönche treiben Handel, die Greise üben sich im Ballspiel, die Jungen im Würfelspiel, die Eunuchen in den Waffen, die germanischen Hilfstruppen in den Wissenschaften.> 
Est locus Oceani [...]

ver ibi continuum est [...];

halant rura rosis, indiscriptosque per agros

fragrat odor; violam, cytisum, serpylla, ligustrum,

lilia, narcissos, casiam, colocasia, caltas,

costum, malobathrum, myrrhas, opobalsama, tura

parturiunt campi [...].

(Sidonius Apollinaris, Carmina 2,407-416)

〈Es gibt einen Ort im Ozean [...] dort währt der Frühling ewig [...]; dort duftet das Land nach Rosen und über den ungeteilten Feldern liegt ein Wohlgeruch; Veilchen, Schneckenklee, Quendel, Liguster, Lilien, Narzissen, Seidelbast, Wasserrosen, Ringelblumen, Kostwurz, Malobathrum, Myrrhe, Balsam, Weihrauch bringt der Boden hervor $[\ldots]$.

Die durchaus beachtliche Anzahl katalogartiger Auflistungen in Sidonius' insgesamt drei Kaiserpanegyriken zeigt, dass er in enkomiastischen Gedichten eine gewisse Wortfülle zwecks Pathossteigerung bewusst anstrebte. ${ }^{25}$ Nun gibt es aber gerade in narrativen Kontexten Situationen, in denen akkumulierende Aufzählungen nicht allein auf emphatische Hervorhebung, sondern zugleich auch auf dynamische Kürze abzielen. ${ }^{26}$ Eine derartige ambivalente Verwendung des versefüllenden Asyndetons lässt sich innerhalb der laus sponsae, der topischen Lobrede auf die Braut, festmachen, die Sidonius im Hochzeitsgedicht auf Ruricius und Hiberia ausgestaltet hat: Die Schönheit der Braut komme, so stellt der Dichter nicht ohne erotischen Unterton fest, der Anmut jener Frauen gleich, denen Jupiter in diversen Gestalten nachgestellt habe:

25 Asyndetische Worthäufungen als Katalog: Sidonius Apollinaris, Carmina 2,239$240 ; 2,395-396 ; 5,207-210 ; 5,336-337 ; 7,74-76 ; 7,80-82 ; 7,323-325 ; 11,17-22$; zu den Satzasyndeta in katalogartiger Aufzählung vgl. weiter unten Anm. 51.

26 In der Gerichtsrede ist dieses Verfahren relativ häufig, für ein Beispiel vgl. oben Anm. 6; in der Dichtung zeigt es sich etwa in den Tragödien Senecas, besonders in Form affektierter Aufforderungen oder raffender Berichte, z. B. Medea 269: egredere, purga regna, letales simul / tecum aufer herbas, libera cives metu ‘Geh weg, reinige mein Königreich, nimm deine todbringenden Kräuter mit, befreie die Bürger von ihrer Angst ; Phoenissae 340-346; Hercules Oetaeus 247-249. Weitere Stellen bietet Canter (1925), S. 170. 
nec minus haec species totiens cui Iuppiter esset

Delia, taurus, olor, Satyrus, draco, fulmen et aurum.

Quare age, iungantur; nam census, forma genusque

conveniunt $[\ldots]$.

(Sidonius Apollinaris, Carmina 11,89-92)

〈Die Schönheit jener Frauen besitzt sie, für die sich Jupiter so oft verwandelte in die delische Göttin, den Stier, den Schwan, den Satyr, die Schlange, den Blitz und das Gold. Deshalb auf denn! Mögen sie vermählt werden! Denn Wohlstand, Schönheit und Herkunft stimmen überein [...].)

Ein einziger Vers genügt, um dem Publikum die siebenfache Verwandlung Jupiters und seine Verbindung mit Cynosura, Europa, Leda, Antiope, Mnemosyne, Semele und Danaë in Erinnerung zu rufen. Verständlich ist dies nur, wenn die Rezipienten sich die dahinterstehenden Erzählungen, etwa aus Ovids Metamorphosen oder einem mythographischen Handbuch, in Erinnerung rufen. Dasselbe gilt für den vorausgehenden Katalog der um Hiberia werbenden mythischen Heroen. ${ }^{27}$ Die beim Leser vorausgesetzte Verfügbarkeit des klassischen Literaturkanons ermöglicht es dem Dichter, die evozierten Erzählkomplexe schlagwortartig in konziser Kürze abzuhandeln, ohne dadurch wortkarg oder kraftlos zu wirken, denn die asyndetische Häufung gewährleistet zugleich, dass der Katalog nicht ohne den Eindruck von Fülle und Pathos ausklingt. Diese Technik scheint sich bewährt zu haben, sie kehrt im zweiten Epithalamium wieder, und zwar gleich mehrfach, einmal erneut anhand der erotischen Abenteuer Jupiters und einmal anhand der Taten des Herkules. ${ }^{28}$

27 Carm. 11,86-88: Te quoque multimodis ambisset, Hibernia, ludis, / axe Pelops, cursu Hippomenes luctaque Achelous, / Aeneas bellis spectatus, Gorgone Perseus. «Auch dich, Hiberia, hätten in vielfältigem Spiel umworben Pelops mit seinem Rennwagen, Hippomenes durch seine Laufkraft und durch seine Faustkampftechnik Achelos, durch Kriegserfahrung Aeneas, mit dem Gorgonenhaupt Perseus.)

28 In ähnlicher Weise behandelt Sidonius die Taten des Herkules auch in Carmina 9,94-100 (s. dazu weiter unten); 13,11-12: taurus, cerva, Gigas, hospes, luctator, Amazon, / Cres, canis, Hesperides sint monimenta viri. «Der Stier, die Hirschkuh, der Riese, der Gastfreund, der Ringer, die Amazone, der Kreter, der Hund, die Hesperiden bezeugen die Tatkraft des Helden.> Zum Herkules-Mythos im poetischen Werk des Sidonius vgl. Prete (1984). 
Iamque Iovem in formas mutat quibus ille tenere

Mnemosynam, Europam, Semelen, Ledam, Cynosuram serpens, bos, fulmen, cygnus, Dictynna solebat.

(Sidonius Apollinaris, Carmina 15,174-176)

«Und schon verwandelt sie [die Webende] Jupiter in jene Formen, in denen er sich Mnemosyne, Europa, Semele, Leda, Cynosura als Schlange, Stier, Blitz, Schwan, Dictynna zu bemächtigen pflegte.>

Praeterea sparsis sunt haec subiecta figuris:

sus, leo, cerva, Gigans, taurus, iuga, Cerberus, hydra,

hospes, Nessus, Eryx, volucres, Thrax, Cacus, Amazon,

Cres, fluvius, Libs, poma, Lycus, virgo, polus, Oete.

(Sidonius Apollinaris, Carmina 15,140-143)

〈Abgebildet waren ferner, bunt über das Gewebe verteilt: der Eber, der Löwe, die Hirschkuh, der Riese, der Stier, der Hügel, Cerberus, die Hydra, der Gastfreund, Nessus, Eryx, die Vögel, der Thraker, Cacus, die Amazone, der Kreter, der Fluss, der Libyer, die Äpfel, der Lyker, die Jungfrau, das Himmelsgewölbe, Oeta.>

Bemerkenswert ist hier, dass Sidonius in beiden Passagen einen Bilderzyklus wiedergibt, der auf einem Gewebe abgebildet ist. Die dem Medium des gewobenen Stoffes eigene bildhaft-sequenzielle Erzählform wird im Gedicht durch das versefüllende Asyndeton gleichsam spiegelbildlich abgebildet; jedes Wort steht emblematisch für eine Tat beziehungsweise eine Metamorphose. Wie die Abbildungen im Bilderzyklus enthalten beide Passagen jeweils nur den Nukleus jener Erzählungen, die im Medium des Textes normalerweise in epischer Breite ausgeführt werden. Diese maximale Verdichtung des Stoffes, hier in der narrativen Form der percursio, ist poetisch virtuos ausgeführt: In der Jupiter-Sequenz enthält der erste Vers den Katalog der Frauen, die der Olympier verführte, der zweite Vers die Gestalt, in der er dies jeweils tat. ${ }^{29}$ Neben der technischen Kunstfertigkeit, dies in eine adäquate

29 Auffallende Ähnlichkeit zeigt ein Gedicht der Anthologia Palatina (IX,48): Zev̀ৎ

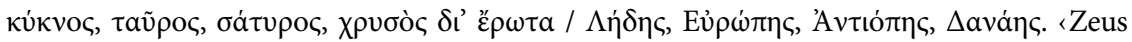
wurde Schwan, Stier, Satyr, Gold wegen Leda, Europa, Antiope, Danae.> Das virtuose metrische Schema ist bei Sidonius rekurrent, vgl. Carmina 2,171-172: quidquid Pythagoras, Democritus, Heraclitus, / deflevit, risit, tacuit [...] «worüber Pythagoras, Demokrit, Heraklit weinte, lachte, schwieg`; 7,79-83: [...] cum per mea iussa iuberent / Sulla, Asiatoge- 
metrische Form zu bringen, kommen hier wirkungsästhetische Aspekte ins Spiel, die für die spätantike Literatur und bildende Kunst generell als charakteristisch gelten dürfen: Die in den zitierten Passagen fassbare mosaikhaft-ornamentale Artistik und den auf das Episodische fokussierten Erzählmodus fasst die jüngere Forschung unter dem Schlagwort des «Juwelenstils» zusammen, eine Ausdrucksform, die von den Rezipienten nicht nur erhöhte Aufmerksamkeit und Konzentration einfordert, sondern auch die Bereitschaft einschließt, aktiv an der Sinngenese zu partizipieren. ${ }^{30}$ Die Verdunkelung des sprachlichen Ausdrucks ist dabei ein erstrebtes Nebenprodukt, das den Exklusivitätsanspruch dieser Literatur zusätzlich unterstreicht. ${ }^{31}$ In der zitierten Herkules-Sequenz sind von den dreiundzwanzig aufgerufenen Taten des Herkules einige Referenzen unklar oder mehrdeutig. ${ }^{32}$ Die durch die Kürze bedingte Ambiguität der Referenz ist im versefüllenden Asyndeton generell erhöht. Sie hat, wie noch auszuführen sein wird, als natürliche und notwendige Grundlage den Kanon.

Spätestens in den letztgenannten Beispielen wird ersichtlich, wie schief Curtius' Deutungsparadigma des formalen Manierismus gegenüber dem hochkomplexen spätantiken Kunstempfinden zu stehen kommt, das neben seiner unverkennbaren Neigung zum 〈barocken Bombast) (als Suggestion quantitativer Fülle) gerade im Kleinen, Verkürzten und Partikulären höchsten Gestaltungswillen entfaltete. ${ }^{33}$

nes, Curius, Paulus, Pompeius / Tigrani, Antiocho, Pyrrho, Persae, Mithridati / pacem ac regna, fugam, vectigal, vincla, venenum sals auf mein Geheiß hin Sulla, Asiaticus, Curius, Paulus, Pompeius von Tigranes, Antiochus, Pyrrhus, Perseus, Mithridates Frieden und Herrschaft, Flucht, Steuern, Ketten, Gift einforderten'; 11,17-19: hic lapis est de quinque locis dans quinque colores: Aethiops, Phrygius, Parius, Poenus, Lacedaemon, / purpureus, viridis, maculosus, eburnus et albus «Marmor aus fünf Regionen findet sich hier leuchtend in fünf Farben: äthiopischer, phrygischer, parischer, punischer, spartanischer - purpurn, grünlich, gefleckt, elfenbeinern, weiß); 23,46-47; 23,300-303. Vgl. weiter unten Anm. 36. 30 Roberts (1989).

31 Vgl. Schwitter (2015).

32 Z. B. Gigans 〈Riese`: Typhoeus; iuga 〈Joch〉, poetisch 〈Hügel`: die Säulen des Herkules; Libs «der Libyer $:$ Antaios.

33 Zur Ästhetik der Kleinform in der Spätantike vgl. zusammenfassend Schwitter (2015), S. 141-148; literarische Kleinformen wie Brief, Epigramm oder Cento florierten, vgl. dazu Formisano / Sogno (2010), und auch in Großformen überwog häufig das Episo- 
Die bemerkenswerte Ambivalenz des hier in Rede stehenden poetischen Gestaltungsmittels liegt in seiner Vereinnahmung gegenläufiger Textstrategien, indem es die Erzählung hinsichtlich des zu bewältigenden Stoffes beschleunigt, in formaler Hinsicht den Leseprozess aber durch Aufschwellung retardiert. Ein anschauliches Beispiel dieses Verfahrens findet sich in Sidonius' Eucharisticon an den Bischof Faustus von Riez:

quique etiam poenas suscepta in carne tulisti,

sustentans alapas, ludibria, verbera, vepres,

sortem, vincla, crucem, clavos, fel, missile, acetum,

postremo mortem, sed surrecturus, adisti.

(Sidonius Apollinaris, Carmina 16,47-50)

«Der Du im Körper, den Du angenommen hast, Qualen ertrugst, indem Du Ohrfeigen, Spott, Schläge, Dornen, den Wurf des Loses, Ketten, Kreuz, Nägel, Galle, Speer, Essig und schließlich den Tod auf Dich nahmst, um wieder aufzuerstehen.)

Die Leiden Christi werden in zweieinhalb Versen anhand von zwölf Begriffen bildhaft verdichtet, sein Martyrium in höchstem Tempo etappenweise nacherzählt. Trotz dieser Akzelerierung hemmt die aufschwellende Worthäufung die sich in der Kürze entfaltende Dynamik und bewirkt dadurch eine pathetische Steigerung des Inhalts. Christus' Leidensweg wird für die Leser in seiner Dauer wie Intensität gleichsam erfahr- und erfassbar.

\section{III.2. Anwendungs- und Wirkungsweisen von asv ${ }^{x}$ in der epigrammatischen Dichtung der lateinischen Spätantike}

Es liegt nahe, dass ein derartiger Erzählmodus, der Kürze mit Emphase verbindet, auch im Gedichttyp des Epigramms Anwendung fand, wo aufgrund des restringierten Schriftraums auf die Verhältnismäßigkeit zwischen Informationswert und sprachlichem Aufwand geachtet werden muss. ${ }^{34}$ Mit

dische, vgl. u. a. zu Claudian Cameron (1970), S. 264-266; zu Ammianus Marcellinus Roberts (1988), S. 181-195, und Wittchow (2001); zu Prudentius Ludwig (1977). Analogien ergeben sich mit den bildenden Künsten, insbesondere mit Architektur, Malerei und Plastik, vgl. dazu Hernández Lobato (2012).

34 Vgl. z. B. die asyndetische Raffung in einem hexametrischen Fünfzeiler des Ennodius, Carmina 2,25,5 (ed. Vogel [1885], S. 136): vivit amor, taurus, mulier sine corpore vero. 
Blick auf das versefüllende Asyndeton kann hier zwischen einer pragmatischen und einer literarisch-imitierenden Spielart unterschieden werden. Pragmatisch meint die notwendige Rücksichtnahme auf die Materialgebundenheit einer Inschrift, meist den Stein, der dem Text nur begrenzte Entfaltung erlaubt. Literarisch-imitierend meint die künstliche Befolgung dieser Restriktion im Kontext der Buchdichtung. Ein schönes spätlateinisches Beispiel für die literarisch-imitierende Variante ist das sogenannte Epitaph auf den Dichter Vergil: Pastor, arator, eques, pavi, colui, superavi, / capras, rus, hostes, fronde, ligone, manu (‘Als Hirt, Pflüger, Reiter, habe ich geweidet, bebaut, besiegt die Ziegen, das Land, die Feinde, mit Laub, mit der Hacke, mit der Hand)). ${ }^{35}$ Vergils Leben, hier gleichgesetzt mit seinem poetischen Cuvre, wird in prägnanter Kürze und in poetisch virtuoser Form zu zwei Versen verdichtet, indem drei viergliedrige und grammatisch identische Sätze aufgelöst und neu arrangiert wurden. ${ }^{36}$ Das Epigramm macht den Eindruck eines Merkverses mit kurzgefasster Inhaltsangabe. ${ }^{37}$ Die Paraphrase der drei Werke Vergils in der Reihenfolge ihrer Entstehung ist dabei auf das reduziert, was sie thematisch bestimmt, nämlich Hirtendichtung, Ackerbau und Kriegswesen.

Anthologia Latina I.2 (ed. Riese [1906]), Nr. 800. Dieselbe Technik, jedoch nicht als Paraphrase, zeigt Anthologia Latina I,1 (ed. Shackleton Bailey [1982]), Nr. 387: Cervus, aper, coluber non cursu, dente, veneno / vitarunt ictus, Maioriane, tuos «Der Hirsch, der Eber, die Schlange, Maiorian, entgingen deinem Schuss nicht mit Lauf, Zahn, Gift . Auf das Epigramm spielt Sidonius Apollinaris in seiner Bittschrift auf Majorian an: Carmina 13,17-18: quem [sc. Majorian] draco, cervus, aper paribus sensere sagittis, / cum dens, cum virus, cum fuga nil valuit ihn, dessen Pfeile die Schlange, der Hirsch, der Eber in gleicher Weise spürten, als Zahn, Gift, Flucht nichts halfen '; so schon im Panegyrikus auf diesen Kaiser: Carmina 5,153-54: [...] tribus hunc tremuere sagittis / anguis, cervus, aper ‘wegen seiner drei Pfeile zitterten vor ihm die Schlange, der Hirsch, der Eber».

36 Das dadurch erzeugte Zeugma bezeichnete die Poetik des Mittelalters als versus rapportati, vgl. Curtius ( $\left.{ }^{3} 1963\right)$, S. 290. Die aufgelöste Satzfolge lautet: pastor pavi capras fronde, arator colui rus ligone, eques superavi hostes manu.

37 Zur Tradition der im Schulkontext anzusiedelnden metrischen argumenta der Spätantike vgl. Friedlein (2002), S. 185-191, mit weiterführender Literatur. 
Kaum weniger virtuos ist ein Epigramm, das der mutmaßlich aus Afrika stammende Dichter Pentadius dem Narcissus-Mythos gewidmet hat. ${ }^{38}$ Die fünf Distichen sind - passend zum Thema - sogenannte «Echoverse», ${ }^{39}$ folgen also dem Prinzip der Epanalepse, wobei der erste Teil des Hexameters (bis zur Penthemimeres) als zweiter Teil des Pentameters wiederkehrt:40

Cui pater amnis erat, fontes puer ille colebat laudabatque undas, cui pater amnis erat.

Se puer ipse videt, patrem dum quaerit in amne, perspicuoque lacu se puer ipse videt.

Quod Dryas igne calet, puer hunc inridet amorem nec putat esse decus, quod Dryas igne calet.

Stat, stupet, haeret, amat, rogat, innuit, aspicit, ardet, blanditur, queritur, stat, stupet, haeret, amat.

Quodque amat ipse facit vultu, prece, lumine, fletu; oscula dat fonti, quodque amat ipse facit.

(Pentadius, $<$ De Narcisso $>=$ Anth. Lat. I.1, ed. Shackleton Bailey [1982],

Nr. 259)

38 Die Salmasianische Anthologie überliefert unter dem Namen des Pentadius mehrere Gedichte; über seine Datierung herrscht Unklarheit, vgl. die Diskussion bei Paolucci (2016), S. 1-16.

39 Versus echoici, vgl. Sidonius Apollinaris, Epistulae 8,11,5: faciebat [sc. Lampridius] siquidem versus oppido exactos tam pedum mira quam figurarum varietate: [...] hexametros crepantes et cothurnatos, elegos vero nunc echoicos, nunc recurrentes, nunc per anadiplosin fine principiisque conexos. «Er verfasste nämlich vollendete Gedichte, bewundernwert sowohl durch die Vielfalt der Metren als auch der Figuren: [...] klangvolle und erhabene Hexameter, elegische Verse bald mit Echowirkung, bald rückläufig, bald durch Anadiplose Anfang und Ende verbindend.)

40 Das Vorbild ist hier Ovid, Amores 1,9,1-2: militat omnis amans et habet sua castra Cupido, / Attice, crede mihi, militat omnis amans. 〈Jeder Liebende ist ein Soldat und sein eigenes Feldlager hat Cupido; glaube mir, Atticus, jeder Liebende ist ein Soldat ; ferner Amores 3,2,27-28; Heroides 5,117-118; Remedia amoris 71-72; zur Epanalepse vgl. Paolucci (2016), S. 17-27. Die Salmasianische Anthologie enthält an anderer Stelle eine Sammlung epanaleptischer Distichen (I,1, ed. Shackleton Bailey [1982] Nr. 25-68), darunter auch zum Narcissus-Mythos (Nr. 26): Dum putat esse parem vitreis Narcissus in undis, / solus amore perit, dum putat esse parem. «Als Narcissus glaubte, einen Gleichen im klaren Wasser zu haben, ging er aus Liebe einsam zugrunde, als er glaube, einen Gleichen im klaren Wasser zu haben.> 
«Sein Vater war ein Flussgott, es verehrte der Knabe die Quellen, er pries das fließende Nass, sein Vater war ein Flussgott.

Sich selbst erblickte der Knabe, als er nach dem Vater suchte im Wasser, in der klaren Quelle sich selbst erblickte der Knabe.

Weil eine Dryade in Liebesglut entflammte, verspottete der Knabe die Liebende, hielt sie nicht für schön, weil eine Dryade in Liebesglut entflammte.

Still steht er da, hängt fest, verliebt sich, fragt, gibt Zeichen, schaut hin, glüht, schmeichelt, klagt an, still steht er da, hängt fest, verliebt sich.

Und was er liebt, kommt von ihm selbst: Gesicht, Bitten, Augen, Flehen;

Küsse gibt er dem Wasser; was er liebt, kommt von ihm selbst.)

Thematisiert wird hier nicht etwa die Aitiologie der Narzisse oder die Tragik unerwiderter Liebe, sondern der kalte Hochmut des schönen Jünglings, der die in ihn verliebte Nymphe Echo verspottet, um dann selbst unvermutet in unglücklicher Liebe zu entflammen. Der Handlungsumschwung vollzieht sich anhand des versefüllenden Asyndetons (vv. 7-8): Die jähe Verbalreihung diversifiziert und dynamisiert die Handlung und versinnbildlicht zugleich den Kontrollverlust des Liebenden. Die Virtuosität der Komposition wird durch Alliteration in den ersten und letzten beiden Wörtern des Hexameters (stat, stupet - aspicit, ardet) sowie durch semantische Adversativstellung zu Beginn des Pentameters (blanditur, queritur) zusätzlich verstärkt. Parallel zu dieser vereindringlichenden formalen Amplifikation findet auf der Ebene der Erzählung eine Verdichtung statt. Inhaltlich stellt der beschriebene Handlungsablauf des Distichons eine raffende Nacherzählung der ovidischen Mythenversion dar, zu der das Epigramm ohnehin starke intertextuelle Bezüge aufweist: ${ }^{41}$

Ovid, Metamorphosen 3,412-467

Hic puer et studio venandi lassus et aestu procubuit faciemque loci fontemque secutus, dumque sitim sedare cupit, sitis altera crevit, dumque bibit, visae correptus imagine formae spem sine corpore amat, corpus putat esse, quod umbra est. Adstupet ipse sibi vultuque inmotus eodem haeret ut e Pario formatum marmore signum.
Pentadius, Narcissus 7-10

stat

415

amat

stupet, vultu

haeret

41 So nimmt etwa in Vers 5 igne calet «sie brennt in Liebesglut Ovids flamma calescit (v. 372) auf. 
Spectat humi positus geminum, sua lumina, sidus et dignos Baccho, dignos et Apolline crines inpubesque genas et eburnea colla decusque oris $[\ldots]$

Dumque petit, petitur, pariterque accendit et ardet. Inrita fallaci quotiens dedit oscula fonti, in mediis quotiens visum captantia collum bracchia mersit aquis nec se deprendit in illis! [...] Spectat inexpleto mendacem lumine formam perque oculos perit ipse suos paulumque levatus ad circumstantes tendens sua bracchia silvas «Ecquis, io silvae, crudelius» inquit «amavit? Scitis enim et multis latebra opportuna fuistis.

[...]

Nam quotiens liquidis porreximus oscula lymphis, hic totiens ad me resupino nititur ore.

posse putes tangi: minimum est, quod amantibus obstat.

Quisquis es, huc exi! quid me, puer unice, fallis

quove petitus abis? Certe nec forma nec aetas

est mea, quam fugias, et amarunt me quoque nymphae!

[...]

Quid faciam? roger anne rogem? quid deinde rogabo?

Quod cupio mecum est: inopem me copia fecit.

O utinam a nostro secedere corpore possem! [...]» aspicit

ardet

oscula dat fonti

lumine

440

rogat

blanditur, prece

455

465

«Hier legte sich der Knabe nieder, erschöpft von der Jagd und der Hitze, dem Anmut des Ortes und der Quelle folgend. Und als er seinen Durst zu stillen trachtete, regte sich in ihm ein anderer Durst. Und als er trank, ergriff ihn das Bild der Schönheit, die er sah, und er liebte eine körperlose Hoffnung, im Glauben, es sei ein Körper, was nur Abbild war. Während er sich selbst bewunderte, verharrte er still mit unbeweglicher Miene wie eine Statue aus parischem Marmor. Auf dem Boden liegend, betrachtete er seine Augen - zwei leuchtende Sterne -, seine Haare, eines Bacchus und Apollo würdig, die zarten Wangen, den schneeweißen Hals und die Zierde seines Gesichts [...]. Und als er begehrte, wurde er selbst begehrt, und zugleich entzündete er Liebesglut und entflammte selbst in ihr. Wie oft gab er vergebliche Küsse dem täuschenden Quellwasser, wie oft tauchte er seine Arme ins Wasser, um nach dem Hals, den er sah, zu greifen, doch bekam er sich selbst nicht zu fassen. [...] Mit unersättlichem Blick betrachtete er die trügerische Schönheit, und an seinen eigenen Augen ging er zugrunde. Er erhob sich ein wenig, streckte 
seine Arme zu den umstehenden Bäumen und sprach: «Hat schon jemals, o ihr Wälder, jemand quälenderes Liebesleid erlitten? Ihr kennt euch doch aus, wart ihr doch schon für viele geeignetes Versteck. [...] Denn sooft ich mich zum Kuss dem Wasser nähere, streckt er sich mir mit dem Gesicht entgegen. Man könnte glauben, ich berühre ihn. Nur ganz wenig steht den Liebenden im Weg. Wer immer du bist, tritt heraus! Weshalb täuschest du mich, einzigartiger Knabe, und wohin gehst du, Begehrter? Gewiss fliehst du nicht vor meinem Aussehen noch meinem Alter, selbst Nymphen waren in mich verliebt! [...] Was soll ich bloß tun? Gebeten werden oder selbst bitten? Worum soll ich dann bitten? Was ich begehre, ist bei mir: Arm hat mich mein Reichtum gemacht. O, könnte ich mich doch von meinem Körper befreien! [...]»>

Die Aufrufung der literarischen Vorlage ist in diesem Fall zwar durchaus intendiert, für das unmittelbare Verständnis des Gedichts aber nicht notwendig - im Gegensatz zur oben zitierten Passage aus Sidonius' Eucharisticon, wo die einzelnen Stationen im Leidensweg Christi ohne Kenntnis der Passion unklar bleiben müssen. Auch hier ist die Anwendungsweise des Stilmittels also ambivalent, changiert das versefüllende Asyndeton zwischen formaler Amplifikation und inhaltlicher Abbreviation.

Die abbreviierend-verdichtende Funktion des versefüllenden Asyndetons lässt sich in der pragmatischen Spielart des Epigramms, etwa in metrischen Grabepitaphien auf Stein, nur vereinzelt nachweisen. Narrative Verdichtung ist in Inschriften, denen ein realweltlicher Anlass zugrunde liegt, auch kaum zu erwarten. Der Bezug zum literarischen Kanon ist, falls überhaupt vorhanden, auf die formal-stilistische Ebene, das heißt auf Junkturen und poetische Wendungen, beschränkt. ${ }^{42}$ Es liegt also kein Referenztext vor, der inhaltlich verkürzt und verdichtet werden müsste. Eine infolge der materialen Gebundenheit notwendige, den Inhalt raffende Funktion besitzt das versefüllende Asyndeton im Epigramm auf einem Grabstein aus der Mitte des 4. Jahrhunderts n. Chr.:

Eheu quos fletus retinet crudele sepulcrum.

Da lector lacrumas et duro flectere casu.

Hic est Simplicius nam funere mersus acerbo

42 Zum Einfluss der klassischen römischen Dichtung auf die Carmina Latina Epigraphica (im Folgenden CLE) vgl. u. a. Lissberger (1934); Hoogma (1959); Cugusi (1982); Cugusi (2007). 
indole sublimis, morum gravitate colendus, praeclarus studiis, primis deceptus in annis. (Carmina Latina Epigraphica 649, ed. Bücheler [1895], Anth.Lat. II.1 = CIL IX 5012)

‘O weh, welche Klageworte hält hier das grausame Grab zurück. Leser, vergieß Tränen und sei gerührt ob des harten Schicksalsschlages: Hier ruht Simplicius vom bitteren Tod verschlungen, hochbegabt, von bewundernswertem Charakter, für seine Gelehrsamkeit bekannt, in frühen Jahren dahingerafft.>

Nach der konventionellen Klageaufforderung an den am Grabmal vorbeischreitenden Leser werden einzelne positive Charakteristika des Verstorbenen kursorisch in Form eines Wortgruppenasyndetons angesprochen: seine Begabung, sein Charakter, seine Gelehrsamkeit sowie sein vorzeitiger Tod. Auch in Grabepitaphien aus der Kaiserzeit ist das versefüllende Asyndeton als Stilmittel bezeugt, meistens in Form einer katalogartigen Aufzählung der topischen Tugendhaftigkeit der verstorbenen Person. Asyndetische Worthäufung dient hier also in erster Linie der aufschwellenden Pathossteigerung, indem auf engstem Raum der Eindruck unerschöpflicher Fülle erzeugt wird. Zur Verdeutlichung seien drei Epitaphien zitiert: ${ }^{43}$

43 Weitere Beispiele des versefüllenden Asyndetons auf Grabepitaphien sind CEL 69,1 (= CIL IX 5557): parentibus praesidium, amiceis gaudium «den Eltern Hilfe, den Freunden Freude> ( asv $\left.^{2}\right)$; CEL 465,4 (= CIL XII 533): integer, innocuus semper, pia mente probatus «rein, stets unbescholten, von bewährter Rechtschaffenheit); CEL 548,4 (=CIL VI 12853): sobria, non moecha, simplex animoque benigno <enthaltsam, keusch, genügsam und mit einem guten Herzen ; CEL 584,1 (= CIL XI 3194): ingenio, virtute, modo, doctrina, decore ‘von gutem Charakter, tugendsam, massvoll, gelehrt, würdevoll`. In Prosa findet sich natürlich dasselbe Verfahren, z. B. Hermann Dessau, Inscriptiones Latinae Selectae II.2, Berlin ${ }^{2}$ 1955, Nr. 8444: Postumia Matronilla inconparabilis coniux, mater bona, avia, piissima, pudica, religiosa, laboriosa, frugi, efficaxs, vigilans, sollicita, univira, unicu$b a$, totius industriae et fidei matrona, vixit annis $n$. LIII mensibus $n$.V. diebus tribus 〈Postumia Matronilla, unvergleichliche Ehefrau, gute Mutter, rechtschaffen, enthaltsam, gottesfürchtig, fleißig, sparsam, tatkräftig, wachsam, umsorgend, nur einmal verheiratet, nur einmal vermählt, emsige und vertrauenswürdige Hausherrin, lebte 53 Jahre, 5 Monate, 3 Tages. 
Dis Manibus sacrum. Liviae Honoratae

fideli, simplici, religiosae, piae,

qualis nec fuit nec esse potest, monimentum

statuit maritus dono memoris gratia.

(Carmina Latina Epigraphica 158, ed. Bücheler [1895], Anth.Lat. II.1 = CIL VIII suppl. 14379)

«Den Manen geweiht. Der Livia Honorata, der treuen, genügsamen, gottesfürchtigen, rechtschaffenen, welche sie weder war noch sein kann, ein Denkmal hat ihr der Ehemann zur Erinnerung gesetzt.>

Pius et sanctus vixi quam diu potui

sine lite, sine rixa, sine controversiis, sine aere alieno,

amicis fidem bonam praestiti,

peculio pauper, animo diutissimus.

Bene valeat is qui hoc titulum perlegit meum.

(Carmina Latina Epigraphica 134, ed. Bücheler [1895], Anth.Lat. II.1 = CIL VI 8012)

«Rechtschaffen und rein lebte ich, solange ich konnte ohne Streit, ohne Zank, ohne Widerspruch, ohne Schulden, den Freunden schenkte ich Vertrauen, an Geld war ich arm, im Herzen überaus reich. Sei gegrüßt, wer diese meine Inschrift liest.>

Hic sita est Amymone Marci optima et pulcherrima, lanifica, pia, pudica, frugi, casta, domiseda.

(Carmina Latina Epigraphica 237, ed. Bücheler [1895], Anth.Lat. II.1 = CIL VI $11602)$

«Hier ruht Amymone, die Tochter des Marcus, die beste und schönste, Wolle spinnend, rechtschaffen, enthaltsam, ehrlich, keusch, häuslich.>

Das letzte Gedicht auf Amymone, die Tochter des Marcus, besteht aus zwei trochäischen Septenaren und befindet sich auf einem Sarkophag aus der Zeit Kaiser Hadrians (reg. 117-138 n. Chr.). Das Asyndeton im zweiten Vers stellt eine pleonastische Erweiterung klassischer Inschriftenformeln auf die tüchtige römische Ehefrau dar.44 Zweihundert Jahre später hat Sidonius

44 CIL I ${ }^{2} 1211$ (2. Jahrhundert v. Chr.): domum servavit, lanam fecit. «Sie behütete das Haus, spann Wolle»; CIL VI 10230,27-29; die spinnende Hausfrau als Sinnbild weiblicher 
Apollinaris denselben Kunstgriff zur ehrenden Amplifikation einer Verstorbenen angewandt:

Occasu celeri feroque raptam gnatis quinque patrique coniugique hoc flentis patriae manus locarunt matronam Philomathiam sepulchro. O splendor generis, decus mariti, prudens, casta, decens, severa, dulcis atque ipsis senioribus sequenda, discordantia quae solent putari morum commoditate copulasti: [...]. (Sidonius Apollinaris, Epistulae 2,8,3 vv. 1-9)

`Vom grausamen Tod den fünf Kindern und dem Vater und dem Gatten unversehens entrissen, liegt hier von den Händen der trauernden Heimat beigesetzt die Hausherrin Philomathia. Schmuck warst du deines Geschlechts, deines Mannes, klug, keusch, würdevoll, ernsthaft, heiter, und was selbst bei den Alten als erstrebenswert galt, was man aber für unvereinbar hielt, hast du harmonisch in dir vereint: $[\ldots] .>$

Das metrische Elogium ist einem Brief beigelegt, in welchem Sidonius dem Adressaten vom Tod einer befreundeten Aristokratin berichtet. Auf Bitten ihres Vaters habe er die beiliegende Inschrift für die Marmorplatte des Grabes verfasst. Die beachtliche Länge des Gedichts in fünfzehn Hendecasyllabi gibt dem Leser einen Eindruck von der Größe des Grabmals und dem Reichtum der Familie.

\section{Den Kanon verdichten - Das asv ${ }^{\mathrm{x}}$ als Gestaltungsmittel der spätantiken Katalogdichtung}

Eine gängige Erscheinungsform der ausgedehnten Reihung koordinierter Glieder ist wie oben festgestellt der Katalog. Auf dem Spektrum der Erscheinungsvarianten stellt die asyndetische Einzelwortreihe, etwa in Form einer

Tugend ist ein Motiv der römischen Elegie, vgl. Ovid, Epistulae 1,77-78; Fasti 2,741-743; Tibull, Carmina 1,3,83-88; zum soziohistorischen Hintergrund vgl. u. a. Lovén (1998). 
detaillierten Namensliste, die Minimalform einer Katalogisierung dar. ${ }^{45}$ In der Antike gehörten Listen und Kataloge seit Beginn der literarischen Tradition zu den poetischen Techniken der Wissensbewältigung: Als faktischer Ausweis der Realienkompetenz des Dichters bildeten sie sich besonders in der heroischen und didaktischen Epik zu einem festen Erzählelement aus, ${ }^{46}$ übernahmen aber auch in anderen Gattungen, etwa in Elegie und Epigramm, eine gestalterische und wissensvermittelnde Funktion, was mitunter, etwa im Falle der hellenistischen 〈Katalogelegie〉, auch zu einer formalen Verselbständigung führte. ${ }^{47}$ Ihre wohl prägnanteste spätantike Wiederbelebung fand die Tradition der hellenistischen Katalogpoesie im Werk des Ausonius. In mehreren Kurzgedichtzyklen werden listenartig variable Gegenstände abgehandelt, in den Caesares die Biographie der römischen Kaiser von Caesar bis Elagabal, im Ordo urbium nobilium die bedeutendsten Städte des römischen Reiches, in den Epitaphia heroum qui bello Troico interfuerunt die Elogien ebendieser Helden. Dabei präsentieren diese Werke das Schulwissen der spätantiken Rhetorikschule in metrisch verdichteter Form, ohne aber pauschal auf die scholastische «Merkdichtung〉 zurückzufallen. ${ }^{48}$ Aufgrund der formal hochelaborierten Wissensverdichtung sind asyndetische Wortreihungen kein bevorzugtes Gestaltungsmittel von Ausonius; dies gilt erst recht für seine virtuosen Technopaignia, in denen er seine technische Kunstfertigkeit anhand zuvor festgelegter Spielregeln im

45 Am anderen Ende steht die Reihung abgeschlossener Erzählungen, vgl. Asper (1998), Sp. 915-916.

46 Dazu allgemein Gassner (1972), Kühlmann (1973), Reitz (2017), zu Homer Visser (1997).

47 Zur hellenistischen Katalogdichtung etwa Gärtner (2008), zu Ovids Exildichtung Bernhard (1986).

48 Dies zeigt sich besonders in der Commemoratio professorum Burdigalensium, einem Katalog der ehemals in Bordeaux lehrenden Grammatik- und Rhetorikprofessoren, die wie bei den Parentalia neben autobiographischen und lokalpatriotischen Elementen die Nähe zur Memorialliteratur sucht. Der Lehrdichtung nahe stehen einzelne Stücke seiner Eclogae, in denen kalendarisches und astronomisches Wissen (z. B. die Tage der Woche oder die Jahreszeiten) listenartig abgehandelt werden. 
Versbau zur Schau stellt. ${ }^{49}$ Charakteristisch für diese monostichischen Kurzgedichte ist indes die asyndetische Hauptsatzreihe, die sich auch in entsprechenden Kataloggedichten in der Anthologia Latina findet..$^{50}$ Bemerkenswert ist, dass auch in der Mosella, mit 483 Hexametern Ausonius' umfangreichstes Gedicht, weder in den breit ausgestalteten ekphrastischen Partien noch in den markanten Katalogen, etwa in dem der Fische (vv. 77-149) oder Architekten (vv. 300-320), auf das versefüllende Asyndeton zurückgegriffen wird. Der stellenweise an Vergils laudes Italiae (Georgica 2.136-176) orientierte hymnische, in der Ekphrase aber ruhige und wohltemperierte Ton wäre mit der Vehemenz dieses Stilmittels auch schwer zu vereinbaren gewesen.

Ungleich stärker auf enkomiastisches Pathos bedacht sind dagegen die oben bereits angesprochenen Katalogreihen in den Gedichten des Sidonius Apollinaris. Versefüllende Asyndeta sowie lange anaphorische Beispielreihen mit quid, quidquid oder nunc verleihen der Rede des Dichters nicht nur die gewünschte Emphase, sondern verweisen zugleich auf das unerschöpfliche Wissen, über das er und die von ihm anvisierte Modellleserschaft in gleicher Weise verfügen. ${ }^{51}$ Bei den in diesen Katalogen aufgeführten Wissensbestän-

49 So gibt es in den Technopaignia Stücke, in denen jeder Vers eine Periphrase für einen Einsilbler bildet. Ein Gedicht besteht aus einer Reihe monostichischer Rätselfragen, wobei der Monosyllabon am Ende die Lösung enthält (Ausonius, Technopaignia 13,1-2): Quis subit poenam capitali iudicio? Vas. / Quod si lis fuerit nummaria, quis dabitur, praes. 〈Wer unterzieht sich einer Strafe im Kapitalprozess? Ein Bürge. Was, wenn es ein Vermögensprozess ist, wer wird gegeben? Ein Garant.>

50 Vgl. Ausonius, Eclogae 17, wo die zwölf Taten des Herkules in Monosticha aufgezählt werden. Dasselbe Phänomen zeigt sich etwa in Anthologia Latina I,1 ed. Shackleton Bailey (1982), Nr. 76 u. I,2 ed. Riese (1906), Nr. 664a (die neun Musen in Monosticha). 51 Eindrücklich sind die Kataloge der antiken Philosophen in Carmina 2,156-181 (mit langen, die einzelnen Lehrsätze paraphrasierenden quidquid-Reihen) und der antiken Schriftsteller in Carmina 23,101-169 (mit mehrfachen et tu- und et te-Reihen); vgl. ferner ebd., 16,99-102: qua nunc Helias, nunc te iubet ire Iohannes, / nunc duo Macarii, nunc et Paphnutius heros, / nunc Or, nunc Ammon, nunc Sarmata, nunc Hilarion. «Das ist der Weg, den zu gehen dir bald Elias, bald Johannes, bald die beiden Macarii, bald auch der Held Paphnutius, bald Or, bald Ammon, bald der Sarmate, bald Hilarion auferlegen.; 15,38-41: quid machina caeli, / quid tellus, quid fossa maris, quid turbidus aer, / quid noctis lucisque vices, quid menstrua lunae / incrementa parent. «Was das 
den handelt es sich ausnahmslos um ein Wissen von und über die Antike, das heißt um jene Form von «Bildungswissen`, das sich die spätrömische Oberschicht in der Schule sowie durch fortwährende Lektüre des tradierten Literaturkanons aneignete. ${ }^{52}$ Es ist daher kein Zufall, wenn in diesen Zusammenhängen die praeteritio als eine privilegierte Darstellungsform hervortritt. Die klassische Rhetorik empfiehlt sie unter anderem zwecks Aussparung von Selbstverständlichem und allgemein Bekanntem, um die Zuhörer nicht unnötig zu langweilen. ${ }^{53}$ Den Adressaten wird somit suggeriert, dass ihnen die bei der Lektüre präsentierten Sachinhalte nicht etwa neu zu vermitteln, sondern als bereits verinnerlichtes Wissen im Gedächtnis abgerufen werden können. Als Extremform präsentiert sich hier das Einleitungsgedicht zu Sidonius' carmina minora-Sammlung (carm. 9). Das an programmatischer Position stehende Stück leistet den exordialen Vorgaben nur teilweise Folge: Zwar wird die Dedikation an Felix über einschlägige Schlüsselbegriffe in der Tradition neoterischer Kleindichtung aufgehoben, ${ }^{54}$ doch statt auf dieser poetologischen Basis zu verkünden, welche Themen behandelt werden, folgt in Form einer praeteritio in über dreihundert Hexametern ein gigantischer Katalog von Dingen, die der Dichter nicht ansprechen will. Non nos currimus aggerem vetustum, «nicht einen altbekannten Weg eile ich entlang〉 (v. 16): Der topische Anspruch auf Erstmaligkeit mutiert zu einer ins Unermessliche gesteigerten recusatio, in der die Themen, die Sidonius programmatisch

Himmelsgestirn, was die Erde, was die Tiefen des Meeres, was die stürmische Luft, was die Wechsel von Tag und Nacht, was die monatlichen Phasen des Mondes in Gang setzen'.

52 Zum Bildungshorizont der spätantiken Oberschicht vgl. neben Marrou (1995) und Gemeinhardt (2007) auch Gerth (2013); zur literarischen Bildungskultur und Bildungssprache ferner Schwitter (2015), S. 80-93; zur Persistenz des klassischen Literaturkanons Eigler (2003).

$53 \quad$ Vgl. Lausberg $\left({ }^{3} 1990\right), \S \$ 882-886$.

54 Aufgerufen wird insbesondere Catull, Carmina 1, durch Versmaß (Hendecasyllabi) und einschlägige Themenwörter (nugae, libellus, charta), ebenso Martial, vgl. Sidonius Apollinaris, Carmina 9,4: dic, dic quod peto, Magne, dic, amabo ssag es mir, sag es mir, Magnus, was ich wissen will, sag es mir, ich bitte dich> mit Martial, Carmina 8,76,1: dic verum mihi, Marce, dic amabo «sag mir die Wahrheit, Marcus, sag sie mir, ich bitte dich . Zum neoterischen Programm vgl. Consolino (1974). 
ablehnt, paradoxerweise zum bestimmenden Thema des Einleitungsgedichts und damit zum Referenzpunkt der Sammlung werden. Die Stoffe, die in langen, sprachlich variationsreichen Beispielreihen zurückgewiesen werden (non hic [...], non quod [...], non tu hic nunc legeris), umfassen weite Teile des antik-paganen Bildungskanons, insbesondere jene Bereiche, die traditionell über die Poesie vermittelt werden. ${ }^{55}$ Erst am Ende des Gedichts kommt Sidonius kurz auf die Stücke seiner Sammlung zu sprechen, jedoch nur, um sie als die Erzeugnisse einer ertraglosen Muse (sterilis Camena) abzuqualifizieren, die kaum das Schreibmaterial wert seien, auf das sie geschrieben wurden. ${ }^{56}$ Die komplexe Metapoetik und die paradoxe Rhetorik des Dedikationsgedichts haben in der jüngeren Forschung zu kontroversen Auslegungen geführt, wobei der Katalog als charakteristisches Kompositionsprinzip in der Diskussion jedoch noch nicht genügend berücksichtigt wurde. ${ }^{57}$ Dessen Relevanz lässt sich aber - zunächst auf formalästhetischer Ebene - anhand des versefüllenden Asyndetons verdeutlichen; so kommt es als extreme Anwendungsform der praeteritio im Gedicht gleich mehrfach zum Zuge:

55 Zurückgewiesen werden die Stoffe der historischen und mythologischen Epik (Alexander der Große, die Argonautensage, die Gigantomachie, die Taten des Herkules usw.) und der Lehrepik (über fremde Länder und Völker, über Kulte und Riten usw.) sowie Dichtungen nach Art bestimmter Dichter (Hesiod, Archilochos, Stesichoros, Pindar, Menander, Vergil, Horaz, Statius, Lucan, Catull usw.). Es kommen aber auch Prosaschriftsteller sowie zeitgenössische Autoren zur Sprache (z. B. Carmina 9,302-310).

56 Sidonius Apollinaris, Carmina 9,318-328: nos valde sterilis modos Camenae / rarae credimus hos brevique chartae, / quae scombros merito piperque portet. Die sechzehn Stücke der Sammlung enthalten ausschließlich Gelegenheitsdichtung (Hochzeitsgedichte, Epigramme, poetische Bittschriften und Einladungsschreiben).

57 Auf diese Diskussion soll an dieser Stelle nicht eingegangen werden; es geht einerseits um die Deutung der werkimmanenten Metapoetik, andererseits um die Frage, ob das Gedicht als Ausdruck eines resignierenden Kulturpessimismus, einer poetischen Aphasie oder eher als christliches Gegenprogramm zur antik-paganen Bildung zu lesen ist. Vgl. dazu bes. Consolino (1974), Hernández Lobato (2010) und Hernández Lobato (2012), S. 401-49, Gerbrandy (2013), Schmitzer (2015) und Schlapbach (2020). Das Gestaltungselement des Katalogs nimmt Schindler (2019) anhand des Dichterkatalogs näher in den Blick. 


\section{Sidonius Apollinaris, Carmina 9}

Non hic antipodas salumque rubrum,

Non hic Memnonios canemus Indos,

Aurorae face civica perustos;

non Artaxata, Susa, Bactra, Carrhas,

non coctam Babylona personabo

(vv. 19-23)

«Ich werde hier nicht von den Antipoden und dem roten Meer, nicht von den morgenländischen Indern singen, verbrannt von Auroras heimischer Fackel; ich werde nicht Artaxata, Susa, Baktra, Carrhae, nicht das gebrannte Babylon laut preisen.>

Nec Phlegrae legis ampliata rura, missi dum volitant per astra montes

Pindus, Pelion, Ossa, Olympus, Othrys

cum silvis, gregibus, feris, pruinis,

saxis, fontibus, oppidis levati

(vv. 88-92)

«Noch wirst du hier von Phlegras verbreiterten Feldern lesen, als hochgeschleuderte Berge um die Sterne flogen: Pindus, Pelion, Ossa, Olympus, Othrys erhoben sich mit ihren Wäldern, Herden, Wild, Schneekuppen, Felsen, Quellen, Siedlungen in die Luft.)

Non hic Herculis excolam labores,

cui sus, cerva, leo, Gigas, Amazon,

hospes, taurus, Eryx, aves, Lycus, fur,

Nessus, Libs, iuga, poma, virgo, serpens,

Oete, Thraces equi, boves Hiberae,

luctator fluvius, canis triformis

portatusque polus polum dederunt.

(vv. 94-100)

〈Ich will hier nicht die Arbeiten des Herkules ausbreiten, welchem der Eber, die Hirschkuh, der Löwe, der Riese, die Amazone, der Gastfreund, der Stier, Eryx, die Vögel, Lycus, der Dieb, Nessus, der Libyer, die Hügel, die Äpfel, die Jungfrau, die Schlange, Oete, die thrakischen Pferde, die spanischen Rinder, der ringende Fluss, der dreiköpfige Hund und der auf den Schultern getragene Himmel den Himmel gaben.>

Non divos specialibus faventes

agris, urbibus insulisque canto,

Saturnum Latio Iovemque Cretae 
Iunonemque Samo Rhodoque Solem,

Hennae Persephonen, Minervam Hymetto,

Vulcanum Liparae, Papho Dionen,

Argis Persea, Lampsaco Priapum,

Thebis Euhion Ilioque Vestam,

Thymbrae Delion, Arcadem Lycaeo,

Martem Thracibus ac Scythis Dianam

(vv. 168-177)

«Nicht singe ich von jenen Göttern, die besonderen Fluren, Städten und Inseln geneigt waren: Saturn Latium und Jupiter Kreta und Juno Samos und Sol Rhodos, Henna Persephone, Minerva dem Hymettos, Vulkan Lipari, Paphos Dione, Argos Perseus, Lampsakos Priapus, Theben Euhion, Ilion Vesta, Thymbra Delius, Arkadien Lykaios, Mars den Thrakern und den Skythen Diana.>

Non Gaetulicus hic tibi legetur, non Marsus, Pedo, Silius, Tibullus, [...]

non Turnus, Memor, Ennius, Catullus

(vv. 260-266)

«Nicht von Gaetulicus wirst du hier lesen, nicht von Marsus, Pedo, Silius, Tibull, [...] nicht von Turnus, Memor, Ennius, Catull.>

An den zitierten Stellen werden einschlägige Namen und poetische Themen listenartig abgehandelt. Die erzielte Wirkung ist dabei stets dieselbe: Erreicht wird die maximale Kondensierung der zurückgewiesenen Referenzstoffe und -werke bei gleichzeitiger formaler Aufschwellung mit dem Effekt pathetischer Steigerung, in Kombination mit dem Eindruck absoluter Vollständigkeit der aufgelisteten Wissensbestände. ${ }^{58}$ Die Komposition hat als natürliche und notwendige Grundlage den klassischen Literaturkanon. Erst dessen fundierte Kenntnis, so wird suggeriert, erlaubt dem Rezipienten ein vollumfängliches Verständnis von Sidonius' stupender, durch gelehrten Detailreichtum ausgezeichneter Poesie. Die recusatio wird damit indirekt zum affirmativen Aufweis eines exklusiven Bildungsguts, das sich Autor und Leser gegenseitig stillschweigend zubilligen. Skepsis hinsichtlich der Authentizität dieser routi-

58 So werden bei Herkules nicht nur die zwölf klassischen Taten, sondern auch die unkanonischen Abenteuer aufgeführt; zu letzteren vgl. Brommer (1984). 
nierten Selbstvergewisserungsstrategie mag grundsätzlich angebracht sein, ${ }^{59}$ doch ändert dies nichts an den elementaren Funktionsweisen des durch den Katalog evozierten Kanons: sozial - das heißt innerhalb der gallo-römischen Bildungselite - im Sinne einer gegen außen gerichteten Distinktion und einer gegen innen gerichteten Identifikation, literarisch im Sinne einer formalästhetischen Steigerung mit entsprechender emotionaler Wirkung einerseits und der Rationalisierung des narrativen Modus andererseits. Durch die Festlegung von standardisierten Bedeutungen und Namen kann der Kanon die Kommunikation zwischen Autor und Leser ungemein beschleunigen; wer den Code beherrscht, dem genügt ein einziges Wort, um ganze Assoziationsfelder zu transportieren und komplexe Narrative aufzurufen. Die komprimierte Kürze erzeugt hier also nur bedingt Dunkelheit, das heißt nur dann, wenn der Dichter bewusst semantische Hürden einbaut, über die der gelehrte Leser stolpern soll.

Die aus unterschiedlichen literarischen Kontexten zusammengetragenen Beispiele dürften die eingangs postulierte ambivalente Wirkungsweise des versefüllenden Asyndetons in der spätlateinischen Dichtung hinreichend verdeutlicht haben. Als Stilmittel war asv ${ }^{x}$ funktionell nicht auf den Effekt der aufschwellenden poetischen Amplifikation beschränkt, wie Curtius und Weyman es darstellten; stattdessen konnte die asyndetische Wortreihung als ein rhetorischer Kunstgriff zur Verdichtung und Verkürzung des poetischen Ausdrucks herausgestellt werden, der sowohl in der traditionsorientierten Buchdichtung wie auch in auf prägnante Kürze bedachten epigraphischen Zusammenhängen Verwendung fand. Die bemerkenswerte funktionale Ambivalenz des Stilmittels widerspiegelt dabei schlaglichtartig das komplexe und divergente Spannungsfeld, in dem sich die ablehnende Aneignung des überkommenen Literaturkanons innerhalb der spätantiken Poesie abspielte.

Rijser (2013) erklärt die vielfältigen, ihm oft inkohärent erscheinenden literarischen und mythologischen Referenzen im Sinne der poetics of inclusion als kulturelles Kapital, durch das Sidonius den Rückbezug seiner eigenen Zeit mit der großen römischen Vergangenheit gewährleisten konnte. Seine Analyse der literarischen Kompetenzen und Interessen des gallischen Publikums, das eher am Klingeln bedeutender Namen interessiert war («jingling bells of grand names and stories», ebd., S. 90), statt die Bezüge auch semantisch zu aktualisieren, schießt meiner Meinung nach aber über das Ziel hinaus. 


\section{Bibliographie}

\section{Primärliteratur}

Anthologia Latina I.1 = Carmina in codicibus scripta, hg.v. David R. Shackleton Bailey, Stuttgart 1982.

Anthologia Latina I.2 = Reliquorum librorum carmina, hg.v. Alexander Riese, Leipzig 1906.

Anthologia Palatina = Anthologia Graeca epigrammatum Palatina cum Planudea, 3 Bde., hg.v. Hugo Stadtmueller, Leipzig 1894-1906.

Aristoteles, Rhetorica $=$ Aristoteles, Ars Rhetorica, hg.v. William D. Ross, Oxford 1959. Auctor ad Herennium = Rhétorique à Herennius, hg.v. Guy Achard, Paris 1989.

Ausonius, Eclogae, Technopaignia = Decimi Magni Ausonii Opera, hg.v. R. P. H. Green, Oxford 1999.

Aquila Romanus, De figuris sententiarum et elocutionis $=$ Rhetores Latini minores ex codicibus maximam partem primum adhibitis, hg.v. Carolus Halm, Leipzig 1863 (Neudruck Frankfurt a. M. 1964), S. 22-37.

Carmina Latina Epigraphica = Anthologia Latina II, 3 Bde., hg.v. Franz Bücheler / Friedrich A. Riese / Ernst Lommatzsch, Leipzig 1895-1926.

Cicero, Pro L. Flacco, In Verrem, In Catilinam = M. Tulli Ciceronis Orationes, 6 Bde., hg.v. Albert C. Clark, Oxford 1905-1911 (zahlreiche Neuauflagen).

Partitiones $=$ M. Tulli Ciceronis Rhetorica II, hg.v. Augustus S. Wilkins, Oxford 1903.

Dracontius, De laudibus Dei = Dracontius, Euvres. Tome I: Louanges de Dieu, Livres I et II, hg.v. Claude Moussy / Colette Camus, Paris 1985.

Ennius, Annales = The Annals of Q. Ennius, hg.v. Otto Skutsch, Oxford 1985.

Ennodius, Carmina = Magni Felicis Ennodi Opera, hg.v. Friedrich Vogel, Berlin 1885 (MGH AA 7).

Gottfried von Straßburg, Tristan $=$ Gottfried von Straßburg. Tristan. Nach dem Text von Friedrich Ranke neu hrsg., ins Neuhochdt. übersetzt v. Rüdiger Krohn, 3 Bde. Stuttgart 1980.

Horaz, Epistulae, Saturae = Quintus Horatius Flaccus, Opera, hg.v. David R. Shackleton Bailey, München / Leipzig ${ }^{4} 2001$.

Iulius Rufinianus, De schematibus lexeos $=$ Rhetores Latini minores ex codicibus maximam partem primum adhibitis, hg.v. Carolus Halm, Leipzig 1863 (Neudruck Frankfurt a. M. 1964), S. 38-62.

Lucilius, Saturae = Luciulius, Satires, 3 Bde., hg.v. F. Charpin, Paris 1978-1991.

Lukrez: De natura deorum = Lucreti De Rerum Natura libri sex, hg.v. Cyrillus Bailey, Oxford 1900.

Macrobius, Saturnalia $=$ Macrobi Ambrosii Theodosii Saturnalia, hg.v. Robert A. Kaster, Oxford 2011. 
Naevius, Bellum Punicum: Fragmenta Poetarum Latinorum, hg.v. Jürgen Blänsdorf, Berlin / New York ${ }^{4} 2011$, S. 42-62.

Ovid, Fasti $=$ P. Ovidi Nasonis Fastorum libri sex, hg.v. D. E. W. Wormell / E. Courtney Leipzig 1978.

Ovid, Amores, Remedia amoris = Ovidius, Carmina amatoria, hg.v. Antonio Ramírez de Verger, München / Leipzig 2003.

Plautus, Amphitruo, Captivi, Persa = T. Macci Plauti Comoediae, 2. Bde., hg.v. Wallace M. Lindsay, Oxford 1904-1905.

Plinius, Epistulae = C. Plini Caecili Secundi epistularum libri decem, hg.v. R. A. B. Mynors, Oxford 1963.

Priscian, Praeexercitamina $=$ Rhetores Latini minores ex codicibus maximam partem primum adhibitis, hg.v. Carolus Halm, Leipzig 1863 (Neudruck Frankfurt a. M. 1964), S. 551-560.

Quintilian, Institutio oratoria $=$ M. Fabi Quintiliani Institutionis oratoriae libri duodecim, 2 Bde., hg.v. Michael Winterbottom, Oxford 1970.

Sedulius, Carmen paschale $=$ Sedulii opera omnia, hg.v. Johannes Huemer, 2. vermehrte Auflage durch Victoria Panagl, Wien 2007 (CSEL 10), S. 1-146.

Seneca, Epistulae = L. Annaei Senecae ad Lucilium Epistulae morales, 2 Bde., hg.v. L. D. Reynolds, Oxford 1965.

Seneca, Phoenissae, Herculens furens, Hercules Oetaeus, Medea $=$ L. Annaei Senecae Tragoediae, hg.v. Otto Zwierlein, Oxford 1986.

Sidonius Apollinaris, Carmina u. Epistulae = Sidoine Apollinaire, Tome I: Poèmes, hg.v. André Loyen, Paris 1960; Tome II-III: Lettres, Paris 1970.

Statius, Thebais = P. Papini Stati Thebais et Achilleis, hg.v. H. W. Garrod, Oxford 1906. Statius, Silvae = P. Papini Stati Silvae, hg.v. Edward Courtney, Oxford 1990.

Sueton, Divus Iulius $=$ C. Suetoni Tranquilli De Vita Caesarum et De Grammaticis et Rhetoribus, hg.v. Robert A, Kaster, Oxford 2016.

Terenz, Andria = P. Terenti Afri Opera, hg.v. Robert Kauer / Wallace M. Lindsay, Oxford 1926.

Vergil, Aeneis = Publius Vergilius Maro, Aeneis, hg.v. Gian B. Conte, Berlin / Boston ${ }^{2} 2019$.

\section{Forschungsliteratur}

Arbusow, Leonid: Colores Rhetorici. Eine Auswahl rhetorischer Figuren und Gemeinplätze als Hilfsmittel für Übungen an mittelalterlichen Texten, zweite durchgesehene und vermehrte Auflage hg.v. Helmut Peter, Göttingen 1963.

Asper, Markus: Art. Katalog, in: HWRh Bd. 4 (1998), Sp. 915-922.

Bernhardt, Ursula: Die Funktion der Kataloge in Ovids Exilpoesie, Hildesheim 1986 (Altertumswissenschaftliche Texte und Studien 15). 
Blasberg, Cornelia: Art. Asyndeton, in: HWRh Bd. 1 (1992), Sp. 1154-1156.

Blettner, Elizabeth: One Made Many and Many Made One: The Role of Asyndeton in Aristotle's Rhetoric, in: Philosophy \& Rhetoric 16 (1983), S. 49-54.

Brommer, Frank: Herakles II. Die unkanonischen Taten des Helden, Darmstadt 1984.

Cameron, Alan: Claudian. Poetry and Propaganda at the Court of Honorius, Oxford 1970.

Canter, Howard Vernon: Rhetorical Elements in the Tragedies of Seneca, Urbana 1925 (University of Illinois Studies in Language and Literature X.1).

Consolino, Franca Ela: Codice retorico e manierismo stilistico nella poetica di Sidonio Apollinare, in: Annali della Scuola Normale superiore di Pisa IV (1974), S. $423-$ 460.

Cugusi, Paolo: Carmina Latina Epigraphica e tradizione letteraria, in: Epigraphica 44 (1982), S. 65-107.

Cugusi, Paolo: Ricezione del codice epigrafico e interazione tra carmi epigrafici e letteratura latina nelle età repubblicana e augustea, in: Peter Kruschwitz (Hg.): Die metrischen Inschriften der römischen Republik, Berlin / New York 2007, S. 1-61.

Curtius, Ernst Robert: Europäische Literatur und lateinisches Mittelalter, München ${ }^{5} 1965$.

Curtius, Ernst Robert: Mittelalterlicher und barocker Dichtungsstil, in: Modern Philology 38 (1940/1941), S. 325-333 (erneut abgedruckt in: Wilfried Barner [Hg.]: Der literarische Barockbegriff, Darmstadt 1975 [Wege der Forschung 358], S. 220-229).

Delz, Josef: Ein umgangssprachliches Asyndeton bei Varro und Petron, in: Museum Helveticum 34 (1977), S. 141.

Dusil, Stephan / Schwedler, Gerald / Schwitter, Raphael (Hgg.): Exzerpieren - Kompilieren - Tradieren. Transformationen des Wissens zwischen Spätantike und Frühmittelalter, Berlin / New York 2016 (Millenium-Studien 64).

Eigler, Ulrich: Lectiones vetustatis. Römische Literatur und Geschichte in der lateinischen Literatur der Spätantike, München 2003 (Zetemata 115).

Elsner, Jaś / Hernández Lobato, Jesús: The Poetics of Late Latin Literature, Oxford 2017 (Oxford Studies in Late Antiquity).

Formisano, Marco: Towards an Aesthetic Paradigm of Late Antiquity, in: Antiquité Tardive 15 (2007), S. 277-284.

Formisano, Marco / Sogno, Christiana: Petite poésie portable. The Latin cento in its Late Antique Context, in: Horster / Reitz (2010), S. 375-392.

Friedlein, Anne: Das Symposium der XII Sapientes. Kommentar und Verfasserfrage, Berlin / New York 2002 (Texte und Kommentare 22).

Gärtner, Thomas: Die hellenistische Katalogdichtung des Phanokles über homosexuelle Liebesbeziehungen. Untersuchungen zur tendenziellen Gestaltung und zum literarischen Nachleben, in: Mnemosyne 61 (2008), S. 18-44.

Gassner, Jakob: Kataloge im römischen Epos: Vergil, Ovid, Lucan, Diss., München 1972. 
Gemeinhardt, Peter: Das lateinische Christentum und die antike pagane Bildung, Tübingen 2007 (Studien und Texte zum antiken Christentum 41).

Gerbrandy, Piet: The Failure of Sidonius' Poetry, in: Johannes A. von Waarden / Gavin Kelly (Hgg.): New Approaches to Sidonius Apollinaris, Leuven u. a. 2013, S. 63-76. Gerth, Matthias: Bildungsvorstellungen im 5. Jahrhundert n.Chr. Macrobius, Martianus Capella und Sidonius Apollinaris, Berlin/ Boston 2013 (Untersuchungen zur antiken Literatur und Geschichte 111).

Hagendahl, Harald: La prose métrique d'Arnobe. Contributions à la connaissance de la prose littéraire de l'empire, Göteborg 1937.

Hernández Lobato, Jesús: Sterilis camena. El Carmen 9 de Sidonio Apolinar o la muerte de la poesía, in: Acme 63 (2010), S. 97-133.

Hernández Lobato, Jesús: Vel Apolline muto. Estética y poética de la Antigüedad tardía, Bern 2012.

Hofmann, Johann Baptist: Lateinische Umgangssprache, Heidelberg ${ }^{4} 1978$.

Hofmann, Johann Baptist: Lateinische Syntax und Stilistik, neubearbeitet von Anton Szantyr, München 1965 (Handbuch der Altertumswissenschaft II.2.2).

Hoogma, Robert Peter: Der Einfluss Vergils auf die Carmina Latina Epigraphica, Amsterdam 1959.

Horster, Marietta / Reitz, Christiane (Hgg.): Condensing Texts - Condensed Texts, Stuttgart 2010 (Palingenesia 98).

Horster, Marietta / Reitz, Christiane: Handbooks, Epitomes, and Florilegia, in: Scott McGill / Edward J. Watts (Hgg.): A Companion to Late Antique Literature, New York 2018 (Blackwell Companions to the Ancient World), S. 431-450.

Kühlmann, Wilhelm: Katalog und Erzählung. Studien zu Konstanz und Wandel einer literarischen Form in der antiken Epik, Diss., Freiburg i. Br. 1973.

Lausberg, Heinrich: Handbuch der literarischen Rhetorik. Eine Grundlegung der Literaturwissenschaft, Stuttgart ${ }^{3} 1990$.

Lissberger, Ewald: Das Fortleben der römischen Elegiker in den Carmina Epigraphica, Diss., Tübingen 1934.

Lovén, Lena Larsson: Lanam fecit. Woolworking and Female Virtue, in: dies. / Agneta Strömberg (Hgg.): Aspects of Women in Antiquity, Jonsered 1998, S. 85-95.

Ludwig, Walter: Die christliche Dichtung des Prudentius und die Transformation der klassischen Gattungen, in: Manfred Fuhrmann (Hg.): Christianisme et formes litteraires de l'antiquité tardive en occident, Genf 1977, S. 303-372.

Marrou, Henri-Irénée: Augustinus und das Ende der antiken Bildung, übers. v. Lore Wirth-Poelchau, hg. und red. v. Johannes Götte, Paderborn / Zürich ${ }^{2} 1995$.

Maurach, Gregor: Enchiridion Poeticum. Zur lateinischen Dichtersprache, Darmstadt ${ }^{2} 1989$.

Paolucci, Paola: Pentadius Ovidian Poet. Music, Myth and Love, Hildesheim 2016.

Pliester, Hans: Die Worthäufung im Barock, Diss., Bonn 1930. 
Prete, Sextus: De Herculis aerumnis apud Sidonium Apollinarem, in: Klaus Sallmann (Hg.): Acta Treverica 1981, Leichlingen 1984, S. 115-119.

Puttfarken, Werner: Das Asyndeton bei den römischen Dichtern der archaischen und klassischen Zeit mit einer Einleitung über die rhetorische Lehre vom Asyndeton, Diss., Kiel 1920.

Reitz, Christiane: Das Unendliche beginnen und sein Ende finden - Strukturen des Aufzählens in epischer Dichtung, in: Christine Schmitz / Angela Jöne / Jan Kortmann (Hgg.): Anfänge und Enden. Narrative Potentiale des antiken und nachantiken Epos, Heidelberg 2017, S. 105-118.

Roberts, Michael: The Treatment of Narrative in Late Antique Literature. Ammianus Marcellinus $(16,10)$, Rutilius Namatianus and Paulinus of Pella, in: Philologus 132 (1988), S. 181-195.

Roberts, Michael: The Jeweled Style. Poetry and Poetics in Late Antiquity, London / Ithaca (NY) 1989.

Schindler, Claudia: Macht und Übermacht der Tradition. Dichterkataloge in der lateinischen Literatur von Ovid bis Sidonius, in: Simone Finkmann / Anja Behrendt / Anke Walter (Hgg.): Antike Erzähl- und Deutungsmuster. Zwischen Exemplarität und Transformation, Berlin / New York 2019 (Beiträge zur Altertumskunde 374), S. $335-358$.

Schlapbach, Karin: Veriora nomina Camenarum. Erudition, Uncertainty, and Cognitive Displacement as Poetic Strategies in Sidonius Apollinaris, in: Journal of Late Antiquity 13 (2020), S. 44-61.

Schmitzer, Ulrich: Sidonius Apollinaris - unfruchtbare Muse oder Erneuerung der Poesie im Zeichen des Mythos?, in: Hartmut Leppin (Hg.): Antike Mythologie in christlichen Kontexten der Spätantike, Berlin / New York 2015 (Millennium-Studien 54), S. 71-92.

Schwitter, Raphael: Umbrosa lux. Obscuritas in der lateinischen Epistolographie der Spätantike, Stuttgart 2015 (Hermes Einzelschriften 107).

Staab, Gregor: Art. Polysyndeton, in: HWRh Bd. 6 (2003), Sp. 1537-1541.

Visser, Edvard: Homers Katalog der Schiffe, Stuttgart / Leipzig 1997.

Weyman, Carl: Beiträge zur Geschichte der christlich-lateinischen Poesie, München 1926 (unveränderter Nachdruck Hildesheim 1975).

Winter-Froemel, Esme: Art. Trikolon, in: HWRh Bd. 9 (2009), Sp. 780-784.

Wittchow, Frank: Exemplarisches Erzählen bei Ammianus Marcellinus. Episode, Exemplum, Anekdote, München 2001 (Beiträge zur Altertumskunde 144). 



\title{
Bühnenrede, kurz
}

\section{Kürzetechniken im Dramenwerk von Andreas Gryphius}

\author{
von \\ Jörg Wesche (Göttingen)
}

\section{I.}

Im Folgenden geht es um den Zusammenhang von Kürze und Bühnenrede. Sowohl sprachliche als auch poetische Gestaltungsmittel sind dabei zu beachten, während Verfahren der Kürzung im Drama - etwa in genrespezifischen Strichfassungen - an dieser Stelle ausgeklammert bleiben. Zugleich führt der an dramatischer brevitas interessierte Ansatz über einen rein brachylogischen Zugang hinaus, indem nicht allgemein nach stilistischer Sprachkürze gefragt wird, sondern auf Kürzetechniken in dialogischer Interaktion scharfgestellt wird. Der Monolog bleibt damit ebenfalls zurückgestellt, selbst wenn es sicher lohnend ist, diese eher unter Weitschweifigkeitsverdacht stehende Form auf Kürze hin zu befragen. Auch bei Gryphius - so viel sei immerhin gesagt - stellt sich die Monologgestaltung in dieser Hinsicht komplex dar. So nimmt etwa der Eingangsmonolog seines Trauerspiels Papinian mit insgesamt 156 Versen nicht weniger als rund 40 Prozent der ersten Abhandlung ein und steht damit quantitativ ungefähr auf Augenhöhe mit berühmten Drameneröffnungen der deutschen Literatur wie dem Eingangsmonolog Fausts bei Goethe (126 Verse) oder Franz Moors in Schillers Die Räuber (130 Zeilen). Unternimmt man den textinternen Vergleich, gestaltet Gryphius den zweiten und dritten Akt des Papinian jedoch gänzlich ohne Monolog; im dritten Akt nimmt der Monolog zudem nur ca. 8 Prozent, im fünften etwa 3 Prozent des Dramentextes ein, ${ }^{1}$ sodass die Form in der Verlaufsstruktur des Stücks dramaturgisch immer weiter zurücktritt. Einen klaren Beleg für monologische Kürze bei Gryphius, die mit poetischen 
Mitteln hergestellt wird, gibt sodann der Eingangsmonolog des Protagonisten in der dritten Szene der dritten Abhandlung im Leo Armenius, dem ersten Trauerspiel von Gryphius. Nachdem Kaiser Leo im Schlaf der unheilverkündende Geist des Tarasius als Todesbote erschienen ist, erwacht er verstört und reflektiert auf den zwischen wahrhaftigem Warnzeichen und Trugbild stehenden Alptraum:

Was bilden wir uns ein?

Sol uns ein leerer Wahn / ein falscher Dunst bewegen?

Sol dises Zittern sich aus Phantasie erregen?

Sol es gantz eitel seyn

Was diß schro̊ckliche Gesichte

Von dem ernsten Blut-Gerichte /

Von Vntergang / Fall / Tod / und Wunden;

Vns in die Seelen eingebunden? $[\ldots]^{2}$

Poetische Kürze stellt sich in diesem Fall durch die Aufspaltung des Alexandriners in Halbverse ein. Die Abweichung vom Versmaß des Alexandriners als allgemeiner Norm des Sprechverses im schlesischen Trauerspiel des 17. Jahrhunderts fällt dabei im gegebenen Szenenausschnitt besonders ins Auge, da die Hauptfigur, nachdem sie hochgeschreckt ist, im verkürzten Eingangsvers zunächst versucht, ins Maß zu finden, daraufhin zwei Alexandriner-Verse zustande bringt, um aus dieser gefassten Rede sogleich wieder herauszufallen. Durch dieses Kontrastierungsverfahren gestaltet Gryphius verstechnisch, wie der Sprecher seine Beherrschung verliert und buchstäblich um Worte ringt. Die Kürzung des Versschemas korrespondiert dabei mit metrischen Wechseln zwischen Jambus und Trochäus (z. B. Von dem ernsten), welche - teils mit daktylischen Anklängen (schröckliche Gesichte) die innere Unruhe des Protagonisten formal zuspitzen. Somit steht die verstechnisch erzeugte Kürze unverkennbar im Dienst der situativen Figurencharakterisierung, die mit der dargestellten Plötzlichkeit des Zauderns gerade durch die artifiziellen Mittel auf der Versebene letztlich einen Spontansprachlichkeitseffekt im Monolog erzeugt. 
Doch soll der Monolog hier nicht weiter zum Thema gemacht werden. Stattdessen steht Bühnensprache im Weiteren vielmehr als Sprache in Interaktion im Fokus. Sie beruht im Drama auf dem Fingieren von kollaborativer Äußerungsproduktion, Sequenzierung und situationaler Einbettung und orientiert sich auch im schriftbasierten Literaturtheater nicht zuletzt konzeptionell mündlich an gesprochener Sprache. Ziel ist somit die Engführung von dramenanalytischen und interaktionslinguistischen Perspektiven im Hinblick auf Kürze im dramatischen Dialog. ${ }^{3}$

Die Eingrenzung auf die Dramen des schlesischen Barockdichters Andreas Gryphius (1616-1664) erklärt sich dabei aus einer doppelten Zielstellung: Zum einen soll eine historische Anwendung der vorwiegend im Feld der Gegenwartssprache entwickelten interaktionslinguistischen Ansätze erprobt und literaturgeschichtlich perspektiviert werden. Zum anderen ist dafür gerade das Dramenwerk von Gryphius heuristisch ergiebig, da es weithin als frühneuhochdeutsches Literaturtheater wahrgenommen wird, das spontansprachlich wenig zu bieten habe. Ohne große Bühnentauglichkeit sei es über deklamatorische, oft episch entfaltete Monologe oder schwülstige Alexandriner in den Trauerspielen unter sprachpatriotischen Vorzeichen auf manieristische Artifizialität im rhetorischen Zeitalter abgestellt, diene im schuldramatischen Kontext vor allem der Einübung argumentativer und rednerischer Fertigkeiten oder vermittele schlicht das christliche Weltbild. ${ }^{4}$ Wie aber kann vor diesem historischen Hintergrund überhaupt von der Inszenierung einer Sprache in Interaktion gesprochen werden, und wo bleibt da die Kürze?

Um diesen Fragen nachzugehen, stützen sich die folgenden Beobachtungen auf eine derzeit im Entstehen befindliche annotierte Datenbank, ${ }^{5}$ welche das vollständige Dramenwerk von Andreas Gryphius enthält und korpusbasiert Fragen zur historischen Stilisierung von Nähesprachlichkeit in literaturund sprachwissenschaftlich abgestimmter Weise untersucht. Die gattungs-

3 Für den literaturwissenschaftlich bisher kaum gesehenen Forschungsansatz der interaktionalen Linguistik grundlegend Imo (2013b).

$4 \quad$ Für den schuldramatischen Kontext etwa Gajek (1993); zur Aufführungspraxis des schlesischen Kunstdramas auch Zielske (1971); oratorische und narrative Tendenzen reflektieren z. B. Schäfer (2007) und Spellerberg (1996).

$5 \quad$ Vgl. https://gryphius.sprache-interaktion.de/ (abgerufen am 28.6.2020). 
spezifische Fokussierung auf Dramentexte ist hier dadurch begründet, dass die «eigentliche Domäne der Dialoganalyse im Bereich der Literatur [...] naturgemäß das Drama» ist. ${ }^{6}$ Denn dort ist aufgrund der nachgebildeten sprachlichen Interaktion zu erwarten, dass konzeptuell mündliche, genauer interaktionale Strukturen besonders zahlreich auftreten. Im Einzelnen richtet sich das Projekt dabei u. a. auf folgende Leitfragen:

- Welche aus der synchron orientierten Forschung zur konzeptionell mündlichen Sprachverwendung bekannten Phänomene der Mündlichkeit lassen sich in den Dramentexten von Gryphius überhaupt lokalisieren? Inwieweit kann man anhand der gefundenen Phänomene in Ansätzen eine historische Mündlichkeit - in Anlehnung an die Annahme von «Sprache als Spur sozialer Interaktion » - rekonstruieren? Welche weiteren Aspekte neben den dialogischen kommen zur Erklärung potentiell mündlicher Phänomene ins Spiel (z. B. rhetorisch-stilistische Mittel), und inwiefern sind seine Stücke auf Sprechbarkeit hin angelegt?8

- Wie korreliert die mündliche Stilisierung der Dramensprache mit der Verlaufsstruktur der szenischen Form? Inwiefern lässt sich somit von einer dramaturgischen Dynamik mündlicher Strukturen sprechen, die auf das Tempo, die Spannungsführung oder situative Einbettung einzelner Szenen im Drama bezogen sind (z. B. Erzeugung von Spontanitätseffekten, Koordination von Figurenrede und Szenenwechsel beziehungsweise Auf- und Abtritt, sprachliche Überleitungen zu Zwischenaktchören oder Zwischenspielen).

- Wie korrelieren v. a. im hoch normierten Bereich des Trauerspiels konzeptionelle Mündlichkeit und artifizielle Versifikation? Vor dem Hintergrund der verbreiteten Einordnung des Schlesischen Kunstdramas als Deklamationstheater - Catharina z. B. erscheint als «deklamatorisch flache» Figur ${ }^{9}$ - hat die Forschung die szenische Flexibili-

6 Hundsnurscher (1994), S. 91.

7 Müller (2012), S. 34.

8 Insbesondere in Weiterführung exemplarischer Studien zu Horribilicribrifax (Haberkamm [1988]) und Leo Armenius (Helmensdorfer [1977]).

$9 \quad$ Koschorke (2006), S. 154. 
sierung des Alexandriners bei Gryphius gesehen. ${ }^{10}$ Diese Befunde werden gezielt mit Blick auf Mündlichkeitseffekte der interaktionalen Sprache in Gryphius' Dramen weitergedacht, um die Spezifik seines theatralen Versgebrauchs - auch im Vergleich zur Gestaltung des Alexandriners in vorwiegend nicht-dialogischen Kleinformen bei Gryphius (besonders Epigramm, Ode und Sonett) - genauer zu bestimmen.

Das Thema Kürze fügt sich dabei insofern in diesen Forschungshintergrund, als gerade die Gestaltungsmittel, die zur Analyse interaktionaler Sprache geeignet sind, aufgrund der dialogischen Sequenzierung vielfach als Kürzetechniken gebraucht werden, wie folgende Übersicht einiger empirischer Kandidaten für interaktionale Sprachstrukturen deutlich macht:

- Anakoluthe, Umstiege und Apokoinu-Konstruktionen ${ }^{11}$

- bestimmte Ellipsentypen ${ }^{12}$

- E-Apokopen, Klitisierungen und Kontraktionen ${ }^{13}$

- Parenthesen ${ }^{14}$ und bestimmte Anaphern ${ }^{15}$

- gesprächstypische Partikeln wie Modalpartikeln, Diskursmarker und Interjektionen $^{16}$

- Frage-Antwort-Sequenzen ${ }^{17}$

- kollaborative Äußerungsproduktionen ${ }^{18}$

Wie Gryphius solche Strukturen in seinen Stücken im Sinn sprachlicher Interaktion und Kürze einsetzt und teilweise mit genuin poetischen Gestaltungsmitteln abstimmt, wird nachfolgend anhand von ausgewählten Beispielen untersucht. Der Analysedurchgang berücksichtigt dabei kleinere Einhei-

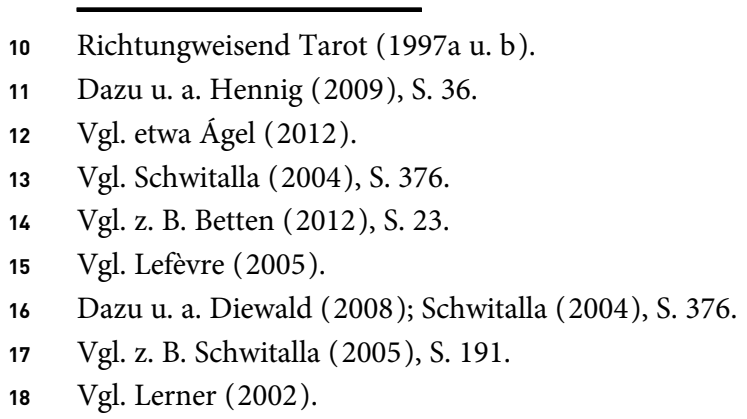


ten wie Klitisierungen, Ellipsen oder Interjektionen sowie komplexere Interaktionsstrukturen wie Frage-Antwort-Sequenzen, Überlappungen, Ins-WortFallen, Antilaben oder Stichomythien.

II.

Das Ausgangsbeispiel gibt die Kerkerszene aus Gryphius' Debütstück Leo Armenius, in der zunächst der spezifische Ellipsengebrauch als interaktionale Sprachkürzetechnik ins Auge fällt. ${ }^{19}$

Ellipsen gehören im Deutschen zu einem inzwischen umfangreich aus unterschiedlichsten linguistischen Teildisziplinen heraus erforschten syntaktischen Phänomen. In einem allgemeinen Sinn sind Ellipsen zunächst einmal unvollständige Sätze, die - denkt man etwa an syntaktische Formen spontansprachlicher Umplanung wie z. B. den syntaktischen Ausstieg (Aposiopese) - nicht pauschal als Figuren geplanter Kürze aufzufassen sind. Gerade in der mündlichen Interaktion, in der die Gesprächsteilnehmer den gleichen situativen Kommunikationskontext teilen, dienen sie jedoch wie z. B. im Fall der Antwortellipse oft zur sprachlichen Verknappung, indem sie (1.) einzelne Redebeiträge abkürzen, (2.) zur Redundanzreduktion führen sowie (3.) durch syntaktische Konstruktionsübernahme schnellere Sprecherwechsel ermöglichen und damit auch die Sequenzierung verdichten. Auch aus interaktionslinguistischer Sicht liegen entsprechend zahlreiche Arbeiten vor, die sich mit Ellipsen in der gesprochenen Sprache befassen. ${ }^{20}$ Was als Forschungsdesiderat allerdings noch aussteht, ist wiederum eine umfassende «Geschichte der Ellipsen", ${ }^{21}$ denn gerade aus historischer Perspektive sind bislang nur wenige Teilbereiche der basalen Kürzetechnik erforscht. ${ }^{22}$ Gleichwohl ist das Feld der Ellipsen beinahe unübersehbar groß.

19 Für die Sicherstellung einer linguistisch adäquaten Beschreibung der nachfolgend untersuchten Satzstrukturen danke ich Wolfgang Imo. Vgl. zur metrischen Variabilität der Passage auch Wesche (2017).

20 Vgl. u. a. Selting (1997) und Imo (2013a).

21 Ágel (2000), S. 1898.

22 Für das Frühneuhochdeutsche Hennig (2013). 
Hier wird daher exemplarisch ein elliptisches Phänomen gewählt, das als interaktionale Ellipse sowohl anhand von gesprochensprachlichen als auch geschriebensprachlichen Daten untersucht wurde: die nicht-finite Prädikationskonstruktion oder auch «Mad Magazine Sentence», die aus einer Juxtaposition von zumeist zwei Nominalphrasen wie «Der Bundespräsident? Ein Betrüger?> besteht und mit der interaktional argumentative Funktionen durchgeführt werden. ${ }^{23}$ Das ausgewählte Beispiel entstammt der fünften Szene im dritten Akt des Leo Arminius, in der ein Wächter dem inhaftierten Verschwörer Michael berichtet, dass sich der Kaiser in den Kerker begeben habe. Michael will dies zunächst nicht glauben:

WÄCHTER. Die helffte diser Nacht war / wie mich dunckt / verlauffen: Als unversehns der Fürst durch die bewehrten Hauffen $\mathrm{Biß}$ in den Kercker trat. MicH. Jst diß woll je erhört! Kenst du ihn? WÄcht. So als mich. Mich. dich hat ein Dunst bethört.

WÄCHTER. Warumb doch glaubt mein Herr / daß ich / was falsch / berichte?

MiCHAEL. Der Kayser? in der Nacht? / es dunckt mich ein Gedichte /

WÄCHTER. Mein Herr / was brächt es mir / Nutz oder Schaden ein?

Michael. Wer schloß den Kercker auff? Wächt. Er selbst. Mich. Kam er allein ?24

Dialogtechnisch zeichnet die vorliegende elliptische Struktur (Der Kayser? in der Nacht?) ein hohes Maß an Interaktionalität aus. Allgemein erfüllen solche nicht-finiten Prädikationskonstruktionen eine "gesprächsstrukturierende 〈Scharnierfunktion $»{ }^{25}$ die sich darin manifestiert, dass der Produzent des Konstrukts «die unterstellte Gültigkeit oder Berechtigung der gesprächsdeiktisch zum Thema gemachten Aussage konversationell als eine kommentierungsbedürftige 〈Problemstelle〉 [markiert], die ein positionierungsrelevantes 〈stance-taking〉 erfordert»; dementsprechend wird die Konstruktion typischerweise in «Argumentations-, Streit- oder 〈Teasing〉-Kontexten» verwendet, wo sie als Positionierungsmittel dient. ${ }^{26}$ Genau dies ist hier dialogtechnisch im Sinn figuraler Spannungsführung zu beobachten: Michael markiert die Aussage des Wächters als Problemstelle und setzt den Wächter

Bücker (2012).

24 Text nach Mannack (1991), S. 74 (Hervorhebung des Verf.).

25 Bücker (2012), S. 162.

26 Bücker (2012), S. 164. 
in einen Rechtfertigungszugzwang. Der Wächter reagiert entsprechend, indem er in einer rhetorischen Frage darlegt, dass er keinen Vorteil aus einer Lüge ziehen kann, dass es also keinen Grund gibt, die Aussage anzuzweifeln. Michael gibt seine Skepsis daraufhin auf und beginnt, Details zu eruieren (Wer schloß den Kercker auff?). Dramaturgisch erscheint die Ungläubigkeit Michaels dabei als Beispiel sprachlicher Stilisierung von Spontaneität und Überraschung. Insofern handelt es sich um eine rhetorische in situ-Technik, welche die szenische Darstellung sprachlich zuspitzt und die Gespanntheit einer Figur hervortreibt, die sich in Kerkerhaft vor der kaiserlichen Anordnung von Folter fürchtet. ${ }^{27}$ Formästhetisch veranschaulicht das Beispiel dabei, wie Gryphius die mündliche Konstruktion mit großem Geschick in das alternierende Versschema einfügt, den Alexandriner als Sprechvers flexibel hält und sprachlich verdichtet.

Diesem spezifischen Ellipsengebrauch stehen ab der Szeneneröffnung flankierend weitere Kürzetechniken zur Seite. Hierzu zählen in der kommunikativen Interaktion insbesondere Stichomythien und mehrfache Sprecherwechsel im Vers (Antilaben) in Frage-Antwort-Sequenzen (МiсH. Wer schloß den Kercker auff? WÄCHT. Er selbst. МiCH. Kam er allein?). Hinzu kommen metrische Klitisierungen (was brächt es mir), Ausrufe (Jst diß woll je erhört!), Anreden (Mein Herr) und Wiederholungen, ${ }^{28}$ welche im Zusammenspiel einen spontansprachlichen Bühneneffekt erzeugen. Letztlich markiert die gesprächsrhetorisch kurzgefasste Passage auch, wie konsequent Gryphius das Drama als Vergegenwärtigungsmedium von Geschichte einsetzt. ${ }^{29}$ Insgesamt belegt das Beispiel eindrucksvoll, wie der Dramatiker als «literarischer Gesprächsanalytiker ${ }^{30}$ seine Dialoge mit einem scharfen Blick auf knappe mündliche Strukturen entwirft.

Versucht man, diese Beobachtung weiter im Dramenwerk abzustützen, bieten dazu vor allem die Sprecherwechsel aussagekräftiges Material. Dies

Vgl. Mannack (1991), S. 75: МiCH. Ich weiß daß er auff mich jetzt neue Marter suche.

28 Vgl. z. B. kurz vor der zitierten Passage Mannack (1991), S. 73: ach! ach! (hier mit performativer Ausdrucksstärkemarkierung durch doppelten Ausrufezeichengebrauch).

29 Zum Status des Stücks im Gattungshorizont des frühneuzeitlichen Geschichtsdramas Niefanger (2005), S. $183-188$.

30 Henne (1980), S. 94. 
gilt für die Komödien und Tragödien, wobei in weitergehenden Analysen zu prüfen wäre, inwiefern interaktionale Kürze bei Gryphius gattungsspezifisch korreliert ist. Die hier nur exemplarisch mögliche Ausweitung der bisherigen Befunde anhand von Sprecherwechseln erfolgt am Beispiel von Überlappungen, Pausen und Stichomythien in Redesequenzen aus dem Doppelspiel Verlibtes Gespente / Die geliebte Dornrose, das Gryphius mit den Genrebezeichnungen «Gesang-Spill» und «Scherz-Spill» versieht. ${ }^{31}$ Es bietet somit einen erweiterten Gattungsrahmen, der ebenso Verspassagen (Verlibtes Gespenste) wie Prosapartien (Die geliebte Dornrose) einschließt.

Wendet man sich zunächst dem Komödienteil des Dramas Die geliebte Dornrose zu, basiert dieser wesentlich auf der satirischen Inszenierung der (dialektalen) ${ }^{32}$ Konfliktsprache des streitenden bäuerlichen Personals. Kennzeichnend für die Sprachkomik ist zudem die (komödientypische) Darstellung kommunikativer Störungen. Als Greger Kornblume zu Beginn des Stücks um Dornroses Hand anhalten will, ist er so verschüchtert, dass er sein Anliegen nur stockend zur Sprache bringt. In der heiklen Gesprächssituation wird er von Dornroses verdutztem Vater Jockel Dreyecke dabei immer wieder nachfragend und missverstehend unterbrochen:

GREGER. Mey eefăltiger Roth were / wer machten Fride / schafft ihre eure Grùte wàg / Jch will men Vetter bereden

ha sol Cuntzen och obschoffen / die zwee spinnen doch ollen okroott on / und - JOCKEL. Was und?

GREGER. Vnd - - - Ey ich kons nicht soyn.

JOCKEL. Ey soy har du Narr - - - ich ho ze thun

GREGER. O ney. Jhr mòcht bưse warden

JOCKEL. Nu ney / soy inde Har.

GREGER. Wen er mer wŏlt ....

JOCKEL. Was?

GREGER. Wen er mer wòlt.

JOCKEL. Wos soll ich den wỏllen?

GREGER. Wen er mer wo̊lt Eure ....

JOCKEL. Je nu wos den? Woß eure den?

GREGER. Wen er mer wo̊lt - - - / Eure - - - / O ich wees nischte wie mer iß.

$32 \mathrm{Zu}$ dieser Besonderheit bei Gryphius Wiesinger (2006). 
JOCKEL. Ney sich / wirst de doch rutt wie enne tudte Leeche / Nu hurtig / soyß raaß.

GREGER. Ja wen er mirs vor weit zu sovn /

JOCKEL. Nu ju / wu sichs ok thun lăst.

GREGER. Nu de Hand druff.

JOCKEL. Nu sich / do hust du se / was weist de den nu?

GREGER. Wen er mer wöllt ... wen er mer wellt ... wen er mer welt ... Eure ... Tochter gahn.

JOCKEL. Ju doch / Ey hyret doch. O ... doß iß gor e ander Wärck. Das Ding ho ich der nich zugesoyt. Ney:

GREGER. Jr hott mer ya de Hand gegahn. ${ }^{33}$

Das Abkürzen der Rede erscheint hier als Forcieren der Sprecherwechsel in der kollaborativen Äußerungsproduktion beider Figuren, die auf diese Weise eigentlich keinen Dialog zustande bringen. Die Grundtechniken des gesamten Redezugs sind der Sprecherwechsel mit Überlappung (overlap) und der Sprecherwechsel mit Pause ( $g a p),{ }^{34}$ die in der Inszenierung von den Schauspielern flexibel variiert werden können. Insofern basiert die mühseligpeinliche Sprachinteraktion auf dem witzigen Changieren zwischen InsWort-Fallen und Aus-der-Nase-Ziehen.

Im Gesangsspielteil Verlibtes Gespenste stößt man auf die wohl wichtigste poetische 〈Turn-taking〉-Technik: die Stichomythie. Als metrisch gebundene Form bildet sie hier den Schlussstein in der untersuchten Beispielreihe. Bevor ich auf das Verlibte Gespenste zurückkomme, sei mit Blick auf die leitende Untersuchungsperspektive vorausgeschickt, dass im Weiteren von folgender Arbeitshypothese ausgegangen wird: Stichomythien erzeugen in der stilisierten sprachlichen Interaktion in Versdramen in zweifacher Hinsicht Kürze, (1.) indem sie einen Redebeitrag im Dramentext jeweils genau auf eine Verszeile beschränken sowie (2.) indem daraus ein dynamisches ‘Turn-taking〉 resultiert, das die Sequenzierung in regulierter Weise verknappt und damit zu einer dramaturgischen Verdichtung der Dialogführung führt, die meistens zur Forcierung der Streitorganisation dient. Die Kürze besteht mithin vor allem in der inszenierten Schlagfertigkeit. Vor diesem

34 Hierzu grundlegend Sacks / Schegloff / Jefferson (1974). Weiterführend Imo / Lanwer (2019), S. 110. 


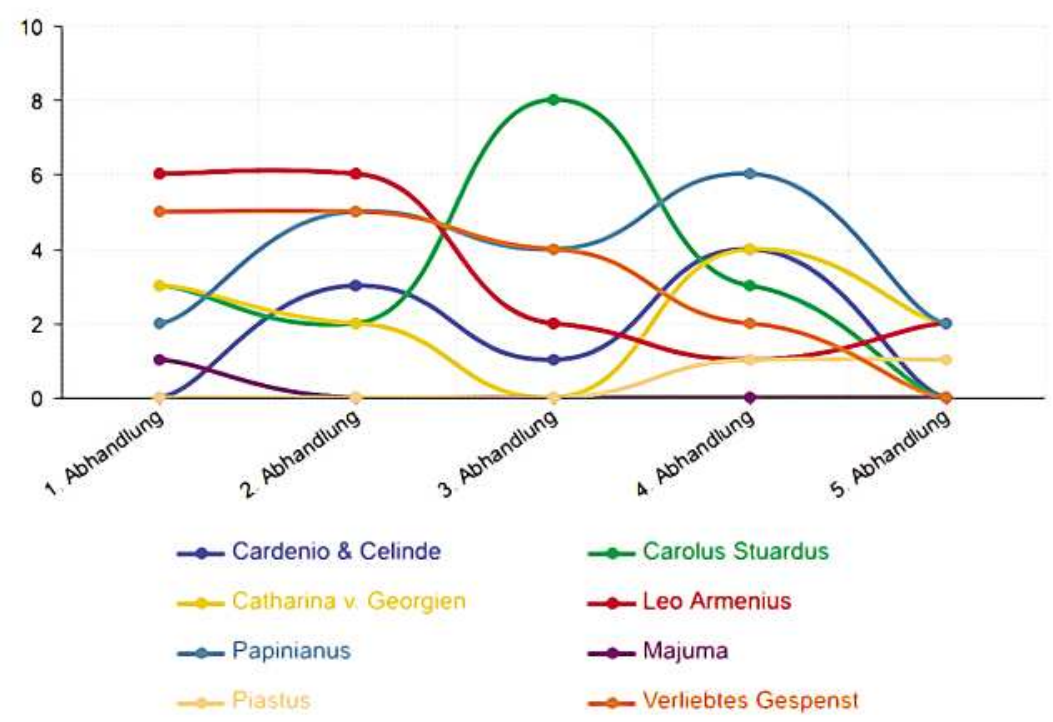

Fig. 1: Stichomythien in Gryphius' Dramenwerk. Gesamtverteilung (Erhebung mit ANNIS3 [http://annis-tools.org/]; abgerufen am 15.6.2020). Zu diesem Auswertungstool von Mehrebenen-Datenbanken Krause / Zeldes (2016).

Hintergrund wird die Stichomythie als versifizierte Zeilenrede hier als genuin poetisches Mittel sprachlicher Kürze in der Sequenzierung des dramatischen Dialogs verstanden, auch wenn der stichomythische Schlagabtausch bisweilen auch zu durchaus umfänglichen Partien ausgebaut werden kann. Dieser begrifflichen Verständigung seien im nächsten Schritt einige quantitative Beobachtungen zur Interaktionstechnik der Stichomythie in Gryphius' Dramenwerk zur Seite gestellt.

Das Schaubild zeigt sämtliche Stichomythien, die in Gryphius' Dramen auf Basis des eingangs genannten Datenbankprojekts identifiziert wurden. Als Stichomythie erfasst sind dabei jeweils Sequenzen ab drei Turns. Annotiert sind zudem die Varianten der Hemistichomythie und Distichomythie sowie schließlich Antilaben als Sprecherwechsel im Vers. Differenziert man das Feld entsprechend weiter aus, ergibt sich das folgende Bild:

Ohne an dieser Stelle ins Detail zu gehen, macht zunächst das erste Schaubild unmittelbar deutlich, dass Gryphius die Technik flächendeckend in seinen Versdramen einsetzt. Berücksichtigt sind dabei allerdings nur die 


\section{Anzahl der Sprechwechsel in den Abhandlungen}

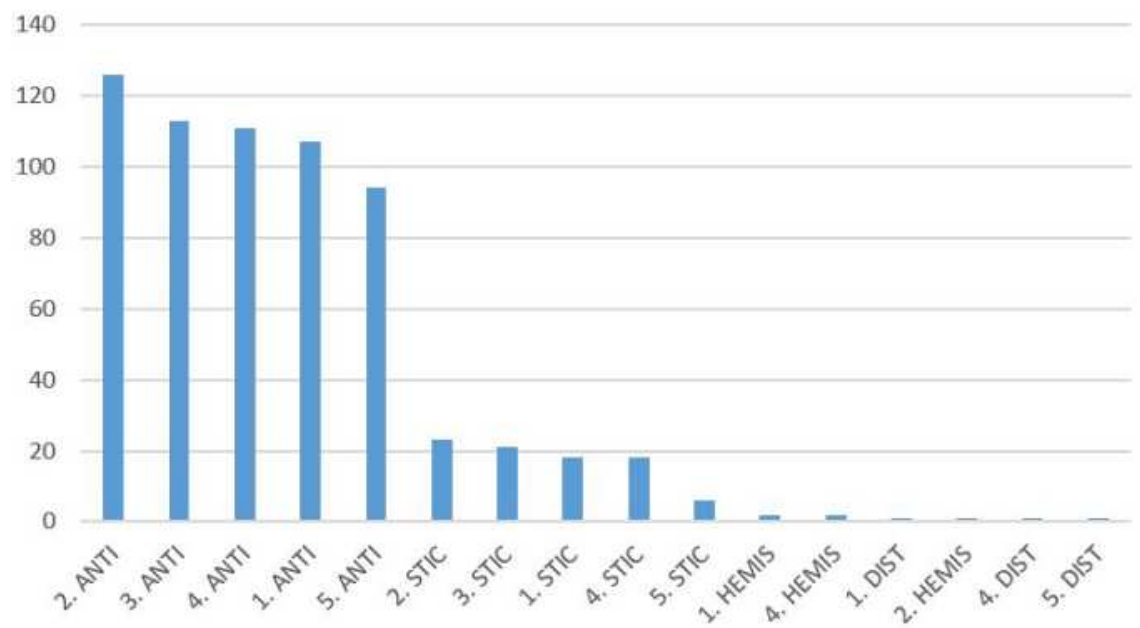

Fig. 2: Quantitative Annäherung zum Gebrauch stichomythischer Varianten und gebrochener Verse (Erhebung mit ANNIS3). Für die Visualisierung der Daten danke ich Lisa Eggert.

Fallzahlen, während über die Länge der einzelnen stichomythischen Passagen noch nichts ausgesagt ist. Auch dies wäre systematisch weiter zu untersuchen. Allgemein kann aber festgehalten werden, dass die Länge in den Dramen erheblich - von drei Turns bis zu einer dreistelligen Versanzahl variiert. Mit Blick auf die Verteilung in der dramatischen Verlaufsstruktur fällt ins Auge, dass Gryphius die Technik - mit Ausnahme von Catharina von Georgien sowie den Singspielen Majuma und Piastus - durchgehend in allen Akten einsetzt. Signifikant erscheint dabei gegen die mutmaßliche Erwartung pyramidaler Bauvorstellungen, dass die Zuspitzungstechnik gerade im oft in einer Gelenkstellung gesehenen dritten Akt tendenziell weniger häufig auftritt (Ausnahme ist hier das Trauerspiel Carolus Stuardus).

Im zweiten Schaubild ist zudem die starke Verbreitung der Antilaben hervorzuheben. Zwar wäre auch hier genauer zu untersuchen, wie häufig Sprecherwechsel in Einzelversen auftreten, doch ist hier (Wortwiederholung) der Eindruck gesichert, dass auch mehrfache Sprecherwechsel im Vers bei Gryphius verbreitet sind. Insbesondere in solchen Fällen ergibt sich in den 
Repliken notwendig eine Kürze, die auf der Aufspaltung des Alexandriners nach mehreren Turns beruht. Aus dieser ausgeprägten Flexibilisierung des Versmaßes resultieren schließlich spontansprachliche Effekte im Text beziehungsweise auf der Bühne, die nach der pragmatischen Logik der Stichomythie vor allem das Ringen um gegensätzliche Positionen und kommunikative Hierarchien vor Augen stellen.

An dieser Stelle kann nun auf das Verlibte Gespenste fokussiert werden. Der dramatische Konflikt dreht sich in diesem Fall um eine Liebeshandlung, die verschiedene Liebeskonstellationen unter den Figuren durchspielt. Der folgende Szenenausschnitt aus dem zweiten Akt zeigt einen Streit zwischen Mutter (Cornelia) und Tochter (Chloris), die beide in Sulpicius verliebt sind und in heikler Verständigung um das Vorrecht auf den Geliebten ringen:

CORNELIA.

Weh mir! was unbesinnte Sinnen!

Kan Kindes-neigung so zerrinnen!

Was sorg ich vil denn zu betrachten /

Die mich nicht wil vor Mutter achten?

Doch straffe hab ich schon in Händen:

Wenn ich sein Liben kan von dir auff mich abwenden.

CHLORIS schlafend.

Ja könt es gleich geschehn /

Vnd Chloris müst es sehn:

Daß dich ein andre solt durch grösser Hold erwerben.

Doch wil ich dein ersterben.

CORNELIA. Was rasen hör ich an / auff Chloris, Chloris auff /

CHLORIS erwachend. Mein süsser Schatz / mein Hertz / gib dich nicht auff den Lauff /

CORNELIA. Was Hertz! was Schatz! ist diß? Kennt man die Mutter nicht.

CHLORIS. Die Mutter leider ach / verkennt ihr Kind und Pflicht!

CORNELIA. Jhr Kind! das weder Zucht noch Ruhm noch Mutter acht!

CHLORIS. Die Mutter acht ich stets / mein Ehr ist unverdacht.

CORNELIA. Das zeigt der schöne Briff / der in dem Busen steckt.

CHLORIS. Durch solche Briefe ward kein keuscher Geist befleckt.

CORNELIA. Hat man bey Keuschen wol von solcher Schrifft gehört?

CHLORIS. Sie kommt von diser Hand die selbst die Mutter ehrt.

CORNELIA. Die Mutter die weit mehr was gutt / denn du / versteht.

CHLORIS seit abw. Vnd leider nach dem Gutt / auff das ich hoffe / geht. 
CORNELIA. Du reuchst noch nach der brust! holt docken vor das Kind.

CHLORIS seit abw. Ja Docken / die beqvem vors Kindes Mutter sind. ${ }^{35}$

Wie Gryphius Kürze auf dramaturgische Zuspitzung bzw. Schlagfertigkeit hin anlegt, zeigt sich in diesem Fall zunächst im knappen Monolog Cornelias, der mit wenigen, zumal auf vier Kola verkürzten Versen in die nachfolgende Gesprächssituation einleitet, in der Chloris aus ihrem Traum erwacht und noch benommen metrisch schwankend - in die Konversation mit der Mutter eintritt. Als sie ganz bei Sinnen ist, wechselt das Register sofort in die (ausschnitthaft zitierte) Stichomythie, sodass die Figuren gleichsam spontan aneinander hochfahren. Das 〈Turn-taking〉 gestaltet Gryphius dabei als Wortgefecht, in dem es nicht um Argumentation oder - wie in stichomythischer Gerichtsrede - gar rhetorische Beweisführung geht, sondern um kommunikative Überlegenheit. Die Passage macht die Stichomythie geradezu zum Streitmuster kollaborativer Äußerungsproduktion, indem es sequenzielle Kürze als schlagfertige Rede auf die Bühne stellt (vgl. z. B. CORNELIA. Hat man bey Keuschen wol von solcher Schrifft gehört? / CHLORIS. Sie kommt von diser Hand die selbst die Mutter ehrt.). Interaktionale Kürze bedeutet in diesem Zusammenhang also Schlagfertigkeit als sverbal dueling.$^{36}$ Dass man an dieser Stelle tatsächlich guten Grund hat, von einer Inszenierung beziehungsweise Bühnensprache auszugehen, belegt das Beispiel nicht zuletzt eindrucksvoll, wenn Gryphius die Stichomythie in den Repliken von Chloris auch aus der Dialogführung auskoppelt und wiederholt als sarkastisches «Seitabwärts〉 einsetzt. Dieser Kunstgriff erscheint ungewöhnlich, da er den metrischen Zusammenhang der Stichomythie als unmittelbare Adressierung in der Figurenrede überschreitet und ins «Beiseite> ausweitet. Unmittelbar zum Tragen kommen im derart vorgeführten Mutter-Tochter-Streit schließlich die inszenatorischen Züge des Streitens. ${ }^{37}$ Spätestens beim «Beiseite〉 kann man also sehen, dass gerne (wie) vor einem Publikum gestritten wird, ob nun im Theater oder in alltäglicheren Zusammenhängen.

36 Dundes (1972).

37 Vgl. Goffmann (2000). 


\section{III.}

Im Gegensatz zur Einstufung des Dramenwerks von Gryphius als sprachartifiziell ausgebautes und monologisierend weitschweifiges Deklamationstheater fokussiert der Beitrag auf Gestaltungsmittel bühnensprachlicher Kürze. In teils quantitativer, teils qualitativer Annäherung zeigt er, dass die exemplarisch untersuchten Kürzetechniken im gesamten Dramenwerk, auch in den vermeintlich metrisch «stillgestellten〉 Trauerspielen verbreitet sind. Methodisch liegt dabei der Ansatz zugrunde, Kürzetechniken nicht aus einer brachylogisch schulrhetorischen Sicht, sondern komplementär das Herstellen von Kürze durch Sprache in Interaktion in den Blick zu nehmen. Die interaktionale Kürze führt dabei allgemein zu einer sprachlichen und metrischen Flexibilisierung, die dialogtechnische und dramaturgische Modifikationen erlaubt, welche das Interaktionsgeschehen zwischen den Figuren intensivieren und auf die Erzeugung von Mündlichkeitseffekten hinzielen. So sind die exemplarischen Befunde letztlich Indikatoren für eine gesprächsrhetorisch stilisierte beziehungsweise inszenierte Mündlichkeit im Dramenwerk von Gryphius.

In den Blickpunkt rückt damit die Frage nach der Textsortenspezifik von Kürze. Im untersuchten Fall geht es um die Relevanz der medialen Grundbedingungen von Drama und Theater, sozusagen um die Kürze in der 〈großen Form〉. Dabei scheinen auch die von Gryphius angewendeten Kürzetechniken auf theatralische Performanz und Transitorik hin angelegt zu sein. Das Kürzekonzept, das hinter der interaktionalen Dialogführung in den Stücken erkennbar wird, steht also durchaus im Dienst eines Schreibens für das Sprechen, das auch im Fahrwasser der schriftfixierten Dichtungsreform von Opitz auf die Entwicklung einer deutschen Bühnensprache auf europäischer Augenhöhe gerichtet ist.

Dies wäre in der Diskussion um den mutmaßlichen Funktionsraum der Stücke - von der Einübung rhetorischer Fertigkeiten durch schultheatralische Musterdialoge über neustoisch geprägte Katharsis und Bewährung des christlichen Publikums bis hin $\mathrm{zu}$ ihrer bevorzugten Wahrnehmung als Bibliodramen - neu zu gewichten. Manche Figuren von Gryphius jedenfalls stimmen darauf ein, wenn sie sich, wie etwa Kaiser Leo, mitunter auch auf Kürze verstehen: 
Verzeih' es / was die Noht mich dưrr' ausreden lehr't.. ${ }^{38}$

Oder um es mit den martialischen Worten des Verschwörers von Crambe im Carolus Stuardus zu sagen:

Ein schnelles Schwerdt verricht weit mehr denn langes Dichten. ${ }^{39}$

\section{Bibliographie}

\section{Primärliteratur}

Mannack, Eberhard: Andreas Gryphius. Dramen, Frankfurt a. M. 1991.

\section{Forschungsliteratur}

Ágel, Vilmos: Junktionsprofile aus Nähe und Distanz. Ein Beitrag zur Vertikalisierung der neuhochdeutschen Grammatik, in: Jochen A. Bär / Marcus Müller (Hgg.): Geschichte der Sprache - Sprache der Geschichte, Berlin 2012 (Lingua Historica Germanica 3), S. 181-206.

Ágel, Vilmos: Syntax des Neuhochdeutschen bis zur Mitte des 20. Jahrhunderts, in: Werner Besch u. a. (Hgg.): Sprachgeschichte. Ein Handbuch zur Geschichte der deutschen Sprache und ihrer Erforschung, Berlin 2000, S. 1855-1903.

Betten, Anne: Direkte Rede und episches Erzählen im Vergleich. Eine syntaktische Reise durch fünf Jahrhunderte (1500-2000), in: Gabriele Leupold / Eveline Passet (Hgg.): Eine Geschichte des Deutschen in Episoden, Göttingen 2012, S. 13-34.

Bücker, Jörg: Sprachhandeln und Sprachwissen. Grammatische Konstruktionen im Spannungsfeld von Interaktion und Kognition, Berlin 2012 (Sprache und Wissen 11).

Diewald, Gabriele: Kontextfaktoren und der Abbau von Satzmodusrestriktionen bei der Grammatikalisierung der Modalpartikeln, in: Ole Letnes u. a. (Hgg.): Modality, Trier 2008 (Fokus 52), S. 129-152.

Dundes, Alan: The strategy of Turkish boys' verbal dueling rhymes, in: John Gumperz / Dell Hymes (Hgg.): Directions in sociolinguistics, New York 1972, S. 130-160.

Gajek, Konrad: Andreas Gryphius auf dem schlesischen Schultheater. Aussagen über Andreas Gryphius' Dramen in Christian Gryphius' Schulactus Von den TrauerSpielen oder Tragodien (1696), in: Stiftung Gerhart-Hauptmann-Haus (Hg.): Weltgeschick und Lebenszeit. Andreas Gryphius. Ein schlesischer Barockdichter aus 
deutscher und polnischer Sicht, Düsseldorf 1993 (Schriften der Stiftung GerhartHauptmann-Haus), S. 95-107.

Goffman, Erving: Wir alle spielen Theater. Die Selbstdarstellung im Alltag, München 2000.

Haberkamm, Klaus: Scherz-Spiel als Sprech-Spiel. Andreas Gryphius' Liebes-Spiel Horribilicribrifax, in: Helmut Arntzen (Hg.): Komödien-Sprache. Beiträge zum deutschen Lustspiel zwischen dem 17. und dem 20. Jahrhundert. Mit einem Anhang zur Literaturdidaktik der Komödie, Münster 1988, S. 1-21.

Helmensdorfer, Urs: Die Kunst, Gryphius zu sprechen. Gedanken zu einer Hörspielproduktion des Leo Armenius, in: Martin Bircher (Hg.): Inszenierung und Regie barocker Dramen. Arbeitsgespräch in der Herzog August Bibliothek Wolfenbüttel 1976. Vorträge und Berichte, Hamburg 1977, S. 11-40.

Henne, Helmut: Probleme einer historischen Gesprächsanalyse. Zur Rekonstruktion gesprochener Sprache im 18. Jahrhundert, in: Horst Sitta (Hg.): Ansätze zu einer pragmatischen Sprachgeschichte, Berlin 1980, S. 89-102.

Hennig, Mathilde: Was ist Kontextkontrolliertheit? Subjektellipsen in neuhochdeutschen Nähetexten als Prüfstein für die grammatische und psycholinguistische Theoriebildung, in: Mathilde Hennig (Hg.): Die Ellipse. Neue Perspektiven auf ein altes Phänomen, Berlin 2013 (Linguistik. Impulse und Tendenzen 52), S. 351-404.

Hennig, Mathilde: Nähe und Distanzierung. Verschriftlichung und Reorganisierung des Nähebereichs im Frühneuhochdeutschen, Kassel 2009.

Hundsnurscher, Franz: Dialog-Typologie, in: Gerd Fritz / Franz Hundsnurscher (Hgg.): Handbuch der Dialoganalyse, Tübingen 1994, S. 203-238.

Imo, Wolfgang: Ellipsen und Verstehen in der Interaktion, in: Mathilde Hennig (Hg.): Die Ellipse. Neue Perspektiven auf ein altes Problem, Berlin 2013 (Linguistik. Impulse und Tendenzen 52), S. 281-320. [=2013a]

Imo, Wolfgang: Sprache-in-Interaktion. Analysemethoden und Untersuchungsfelder, Berlin 2013. [ $=2013 \mathrm{~b}]$

Imo, Wolfgang / Lanwer, Jens Philipp: Interaktionale Linguistik. Eine Einführung, Stuttgart 2019.

Koschorke, Albrecht: Das Begehren des Souveräns. Gryphius' Catharina von Georgien, in: Daniel Weidner (Hg.): Figuren des Europäischen. Kulturgeschichtliche Perspektiven, Paderborn 2006, S. 149-162.

Krause, Thomas / Zeldes, Amir: ANNIS3. A new architecture for generic corpus query and visualization, in: Digital Scholarship in the Humanities 31 (2016), S. 118-139.

Lerner, Gene H.: Collaborative turn sequences, in: Gene H. Lerner (Hg.): Conversation Analysis. Studies from the first generation, Amsterdam 2002, S. 225-256.

Lefèvre, Michel: Anaphorika in der deutschen Sprache des 17. Jahrhunderts am Beispiel der Trauerspiele von Andreas Gryphius, in: Franz Simmler (Hg.): Syntax, Althoch- 
deutsch - Mittelhochdeutsch. Eine Gegenüberstellung von Metrik und Prosa, Berlin 2005 (Berliner sprachwissenschaftliche Studien 7), S. 223-241.

Müller, Marcus: Vom Wort zur Gesellschaft. Kontexte in Korpora, in: Ekkehard Felder / Friedemann Vogel (Hgg.): Korpuspragmatik, Berlin 2012, S. 33-82.

Niefanger, Dirk: Geschichtsdrama der Frühen Neuzeit 1495-1773, Tübingen 2005.

Sacks, Harvey / Schegloff, Emanuel A. / Jefferson, Gail: A Simplest Systematics for the Organization of Turn Taking for Conversation, in: Language 50 (1974), S. 696-735. Schäfer, Armin: Indirekte Reden im Trauerspiel. Andreas Gryphius' Papinianus, in: Bettine Menke/ Christoph Menke (Hgg.): Tragödie - Trauerspiel - Spektakel, Berlin 2007 (Theater der Zeit: Recherchen 38), S. 32-52.

Schwitalla, Johannes: Sprach- und Dialoggestaltung in Andreas Maiers Roman Wäldchestag, in: Anne Betten / Monika Dannerer (Hgg.): Dialogue Analysis IX. Dialogue in Literature and the Media, Tübingen 2005, S. 183-195.

Schwitalla, Johannes: Unterschiede zwischen authentischer und simulierter gesprochener Sprache in fiktionalen Texten, in: Václav Bok / Ulla Williams / Werner WilliamsKrapp (Hgg.): Studien zur deutschen Sprache und Literatur, Hamburg 2004 (Studien zur Germanistik 10), S. 371-388.

Selting, Margret: So genannte «Ellipsen〉 als interaktiv relevante Konstruktionen? Ein neuer Versuch über die Reichweite und Grenzen des Ellipsenbegriffs für die Analyse gesprochener Sprache in der konversationellen Interaktion, in: Peter Schlobinski (Hg.): Syntax des gesprochenen Deutsch, Opladen 1997, S. 117-156.

Spellerberg, Gerhard: Narratio im Drama oder: Der politische Gehalt eines «Martyrerstuckes». Zur Catharina von Georgien des Andreas Gryphius, in: Gabriela Scherer / Beatrice Wehrli (Hgg.): Wahrheit und Wort. Festschrift für Rolf Tarot, Bern 1996, S. 437-461.

Tarot, Rolf: Der Alexandriner als Sprechvers im barocken Trauerspiel, in: Hans Feger (Hg.): Studien zur Literatur des 17. Jahrhunderts. Gedenkschrift für Gerhard Spellerberg (1937-1996), Amsterdam 1997, S. 377-401. [= 1997a]

Tarot, Rolf: Die Kunst des Alexandriners im barocken Trauerspiel, in: Simpliciana 19 (1997b), S. 125-154. [= 1997b]

Wesche, Jörg: Verse Games. Meter and Interactional German in the Baroque Plays of Andreas Gryphius, in: Daniel S. Mayfield (Hg.): Rhetoric and Drama, Berlin / Boston 2017, S. 135-150.

Wiesinger, Peter: Der schlesische Dialekt im Scherzspiel Die geliebte Dornrose von Andreas Gryphius, in: Franz Simmler / Eugeniusz Tomiczek (Hgg.): Sprachwissenschaft, Breslau 2006, S. 89-110.

Zielske, Harald: Andreas Gryphius' Catharina von Georgien auf der Bühne. Zur Aufführungspraxis des schlesischen Kunstdramas, in: Maske und Kothurn 17 (1971), S. 117. 
Kürzung im Kontext kulturhistorischer Diskurse 



\section{Diskursive Evaluation der histoire}

\section{Herborts Liet von Troye im Spannungsfeld von brevitas, adaptatio und aemulatio}

von

Ricarda Bauschke (Düsseldorf)

\section{I.}

Die Beschäftigung mit abbreviatio in der volkssprachigen Dichtung des Mittelalters führt unweigerlich zu Herborts von Fritzlar Trojaroman. Im zweiten Jahrzehnt des 13. Jahrhunderts dichtet der hessische Kleriker im Auftrag des Landgrafen Hermann von Thüringen eine deutsche Ilias. ${ }^{1} \mathrm{Er}$ benutzt dafür den altfranzösischen Roman de Troie des Benoît de Ste-Maure als Vorlage ${ }^{2}$ und reduziert die rund 30.000 Verse seiner Quelle um ein gutes Drittel auf knapp 18.500 Verse. Seine Absicht, sich kurz zu fassen, tut er programmatisch im Prolog kund: ${ }^{3}$

sol mir dar ane gelingen

so lenge ich ez mit willen niht:

ich spreche von Troyge daz lieht.

(vv. 96-98)

1 Grundlegende Informationen bieten Steinhoff (1981) und Lienert (2001), hier: S. $111-120$.

2 Immer noch maßgeblich ist die Ausgabe von Constans (1904-1912). Vergleichende Untersuchungen zu Benoît und Herbort bieten Bauschke (2006) und Herberichs (2010). $3 \quad$ Alle Versangaben und Zitate folgen der Ausgabe von Frommann (1837). Da die Edition lediglich einen diplomatischen Abdruck der Heidelberger Handschrift bereitstellt, habe ich zur leichteren Lektüre für die zitierten Textpassagen Änderungen gegenüber der Ausgabe vorgenommen: Abbreviaturen erscheinen aufgelöst, die wechselnden u- und vGraphien sind nach ihrem neuhochdeutschen Lautwert getrennt, gleiches gilt für i- und jSchreibungen. Schaft-f drucke ich als Rund-s. Eigennamen werden großgeschrieben; eine dem neuhochdeutschen Gebrauch entsprechende Interpunktion soll das Verständnis erleichtern. 
Diesen abbreviatorischen Impetus spielt Herbort anhand von Erzählerkommentaren auch im weiteren Verlauf seiner Narration immer wieder ein: waz sol umbe rede me (v. 7.971), waz woltir mere (v. 10.459), waz wolt ir nu mere (v. 12.902), solde ich ez uch leren, / ich enkunde ez niht vollen comen (vv. 13.424f.) u. ö. Der verkürzende Duktus und dessen autoreferentielle Selbstinszenierung korrespondieren nicht mit den Verfahrensweisen anderer deutschsprachiger Dichter, deren Werke auf romanischen Quellen basieren. Im Vergleich zu ihren altfranzösischen Bezugstexten fallen die deutschen Bearbeitungen in der Regel deutlich länger aus. Es gehört nachgerade zu den Konstitutionsbedingungen der sogenannten adaptation courtoise, ${ }^{4}$ dass mittelhochdeutsche Erzählwerke, die auf französischen Vorlagen fußen, im Sinne einer amplificatio inhaltlich vermehrt werden, also mit der Kategorie der dilatatio materiae zu fassen sind. ${ }^{5}$ Entsprechend hat die Forschung einige Versuche unternommen, um den Sonderweg Herborts literaturgeschichtlich einzuordnen und sein spezifisches Unterfangen zu erklären. ${ }^{6}$

In der Frühzeit der Beschäftigung mit dem Liet von Troye werden in einer biographisierenden Manier Herborts lateinische Bildung und sein klerikaler Stand angeführt, um daraus abzuleiten, dass der Dichter allein geistlichen Verstehenshorizonten verpflichtet gewesen sei und deshalb mit den höfisierenden Aneignungen weltlicher Erzählwerke nichts habe anfangen können. ${ }^{7}$ Diesem Votum gesellt sich früh eine grundsätzliche qualitative Abwertung bei. So meint Wilhelm Reuß auf der Basis seiner Sprachuntersuchung, Herbort zu einem «Dichter dritten Ranges» degradieren zu müssen. ${ }^{8}$

4 Die Begriffsbildung geht auf Huby (1968) zurück, das vermeintliche Verfahren und die sich daraus ergebenden methodischen und hermeneutischen Konsequenzen kritisieren u. a. Wolf (1977) - mit Gegendarstellung durch Huby (1983) - und Pérennec (1984). Bauschke (2006) verwendet lediglich den Begriff adaptation courtoise und rekonstruiert Aspekte eines quellenaneignenden Dichtens neu, ohne die problematischen Implikationen von Hubys Entwurf zu übernehmen.

5 Siehe hierzu die grundlegende Darstellung durch Worstbrock (1985).

6 Ein umfassender Überblick zur Herbort-Forschung findet sich bei Bauschke (2006), S. $10-42$.

7 Dies betrifft, wie zuerst Schade (1955), S. 1-80, gezeigt hat, insbesondere Herborts Umgang mit den antiken Göttern, die im christlichen Weltbild des Klerikers immer problematisch bleiben.

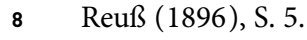


Friedrich Vogt vertritt die Meinung, es fehle dem Liet von Troye «nicht an Ungeschicktheiten und Geschmacklosigkeiten "; Gustav Ehrismann moniert den ungewandten und geschmacklosen Stil; ${ }^{10}$ Hermann Menhardt konstatiert: «Herbort von Fritzlar ist kein stern erster größe am himmel der mhd. litteratur. [...] im stil und in der höfischen bildung steht er hinter den großen meistern zurück.» ${ }^{11}$ Bei Hermann Schneider wird Herbort zum "plumpen Gesellen». ${ }^{12}$ Helmut de Boor sieht in Herbort einen shausbackenen> Gelehrten, dessen literarische Leistung - an Heinrich von Veldeke und dessen Eneasroman gemessen - einen Rückschritt darstelle. ${ }^{13}$ Noch Max Wehrli urteilt vernichtend, nämlich indem er die Verstechnik für unmodern hält, die Darstellung für roh und massiv, und er behauptet zudem, die von Benoît ausgebauten Liebesepisoden übernehme Herbort nur schlecht und recht. ${ }^{14}$

Beide Aspekte - Klerikertum und Unvermögen - besitzen ein Ankergewicht in Herborts Selbstaussagen. So heißt es im Epilog zum Liet von Troye:

Ir hat diz getichte wol gehort.

ez tichte von Fritzlar Herbort,

ein gelarter schulere.

ez en ist nicht achbere,

daz er icht dichten kan

(vv. 18.449-18.453)

Auch andernorts legt Herbort Wert auf seine lateinische Gelehrtheit. Wenn sich die Gelegenheit bietet, nimmt er auf das Bildungssystem Bezug und alludiert dabei immer wieder das brevitas-Prinzip. ${ }^{15}$ Gleichwohl sitzen die

$9 \quad \operatorname{Vogt}(1913)$, Zitat S. 107.

10 Ehrismann (1927), S. 103.

11 Menhardt (1928), S. 225. Die Kleinschreibung entspricht dem Original.

12 Schneider (1943), S. 271.

13 de Boor $\left(1949 /{ }^{11} 1991\right)$, S. 48 u. 52.

14 Wehrli (1980), S. 250.

15 Vgl.: kurtzlichen ich lere, / wie die kunste weren. / an einer leret man buchstaben. I die ander ist erhaben, / als ich uch wil innen, / zu den scharfen sinnen, / die dritte zu der werlde zirde, / zu dem sange die vierde, / die funfe leret mezzen wol, / die seste wie man zelen sol. / die sibende leret die list, / waz wunders an dem gestirne ist (vv. 7.665-7.676); 
älteren Deutungen, was die selbstabwertende Äußerung im Epilog betrifft, einer rhetorischen Figur auf; ${ }^{16}$ denn direkt nach der Unfähigkeitsbeteuerung formuliert Herbort den Anspruch, durchaus seinen Platz in der Reihe der Dichter finden zu wollen:

ez en ist nicht achbere, daz er icht dichten kan, doch so nimet er sis an mit andern tichteren, der schar wil er meren. er gert anders lobes niet. alsus endet sich diz liet.

(vv. 18.452-18.458)

Ähnliches lässt sich für ein besonderes Bild feststellen, das im Prolog entworfen wird:

von dem blinden spreche ich me, wen daz ich selbe muz e daz stuppe uz den augen lesen

(vv. 27-29)

Herbort beschreibt einen ungebildeten Dichter als vorschnell (wenne der ungelerte ist balt, v. 12) und vergleicht ihn mit einem Blinden, um dann allerdings einzuräumen, er selbst müsse sich erst das Staubkorn aus den Augen wischen, also seine eigene - gleichwohl nur momentane - Trübung der Sehkraft beheben. Auch an dieser Stelle entlarvt sich der Ausdruck affektierter Bescheidenheit unmittelbar als nur vorgeschoben; denn das Bild ist der Bergpredigt entlehnt, und dort heißt es: hypocrita eice primum trabem de oculo tuo et tunc videbis eicere festucam de oculo fratris tui (Mt 7,5). Anstelle des nicht gesehenen Balkens im eigenen Auge reklamiert Herbort nun für sich noch weniger als den Splitter, der biblisch im Auge des anderen sitzt, sodass das große Holzstück für den imaginierten Kontrahenten übrig

swaz Plato gescriben hat, / sine kunst unde sine list, / die zu Paris genge ist / me denne anderswa, / daz ist dialectica (vv. 10.670-10.674).

16 Wie resistent sich eine Fehleinschätzung in der Forschung fortschreiben kann, zeigt sich im Fall von Johnson (1999), der den vielfältig formulierten Bescheidenheitstopoi im Liet von Troye jeweils einen «objektiven Wahrheitsgehalt» beimisst, der auf Herborts «mangelnde Praxis in der Dichtkunst» verweise (Zitate S. 283). 
bleibt. Der Vergleich wirkt also nur bei flüchtiger Lektüre bescheiden und ist ironisch zu verstehen. Dies erzeugt eine Sphäre besonderer Souveränität. Indem Herbort ein biblisches Gleichnis in dessen Gegenteil verkehrt, unterstreicht er seine klerikale Selbstinszenierung. Damit entpuppen sich die vermeintlichen Eigenabwertungen als klassische Bescheidenheitstopoi oder deren ironische Brechungen zum Zwecke des Selbstlobes.

Den naheliegenden Versuch, die stilistischen Eigenarten des Liet von Troye, die Herbort von anderen Bearbeitungen französischer Quellen unterscheiden und die damit in der Forschung Irritationen hervorgerufen haben, in Verbindung mit der lateinischen Trojatradition zu sehen, die Herbort als Gebildetem leicht zugänglich gewesen sein müsste, unternimmt zuerst Hermann Dunger, dies allerdings nur halbherzig und im Ergebnis ohne wesentlichen Erfolg. Ihm gelingt zwar der Nachweis, dass Herbort Kenntnisse von Ovid und Statius besessen haben muss, doch einen eigenständigen Rückgriff des mittelhochdeutschen Dichters auf weitere lateinische Quellen lehnt er kategorisch ab. ${ }^{17}$ Erst Worstbrock kann eine ganze Reihe von kleineren lateinischen Trojatexten zusammenstellen und deren Einfluss auf das Liet von Troye nachweisen. ${ }^{18}$ Hans Fromm setzt diesen Weg fort und macht dabei die wichtige Feststellung, dass «Herborts Kenntnis lateinischer Trojadichtung [...] wahrscheinlich weiter gespannt [war] als bis zu den Texten, die zufällig auf uns gekommen sind»; und er ergänzt an gleicher Stelle: «Die Frage, ob Herbort die Trojaepen des Simon gekannt hat oder nicht, erscheint mir zweitrangig. Es ist der Werktypus, der wichtig ist.» ${ }^{19}$ Es wird darauf zurückzukommen sein.

Im Fahrwasser von Fromm bewegt sich Elisabeth Schmid. ${ }^{20}$ Sie listet zahlreiche Belegstellen auf, die zeigen können, dass Herbort im Liet von Troye schulbuchmäßig rhetorische Verfahren im Sinne der brevitas aktualisiert. Dabei beschreibt sie nicht nur die abbreviatio als Habitus der Erzählerfigur, sondern meint zugleich vorführen zu können, wie auch das Handeln der Protagonisten von Eile bestimmt sei. Sie versteht dies als Indiz für das

17 Dunger (1869), S. 41: «doch nehmen wir nirgends eine Spur wahr, dass er diese lateinischen Quellen selbständig benützt habe».

18 Die Studie von Worstbrock (1963) ist noch immer maßgeblich.

19 Fromm (1993), S. 256.

20 Schmid (1997) und Schmid (1998). 
«Unbehagen des Klerikers» gegenüber dem zu bearbeitenden Stoff; Herbort habe seine Erzählung besonders schnell hinter sich bringen wollen, weil er sich bei der Textherstellung gelangweilt habe. ${ }^{21}$ Letztlich reiht sich damit auch Schmid in die Tradition der Abwertungen des Liet von Troye ein. Sie versucht, den Autor Herbort von dieser Negativeinschätzung auszunehmen, indem sie ihm einen Vorbehalt gegenüber dem eigenen Text unterstellt.

Ricarda Bauschke hat mehrfach vorgeschlagen, Herborts spezifische Darstellungsweise als Ausdruck einer bewusst vollzogenen Diskursmischung $\mathrm{zu}$ verstehen. ${ }^{22}$ Im Liet von Troye, so lautet die These, aktualisieren sich gleichermaßen zwei konkurrierende Erzählverfahren: zum einen die sogenannte adaptation courtoise, wie sie Hartmann, Wolfram und andere höfische Dichter in ihren Bearbeitungen altfranzösischer Vorlagen verfolgen, ${ }^{23}$ zum anderen die Verwendung abbreviatorischer Rhetorik, die insbesondere in der lateinischen Dichtungstradition gepflegt wird. Es entsteht durch diese Kontamination im Liet von Troye ein hybrider Text mit dem Ziel, höfisierende Dichtungsverfahren in ihre Grenzen zu verweisen. Während Fromm noch davon ausgeht, dass Herbort den Krieg selbst kritisiert habe, ${ }^{24}$ meint Bauschke, dass sich sein Impetus auf eine poetologische Dimension richtet, es Herbort also darauf anlegt, idealisierende Darstellungsmodelle, wie sie die höfische Dichtung kennzeichnen, $\mathrm{zu}$ demontieren und als rein utopische Konstrukte auszustellen. Herbort ist die höfisierende Bearbeitungstechnik altfranzösischer Quellen wohl bekannt gewesen, er hat sich ihr aber in wesentlichen Punkten absichtsvoll verschlossen. ${ }^{25}$

II.

In dem hier entworfenen Zusammenhang soll es nun in erster Linie um die andere Tradition gehen, die im Liet von Troye aufgerufen und fortgeschrie-

$21 \quad$ Schmid (1997), S. 207.

22 Zuerst in kleineren Vorstudien Bauschke (2003) und Bauschke (2004), dann als umfassender Entwurf Bauschke (2006).

23 Dazu grundlegend Bauschke (2006). Vgl. auch die unabhängig von Herbort angestellten Überlegungen zur adaptation courtoise in Bauschke (2005) und Bauschke (2012).

24 So die Hauptthese von Fromm (1993).

25 Am ausführlichsten in Bauschke (2006). 
ben wird, nämlich das abbreviatorische Erzählen von Troja, umgesetzt mit dem rhetorischen Rüstzeug des lateinisch Gebildeten. Gegen Ende des 12. Jahrhunderts finden sich auffallend viele Kurzbearbeitungen antiker Stoffe in lateinischer Sprache, der Untergang Ilions gehört dabei zu den bevorzugten Themen. ${ }^{26}$ Es wäre allerdings zu holzschnittartig, der Gruppe des höfischen Publikums, das mediävalisierende Antikenromane in der französischen beziehungsweise deutschen Volkssprache hörte, einfach nur eine geschlossene Gruppe klerikaler Troja-Leser gegenüberzustellen. Das ist in der Vergangenheit meist der Fall gewesen, wenn Herborts Oszillieren zwischen konkurrierenden Erzählverfahren beschrieben werden sollte. MarcRené Jung geht von verschiedenen Traditionssträngen und Adressatenkreisen sogar im lateinisch gebildeten Milieu aus. ${ }^{27}$ Für ihn gibt es drei Gruppen: 1. Kleriker mit antiker Bildung, welche die klassischen lateinischen Werke lasen; 2. Kleriker, die ihr Wissen über die Antike aus den Universalgeschichten bezogen, etwa der des Frechulf von Lisieux, der im 9. Jahrhundert eine anonyme Dares-Bearbeitung in seine erzählende Chronik integrierte $;^{28} 3$. Kleriker, die auf ekklesiastische Historiographie zurückgriffen, in der die griechische Geschichte praktisch nicht vorkam. ${ }^{29}$ Herbort wäre wohl einer einzelnen Gruppe nur schwer zuzuordnen, zumal sich die Frage stellt, ob die von Jung vorgenommene Kategorisierung wirklich in der von ihm postulierten Ausschließlichkeit anzusetzen ist. ${ }^{30}$ Dies betrifft bereits die Situation in Frankreich, für die Jung seine Überlegungen entwickelt, und gestaltet sich umso schwieriger für die deutschsprachige Antikenrezeption. So ließen sich unter Umständen - für Romania und Germania - gemischte Zuhörerkreise reklamieren, die sich aus Gelehrten und Laien zusammensetzen. Für das

26 Siehe dazu Worstbrock (1965).

27 Jung (1997) behandelt allgemein die Vermittlung griechischer Wissensarchive über die latinitas ins gelehrte Mittelalter. Volkssprachige Fassungen liegen nicht in seinem Fokus.

28 Frechulf hat im Rahmen seines Kompilationsprozesses die Historia Daretis Frigii de origine Francorum deutlich gekürzt, siehe dazu Jung (1997), S. $191 \mathrm{f}$.

29 Jung (1997), hier speziell S. 192.

30 Siehe dazu unten. 
deutsche Publikum wären ohnedies wohl andere Bildungsvoraussetzungen anzunehmen. ${ }^{31}$

Den Anfang der Werkreihe, die für die mittelalterliche Schullektüre relevant wird, macht im Prinzip bereits die Ilias Latina des Baebius Italicus. Sie markiert zugleich den Beginn der abbreviatorischen Trojarezeption. Schon im 1. nachchristlichen Jahrhundert entstanden, reduziert sie die 15.680 Verse des homerischen Epos auf 1.070 lateinische Verse. ${ }^{32}$ Es folgt eine auf lange Zeit relevante Phase verknappender Kurzprosa, namentlich verbunden mit Dictys Cretensis und den Ephemeridos belli Troiani libri33 sowie Dares Phrygius mit seiner De excidio Troiae historia. ${ }^{34}$ Die als Kriegstagebücher gestalteten Berichte betonen die Faktualität des Stoffes und bilden die Grundlage des mittelalterlichen Erzählens von Troja. ${ }^{35}$ Ihnen gegenüber steht bisher monolithisch das von Rawlinson entdeckte Excidium Troiae, eine von dem Dares-Strang gänzlich unabhängige Troja-Erzählung, einziger Beleg für das parallele Fortleben der antiken Tradition neben der Dares-Rezeption; auch das Excidium Troiae wechselt das Register hin zur Prosa. ${ }^{36}$ Die mittelalterlichen Redaktionen in lateinischer Sprache schlagen dann einen bemerkenswerten Weg ein: Sie reklamieren für sich einerseits wiederum Faktizität, sehen sich selbst also auf der Seite der Geschichtsschreibung, greifen zu einem großen Teil aber andererseits auf eine poetische Diktion zurück, indem sie zur gebundenen Rede wechseln. ${ }^{37}$ Auch diese Dichtungen folgen im größten Teil dem Prinzip der abbreviatio. Obwohl in

31 So urteilt in anderem Zusammenhang Mertens (1997).

32 Ausgabe durch Scaffai (1982). Vgl. auch den Beitrag von Christiane Reitz, in diesem Band.

33 Ergänzend zur Ausgabe durch Eisenhut (1973) siehe Marblestone (1970).

34 Vgl. die Ausgabe von Meister (1873) sowie deren Abdruck mit Übersetzung und anschließender Untersuchung durch Beschorner (1992).

35 Darüber handelt grundlegend Merkle (1990).

36 Siehe die Ausgabe von Atwood / Whitaker (1944).

37 Dies trifft etwa auf das aus 3.673 Hexametern bestehende, in sechs Bücher gegliederte Epos Frigii Daretis Ylias des Joseph Iscanus zu, das der Engländer aus Exeter zwischen Februar 1188 und Juni 1190 vollendet. Er distanziert sich von den heidnischen, die 〈Wahrheit〉 verdrehenden Dichtern und bezieht sich auf Dares als Quelle; dennoch scheut Joseph nicht die amplificatio mythologischer Anteile, die aus christlicher Sicht problematisch sind. Ausgabe durch Gompf (1970). 
der Volkssprache amplifizierende Versionen aufkommen, wie nämlich der Roman de Troie Benoîts um ca. 1160/70 und über ein Jahrhundert später der Trojanerkrieg Konrads von Würzburg, ${ }^{38}$ setzt sich in der lateinischen Dichtkunst die brevitas-Tradition auch im 13. Jahrhundert noch fort; Albert von Stade etwa wird 1249 in seinem Troilus eine zwölftägige Schlacht vor Troja in 14 Versen abhandeln. ${ }^{39}$

brevitas bleibt dabei stets eine relationale Kategorie, ${ }^{40}$ die sich auf die Länge der homerischen Ilias bezieht, welche im Mittelalter gar nicht bekannt war. Das ist nicht unproblematisch. Wird der «klassische〉 Strang (Vergil, Ovid, Ilias latina) mit der Dares-Rezeption, welche die antike Tradition nahezu ablöst, verglichen, dann zeigen die Werke, die den Acta diurna verpflichtet sind, durchaus amplifikatorische Tendenzen. Jung bietet eine Zusammenstellung, die das verdeutlichen kann:41 Die meist in Distichen verfassten Kurzresümees der «klassischen` Reihe setzen auf ein vorhandenes Bildungswissen und rufen im Prinzip nur die Erinnerung an den Trojanischen Untergang auf, ${ }^{42}$ während die in der Dares-Tradition stehenden Werke die trojanische Geschichte mit dem Impetus berichten, neues Wissen zu schaffen beziehungsweise altes Wissen einem neuen Publikum zu erschließen. ${ }^{43}$ Auch sie sind im Vergleich zur homerischen Ilias kürzer, zeigen in ihrer eigenen Gruppe jedoch eine Tendenz zur Längung. Im Falle des Pariser

38 Neben der Ausgabe von v. Keller (1958) nun die Neuedition durch Thoelen / Häberlein (2015) sowie grundlegend Lienert (1996).

39 Siehe dazu den Überblick bei Lienert (2001). Zu verschiedenen volkssprachigen Rezeptionsstufen vgl. auch Bauschke (2014).

40 Vgl. dazu grundsätzlich Baumbach / Bär (2012), S. ix -xxi. Zum relativen Kriterium epischer Länge im Kontext der antiken Kleinepik vgl. S. xiif.

41 Die Tabellen von Jung (1997) finden sich auf S. 195-197.

42 Jung (1997), S. 195, nennt Gottfried von Reims († 1095), Hildebert von Lavardin $(\dagger 1134)$, Baudri von Bourgueil ( $\dagger 1130)$, Pergama flere volo (CB 101), Fervet amore Paris (CB 102), Hugo Primas von Orléans (†1160), Petrus Sanctonensis (Mitte 12. Jahrhundert) u. a. Vgl. dazu auch die untenstehenden Ausführungen.

43 Hier nennt Jung (1997), S. 195, neben Joseph Iscanus die Ylias des Simon Aurea Capra sowie die anonyme Historia Daretis Frigii, siehe zu beiden ausführlicher unten. 
Kanonikers Simon Aurea Capra (Mitte 12. Jahrhundert) konzentriert sich das Phänomen in ein und demselben Dichter, weil Simon selbst eine Ylias in unterschiedlichen Fassungen verschiedener Länge herstellt. Jürgen Stohlmann $^{44}$ und noch Fromm ${ }^{45}$ gehen von drei bis vier Versionen aus, Sébastian Peyrard ${ }^{46}$ dagegen akzeptiert nur zwei völlig eigenständige Fassungen. Die knappste Version besteht aus 150 Distichen, die längste aus 497. Alle drei Philologen erkennen an, dass die Kurzfassung zuerst entsteht und in der Langfassung aufgeht beziehungsweise durch diese abgelöst wird. Damit ergibt sich - innerhalb der abbreviatorischen Trojaberichte betrachtet durchaus eine Tendenz zur amplificatio. Die Beurteilung, ob die Darstellung der brevitas oder der amplificatio verpflichtet ist, wird also zu einer Frage der Perspektive. Auf einer anderen Ebene bewegt sich zudem der Aspekt der Diktion; denn auch ein quantitativ umfängliches Werk kann auf der sprachlichen Oberfläche vom Darstellungsmodus her abbreviatorisch angelegt sein. Das ist bei Herbort der Fall.

III.

Die im mittelhochdeutschen Liet von Troye aktualisierten Verfahren des verkürzenden Sprechens erschließen sich im Spannungsfeld lateinischer Poetiken des Mittelalters. In ihnen wird die abbreviatio als Stilideal propagiert. Schon der in Paris nachweisbare Matthieu de Vendôme hebt in seiner 1175 entstandenen Ars versificatoria die Kürze als «moderne〉 Dichtungsweise hervor, obwohl er die Antithese von dilatatio und abbreviatio selbst nicht formuliert. ${ }^{47}$ Geoffroi de Vinsauf stellt in seiner vermutlich zwischen 1208 und 1213 entstandenen Poetria nova dann explizit amplificatio und abbreviatio einander gegenüber. ${ }^{48}$ Er liefert zudem einen Katalog mit sieben rhetorischen Mitteln für die abbreviatio, die Herbort im Liet von Troye alle umsetzt.

\footnotetext{
44 Stohlmann (1976).

45 Fromm (1993).

46 Peyrard (2017).

47 Vgl. Faral (1924/1958), S. 180 - 182. Siehe dazu auch Curtius $\left(1948 /{ }^{11} 1993\right)$, S. $481 \mathrm{f}$.

48 Abdruck der Poetria nova durch Faral, ebd., S. 197-262, zur Datierung S. 33. Vgl. grundsätzlich auch die Abhandlung von Kelly (1969).
} 
Es sind dies: Emphase, articulus, ablativus absolutus-Konstruktionen, Vermeidung von Wiederholungen, Ellipse und Allusion, asyndetische Reihungen, Verschmelzung beziehungsweise Zusammenfassung. ${ }^{49}$ Überall dort, wo die mittelhochdeutsche Sprachpraxis es zulässt, aktualisiert Herbort diese brevitas-Strategien und bewirkt dadurch seine verkürzende Darstellung des Trojastoffes. Wichtig dabei ist, dass weder die Poetik des Matthieu noch die des Geoffroi ein normatives Regelwerk bieten. Vielmehr fixieren beide mit der brevitas ein Stilprinzip, das einen festen Bestandteil der Schulrhetorik bildet und bereits praktiziert wird. In der Ausführung durch Herbort fallen oft mehrere Phänomene zusammen, was an einigen repräsentativen Beispielen vorgeführt werden soll.

Typisch für den Darstellungsstil im Liet von Troye sind asyndetische Reihungen:

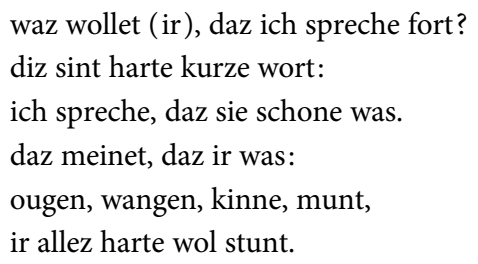

(vv. 8.569-8.574)

In der zitierten Passage wird die konjunktionslose Verbindung von Substantiven, die hier als versefüllendes Asyndeton ${ }^{50}$ gestaltet ist, mit Ellipse, Allusion und der semantischen Gedanken-Emphase verbunden, die Heinrich Lausberg - mit Quintilian als Gewährsmann - in der Unterdrückung, also dem Verzicht sprachlicher Materialisierung, realisiert sieht. ${ }^{51}$ Im konkreten Beispiel bedeutet dies, dass Herbort auf das konventionalisierte Frauenlob anspielt, eine echte descriptio aber ausspart und stattdessen den positiven Eindruck, der sich qua Beschreibung vermitteln sollte, in zwei Erzählerwertungen kondensiert: ich spreche, daz si schone was (v. 8.571) sowie ir allez harte wol stunt (v. 8.574). Sie umrahmen die eigentliche Schilderung, die als vierteiliges Asyndeton nur noch den Rumpf einer descriptio repräsentiert.

49 Die entsprechende lateinische Passage findet sich in Faral (1924/1958), S. 218 f. Dazu auch Bauschke (2006), S. 246-254.

50 Vgl. zu diesem Stilmittel den Beitrag von Raphael Schwitter, in diesem Band.

51 Lausberg $\left(1960 /{ }^{3} 1990\right), \S 905 \mathrm{f}$. 
Metapoetisch thematisiert wird das Verfahren durch die autoreferentielle Weigerung, ausführlicher zu beschreiben, wobei die rhetorische Frage das implizierte Publikum kommunikativ in die abbreviatorische Erzählweise einbindet. ${ }^{52}$ Eine solche Konzentration, die das Frauenlob summarisch und damit lakonisch wirkend abhandelt, ist Symptom einer erzählerischen Distanznahme, die sich entsprechend auf den Rezeptionsmodus (zustimmend oder ablehnend) auswirkt; denn im Sinne des Horaz'schen aptum sollen Gegenstand und Darstellungsweise miteinander korrespondieren.53 Wenn nun Herbort seiner Protagonistin eine umfängliche Entfaltung ihrer äußeren Vorzüge vorenthält, stellt er die Berechtigung ihres Lobes indirekt zur Disposition, und die vermeintliche laudatio entpuppt sich als ironische Brechung. ${ }^{54}$

Das Asyndeton ist oft in Kombination mit dem articulus-Phänomen zu finden, das Lausberg unter dem Stichwort comma abhandelt: ${ }^{.5}$

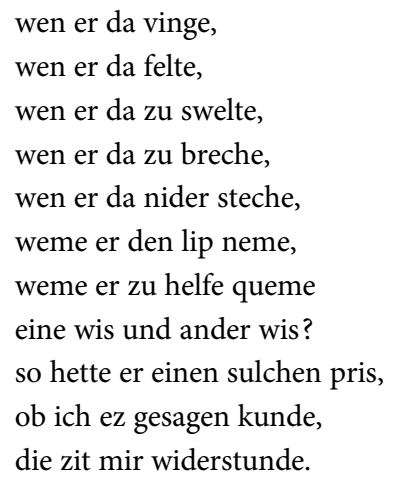

Wie Fragerhetorik, Rezipientenbezug und brevitas-Konzept ineinandergreifen, beobachtet für die Ilias Latina Reitz (2007), S. 334-351, bes. S. 347.

53 Die Bedeutung dieses Prinzips für die mittelalterliche Dichtkunst im Spiegel der amplificatio bespricht Worstbrock (1985), S. 4 f.

54 Auch die Ironie ist ein Habitus, der als typisch für den Erzählgestus im Liet von Troye gelten kann, darüber handeln Fromm (1993) und Bauschke (2006). Die gerade im Hinblick auf die Minnenarrationen häufigen ironischen Brüche diskutiert Bauschke (2017).

55 Lausberg $\left(1960 /^{3} 1990\right), \$ 935-940$. Nach Lausberg sind übliche lateinische Bezeichnungen caesum, incisium, particula, articulus. 
wolde ich die zit dar zu han, so muste ich ander rede lan.

(vv. $5.570-5.582)$

Die zahlreichen Kampfleistungen verschmelzen in einer zusammenfassenden Reihung der möglichen Arten, wie der Gegner überwunden werden kann; insbesondere der anaphorische Beginn wen er da vermittelt den Eindruck unzähliger Kontrahenten, wie es einer Massenschlacht vor Troja auch angemessen ist. Zugleich lassen sich die Verben in chronologischer Reihenfolge als verknappte Darstellung eines einzelnen Kampfablaufes lesen (Fangen, Umwerfen, Schwächen, Zerbrechen, Niederstechen, Töten). Diese im Krieg immer wiederkehrenden Vernichtungshandlungen konzentriert Herbort hier in einer verkürzten Schilderung..5 Der neue Gedanke weme er $z u$ helfe queme (v. 5.576) bringt neben der Aggression gegen den Feind dann auch kurz die Unterstützung für die eigenen Leute ins Spiel. Herbort erweitert damit die Perspektive und erzeugt mit wenigen Worten ein repräsentatives Gesamtbild kriegerischer Aktivitäten auf dem Schlachtfeld. Mit diesem darstellerischen Konzentrat kombiniert er eine indirekte praeteritio-Formel («Mir fehlt die Zeit; würde ich sie mir nehmen, fehlte sie für anderes, sprich: ich schreite jetzt voran`). ${ }^{57} \mathrm{Im}$ Liet von Troye werden also schulbuchmäßig abbreviatorische Verfahren aktualisiert, wobei die Verknüpfung mehrerer Phänomene die brevitas-Diktion noch potenziert. Zudem wird das verkürzende Sprechen als solches vom Erzähler thematisch gemacht. Laut Fromm hat Herbort dabei insbesondere die Ylias des Simon

56 Weitere Belege wären etwa die parallelisierende Aufzählung unterschiedlicher Todesarten: der lac erschozzen, / der lac erstochen, / dirre zu brochen, / dirre zu bletzet, / jener zu quexet, / dirre ertruncken, der ertrat (vv. 5.858-5.863), oder die summarische Aufstellung divergierender Kampfgründe: jegelicher durch daz rechte, / etlicher durch sin geslechte, I ettelicher durch fru[n]tschaft, / etlicher durch ritterschaft, / etlicher durch minne (vv. 4.083-4.087). Die Einzelmotivationen verschmelzen zu einer «Sammelbegründung〉 und zeigen damit, dass in den Massenschlachten großer Kriege der singuläre Kämpfer und seine inneren Dispositionen nivelliert werden.

57 Häufiger treten die expliziten Formulierungen der Kürzungsabsicht auf, z. B. daz ich die rede kurze (v. 4.080). Siehe dazu auch Frick (2020). 
Aurea Capra als stilistisches Vorbild gedient. ${ }^{58}$ Sie setzt in lateinischer Sprache das brevitas-Prinzip vorbildhaft um.

Die Dynamisierung der erzählten Vorgänge gelingt Herbort auch durch die Verwendung der percursio:

er sluc dem rosse in den bug,

dem ritter in den enkel,

dem pherde an den schenkel,

dem ritter durch daz bein.

er gemachte in zwein,

daz sie bi der erden

lam musten werden.

(vv. 9.060-9.066)

Jedes der genannten Details verdiente eine ausführlichere Behandlung. In der gerafften Darstellung aber kontaminieren Reiter und Pferd, und dies spiegelt das unübersichtliche Durcheinander im Krieg, wo einzelne Vorgänge zu einem großen Bild zusammenfließen. ${ }^{59}$ Das Beachtliche an einem solchen Verfahren ist, dass Herbort im höfischen Kontext, also für ein Publikum, das Jung deutlich von den verschiedenen klerikalen Rezipiententypen abgrenzt, ${ }^{60}$ eine rhetorische Tradition des Erzählens von Troja aufruft, die auf lateinischen Vorbildern fußt und damit gerade nicht dem höfischen Erwartungshorizont entspricht.

Herborts Abhängigkeit sowohl von der Dares-Linie als auch vom 〈klassischen`Strang geht über stilistische Aspekte weit hinaus. Zuerst Franz Josef Worstbrock $^{61}$ und dann Rüdiger Schnell ${ }^{62}$ können den Einfluss Ovids

58 Fromm (1993) liefert zahlreiche Beispiele; sie werden ergänzt durch Bauschke (2006).

59 Auch Hahn (1996) analysiert die Kriegsdarstellung, hat dabei aber insgesamt einen anderen Fokus. Vgl. ebenso die Überlegungen von Schmid (1998).

60 Jung (1997), S. 192. Vgl. auch meine obigen Ausführungen.

61 Worstbrock (1963), hier: S. 255 f. Er listet eine ganze Reihe von Bezugsmöglichkeiten auf und zieht daraus allgemeine Schlüsse auf Herbort als litteratus, eine vergleichende Detailanalyse der korrespondierenden Textpassagen unternimmt er nicht.

62 Schnell (1975) stellt seine Überlegungen in einen weiteren Rahmen mitteldeutscher Ovid-Rezeption und bezieht den Minnesänger Heinrich von Morungen mit ein. 
nachweisen. Einzelne Motive klingen an die Metamorphosen an; ${ }^{63}$ Jasons distanzlose Werbung um Medea scheint nach der Ars amatoria gestaltet zu sein. ${ }^{64}$ Die Kindheit Achills beim Kentauren Chiron ergänzt Herbort gegenüber seiner Quelle Benoît; er könnte dafür direkt auf die Achilleis des Statius zurückgegriffen haben ${ }^{65}$ oder aber, wie beim Sirenenabenteuer des Ulixes, auf die Fabeln des Hyginius. ${ }^{66}$ Die grausamen Kriegsdetails, die Herbort im Liet von Troye ausstellt, könnten, so urteilt Fromm, wiederum aus der Ylias des Simon Aurea Capra stammen. ${ }^{67}$ Das Bild der überwucherten Ruinen, wo Gräser und Büsche die Grundmauern des einst prächtigen Troja bewachsen, hat Herbort mit dem berühmten Carmen Buranum 101 gemein, Pergama

63 Die Ausweitung der Zauberkünste Medeas auf ihre Macht, die Bahn des Mondes zu verändern (des nachtes sie den manen beswur, / daz er hinderwer vur, vv. $575 \mathrm{f}$.), könnte ebenso an die Metamorphosen anklingen (te quoque, Luna, traho, quamvis Temesaea labores / aera tuos minuant, 7.207f.) wie Hectors affektische Rede (bin ich, der wilen bestunt / Cerberum den helle hunt, vv. $425 \mathrm{f}$.), mit der er an die Bezwingung des Cerberus erinnert (nec forma triplex tua, Cerbere, movit, 9.185). Zitate nach der Ausgabe von v. Albrecht (2010).

64 Die längere Passage mit Kleiderputzen und Näherrücken bespricht Schnell (1975), S. $141 \mathrm{f}$. Schulmeisterlich projiziert Herbort auf Jason ein Annäherungsverhalten, das Ovid in der Ars amatoria vorschlägt (Liet von Troye, vv. 701-712, bzw. Ars amatoria 1,139-151; Versangaben nach der Edition von Holzberg [2000]).

65 Die musischen, durch die Anleitung Chirons erworbenen Qualitäten Achills, auf die Herbort, vv. 6.294f. (ouch larte er in von spil / gefucheit maniger hande), anspielt, thematisiert Statius explizit: [...] modo dulcia notae / fila lyrae tenuesque modos et carmina monstrat / Chironis ducitque manum digitosque sonanti / infringit citharae (1,572-575). Statius zitiert nach Rupprecht (1984).

66 Die Episode der singenden Meerfrauen berichtet Hyginius recht sachlich (Fabula 125,13; Angabe nach Boriaud [2003]), während Ovid in der Ars amatoria (1,311-314) den Sirenenmythos auf das Liebesthema hin funktionalisiert und dabei den betörenden Gesang hervorhebt. Herborts Diktion (vv. 17.696-17.714) erinnert eher an den berichtenden Stil des Hyginius, während die Konzentration auf den Gesang ihn an Ovid heranrückt.

67 Fromm (1993). In Ovids Metamorphosen vorgebildet sind wiederum der vom Blut rot gefärbte Strand (12,71f.), die im Laufe des Kampfes heraushängenden Gedärme $(12,390)$ und die teilweise herausquellende Lunge (6,250), alles drastische Kriegsdetails, deren Verwendung die ältere Forschung Herbort vorgeworfen hat (s. o.). Vgl. dazu Hahn (1996), S. 112. 
flere volo. ${ }^{68}$ Aus den Acta diurna des Dares selbst könnten nicht nur die vielen Zeitangaben stammen, mit denen Herbort sein Liet von Troye strukturiert, ${ }^{69}$ sondern ganz grundsätzlich der historiographische Impetus, mit dem erzählt wird. Damit sind zahlreiche der Werke, die Jung anführt, in Herborts Trojaroman eingeflossen, ${ }^{70}$ oder anders formuliert: Das mittelhochdeutsche Liet von Troye hat Teil an einer Trojatradition, die lateinisch etabliert ist und mit dem Verfahren der brevitas operiert.

\section{IV.}

Dieses diffuse Bild vielfältiger Einflüsse unterschiedlichen Bedeutungsgrades zeigt die intensive Partizipation Herborts am gelehrten Trojadiskurs. Bleibt zwar der Status zahlreicher Interferenzen unklar (freie Assoziation, Nachahmung, Intertextualität), so lässt sich durchaus eine Kontaktlinie stärker konkretisieren; denn gerade Herborts neuartige Positionierung zwischen poetischer Überformung mit einem Rüstzeug schulrhetorischer Provenienz einerseits und angeblicher historiographischer Faktentreue andererseits ist nicht ohne Vorbild. Sie bestimmt vielmehr nachweislich eine um 1150 entstandene lateinische Dares-Versifikation, die sogenannte Anonymi Historia Troyana Daretis Frigii.71 Worstbrock macht auf den Text, der aus 918 Hexametern besteht, aufmerksam, allerdings nur ganz allgemein als Beleg für

68 Der lateinische Text (Abdruck mit Übersetzung von Vollmann [1987]) setzt mit einer Klage um die zerstörte Stadt ein, an deren vormaligem Standort nunmehr die Wildnis wuchert: Pergama flere volo, / fato Danais data solo, // Solo capta dolo, / capta redacta solo (1 f.). Herbort stimmt in diese Klage ein und nimmt das Naturmotiv auf, allerdings für seine Schilderung der ersten Zerstörung Trojas: owe schone geine, / owe burg reine, / daz da wassen sol daz gras / da die schone Troyge was, / busche unde heide (vv. 1.7371.741).

69 Das besondere Strukturphänomen erkennt zuerst Diebel (1921). Fromm (1993) deutet es im Hinblick auf seine These zur Kriegskritik bei Herbort; Bauschke (2006) fokussiert das metapoetische Potential.

$70 \quad$ Jung (1997). Siehe dazu oben die Anm. 41 u. 42.

71 Die Ausgabe von Stohlmann (1968) bietet zugleich eine umfangreiche Untersuchung, die das potentielle Referenzmaterial des Werkes aufarbeitet. 
die lateinische Trojatradition. ${ }^{72}$ Die tieferen Verbindungen mit dem Liet von Troye erkennt er nicht, und dies, obwohl Herbort selbst einen intertextuellen Bezug herstellt. In seinem bescheidenheitstopisch aufgeladenen Prolog reklamiert Herbort für sich, das fünfte Rad am Troja-Wagen zu sein:

wil ich die formen merken, so muz ich drisinnic sin;

eine ist kriechisch, ein latin unde des welschen buches ein. zwischen den lesten sinnen zwein nim ich nu den dritten unde folge im so mitten, daz er min rechte geleite ist an des tutschen buches list. nu hant ez ander lute gemachet me ze dute; den ist ez vil wol gelungen. sint ez aber von drin zungen mit eime sinne ist her gescriben, des bin ich dar zu beschiben, daz ich si daz fierde rat. daz ist rechte sus bestat: sint ich von den drin quam, daz man mich zu dem fierden nam. hat ez ein ander follen bracht als ich zu dem fierden wart gedacht, so zele man mich zu dem funften rade; unde frume ich niht, ich bin niht schade. ich buwe doch die strazzen, die sie hant gelazzen manigen rat ane bane, unde baniche minen sin dar ane (vv. 62-88)

Eigentlich müsste Herbort nach den drei vorangehenden Stufen «Griechisch〉, 〈Latein〉, 〈Französisch〉 nun mit dem 〈Deutschen〉 als viertem Rad den Wagen komplettieren, stattdessen zieht er sich freiwillig auf den fünften Platz eines Deichselrades zurück, weil ihm dies eine Bahn außerhalb der eingefah- 
renen Spuren ermöglicht. ${ }^{73}$ Ein solcher Novitätsanspruch ist alles andere als bescheiden, die captatio benevolentiae damit durchschaubare Maske, hinter der sich ein großes Selbstbewusstsein verbirgt. Auch die Formulierung unde frume ich niht, ich bin niht schade (v. 84) ist ein gängiger Topos. Beachtlich scheint nun, dass sich eine vergleichbare Phrase ebenso in der anonymen Historia Troyana findet: Obsecro, ut, si que scribo nulli videant profutura, nulli tamen intelligant nocitura ( $9 \mathrm{f}$., <Wenn das, was ich schreibe, keinem nützlich scheinen sollte, so schwöre ich, dass es dennoch keinem zum Schaden gereichen wird $)$. Der in Prosa verfasste Prolog zeigt mithin eine Erzählerhaltung, die auch Herbort verwendet. Überdies enthält das Proömium des lateinischen Werkes weitere Elemente, die für das Liet von Troye eine Rolle spielen:

Historiam Troye figmenta poetica turbant; Unde licet magnis Fortuna sit invida ceptis Dignaque tam longis non sit michi buccina bellis, Mens tamen incaluit vestigia fida sequendo Daretis Frigii Troyanum scribere bellum. At michi Cyrreo, si quis respondet, ab antro Ad mea scripta deum non estimo sollicitandum,

Den Prolog interpretieren in jüngerer Zeit Bauschke (2006), Kellner (2006) und Herberichs (2010). - Eine Krux der Forschung liegt in der Interpretation von vv. 66-68: zwischen den lesten sinnen zwein / nim ich nu den dritten / unde folge im so mitten. Joseph (1886), S. 397, urteilt: «Zwischen den lesten sinnen zwein, d. i. dem lateinischen und dem welschen, Nim ich nû den dritten, d. i. das welsche, nämlich als drittes glied der ganzen reihe.» (Graphie und Orthographie nach dem Original). Problematisch an dieser Deutung bleibt, dass Herbort zwei verschiedene Zählweisen anwenden und diese - ohne erklärende Markierung - ineinander verschränken müsste. Angesichts seiner stringenten, durchsichtigen und ausführlichen vorangegangenen Prologargumentation scheint eine solch kryptische Formulierung eher unwahrscheinlich. Entsprechend zieht schon Baesecke (1908), S. 368, eine andere Interpretation in Erwägung: «66/67 möchte man, besonders auch wegen mitten 68 so deuten, dass der neue weg zwischen dem zweiten und dritten ligt [sic], dass also Herbort die französische un d die lateinische vorlage benutzt hätte.» (Graphie und Orthographie nach dem Original). Baesecke wird diese Option später fallen lassen, doch angesichts des Befundes, den die Analyse durch Bauschke (2006) hervorgebracht hat, nämlich dass Herbort sowohl den Roman de Troie als auch lateinische Referenztexte als Vorlage benutzt, ist zu ihr zurückzukehren. 
Scilicet Aoniis me iudice vatibus impar.

At cui mira magis quam vera canenda videntur,

Ille caballinam scripturus vadat ad undam,

Ut virides hedere cingant ornentque poetam.

Non ego sum, quoniam nil fingo, poeta vocandus.

(vv. 1-12)

«Die poetische Gestalt stört die Geschichte von Troja: Auch wenn Fortuna gegenüber dem großen Unterfangen missgünstig und das Horn des langen Krieges mir nicht so würdig sein mag, brannte der Geist dennoch darauf, den zuverlässigen Spuren zu folgen und den Trojanischen Krieg des Dares Phrygius zu beschreiben. Wenn aber ein Gott [quis: erg. deus] aus der Höhle bei Cirra Orakel erteilt, glaube ich nicht, diesen meiner Schriften wegen beunruhigen zu müssen, mag er auch nach meinem Urteil den Musen des Helikon ungleich sein. Wem aber das zu Besingende eher wundersam als wahr scheint, der möge zum Schreiben auf die Pferdeweide schreiten, damit grünender Efeu den Dichter umgibt und schmückt. Weil ich nichts erdichte, bin ich nicht Dichter zu nennen.>

Gleich der erste Vers artikuliert den Vorwurf, poetische Überformungen verfälschten die historische Wahrheit, und auch in der wirkungsvollen Abschlusssentenz distanziert sich der Anonymus von den poetischen Umsetzungen des Trojastoffes. In der Praxis der nachfolgenden Dichtung wird sich der Historia Troyana-Verfasser dann allerdings ebenso als poeta zeigen und nicht als Historiograph; die Ablehnung der Bezeichnung in Vers 12 ist mithin rein kosmetischer Natur. ${ }^{74}$ Ganz in der Dares-Tradition stehend, dichtet dann auch der Anonymus unter den Vorzeichen der brevitas:

Advexit notam Troyanus adulter amicam

Famam, iura, fidem, patriam, bona multa, parentes

Postponens turpi - furor o crudelis - amori

(vv. 13-15)

«Der ehebrecherische Trojaner [i. e. Paris] hat die berühmte Geliebte hergeführt und stellte - oh grausame Raserei - die schändliche Liebe über Ruf, Gesetze, Treue, Heimat, großen Reichtum, Eltern.>

Es finden sich mit der asyndetischen Reihung, der Emphase und der Allusion die typischen verkürzenden Verfahren, welche die zeitgenössische lateinische

74 Knapp (1980) bespricht die unterschiedlichen Erzählerinszenierungen im Spannungsfeld von Geschichte und Fiktion. 
Tradition des Erzählens von Troja ausmachen und die auch den Stil des mittelhochdeutschen Liet von Troye prägen. Es scheint daher durchaus plausibel, dass Herbort die Historia Troyana als eine maßgebliche lateinische Bezugsquelle benutzt hat. ${ }^{75}$

\section{v.}

Der handschriftliche Befund kann diese Einschätzung stützen und dabei noch Weiteres zutage fördern: Zwei der insgesamt fünf Manuskripte, in denen die Historia Troyana überliefert ist, bieten ein regelrechtes TrojaPotpourri. ${ }^{76}$ Insbesondere der Pariser Pergament-Codex 8430 aus dem letzten Drittel des 13. Jahrhunderts spielt für die Beurteilung von Herborts dichterischer Tätigkeit eine zentrale Rolle. ${ }^{77}$ Die Sammelhandschrift enthält Bernards von dem Geist Palpanista, eine Hofsatire gegen Schmeichler in 1.007 Hexametern, deren durchrhetorisierte Sprache mit Parallelismen und

75 Stohlmann (1968), Zusammenfassung S. 198, sieht allgemeine Übereinstimmungen der Historia Troyana mit Pergama flere volo und Troja-Stücken des Gottfried von Reims, des Baudri von Bourgueil, des Petrus Sanctonensis und des Hugo Primas von Orléans. Sichere Verbindungen konstatiert er zur Ylias des Simon Aurea Capra und zu Benoîts Roman de Troie. Eine Kenntnisbeziehung setzt er voraus zur Frigii Daretis Ylias des Joseph Iscanus und zur Alexandreis Walthers von Châtillon, wobei nicht sicher sei, wer von wem abhänge. Neben der Hauptquelle Dares hat laut Stohlmann wohl auch Albert von Stade für seinen Troilus die Historia Troyana benutzt. Dass Herborts Liet von Troye unerwähnt bleibt, resultiert wohl aus der üblichen Vernachlässigung des Werkes in der Forschung im Zeitraum von Stohlmanns Publikation.

76 Allgemeine Informationen zur Überlieferungssituation liefert Stohlmann (1968) im Eingang zu seiner kritischen Textausgabe.

77 Das Manuskript im Quartformat (21,3 x 14,5 cm), 77 Blätter, ist zweispaltig beschrieben und mit rubrizierten Initialen versehen. Die Historia Troyana beginnt auf fol. $9^{\text {ra }}$ und endet $16^{\mathrm{vb}}$. Eine ausführliche Handschriftenbeschreibung bieten Stohlmann (1968) und Peyrard (2007). Die Handschrift selbst ist in einem fragilen Zustand; durch die defekte Lagenbindung drohen zahlreiche Doppelblätter auseinanderzufallen. Ich danke der Bibliothèque National in Paris, dass ich das Manuskript im Februar 2019 dennoch einsehen durfte. 
Asyndesen arbeitet. ${ }^{78}$ Es folgt von der gleichen Hand die anonyme Historia Troyana Daretis Frigii, die eine spätere Hand aus dem 17. Jahrhundert Dares selbst zuschreibt. ${ }^{79}$ Im Typ einer Kopfzeile nimmt diese deutlich jüngere Hand auch bei den anderen Werken Identifizierungen und Zuordnungen vor. Auf die Historia Troyana folgt von einer zweiten mittelalterlichen Hand die Ylias des Simon Aurea Capra in ihrer langen Version, wobei nach ca. der Hälfte der Abschrift die Hand wechselt und wieder der erste Schreiber zum Zuge kommt. Von ihm stammen auch die beiden sich anschließenden Werke Ovids, die Ars amatoria und die Amores, sowie das kurze Carmen Hildeberts von Lavardin, De humano semine. ${ }^{80}$ Eine dritte Hand fügt das Carmen Buranum Pergama flere volo an, das vom Layout nahtlos übergeht in den Beginn von Viribus arte minis, einer Destructio Troiae in 62 leoninischen Distichen von Petrus Sanctonensis, ebenfalls Mitte 12. Jahrhundert. ${ }^{81}$ Die vierte und letzte Hand trägt eine anonyme Elegie mit dem Titel Pamphilus

78 Bernard von dem Geist, auch Bernardus Geystensis, dichtete den Palpinista zwischen 1246 und 1250, vgl. hierzu Stohlmann (1968), S. 237.

79 Stohlmann, ebd., S. 235 f. und S. 240 f., unterscheidet lediglich zwei Schreiber, einen für die gesamte Textabschrift und eine spätere Hand aus dem 17. Jahrhundert, welche die einzelnen Werke durch Überschriften identifiziert. Diese jüngere Hand korrespondiert mit dem Besitzereintrag auf fol. $1^{\mathrm{r}}$. Dass alle mittelalterlichen Stücke auf nur einen Schreiber zurückgehen, lässt sich aufgrund meiner Autopsie nicht halten. Stohlmann, der das Manuskript selbst nicht im Original einsehen konnte, ignoriert zudem die brieflichen Informationen, die ihm der Pariser Bibliothekar und eine Forscherin des Institut de Recherches Paris übermittelt haben; beide plädieren für mehrere Hände.

80 Hildebert von Lavardin $\left({ }^{\star} 1056, \uparrow 1133\right)$ war Erzbischof von Tours und als Verfasser von Traktaten und Dichtungen sehr produktiv. Siehe dazu v. Moos (1965).

81 Manitius (1931), Bd. III, S. 647, berichtet von Überlieferungsverbünden, die das Gedicht des Petrus Sanctonensis fälschlich mit dem ersten Buch von Simon Aurea Capra verknüpfen. Der Bericht steigt mit einer allgemeinen Klage über den Untergang Trojas ein, weist Helena die Schuld zu, fasst den Angriff auf die Stadt und die List mit dem hölzernen Pferd zusammen, erwähnt die Ruinen als Wohnort wilder Tiere, springt dann in die Aeneas-Geschichte, wo er den Kampf gegen Turnus und die Verbindung mit Lavinia anspricht, um daraus schließlich die Gründungsgeschichte des römischen Volkes und dessen Weltherrschaft abzuleiten. 
ein, ${ }^{82}$ die Verskomödie Geta des Vitalis von Blois, ${ }^{83}$ in welcher der Amphitryon-Stoff verarbeitet wird, sowie alle sechs bekannten Elegien des Maximianus. ${ }^{84}$ Am Schluss verzeichnet nochmal die erste Hand ein Mini-Exzerpt der Ovid'schen Heroides. In konzentrierter Form repräsentiert das Manuskript mittelalterliches Antikewissen mit zwei Schwerpunktthemen: Troja und Liebe. ${ }^{85}$

Aus der Zusammenstellung lassen sich zahlreiche Schlüsse ziehen:

1. Die oben skizzierte, von Jung vorgenommene kategorische Blockbildung differenter Adressatenkreise wird problematisch. Offensichtlich konnte sehr wohl die Rezeption klassischer antiker Dichtung und mittelalterlicher Aneignungen auf ein gemeinsames Publikum zielen. Herbort in jedem Fall war ein Kleriker, der sich für seine volkssprachige Dichtung aus beiden lateinischen Traditionen bedient hat.

2. Herborts Kompilationstätigkeit erscheint weit weniger spektakulär als bisher angenommen. Wenn die von ihm verwendeten Referenztexte sich in einem Manuskript zusammenschließen können, lässt dies zum einen vermuten, dass es weitere und ältere Sammelhandschriften dieses Typs gegeben haben wird, die bereits Herbort benutzen konnte; zum anderen bezeugt das Pariser Manuskript als Abbild bestimmter Rezeptionsgewohnheiten, dass die Zusammenschau der betreffenden Werke ein völlig naheliegender Vorgang ist, sozusagen

82 Pamphilus ist die Hauptfigur zweier lateinischer Komödien, siehe dazu Manitius (1931), Bd. III, S. 1026-1028 (Pamphilus und Gliscerium) und S. 1032-1034 (Pamphilus de Amore).

83 Der Geta des Vitalis von Blois geht auf eine Komödie des Plautus zurück und ist als eine die antike Dichtung verkürzende Version - wohl um 1150 entstanden. Edition durch Paeske (1976).

84 Maximianus (Mitte 6. Jahrhundert n. Chr.) stellt als lateinischer Dichter der Spätantike ein Bindeglied zwischen antiker (Ovid) und mittellateinischer Dichtung (Hildebert, Vitalis, Simon) dar. Die Handschrift versammelt damit Werke einer umfassenden chronologischen Spannbreite. Siehe Schneider (2003).

85 Die Historia Troyana steht also im Überlieferungsverbund mit mehreren der Werke, zu denen Stohlmann (1968) inhaltliche Verbindungen ermittelt hat; siehe die obige Auflistung in Anm. 75. 
eine in klerikalen Kreisen gängige Praxis, an der auch Herbort teilhat.

3. Die Bedeutung der anonymen Historia Troyana für Herborts Liet von Troye ist offenbar noch nicht ausreichend untersucht worden. Die Forschung hat sich sehr auf die Analysen von Fromm ${ }^{86}$ verlassen und in erster Linie Herborts Bezug auf die Ylias des Simon Aurea Capra fortgeschrieben, anstatt nach ergänzenden Parallelquellen zu suchen.

\section{VI.}

Im Spiegel der abbreviatorischen Troja-Werke wie der anonymen Historia Troyana und der Ylias des Simon müssen wohl Herborts Selbstaussagen in Prolog und Epilog differenzierter betrachtet werden. Der Hinweis, das Liet von Troye nicht zu erweitern (so lenge ich ez mit willen niht, v. 97), markiert gegenüber Benoîts amplifizierender höfischer Darstellungsweise ablehnende Distanz. Bezogen auf die klerikale Trojatradition aber ist es der Versuch, eine insgesamt zu lang geratene deutsche Nachdichtung dennoch an die Reihe lateinischer Erzählungen von Troja anzuschließen. Herbort bewegt sich damit in der Tat auf einer Spur ane bane (v. 87): Für die gewählte Sprache und die Erwartungen, die er mit dem Rückgriff auf Benoît erzeugt, gerät sein Trojaroman zu kurz; im Hinblick auf die lateinischen Troja-Entwürfe, die Herbort als rhetorisches Modell verwendet, amplifiziert er jedoch das Thema. Was für Fromm wie Kriegskritik wirkt oder Schmid als Langeweile deutet, ${ }^{87}$ setzt eine von Benoîts Roman de Troie kommende Perspektive voraus. Vermutlich aber ist das stilistische Gewand der brevitas, in welches Herbort seinen Trojaroman kleidet, ein Mittel, um den amplifikatorischen Umgang mit der klerikalen Tradition zu verhüllen. Die abbreviatorische Rhetorik kaschiert die inhaltliche Längung. Auch für die Epilogaussage wäre damit noch mal neu zu prüfen, ob Herbort nicht ganz bewusst zwei Dichtertypen gegeneinander ausspielt: 
doch so nimet er sis an

mit andern tichteren,

der schar wil er meren.

(vv. 18.454-18.456)

Auf beide Inszenierungsgesten bezogen, die des höfischen Amplifizierers und die des lateinischen Abbreviators, bleibt Herbort selbst stets ein Grenzgänger, nicht aus Unvermögen, sondern weil die Verquickung beider Paradigmen auf deren jeweilige aemulatio zielt.

\section{Bibliographie}

\section{Primärliteratur}

Baebii Italici Ilias latina, hg.v. Marco Scaffai, Bologna 1982 (Edizioni e saggi universitari di filologia classica 28).

Le Roman de Troie par Benoît de Sainte-Maure, hg.v. Léopold Constans, 6 Bde., Paris 1904-1912, Nachdruck New York / London 1968.

Carmina Burana. Texte und Übersetzungen, hg.v. Benedikt Konrad Vollmann, Frankfurt a. M. 1987 (Bibliothek des Mittelalters 13).

Daretis Phrygii De excidio Troiae historia, hg.v. Friedrich Meister, Leipzig 1873.

Dictys Cretensis Ephemeridos belli Troiani libri a Lucio Septimio ex graeco in latinum sermonem translati, hg.v. Werner Eisenhut, Leipzig 1973.

Excidium Troiae, hg.v. Elmar Bagby Atwood / Virgil K. Whitaker, Cambridge (Mass.) 1944.

Herbort's von Fritslâr liet von Troye, hg.v. Karl Frommann, Quedlinburg / Leipzig 1837

(Bibliothek der gesammten deutschen National-Literatur von der ältesten bis auf die neuere Zeit 5), Nachdruck Amsterdam 1966.

Anonymi Historia Troyana Daretis Frigii. Untersuchungen und kritische Ausgabe, hg.v. Jürgen Stohlmann, Wuppertal u. a. 1968 (Beihefte zum Mittellateinischen Jahrbuch 1).

Hygin, Fables, hg.v. Jean-Yves Boriaud, Paris 2003 (Collection des universités de France 344).

Joseph Iscanus, Frigii Daretis Yliados libri sex, Werke und Briefe, hg.v. Ludwig Gompf, Leiden / Köln 1970 (Mittellateinische Studien und Quellen 4).

Konrad von Würzburg, Der Trojanische Krieg, hg.v. Adalbert v. Keller, Stuttgart 1958 (StLV 44), Nachdruck Amsterdam 1965.

Konrad von Würzburg, Trojanerkrieg und die anonym überlieferte Fortsetzung. Kritische Ausgabe v. Heinz Thoelen / Bianca Häberlein, Wiesbaden 2015 (Wissensliteratur im Mittelalter 51). 
Publius Ovidius Naso, Liebeskunst - Ars Amatoria. Lateinisch / Deutsch, hg. u. übers. v. Niklas Holzberg, Düsseldorf / Zürich 2000.

Publius Ovidius Naso, Metamorphosen. Lateinisch / Deutsch, hg. u. übers. v. Michael v. Albrecht, Stuttgart 2010 (RUB 1360).

Publius Papinius Statius, Achilleis. Das Lied von Achill. Lateinischer Text mit Einleitung, Übersetzung, kurzen Erläuterungen, Eigennamenverzeichnis und Nachwort, hg.v. Hermann Rupprecht, Mitterfels 1984.

Der Geta des Vitalis von Blois. Kritische Ausgabe v. Arnold Paeske, Köln 1976.

\section{Forschungsliteratur}

Baesecke, Georg: Herbort von Fritzlar, Albrecht von Halberstadt und Heinrich von Veldeke, in: ZfdA 50 (1908), S. 366-382.

Baumbach, Manuel / Bär, Silvio: A Short Introduction to the Ancient Epyllion, in: dies. (Hgg.): Brill's Companion to Greek and Latin Epyllion and Its Reception, Leiden 2012.

Bauschke, Ricarda: Geschichtsmodellierung als literarisches Spiel. Zum Verhältnis von gelehrtem Diskurs und Geschichtswahrheit in Herborts Liet von Troye, in: Christa Bertelsmeier-Kierst / Christopher Young (Hgg.): Eine Epoche im Umbruch. Volkssprachliche Literalität 1200-1300. Cambridger Symposium 2001, Tübingen 2003, S. 155-174.

Bauschke, Ricarda: Strategien des Erzählens bei Herbort von Fritzlar. Verfahren interdiskursiver Sinnkonstitution und ihr Scheitern im Liet von Troye, in: Wolfgang Haubrichs / Eckart Conrad Lutz / Klaus Ridder (Hgg.): Erzähltechniken und Erzählstrategien in der deutschen Literatur des Mittelalters, Berlin 2004 (Wolfram-Studien XVIII), S. 347-365.

Bauschke, Ricarda: adaptation courtoise als «Schreibweise`. Rekonstruktion einer Bearbeitungstechnik am Beispiel von Hartmanns Iwein, in: Elizabeth Andersen / Manfred Eikelmann / Anne Simon (Hgg.): Texttyp und Textproduktion in der deutschen Literatur des Mittelalters, Berlin / New York 2005 (Trends in Medieval Philology 7), S. 65-84.

Bauschke, Ricarda: Herbort von Fritzlar, Liet von Troye. Antikerezeption als Diskursmontage und Literaturkritik, Habilitation (masch.), FU Berlin 2006.

Bauschke, Ricarda: Chrétien und Wolfram. Erzählerische Selbstfindung zwischen Stoffbewältigung und Narrationskunst, in: Klaus Ridder (Hg.): Wolframs ParzivalRoman im europäischen Kontext, Berlin 2012 (Wolfram-Studien XXIII), S. 113130.

Bauschke, Ricarda: Der altfranzösische Trojaroman. Die mhd. Trojaromane, in: Geert H. M. Claassens / Fritz Peter Knapp / Hartmut Kugler (Hgg.): Historische und religiöse Erzählungen, Berlin / Boston 2014 (GLMF 4), S. 117-127; 127-150. 
Bauschke, Ricarda: Komische Ausgleichsstrategien des «Tragischen〉 im Minnediskurs des Liet von Troye, in: Regina Toepfer (Hg.): Tragik und Minne, Heidelberg 2017 (Studien zu Literatur und Erkenntnis 12), S. 155-176.

Benecke, Georg / Müller, Wilhelm / Zarncke, Friedrich: Mittelhochdeutsches Wörterbuch [BMZ], 3 Bde., Leipzig 1854-1861, 3. Nachdruckaufl. Hildesheim u. a. 1986.

Beschorner, Andreas: Untersuchungen zu Dares Phrygius, Tübingen 1992 (Classica Monacensia 4).

de Boor, Helmut/ Newald, Richard: Geschichte der deutschen Literatur von den Anfängen bis zur Gegenwart. Bd. 2: Helmut de Boor: Die höfische Literatur. Vorbereitung, Blüte, Ausklang. 1170-1250, 1. Aufl. 1949, 11. Aufl. bearb. v. Ursula Hennig, München 1991.

Curtius, Ernst Robert: Europäische Literatur und lateinisches Mittelalter, Bern 1948, 11. Aufl., Tübingen / Basel 1993.

Diebel, C. H.: Ein eigentümliches Ordnungsprincip bei Herbort von Fritslar, in: PBB 45 (1921), S. 467-472.

Dunger, Hermann: Die Sage vom trojanischen Kriege in den Bearbeitungen des Mittelalters und ihre antiken Quellen, Leipzig 1869.

Ehrismann, Gustav: Geschichte der deutschen Literatur bis zum Ausgang des Mittelalters, Teil II,2/1: Die mittelhochdeutsche Literatur. Blütezeit, München 1927 (Handbuch des Deutschen Unterrichts an höheren Schulen, Bd. 2,2,II,1).

Faral, Edmond: Les arts poétiques du XII ${ }^{e}$ et du XIII ${ }^{e}$ siècle. Recherches et documents sur la technique littéraire du moyen age, Paris 1924, Nachdruck 1958 (Bibliothèque de l'École des Hautes Études 238).

Frick, Julia: ez wâre ze sagene al ze lank. Zum Stellenwert der 〈Kürze-Topoi〉 im mittelhochdeutschen Antikenroman, in: ZfdPh 139 (2020), S. 353-378.

Fromm, Hans: Herbort von Fritslar. Ein Plädoyer, in: PBB 115 (1993), S. 244-278.

Hahn, Reinhard: Zur Kriegsdarstellung in Herborts von Fritzlar Liet von Troye, in: Kurt Gärtner / Ingrid Kasten / Frank Shaw (Hgg.): Spannungen und Konflikte menschlichen Zusammenlebens in der deutschen Literatur des Mittelalters. Bristoler Colloquium 1993, Tübingen 1996, S. 102-112.

Herberichs, Cornelia: Poetik und Geschichte. Das Liet von Troye Herborts von Fritzlar, Würzburg 2010 (Philologie der Kultur 3).

Huby, Michel: L'adaptation des Romans courtois en Allemagne au XII ${ }^{e}$ et au XIII ${ }^{\mathrm{e}}$ siècle, Paris 1968 (Publications de la faculté des lettres et sciences humaines de ParisNanterre).

Huby, Michel: Zur Definition der adaptation courtoise. Kritische Antwort auf kritische Anmerkungen, in: GRM 33 N. F. (1983), S. 301-322.

Johnson, L. Peter: Die höfische Literatur der Blütezeit, in: Joachim Heinzle (Hg.): Geschichte der deutschen Literatur von den Anfängen bis zum Beginn der Neuzeit, Bd. 2: Vom hohen zum späten Mittelalter, Teil 1, Tübingen 1999. 
Joseph, Eugen: Die Zeugnisse für eine deutsche Trojadichtung vor Herbort, in: ZfdA 30 (1886), S. 395-399.

Jung, Marc-René: L'histoire grecque: Darès et les suites, in: Emmanuèle Baumgartner / Laurence Harf-Lancner (Hgg.): Entre fiction et histoire: Troie et Rome au Moyen âge, Paris 1997, S. 185-206.

Kellner, Beate: Daz alte buoch von Troye [...] daz ich ez welle erniuwen. Poetologie im Spannungsfeld von ‘wiederholen) und «erneuern` in den Trojaromanen Herborts von Fritzlar und Konrads von Würzburg, in: Gert Dicke / Manfred Eikelmann / Burkhard Hasebrink (Hgg.): Im Wortfeld des Textes. Worthistorische Beiträge zu den Bezeichnungen von Rede und Schrift im Mittelalter, Berlin / New York 2006 (Trends in Medieval Philology 10), S. 231-262.

Kelly, Douglas: Theory of Composition in Medieval Narrative Poetry and Geoffrey of Vinsauf's Poetria Nova, in: Mediaeval Studies 31 (1969), S. 117-148.

Knapp, Fritz Peter: Historische Wahrheit und poetische Lüge. Die Gattungen weltlicher Epik und ihre theoretische Rechtfertigung im Hochmittelalter, in: DVjs 54 (1980), S. 581-635, wiederabgedruckt in: ders.: Historie und Fiktion in der mittelalterlichen Gattungspoetik. Sieben Studien und ein Nachwort, Heidelberg 1997 (Beiträge zur älteren Literaturgeschichte), S. 9-64.

Lausberg, Heinrich: Handbuch der literarischen Rhetorik. Eine Grundlegung der Literaturwissenschaft, Stuttgart 1960, 3. Aufl. mit einem Vorwort v. Arnold Arens, Stuttgart 1990.

Lienert, Elisabeth: Geschichte und Erzählen. Studien zu Konrads von Würzburg Trojanerkrieg, Wiesbaden 1996 (Wissensliteratur im Mittelalter 22).

Lienert, Elisabeth: Deutsche Antikenromane des Mittelalters, Berlin 2001 (Grundlagen der Germanistik 39).

Manitius, Max: Geschichte der lateinischen Literatur des Mittelalters, Bd. 3: Vom Ausbruch des Kirchenstreites bis zum Ende des zwölften Jahrhunderts, München 1931 (Handbuch der Altertumswissenschaft Abt. 9 / Teil 2, Bd. 3).

Marblestone, Howard Jeffrey: Dictys Cretensis. A Study of the Ephemeris Belli Troiani as a Cretan Pseudoepigraphon, Diss., Brandeis Univ. 1970.

Menhardt, Hermann: Herbortstudien, in: ZfdA 65 (1928), S. 225-254; 66 (1929), S. 173-200; 77 (1940), S. 256-264.

Merkle, Stefan: Troiani belli verior textus. Die Trojaberichte des Dictys und Dares, in: Horst Brunner (Hg.): Die deutsche Trojaliteratur des Mittelalters und der Frühen Neuzeit, Wiesbaden 1990 (Wissensliteratur im Mittelalter 3), S. 490-522.

Mertens, Volker: Dialog über die Grenzen: Minnesänger - Trobadors - Trouvères. Intertextualität in den Liebesliedern Rudolfs von Fenis, in: Ulrich Müller u. a. (Hgg.): Kritische Fragen an die Tradition. Festschrift Claus Träger, Stuttgart 1997 (StAG 340), S. 15-41. 
von Moos, Peter: Hildebert von Lavardin, 1056-1133. Humanitas an der Schwelle des höfischen Zeitalters, Stuttgart 1965 (Pariser Historische Studien 3).

Pérennec, René: Recherches sur le roman arthurien en vers en Allemagne au XII ${ }^{\mathrm{e}}$ et XIII ${ }^{\mathrm{e}}$ siècles, 2 Bde., Göppingen 1984 (GAG 393 I/II).

Peyrard, Sébastien: L'Ilias de Simon Chèvre d'Or. Diplôme d'archiviste paléographe. École nationale des Chartes, Paris 2017.

Reitz, Christiane: Verkürzen und Erweitern. Literarische Techniken für eilige Leser? Die Ilias latina als poetische Epitome, in: Hermes 135 (2007), S. 334-351.

Reuß, Wilhelm: Die dichterische Persönlichkeit Herborts von Fritzlar, Diss., Gießen 1896. Schade, Günter: Christentum und Antike in den deutschen Troja-Epen des Mittelalters (Herbort von Fritzlar, Konrad von Würzburg, Der Göttweiger Trojanerkrieg), Diss., Berlin 1955.

Schmid, Elisabeth: Ein Trojanischer Krieg gegen die Langeweile, in: Wolfgang Harms / Jan-Dirk Müller (Hgg.): Mediävistische Komparatistik. Festschrift für Franz Josef Worstbrock zum 60. Geburtstag, Stuttgart / Leipzig 1997, S. 199-218.

Schmid, Elisabeth: Benoît de Sainte-Maure und Herbort von Fritslar auf dem Schlachtfeld. Zwei Stichproben aus dem Trojanischen Krieg, in: Ingrid Kasten / Werner Paravicini / René Pérennec (Hgg.): Kultureller Austausch und Literaturgeschichte im Mittelalter. Kolloquium im Deutschen Historischen Institut Paris 16.-18.3.1995, Sigmaringen 1998 (Beihefte der Francia 43), S. 175-184.

Schneider, Hermann: Heldendichtung, Geistlichendichtung, Ritterdichtung, 2. Aufl. Heidelberg 1943 (Geschichte der deutschen Literatur 1).

Schneider, Wolfgang Christian: Die elegischen Verse von Maximian. Eine letzte Widerrede gegen die neue christliche Zeit. Mit den Gedichten der Appendix Maximiana und der Imitatio Maximiani. Interpretation, Text und Übersetzung, Stuttgart 2003 (Palingenesia 79).

Schnell, Rüdiger: Andreas Capellanus, Heinrich von Morungen und Herbort von Fritslar, in: ZfdA 104 (1975), S. 131-151.

Steinhoff, Hans-Hugo: Herbort von Fritzlar, in: ${ }^{2}$ VL Bd. 3 (1981), Sp. 1027-1031.

Stohlmann, Jürgen: Magister Simon Aurea Capra. Zu Person und Werk des späteren Kanonikers von St. Viktor, in: Guy Cambier (Hg.): Hommages à André Boutemy, Brüssel 1976 (Collection Latomus 145), S. 343-366.

Vogt, Friedrich / Koch, Max: Geschichte der Deutschen Literatur von den ältesten Zeiten bis zur Gegenwart, 3., neubearb. u. vermehrte Aufl., Bd. 1, Leipzig / Wien 1913.

Wehrli, Max: Geschichte der deutschen Literatur vom frühen Mittelalter bis zum Ende des 16. Jahrhunderts, Stuttgart 1980, ${ }^{2} 1984$ (Geschichte der deutschen Literatur von den Anfängen bis zur Gegenwart 1).

Wolf, Alois: Die adaptation courtoise. Kritische Anmerkungen zu einem neuen Dogma, in: GRM 27 (1977), S. 257-283. 
Worstbrock, Franz Josef: Zur Tradition des Troiastoffes und seiner Gestaltung bei Herbort von Fritzlar, in: ZfdA 92 (1963), S. 248-274.

Worstbrock, Franz Josef: Translatio artium. Über die Herkunft und Entwicklung einer kulturhistorischen Theorie, in: Archiv für Kulturgeschichte 47 (1965), S. 1-22.

Worstbrock, Franz Josef: Dilatatio materiae. Zur Poetik des Erec Hartmanns von Aue, in: Frühmittelalterliche Studien 19 (1985), S. 1-30. 



\section{Geistliche Lieder als theologische Ver-Dichtung mystischer Theologie*}

von

Almut Suerbaum (Oxford)

\section{I. brevitas zwischen abbreviatio und amplificatio}

Exposé und Einleitung dieses Bandes konkretisieren, was der dezidiert lateinische Tagungstitel bereits andeutet: Es geht im Hauptteil dieses Projektes um Verfahren der Verkürzung, die ihren Ursprung in der antiken Rhetorik haben. Dort ist die abbreviatio neben der amplificatio eine Technik, welche der narratio zugerechnet wird. Allerdings ist zugleich zu beachten, dass dieser Begriff der narratio nicht deckungsgleich mit dem modernen Gattungsbegriff des Erzählens ist, sondern eine Diskursart bezeichnet. Zudem erinnert der Beitrag von Thomas Haye in diesem Band sehr deutlich daran, dass brevitas in bestimmten Kontexten nicht allein eine literarische oder rhetorische Frage des Stils ist. Als Mittel der polemischen Komplexitätsreduktion ist sie durchaus nicht immer neutral oder weltfremd, sondern vermag als griffig-vereinfachender und wirksamer politischer 〈Slogan〉 in steter Wiederholung ungeachtete Wirkung zu erzeugen - die Rede vom «taking back control〉 reduziert komplexe, über Jahrzehnte gewachsene internationale Beziehungen auf ein einfaches Feindbild und hat gerade dadurch offenbar ihre Wirkung erzeugt. ${ }^{2}$ Deutlich wird allerdings auch, dass es nicht ganz einfach ist, solche Wirkung von Abbreviaturen genau zu beschreiben, dass zudem die Beschreibungen solcher Wirkungen nicht verallgemeinerbar sind, sondern stark von der literarischen, kulturellen und

* Durch die pandemiebedingte Schließung aller Bibliotheken ist es bei einer nur leicht bereinigten Vortragsfassung geblieben. Ich danke Julia Frick und Oliver Grütter für ihre Geduld.

2 Vgl. den Beitrag von Thomas Haye, in diesem Band. 
gesellschaftlichen Situierung der Texte in Rezeptions- und Produktionskontexten abhängen.

Auf den ersten Blick fällt das hier vorgestellte Material daher auf doppelte Weise aus dem Rahmen: Es ist lyrisch, nicht erzählend, zudem entstammt es einem Milieu von Laienfrömmigkeit, bei dem wir in der Regel nicht davon ausgehen dürfen, dass es dort eine unmittelbare Vertrautheit mit lateinischer Regelpoetik oder Rhetorik gibt. Darin unterscheidet es sich grundsätzlich von dem Text Herborts von Fritzlar, für den Ricarda Bauschke neuerlich nachgewiesen hat, wie nah er an den Entwicklungen im Lateinischen steht. Mystische Lieder entstammen dagegen einem Kontext, bei dem genau diese Kenntnis lateinischsprachiger rhetorischer Traditionen nicht vorausgesetzt werden kann. Dennoch aber stehen auch diese Lieder nicht isoliert im Raum, sondern sind als Teil eines kulturellen Netzwerkes zu verstehen, auf das so unterschiedliche Entwicklungen wie der von Oliver Grütter vorgestellte protestantisch-reformatorische Streit um den Descensus ${ }^{3}$ wie auch die von Marc-Aeilko Aris untersuchten spätmittelalterlichen Reformbewegungen des 15. Jahrhunderts rekurrieren:4 Sowohl die spätmittelalterlichen Bewegungen der observanten Reform wie die protestantischen Reformatoren reagieren auf Aspekte einer Kultur mystischen Denkens, Erlebens und Singens, die hier im Vordergrund stehen soll.

Angesichts der so skizzierten kulturellen Vernetzung ist die Auseinandersetzung mit geistlichen Liedern produktiv, da gerade über eine differenzierende Betrachtung von Techniken der abbreviatio Aufschluss darüber zu erhalten ist, was die Literarizität solcher Texte angeht, welche sich mit durchaus komplexen theologischen Sachverhalten in liedhafter Form beschäftigen. Zudem dürfte es kein Zufall sein, dass nicht nur Eberhards Laborintus, sondern auch die Überlegungen von Paul Zumthor zum Thema 〈Brevity as Form〉 («La Brièveté comme Forme», 1983) mit lyrischen Beispielen schließen, obschon der Beitrag zwar in der Zeitschrift Narrative erneut erschienen ist und sich vor allem narrativen Kurzformen widmet. Zumthor hebt hervor, dass Kürze immer ein Strukturmodell darstelle: 
[B] revity is never random but constitutes a structuring model. This is doubtless why Latin rhetoric had recourse to the term brevitas (sermo brevis, ‘brief discourse)) to designate not a model per se, but a virtus (capacity or virtue), a modality, and (in the scholastic sense) a qualitas (quality or property) of formal structure. ${ }^{5}$

Zumthor versteht also brevitas nie als Zufallsprodukt einer Textlänge, die so oder auch anders hätte ausfallen können, sondern als positiv konnotiertes Ideal einer besonders effizienten Struktur, bei der es nichts Überflüssiges gebe. Anhand der liedhaften Texte müsste allerdings noch einmal genauer untersucht werden, wie es um das Verhältnis zwischen abbreviatio und amplificatio steht oder, anders gefragt, ob Kürze als positiv zu bewertende Reduktion auf das Wesentliche und daher auch als Ergebnis eines gezielten Prozesses zu bewerten ist oder ob man sie in anderen Kontexten auch als noch unentfaltetes Potenzial auffasst, das erst in der augmentierenden Fülle der amplificatio seine volle Wirkung entfalten kann.

\section{II. abbreviatio und Klarheit}

Die Einleitung dieses Bandes erinnert daran, dass mittelalterliche rhetorische Traktate eine Verbindung zwischen brevitas und Klarheit der Darstellung herstellen, sodass Kürze quantitativ eine Reduktion, qualitativ dagegen eine Verbesserung darstellt, auch wenn durchaus offen ist, ob dieser Qualitätsgewinn eine ästhetische Kategorie ist oder aber eher eine hermeneutische. Die Rhetoriken konzedieren allerdings zugleich, dass diese Resultate keinen linearen Prozess beschreiben, sodass extreme brevitas zu Dunkelheit und Unklarheit führen könne, wie bereits Horaz in der Ars poetica zu bedenken gegeben hatte:

breuis esse laboro, obscurus fio.

(Horaz, Ars poetica, vv. 25 f.) ${ }^{6}$

〈Ich bemühe mich, kurz zu sein, und werde dunkel [d. h. unverständlich].» 
Was bei Horaz als Katalog potentieller Hindernisse begegnet, wird im Rahmen mittelalterlicher poetischer Diskussionen zu einem zentralen Punkt ästhetischer Debatten, wenn es um den Status der Dunkelheit als literarischer Kategorie geht: Ist sie als Abweichung von den Idealvorstellungen der Klarheit und Durchsichtigkeit zu verstehen oder äußert sich in ihr geradezu programmatisch das unhintergehbare Moment des Literarischen? Dazu hatte die von Susanne Köbele konzipierte Zürcher Tagung zur literarischen wildekeit Wesentliches beigetragen, und ich möchte an dieser Stelle mit meinen Überlegungen zu geistlichen Liedern ansetzen. ${ }^{7}$

\section{III. abbreviatio und narratio}

In seiner Poetria nova diskutiert Galfried von Vinsauf das Phänomen der abbreviatio auf eine Weise, die auch die nachfolgenden Diskussionen prägt, nämlich als antithetischen Gegensatz zur amplificatio. Um sich kurz zu fassen, so lautet sein betont knapp gehaltener Rat, solle man also schlicht all das meiden, was im vorausgegangenen Kapitel als Mittel der amplificatio aufgelistet worden war. Doch belässt er es dann doch nicht bei solcher Kürze und hebt stattdessen hervor, welche Mittel besonders geeignet sind: Neben der Vermeidung von Wiederholung sind es vor allem syntaktische Mittel, so der Gebrauch des ablativus absolutus, aber auch der Verzicht auf Konjunktionen, die Markierung syntaktischer Verbindungen und schließlich der Verzicht auf Verben. ${ }^{8}$ Während Galfried seine Diskussion auf den Bereich von Rhetorik und Erzählung fokussiert, ist allerdings frappierend, wie nah einige der von Galfried in seiner Poetik namhaft gemachten Strategien dem stehen, was neuere methodische Überlegungen zu den Charakteristika lyrischen Sprechens zählen.9 Daher gehört eine Untersuchung lyrischer Texte

8 Geoffroi de Vinsaulf: Poetria nova, in: Faral, Edmond (1924), S. 194-262. Vgl. Copeland / Sluiter (2012) sowie Purcell (1996). Für die englische Übersetzung von Galfrieds Poetria Nova siehe Nims (2010). Zu den Konsequenzen einer Befolgung solcher Ratschläge für epigrammatische Dichtung vgl. die Einleitung von Frick und den Beitrag von Raphael Schwitter, in diesem Band.

$9 \quad$ Vgl. Linden (2011); Kablitz (2013); Culler (2015). 
sehr zentral zum Themengebiet des vorliegenden Bandes. In drei Schritten wird dieser Beitrag untersuchen, auf welche Weise geistliche Liedformen mit Verfahren der Verkürzung und vor allem der Verdichtung arbeiten. Wichtig ist dabei zugleich, die Texte und die in ihnen sich manifestierenden Verfahren in ihrem kulturellen Kontext zu verstehen.

\section{Liedformen im Kontext mystischer Theologie}

Inwiefern also gehören liedhafte Formen in den Kontext von Phänomenen der abbreviatio? Wie inzwischen vor allem durch die sammelnden Arbeiten von Judith Theben bekannt ist, gibt es im Spätmittelalter eine oft breiter als zunächst angenommene Gruppe von geistlichen Liedern, die als «mystisch» bezeichnet werden können, da sie Zentralbegriffe einer spekulativen Theologie betreffen, welche wir mit den Namen Eckhart und Tauler verbinden. ${ }^{10}$ Sie entstammen damit einem sehr speziellen, allerdings für uns inzwischen recht gut greifbaren Milieu. Es ist gekennzeichnet durch drei Koordinaten: funktionelle Zweisprachigkeit, die sich zwischen Latein und Volkssprache bewegt; theologische Exklusivität, die bis an den Rand der Heterodoxie reicht und im Zentrum eine unmittelbare, nicht durch Institutionen oder Sakramente vermittelte Gotteserfahrung umkreist; soziale Offenheit, da im Zentrum Laien stehen - von Klosterfrauen bis hin zu städtischen Laienkreisen. ${ }^{11}$

Ihre theologische Entfaltung findet diese Bewegung sowohl in literarischen Texten wie dem Fließenden Licht der Gottheit mit seinem zwischen Prosa und Lyrik changierenden Kompositcharakter als auch in Predigt- und Traktatsammlungen. Sowohl Eckhart wie auch Tauler sind allerdings nicht nur Meister theologischer Spekulation und sprachphilosophischer Reflexion über die Grenzen des in der Sprache Sagbaren, sondern zugleich Meister einer Prosa, die komplexe, hochkontroverse Einsichten so an ein Publikum adressiert, dass bei den Hörern Erkenntnisprozesse angeregt, aber auch innere Bewegungen erzeugt werden. Burkhard Hasebrinks Begriff dafür ist wohl immer noch die konziseste Art, diese Form von Performativität zu beschreiben: Er entwickelt anhand von Eckharts deutschen Predigten den

11 Zum theologischen Umfeld McGinn (1998); McGinn (2005); Ruh (1993). 
Begriff von der inzitativen Rede` und versteht darunter Sprachformen, die innere Prozesse nicht allein beschreiben und analysieren, sondern sie sprachlich auslösen. ${ }^{12}$

Eckharts volkssprachige Predigten sind im Umkreis der Dominikanerinnenklöster entstanden, und auch Tauler hat sowohl in Straßburg wie Köln für Dominikanerinnen gepredigt. Zugleich aber gibt es, das hat sich in den letzten Jahren immer deutlicher herauskristallisiert, im Umkreis dieser Dominikanerinnenkonvente Praktiken, in denen diese Predigten nicht nur als Texte archiviert, gesammelt, übersetzt, kompiliert und wohl auch exzerpierend gekürzt, sondern auch kreativ adaptiert werden: Immer wieder überliefern Handschriften mit Traktat- und Predigttexten geistliche Lieder, deren Zentralbegriffe deutlich dem Umfeld der mystischen Theologie Taulers und Eckharts entstammen.

Es handelt sich bei diesen Liedformen also um das Gegenteil dessen, was Richard Trachsler an der französischen mise en prose konstatiert. ${ }^{13}$ Wo dort die dérimage aus Verserzählungen Prosakurztexte macht, entstehen hier in einem Verfahren der rimage aus diskursiven Prosatexten Liedformen - meist gereimt, oft strophisch. Kurt Ruh hatte erstmals auf solche Praktiken aufmerksam gemacht und sie zugleich in Beziehung zu ihrem Entstehungsmilieu gesetzt:

Die Autoren - vielfach waren es Klosterfrauen - sind nicht darauf ausgegangen, geistliche Prosa, etwa zum Zwecke besserer Memorierbarkeit, in Verse umzusetzen, sondern sie wollten auf «schöne Weise` erbauen und schöpften dazu aus einem aus Predigten und Traktaten geschöpften Fundus von mystischen Begriffen und Vorstellungen, einem Stichwörter-Repertoire sozusagen, das sie in freier Weise verwendeten. ${ }^{14}$

Das ist in einzelnen Aspekten sowohl zeitgebunden wie problematisch, besonders in der Genderzuschreibung und der binären Gegenüberstellung intellektueller und gefühlsbetonter Zugänge. Unterstellt ist damit vor allem, dass es sich in den liedhaften Kurzformen um Phänomene von Komplexi-

Hasebrink (1992).

Vgl. den Beitrag von Richard Trachsler, in diesem Band.

Ruh (1993), S. 191. 
tätsreduktion handelt - eine Schlussfolgerung, die zwar durchaus nicht ausgeschlossen, aber eben auch nicht notwendig ist, weder bei Texten, die von und für Frauen verfasst sind, noch bei solchen, die statt des Lateinischen die Volkssprache wählen. Sehr genau benannt ist damit aber, welche Bedeutung textgenerierende Verfahren haben, die sowohl die uns vertraute Trennung von Produktion und Rezeption wie die Differenzierung von Autorin und Schreiberin unterlaufen. Diesem Verhältnis von Verdichtung und Komplexität werden daher die folgenden Überlegungen nachgehen.

\section{Verdichtung: Kürze oder Dunkelheit?}

Wie liedhafte Texte aus dem oben skizzierten Milieu aussehen, sollen hier stellvertretend zwei Beispiele illustrieren, die beide dominikanischem Milieu entstammen, allerdings auch darüber hinaus überliefert sind. Schon Pfeiffer hatte aus einer Einsiedler Handschrift ein Lied mit dazugehörigem Prosatext ediert, das in der Handschrift als Von dem überschalle (Über die Übertöne) bezeichnet wird. ${ }^{15}$ Dieser Titel benutzt einen Begriff, der im Lied als Schlusswort verwendet wird; er ist zudem ein Hapax in der mittelhochdeutschen Literatur, das erst im Liederbuch der Clara Hätzlerin wieder aufgenommen wird. ${ }^{16}$ Er rekurriert im Kontext anderer Komposita sowie der räumlichen Vorstellung einer Bewegung in daz hohste auf die Transzendenz, welche zugleich tiefster Grund und höchste Höhe ist. Bereits der Titel stellt so in der Rubrizierung der Handschrift eine Verdichtung und Komprimierung dessen dar, was das Lied verhandelt:

Von dem überschalle

Wer noch helle noch himelrich, dennoch so wolt ich minnen, got, suszer vater, dich in diner hohen nature, daran die driheit stat in eyner enikait, da zy er vermugentheit an hat.

$[\ldots]$

Pfeiffer (1857); Theben (2010), S. 366-392 u. 496-498.

16 Vgl. Eintrag «überschalle〉 in [http://woerterbuchnetz.de] 31.05.2020. 
Ez luchtet vz der enikeit eyn envaldig licht, eyn purheit dez geistes, an yme selb ist er worden nicht, an im selbe, daz ist war, gar an den werken ire kreften an blosheit stan.

Da geyst vf nicht an enikeyt bestat, da verluset her daz mittel von gotlichen art, da ist er entsunken der naturlichen sin, inwesende da blibit ein kleines gensterlin.

Da ist er geschaffen von nichte icht, daz icht, daz ist gezogen von sines nichtes ist icht, daz icht is blosheit, in den personen ein wesen, da sich der geyst engeystet in enikeyt. ${ }^{17}$

Die metrische Form des Liedes ist unschwer erkennbar und zudem hörbar: Es handelt sich um Kürenbergerstrophen aus paargereimten Langzeilen mit Zäsur. Das Lied thematisiert die bedingungslose Liebe zu Gott, einem Gott zudem, dessen Paradoxien sich dem Verstand entziehen und jenseits des Sagbaren liegen, dennoch aber das Ziel bilden:

alsus svln [sic] ir minnen, kinder, vber al

vnd ilen in das hohste das ist der uberschal.

$(\mathrm{XV}, 2 \mathrm{f}$.

In den Handschriften wird dieses Lied von einem als glose bezeichneten Prosatext begleitet, dessen Wortmaterial dem des Liedes nahesteht, dieses aber diskursiv organisiert:

Dis ist die glose vber den vberschall

Nu merke: das rehte volmahte wesen des geistes ist, ob noch helle noch himelreich weren, daz er got doch minnen solte durh sin eigine guote. Man sol minnen die driheit der person in der einekeit der naturen vnd die einekeit der nature in der

17 〈Von dem überschalle`, Strophen I, X-XII, zitiert nach der Ausgabe von Theben (2010), S. 372-376, welche nicht nur die von Pfeiffer edierte Einsiedler Handschrift, sondern auch die etwas leichter verständliche Fassung der Handschrift, Staatsbibliothek zu Berlin, Preußischer Kulturbesitz, Ms. Germ. quart. 191 (Provenienz: St Nikolaus in undis) zugrunde legt. Lesarten dort S. 376-377. 
driheit der person. die driheit hat it mvgetheit an der einekeit vnd die einikeit hat ir wurdekeit an der driheit.

Für uns sind die theologisch komplexen Begriffe trinitarischer Spekulation im Kommentar leichter nachvollziehbar, da Prosa das Medium diskursiver Reflexion ist. Zugleich erlaubt uns ein Vergleich zwischen Prosa und Liedstrophe, die im Lied angewandten Strategien der Verkürzung im lyrischen Text greifbar zu machen. Während fast alle Substantive in beiden Textformen auftreten, sind die syntaktischen Unterschiede dagegen sehr deutlich. In der Liedstrophe fehlen weitgehend die logischen Verknüpfungen durch Konjunktionen; dort, wo sie vorhanden sind, etwa in der adversativen Gegenübersetzung dennoch (I,2), markieren sie den Kontrast sehr viel stärker, da die Gegensätze in zwei Zeilen einander gegenübergestellt werden. Im Gegensatz zur Prosa des Kommentars, dessen Strukturen durch Verbformen markiert werden, fehlen finite Verbformen in der Liedstrophe fast völlig, sodass die Zentralbegriffe in den abstrakten Substantiven hervortreten. Zwar steuern die ersten zwei Zeilen der ersten Strophe auf das Verbum minnen, d. h. auf die Liebe zu Gott, hin, an welcher das lyrische Ich festhalten will, selbst wenn es weder Himmel noch Hölle mehr gebe. Doch Fokus der Strophe ist die Natur Gottes, dem diese Liebe gilt, eine Natur, welche auf paradoxe Weise dryheit und einekeit miteinander verbinde. Indem die Liedstrophe auf finite Verben verzichtet, bewirkt sie im Gegensatz zur Prosafassung eine Entzeitlichung der Aussagen, sodass der Bezug auf Weltzeit und Jenseits nicht mehr markiert ist, sondern auf gleicher Stufe mit der Paradoxie von Dreiheit und Einigkeit angesiedelt wird. Auch die theologischen Bezüge der Trinität sind stark verkürzt - gegeneinander stehen Dreiheit und Einheit, während der Kommentar daran erinnert, dass es um die drei Personen in einer Natur geht. Abweichend von der Prosafassung allerdings hebt die Liedfassung hervor, dass Dreiheit und Einheit nicht völlig parallel nebeneinanderstehen, denn sie doppelt in einer sicher Eckhart entstammenden Wendung den Begriff der Einheit, indem sie von der eyne $[n]$ enikait $(\mathrm{I}, 4)$ spricht. Das widerspricht den literarischen Prinzipien der Dichte, welche Wiederholungen in der Regel meiden, schafft aber genau die Wendung von orthodox theologischer Darstellung der Trinität zu einer mystischen Perspektive, in der mit der Einheit die Aufhebung der Differenzen ins Zentrum rückt. 
Auf syntaktischer Ebene manifestiert also das Lied das, was Sandra Linden an anderer Stelle in einer Untersuchung des Fließenden Lichts als «Verdichtung» bezeichnet hatte. ${ }^{18}$ Zugleich bewirkt diese sprachliche Verdichtung unter Verzicht auf markierte logische Bezüge eine Intensivierung. Allerdings handelt es sich bei dem hier vorgestellten Ensemble Von dem überschalle insofern um einen Sonderfall, als dass sich die Beziehung zwischen Prosatext und Lied nicht einfach sequenziell verstehen lässt. Es gibt nämlich in der deutschen Literatur des Mittelalters nur noch einen anderen Fall, in dem ein Lied mit zugehörigem Kommentar überliefert ist - das ungleich bekanntere Granum sinapis. In beiden Fällen rekurrieren die Liedtexte zwar erkennbar auf Eckhart, sowohl in den Begriffen und Bildern wie in den theologischen Zentralgedanken. ${ }^{19}$ Doch der Prosatext ist deutlich nachgängig, denn er wird als glosa, also erklärende Erläuterung, bezeichnet und markiert in der Version der Einsiedler Handschrift sogar, auf welche Strophe sich jeder Absatz bezieht. Was wir beobachten, ist also ein doppelter Weg der Komprimierung und Dekomprimierung, in der die lyrische Verdichtung zurückgeführt wird in eine diskursive, deutlich längere, syntaktisch planere Erläuterung - eine Erläuterung zudem, die das Lied erneut in den exegetischen Kontext der explanatorischen Lektüre einbindet. Das dürfte der theologischen Sprengkraft der unio-Erfahrung geschuldet sein, deren brevitas in ihren paradoxen Engführungen wiederum auslegungsbedürftig ist.

\section{VI. abbreviatio als poetische Kohärenzstiftung}

Kontrastierend möchte ich ein zweites Beispiel dagegenstellen, das in seiner unkommentierten Form eher der Regel entspricht: Das Lied Ich solt mich leren lossen, das im Dominikanerinnenkloster Unterlinden in Colmar entstanden und dort auch in einer Handschrift des 15. Jahrhunderts überliefert ist. ${ }^{20}$ Es gibt mindestens vier weitere Handschriften und zudem variierende Parallelfassungen, sodass wir es auch hier nicht einfach mit dem dilettieren-

Linden (2011), S. 361.

Maßgeblich zum Granum sinapis Köbele (2004).

Zum Überlieferungskontext Theben (2010), S. 399-402 u. 454-456. 
den Experiment einer einzelnen Nonne zu tun haben, wie die «Mythisierungen > das manchmal suggerieren. Die erste Strophe des Liedes lautet wie folgt:

Ich solt mich nun leren lossen, es wer wol me denn zit:

got für kümt mit alle min strossen,

ich bin trostes worden fry.

jch solt mich nun leren liden,

daz wer das hochste gesetz,

zitlichen trost vermiden:

got het ich sin schier ergetzt.

Repetitz:

las alle ding entwerden

und löfen vf ir zil,

ler dich selb absterben

vnd wellen, waz got wil. ${ }^{21}$

Formal liegt auch hier ein Strophenlied vor; in der Handschrift ist es als fortlaufender Text geschrieben, aber mit Reimpunkten als Verstext markiert und so in seiner Strophenform rekonstruierbar. Die metrische Form orientiert sich an der Hildebrandsstrophe mit Refrain, wobei die editorische Entscheidung darüber, ob der Text als halbe Hildebrandsstrophe, also eine vierzeilige Strophe, oder aber achtzeilig als volle Hildebrandsstrophe aufzufassen sei, unterschiedlich ausfällt. ${ }^{22}$ Die Bezüge zur mystischen Theologie sind ebenfalls deutlich hörbar - inspiriert wohl von Tauler, geht es hier nicht um die Natur Gottes und der Gottheit wie in Von dem überschalle, sondern um das, was im lyrischen Ich vorgeht. Thematisiert wird der Vorgang dessen, was der Refrain entwerden nennt, also den Vorgang der progressiven Selbstentäußerung, der seit Eckhart gelassenheit genannt wird (vgl. Vers 1 des Liedtextes) und damit eine radikale Umsemantisierung monastischer Askesepraktiken ins Innere verlegt. ${ }^{23}$ Analogien sind oft problematisch; dennoch dürfte der moderne Begriff von «mindfulness` als Heraustreten aus der trotzdem nicht aufgehobenen Zeitlichkeit, um allein im Augenblick zu

21 Zitiert nach Theben (2010), S. 399.

22 Zur Diskussion vgl. ebd., S. $454 \mathrm{f}$.

23 Vgl. Hasebrink / Bernhardt / Früh (2012). 
leben, gewisse Parallelen aufweisen. ${ }^{24}$ Im Lied wird dies bereits in der ersten Strophe über die Gegenüberstellung von lossen und liden markiert und dann im Refrain mithilfe des ziellosen und zugleich auf sein negatives Ziel zulaufenden Begriffs vom entwerden aufgegriffen. Damit wird der performative Charakter des Liedes offensichtlich, denn die durch Pseudo-Dionysius Areopagita inspirierte negative Theologie der Willensentäußerung wird nicht beschrieben, sondern im Vollzug des Liedes prozessualisiert. Auch hier geht der Vorgang der lyrischen Verdichtung einher mit einer Entzeitlichung, die das nun des Loslassens inszeniert. ${ }^{25}$

Zugleich aber führt die Verabschiedung von der narrativen und diskursiven Linearität gerade nicht, wie man erwarten könnte, zu einer Reduktion auf den einen Punkt, denn das Lied bedient sich auf mehr als einer Ebene der über Wiederholungen erzeugten Zirkularität, sowohl in der wiederkehrenden Melodie des jeweils neuen Stropheneinsatzes wie auch im jeweils neuen Aufgreifen des Grundthemas im Refrain.

Produktionsästhetisch hat eine solche Zirkularität zur Folge, dass Grenzen zwischen Fassungen kaum noch zu bestimmen sind, denn die Strophenfolge und -anzahl variiert zwischen den fünf Überlieferungsträgern. Zugleich aber lenkt sie unser Augenmerk darauf, dass in diesem durch tägliche lectio geprägten Milieu Formen der Wiederholung es erlauben, auf je unterschiedlicher Ebene Verbindungen entstehen zu lassen.

\section{Lyrik und Abbreviatur}

Was lässt sich also aus diesem Material für eine Beschäftigung mit der Frage nach der abbreviatio gewinnen?

Erstens dürfte deutlich geworden sein, dass auf der Textoberfläche die hier beobachtbaren Verfahren der Verdichtung oft frappant nahe bei den sieben Schritten der abbreviatio liegen, wie sie Galfrieds Poetria Nova beschreibt. Anders als im Fall Herborts allerdings, den Ricarda Bauschke in

24 Vgl. Langer (1989).

25 Zu Stukturen der Zeitlichkeit und dem Begriff des ewig nû bei Eckhart, welche hier anklingen, vgl. Largier (1989). 
diesem Band diskutiert, ${ }^{26}$ soll keineswegs behauptet werden, dass es direkte Verbindungen zwischen dem lateinischen Schulautor und der Textgenerierungspraxis der mystischen Lieder gäbe. Vielmehr wird deutlich, dass die bei Galfried beschriebenen poetischen Verfahren in der Tat nicht nur Erzähltexte betreffen, sondern geradezu das auf den Punkt bringen, was neuere Lyrikuntersuchungen aus je unterschiedlicher Perspektive beleuchten: die Schaffung einer Sprachform, welche unter Verzicht auf syntagmatische und syntaktische Kohärenzen eine neue, andere Form der Kohärenz stiftet, welche zentral über die Klanglichkeit bestimmt ist und affektiv wirkt. ${ }^{27}$

Zweitens ist zu konstatieren, dass diese Prozesse lyrischer Verdichtung sich trotz solcher Berührungen mit Verfahren der abbreviatio in schulrhetorischen Kontexten zugleich wesentlich unterscheiden. Das in Lied und Kommentar auf Eckhart rekurrierende Lied Von dem überschalle ist dafür das deutlichste Beispiel. Zwar stellen Eckhart und Tauler für mystische Lieder einen Prätext dar, der Konzepte und zentrales Vokabular liefert, doch ist in aller Regel davon auszugehen, dass diese Prätexte nicht als Texte vorliegen. Ähnlich wie die von Nikolaus Henkel und Rita Copeland untersuchten Modi des Übersetzens markieren die Liedformen einen Zustand, der Kenntnis des Prätextes zwar voraussetzt, ihn aber im verdichtenden Umschreiben adaptiert. ${ }^{28}$ Wir greifen also in diesem vornehmlich dominikanisch und städtisch geprägten Milieu Formen einer Praxis, die nicht nach Regeln gelehrt wird, sondern aus dem Umgang mit Texten, Kontexten und Konzepten erwächst. Zugleich fallen damit die uns so vertrauten Hierarchien zwischen Autor und Schreiber, aber auch Original und Kopie zusammen, da sowohl Lese- wie auch Schreibprozesse zyklisch statt linear ausgeübt werden. ${ }^{29}$

Drittens schließlich weisen die mystischen Lieder darauf hin, dass Verfahren der Verdichtung sowohl Intellekt wie Affekt betreffen. Auch Galfrieds Poetik beschränkt sich durchaus nicht darauf, objektiv-neutrale Regeln zu sammeln und $\mathrm{zu}$ ordnen: Wenn er für die fortschreitende Komprimierung der Schneekind-Erzählung auf zwei Distichen dazu rät, das

Vgl. den Beitrag von Ricarda Bauschke, in diesem Band.

27 Vgl. Culler (2015); Kablitz (2013); Kellner (2018).

28 Vgl. Copeland (1991); Henkel (2017).

$29 \mathrm{Zu}$ solchen Verwerfungen etablierter Hierarchisierungen Dinshaw (2012).
} 
Eisen der Materie im Feuer des Herzens zu erhitzen, ist mit der pointierten Schmiede-Metaphorik präzise der affektive Effekt der Verdichtung ins Bild gerückt.

Noch in der Reformbewegung des 15. Jahrhunderts wird die Sprengkraft dieser affektiven Aufladung lyrischer Formen spürbar. Sie ist den Reformern wegen ihrer unkontrollierbaren inneren Bewegung suspekt, dennoch aber steht sie durch die in der Reform geforderte Einbindung in einfache, schlichte Formen der Observanz vor der Herausforderung, in dieser Regelbindung die Intensität der in den Liedern und Visionserzählungen performativ eingeübten Erfahrung nicht aufzugeben. ${ }^{30}$ So theologisch prekär daher der Umgang mit lyrischer Verdichtung ist, so wirksam erweist er sich. Uns erlaubt er einen Blick auf ein spezifisch geprägtes Milieu, in dem diese Form der Verdichtung habitualisierte Praxis ist: kurz, aber weder simpel noch einfach.

\section{Bibliographie}

\section{Primärliteratur}

Deutsche Mystiker des 14. Jahrhunderts. Bd. 2: Meister Eckhart, hg.v. Franz Pfeiffer, Göttingen 1857.

Geoffroi de Vinsauf: Poetria nova, in: Faral, Edmond (Hg.): Les arts poétiques du XIIe et XIIIe siècle: recherches et documents sur la technique littèraire de moyen age. Paris 1924. S. 194-262.

Quintus Horatius Flaccus. Opera, hg.v. David R. Shackleton Bailey, Berlin 2008 (Bibliotheca Scriptorum Graecorum et Romanorum Teubneriana).

\section{Forschungsliteratur}

Aris, Marc-Aeilko: Lesen und Erneuern. Kulturelle Implikationen der spätmittelalterlichen Klosterreform, in: Franz Xaver Bischof / Martin Thurner (Hgg.): Die benediktinische Klosterreform im 15. Jahrhundert, Berlin 2013 (Veröffentlichungen des Grabmann-Instituts zur Erforschung der mittelalterlichen Theologie und Philosophie 56), S. 291-301. 
Copeland, Rita: Rhetoric, Hermeneutics, and Translation. Academic Traditions and Vernacular Texts, Cambridge 1991.

Copeland, Rita / Sluiter, Ineke (Hgg.): Medieval Grammar and Rhetoric. Language Arts and Literary Theory. AD 300-1475, Oxford 2012.

Culler, Jonathan: Theory of the Lyric, Harvard 2015.

Dinshaw, Carolyn: How soon is now? Medieval Texts, amateur readers, and the queerness of time, Durham / London 2012.

Hasebrink, Burkhard: Formen inzitativer Rede bei Eckhart. Untersuchungen zur literarischen Konzeption der deutschen Predigt, München 1992 (Texte und Textgeschichte 32 ).

Hasebrink, Burkhard / Bernhardt, Susanne / Früh, Imke (Hgg.): Semantik der Gelassenheit. Generierung, Etablierung, Transformation, Göttingen 2012 (Historische Semantik 17).

Henkel, Nikolaus: Reduktion als poetologisches Prinzip. Verdichtung von Erzählungen im lateinischen und deutschen Hochmittelalter, in: Franz-Josef Holznagel/ Jan Cölln (Hgg.): Die Kunst der brevitas. Kleine literarische Formen des deutschsprachigen Mittelalters, Berlin 2017 (Wolfram-Studien XXIV), S. 27-55.

Jones, Claire Taylor: Ruling the Spirit. Women, Liturgy, and Dominican Reform in Late Medieval Germany, Philadelphia 2018.

Kablitz, Andreas: Kunst des Möglichen. Theorie der Literatur, Freiburg u. a. 2013 (Litterae 190).

Kellner, Beate: Spiel der Liebe im Minnesang, Paderborn 2018.

Köbele, Susanne: Das 〈Schrumpfen〉 der Rede auf dem Weg zu Gott. Aporien christlicher Ästhetik (Meister Eckhart und das Granum sinapis - Michel Beheim - Sebastian Franck), in: Poetica 36 (2004), S. 119-147.

Köbele, Susanne / Frick, Julia (Hgg.): wildekeit. Spielräume literarischer obscuritas im Mittelalter, Berlin 2018 (Wolfram-Studien XXV).

Langer, Ellen J.: Mindfulness, Cambridge / Mass. 1989.

Largier, Niklas: Zeit, Zeitlichkeit, Ewigkeit. Ein Aufriss des Zeitproblems bei Dietrich von Freiberg und Meister Eckhart, Bern u. a. 1989 (Deutsche Literatur von den Anfängen bis 1700, vol. 8).

Leppin, Volker: Luthers mystische Wurzeln, München ${ }^{2} 2017$.

Linden, Sandra: Der inwendig singende Geist auf dem Weg zu Gott. Lyrische Verdichtungen im Fließenden Licht der Gottheit Mechthilds von Magdeburg, in: Bleumer, Hartmut / Emmelius, Caroline (Hgg.): Lyrische Narration - narrative Lyrik. Gattungsinterferenzen in der mittelalterlichen Literatur, Berlin / New York 2011 (Trends in Medieval Philology 16), S. 359-386.

McGinn, Bernard: The Flowering of Mysticism, New York 1998.

McGinn, Bernard: The Harvest of Mysticism, New York 2005.

Nims, Margaret F.: Poetria Nova. Galfredus de Vino Salvo, Toronto 2010. 
Purcell, William M.: Ars poetriae. Rhetorical and Grammatical Invention at the Margin of Literacy, Colombia 1996.

Ruh, Kurt: Geschichte der abendländischen Mystik, Bd. 3: Die Mystik des deutschen Predigerordens und ihre Grundlegung durch die Hochscholastik, München 1993.

Suerbaum, Almut: Tauler Reception in Religious Lyric. The (pseudo-)Tauler cantilenae, in: Ons geestelijk erf 84 (2013), S. 41-54.

Theben, Judith: Die mystische Lyrik des 14. und 15. Jahrhunderts. Untersuchungen Texte - Repertorium, Berlin / New York 2010 (Kulturtopographie des alemannischen Raums 2).

Zumthor, Paul: Brevity as form (trans. by Laurence T. Moscato and William Nelles), in: Narrative 24 (2016), S. 73-81 (ursprüngl. erschienen als: La Brièveté comme Forme, in: Michelangelo Picone / Giuseppe Di Stefano / Pamela D. Steward (Hgg.): La Nouvelle. Formation, codification et rayonnement d’un genre médiéval. Actes du colloque international de Montréal 1982, Montréal 1983, S. 3-8). 


\section{Das Heilige im Gebrauch}

\section{Zur kompilatorischen Form der Legende}

von

Hans Jürgen Scheuer (Berlin)

\section{I.}

Als Gottfried Keller aus Widerwillen gegen die Weitschweifigkeit und den erbaulichen Ton von Kosegartens lutheranischer Legendensammlung ${ }^{1}$ zur geballten literarischen Replik seiner Sieben Legenden (1872) ausholte, erklärte er im knappen Vorwort seines Büchleins die eigene Intention damit, dass er in der «kirchliche[n] Fabulierkunst [...] die Spuren einer ehemaligen mehr profanen Erzählkunst oder Novellistik» avant la lettre freilegen wolle. ${ }^{2}$ Damit projizierte er die Form realistischen Erzählens, das in Boccaccios Novelle sein kanonbildendes Modell hat, auf eine - von der bürgerlichen Ästhetik aus gesehen - apokryphe kleine Form zurück, die ihre religiöse Evidenz und Verbindlichkeit, verankert im liturgischen Festkalender beziehungsweise in der täglichen klösterlichen Tischlesung, längst eingebüßt hatte. ${ }^{3}$ Dem Literatursystem des ausgehenden 19. Jahrhunderts musste die Legende als eine Art Anti-Literatur erscheinen. Bestenfalls konnte man ihr durch Operationen der Ironisierung, Psychologisierung und Ästhetisierung

1 Vgl. Kosegarten (1804).

$2 \quad$ Keller (1872), S. V.

$3 \quad$ Historisch steht dagegen Boccaccios Novellistik in apokrypher Relation zur Legende. So zeigt Decamerone I,1 eine Novelle in statu nascendi, deren Pointe darin besteht, dass sich die Produktion des falschen Heiligen San Ciappelletto (alias Ser Cepparello, Notar aus Prato) literarisch der Bemäntelung durch Muster der Martinslegende bedient; vgl. Scheuer, Martiniloben (2019), S. 293-318. Moritz Rauchhaus spricht mit Blick auf die Bestimmtheit der Legende durch das mysterium nominis ihres Protagonisten oder ihrer Protagonistin vom «fluiden Umgang mit Eigennnamen», durch den Dec. I,1 «schließlich zur Novelle wird»; Rauchhaus (2020), S. 145. 
ein Randdasein zubilligen - eben im Sinne einer Vorschule der novellistischen Schreibweise oder schlicht als amüsierliche Kuriosität aus unerleuchteten, nicht reformierten Zeiten. Fortan und bis heute ist jede poetische oder theoretische Beschäftigung mit der Legende als Form exemplarischer religiöser Kommunikation davon abhängig, wo die Rekonstruktionen ihrer ferngerückten Pragmatik und ihrer abhandengekommenen Verfügbarkeit ansetzen: in Praktiken laikaler Frömmigkeit oder im klerikal-monastischen Raum, in lokalen Kultgebräuchen der Reliquienverehrung oder in aktengestützten Verfahren institutionalisierter Heiligsprechung, in der Umschrift antiker Viten auf Konversionsereignisse oder in der gelehrten Technik der Kompilation exemplarischer Episoden und Aussprüche religiöser Leitfiguren etc.

André Jolles' morphologischer Versuch, die Legende in den Kanon der Einfachen Formen $(1930)^{4}$ zu integrieren, entspringt derselben Literatursituation wie Kellers Legendenkranz. Sein Konzept, das elementare Denkformen, gekoppelt an unverwechselbare «Sprachgebärden», als vorliterarische Elemente beschreibt, aus denen sich Literatur als "angewandte Form» systematisch entwickeln lasse, geht ebenfalls aus der Auseinandersetzung mit Boccaccios Novellistik hervor. ${ }^{5}$ Um die Legende zu retten, setzt Jolles zwei Akzente: Zum einen bindet er sie mit Rücksicht auf das kirchenrechtlich ausdifferenzierte Kanonisierungsverfahren und auf die gegenreformatorische Archivierung der Acta Sanctorum durch die Bollandisten an frühneuzeitliche Gebrauchszusammenhänge zurück. Zum anderen strebt Jolles danach, in der Tradition der imitatio Christi den grundlegenden Gestus legendarischen Erzählens durch die Demonstration eines imitabile zu erfassen und es durch Engführung mit der Reliquie und dem Heiligenattribut dingfest zu machen. $\mathrm{Ob}$ es sich dabei um eine Ontologisierung symbolischer Operationen handelt, sei dahingestellt.6 Wichtiger und den ästhetischen Diskussionen seiner Zeit näher scheint mir Jolles' Ziel, durch die Angabe eines klar konturierbaren

$4 \quad$ Jolles $\left({ }^{6} 1982\right)$.

5 Vgl. Eikelmann (1997), S. 422-424.

6 Vgl. Strohschneider (2002), S. 109-147. Strohschneider spricht hier von einer «regressiven Erzählmorphologie» und kritisiert Jolles’ «ontologisierendes Konzept von Sprache als Moment einer unvermittelten Gegenwärtigsetzung von Transzendentem» (S. 113, Anm. 15). In dieselbe Kerbe schlägt die These von der «sprachsubstantialistisch eingefärbten Morphologie» bei Köbele (2012), S. 366. 
«intentionalen Objekts» ${ }^{7}$ eine Größe zu gewinnen, die sich nicht weiter reduzieren lässt, wenn nicht das Phänomen Legende ganz verloren gehen soll. Gemessen am Prozess der Kanonisierung eines oder einer Heiligen bietet das imitabile ein Beweismittel, das den Status der Heiligkeit vergegenständlichen soll. Solche Verdinglichung zielt auf Ostentation. Ohne ihren liturgischen Gebrauchszusammenhang bleibt sie jedoch theatral - und das weist auf das eigentliche Problem des Jolles'schen Legendenbegriffs: Er ist das Produkt eines forcierten symbolistischen Ästhetizismus, seine Einfachheit eine fingierte, aus archaischer Magie und modernem Verfahrenswissen zusammengesetzte, in summa: ein paradox nachträgliches Ursprungsphantasma. $^{8}$

7 Der Begriff des intentionalen Objekts〉 geht auf Franz Brentanos Psychologie vom empirischen Standpunkte zurück und hat bis hin zu Walter Benjamin stark in die Kunstkritik und Ästhetik der Moderne gewirkt. Brentano definiert folgendermaßen: «Jedes psychische Phänomen ist durch das charakterisirt, was die Scholastiker des Mittelalters die intentionale (auch wohl mentale) Inexistenz eines Gegenstandes genannt haben, und was wir, obwohl mit nicht ganz unzweideutigen Ausdrücken, die Beziehung auf einen Inhalt, die Richtung auf ein Object (worunter hier nicht die Realität zu verstehen ist), oder die immanente Gegenständlichkeit nennen würden. Jedes enthält etwas als Object in sich, obwohl nicht jedes in gleicher Weise. In der Vorstellung ist etwas vorgestellt, in dem Urtheile ist etwas anerkannt oder verworfen, in der Liebe geliebt, in dem Hasse gehasst, in dem Begehren begehrt u.s.w. Diese intentionale Inexistenz ist den psychischen Phänomenen ausschliesslich eigenthümlich». Brentano (1874), hier Bd. 1, S. 115 f. Brentanos Rede von der 〈intentionalen Inexistenz〉 ist gezielt zweideutig: «Unter der Inexistenz ist dabei keineswegs eine Nicht-Existenz zu verstehen, sondern eine immanente Existenz bzw. ein Innewohnen im wörtlichen Sinn: In jedem geistigen Phänomen existiert ein Gegenstand»; Perler (2004), S. 4. Das macht das Konzept für die klassische Symboltheorie, die sich zentral mit der Frage nach psychischer Repräsentanz der Wahrnehmung beschäftigt, so attraktiv.

8 In jener gesteigerten Artifizialität der Einfachheit liegen die Produktivität und das unausgesetzte Fortleben der Legende begründet, das historistische Fortschrittsnarrative empfindlich stört: «Das Aufbrechen der Chronologie ist hier die Leistung der Legende als Form: Nach Jolles «zerbricht〉 die Legende 〈das Historische〉 eines individuellen Lebenslaufes «in seine Bestandteile), um diese in einer vom Theologoumenon der Nachahmung, also der christlichen imitatio Christi, «bedingten Reihenfolge wieder auf[zubauen]〉. Bei Jolles zeitigt die Form allererst und buchstäblich den Verlauf des Heiligenlebens. Diese Formleistung ist im Übrigen nicht auf mittelalterliche Legenden beschränkt»; Geulen 
Einige Jahre nach Gottfried Keller beschreitet Hermann Usener mit der philologisch-religionswissenschaftlichen Sammlung seiner Legenden der Pelagia (1879) einen dritten Weg, um die Legendenform für moderne Erkenntnisinteressen herzurichten. Sein Realismus ist derjenige der altertumswissenschaftlichen Realienkunde. Als Ritualist schließt er von den Heiligennamen auf die Umstände des Heiligenkults, seine Situierung in Raum und Zeit. Anhand einer Serie von Exempeln in Kleinasien beheimateter Märtyrerinnen, deren Namen eine Affinität zum Meer ausdrücken (Pelagia, Marina, Maria), von marinen Attributen wie Perle (Margarita-Reparata) und Purpur (Porphyria-Pelagia) abgeleitet sind beziehungsweise Epiklesen antiker Göttinnen aufgreifen (wie Anthusa, Athanasia, Eugenia, Apollinaris, Theodora und Matrona), identifiziert Usener Bruchstücke eines älteren Sakralkomplexes, den die christliche Legendenbildung absorbiert und umgewertet habe, ohne ihn je ganz zu verwerfen: Sie gehörten in den Umkreis des zwischen Syrien und Ägypten verbreiteten Aphrodite-Kults, wie aus dem allen gemeinsamen Motiv des Geschlechtswechsels zu schließen sei:

Die bizarre vorstellung der mannweiblichkeit, des hermaphroditismus wie des geschlechtswechsels [...] war wohl nirgends so sehr ausgebildet wie in Vorderasien, und vornehmlich an Aphrodite. Die götttin von Amathus auf Kypros, in weiberkleidern zwar, aber mit bart und allem was den mann macht ausgestattet, war eben so sehr Aphroditos wie Aphrodite: männer opfern ihr in frauenkleid, frauen in männlichem. ${ }^{9}$

(2017), S. 370. Dass in der Zertrümmerung des einzelnen Lebenslaufs und seinem ReArrangement im Lichte eines höheren Lebens eine immense utopische Energie steckt, die sich gerade die avantgardistische Literatur des 20. Jahrhunderts nicht entgehen lässt, zeigt etwa die polemische Wiederbelebung der Wüstenväterlegenden durch Hugo Ball. In seinem Buch Byzantinisches Christentum. Drei Heiligenleben (1923) und im Kontext seiner Kritik der deutschen Intelligenz (1919) hält er der protestantisch geprägten, obrigkeitsstaatlichen Biographie (die ihr Telos in der preußischen Beamtenlaufbahn fand) die ekstatische Lebensform der Legende entgegen - angesichts des Ersten Weltkriegs in radikal pazifistischer, anarchischer Absicht; vgl. dazu Flasch (2000), S. 202-223.

9 Usener (1879), S. XXIII. 
Die von Usener zusammengestellten christlichen Legenden überführen das rituelle Crossdressing ins Erzählmotiv der Monachoparthenia, ${ }^{10}$ der vermeintlichen Geburt eines Kindes durch einen Mönch (als verquerer imitatio der messianischen Jungfrauengeburt). Denn sämtliche Frauengestalten wechseln im Zuge ihrer Hinwendung zu Christus ihr Geschlecht und ihre Rolle, um der Ehe, der Sünde oder der Vergewaltigung durch einen Mächtigen zu entgehen. Sie treten unter männlichem Namen (meist erzeugt durch eine grammatische Motion von der femininen zur maskulinen Endung) in ein Kloster ein, wo die Entdeckung ihres verborgenen biologischen Geschlechts nach einem Leben in extremer Askese (oft angestoßen durch eine untergeschobene Vaterschaft) zum Ausweis ihrer besonderen Hingabe an den göttlichen Bräutigam wird. Wenn aber Ritual und Kultname die Bindung an den Mythos verlieren, schwindet mit der Referentialität auch ihr Gehalt. Zurück bleibt ein bloßes Handlungsschema, eine Allegorie der Heiligkeit, die weniger ein religiöses Zeugnis oder Bekenntnis ablegt, als dass sie in religionsgeschichtlicher Perspektive eine psychische Disposition ausstellt besonders in Kontexten, in denen das Religiöse mit dem Erotischen und mit der Wahrnehmung des Schönen verschwimmt.

Eine vierte Variante moderner Reinterpretation der Legende besteht schließlich darin, sie als diejenige Form zu verstehen, in der die «Unverfügbarkeit des Heiligen» zur Darstellung komme. ${ }^{11}$ Mit dem aus der theologischen Hermeneutik Rudolf Bultmanns entlehnten und in die Systemtheorie Niklas Luhmanns übertragenen Begriff wird das Heilige als «Distanzkategorie» bestimmt - mit dem Kollateraleffekt, dass neben der Verfügbarkeit des Heiligen der Aspekt der Verfügbarkeit seines Exemplums gleich mit aus dem Blick gerät. Die Legende erscheint dann selbst als Form, die nicht mehr zur Verfügung steht, um ihren Gegenstand verfügbar zu machen, obwohl ihr historischer Gebrauch in Andacht, Predigt und Katechese doch auf nichts

10 Zur Übersicht vgl. Wehse (1987), Sp. 168-186. In der aktuellen kunst- und literaturgeschichtlichen Diskussion wird das Crossdressing-Motiv vor allem im Kontext der Genderforschung behandelt, vgl. z. B. Tammen (2009), S. 43-68, sowie Losert (2008).

11 Wesentlich für die Karriere des Schlagworts in der germanistischen Mediävistik sind die Arbeiten Peter Strohschneiders zur Legende, die vor allem Konrad von Würzburg im Auge haben, einen Autor von ausgeprägtem Kunst- und literarischem Formbewusstsein; vgl. zur Theoriebildung zusammenfassend Strohschneider (2014), S. 170-190. 
anderes hinauswill als auf «Entgrenzung, Veralltäglichung und Vergewöhnlichung des Heiligen ».12 Solche Abstraktion der Legende von ihrer Aufgabe, religiöses Denken, Erinnern und Imaginieren im andächtigen Lesen oder Zuhören innerweltlich stetig zu exerzieren, bildet die theologisch-dogmatische Spielart ihrer Ästhetisierung und Veruneigentlichung. Sie entfremdet die Legende von ihrem Sitz im Leben, der meditierenden Frömmigkeitsübung, und löst im Namen des «ganz Anderen» die Beispielerzählung von den inneren und äußeren Handlungen, die das Heilige aktualisieren und der religiösen Erfahrung qua Lesung nahebringen sollen.

Die Sicht auf den Kernbereich der Legende ist modernen Leserinnen und Lesern also massiv verbaut: sowohl durch theologisch-konfessionelle als auch durch ästhetische und wissenschaftsdisziplinäre Vorannahmen, die hindernd und distanzierend im Wege stehen. Auch Merkmalstypologien lösen die Blockade nicht auf. Natürlich spielen Name, Ort und Zeit für die biographische Bestimmtheit der Legende eine ebenso wesentliche Rolle wie mythische Erzählmuster für die Markierung sakraler Auserwähltheit. Sie beruht zugleich auf einer Inklusion in die Kirche der Heiligen wie auf einer Exklusion aus der weltlichen Gemeinschaft, meist vermittelt über demonstrative Formen des Selbstopfers, der blutigen passio oder der virtuosen Askese. Hinzu treten Mirakel, die in der Kontinuität der Charismata Christi und seiner Apostel stehen, und Translationsberichte, die davon erzählen, wie der Leichnam überführt, die Reliquien wiederaufgefunden, umgebettet und an eine neu gegründete Kultstätte gebracht werden. Denn die konsekrierten Überreste müssen stets Wege in der Welt zurücklegen, damit ihre Heilswirksamkeit zum einen sich verbreiten, zum anderen am festen Ort zum festgelegten Termin der Kirchweihe zu Ehren der oder des Titularheiligen sich vertiefen kann. Gleichwohl erlauben jene Umstände allenfalls das Feld der Hagiographie grob abzustecken, aus dem dann Heiligenvita, Legende und Mirakel herausgelöst werden können, ohne dass auf Basis der stofflichen circumstantiae definierbar wäre, wo exakt die Grenzen zwischen den Formen these vgl. Koch (2012), S. 77-92, sowie - für das hier verhandelte Textfeld einschlägig Prautzsch (2018), S. 90-110. Die Rückwendung der Legendenforschung zu den diversen Kontexten ihres Gebrauchs vollzieht der Band von Weitbrecht u. a. (2019); vgl. bes. die programmatischen Bemerkungen der Einleitung, S. 9-21. 
verlaufen. ${ }^{13}$ Fließende Übergänge charakterisieren hier nämlich Überlieferung und Mitüberlieferung. Dem trägt Hans Ulrich Gumbrechts Begriffsprägung vom «Faszinationstyp Hagiographie» Rechnung. ${ }^{14}$ Sie zieht die Konsequenz aus der Einsicht, dass Legende eine schriftgebundene Exempelfunktion, aber keine typisierbare Gattung bezeichnet. Mit jener Formel verschiebt sich die Aufmerksamkeit von der Materie der Erzählung auf die mentale Haltung der Erzähler, Sammler, Leser und Hörer. Sie lässt das Faszinosum mythischen Denkens und magischen Handelns mit dem Glücksversprechen mirakulöser Erlösung und mit der Teilhabe am Heil durch imitatio und meditatio in einer historisch je $\mathrm{zu}$ bestimmenden Konstellation zusammentreten.

Dennoch bleibt die Frage bestehen, ob sich innerhalb einer solchen historischen Konstellation nicht doch ein intrinsisches Momentum benennen ließe, das zwischen Vita und Mirakel den Ausschlag zur Legende gäbe und sie als distinkte Literaturform zur Geltung brächte. In den folgenden Überlegungen suche ich jenes Momentum in einer Kombination von Kürze, Serialität und Typusbildung im Prozess der sequentiellen Ausdifferenzierung der kleinen Form. Denn zwar kann man literarische Kürze (brevitas) nicht in absoluten Vers- oder Seitenzahlen angeben; insofern ist die Legende nicht per se kurz. Doch belegt ihre Entstehung durch das Verfahren der compilatio, dass sie aus exzerpierten, durch Einkürzen der Quellen (abbreviatio) herausgeschnittenen Bauelementen, Motiven und Modulen besteht. Das aber

13 Als besonders schwierig erweist sich die Abgrenzung zwischen Heiligenvita und Legende. Vermutlich ist sie nur aus der Gebrauchssituation heraus zu ermitteln, da Legenden wegen ihrer Verwendung im Kontext von Tischlesungen oder Messfeiern nicht den Umfang eines libellus annehmen können. Doch das ändert sich bereits im Kontext des Legendars durch die Tätigkeit des Kompilators. Dessen Materialsammlung kann derartig anschwellen, dass sich die Legende in ein Florilegium von Sprüchen und Anekdoten verwandelt (wie etwa die Fioretti di San Francesco zeigen; vgl. die zweisprachige Ausgabe von Courbier [1956]). Die Behauptung einer größeren biographischen Authentizität (wie sie etwa von Sulpicius Severus ins Spiel gebracht wird, der den Heiligen Martin von Tours persönlich aufsuchte) ginge fehl: Das Genre der Vita in der Tradition der antiken ßio ist

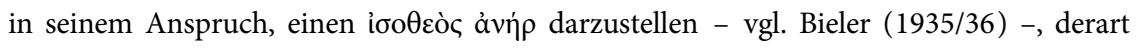
durchstilisiert, dass die Schematik und ihre Versatzstücke überall durchschlagen.

14 Vgl. Gumbrecht (1979), S. 37-84. 
versetzt die Legende in die Lage, intertextuell sowohl in Legendar und Sammelhandschrift als auch durch wiederholte Spiegelung in diachronen Textreihen variierend und negierend, invertierend und intensivierend immer vielfältigere Heiligkeitstypen vor Augen zu stellen. ${ }^{15}$ So wiederum kann die Legende im hagiographischen Feld als diejenige Form erfasst werden, die das Heilige dadurch zu weiterem frommem Gebrauch präpariert, dass sie es in Sentenz, Gestus und Performanz zu einer wiedererkennbaren Pathosformel verdichtet, die in dem Maße sichtbar hervortritt, in dem eine Pathosformel auf die andere reagiert. ${ }^{16}$

Wie eine solche Pathosformel konstruiert und rekonstruiert werden könnte, mag vorerst ein Beispiel andeuten, bei dem zur Ermittlung des pathoserzeugenden Motivs eine komplexere literarische Form als die Legende behilflich ist. Useners Pelagia-Sequenz nämlich lässt sich, vermittelt über das Basismotiv der Monachoparthenia, um die Anti-Legende der Päpstin Johanna erweitern und so aus dem engeren ritualistischen Kontext lösen. Die Geschichte der Päpstin ist aus chronikalischen Notizen (Martin von Troppau) und biographischen Skizzen (Giovanni Boccaccio) von Dietrich Schernberg 1480 in das Schön spiel von Frau Jutten ${ }^{17}$ verwandelt worden: in eine von einem Teufels- und Gerichtsspiel gerahmte Tragikomödie über die zuletzt in den Himmel erhobene Teufelsbündnerin, deren Pathosformel das Stück in signifikanten Tableaus herausarbeitet. Sie zeigt sich, verbunden mit einer Serie von Investituren und Revelationen, in einem vierfältigen Gestus des Entbindens:

- im Exorzismus, den die Päpstin am Sohn eines römischen Senators im Namen des Heiligen Nikolaus vollziehen soll: Das kann ich jtzund

15 Die Grundunterscheidung vom Märtyrer- und Bekennerheiligen (martyres / confessores) erfasst zwar einen wichtigen Übergang, den Ursprung der Auserwähltheit und ihrer Bewährung betreffend - vgl. Feistner (1995) -, wird aber bei weitem nicht dem fein skalierten Spektrum der Typenbildung durch Viten- und Episodenstrukturen gerecht.

16 Zum Warburg'schen Begriff der Pathosformel vgl. Michaud (2007) sowie Didi-Huberman (2010).

17 Dietrich Schernberg, Ein Schœen Spiel von Frau Jutten, im Folgenden zitiert nach Lemmer (1971). 
nicht volenden / Sondern will euch mein Cardinel senden [...] Die sollen jhn wol entbinden / Von solchem bösen feinde (vv. 711-716);

- in der monströsen Niederkunft der Päpstin, die ihr zugleich den Lebensfaden durchtrennt;

- in der Absolution durch den Erlöser dank der Fürsprache Marias und des Heiligen Nikolaus: Jr solt erhört sein on argen wahn. / Sindt du mich hast so hoch vermant / So geb ich dir die Sünderin an die hand / Vnd sol gentzlich entpunden sein / Von jhrer engstlichen pein (vv. 1.542-1.546); sowie

- in der messianischen Auslösung Johannas aus dem Pakt mit dem Teufel: Darumb will ich jhr zu guthe / Senden meinen Englischen botten / Der sie schnelliglich sol entbinden / Von dem Teuflischen gesinde / Vnd sol sie führen schnelliglich / In das ewige Himelreich (vv. 1.551-1.556).

Wo ein solches entbinden nicht drastisch in Szene gesetzt wird wie in der Geburts- und Todesszene Juttens, taucht es als Signalwort in der Figurenrede auf und wird durch gezieltes Wiederholen zum typusbildenden Paradigma, in dem sich die Heiligung der Sünderin ausprägt. Nicht zufällig vollzieht sich jenes Geschehen an einer widersprüchlich zusammengesetzten Figur: Sie verbindet den biologischen Körper einer Frau mit dem Amtskörper des Papstes, dessen Aufgabe in der Nachfolge des Petrus darin besteht, auf Erden zu binden und zu lösen, was im Himmel ge- und entbunden werden soll.18 Das Pathos der Formel entspringt also ihrer inhärenten Widerspruchsspannung - ein Muster, dem ich im Folgenden am Beispiel einiger Schlüsselfiguren kirchlichen und monastischen Amtsverständnisses nachgehen möchte:

18 Vgl. Mt 16,19 (Vulgata): Et tibi dabo claves regni colorum. Et quodcumque ligaveris super terram, erit ligatum et in colis: et quodcumque solveris super terram, erit solutum et in colis. Entsprechend heißt es etwa in den Acta Petri des Passional (2013): die sluzzele wurden im bevoln / zu des himels pforten, / daz er mit sinen worten / mohte binden und enpinden (vv. 19.018-19.021). Schernbergs Dramatisierung der Legende demonstriert, was das im Extremfall bedeuten kann: dass durch den göttlichen Gnadenakt die diabolisch unterwanderten sakralisierten Bindungen wieder rückgängig gemacht werden können. 
an Martin von Tours und Dominikus von Caleruega, an Severin von Köln und Franziskus von Assisi in ausgewählten Fassungen ihrer Viten.

II.

Wie genau wäre das Wechselspiel von Kürze und Kürzung zu denken? Wenn Hans Blumenbergs Anthropologische Annäherungen an die Rhetorik nicht fehlgehen und seine Bestimmung das Richtige trifft, dass «Evidenzmangel und Handlungszwang [...] die Voraussetzungen der rhetorischen Situation» seien, ${ }^{19}$ dann bilden brevitas und abbreviatio exemplarische Strategien zur Bewältigung der epistemischen und existentiellen Beschränktheit des Menschen. Auf beide Limitationen kann er sprachlich reagieren: mit fortgesetzter Metaphernbildung. ${ }^{20}$ Dabei gehorcht brevitas dem Drang, die Kluft zwischen Erkenntniswillen und Wahrheit durch sprachbildliche Verdichtung des Redestoffs qualitativ zu verringern, während abbreviatio quantitativ Rücksicht auf den Zeit- und Entscheidungsdruck unter stets fragilen Lebensumständen nimmt, die ein entschiedenes Behandeln der materia auch ohne letzte Gewissheit über ihren Wahrheitsgehalt fordern. Obwohl beide Begriffe also in unterschiedlichen Dimensionen des Sprachgebrauchs operieren, bleiben qualitativer und quantitativer Aspekt der kurzen Rede immer aufeinander bezogen: Von einer gelungenen abbreviatio kann man nämlich nur dann sprechen, wenn die Reduktion der Redeausdehnung das Material schärft und durch Selektion neu akzentuiert, statt es zu verdunkeln oder einzunebeln (obscuritas); von einer Intention auf brevitas selbst dann, wenn eine Ampli-

19 Blumenberg (1981), S. 104-136, hier: S. 117.

20 Dazu wiederum Blumenberg: «Aber von den Griechen selbst ist die Überredung in den Gegensatz zur Überwältigung gestellt worden: im Umgang der Griechen mit Griechen, so Isokrates, sei das Überreden angemessen, im Umgang mit Barbaren der Gebrauch der Macht; aber diese Differenz ist als eine der Sprache und der Bildung verstanden, weil Überredung Gemeinsamkeit eines Horizontes voraussetzt, der Anspielung auf Prototypisches, der Orientierung an der Metapher, am Gleichnis.» Ebd., S. 111. Vor dem Hintergrund der klassischen Definition Quintilians der metaphora continua könnte man aus anthropologischer Sicht daher auch von der Unvermeidlichkeit der Allegorie sprechen. $\mathrm{Zu}$ deren metamorphotischer Entfaltung durch Variantenbildung und Auslegung vgl. Scheuer (2017), S. 57-75. 
fikation des Redegegenstandes erst den Raum für Vertiefung schafft, in den dann knappe Spruchakte, prägnante Metaphern oder pointierte, diagrammartig aufbereitete Denkmuster zusätzlich eingesenkt werden. Der Modus der Kürze und das Verfahren des Kürzens dienen dabei synergetisch dem einen Ziel: Qualitäten durch Quantifizierung wahrnehmbar, beurteilbar und erinnerbar zu machen.

Eine charakteristische Praxis, die sich in der mittelalterlichen Schriftkultur aus jenem Interesse an sprachlicher und imaginärer Intensität ergibt, ist die Technik der Kompilation, eines ihrer Hauptbetätigungsfelder im 13. Jahrhundert die Sammlung von Legenden. ${ }^{21}$ So stellt etwa eine Quelle der Legenda Aurea, die Abbreviatio in gestis et miraculis sanctorum des Dominikaners Jean de Mailly (1225-1230), die Operation der Kürzung schon in ihrem Titel aus. Werke solch kompendiösen Zuschnitts dienen im Ordenskontext dazu, dem Lesegebot nachzukommen, das im Kleinen den Tagesablauf der Mönche, im Großen und Ganzen den Haushalt ihrer Lebenszeit mit reguliert: Jetz bett / jetz liß / jetz arbeith / jetz iß / So wird dir leicht das Leben / Und kurz die Zeit darneben. ${ }^{22}$ Dabei erschöpft sich die Tätigkeit des Kompilators nicht im Aufspüren von Quellen und im Anhäufen von Exzerpten. Vielmehr gehört das compilare zu den Produktivkräften der gelehrten Schriftpraxis. In der Einleitung zur Neuedition und -übersetzung der Legenda Aurea des Jacobus de Voragine bemerkt Bruno Häuptli deshalb:

Laut Isidor von Sevilla «vermischt der Kompilator fremde und eigene Worte` [Is. orig. 10,44]. Die Bedeutung von compilare bleibt aber im 13. Jh. nicht auf das negativ konnotierte Kompilieren beschränkt, sondern ist oft gleichbedeutend mit Verfassen. [...] Jacobus sieht sich also sowohl als Redaktor wie als Autor der L[egenda] A[urea]. Aus dem Umfang und der Komplexität seines Hauptwerks zu schließen, gingen jahrelange Vorarbeiten voraus, die er, offenbar im Auftrag des Ordens und, wie neue Untersuchungen nahelegen, mit Unterstützung durch ein Redaktorenteam, neben den Aufgaben als Lektor und als Prior erledigte, so daß er das Werk zwischen 1263 und 1266 abschließen konnte. ${ }^{23}$

21 Zum spätantiken und mittelalterlichen Verständnis von compilatio vgl. Jones (2019), S. 251-279; Rener (1995), S. 193-210.

22 Schuster (1740), S. 408; vgl. auch Kaftan (2014), S. 415-421.

23 Häuptli (2014), Bd. 1, S. 16 f. 
Dem komplexen, die Kohärenz der Legende herstellenden Verfahren hat Dietrich von Apolda in seiner Vita S. Elyzabeth eine Beschreibung gewidmet, die detailliert vor Augen führt, wie vom Auffinden und Sichern des Materials an die Arbeit des Kompilators seinen Stoff transformiert:

paucissima de hiis, que scripta habui, deposui; sed incomposita et sparsa composui, inordinate ordinavi, indistincta distinxi et ornavi, prout potui, impolita. Multa interserui et apposui et, sicut congruere credidi, materie adaptavi personarum nomina, dignitates et officia, locorum vocabula et tempora exprimendo. Quedam, sicut in scriptis repperi, de verbo ad verbum posui et nonnulla eciam variavi et universa et diversa in unum colligens hoc opusculum compilavi.

〈Von dem, was mir schriftlich vorlag, habe ich nur wenig ausgelassen. Ich habe jedoch Ungefügtes und Verstreutes zusammengestellt, Ungeordnetes in die richtige Reihenfolge gebracht, Unklares verdeutlicht und den schlichten Stoff, so gut ich es vermochte, in ausgefeilter Sprache dargeboten. Vieles habe ich außerdem ergänzt und hinzugefügt und dort, wo es mir passend erschien, in den Stoff eingeschoben, wobei ich die Namen der Handelnden, ihren Rang, ihre Ämter und die Namen der Schauplätze wie die Daten angegeben habe. Manches habe ich wortwörtlich so, wie ich es in den schriftlichen Vorlagen vorfand, übernommen, anderes habe ich jedoch geändert und ich habe alles Material, zuweilen auch ganz Unterschiedliches, zusammengetragen und daraus dieses Werk geschaffen. ${ }^{24}$

Das mit dem Gesamtbild der Vita Übereinstimmende (universa) und das in Einzelheiten Abweichende (diversa) in eine Darstellung zu überführen (in unum colligere), definiert die Gesamtaufgabe des werkbildenden Kompilierens (opusculum compilavi). In ihrem Rahmen kommen sämtliche produktiven officia oratoris zum Zuge:

- die inventio durch das Aussondern des Überflüssigen (deponere),

- die dispositio durch das Zusammenstellen und Anordnen des ausgewählten Stoffes (componere / ordinare),

24 Übers. Rener (2007), S. 26f. Eine ähnliche Tätigkeitsliste hat Dietrich von Apolda dem ersten Prolog seiner Vita des Heiligen Dominikus hinzugefügt, die er parallel zur Elisabethvita verfasst hat. In bemerkenswerter Weise lehnt er es dabei ab, dass seine Kompilation als Legende bezeichnet werden dürfe: Nec volo, quod Legendae vocabulo censeatur, sed libellus de Vita \& obitu \& miraculis sancti Dominici, \& de Ordine, quem instituit, nominetur. Vgl. Acta Sanctorum Augusti I (1733), S. 562-632, hier: S. 563 BC. 
- die elocutio durch das stilistische Markieren von Unterscheidungen (distinguere / ornare).

- Darüber hinaus schließt der Kompilator Lücken (interserere / apponere), indem er Namen und Amtsbezeichnungen, Orts- und Zeitbestimmungen nachträgt oder mit seinen Quellen abgleicht (materie adaptare), an deren Wortlaut er sich ansonsten entweder buchstäblich hält (de verbo ad verbum ponere) oder die er der eigenen Diktion angepasst hat (variare).

Mit anderen Worten: Beim Kompilieren ist das vollständige rhetorische Instrumentarium der mittelalterlichen Schulpoetik am Werk. ${ }^{25}$

Das hat Folgen für den Gehalt des Dargestellten: Systematische Kompilation ist die Grundlage intensivierender Stoffaneignung; sie lässt jedes Wiedererzählen auch dann als ein Kommentieren erscheinen, wenn ausdrückliche diskursive Zusätze des Kompilators fehlen. Schon der Vergleich unterschiedlicher Fassungen einer Legende oder eines Motivkreises innerhalb einer Legendensammlung macht deutlich, dass jedes Durcharbeiten des Materials eine eigene Umschrift und Transformation leistet. Sie wiederum stempelt jede ihrer Vorlagen zur sekundären Bearbeitung eines Textes, dessen Archetyp sich nirgends sicherstellen lässt, auch wenn er als Substrat durch jeden Akt der abbreviierenden (oder amplifizierenden) Akzentverschiebung hindurchscheint. Darin entspricht die Darstellung der Legende den anderen Formen des Denkens in Exempeln: Welche Variante auch immer vorliegt, stets gibt sie in ihrer Eigenart «Beispiel einer allgemeinen Regel, die man nicht angeben kann», ${ }^{26}$ ohne dass man ihrem Imperativ folgt: sie zu lesen!

Wie aber vermag die Legende im Modus der brevitas und mit dem Verfahren der abbreviatio die spezifische Regel eines Heiligenlebens zu erfassen? Wie lässt sich die Wahrnehmung der Heiligen durch Kürzung

25 Über die Verfahren der mittelalterlichen Poetik, Prägnanz durch abbreviatio herzustellen, vgl. Waltenberger (2019), S. 21-43.

26 Die Formulierung stammt aus Immanuel Kants Kritik der Urteilskraft, $\$ 18$ («Was die Modalität eines Geschmacksurteils sei»). Sie dient dort der Charakterisierung des ästhetischen Urteils und seiner allgemeinen exemplarischen Verbindlichkeit. Vgl. dazu Agamben (2009) sowie Willer / Ruchatz / Pethes (2007), S. 7-59. 
schärfen, wie eine Legende als Kompilationsprodukt in aller Kürze (breviter) zuspitzen? Gibt es eine Größe, an der sich innerhalb einer Vita Maß dafür nehmen ließe, was getilgt werden kann und was dadurch hervorgehoben werden soll? Der anonyme moselfränkische Bearbeiter der Legenda sancti dominici vulgariter ${ }^{27}$ aus dem Jahr 1467 gibt im Prolog seines libellus zu verstehen, dass er sich darüber Gedanken gemacht hat, unter welcher Voraussetzung ein solches Maß aus der Folge mehrerer oder doch mindestens aus der Juxtaposition zweier Heiligenviten herauszulesen sei:

Sente dominicus leuen ouerdreit sich an vil punten mit sente mertyns leuen, vnd besunder dar an dat dominicus haet in synen sterfflichen dagen dry doiden erwecket als ouch sente mertin vur yme gedaen hatte. Darumb want ich vur eyme iaire gedutschet haen sente mertins leuen, der eyne van den alden heiligen ist, vnd bynnen dusent vnd lxvi iairen nyet in hait gelebt uff erden, begeren ich ouch nu als man schribet na cristus geburte dusent vier hundert vnd lxvij iaire in dat dutzhe zo setzen sent dominicus leben, der eynre van den niuwen heiligen ist, vnd bynnen drittehalff hundert iaren uff erden gelebet hait. ${ }^{28}$

27 Es handelt sich um die sogenannte Prosafassung II der deutschen Dominikus-Vita, die nicht von der lateinischen Vita Dietrichs von Apolda abhängig sei, vgl. WilliamsKrapp (1979), Sp. 186-188, hier: Sp. 188, sowie ders. (1998), S. 147-173, hier: S. 154 f. Die Vita ist überliefert in der Handschrift Kues, Hospitalbibliothek, cod. 109; zur Beschreibung der Handschrift vgl. Marx (1905), S. 108 f. Die Fassung der Kueser Handschrift ist bislang nicht ediert, eine Ausgabe durch Marco Brösch (Trier, Cusanus-Bibliothek Bernkastel-Kues) jedoch avisiert. Ich danke Herrn Brösch und dem Cusanus-Institut für die Bereitstellung eines Digitalisats des Mikrofilms. Die folgenden Zitate sind eigene Transkriptionen; Kürzel wurden aufgelöst. Zur gezielten Verknüpfung und wechselseitigen Erhellung von Heiligkeitstypen am Beispiel von Martins-, Dominikus- und Elisabethviten vgl. demnächst die gemeinsame Studie von Caroline Emmelius und Hans Jürgen Scheuer zum Thema Korrelierte Heiligkeit. Legendarische Parallelviten in der dominikanischen Hagiographie.

28 Kues, Hospitalbibliothek, cod. 109, f. 2r. Die Funktion der Zahlenangaben scheint mir unklar oder defekt: Geht es dem Kompilator darum anzugeben, wie lange die beiden Heiligen Martin und Dominikus nicht mehr auf Erden leben? Abgesehen von der fehlenden Exaktheit der Lebensdaten, müsste dann aber nicht die Verneinung nyet in hait gelebt bei Dominikus ergänzt werden? 
Auf den ersten Blick scheinen die Vergleichspunkte kontingent: Dass er die Dominikus-Vita im Anschluss an das Martinsleben übersetzt habe und dass beide Heilige die gleiche Zahl von Toten erweckt hätten, nimmt sich wie ein Zufall aus, dem lediglich der Kompilator aus eigener Perspektive und Willkür Bedeutung zumisst. Erst durch seine Bemerkung, der erste gehöre zu den alten, der zweite zu den neuen Heiligen, wird das Prinzip seiner Deutung offenbar: Beide Leben sollen so gelesen werden, dass sie zueinander in ein typologisches Verhältnis treten. In einer solchen Relation von Alt und Neu bilden sie Parallelviten, die den Leser - analog zur antiken, von Plutarch geübten Form der Kritik - zu einer Synkrisis drängen. Von ihr aus fällt Licht auf das Heil, dessen kontinuierliche Wirkung sich im Wechselspiel von Typus und Antitypus diskontinuierlich manifestiert. Das beginnt bei den Namen der Protagonisten: Sowohl Martin als auch Dominicus sind Träger eines mysterium nominis ${ }^{29}$ - der eine, insofern er, wie die Legenda Aurea erklärt, den Kriegsdienst bezeichnet (quasi Martem tenens) ${ }^{30}$, den er missionierend und Irrlehren bekämpfend als prototypischer miles Christi ableistet; der andere, insofern ihn der Traum seiner Mutter vor der Geburt als ebenfalls prototypischen «Hund des Herren〉 (Domini canis) auszeichnet:

E aber iohanna dominicum geberde do saich sy vur hyn eyn gesiechte dat ir von gode in gegeben wart, want sy beduchte dat sy in yrtem lybe dröche eynen hunt der eyne byrnende fackel in syme munde hatte vnd er gienck uis yrem licham vnd entphengede mit dem fuyre synre fackelen die gantze werlt. ${ }^{31}$

29 Grundlegend zur mittelalterlichen Vorstellung des Erzählens als Entfaltung des Protagonistennamens, der die Signatur der gesamten epischen Großform in sich trägt und wie ein Topos unterschiedliche Erkenntnisoptionen eröffnet: Reich (2011), bes. S. 13-91. Zur Bedeutung des Namens speziell in der Legende vgl. Koch (2019), S. 25-44.

30 Jacobus de Voragine, Legenda Aurea, 741, zitiert nach der Ausgabe von Häuptli (2014), Bd. 2, S. 2140.

31 Kues, Hospitalbibliothek, cod. 109, f. 4v. Dietrich von Apolda schreibt entsprechend: visione futuri partûs indicativâ à Domino caelitus praeventa est: vidit enim se gestare catulum in utero, qui ardentem in ore faculam bajulabat; egressus autem ex utero totum mundum ignibus de ore suo procedentibus incendebat. Acta Sanctorum Augusti I (1733), S. 566 C/D. 
Dabei deute die brennende Fackel auf das Wort des Dominikus und des Ordo Praedicatorum voraus, das die Welt in Brand setze und im Kampf gegen die Häretiker erleuchte. Die Wucht beider Etymologien liegt darin, dass sie die Instrumentalität der Gewalt beim Verbreiten und Verteidigen des christlichen Glaubens rechtfertigen: Liegt die alte Macht darin, dass das Christentum imperial wird und sich militarisiert mit der Konsequenz, dass der Widerspruch zwischen Christ- und Soldat-Sein im Vorbild Martins von Tours koinzidiert, so zeigt sich die neue Macht als sprachliche Überwältigung der Gegner durch die Waffen der Predigt und der Bildung an dem ansonsten unsagbar keuschen und grenzenlos lernbegierigen Ordensgründer Dominikus. $^{32}$

Das so in einem argumentum a nomine exponierte Grundmotiv des jeweiligen Heiligen wird im weiteren Verlauf der Lebensberichte episodisch entfaltet, das heißt: seinem sensus historicus entsprechend in einer linearen historia veranschaulicht und ausgelegt. Schon der erste Biograph des Heiligen Martin, Sulpicius Severus, hatte im Prolog seiner Vita sancti Martini ${ }^{33}$ darauf aufmerksam gemacht, dass die Aufgabe der antiken Biographie, in einer Serie von Taten und Aussprüchen den unverwechselbaren Intelligenztyp ihrer Leitfigur auszuprägen, christlich überformt werden solle. Ziel solcher Umschrift sei nun, einen je besonderen Heiligkeitstyp vor Augen zu stellen, dessen virtus Leben und Leiden Christi aktualisiere und ad veram sapientiam et caelestem militiam divinamque virtutem ( $\mathrm{zu}$ wahrer Weisheit, himmlischem Kriegsdienst und göttlicher Tugend`) fortschreibe, ne is lateret qui esset imitandus («damit der, den es nachzuahmen gelte, nicht im Verborgenen bleibe $).{ }^{34}$ Die Formel jener virtus wird dabei zwar durch Wundertätigkeit des Heiligen über den Tod hinaus ergänzt und bekräftigt. Insgesamt aber

32 Darauf deutet der zweite Traum der Johanna hin: Sy sach in dem gesychte dat kynt domynicus vnd sach dat it hatte vur syner styrnen eynen fyn schynenden steren vnd der erluchte mit syme glantze alle erttrich vnd auch den hemel. Kues, Hospitalbibliothek, cod. 109, f. 5r.; vgl. Acta Sanctorum Augusti I (1733), S. 566 D: sacer infans Dominicus per visum apparuit, stellam praefulgidam habens in fronte, cuius splendore nimio totius mundi facies illuminata radiabat.

33 Sulpicius Severus, Vita sancti Martini, im Folgenden zitiert nach der Ausgabe Huber-Rebenich (2010).

34 Sulp. Sev., Vit. Mart. 1,6. 
bleibt die Charakteristik des Typus wesentlich an das Handeln und Sprechen in der Welt gebunden. Die Heiligkeit der dargestellten Lebensform spielt sich also da ab, wo die Legende als zu lesende selbst angesiedelt ist: in der Sphäre des sprachlichen oder gestischen Pragmas.

Bei Martin von Tours verdichtet sich solches Tun in einem doppelten Gestus: einem Akt des Bedeckens und einem komplementären Akt des Entblößens. Damit verschränkt die Vorstellung dieses speziellen Heiligen zwei unversöhnliche Gegensätze zu einem neuartigen Typus. Indem Martin nämlich seinen Mantel teilt, bekleidet er den Bettler zu Amiens aus christlicher Barmherzigkeit. Dadurch, dass er dessen Blöße deckt, verstümmelt er jedoch seine Uniform und gibt durch partielle Selbstentblößung seinen militärischen Rang der Lächerlichkeit preis, ${ }^{35}$ an dem er gleichwohl mit der ihm verbliebenen zweiten Mantelhälfte Zeit seines Lebens festhält - auch außerhalb der römischen Legion. Das führt zu einer doppelten Anerkennung. Indem ihm Christus in der folgenden Nacht, bedeckt mit der Mantelhälfte des Bettlers, in einer Traumvision erscheint, macht er deutlich, dass Martin zum einen durch seine entblößende Tat das Wort des Herrn erfüllt habe: amen dico vobis quamdiu fecistis uni de his fratribus meis minimis mihi fecistis (Mt 25,40). Das aber kommt zum anderen Martins vorweggenomme-

35 Sulp. Sev., Vit. Mart. 3,2: Interea de circumstantibus ridere nonnulli, quia deformis esse truncatus habitu viderentur; multi tamen, quibus erat mens sanior, Altius gemere, quod nihil simile fecissent, cum utique plus habentes vestire pauperem sine sua nuditate potuissent. "Unterdessen lachten einige der Umstehenden, weil er mit seinem verstümmelten Gewand entstellt aussah. Viele aber, die bei besserem Verstand waren, seufzten tief, weil sie nichts dergleichen getan hatten, obwohl sie durchaus mehr besaßen und den Armen hätten bekleiden können, ohne sich selbst zu entblößen», Huber-Rebenich (2010), S. 17. Die Passage reflektiert auf die Wirkung der Pathosformel in statu nascendi. Nach Maximilian Benz werde «hier die Zerstückelung, die einst dem corpus des Märtyrers zuteilwurde, auf ein Bekleidungsstück verschoben, dessen partes dann auch für das Ganze stehen können»; Benz (2019), S. 133. Spott und Seufzen der Betrachter würden insofern noch zur Christomimesis des Märtyrers gehören. Gleichwohl ist der trunkierte Mantel eine Hülle: nicht der Körper selbst, sondern ein symbolischer Zweitkörper, der als Phantasma in den spirituellen Raum der Traumvision eindringen kann. Von dort wirkt er in die irdische Ordnung zurück. Das Seufzen der Betrachter bezieht sich so, im situativen Kontext gesehen, auf die verspätete Erkenntnis, dass sie anders als Martin das Gebot der Barmherzigkeit nicht erfüllt haben. 
ner Aufnahme in die Legion der Heiligen gleich. Es ist, als hätte der Messias selbst den Katechumenen Martin mit der zweiten soldatischen Mantelhälfte wie mit einem Taufgewand investiert und ihn durch solche Bedeckung in einen neuartigen Stand erhoben. Ihn bringt Martin vor Kaiser Julian auf die paradoxe Formel, die fortan die Devise seines Lebens ausmacht: Christi ego miles sum: pugnare mihi non licet («Ein Soldat Christi bin ich: Zu kämpfen ist mir nicht erlaubt $>){ }^{36}$

Bei Dominicus markieren gleich zwei Episoden den Paradigmenwechsel vom alten militärisch-monastischen zum neuen missionarisch-gelehrten Selbstverständnis. Beide behandeln die Insistenz der Lehre, die materiell und immateriell selbst der Vernichtung durch die Elemente trotzt: Weder Wasser noch Feuer können den Büchern und den Glaubensregeln des Dominikus etwas anhaben, ohne dass der Heilige zur Rettung der Schriften mehr beitragen müsste als seine unmittelbare Berührung mit den Schriftträgern. In der ersten Szene fallen ihm beim Überqueren eines Flusses sämtliche Bücher, die er als Wanderprediger unter seinem Gewand trägt, ins Wasser. Drei Tage lang liegen sie ohne schützende Hülle am Grund des Flusses, bis ein Fischer sie statt eines Fanges wieder zutage fördert. Unversehrt, als seien sie die ganze Zeit über sicher in einem Schrein aufbewahrt worden, senden erber lude sie dem Dominikus nach Toulouse zurück. Die zweite, ungleich berühmtere Szene spielt sich in Fanjeaux, dem antiken fanum Iovis, ab: im Zentrum des theologischen Streits mit den Katharern. Dort kommt es zu einer Disputation, in deren Verlauf beide Parteien ihre Glaubensgrundsätze niederschreiben, damit ein Schiedsgericht darüber befinden könne, welche Positionen mit dem Evangelium übereinstimmen und welche nicht. Die bestellten Richter gehen nun nicht zur fachlichen Prüfung der Thesenpapiere über, sondern entscheiden sich für eine Feuerprobe. Dabei geht das katharische Schriftstück sogleich in Flammen auf, während die Schrift des Dominikus dreimal den Flammen übergeben wird und jedes Mal der Einäscherung entgeht, indem sie unbeschädigt dem Feuer entspringt und dadurch spektakulär bestätigt wird. Der Kontakt der rechten Lehre mit den Elementen gestaltet sich so als eine Wasser- beziehungsweise Feuertaufe und darüber hinaus als schriftgeleitete revelatio des Auferstehungsmysteriums und somit 
des Kerns der Guten Botschaft. ${ }^{37}$ Verknüpft werden jene beiden Schlüsselepisoden der Vita des Dominikus wiederum mit einer typusbildenden Sprachgeste. Sie besteht zwar nicht wie bei St. Martin in einer zitierbaren Sentenz, wohl aber im wiederkehrenden Bezug auf die Regel, die der Ordensgründer seinen Dominikanern mit auf den Weg gibt. Dabei erstreckt sich seine Keuschheit gerade auch auf das Sprechen: Er hielt den orden selbes strencklich an cleydunge an fasten an armoet an korganck an predigen an wenich reden vnd an swigen. ${ }^{38}$ Nicht selbst reden, sondern Sprachrohr sein für die Verkündigung des Gotteswortes - dat syne broder alle zyt redten mit gode ader van gode ${ }^{39}$ - macht den dominikanischen Typus aus. Er führt der Spruch- und Gesten-Topik der Heiligkeit die neue Pathosformel des studierten Sprachasketen hinzu. Nichts macht den Heiligen Dominikus greifbarer als jene Allegorisierungen der Lehre nach außen wie nach innen in den Orden hinein.

III.

Auf der Suche nach weiteren Beispielen, die es erlauben, Heiligkeitstypen aus intertextuellen Relationen zwischen Legenden zu isolieren, erweist sich die Vita Sancti Martini nicht nur wegen ihrer literaturgeschichtlichen Priorität als günstiges Paradigma. Das gilt umso mehr, als die Pathosformel, die es im Vollzug der Mantelteilung Martins ermöglichte, den Christen mit dem Legionär in einer Gestalt zu verschränken, schon innerhalb der Legende weiterentwickelt wird. Indem eine zweite Episode sie wieder aufnimmt, überträgt sie nämlich das De- und Investiturexempel auf die Widerspruchsspannung zwischen Kirchenamt und Eremitentum: Ganz gegen seinen Willen wird Martin zum Bischof von Tours berufen und fährt dennoch fort, wie ein Mönch Verzicht zu üben. So verschenkt er die Tunika unter seinem Ornat erneut an einen unbekleideten Bettler, diesmal unmittelbar vor der Hostie, wenn es darum geht, sie im Mirakel als lebendigen Leib Christi auszustellen; vgl. Scheuer (2015), S. 83-100.

38 Kues, Hospitalbibliothek, cod. 109, f. 12v.

39 Ebd., f. 15v. 
Feier der Heiligen Messe, ohne seine eigene Nacktheit rechtzeitig und angemessen bedecken zu können. Ihm steht dazu nur eine paenula, ein notdürftig übergestreiftes textiles Fast-Nichts, zur Verfügung. Allein das Eingreifen der Engel kann verhindern, dass er sich bei der Elevation der Hostie während des Hochamts selbst entblößt. Damit hätte er nach der gestörten Einkleidung in der Sakristei das Messritual noch ein zweites Mal unterbrochen, ja vollends ruiniert. Dank des himmlischen Paraments, das ganz aus Goldglanz besteht, kann er nun aber demonstrativ die Nacktheit des eremitischen Asketen mit der liturgischen Erfüllung seines Bischofsamtes verknüpfen. Die Legenda aurea hält die Bedeutung des Messwunders durch ein kompilatorisch hinzugefügtes Gleichnis fest: Der Anblick eines geschorenen Schafes auf einem Bauernhof habe Martin zum Ausruf veranlasst, nun sei das Gebot des Evangeliums erfüllt; das nackte Schaf - damit ist zugleich typologisch auf das Opferlamm Jesus Christus verwiesen - habe zwei Gewänder besessen und eines davon einem Bedürftigen überlassen: ita et vos, inquit, facere debetis - 〈So, sprach er, sollt auch ihr handeln!.$^{40} \mathrm{Am}$ Körper des Bischofs Martin wird die Blöße zur Ostentation des von den Engeln Gottes verklärten Tugendkleides des Menschen, wie es durch die imitatio des Gotteslammes zum Vorschein kommt. Man könnte daher zusammenfassend zum Gestus der Martinsheiligkeit sagen:

An Martin bedeckt und enthüllt jener doppelte Akt [des Bedeckens und Entblößens] eine hybride Identität: einen Soldaten/Heiligen und künftighin einen Mönch/ Bischof, der gleichsam das härene Kleid des Asketen unter der Robe des Kirchenfürsten trägt. Das macht St. Martin zum Prototypen einer bis dahin nicht denkbaren, neuen Form von Heiligkeit, die sich weder im Märtyrer noch im eremitischen Bekenner verkörpert, sondern in einem spezifischen, unauflöslich widerspruchsvollen Phantasma aus mönchischer Askese und militärischem Amtsverständnis. ${ }^{41}$

Genau an jenem Knotenpunkt bildet die Pathosformel einen Spross, der in der Vita et translatio sancti Severini, ${ }^{42}$ des dritten Bischofs von Köln, eine eigene Legende austreibt. Sie verhält sich komplementär zur Basisbiographie

40 Jacobus de Voragine, Legenda Aurea, 747. Häuptli (2014), Bd. 2, S. 2156.

41 Scheuer (2019), S. 300.

42 Vita et Translatio Sancti Severini. Zitiert nach der Ausgabe von Päffgen / Pangerl (2011), S. 543-581. 
nach Sulpicius Severus. Denn beide Viten stützen sich wechselseitig, indem sie eine bestimmte Signatur von Heiligkeit übermitteln, beglaubigen und übertragen. Bei Martin von Tours besteht sie, wie gesehen, im Typus des miles Christianus. Die Severinsvita bestärkt die Wirksamkeit jener Formel durch ihre paradox nachgetragene, postfigurative Zeugenschaft, während die Martinsvita die von ihr präfigurierte Heiligkeit Martins im Gegenzug auf seinen Zeugen Severin überträgt. Abgesehen nämlich von den allfälligen, in seiner Vita nur summarisch abgehandelten Heilungswundern des Bischofs, zeichnet sich Severins Leben nur durch zwei besondere Ereignisse aus: Zum einen widerfährt ihm im Beisein seines Archidiakons eine Audition. Er vernimmt den Engelsgesang, den die Himmelschöre in dem Augenblick erklingen lassen, als der gerade verschiedene Heilige Martin über die Schwelle des Jenseits tritt und in die militia Dei, die Gemeinschaft der Heiligen, aufgenommen wird. Der Diakon bemerkt davon nichts. Selbst auf Severins insistentes Nachfragen hin hört er nur ein undefinierbares Rauschen im Kirchenraum. Die mirakulöse Zeugenschaft kann also ihrerseits nicht bezeugt werden. Das transzendente Geschehen bleibt dadurch jeder Profanation entzogen, sodass sich aus irdischer Perspektive letztlich gar nichts Erkennbares ereignet hat. ${ }^{43}$

Zum anderen erscheint Severin einem Eremiten, nachdem der von Gott erbeten hat, ihm doch zu zeigen, mit wem zusammen er einst den Lohn für seine Enthaltsamkeit empfangen werde. Die Szene, die ihm daraufhin geboten wird, schockiert den Einsiedler: Ein Engel stellt ihm nämlich den Bischof beim Bankett vor Augen, wie er es sich an einer reichlich gedeckten Festtafel der Kölner Bürger rheinisch gut gehen lässt. Jene Vision dient einerseits zur Mahnung des Asketen, dass sein Weg des Verzichts nicht als einziger und privilegierter zu Gott führe; andererseits verbindet der Engel die Schau mit dem Zusatz, Severin achte die zu seinen Ehren ausgestellte Üppigkeit ebenso sehr wie der Einsiedler sein hölzernes Trinkgefäß - in gut

43 Das entspricht präzise der bemerkenswerten Definition, die Caesarius von Heisterbach dem Mirakel gegeben hat: Miraculum dicimus quicquid fit contra solitum cursum naturae, unde miramur. Secundum causas superiores miraculum nihil est. Caesarius von Heisterbach, Dialogus Miraculorum, zitiert nach der Ausgabe von Schneider / Nösges (2009), S. 1894. 
kynisch-christlicher Tradition nämlich gar nicht. Zu diesen beiden Szenen bemerkt der Kompilator der Legende:

Haec ergo duo Beati Severini virtutum insignia, quae proposuimus ad experimendum bonitatis ejus meritum, ut puto, sufficerent, etiamsi plura non fuissent.

〈Diese beiden auszeichnenden Belege für die Tugenden des Heiligen Severin, die wir hier vorgestellt haben, mögen dazu ausreichen, das Verdienst seiner Güte darzustellen, auch wenn es nicht gerade viele sind. ${ }^{44}$

Mit anderen Worten: Weiter reduzieren ließen sich jene insignia virtutum Severins sicherlich nicht. Dass sie dennoch dazu ausreichen, seine Heiligkeit auszuprägen, liegt daran, dass sie den Kern der Legendenbildung sichtbar machen: Sie adressieren noch einmal die Pathosformel des vorangegangenen Martin'schen Heiligkeitstypus und unterstreichen deren Funktionalität als Quelle fortgesetzter Heiligung: den christlichen Dienst an Gott als Kriegsdienst und die Versöhnbarkeit des Widerspruchs von Askese und Kirchenamt.

Ein letztes Beispiel soll genügen, um zu belegen, wie eine einmal geprägte Pathosformel ihr Nachleben ausbildet, indem sie durch ihre Einprägsamkeit den Anstoß dazu liefert, neue, sich vom Bekannten absetzende Typoi zu finden. Ähnlich wie Dominikus gehört auch sein jüngerer Zeitgenosse Franziskus $\mathrm{zu}$ jenen neuen Heiligen, deren Imitationsleistung sich ebenso auf die Martinsvita bezieht, wie sie sich entschieden von ihr absetzt. Das wird dadurch deutlich, dass Franz von Assisi, Sohn eines Tuchhändlers und daher von Haus aus mit Fragen der Bekleidung beschäftigt, zunächst eine Phase der Martinsheiligkeit durchläuft: ${ }^{45}$ Nachdem er sich zur Abkehr

44 Vita Severini. Päffgen / Pangerl (2011), S. 557.

45 Explizit wird das Muster bei Lamprecht von Regensburg in seinem Sanct Francisken Leben (nach der ersten Vita des Thomas von Celano) angesprochen, wenn er in vv. 2.904-2.917 schreibt: Sant Francisk was sô milte, / daz in des niht bevilte, / wenn er wan einen roc truoc an, / daz er den einem armen man schiere hete geteilet mite. / erhete ouch einen höveschen site: / er bat die rîchen liute, daz / si ime lihen etewaz, / kürsen oder umbekleit. / daz was im von in unverseit. / er sprach: ‘ich nim diz gewant, / daz es iu niht mê kumt ze hant.> / swâ im bequam ein armez dan, / dem gap erz froelîchen an. Hier und im Folgenden zitiere ich nach der Ausgabe Weinhold (1880). 
vom weltlichen Leben eines Kaufmannssohnes entschlossen hat, kehrt er, spirituell gerüstet, in seine Heimatstadt Assisi als ein novus Christi miles ${ }^{46}$ zurück. Dort verwirft er sein irdisches Hab und Gut zugunsten des wahren Schatzes seiner Seele und unterzieht sich einer Serie von weltlichen Devestituren und geistlichen Investituren, bis er sein eigenes Modell gefunden und realisiert hat. Er wird die imitatio Christi so weit vorantreiben, dass seine obsessive Identifikation mit dem Messias, dem Evangelium und der Schöpfung Gottes eine neue Pathosformel hervorbringt: den Narren in Christo. Als ein solcher macht er sich allen Kreaturen Gottes gleich, denen er unterschiedslos zu predigen beginnt, betrachtet selbst die Buchstaben heidnischer Schriften als göttliche Geschöpfe, weil sie den Namen Gottes enthalten könnten, ${ }^{47}$ und verleibt sich schließlich sogar die figura Christi ein, indem er die Stigmata des Gekreuzigten auf den eigenen Körper übertragen lässt, nachdem er zuvor schon danach getrachtet hatte, durch den Zuschnitt seines Habits selbst zum Kreuz zu werden. Seine Weise, das eigene Leben der Vita Christi anzuähneln, ist so radikal, dass die forcierte Imitation das Original zu vervollkommnen versucht: crux und crucifixus verschmelzen in einer Person. Darin besteht die unverwechselbare Haltung des Franziskus, die jedem

46 Vita prima di S. Francesco d'Assisi del B. Tommaso da Celano, zitiert nach der Ausgabe von Amon (1880), S. 28 (1 Cel. 4): Cumque versus civitatem Assisii remearet, reperit juxta viam quondam ecclesiam, quae in honorem sancti Damiani fuerat antiquitus fabricate, sed casum proximum ex vetustate nimia minabatur. Ad quam novus Christi miles adveniens, pietate tantae necessitatis commotus cum timore ac reverentia introivit. Lamprecht von Regensburg nennt Franziskus einen helt, / den got ze kemphen hât erwelt (vv. $737 \mathrm{f}$. ).

47 Vgl. Lamprecht von Regensburg, Sanct Francisken Leben: swâ man gotes namen nante, / der name in vor liebe brante / und tet sînem herzen sô wol, / daz sîn muot wart von fröuden tol. / swâ er unwerde ligende vant / dehein schrift, die leit er zehant / an ein êrbaere stat dur daz, / obe von got dran etewaz / stüende oder sîn süezer nam. / der heiden schrift taet er alsam. / nû fragt ein bruoder, wârum er / der heiden schrift taet alse der. / dô sprach er: «man mac gotes namen / mit ir schrift setzen ouch zesamen.> / durh got êrt er ouch die buochstaben, / daz er sie niht liez abeschaben. / so er einen brief schrîben hiez, / von dem er niht tilegen liez, / wart dâran von unbesiht / geschriben ungerehtes iht (vv. 3.059-3.078). 
Außenstehenden als Wahn erscheinen muss. ${ }^{48}$ Ausgangspunkt seiner Karriere als Heiliger aber ist wie bei Martin eine Szene der Entblößung und Bedeckung. ${ }^{49}$ Als Franziskus' Vater ihn wegen der Verachtung seines Geschäftes vor dem Bischof der Stadt zur Rede stellen will, reagiert er, indem er sich als neuer Adam im Tugendkleid Martins präsentiert. In Lamprechts von Regensburg Sanct Francisken Leben heißt es entsprechend:

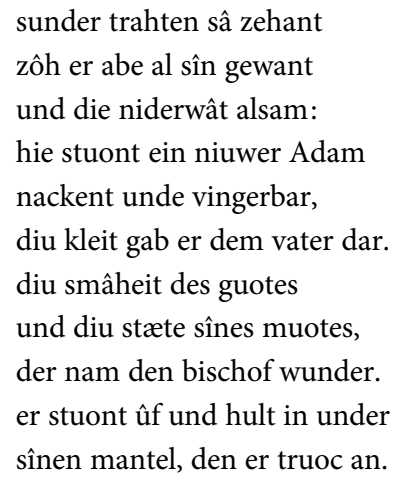

(vv. 870-880)

Das Plädoyer für willeclîchiu armuot (v. 265), das Lamprecht in seinem Prolog anspricht, scheint ebenso in der Nacktheit des Heiligen auf wie in der Bedeckung seiner Blöße durch den Mantel des Bischofs die von Franziskus stets angestrebte päpstliche Protektion seines Ordens. Unter dem Zeichen solcher Abkehr vom leiblichen und Hinwendung zum geistlichen Vater steht Franziskus' Lebensweg, auf dem der Patriziersohn, der anfangs wie ein höfischer Ritter nach Apulien auf Aventiure ausreiten möchte, zum Bettelmönch wird. Nun im hadertuoch statt in scharlachens gewant (vv. $895 \mathrm{f}$.) invertiert sein Leben das Vorbild Martins, indem er nach einem Überfall von Straßenräubern selbst zum Nackten im Schnee wird, dann zu einem kuchengarzîn im Kloster ân rock und âne schapprûn, nur mit einem hemde bekleidet (vv. 925-927), bis ihm ein Freund ein rockelîn (v. 936) spendet und er in weltlicher Kleidung in einem Hospiz für Aussätzige dient, wo er

48 Sie lässt sich durchaus auch als Krankengeschichte rekonstruieren, vgl. Cancik (1978), S. $95-119$.

49 Vgl. Schneider (2019). 
lernt, was gerne geben im Sinne völliger Verausgabung wirklich heißt. ${ }^{50}$ Seine weitere Karriere zum Heiligen bleibt am Gewandwechsel ablesbar: Er tauscht das einsidel gewant (v. 1.125) mit Stab, Ledergürtel und festem Schuhwerk gegen einen einfachen rock, dem kriuze glîch (v. 1.156), und einen schlichten Strick anstelle des Gürtels, um fortan so mit seinen Brüdern der vita Apostolica des Evangeliums näherzukommen. Den passenden Wahlspruch entnimmt er Psalm 54 (in der Variante des Gregorianischen Graduale):

〈jacta cogitatum tuum in domino et ipse te enutriet,〉

daz kiut: lâ dich an unsern herrn,

sô nert er dich von allem werren〉.

(vv. $1.329-1.331)$

Wie einst Martin von Tours folgt er damit zugleich dem Herrenwort:

Deswegen sage ich euch: Macht euch keine Sorgen um euer Leben, was ihr essen und was ihr trinken sollt, auch nicht um euren Leib, was ihr anziehen sollt. Ist nicht das Leben wertvoller als die Nahrung und der Leib wertvoller als die Kleidung? / Sehet die Vögel des Himmels an: sie säen nicht und ernten nicht und sammeln nichts in Scheuern, und euer himmlischer Vater ernährt sie doch. Seid ihr denn nicht viel mehr wert als sie? / Wer von euch vermöchte aber mit all seinem Sorgen der Länge seiner Lebenszeit auch nur eine einzige Spanne zuzusetzen? / Und was macht ihr euch Sorge um die Kleidung? Betrachtet die Lilien auf dem Felde, wie sie wachsen! Sie arbeiten nicht und spinnen nicht; / und doch sage ich euch: Auch Salomo in aller seiner Pracht ist nicht so herrlich gekleidet gewesen wie eine von ihnen.

(Mt 6, 25-29)

Im selben Zusammenhang steht offensichtlich die bereits erwähnte Identifikation des Franziskus mit allen Lebewesen aufgrund geteilter Kreatürlichkeit. Aufschlussreich im Sinne der kompilatorischen Fertigung von Legenden ist

50 Es wäre im Sinne der These von der Proliferation und Weiterentwicklung legendarischer Pathosformeln interessant, der Spur zu folgen, die Lamprecht von Regensburg legt, indem er im Anschluss an die Hospiz-Episode und an die Erwähnung der Heiligen Clara und des Clarissenordens einen Exkurs über die Heilige Elisabeth von Thüringen einschaltet. Am Elisabethleben des Caesarius von Heisterbach und des Dominikus-Biographen Dietrich von Apolda lässt sich die Weiterentwicklung der franziskanischen und dominikanischen Pathosformel beobachten. Zur Pathosformel der Devestitur in Dietrichs Elisabethvita vgl. Emmelius (2021). 
dabei neben den bekannten Szenen, in denen Franziskus den Vögeln und Fischen predigt, die Insistenz der Episode vom geschorenen Schaf. Lamprecht baut sie zu einer Sequenz aus, die eine bemerkenswerte Ökonomie der Besitzlosigkeit entwirft: Auf seinem Weg durch die Mark Ancona verfällt Franziskus angesichts eines Lammes, das er unter dem Nutzvieh eines Bauernhofes entdeckt, in tiefen Jammer. Er möchte es durch Kauf vor seinem Schicksal bewahren, verfügt aber zusammen mit seinem Mitbruder und Reisegefährten Paulus nur über zwei Röcke als Tauschwert. Schließlich übernimmt ein vorbeireisender Händler den Kaufpreis. Franziskus und Paulus wiederum überlassen ihr Lamm den Klosterfrauen von St. Severin zur Pflege, die nach geraumer Zeit einen Rock aus der Wolle des Schafes an Franziskus nach Portiuncula senden. Der Jammer von ehemals verkehrt sich in unaussprechliche Freude: ze den zîten dô er dâ / ein capitel begie / den roc er trûtliche enphie. / er halst in unde kust in sâ / und zeict in den die stuonden dâ (vv. 2.987-2.991). Die einfache Geschichte erhält nun eine signifikante Reprise unter umgekehrten Vorzeichen: Franziskus begegnet einem Mann, der mit zwei Lämmern zum Markt unterwegs ist, um sie zur Schlachtung und zum Verzehr zu verkaufen. Er tauscht sie ihm ab gegen den gefütterten Rock, den ihm zuvor ein frommer Mann gegen den Frost geschenkt hat: des koufes was der man gemeit, / er gap diu lember um daz kleit / daz was wol in tiurer ahte (vv. 3.008-3.010). Da er und Paulus sich aber außerstande sehen, die Tiere zu versorgen, schenkt Franziskus sie dem früheren Besitzer zurück mit der heilig-einfältigen Bitte: «nim dich diu lember wider an, / sprach er, und habes in dîner huote / und verkoufe siu niht mê. / tuo in swaz du maht ze guote / und tuo in ouch niht mê wê! / daz sprach er in einvaltem muote (vv. 3.017-3.022). Das Modell, das Franziskus nach zeitweiliger Wertsteigerung (zusätzlicher Wollrock, zusätzliches Lamm) mit leeren Händen aus den Tauschvorgängen hervorgehen lässt (ohne gefütterten Rock und ohne die beiden Lämmer), illustriert die Pathosformel vom pazzo, dem Narren Gottes: Als ein 〈Franz im Glück〉 spottet er nach irdischen Maßstäben jeder ökonomischen Rationalität, indem er der göttlichen Ökonomie der überbor- 
denden Gnadenfülle im Zeichen unbedingter armuot des irdischen Lebens zu modellhafter Anschauung verhilft. ${ }^{51}$

\section{IV.}

Das Ensemble der von mir zusammengestellten Legenden und Heiligenviten ersetzt zwar keine systematische Untersuchung, sollte aber unter dem Aspekt der kompilatorischen Form das von der antiken Viten-Tradition im Anschluss an deren Umschrift durch Sulpicius Severus inspirierte Konzept der Heiligkeitstypen beispielhaft exponieren. Verstanden als Pathosformel, die in der literarischen Imagination über innertextlich verschränkte Motive und intertextuell aufgespannte Netze immer neue beziehungsreiche Varianten hervorbringt, könnte in jener Kombination von Spruchakt, Gestus und einprägsamer Typusbildung ein wesentliches Kriterium dafür gefunden sein, was die Legende zu einer kurzen Form in pragmatischer Hinsicht macht. Sie präpariert das Heilige für den Gebrauch, macht es der Vorstellung verfügbar und der Andacht zugänglich, indem sie es durch das Aneinanderreihen verdichteter Allegorien (etwa in sprechenden Namen) und episodisch aufgefädelter Allegoresen vertieft und intensiviert, es also gleichermaßen mit den Mitteln der Poetik und des (narrativen, dem sensus historicus folgenden) Kommentars präsentiert. Gerade in jener Simultaneität von Implikation und Explikation, Einfaltung und Ausfaltung, ermöglicht durch das Verfahren der compilatio und ihren komplikativen Effekt, liegt der Grund, warum Aby Warburgs Begriff der Pathosformel ${ }^{52}$ gegenüber anderen terminologischen Ansätzen, zumal der einfachen Form nach André Jolles, der Vorzug gebührt: Sie erlaubt es, Heiligkeit aus dem Kontext ihrer vormodernen, genauer: vorreformatorischen Praxis und Überlieferung heraus als konzentrierte formative Energie zu beschreiben. Dabei zeigt die Pathosformel die Grenze der

51 Vgl. zum Komplex der oikovouia $\theta \varepsilon o \tilde{~} /$ dispensatio Dei den Artikel Christliche Ökonomik, Scheuer (2019), S. 371-388.

52 Auf jener gedanklichen Basis ließe sich eine Kartierung der Heiligkeitstypen nach Art einer oder mehrerer Mnemosyne-Atlastafeln denken: Die Zahl der aus hagiographischen Quellen entwickelten Ausprägungen des Heiligen dürfte im Sinne der figuralen Verfügbarkeit zwar vielfältig, aber in ihren Metamorphosen dennoch überschaubar sein. 
Abbreviierbarkeit von Legenden an. Ihr Grenzwert zeichnet sich da ab, wo die Widerspruchsspannung, aus der ihre Unverwechselbarkeit und Evidenz entspringt, angetastet, entparadoxiert und aufgelöst würde. Deshalb gibt es

- keine Johannalegende ohne die Polarität des päpstlichen Privilegs, zu binden und zu entbinden;

- keine Martinslegende ohne den Widerstreit von Entblößen und Bedecken;

- keine Severinslegende, die nicht die Paradoxie von Militanz und Askese noch am jeweiligen Gegenort jener Haltungen, im Dom bzw. beim Festbankett, bezeugte;

- keine Dominikuslegende, ohne dass äußerste Keuschheit und höchste Sprachgewalt zusammengespannt würden;

- keine Franziskuslegende, die nicht Pathos und Pathologie in der ebenso leidenschaftlichen wie wahnhaften Christomimesis des Narren Gottes verschränkte.

Nur dadurch, dass die jeweilige Exemplifikation der Heiligkeit jene Polaritäten vergegenwärtigt, kann die Legende als Produkt fortgesetzter Exzerption und Kompilation qualitativ verdichtend und quantitativ reduzierend ihren Gehalt metaphorisch transportieren, um ihn durch Zeit und Raum verfügbar zu halten.

\section{Bibliographie}

\section{Primärliteratur}

Acta ampliora, quae $\mathrm{F}$. Theodoricus de Appoldia [...] ex variis antiquioribus monumentis collegit, in: Acta Sanctorum Augusti, Bd. 1, hg.v. Johannes Bapt. Sollerio u. a., Antwerpen 1733, S. 562-632.

[Anon.:] Blümlein vom heiligen Franziskus, hg. u. übers. v. Heinz Courbier, München ${ }^{2} 1956$.

[Anon.:] Passional. Buch II: Apostellegenden, hg.v. Annegret Haase, Martin Schubert u. Jürgen Wolf, Berlin 2013 (DTM XCI/2).

[Anon.:] Die Vita et Translatio Sancti Severini (BHL 7647/7648) in kommentierter Übersetzung Bernd, hg.v. Bernd Päffgen u. Daniel Carlo Pangerl, in: Joachim Oepen u. a. (Hgg.): Der hl. Severin von Köln. Verehrung und Legende. Befunde und 
Forschungen zur Schreinöffnung von 1999, Siegburg 2011 (Studien zur Kölner Kirchengeschichte 40), S. 543-581.

Caesarius von Heisterbach: Dialogus Miraculorum. Dialog über die Wunder. Lateinisch -

Deutsch, eingel. v. Horst Schneider, übers. u. komm. v. Nikolaus Nösges u. Horst Schneider, 5 Bde., Turnhout 2009.

Dietrich von Apolda: Das Leben der Heiligen Elisabeth, hg.v. Monika Rener, Marburg 2007 (Veröffentlichungen der Historischen Kommission für Hessen 67.3).

Jacobus de Voragine: Legenda Aurea. Goldene Legende, hg. u. übers. v. Bruno W. Häuptli, 2 Bde., Freiburg i. Br. 2014.

Keller, Gottfried: Sieben Legenden, Stuttgart 1872.

Ludwig Theoboul (Gotthard) Kosegarten: Legenden, 2 Bde., Berlin 1804.

Lamprecht von Regensburg: Sanct Francisken Leben und Tochter Syon, hg.v. Karl Weinhold, Paderborn 1880.

Schernberg, Dietrich: Ein Schœn Spiel von Frau Jutten. Nach dem Eislebener Druck von 1565 hg.v. Manfred Lemmer, Berlin 1971 (Texte des späten Mittelalters und der frühen Neuzeit 24).

Schuster (Sutor), Andreas: Der hundert-Augige blinde Argos, und zwey-Sichtige Janus, Augsburg / München 1740.

Sulpicius Severus: Vita sancti Martini. Das Leben des heiligen Martin, hg. u. übers. v. Gerlinde Huber-Rebenich, Stuttgart 2010.

[Thomas von Celano:] Vita prima di S. Francesco d'Assisi del B. Tommaso da Celano, hg.v. Leopoldo Amon, Rom 1880.

\section{Forschungsliteratur}

Agamben, Giorgio: Signatura rerum. Zur Methode, aus dem Italienischen v. Anton Schütz, Frankfurt a. M. 2009.

Benz, Maximilian: Konkurrenz und Institutionalisierung in der Spätantike, in: Weitbrecht u. a. (2019), S. 115-136.

Bieler, Ludwig: $\Theta E I O \Sigma$ ANHP. Das Bild des göttlichen Menschen in Spätantike und Frühchristentum, Darmstadt 1967 (Nachdruck der Ausgabe Wien 1935/36).

Blumenberg, Hans: Anthropologische Annäherung an die Aktualität der Rhetorik, in: ders.: Wirklichkeiten, in denen wir leben. Aufsätze und eine Rede, Stuttgart 1981, S. $104-136$.

Brentano, Franz: Psychologie vom empirischen Standpunkte, 2 Bde., Leipzig 1874.

Cancik, Hubert: Grundzüge franziskanischer Leidensmystik. Zur Religionsgeschichte des Schmerzes, in: ders. (Hg.): Rausch, Ekstase, Mystik. Grenzfiguren religiöser Erfahrung, Düsseldorf 1978, S. 95-119.

Didi-Huberman, Georges: Das Nachleben der Bilder. Kunstgeschichte und Phantomzeit nach Aby Warburg, aus dem Französischen v. Michael Bischoff, Berlin 2010. 
Eikelmann, Manfred: Art. Einfache Formen, in: RLW Bd. 1 (1997), S. 422-424.

Emmelius, Caroline: Gelübde und Selbstdevestitur. Narrative Konfigurationen der Weltabkehr in der frühen Elisabeth-Hagiographie (Konrad von Marburg, Dietrich von Apolda), in: Udo Friedrich / Ulrich Hoffmann / Bruno Quast (Hgg.): Anthropologie der Kehre. Figuren der Wende in der Literatur des Mittelalters, Berlin / Boston 2021 (Literatur - Theorie - Geschichte 21), S. 103-126.

Feistner, Edith: Historische Typologie der deutschen Heiligenlegende von der Mitte des 12. Jahrhunderts bis zur Reformation, Wiesbaden 1995 (Wissensliteratur im Mittelalter 20).

Flasch, Kurt: Hugo Ball und der Erste Weltkrieg, in: ders.: Die geistige Mobilmachung. Die deutschen Intellektuellen und der Erste Weltkrieg. Ein Versuch, Berlin 2000, S. $202-223$.

Geulen, Eva: Keep it Simple, Making it Difficult. Morphologische Reihen bei Goethe und anderen, in: Albrecht Koschorke (Hg.): Komplexität und Einfachheit. DFG-Symposion 2015, Stuttgart 2017, S. 357-373.

Gumbrecht, Hans Ulrich: Faszinationstyp Hagiographie. Ein historisches Experiment zur Gattungstheorie, in: Christoph Cormeau (Hg.): Deutsche Literatur im Mittelalter. Kontakte und Perspektiven. Hugo Kuhn zum Gedenken, Stuttgart 1979, S. 37-84.

Hamm, Berndt: Heiligkeit im Mittelalter. Theoretische Annäherungen an ein interdisziplinäres Forschungsvorhaben, in: Nine Miedema / Rudolf Suntrup (Hgg.): Literatur - Geschichte - Literaturgeschichte. Beiträge zur mediävistischen Literaturwissenschaft. Festschrift für Volker Honemann zum 60. Geburtstag, Frankfurt a. M. / Berlin 2003, S. 628-645.

Jolles, André: Einfache Formen. Legende, Sage, Mythe, Rätsel, Spruch, Kasus, Memorabile, Märchen, Witz, Tübingen ${ }^{6} 1982$.

Jones, Claire Taylor: Exemplarität und Legitimierung. $\mathrm{Zu}$ den Visionen aus der Lux divinitatis in der Dominikus-Vita des Dietrich von Apolda, in: Caroline Emmelius / Balász J. Nemes (Hgg.): Mechthild und das Fließende Licht der Gottheit im Kontext. Eine Spurensuche in religiösen Netzwerken und literarischen Diskursen im mitteldeutschen Raum des 13.-15. Jahrhunderts, Berlin 2019 (ZfdPh Beihefte 17), S. 251279.

Kaftan, Oliver J.: Ora et labora - (k)ein benediktinisches Motto. Eine Spurensuche, in: Erbe und Auftrag 90 (2014), S. 415-421.

Koch, Elke: Bedingungen und Elemente des Erzählens von jenseitiger Heilsmittlerschaft: Namenspraxis und Mirakelstruktur in Michael-Legenden, in: Weitbrecht u. a. (2019), S. 25-44.

Koch, Elke: Zwischenstufen. Überlegungen zur Transzendenzproblematik in geistlichen Spielen, in: Ingrid Kasten (Hg.): UnVerfügbarkeit, Berlin 2012 (Paragrana 21.2), S. 77-92. 
Köbele, Susanne: Die Illusion der einfachen Form. Über das ästhetische und religiöse Risiko der Legende, in: PBB 134 (2012), S. 365-404.

Losert, Kerstin: Überschreitung der Geschlechtergrenzen? Zum Motiv der Frau in Männerkleidern im Dolopathos des Johannes de Alta Silva und anderen literarischen Texten des Mittelalters, Bern 2008 (Lateinische Sprache und Literatur des MA 43).

Marx, Jakob: Verzeichnis der Handschriften-Sammlung des Hospitals zu Cues bei Bernkastel an der Mosel, Trier 1905.

Michaud, Philippe-Alain: Aby Warburg and the Image in Motion, aus dem Französischen v. Sophie Hawkes, New York 2007.

Perler, Dominik: Theorien der Intentionalität im Mittelalter, Frankfurt a. M. ${ }^{2} 2004$.

Prautzsch, Felix: Die Wahrheit der Legende. Geltungsbedingungen und Geltungsstrategien legendarischen Erzählens am Beispiel der Legenda aurea, in: Diegesis 7 (2018), S. 90-110.

Rauchhaus, Moritz: Hagiographie für Notare. Über die spätmittelalterliche Prosalegende und ihr Verhältnis zur Novelle, Diss. masch., HU Berlin 2020.

Reich, Björn: Name und maere. Eigennamen als narrative Zentren mittelalterlicher Epik. Mit exemplarischen Einzeluntersuchungen zum Meleranz des Pleier, Göttweiger Trojanerkrieg und Wolfdietrich D, Heidelberg 2011 (Studien zur historischen Poetik $8)$.

Rener, Monika: Compilatio - ex diversis collecta compositio. Eine spätmittelalterliche Werkform, dargestellt am Beispiel der Vita S. Elyzabeth und der Vita S. Dominici des Dietrich von Apolda, in: Archiv für Diplomatik 41 (1995), S. 193-210.

Scheuer, Hans Jürgen: Christliche Ökonomik, in: Joseph Vogl / Burkhardt Wolf (Hgg.): Handbuch Literatur und Ökonomie, Berlin / Boston 2019, S. 371-388.

Scheuer, Hans Jürgen: Das Martiniloben. Zur Prägnanz der Heiligenvita beim Stricker und bei Boccaccio, in: Friedrich Michael Dimpel / Silvan Wagner (Hgg.): Prägnantes Erzählen, Oldenburg 2019 (Brevitas 1 - BmE Sonderheft), S. 293-318 [https://doi. org/10.25619/BmE2019357].

Scheuer, Hans Jürgen: Faltungen. Brevitas, Allegorie und Exemplarität in mittelalterlichen Transformationen Ovids, in: Franz-Josef Holznagel / Jan Cölln (Hgg.): Die Kunst der brevitas. Kleine literarische Formen des deutschsprachigen Mittelalters, Berlin 2017 (Wolfram-Studien XXIV), S. 57-75.

Scheuer, Hans Jürgen: Opferrivalität. Die Juden-Christen-Kontroverse in Fronleichnamsspiel, Eucharistiemirakel und Schwank des späten Mittelalters, in: Susanne Knaeble / Silvan Wagner (Hgg.): Gott und die heiden. Mittelalterliche Funktionen und Semantiken der Heiden, Berlin / Münster 2015 (Bayreuther Forum TRANSIT Kulturwissenschaftliche Religionsstudien 13), S. 83-100.

Schneider, Almut: Buch - Gewand - Text - Körper. Reflexionen des Medialen im legendarischen und höfischen Erzählen der Vormoderne, in: Ursula Röper / Hans 
Jürgen Scheuer (Hgg.): Paramente in Bewegung. Bildwelten liturgischer Textilien (12. bis 21. Jahrhundert), Regensburg 2019, S. 97-110.

Strohschneider, Peter: Höfische Textgeschichten. Über Selbstentwürfe vormoderner Literatur, Heidelberg 2014 (GRM Beiheft 55).

Strohschneider, Peter: Textheiligung. Geltungsstrategien legendarischen Erzählens im Mittelalter am Beispiel von Konrads von Würzburg Alexius, in: Gert Melville / Hans Vorländer (Hgg.): Geltungsgeschichten. Über die Stabilisierung und Legitimierung institutioneller Ordnungen, Köln u. a. 2002, S. 109-147.

Tammen, Silke: Nuda veritas im Mönchsgewand. Die Ver- und Entwicklung einer gemalten Heiligenlegende, in: Annette Simonis (Hg.): Intermedialität und Kulturaustausch. Beobachtungen im Spannungsfeld von Künsten und Medien, Bielefeld 2009, S. 43-68.

Usener, Hermann: Legenden der Pelagia. Festschrift für die XXXIV. Versammlung deutscher Philologen und Schulmänner zu Trier, Bonn 1879.

Waltenberger, Michael: «Bedeutungsschwangerschaften`. Überlegungen zu Prägnanz und Pointierung mit Lessing und Galfred von Vinsauf, in: Friedrich Michael Dimpel / Silvan Wagner (Hgg.): Prägnantes Erzählen, Oldenburg 2019 (Brevitas 1 - BmE Sonderheft), S. 21-43 [https://doi.org/10.25619/BmE2019360].

Wehse, Rainer: Art. Frau in Männerkleidung, in: Enzyklopädie des Märchens Bd. 5 (1987), Sp. 168-186.

Weitbrecht, Julia u. a.: Legendarisches Erzählen. Optionen und Modelle in Spätantike und Mittelalter, Berlin 2019 (Philologische Studien und Quellen 273).

Willer, Stefan / Ruchatz, Jens / Pethes, Nicolas: Zur Systematik des Beispiels, in: dies. (Hgg.): Das Beispiel. Epistemologie des Exemplarischen, Berlin 2007, S. 7-59.

Williams-Krapp, Werner: Kultpflege und literarische Überlieferung. Zur deutschen Hagiographie der Dominikaner im 14. und 15. Jahrhundert, in: André Schnyder u.a. (Hgg.): Ist mir getroumet mîn leben? Vom Träumen und vom Anderssein. Festschrift für Karl-Ernst Geith zum 65. Geburtstag, Göppingen 1998 (GAG 632), S. $147-173$.

Williams-Krapp, Werner: Art. Dominikus (Prosalegenden), in: ${ }^{2}$ VL Bd. 2 (1979), Sp. $186-188$. 


\section{Zeitsparende Epik}

\section{Die Inhaltsangaben (argumenta) zur Laurentias des Giovanni Mario Filelfo (1426-1480)}

von

Thomas Haye (Göttingen)

\section{Einleitung}

Giovanni Mario Filelfo (1426-1480) entspricht wie kein Zweiter dem Klischee des humanistischen Intellektuellen, der als irrlichternder Glücksritter von Hof zu Hof zieht, um mithilfe seiner poetischen Kunst in den Genuss von Wohlstand und sozialer Absicherung zu gelangen. ${ }^{1}$ Dass er trotz seiner hohen dichterischen Begabung an keinem Ort Fuß fassen konnte, beruhte nicht nur auf einem offenbar recht instabilen Charakter, sondern auch auf einer familiären Bürde: Da es sich sein Vater Francesco mit Cosimo de' Medici verscherzt hatte, blieben der Familie Filelfo die Florentiner Türen lange Zeit verschlossen. Immerhin kann sich die moderne Philologie darüber freuen, dass Giovanni Mario in seinem verzweifelten Streben nach Glück die geradezu unglaubliche Zahl von ca. 270 lateinischen, griechischen und volkssprachlichen Texten beziehungsweise Textgruppen hervorgebracht hat. ${ }^{2}$ Nicht zu Unrecht rühmt er sich in seiner 1471, d. h. im Alter von lediglich 45 Jahren verfassten Elegie De voluminum suorum numero, mehr Verse verfasst zu haben als Ovid und Vergil: ${ }^{3}$ Versibus explicui jam multa volumina nostris: / Me brevior Naso, meque Maro brevior (vv. 17f.). Zudem findet man in seinem Euvre eine beeindruckende Serie großer Epen und episierender Gedichte, ${ }^{4}$ die primär panegyrisch angelegt und durch Claudian geprägt

1 Zur Person vgl. einführend Pignatti (1997); Giustiniani (2002).

2 Zum literarischen Werk vgl. Agostinelli / Benadduci (1899), S. 29-74.

3 Ediert ebd., S. 31-34, hier 31.

4 Vgl. Hofmann (2001), S. 147; Belloni (1908-1911), S. 107-110 u. 354. 
sind. ${ }^{5}$ Hervorzuheben sind hier der im Jahre 1458 komponierte Dentraretos auf Francesco Sforza, die 1461 abgeschlossene Felsineis über Bologna, ${ }^{6}$ die 1463/1464 gedichtete Cosmias über Cosimo de' Medici, ${ }^{7}$ die 1464 vollendete Martias für Federico da Montefeltro, ${ }^{8}$ die ebenfalls 1464 erstellte Herculeia für Ercole I. d'Este, ${ }^{9}$ die 1465 komponierte Minerva für Wilhelm von Montferrat, die 1474 abgeschlossene Laurentias für Lorenzo de' Medici sowie die 1476 geschriebene Amyris zu Ehren Mehmets II. ${ }^{10}$

Einige wenige Beispiele genügen, um Filelfos außergewöhnliche Produktivität zu illustrieren: Die Martias und die Cosmias umfassen jeweils ca. 2.500 Verse, die Amyris ungefähr 4.800 Verse, die Laurentias knapp 12.000 Verse und die Herculeia sogar etwa 17.500 Verse. Angesichts solcher Zahlen erweist sich Giovanni Mario Filelfo als fleißigster beziehungsweise als zügellosester Epiker der italienischen Hochrenaissance. ${ }^{11}$ Auf den ersten Blick erscheint es daher unangemessen, einen solchen Dichter mit dem poetischen Prinzip der brevitas in Verbindung bringen zu wollen. Doch gerade das offenkundige Fehlen der Kürze macht ihn zu einem idealen Objekt, wenn man vormoderne Techniken der Kürzung zu untersuchen trachtet. ${ }^{12}$ Denn es stellt sich die Frage, wie man mit derart umfangreichen Textmassen umgehen, wie man sie lesen und rezipieren kann. Moderne Philologen verfügen glücklicherweise über unendlich viel Zeit und können solche Epen über Jahre hinweg gründlich studieren. Wie bewältigten jedoch die Zeitgenossen dergleichen

5 Zu Claudians Panegyrik vgl. Schindler (2009), S. 59-172; zu seiner Vorbildfunktion vgl. Döpp (1989).

6 Vgl. Hofmann (2001), S. 147; Pignatti (1997), S. 628; Agostinelli / Benadduci (1899), S. 53, Nr. CCXX.

7 Vgl. Haye (2016).

8 Vgl. Hofmann (2005), Hofmann (2007).

9 Vgl. zuletzt Haye (2017).

10 Vgl. Manetti (1978).

11 Aus der umfangreichen Forschungsliteratur $\mathrm{zu}$ den neulateinischen Epen vgl. Kallendorf (2014), Hofmann (2001), Belloni (1908-1911).

$12 \mathrm{Zu}$ den antiken und mittelalterlichen Kürzungs- und Verdichtungstechniken vgl. Reitz / Horster (2010), Dusil / Schwedler / Schwitter (2017), Henkel (2017), Frick (2018). 
Versfluten? - Als Beispiel zur Beantwortung dieser Frage soll hier die 1474 komponierte, bislang unedierte Laurentias ausgewählt werden. ${ }^{13}$

\section{Die Laurentias: Überlieferung, Struktur und Inhalt}

Wie die anderen Epen Filelfos, so wird auch die Laurentias lediglich in einer einzigen Handschrift (London, British Library, Harley 2522) überliefert. ${ }^{14}$ Bei diesem kostbaren Pergamentcodex, welcher nur den einen Text enthält, handelt es sich offenkundig um das Widmungsexemplar. Filelfo hat das Gedicht von einem Kalligraphen niederschreiben lassen, die Abschrift jedoch anschließend selbst durchkorrigiert und eigenhändig um eine Schlusspartie (fol. $244^{v}-245^{v}$ ) ergänzt. Das erste, vermutlich mit einer kostbaren Initiale verzierte Blatt des Codex wurde später herausgeschnitten, sodass heute die erste Hälfte des Prologs zum ersten Buch fehlt. Die noch erhaltenen Anfänge der übrigen sieben Praefationes, die jeweils einleitenden Verse aller acht Bücher sowie der Beginn des Epilogs weisen aufwendig gestaltete Goldinitialen auf. Zudem sind die Überschriften durch romanisierende Majuskeln hervorgehoben.

Mit ihrer Gliederung in acht Bücher verweist die Laurentias zumindest indirekt auf Homer (Ilias und Odyssee mit je 24 Gesängen) sowie auf Vergil und Statius (Aeneis beziehungsweise Thebais mit je zwölf Büchern). Dabei ist - nach dem Vorbild Claudians - jedem hexametrischen Buch ein distichischer Prolog im Umfang von je hundert Versen vorgeschaltet. ${ }^{15}$ Im ersten Prolog verweist Filelfo auf die Bedeutung der vergilischen Aeneis für den Nachruhm des Augustus und suggeriert, dass Lorenzo de' Medici in gleicher

13 Eine Edition des Epos ist in Vorbereitung.

14 Zum Codex vgl. British Museum (1808), Nr. 2522; Wright (1972), S. 151 u. 162; Manetti / Rao (1992), S. 45 f., Nr. 2.19 (Roberta Manetti).

15 Wegen des Fehlens des ersten Blattes sind von der Praefatio zum ersten Buch nur noch 59 Verse erhalten. In Analogie zu den Vorreden der anderen Bücher darf man annehmen, dass 41 Verse verloren sind. 
Weise durch die Laurentias glorifiziert werden könne. ${ }^{16}$ Der Leser erfährt zudem, dass Filelfo das Widmungsexemplar nicht persönlich überreicht, sondern durch Dritte übermittelt hat. ${ }^{17}$ Giovanni Mario will das panegyrische Werk als Beweis seiner Ergebenheit gegenüber Lorenzo verstanden wissen und erinnert ihn daran, dass er zuvor - sc. in der 1463/64 komponierten Cosmias - bereits seinen Vater Piero und seinen Großvater Cosimo verherrlicht habe. ${ }^{18}$ Das 1.195 Hexameter umfassende Buch 1 handelt gemäß seiner Überschrift [...] de fatis ortuque Laurentii Medicis clarissimi urbis Florentiae primatis, cuius natalitiis intersunt multa numina (fol. $2^{\mathrm{r}}$ ) und beginnt in vergilischem Ton: Fata cano et summi leges et iussa tonantis / In Medicem commissa domum iuvenemque beatum, [...] (ebd.).

In der auf fol. $27^{\mathrm{r}}$ beginnenden Praefatio zu Buch 2 beschäftigt sich der Dichter erneut mit dem vergilischen Vorbild und dessen Themenwahl: Vergil habe in seinem Epos zwar vordergründig den eher unbedeutenden Aeneas behandelt, doch eigentlich handele es sich um ein Lobgedicht auf den Kaiser (Caesar / Augustus) - d. h. auf einen Zeitgenossen. ${ }^{19}$ In seiner eigenen Epoche, so konstatiert Filelfo, sei nur Lorenzo ähnlich verehrungswürdig, da dieser als Einziger die Poeten für ihre Dienste und geistige Arbeit belohne. ${ }^{20}$ Zwar habe er, Giovanni Mario, bislang noch nichts von Lorenzo erhalten,

16 Vgl. fol. $1^{\text {r }}$ : Legisti, Augusto quantum sua profuit aetas, / Qui nihil egregiis doctiloquisque negat, / Quorum opera est nullo Caesar moriturus in aevo, / Virgilii siquidem vivit ubique manu.

17 Vgl. fol. $1^{\mathrm{v}}$ : Sed si mitto aliquid dignum quandoque Philelfi / Nomine, grata tibi victima nostra siet. Es ist bemerkenswert, dass hier nur der Familienname, nicht aber der Vorname des Dichters genannt wird. Giovanni Mario evoziert also auch die Erinnerung an seinen berühmten Vater Francesco, den Verfasser der epischen Sforcias.

18 Vgl. fol. $1^{\mathrm{v}}$ : Argumenta animi tamen haec sunt optima nostri, / Qui velit esse tuo carus honore tibi, / Exacto recitet qui tempore dona parentis / Multa tui et clari denique munus avi. Auffällig ist hier die ambivalente Sprache: Die Wörter dona und munus meinen die - sc. geistigen und charakterlichen - «Gaben` der beschriebenen Personen, verweisen aber auch auf mögliche Gratifikationen für die erbrachte dichterische Leistung.

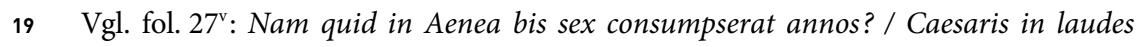
struxit id artis opus. / Non erat Aeneas tanti, sed Caesare dignum / Carmen erat [...].

$20 \mathrm{Vgl}$. fol. $27^{\mathrm{v}}$ : Unus honorasti vates solusque dedisti / Hactenus ingeniis praemia et officiis. 
doch erhoffe er sich für das jetzt vorliegende Epos eine Gratifikation. ${ }^{21}$ Die dichterische Leistung erscheint angesichts solcher Aussagen als eine kulturelle Investition. Das auf Repräsentation bedachte Geschlecht der Medici gilt dem Autor als eine interessante Aktie, die Rendite abzuwerfen verspricht. Filelfo erklärt, dass Lorenzo für ihn wie ein Kaiser sei, den er rühmen müsse. ${ }^{22}$ Ein Vergil stehe für diese Aufgabe nicht mehr zur Verfügung, doch werde er, Giovanni Mario, Lorenzo mit gleicher Kunstfertigkeit berühmt machen. ${ }^{23}$ Im Haupttext des zweiten, 1.194 Hexameter umfassenden Buchs spricht Filelfo sodann ausführlich [...] de poetarum defectu deque Cosmi ac Petri rebus gestis (Überschrift auf fol. $29^{\mathrm{r}}$ ).

In der auf fol. $54^{\mathrm{r}}$ beginnenden Praefatio zu Buch 3 gibt sich Filelfo der Gewissheit hin, dass Lorenzo das Epos nicht geringschätzen, sondern so begrüßen werde, als ob die Verse von Vergil selbst stammten. ${ }^{24}$ Der 1.227 Hexameter umfassende Haupttext handelt [...] de paternis avitisque in Laurentio Medice seminariiis et de pietate Laurentii Medicis in patriam (Überschrift auf fol. 56 ${ }^{\mathrm{v}}$ ). In der auf fol. $82^{\mathrm{r}}$ einsetzenden Praefatio zu Buch 4 erläutert der Dichter einleitend, dass er ursprünglich die Absicht gehabt habe, den Text auf den Umfang von zwei vergilischen Büchern zu beschränken, doch habe er sich im Verlaufe der Arbeit nicht mehr zügeln können. ${ }^{25}$ So spricht er nun im 1.289 Hexameter umfassenden Haupttext ausführlich [...] de Laurentii [...] splendore ac aliis laudibus (Überschrift auf fol. 84 ${ }^{\mathrm{r}}$ ). Filelfo verherrlicht hier nicht nur Lorenzo selbst, sondern auch andere

21 Vgl. fol. 27 : Et quanquam nobis nihil hactenus ipse dedisti, / Fama tamen nostra sit tua culta fide. / Sperandum est melius tanto fortasse labori, / Cum soleas rebus reddere plura datis.

22 fol. $27^{\mathrm{v}}-28^{\mathrm{r}}$ : Tu mihi sis Caesar novus, alter; et unus honores / Promereare, quibus carmina ductus aro.

23 Vgl. fol. 28 : Aenea melior nullo potes esse Marone / Notus, eris Mario cognitus arte pari.

24 Vgl. fol. 56 ${ }^{\mathrm{r}}$ : Despicies nec enim, superum quae missa favore / Sunt studii atque animi pignora nostra boni, / Nec minus haec laeta, Laurenti, fronte videbis, / Quam si Virgilii carmina facta manu.

25 Vgl. fol. 82 ${ }^{\mathrm{r}}$ : Non erat hoc animus carmen prolixius esse / Quam duo Virgilii carmina in Aeneide. / At postquam coepit pelagus percurrere navis, / Vix possim longa fraena parare via. 
berühmte Zeitgenossen aus dessen Umfeld. Wiederum nach einer auf fol. $111^{\mathrm{r}}$ einsetzenden Praefatio spricht das 1.348 Hexameter umfassende Buch 5 [...] de origine belli in Flaminia pro exulibus Florentinis a Bartholomaeo Coleone nuper initi (Überschrift auf fol. $113^{\mathrm{r} / \mathrm{v}}$ [im Codex fälschlich als $119^{r / v}$ gezählt]). Nach einer auf fol. $141^{v}$ beginnenden Praefatio erzählt der Dichter in dem 1.644 Hexameter umfassenden Haupttext von Buch 6 [...] de prosecutione belli pro exulibus in Florentinos in Flaminia initi (Überschrift auf fol. $143^{\mathrm{v}}$ ). Buch 7 beginnt mit einer Praefatio auf fol. $178^{\mathrm{r}}$, der 1.395 Hexameter umfassende Haupttext auf fol. $180^{\mathrm{r}}$ mit der Überschrift: [...] de iis quae vidit somno intellectiva visione Laurentius [...]. Der Protagonist begibt sich hier in einer Traumszene in die Unterwelt und wird dort von Cosimo zur Verteidigung des Christentums aufgerufen. Nach einer auf fol. $208^{\mathrm{r}}$ beginnenden Praefatio handelt der 1.599 Verse enthaltende Haupttext von Buch 8 [...] de avita admonitione atque de futuris in Laurentio Medice Florentinae urbis primate fatis (Überschrift auf fol. 210v ). Die Belehrung des Enkels wird hier somit fortgesetzt. Das Buch endet mit fol. $244^{\mathrm{r}}$. Darauf folgt auf fol. $244^{\mathrm{v}}-245^{\mathrm{v}}$ ein paratextueller Schluss im Umfang von 68 Versen, auf den noch näher einzugehen sein wird.

Die quantitativen Dimensionen der Laurentias sind beeindruckend: In der Summe ergeben die Haupttexte der acht Bücher 10.891 Verse. Hinzu kommen acht Praefationes zu je 100 Versen (hiervon fehlen 41 Verse in Praefatio 1) sowie die 68 Verse des Schlusswortes. Der Gesamtumfang des Werkes beträgt damit 11.759 Verse (davon sind 11.718 erhalten). In quantitativer Hinsicht überragt die Laurentias die knapp 10.000 Verse umfassende Aeneis - was zweifellos Filelfos Absicht gewesen ist und seinem Überbietungswahn entsprochen hat. Erneut stellt sich die Frage: Wie konnten der Widmungsnehmer Lorenzo und dessen gelehrte Berater ein solches Epos überhaupt in angemessener Zeit rezipieren?

\section{Die Widmung und Lorenzos Reaktion}

Obwohl der Anfang des Epos verloren ist, sind wir über die Hintergründe der Entstehung recht gut unterrichtet. In der zweiten Hälfte des 15. Jahrhunderts waren die Medici aufgrund ihrer Bereitschaft, in repräsentative Kunst 
$\mathrm{zu}$ investieren, für alle zeitgenössischen Dichter höchst attraktiv. ${ }^{26}$ Umso bedauerlicher musste es daher gewesen sein, dass sich Francesco Filelfo in den 1430er-Jahren mit Cosimo überworfen hatte. Die folgenden Jahrzehnte beinhalteten den Versuch einer Wiederannäherung der Familie an das mächtige Florentiner Geschlecht. Sowohl Francesco als auch sein Sohn Giovanni Mario umwarben Cosimo (1389-1464), dessen Sohn Piero (14151469) sowie den Enkel Lorenzo (1449-1492). Nachdem Giovanni Mario 1463/1464 die Cosmias gedichtet hatte (ohne erkennbare Wirkung), setzte er zehn Jahre später seine Hoffnungen auf den literarisch interessierten und mäzenatisch sehr aktiven Lorenzo. ${ }^{27} \mathrm{Zu}$ dieser Zeit war seine Lebenssituation allerdings weit weniger prekär als in früheren Jahren. Er hielt sich seit 1471 mit Unterbrechungen - in Ancona auf und lehrte ohne unmittelbare Sorgen als Professor der Rhetorik. ${ }^{28}$ Dennoch bewegten ihn die eigene Unzufriedenheit und die Hoffnung auf eine Verbesserung seiner materiellen und sozialen Situation dazu, sich weiterhin an anderen Orten zu bewerben. In einem kritisch-reservierten Brief vom 27. September 1474 versucht Francesco Filelfo solche Pläne seines Sohnes zu bremsen. Offenbar hatte ihm Giovanni Mario mitgeteilt, dass er die Hoffnung hege, eine Anstellung bei König Ferdinand I. (Kg. 1458-1494) in Neapel zu erhalten. Francesco äußert seine Zweifel und rät ihm, in Ancona zu bleiben. Dort habe er eine ruhige Stellung, zudem sei er auch bereits zu alt, um noch ständig in der Welt umherzureisen. ${ }^{29}$ Doch sein Sohn hat - neben Neapel - noch ein anderes Eisen im Feuer: Wenige Wochen später, am 13. November 1474, vollendet Giovanni Mario das Widmungsexemplar der Laurentias. ${ }^{30}$ Dass er sich nun auf Florenz konzentriert, scheint sein Vater nicht nur zu billigen, sondern auch aktiv zu unterstützen. Denn am 6. Dezember 1474 sendet Francesco aus Florenz

\footnotetext{
26 Vgl. zuletzt Leuker (2007).

27 Zu ihm vgl. einführend Walter (2003).

28 Vgl. hierzu Manetti / Rao (1992), S. 45 f., Nr. 2.19 (Roberta Manetti).

29 Quae vero significasti de Pherdinando rege, audivi non invitus, modo ita res habeat, ut scribis. Maluissem enim tibi servasses quem fortuna locum apud Anconitanos quietissimum obtulerat, cum non sis iam id natus aetatis, ut quottidie huc atque illuc naviges. Ed. De Keyser, Bd. 4 (2015), S. 1693 f. (Brief 41.03), die zitierte Stelle hier S. 1693.

30 Vgl. hierzu den Kolophon auf fol. $245^{\mathrm{v}}$ : Marius Philelfus manu propria Idibus Novembris $1^{\circ} 4^{\circ} 7^{\circ} 4^{\circ}$.
} 
einen kurzen Brief an Lorenzo, in dem er bedauert, dass ein persönliches Treffen (sc. in Florenz) nicht zustande gekommen sei (Lorenzo weilt gerade im Gebiet von Pisa). ${ }^{31}$ Die Dinge, die er mit ihm bereden wolle, müssten sie nun brieflich klären. Tatsächlich offenbart er sein Anliegen in einer schon am Folgetag verschickten Epistel (7. Dezember 1474 an Lorenzo):32

In questo restoro ve pregho mostrate a Stephano Torregiani, gentile homo d'Ancona et genero de Mario mio figliolo, quanto me amate; il quale mio figliolo ve manda una bellissima opera a donare. Farrete grandissimo honore a cotesto Studio de Pisa se'l condurrete a leggere con degno salario, al che fare quanto più posso ve pregho.

Der Vater erwähnt hier Stefano Torrigiani / Torregiani, den Schwiegersohn Giovanni Marios, welcher offenbar den Auftrag hat, das Epos dem Widmungsnehmer in Pisa zu überreichen. Zugleich unterstützt er die mit diesem Werk verbundenen Hoffnungen des Sohnes: Als Dank möge Lorenzo dem Dichter eine ordentlich bezahlte Professur (sc. für Rhetorik) an der Universität Pisa übertragen. Francesco Filelfos Brief lässt sich als eine vorbereitende und flankierende Maßnahme verstehen, welche die Chance der Widmungsannahme erhöhen und die Entlohnung in die richtige Richtung lenken soll. Es wäre würdelos gewesen, wenn der Dichter selbst in seiner Widmung einen so konkreten Wunsch geäußert hätte. Doch hat parallel zu Francesco zweifellos auch der Überbringer, Stefano Torrigiani, die Hoffnungen des Dichters mündlich zum Ausdruck gebracht. In einem Brief vom 17. Dezember 1474 bedankt sich Lorenzo bei dem in Ancona weilenden Giovanni Mario Filelfo: ${ }^{33}$

Laurentius Medices Mario suo Philelpho salutem. Laurentias tua, imo mea, quam dono misisti ad me, adeo mihi grata iucundaque est, ut ingrata iniucundaque omnia effecerit mihi, quae antea solita sunt afferre et iucunditatem et gratiam. Effecit tua poesis, dum de me tam honorifice, tam heroice loqueris, ut carior acceptiorque mihi

31 Putabam fore ut, Romam versus iter faciens, te Florentiae offenderem; id quod valde cupiebam, quoniam permulta essem commentaturus tecum; quae postea per mutuas litteras agamus, necesse fuerit. Tu in Pisano te oblectato. Ego ad Urbem propero. Ed. De Keyser, Bd. 4 (2015), S. 1707 (Brief 41.23).

32 Zitiert nach Fubini (1977), S. 63.

33 Zum Brief vgl. ebd., S. 62-64 (Nr. 183), Text hier S. 63 f. 
ipsi sim factus. Bene iam habet, Philelphe: sum ego etiam tuis Musis et Apolline non indignus visus de quo canerent. Putabam satis esse si Cosmum avum illum meum patriae parentem extulissent laudibus ad coelum; noluisti ibi quiescere, Philelphe: Laurentiada scribis etiam, qua ego et vivus et vita functus non ignobilis sim. Immortale hoc beneficium est nec nisi immortali aliquo munere rependendus ${ }^{34}$. Id ego non potui deligere, ut retuli Turioni tuo, qui librum detulit ad me. Expectabo ego in qua re me velis, ut gratus saltem videar erga te. Non erit tibi quicquam difficile, qui Laurentiada scripseris. Caetera a Turione intelliges. Vale.

Lorenzo signalisiert hier, dass ihm das panegyrische Werk willkommen und er die Dedikation somit grundsätzlich zu akzeptieren bereit sei. Er erinnert ferner daran, dass Giovanni Mario Filelfo auch bereits seinen Großvater Cosimo in einem ähnlichen Epos behandelt habe. Sodann geht er auf die Frage einer möglichen Entlohnung ein. Die Antwort erscheint auf den ersten Blick zwar überaus positiv, bleibt aber letztlich im Ungefähren: Dem unsterblichen Geschenk entspreche eine unsterbliche Gegenleistung - doch sei es ihm, Lorenzo, unmöglich gewesen, eine solche zu finden beziehungsweise auszuwählen. Alles Weitere werde er von Torrigiani - sc. bei dessen Rückkehr nach Ancona - im mündlichen Gespräch erfahren. Nach einer klaren Zusage hört sich das nicht an. Hätte Lorenzo dem von Torrigiani vorgetragenen Wunsch entsprechen wollen, so hätte er dies auch in seinem Brief an den Dichter explizit erwähnen können. Stattdessen quantifiziert er den kulturellen Wert des Epos in wolkigen Worten als «unermesslich), weshalb auch die Belohnung (unermesslich), d.h. nicht quantifizierbar sei.

Auf der mündlichen Ebene enthielt Lorenzos Reaktion ein durchaus konkretes Angebot: Wie wir aus einem auf den 18. Januar 1475 datierten Brief des Piattino Piatti an Giovanni Mario Filelfo erfahren, stellte Lorenzo lediglich die einmalige Zahlung von 300 Dukaten in Aussicht. ${ }^{35}$ Diese Summe entsprach zwar dem durchschnittlichen Jahresgehalt eines RhetorikProfessors; eine ordentliche Bestallung und dauerhafte Ernennung zum Professor in Pisa beinhaltete die Offerte jedoch nicht. Giovanni Mario Filelfo war hierüber zweifellos enttäuscht. Ob die beiden Parteien dennoch eine Übereinkunft erzielt haben, bleibt ungewiss. Aufgrund des Umstandes, dass 
das Widmungsexemplar, welches zugleich den unikalen Überlieferungsträger des Epos darstellt, nicht in die Biblioteca Laurenziana Eingang gefunden hat, könnte man vermuten, dass die Dedikation letztlich gescheitert sei und Lorenzo den Codex an den Autor zurückgeschickt habe. ${ }^{36}$ Doch lassen sich hiergegen drei Argumente anführen: Erstens sagt die Tatsache, dass sich die Handschrift seit dem frühen 18. Jahrhundert in England befindet, nichts über die vorherigen Aufbewahrungsorte und Besitzverhältnisse aus. Zweitens weist der Codex recht aufwendige Initialen auf, wie sie oftmals erst nach Dedikationsannahme und auf Kosten des Widmungsnehmers eingefügt wurden. Drittens hätte der Dichter aus einer Ablehnung des Angebotes keinerlei Vorteile gezogen: Das Epos war ganz auf Lorenzo zugeschnitten und ließ daher keine modifizierende Zweitverwertung zu. Entweder akzeptierte Filelfo die - durchaus stattliche - Einmalzahlung oder er ging völlig leer aus. Einem Dichter wie ihm, der unter chronischem Geldmangel litt, dürfte die Entscheidung nicht schwergefallen sein. Dergleichen Misserfolge waren ihm schon häufiger widerfahren.

\section{Die Prüfung des Textes: das Instrument der argumenta}

Die Kernfrage lautet: In welchem Modus wird ein 11.759 Verse umfassendes Epos im Jahre 1474 überhaupt rezipiert? Es ist kaum denkbar, dass ein Quasi-Fürst wie Lorenzo de' Medici oder einer seiner gelehrten Berater den gesamten Text durchgelesen hat. Hiergegen spricht bereits der zeitliche Ablauf: In dem genannten, auf den 7. Dezember 1474 datierten Brief an Lorenzo kündigt Francesco Filelfo an, dass Torrigiani ein Epos überbringen werde. Lorenzos Dankesbrief an Giovanni Mario, in dem er auf das bereits stattgefundene Gespräch mit Torrigiani Bezug nimmt und bei dessen Abfassung er offenbar schon über das Entlohnungsangebot entschieden hat, datiert auf den 17. Dezember 1474. Selbst wenn Lorenzo den Überbringer Torrigiani bereits am 8 . Dezember empfangen haben sollte, standen für die Lektüre und Bewertung des Textes maximal zehn Tage zur Verfügung. Man darf nicht annehmen, dass sich in Lorenzos Umfeld tatsächlich jemand die Mühe gemacht hat, zehn Arbeitstage in eine gründliche Lektüre des Werkes zu 
investieren. Das Genre des Epos gilt zwar innerhalb der modernen Latinistik als Krone der Literatur, doch ist zu bedenken, dass die Initiative zur Produktion neulateinischer Epen im Regelfall von den jeweiligen Autoren ausging, nicht etwa von den späteren Widmungsnehmern. Die panegyrischen Texte wurden den Fürsten angetragen - oftmals mit unbefriedigendem Ausgang. ${ }^{37}$ Die hochfliegenden Erwartungen der Epiker erfüllten sich kaum. Ihre literarischen Leistungen stießen an den Höfen zwar nicht auf dezidierte Ablehnung, häufig jedoch auf allenfalls lauwarmes Interesse. Die Geschichte der neulateinischen Epik ist daher primär eine Geschichte des Scheiterns. Sofern die Dedikation tatsächlich akzeptiert wurde, wanderten die Widmungsexemplare rasch in die jeweilige Fürstenbibliothek. Die Prachthandschriften mögen bisweilen zum Zwecke der Repräsentation und im Sinne einer symbolischen Kommunikation einzelnen auswärtigen Besuchern gezeigt worden sein, doch erfuhren die enthaltenen Texte keine kohärente Lektüre oder weitergehende propagandistische Nutzung.

Hier unterscheidet sich die Perspektive der Produzenten, welche ihre Werke oftmals als zweite Aeneis verstanden und den Widmungsnehmern einen ewigen und weltweiten Ruhm versprachen, deutlich von der Wahrnehmung der zeitgenössischen Rezipienten. Letztere dürften die Laurentias primär über deren Schlussteil erfasst haben, welcher im Widmungscodex auf fol. $244^{\mathrm{v}}-245^{\mathrm{v}} \mathrm{zu}$ finden ist. Unter der in Majuskeln geschriebenen Überschrift Marii Philelfi ad clarissimum et magnanimum urbis Florentinae optimatem atque primatem, Laurentium Medicem, Laurentiados argumenta (fol. 244 ${ }^{v}$ ) liest man hier 68 Verse, in denen der Autor wichtige Informationen übermittelt. ${ }^{38}$ Dass dieser heterogene Abschnitt einen paratextuellen Charakter hat, ergibt sich bereits aus der Wahl des elegischen Distichons. Zudem offenbart sich ein persönlicher, Lorenzo unmittelbar ansprechender Ton aus der Tatsache, dass diese Verse - anders als der Rest des Textes nicht von einem beauftragten Kalligraphen, sondern offenbar von Filelfo selbst niedergeschrieben worden sind. ${ }^{39}$ Hier heißt es:

37 Vgl. Lippincott (1989), S. $427 \mathrm{f}$.

38 Der Textausschnitt ist fehlerhaft abgedruckt in: Carmina illustrium poetarum Italorum, Vol. 7 (1720), S. 166-168. Die folgenden Zitate sind nicht dieser Edition, sondern der Handschrift entnommen.

39 Im Kolophon heißt es: manu propria. 


\section{[fol. 244 ]}

Marii Philelfi ad clarissimum et magnanimum urbis Florentinae optimatem atque primatem, Laurentium Medicem, Laurentiados argumenta

Denique et octavus liber ad tua limina venit.

Signavit calcem, quo mea meta ${ }^{40}$, suam.

Primus enim, quae sint coelo tua fata, recenset,

Syderibusque, ${ }^{41}$ quibus sis satus ante Iovem.

5 Explicat alter, inops ut sit nunc sacra poesis

Palleat et tremulo corpore tota rigens

Atque ideo nulli veterum cognomine digni,

Praemia sint quoniam nulla parata bonis;

Et quia tu nostris das solus vatibus aurum,

10 In tua conveniunt fata canenda deae.

Tertius, et patriae decus et tua tecta quibus sint

Splendida muneribus quoque cliente, refert.

Quartus honorat opesque tuas titulosque tuorum,

Utque tyrannorum nomen et arma fugis. ${ }^{42}$

15 At quintus sextusque docent, quae castra pararint

Coleo et Insubrum ${ }^{43}$ dux quibus atque locis. ${ }^{44}$

Septimus, ut Stygiam somno penetraveris urbem

Videris et multos non sine laude viros.

Ultimus ad summi te pervenisse tonantis

20 Regna refert, animis sunt ubi dona piis.

[fol. $245^{\mathrm{r}}$ ]

Primus originibusque tuis meritisque tuorum

Ergo favet, Cosmi nuncius atque Petri.

Mox tibi naturae enarrat data dona secundus,

Quando tuae laudi numina bina favent.

25 Quae tibi fortunae sint munera, tertius affert,

$40 \quad$ Korrigiert aus moeta.

41 So die Interpunktion der Handschrift.

42 Gemeint ist jene Verschwörung, die Luca Pitti 1466 erfolglos gegen Piero de’ Medici anzettelte.

43 Korrigiert aus Insubrium. Gemeint ist der Mailänder Herzog Galeazzo Maria Sforza (1466-1476).

44 Bartolomeo Colleoni (ca. 1400-1475), venezianischer Heerführer, unterstützte 1467 die aus Florenz verbannten und mit den Medici verfeindeten Albizzi. 
Quandoquidem felix his sine nemo perit. ${ }^{45}$

Quartus habet moresque tuos moresque clientum,

Corporis et casus praemia mixta canit.

Scribit opus quintus sextusque, quod inde refulget,

30 Qua tua summa domus mente pericla ferat,

Quam tibi sit Mavors patriaeque domesticus almae

Quaque tibi pariant arte trophaea duces.

Mentis opes reliqui exponunt, pietasque fidesque

Quanta tibi et quae sit gratia parta dei,

35 Quid tibi constituant caeli sacra numina puri,

Utque tuis nequeat vulgus obesse bonis,

Quave graves possis curas lenire medela,

Quae patriae cogunt te studuisse tuae.

‘[1-2] Schließlich ist auch das achte Buch zu Deiner Schwelle gelangt. Es hat seinen Schluss dort angezeigt, wo meine Ziellinie [sc. ist]. [3-4] Das erste [sc. Buch] erzählt nämlich, welches Dein Schicksal im Himmel und bei den Sternen ist, von denen $\mathrm{Du}$ in Gegenwart Gottes gezeugt bist. [5-8] Das zweite [sc. Buch] erläutert, wie mittellos die heilige Poesie heute ist und wie bleich, ganz erstarrt mit zitterndem Körper, und dass es deshalb keine [sc. Dichter] gibt, die der [sc. großen] Namen der Alten würdig sind, weil den guten [sc. Dichtern] keine Belohnungen bereitet worden sind. [9-10] Und weil Du allein unseren Poeten Gold gibst, kommen alle Göttinnen [sc. die Musen] zusammen, um Dein Schicksal zu besingen. [11-12] Das dritte [sc. Buch] berichtet, durch welche Ehren und durch welche Anhänger die Zier des Vaterlandes und Dein Haus erstrahlen. [13-14] Das vierte [sc. Buch] ehrt Deine Macht und den Ruhm der Deinen und [sc. erzählt], wie Du dem Namen und den Waffen von Tyrannen entkommst. [15-16] Doch das fünfte und das sechste [sc. Buch] lehren, welche Feldzüge Colleoni und der Herzog von Mailand an welchen Orten unternommen haben. [17-18] Das siebte [sc. Buch erzählt], wie Du im Traum zur Unterweltstadt vorgedrungen bist und viele sehr ruhmreiche Männer erblickt hast. [19-20] Das letzte [sc. Buch] berichtet, dass Du zum Reich des höchsten Gottes gelangt bist, wo sich die Gaben für die frommen Seelen befinden.

[21-22] Das erste [sc. Buch] widmet sich also Deinen Ursprüngen und den Verdiensten der Deinen, es kündet von Cosimo und Piero. [23-24] Unmittelbar danach erzählt das zweite [sc. Buch] von den Gaben, welche Dir die Natur gegeben

45 Hier sind entweder zwei Gedanken kontaminiert (siehe die nachstehende Übersetzung) oder aber es ist statt perit die Konjektur potest einzusetzen. 
hat, da doch diese beiden göttlichen Mächte [sc. Cosimo und Piero] Deinen Ruhm begünstigen. [25-26] Das dritte [sc. Buch] berichtet, welche Gaben Du von Fortuna erhalten hast, da ja niemand ohne sie Glück hat und [sc. daher] untergeht. ${ }^{46}$ [2728] Das vierte [sc. Buch] behandelt Deinen Charakter und den Charakter Deiner Anhänger, und es besingt ohne scharfe Trennung sowohl die Vorzüge Deines Körpers als auch die glücklichen Zufälle [sc. welche Dir widerfahren sind]. [29-32] Das fünfte und sechste [sc. Buch] beschreiben Deine Leistungen, welche hierauf erstrahlen, [sc. sie beschreiben], mit welcher [sc. unerschütterlichen] Einstellung Dein berühmtes Haus Gefahren erträgt, wie vertraut Dir und dem geliebten Vaterland der Krieg ist und durch welche Kunst Deine Heerführer Dir Siege schenken. [33-38] Die übrigen [sc. Bücher] erklären Deine geistigen Gaben; [sc. sie erklären,] wie ausgeprägt Deine Frömmigkeit und Dein Glaube sind und welche Gnade Dir Gott gewährt hat, was die heiligen Mächte des reinen Himmels für Dich bestimmen und warum die breite Masse Deinen rechtschaffenen Anhängern ${ }^{47}$ nicht schaden kann und mit welcher Medizin Du ihre großen Sorgen lindern kannst, welche Dich zwingen, Dich um Dein Vaterland zu kümmern.>

Soweit die Inhaltsangabe. Ohne Zäsur mündet diese nun in einen eindeutig epilogischen, aus 30 Versen bestehenden Teil, in dem sich Filelfo als Dichter empfiehlt und für den Fall einer Förderung durch Lorenzo die Schaffung weiterer panegyrischer Lieder verspricht. Dabei gibt er seiner Zuversicht Ausdruck, dass ihn Lorenzo tatsächlich als Dank für das Epos entlohnen werde:

Cetera, quae desunt de teque tuisque, canemus,

40 Cum dabis ingenio vimque modumque meo,

Hoc est, materiam cum trades carminis illam,

Quae tibi sitque tuis gratior officiis.

Nam quod munificus mihi sis sine fine futurus,

Is dubitet, cui non cognitus esse queas.

[fol. $245^{\mathrm{v}}$ ]

45 Haud $^{48}$ ingratus enim potes esse hominumque labores

46 Im Falle der Konjektur potest alternativ zu übersetzen: ‘[.. ] ohne sie Glück haben kann >.

47 Alternativ könnte man bonis als Neutrum (〈Vorzüge`) auffassen. Vgl. v. 8 (bonis als Masculinum) u. v. 59 (bonis als Neutrum).

48 Offenbar mit anderer Tinte nachgezogen. 
Compensas multo pluribus officiis.

Hoc magis usque faves, Laurenti dive, poetis,

Qui tibi perpetuum nomen in orbe parent.

Mit dem in Vers 46 abschließenden Wort officiis deutet Filelfo an, dass er nicht etwa nur ein Geldgeschenk, sondern die Übertragung eines Professorenamtes (sc. in Pisa) erwartet. Die letzten Verse dieses epilogischen Abschnittes verarbeiten den topischen Gedanken, dass ruhmreiche Leistungen die Kritik neidischer Mitmenschen auf sich zögen. Doch zeigt sich Filelfo unerschrocken: Je mehr man ihn beneide, desto stärker werde ihn Lorenzo unterstützen:

Haud vereor, multi vates quod saepe verentur,

50 Oppugnet ne me murmure livor edax.49

Non nisi grandiloquosque viros laudesque merentes

Aggreditur; parvis retia nulla parat.

O utinam invidia dignus sim, carmina cuius

Invidus assidue dicat inepta miser!

55 Tunc ego posse rear vel posteritate potiri

Et parvum ingenii non ${ }^{50}$ meruisse decus.

Invidia insignes meritis oppugnat, honores

Quae dolet illorum, quos videt eximios.

Alteriusque bonis cruciatur et anxia semper

60 Egregiis titulis detrahit ore truci.

Dentibus est uncis, atra rubigine tinctis,

Pallidior buxo, lumine foeda fero.

Territat haec urbes atque alta palatia regum,

Quique pavent, cupiunt censeruisse manus.

65 Quandoquidem claris haec proelia regibus offert,

Negligit indignos livor honore duces.

Quo magis invideant, Medices Laurentius heros

Me magis officiis atque fovebit ope.

Marius Philelfus manu propria Idibus Novembris $1^{\circ} 4^{\circ} 7^{\circ} 4^{\circ}$ 
Im letzten Vers des Epos verweist das Wort officiis erneut auf die konkrete Erwartung des Dichters, mit einer festen Anstellung belohnt zu werden.

Dieser finale, von Filelfo in der Überschrift als argumenta bezeichnete und 68 Verse umfassende Abschnitt ist in jeder Hinsicht bemerkenswert. Denn der Autor vermengt hier zwei grundsätzlich zu trennende Traditionen: erstens die Tradition der paratextuellen argumenta, zweitens die Tradition des extrathematischen Epilogs. Letzterer ist an dieser Position im Codex keineswegs ungewöhnlich. Hier spricht der Verfasser - wie viele andere Schriftsteller vor ihm - über gängige Themen: Er appelliert an die Gunst des potentiellen Mäzens, lobt die eigene Leistung und verspricht weitere panegyrische Werke.

Der erste, die argumenta enthaltende Teil des finalen Abschnitts ist an dieser Stelle hingegen bemerkenswert. Indem Filelfo hier die einzelnen Bücher seines Epos knapp resümiert, und dies auch noch zweimal nacheinander, knüpft er an eine bereits in der Antike etablierte Konvention an: Das paratextuelle argumentum, in dem der Inhalt eines Dramas oder anderen längeren Werkes (insbesondere eines Epos) mit äußerster Knappheit und in klarer Sprache zusammengefasst und diesem vorangestellt wird, ist bekanntlich eine Erfindung der Philologie und Grammatikschule..51 Nach griechischem Vorbild haben römische Grammatiker für die Dramen des Plautus und Terenz metrische argumenta entwickelt (so etwa der Philologe C. Sulpicius Apollinaris im 2. Jahrhundert n.Chr. für Terenz). ${ }^{52}$ Auch die vergilische Aeneis hat aufgrund ihrer Bedeutung für den Schulunterricht ein breites Spektrum versifizierter, die memoria stützender Inhaltsangaben nach sich gezogen; sie werden teils innerhalb der Anthologia Latina, teils auch separat überliefert:53 so etwa die Pentasticha de duodecim libris Aeneidos (AH 140), Decasticha (AH 176), Tetrasticha in cunctis libris Vergilii (AH 178), Monosticha in libris Aeneidos (AH 179), Hemistichia in libris Aeneidos (AH 181) oder die ebenfalls von C. Sulpicius Apollinaris verfassten Hexasticha in libris Aeneidos (AH 177). Neben der vergilischen Aeneis ist auch die Thebais des Statius in der Antike durch metrische argumenta aufbereitet

52 Vgl. Opitz (1883).

53 Vgl. Senis (1984). 
worden, um jungen Schülern den Einstieg in die Lektüre des Werkes zu erleichtern. ${ }^{54}$ Das Mittelalter hat diese antike Tradition insbesondere im Bereich der Epik unter denselben didaktischen Vorzeichen weitergeführt: Metrische Zusammenfassungen, die den einzelnen Büchern vorangestellt sind, findet man etwa bei der Alexandreis des Walter von Châtillon ${ }^{55}$ oder beim Ernestus des Odo von Magdeburg ${ }^{56}$.

Das Instrument der vorangestellten argumenta entdecken wir auch bei einzelnen Epen der Renaissance, so etwa bei der Carlias des Ugolino Verino. ${ }^{57}$ In solchen Paratexten manifestiert sich zweifellos der Wunsch der Autoren, den antiken Konventionen, wie man sie bei der Aeneis und Thebais beobachten konnte, nachzueifern. Das Beispiel der Laurentias offenbart jedoch eine graduelle Neufunktionalisierung der alten Technik: Giovanni Mario Filelfo positioniert seine von ihm sogenannten argumenta nicht etwa am Anfang des Epos und auch nicht vor den einzelnen Büchern des Werkes, sondern am Ende des Opus. Zudem vermengt er das Genre mit einem extrathematischen Epilog und löst auch die strenge Systematik auf, die solche Zusammenfassungen aus didaktischen Gründen aufweisen sollen. So werden manche Bücher von ihm in zwei Versen, andere in vier oder gar sechs subsumiert. Darüber hinaus durchmustert Filelfo nicht nur einmal, sondern sogar zweimal den Inhalt des Epos (gemäß dem rhetorisch-poetischen Prinzip der variatio setzen die beiden Durchgänge unterschiedliche Akzente und enthalten voneinander abweichende Informationen). Ferner stammen anders als in der Antike - die argumenta nicht von einem späteren Kommentator, sondern vom Dichter selbst. Mehr noch: Dass Filelfo im Widmungsexemplar nur die argumenta eigenhändig niedergeschrieben und hierdurch somit ein persönliches statement abgegeben hat, zeigt hinreichend, wie wichtig ihm gerade dieser Abschnitt des Textes ist. In der Laurentias sind die argumenta also nicht etwa mnemotechnische oder didaktische Hilfsmittel für schulische Leser, sondern eine beziehungsweise die Schlüsselpartie des Gesamtwerkes, welche sich an den hochgestellten Widmungsnehmer richtet. - Es handelt sich um ebenjene Verse, die dieser (oder einer

\footnotetext{
$54 \quad$ Vgl. zuletzt Jakobi (1989).

55 Vgl. die Edition von Colker (1978).

56 Vgl. die Ausgabe von Gansweidt (1989).

57 Vgl. die Edition von Thurn (1995), S. 136-139 (Hs. L, Autograph des Dichters).
} 
seiner Berater) unbedingt lesen muss, um sich über den Inhalt und die Struktur des Werkes sowie über die Absichten des Dichters in aller Kürze zu informieren. Im Rahmen der Dedikationsverhandlungen dürften an Lorenzos Hof nur die abschließenden argumenta geprüft worden sein. Angesichts des monumentalen Umfangs, den die Laurentias aufweist, darf man sogar vermuten, dass diese Inhaltsangaben auch im weiteren Rezeptionsverlauf nicht nur zur ersten Orientierung dienten, sondern eine Lektüre des vollständigen Epos sogar weitgehend überflüssig machten.

Mit seinem gestuften Vorgehen berücksichtigt Filelfo die unterschiedlichen Leserinteressen und Rezeptionsmodi. So mag er sich erstens als eitler Autor, der er war, gewünscht haben, dass die Schüler florentinischer Schulen eines Tages gezwungen wären, die 11.759 Verse seiner Laurentias wie eine zweite Aeneis vollständig durchzuarbeiten. Ferner mochte er zweitens darauf gehofft haben, dass interessierte Kreise an den oberitalienischen Höfen zumindest die insgesamt 800 Verse der acht metathematischen Praefationes läsen. Doch konnte er drittens fest darauf vertrauen, dass der anvisierte Dedikationsnehmer (oder einer seiner Berater) zumindest die 68 Verse der abschließenden argumenta zur Kenntnis nahm. Durch dieses zeitsparende Format wurde das Epos dem Leser in radikaler Reduktion und Verdichtung präsentiert. Erst die Kürze des argumentum kompensierte die epische Länge des Werkes.

\section{Bibliographie}

\section{Primärliteratur}

Der Ernestus des Odo von Magdeburg. Kritische Edition mit Kommentar eines lateinischen Epos aus dem 13. Jahrhundert, hg.v. Birgit Gansweidt, München 1989 (Münchener Beiträge zur Mediävistik und Renaissance-Forschung 39).

Francesco Filelfo. Collected Letters. Epistolarum Libri XLVIII, Bd. 1-4, hg.v. Jeroen de Keyser, Alessandria 2015 (Hellenica 54).

Galteri de Castellione Alexandreis, hg.v. Marvin L. Colker, Padua 1978 (Thesaurus mundi 17).

Lorenzo de' Medici, Lettere, Vol. 2 (1474-1478), hg.v. Riccardo Fubini, Florenz 1977.

Ugolino Verino, Carlias. Ein Epos des 15. Jahrhunderts erstmals hg.v. Nikolaus Thurn, München 1995 (Humanistische Bibliothek. Texte und Abhandlungen II 31). 


\section{Forschungsliteratur}

Agostinelli, Lavinio / Benadduci, Giovanni: Biografia e bibliografia di Giovan Mario Filelfo, Tolentino 1899.

Belloni, Antonio: Il poema epico e mitologico, Mailand o. J. [1908-1911] (Storia dei generi letterari italiani).

British Museum (Hg.): A Catalogue of the Harleian Manuscripts in the British Museum, Bd. 2, London 1808.

Carmina illustrium poetarum Italorum, Bd. 7, Florenz 1720.

Döpp, Siegmar: Claudian und lateinische Epik zwischen 1300 und 1600, in: Res publica litterarum 12 (1989), S. 39-50.

Dusil, Stephan / Schwedler, Gerald / Schwitter, Raphael (Hgg.): Exzerpieren - Kompilieren - Tradieren. Transformationen des Wissens zwischen Spätantike und Frühmittelalter, Berlin 2017 (Millennium-Studien 64).

Frick, Julia: abbreviatio. Zur historischen Signifikanz von Kürzungsfunktionen in der mittelhochdeutschen höfischen Epik des 13. Jahrhunderts. Eine Projektskizze, in: PBB 140 (2018), S. 23 -50.

Giustiniani, Vito R.: Filelfo, Giovanni Mario, in: Lexikon des Mittelalters 4 (2002), Sp. $445 \mathrm{f}$.

Haye, Thomas: Die Cosmias des Giovanni Mario Filelfo (1426-1480), in: Patrick Baker u. a. (Hgg.): Portraying the Prince in the Renaissance. The Humanist Depiction of Rulers in Historiographical and Biographical Texts, Berlin / Boston 2016 (Transformationen der Antike 44), S. 271-286.

Haye, Thomas: Die Herculeia des Giovanni Mario Filelfo (1426-1480), in: Christine Schmitz / Jan Telg genannt Kortmann / Angela Jöne (Hgg.): Anfänge und Enden. Narrative Potentiale des antiken und nachantiken Epos, Heidelberg 2017 (Bibliothek der klassischen Altertumswissenschaften 154), S. 329-345.

Henkel, Nikolaus: Reduktion als poetologisches Prinzip. Verdichtung von Erzählungen im lateinischen und deutschen Hochmittelalter, in: Franz-Josef Holznagel / Jan Cölln (Hgg.): Die Kunst der brevitas. Kleine literarische Formen des deutschsprachigen Mittelalters, Berlin 2017 (Wolfram-Studien XXIV), S. 27-58.

Hofmann, Heinz: Von Africa über Bethlehem nach America: Das Epos in der neulateinischen Literatur, in: Jörg Rüpke (Hg.): Von Göttern und Menschen erzählen. Formkonstanzen und Funktionswandel vormoderner Epik, Stuttgart 2001 (Potsdamer Altertumswissenschaftliche Beiträge 4), S. 130-182.

Hofmann, Heinz: Die Martias des Giovanni Mario Filelfo, in: Neulateinisches Jahrbuch 7 (2005), S. 131-149.

Hofmann, Heinz: Text- und Interpretationsprobleme im ersten Buch der Martias von Giovanni Mario Filelfo, in: Maria Berggren (Hg.): Miraculum eruditionis. Neo-Latin 
studies in honour of Hans Helander, Uppsala 2007 (Acta Universitatis Upsaliensis. Studia Latina Upsaliensia 30), S. 125-140.

Jakobi, Rainer: Alte und neue metrische Argumente zum ersten Buch von Statius' Thebais, in: Hermes 117 (1989), S. 241-244.

Kallendorf, Craig: The Neo-Latin Epic, in: Philip Ford u. a. (Hgg.): Brill's Encyclopaedia of the Neo-Latin World. Macropaedia, Leiden / Boston 2014, S. 449-460.

Leuker, Tobias: Bausteine eines Mythos. Die Medici in Dichtung und Kunst des 15. Jahrhunderts, Köln 2007.

Lippincott, Kristen: The neo-Latin historical epics of the north Italian courts. An examination of «courtly culture) in the fifteenth century, in: Renaissance Studies 3 (1989), S. 415-428.

Manetti, Aldo: Giovanni Mario Filelfo, Amyris. Critical edition with introduction, commentary, and notes, Bologna 1978.

Manetti, Roberta / Rao, Ida Giovanna: Maestri di scuola, professori allo Studio di Pisa, in: Anna Lenzuni (Hg.): All'ombra del lauro. Documenti librari della cultura in età laurenziana, Florenz 1992, S. 43-61.

Opitz, Kurt Richard: De argumentorum metricorum latinorum arte et origine, Diss., Leipzig 1883.

Pignatti, Franco: Filelfo, Giovanni Mario, in: Dizionario Biografico degli Italiani 47 (1997), S. 626-631.

Rädle, Fidel: Argumentum (2), in: RLW Bd. 1 (2007), S. 132 f.

Reitz, Christiane / Horster, Marietta (Hgg.): Condensing texts - condensed texts, Stuttgart 2010 (Palingenesia 98).

Schindler, Claudia: Per carmina laudes. Untersuchungen zur spätantiken Verspanegyrik von Claudian bis Coripp, Berlin / New York 2009 (Beiträge zur Altertumskunde 253).

Senis, Gabriella: Argumenta Vergiliana, in: Enciclopedia Virgiliana, Bd. 1, Rom 1984, S. $310-312$.

Walter, Ingeborg: Der Prächtige. Lorenzo de’ Medici und seine Zeit, München ${ }^{2} 2003$.

Wolf, Simon: Art. Argumentum, in: HWRh Bd. 10: Nachträge (2012), Sp. 51-59.

Wright, Cyril Ernest: Fontes Harleiani. A Study of the Sources of the Harleian Collection of Manuscripts in the British Museum, London 1972. 


\section{Johann Spangenbergs Epitome der Victoria Christi $\boldsymbol{a b}$ inferis (Helius Eobanus Hessus) im reformatorischen und kontroverstheologischen Zusammenhang}

von

Oliver Grütter (Zürich)

In der Korrespondenz des Mutianus Rufus ${ }^{1}$ findet sich ein auf den 21. April 1517 datiertes Schreiben an den «verehrte[n] Prior» Johann Lang, den Martin Luther im Jahr zuvor mit der Leitung des Erfurter Augustinerklosters betraut hatte. ${ }^{2}$ Anlass dieses Briefes ist die jüngste Veröffentlichung des mit Mutian und Lang befreundeten Helius Eobanus Hessus: die hexametrische Victoria Christi ab inferis, ${ }^{3}$ worin der Neulateiner auf der Grundlage des Evangelium Nicodemi eine literarisch anspruchsvolle Ausgestaltung des descensus Christi in 487 Versen unternimmt, die das Vorbild Vergils, Ovids und Claudians verrät.4 Über die Zulässigkeit eines solchen Unterfangens sind sich Mutian und Lang uneins. Mutian verteidigt den geradezu visionären Dichterseher und legitimiert die entschieden ästhetische Umsetzung der Höllenfahrt mit Hinweis auf die Präsenz von Metaphern und Redeschmuck in den Evangelientexten. Der Briefsteller plädiert gar für einen poetischen Diskurs eigenen Rechts, den er von der «befremdliche[n] Kontroverse» der spitzfindig argumentierenden Theologen abzusetzen sucht - ob Christus realiter oder secundum effectum in die Hölle vordrang? Wichtiger als derlei Subtilitäten sei für die Dichter das Festhalten am Glaubensbekenntnis:

$1 \mathrm{Zu}$ Mutians Leben und Werk vgl. Bernstein / Huber-Rebenich (2010); Rädle (2013).

2 Zu Langs Leben vgl. Stupperich (1982), S. 540.

3 Zitiert nach: Vredeveld (2012). Die Übersetzungen der lateinischen Zitate stammen hier und im Folgenden von mir, O. G.

$4 \quad$ Vredeveld (2009), S. 252: «In short, Eobanus recounts the Gospel of Nicodemus, via Muzio [scil. Macario Muzio, O. G.], in the language of Vergil, Ovid, and Claudian.» 
S. p. d. Patere, mi Lange, prior reverende, ut in re mellita festivaque iocemur. Quid tibi recinit olorina Sybylla? Vidit aperte, non per transennam, Christi, regis nostri, conflictum cum satanę legionibus et auxiliis. Victoriam luculenter descripsit. Si licet eiusmodi calamistris inurere rem sacram, et laudem meruit Eobanus et orthodoxę plebi profuit. Sed non video, cur non liceat: cum evangeliste metaphoris et poetarum floribus gaudeant. [...] Poeta ius suum tenuit, cui si accedimus, ridiculi videbuntur Thomas, Scotus, cęteri, qui barbare philosophantur. Querunt anxie nimis et supersticiose, utrumne anima realiter an secundum effectum tantum demigrarit ad inferos. Mira controversia! Quasi satis non sit poetis, qui viderunt pugnam, et symbolo fidei credidisse. ${ }^{5}$

‘[Mutianus Rufus] wünscht [Johann Lang] alles Gute. Nimm hin, mein lieber Lang, verehrter Prior, dass wir bei einer lieblichen und feierlichen Angelegenheit scherzen. Was lässt dir die Schwanensibylle [scil. Helius Eobanus Hessus, O. G.] wiederhallen? Er sah deutlich, nicht wie durch ein Gitter, den Kampf Christi, unseres Königs, mit den Heerscharen und den Truppen Satans. Seinen Sieg schilderte er ganz gut. Wenn es beliebt, einen heiligen Gegenstand so mit seinen Friseurkünsten aufzuputzen, ${ }^{6}$ hat Eoban Lob verdient und dem rechtgläubigen Volk genützt. Aber ich sehe nicht, weshalb es nicht belieben sollte - immerhin erfreuen sich die Evangelisten an Metaphern und am Schmuck der Dichter. [... Der Dichter hält an seinem Recht fest; wenn wir dem zustimmen, werden Thomas [von Aquin], [Duns] Scotus und die übrigen, die scholastische Philosophie betreiben, lächerlich erscheinen. Sie fragen allzu bang und kleinlich, ob die Seele [Christi] wirklich oder nur ihrer Wirkung nach in die Unterwelt hinabstieg. Eine befremdliche Kontroverse! Gerade so, als ob es für Dichter, die den Kampf schauten, nicht genug wäre, auch auf das Glaubensbekenntnis vertraut zu haben.>

Mutians Parteinahme betrifft in grundsätzlicher Weise die Frage, inwieweit geistliche Dichtung mit formalen Ansprüchen der exegetischen Absicherung bedarf. Seine Antwort hierauf fällt humanistisch aus: Mutian behauptet die Unabhängigkeit christlicher Poesie von der diskreditierten Scholastik und profiliert den Dichter, indem er die ihm eigene Klarsicht (aperte, non per transennam) suggestiv zum Primat über den pedantischen Quaestionenmo-

6 Eigentlich: «einem heiligen Gegenstand das Haar so mit dem Brenneisen zu kräuseln`. Das Kräuseln der Haare mit einem Brenneisen (calamister) ist Metapher für die sprachlich-ästhetische Ausgestaltung. Vgl. den Eintrag im Neuen Georges, Bd. 2, Sp. 2705, s. v. «inuro». 
dus (querunt anxie) erhebt. Zu verantworten hat sich geistliche Dichtung, so die Überzeugung Mutians, allein vor dem autoritativen Symbolum fidei.

Nicht zuletzt in wirkungsgeschichtlicher Perspektive ist von Interesse, dass Mutian für eine von theologischen Querelen unbelastete Poesie eintritt. Fest verankert im reformatorischen Kontext scheint ein markantes, lange Zeit jedoch unerkanntes Rezeptionsdokument der Victoria Christi. Gemeint ist ein Text, der bis zuletzt als ps.-juvencische Schrift spät- oder nachantiker Provenzienz gehandelt wurde, da er über Umwege in eine Basler Ausgabe jenes frühchristlichen Dichters gelangte. Erst Harry Vredeveld konnte im Zuge seiner editorischen Arbeit an Hessus' Werk den philologischen Nachweis erbringen, dass es sich bei dieser Dichtung mit dem Titel Triumphus Christi heroicus ${ }^{7}$ um eine Kurzfassung der Victoria Christi, beim Epitomator aber um den Nordhäuser Reformator Johann Spangenberg handelt, ${ }^{8}$ der 1539 die erste lateinische Evangeliendichtung mit Versparaphrasen zu sämtlichen Perikopen der Sonntage veröffentlichte. ${ }^{9}$ Die katechetische Anlage dieser Evangelia dominicalia, die Spangenberg dem Sohn des Justus Jonas zueignet, steht beispielhaft für das Werkprofil des engagierten Pädagogen, der mit Lehrbüchern für den Latein-, den Musik- und den religiösen Unterricht, mit Erbauungsschriften, Predigt- und Liedsammlungen hervortrat. ${ }^{10}$ Im Anhang der Perikopenparaphrasen gibt Spangenberg den Triumphus Christi bei, der die Hessus'sche Vorlage auf 108 Hexameter verkürzt. Die (zunächst) quantitative Reduktion des Bezugstextes geht dabei mit einer qualitativen einher, indem der Erzähler eine explizit knappe Ausdrucksweise kultiviert - brevitas erscheint als das der abbreviatio gemäße Stilideal. Über diese «doppelte Bündigkeit» stellt sich in formaler Hinsicht der Zusammenhang des Triumphus Christi mit der Perikopendichtung her. Es ist der Anspruch auf Prägnanz, der Paraphrasen und Epitome miteinander verbindet: Die Evangelia dominicalia zielen auf keine «fortlaufende epische Bearbeitung ganzer biblischer Bücher», sondern versammeln «kürzere[ ] Gedichte[ ]», die auf spezifische Abschnitte im Ausgangstext bezogen sind. ${ }^{11}$

7 Zitiert nach Vredeveld (2012).

8 Vgl. Vredeveld (2012), S. 446-455.

9 Krummacher (1976), S. 94.

10 Vgl. Illg (2017), Sp. 66.

11 Krummacher (1976), S. 99. 
Mit besonderer Aufmerksamkeit für die Thematisierung der brevitas in der Erzählung selbst zeichnet der vorliegende Beitrag in einem ersten Schritt Spangenbergs 〈Epitometechnik $\rangle^{12}$ an exemplarischen Textpartien nach (I.). Eine Würdigung des Textes kann sich darin allerdings nicht erschöpfen. Spangenberg ist es nämlich nicht nur um eine narrative Entwicklung der Höllenfahrt zu tun. Tatsächlich bieten allein die ersten 80 Verse des Triumphus Christi eine Epitome der Vorlage, ${ }^{13}$ die verbleibenden 28 aber sind für explicatio und applicatio reserviert. Damit wird die eigentliche Narration mit Elementen einer Predigt ergänzt. ${ }^{14}$ Inwiefern die reformatorische Disposition des Textes dort zur Geltung kommt, gilt es in einer theologisch informierten Analyse nachzuverfolgen (II.). Diese systematische Kontextualisierung möchte ich zuletzt historisch öffnen und zur Diskussion stellen, dass die Überlieferung des Triumphus Christi eine kontroverstheologische Indienstnahme des Textes im Streit um die orthodoxe Auslegung der Höllenfahrt nahelegt eine Indienstnahme, für die sich die Epitome in ihrer narrativen wie exegetischen Prägnanz geradezu anbieten musste (III.). Wo also Mutian Hessus' Vorlage vom theologischen Diskurs distanzieren will, stellt sich die Situation in Spangenbergs Fall gerade umgekehrt dar: Mit ihrer (späteren) Instrumentalisierung hat sie an der innerlutherischen Auseinandersetzung um die Höllenfahrt teil.

Bevor ich markante und beispielhafte Kürzungsverfahren der Epitome genauer beschreibe, möchte ich einen Eindruck von ihrer Vorlage geben. Für eine Annäherung an die Poetik der Victoria Christi empfiehlt sich das Widmungsgedicht an Heinrich Eberbach, ${ }^{15}$ der den Adressanten Hessus zeitweilig in seinem Erfurter Haus beherbergte, worauf die Rede von den merita in v. 29 anspielt. Um den Freundschaftsdienst angemessen zu vergüten, so Hessus, müsste er Eberbach mit Gesängen iliadischen Ausmaßes bedenken. Indessen möge jener sich mit dem «Wenigen» bescheiden, das er ihm darbringt:

12 Ich übernehme diese Prägung hier und im Folgenden von Reitz (2007), S. 336.

13 Vredeveld (2009), S. 258, hält fest, dass es sich beim Triumphus Christi «for the most part» um «an epitome of Eobanus' Victoria Christi» handle.

14 Als «Grundelemente» einer Predigt bestimmt explicatio und applicatio (zum Beispiel) Beutel (2005), Sp. 48.

15 Zitiert nach Vredeveld (2012), S. 458-461. 
Quod si pro meritis cupias tibi digna remitti,

Sperare ingentes iam potes Iliadas.

Accipe parva tamen quo sunt data pectore [...].

(vv. 29-31)

«Solltest du aber wünschen, dass dir für deine Verdienste [um mich] etwas Angemessenes erstattet werde, könntest du wirklich auf gewaltige Iliaden hoffen. Nimm dennoch dies Wenige in der Gesinnung auf, in der es [dir] dargebracht ist $[\ldots]$.)

Das hyperbolische Gedankenexperiment signalisiert einen Anschluss an die epische Tradition. In dieselbe Richtung weist auch ein präzisierender Zusatz im Titel, der die Victoria Christi als carmen heroicum ausweist und damit der epischen Versdichtung zuordnet. ${ }^{16}$ Allerdings schreibt sich Hessus, wenn er die eigenen parva von den voluminösen Iliaden absetzt, nicht in einen groß-, sondern in einen kleinepischen Diskurs ein. Der für sämtliche Formate epischer Dichtung offene Ausdruck carmen heroicum meint hier also näherhin ein Epyllion. ${ }^{17}$ Doch obschon das carmen mit rund 500 Versen im Umfang einem antiken liber entspricht und so deutlich hinter den (hypothetischen) Iliaden zurückbleibt:18 In der Praxis behauptet Hessus die Epizität seines Werkes emphatischer, als es das Widmungsgedicht in seiner bescheidenheitstopischen Brechung vermuten ließe. ${ }^{19}$ Wie Einnahme und Zerstörung der Hölle und der Kampf mit Satan thematisch an die Großdichtung anschließen, so entspricht die Verortung der Höllenfahrt im übergreifenden heilsgeschichtlichen Sinnzusammenhang ${ }^{20}$ den Dimensionen eines Epos: Am Beginn des Textes stehen Schöpfung und Sündenfall, am Ende Auferstehung und Himmelfahrt Christi. Epische Reminiszenz ist auch die Inspirationsbitte an Christus, die den Text eröffnet und den Musenanruf variiert. Ebenfalls aus der Großdichtung vertraut sind (umfangreichere) Ansprachen (Satan an die Höllenbewohner; der Psalmist an Christus; Christus an die Propheten) und Festszenen (die Verherrlichung Christi durch die Propheten). Hinzu

\footnotetext{
16 Zum carmen heroicum vgl. Korn / Werle / Worms (2018).

17 Zum neulateinischen Epyllion vgl. Korenjak (2012).

18 Zur Länge als notwendig relativem Gattungsmerkmal eines Epyllions vgl. Baumbach / Bär (2012), S. xiif.

19 Zu den folgenden epischen Bausteinen vgl. Schönhaar (1994), Sp. 1328.

20 Vgl. Vredeveld (2012), S. 446.
} 
kommen epitheta ornantia, so etwa $\mathrm{Di}[\mathrm{s}]$ avar[us] (v. 190), Victor omnipotens (vv. 202f.), Agnifer iuvenis (v. 336 [für Johannes den Täufer]), und Vergleiche. So veranschaulicht ein ausgedehntes Simile die panikartige Flucht der Unterweltmächte vor dem eindringenden Christus:

Haec ubi dicta, animis pavor incidit. Ocyus omnes

Qua via cuique ruunt totisque sine ordine castris

Turmatim effugiunt. Non plures aere guttae

Deciderant cum saevit hyems pluvialis ab alto;

Non tot ad Hesperium littus volvuntur arenae,

Cum Notus incubuit gravior verritque procellas;

Non tam precipiti lapsu cecidere solutis

Arboribus glandes Borea populante decorem

Sideris autumni iuga per Dodonia late

Sive per Hercinios saltus Alpesque nivosas

Seu magis Obnobiis querceta virentia saxis.

(vv. 208-218)

«Als er [scil. Christus] dies gesagt hat, überkommt sie Entsetzen. Sogleich stürmen sie hervor, jeder auf seinem Weg und fliehen scharenweise ohne Ordnung aus allen Lagern. Nicht zahlreicher fallen vom Himmel die Tropfen, wenn aus der Höhe Regen niederprasselt; nicht so viele Sandkörner werden ans hesperische Ufer geschwemmt, wenn der Südwind kräftiger hereingedrungen ist und Stürme vor sich herfegt. Nicht in so jähem Sturz fallen Eicheln aus entwurzelten Bäumen, wenn der Nordwind die Zierde des Herbstes weit über die dodonischen Bergrücken oder den Hercynischen Wald und die schneeigen Alpen oder vielmehr die grünenden Eichenwälder im obnobischen Gebirge hinweg verheert.)

Als Beispiele für Hessus' epische Technik dürfen schließlich Kataloge gelten. ${ }^{21}$ Der eine listet die ob der Ankunft Christi erstarrten Höllenbewohner, der andere die in der Vorhölle ausharrenden Patriarchen. Über gattungstypologische Aspekte hinaus ist Ersterer auch deshalb von Interesse, da er Licht auf die antikisierende Optik des Textes wirft: Als Styx, Tartarus oder Erebus bezeichnet, wird die Hölle von den Furien und Parzen, von Aeacus, Radamanthus, Minos, Tantalus, Ixion, Sisyphus und Prometheus bevölkert. Den Limbus patrum dagegen begreift Hessus als Elysium. Solch eine der antiken 
Vorstellungswelt gemäße Hölle stimuliert gleichfalls die aus der Divina Commedia vertraute Hercules-Christus-Typologie, der gemäß die Hadesfahrt jenes Heros den descensus Christi präfiguriert. ${ }^{22}$ Mit dem Freundespaar Theseus und Pirithous sowie Aeneas baut der Erzähler diese halbbiblische Typologie ${ }^{23}$ zu einer Reihe aus, die den besonderen Rang Christi unter den Hadesfahrern sinnfällig macht. Vor jenen zeichne den Gottessohn aus, dass allein er die Tore zur Hölle niederriss. Auffälligerweise ist der Einsatz der Hercules-Christus-Typologie dabei nicht der Erzählinstanz allein vorbehalten. Auch der mit dem römischen Unterweltgott Dis identifizierte Satan zieht in seiner Ansprache an die socii (v. 104) den Vergleich zum Heros:

Eheu quam timeo ne fortior Hercule nostras

Destructurus opes veniat nec vincula tantum

Rupturus Stygioque canem tracturus ab antro,

Sed magis insignem ducturus ad aurea praedam

Sidera.

(vv. 122-126)

«Ach, wie fürchte ich doch, dass er, stärker noch als Hercules, kommt, unsere Macht zu zerstören und nicht nur die Bande zu brechen und den Hund aus der stygischen Höhle zu zerren, sondern eine weit herausragendere Beute $\mathrm{zu}$ den goldenen Sternen zu führen!)

Gerade am Beispiel der Hölle ist zu ermessen, welche Bedeutung die Mythologie als Bildspenderin für das Kolorit des Textes hat. Kennzeichnend für den Umgang mit dieser Mythologie scheint eine Ambivalenz, die sich in spontanen Konkurrenzen zwischen paganer und christlicher Weltdeutung bemerkbar macht. ${ }^{24}$ So ist der Schöpfungsbericht zu Beginn des Textes zwar

22 Vgl. Schmidt (1990), S. 118-123 (der Hinweis auf Dantes Divina Commedia S. 122).

23 Dazu Ohly (1988), S. 34 f.

24 Als absichtsvoll inszeniert liest sich diese Konkurrenz gerade vor dem Entstehungshintergrund von Hessus' Epyllion, nämlich der Dichterfehde zwischen dem Erfurter Poeten und Johannes Dantiscus (dazu einlässlich Vredeveld [2012], S. 429-433): Hessus geriet bei Dantiscus in Kritik, weil er in einem Hochzeitsgedicht für den Krakauer König Sigismund und dessen Frau Barbara nicht Phoebus oder die Musen anrief, sondern seine Inspirationsbitte an Christus richtete - und dies, obschon er sich mit einem Hochzeitsgedicht nicht in einem geistlichen, sondern weltlichen Genre bewegt: «It was this showy 
nach der Kosmogonie in Ovids Metamorphosen modelliert, ${ }^{25}$ gleichzeitig schließt der Erzähler die deukaliontische Flut und den Prometheus-Mythos aus dem eröffnenden Schöpfungsbericht explizit aus und kontrastiert die als nug[ae] mendac[es] (v. 57) disqualifizierten Mythen um Jupiters Kindheit mit der christlichen recta fides (v. 58). Zur Distanznahme von der antiken Mythologie veranlassen den Dichter außerdem die Rötung von Sonne und Mond und der Einbruch der Nacht beim Tod Christi. Er konfrontiert die (antike) magische Erklärung für Mondfinsternisse ${ }^{26}$ mit dem Klarblick des verständigen Areopagiten, der den wahren Grund für die nach dem Kreuzestod auftretenden Phänomene intuierte:

Desinite, ah fatuae mentes, per carmina quemquam

Credere posse vices naturae invertere et ipsam

Ducere de caelo lunam magicisque susurris

Concutere immotae solidissima pondera terrae.

Viderat ista procul Dyonisius Attide terra

Atque ait: ‘Aut mundus finem casumque minatur

Aut mala naturae patitur Deus ultima, nam nec

Sponte sua tantos cogit natura labores.)

O divinum animi lumen mentemque beatam,

Quae potuit causam insoliti cognoscere motus!

(vv. 77-86)

〈Ach, ihr närrischen Seelen, glaubt nicht länger, irgendeiner könne mit Zaubersprüchen den natürlichen Lauf verkehren, den Mond selbst vom Himmel herabführen und mit magischem Geflüster die besonders feste Masse der unbeweglichen Erde erschüttern. Dionysius sah diese [Phänomene] in Athen aus der Ferne und sagte: «Entweder droht der Kosmos Ende und Untergang an oder der Gott der

invocation to Christ and rejection of the pagan gods that had provoked the poetic confrontation in Cracow.» Vredeveld (2012), S. 432. Ergebnis dieser "poetic confrontation» ist die Victoria Christi. Wenn Hessus dort «richtigerweise〉 Christus anruft (vgl. Vredeveld [2012], S. 432) und er seine Verachtung für die veterum delyramenta deorum [^das alberne Zeugs der alten Götter> (v. 6)] kundtut, so dürfte sich diese (kokettierende) Distanznahme von der mythologischen Welt in entsprechenden Gegenüberstellungen von Paganem und Christlichem fortsetzen.

25 Vgl. Vredeveld (2012), S. 655, ad vv. 8-26.

26 Dahinter steht die Vorstellung, dass thessalische Hexen den Mond mit ihren Zaubersprüchen hinunterzuziehen vermöchten. Vgl. Roscher (1890-1897), Sp. 3164-3166. 
Natur leidet die schlimmsten Übel, denn nicht aus freien Stücken häuft seine Natur so großes Leid zusammen.> O göttliche Einsicht und glückliche Seele, die den Grund für das ungewöhnliche Beben erkennen konnte!>

Dieser Textausschnitt macht als weitere Eigenart der Victoria Christi ihre Affinität zur Lehrdichtung deutlich, die in der (vergilischen) Junktur causam cognoscere (v. 86) auch ein phrasematisches Echo findet. ${ }^{27}$ Besonders ausgeprägt ist die Nähe zur Gattung der wissensvermittelnden Dichtung ${ }^{28}$ naturgemäß im ovidisierenden Schöpfungsbericht; doch auch die Schilderung des Sündenfalls steht unter lehrdichterischen Vorzeichen. Mit spezifischem, aus dem aitiologischen Sprachschatz entlehntem Vokabular ${ }^{29}$ begründet der Dichter als christlicher Anthropologe die sündige conditio humana des Menschengeschlechts. Legt der gemeinplätzige Inhalt dieser wissensvermittelnden Akte aber eher eine poetische denn eine didaktische Motivation nahe, so können kaum Stellen beigebracht werden, wo Position in einem theologischen Aushandlungsprozess bezogen würde - mit einer bemerkenswerten Ausnahme: Zwar habe, so kommentiert der Erzähler, Christi Körper, nicht aber seine Gottheit tot im Grab gelegen (vv. 433-435) - damit reagiert der Text auf eine (scholastische) controversia. ${ }^{30}$ Die Beiläufigkeit dieser Bemerkung wird dabei insofern relativiert, als Drucke, die von Hessus' Schülern annotiert wurden, an ebenjener Stelle reiche Anmerkungen enthalten. ${ }^{31}$

27 Vredeveld (2012), S. 661, ad v. 86, führt als Parallelstelle Ov. trist. 5,4,7 an (für die insolit $[i]$ motus verweist er auf Verg. georg. 1,475, für den Versschluss cognoscere motus aber auf Germanicus). M.E. dürfte Hessus an dieser Stelle jedoch primär auf Verg. georg. 2,490 anspielen; dies legt die Form der Seligpreisung (‘Makarismos`) nahe: Felix qui potuit rerum cognoscere causas.

28 Diese kann ebenfalls unter den Begriff des carmen heroicum fallen. Vgl. Korn / Werle / Worms (2018), S. 4. Zur wissensvermittelnden Dichtung in der Frühen Neuzeit vgl. Kühlmann (2016).

29 Aitiologische Diktion lassen in den vv. 39-46, welche die conditio humana aus dem Sündenfall herleiten, wiederholtes hinc und inde (〈daher〉) anklingen. Vgl. zu diesen und ähnlichen Indikatoren aitiologischer Narration Loehr (1996), S. 115, 122, 133 u. 136, des Weiteren Waldner (2007), S. 213.

$30 \quad$ Vgl. Vredeveld (2012), S. 487, Anm. 27.

31 Vgl. ebd. 
Auch wenn diese knappe Skizze das Profil der Victoria Christi, die der Editor Vredeveld zur 〈rätselhaftesten〉 von Hessus' Dichtungen erklärt, ${ }^{32}$ nicht erschöpfend darstellen kann, mag das Bisherige immerhin einen Eindruck von der eigentümlichen Sättigung des Textes, der virtuos verschiedene Register und Modi der antiken Dichtungstradition kombiniert, gegeben haben. Das so entstandene Bild dürfte im unmittelbaren Kontrast mit Spangenbergs Triumphus Christi noch zusätzlich Kontur gewinnen.

I.

Während Hessus' Erzähler zwar auf das descensus-Narrativ fokussiert, dabei aber stets das Ganze der Heilsgeschichte im Blick hat, präsentiert sich das Verhältnis zwischen Vorlage und Bearbeitung in dieser Hinsicht invers, da Spangenberg Kürze sowohl zum Maßstab des Umfangs wie der Ausgestaltung der Narration erhebt. Hält man die Epitome zum Vergleich neben die Victoria Christi, sticht denn auch als Erstes hervor, dass Spangenberg von einer Kosmogonie absieht, die Kurzfassung also unmittelbar mit der Kreuzigung einsetzt:

Cum faber astrorum mortis pateretur acerbum

In cruce supplicium, sese non posse dolores

Ferre Creatoris mundus clamabat, et astra.

(vv. 1-3)

‘Als der Erschaffer der Sterne am Kreuz bittere Todesqual litt, schrien die Welt und die Sterne, sie vermöchten das Leiden des Schöpfers nicht zu ertragen.>

Dabei ist eine Arbeit am Vorlagentext wenigstens in den ersten drei Versen kaum erkennbar. Die Rede vom Creator findet sich zwar ähnlich bei Hessus, der vom Tod des Schöpfers handelt (Morte Creatoris, v. 67); die Antonomasie faber astrorum, die ohne Entsprechung in der Victoria Christi ist, führt jedoch zu einer Antiphon aus der Osterliturgie beziehungsweise zu deren versifizierter Adaption durch Hrotsvit von Gandersheim in der Passio Sancti Dionisii egregii martyris. ${ }^{33}$ Auf die ersten Hexameter seiner Kurzfassung

$33 \mathrm{Zu}$ den Einzelheiten vgl. Vredeveld (2012), S. 686f., ad vv. 1-6. 
verteilt Spangenberg Wortmaterial aus v. 2 jener Legende (ich zitiere im Folgenden sowohl Verslegende wie Antiphon):

Dum factor summae, mediae rationis et imae

In cruce supplicium mortis pateretur amarum, $[\ldots] .^{34}$

«Als der Schöpfer des obersten, mittleren und untersten Bezirks ${ }^{35}$ am Kreuz bittere Todesqualen litt, [...].)

Cum / Dum Fabricator mundi mortis supplicium pateretur in cruce, clamans voce magna tradidit spiritum, [...]; terrae motus enim factus fuerat magnus, quia mortem Filii Dei clamabat mundus se sustinere non posse. ${ }^{36}$

«Als der Schöpfer der Welt am Kreuz Todesqualen litt, gab er, mit lauter Stimme schreiend, den Geist auf, [...]; denn ein großes Erdbeben ereignete sich, weil die Welt schrie, dass sie den Tod des Gottessohns nicht ertragen könne.>

Die trivial anmutende Beobachtung, dass sich für die Verkürzung eines Textes auch Versatzstücke aus anderen als ebendiesem Text empfehlen können, mag systematisch für die Tatsache sensibilisieren, dass abbreviationes trotz ihres unmittelbaren Vorlagenbezugs souveräne Anspielungshorizonte etablieren können, die sich über Rekurse auf spezifische Intertexte herausbilden. Im vorliegenden Fall ist die Allusion literarhistorisch signifikant. Wiederentdeckt wurde Hrotsvit nämlich erst um die Jahrhundertwende, als Konrad Celtis 1501 eine 1493 von ihm gefundene Handschrift der altdeutschen Dichterin veröffentlichte. ${ }^{37}$

Wird Hessus zu Beginn also nicht eigentlich mit Hessus verkürzt, können wir bereits im Hinblick auf die vv. 4f. Grundsätzliches über Spangenbergs Epitometechnik lernen, da er sich dort streng an den vv. 7174 aus der Vorlage orientiert. Letztere lauten:

\footnotetext{
34 Zitiert nach Homeyer (1970), S. 193. Hervorhebungen von mir, O. G.

35 Zum Begriff ratio an dieser Stelle Homeyer (1970), S. 193.

36 Zitiert nach Vredeveld (2012), S. $686 \mathrm{f}$.

37 Entsprechend ist der Rekurs auf Hrotsvit philologisch entscheidend für die Datierung des Triumphus Christi sowie für die Frage des Abhängigkeitsverhältnisses zwischen Vorlage und Bearbeitung. Vgl. ebd., S. 450.
} 
Continuo invasit terram nox atra trementem

Confusumque cahos et iam non cognita rerum

Tempestas, procul et montes et rupibus altis

Culmina conciderant duris horrentia saxis,

[...].

(vv. 71-74)

«Am nächsten Tag befielen schwarze Nacht, ein vollendetes Chaos und eine bis anhin nie gekannte Unruhe kosmischen Ausmaßes die zitternde Erde. In der Ferne stürzten Berge und Gipfel, die vor harten Felsen starrten, von hohen Klippen hinunter.>

Bei Spangenberg wird daraus:

Ignivomi solis lumen nox abstulit atra.

Contremuit tellus, scopuli rupesque dehiscunt.

«Die Nacht raubte das Licht der feuerspeienden Sonne. Die Erde bebte, Felsen und Klippen spalteten sich.>

Evident ist die Texttreue der Kurzfassung. ${ }^{38}$ Wörtlich übernimmt der Reformator die Prägung nox atra, terram trementem entspricht in lexikalischer beziehungsweise morphologischer Variation Contremuit tellus. Reduzierend wirkt sich nun zunächst der Verzicht auf erstens partizipiale, zweitens adjektivische Ergänzungen aus, wie sie sich im Vorlagentext finden (man beachte: rupibus altis und Culmina horrentia sowie duris saxis). Ohne Entsprechung bei Spangenberg sind überdies solche Ausdrücke, die sich der unmittelbaren Anschauung entziehen, namentlich die Abstrakta Confusum [ ]cahos und rerum Tempestas. Weiter ist das Prinzip der abbreviatio im Vers- und im Satzbau wirksam. Während in Hessus' Kleinepos Versgrenzen syntaktisch überspielt werden, korrespondiert im Triumphus Christi v. 4 mit einem, v. 5 sogar mit zwei Hauptsätzen, die noch dazu asyndetisch ${ }^{39}$ gekoppelt sind. Spangenbergs Text zeigt so eine stärker bibelsprachliche Orientierung:40 Parataxe und Reihung der außergewöhnlichen Naturphäno-

38 Vredeveld (2012), S. 447 (über den Triumphus Christi): «Of its 108 hexameters, a great many are either identical or certainly very similar to those in Eobanus' epyllion.»

39 Vgl. dazu Schwitter, in diesem Band.

40 Für diesen freundlichen Hinweis danke ich Susanne Köbele. 
mene - die bebende Erde, das berstende Gebirge - evozieren den evangelischen Bericht auch stilistisch (Mt 27,51): Et terra mota est et petrae scissae sunt («Und die Erde bebte, und Felsen wurden gespalten`). ${ }^{41}$ Indem Spangenberg das vorfindliche Wortmaterial bearbeitet, nimmt er zugleich Maß an der Heiligen Schrift.

Komplexer verhält es sich indessen mit einer Kürzungsoperation, die auf Ebene der copia verborum anzusiedeln ist: Den montes, rup[es], Culmina und sax $[a]$ in der Victoria Christi entspricht bei Spangenberg die vergilische Junktur ${ }^{42}$ scopuli rupesque. Diese reduziert den Wortbestand gegenüber der Vorlage um die Hälfte, fügt sich allerdings nicht nahtlos in ein «ökonomisch〉 geleitetes Kürzungsparadigma, da sie mit rup[es] einen bedeutungsähnlichen, streng genommen «verzichtbaren` Ausdruck in den Text einführt. Bedenkt man jedoch die rhetorische Wirkung der Junktur, die in den Georgica einen hyperbolischen Effekt zeitigt, ${ }^{43}$ erscheint sie durchaus funktionstragend: Ihr Einsatz erlaubt es dem Epitomator, das gesteigerte Pathos der Kreuzigungsszene noch in deren Verkürzung nachzuvollziehen. Das Beispiel illustriert mithin, dass Abbreviation als quantitatives Phänomen nicht ohne Rücksicht auf die qualitativen Aspekte eines Textes geschehen muss.

Tritt das Stilideal der brevitas in den obigen Versen aber in besonderem Maße zutage, so besteht die Pointe nun darin, dass dieses Ideal als solches in v. 5 reflektiert wird. Dessen Basis bildet Hessus' Evokation der um Christus trauernden Natur:

Totaque naturae facies miserabilis atro

Tabuerat luctu et casu moerebat amaro.

(vv. $75 \mathrm{f}$ )

«Das ganze Ansehen der jammervollen Natur siechte in schwarzer Trauer dahin und war tief betrübt über den herben Tod.>

Anders als im zuvor diskutierten Beispiel scheint das Pathos dieser Zeilen nahezu lakonisch verdichtet; seine knappe Ausdrucksweise rechtfertigt der Erzähler, indem er den Nutzen einer wortreicheren Schilderung rhetorisch

41 Text und deutsche Übersetzung zitiert nach: Hieronymus: Biblia Sacra Vulgata (2018).

42 Vgl. ebd., S. 687, ad v. 5.

43 Vgl. Erren (2003), S. 670, ad Verg. georg. 3,253. 
infrage stellt: Et quid opus multis? Lugebant cuncta creata ( $\prec$ Was bedarf es vieler Worte? Es trauerte die ganze Schöpfung〉, v. 5). Solche und ähnliche Fragen firmieren in der Rhetorik als «Abbruchsformeln`;4 bei Spangenberg scheinen sie in einer Weise funktionalisiert, dass an ihnen Kürze als leitendes Prinzip der narrativen Technik gespiegelt wird. Dies mag nebst dem angeführten locus eine zweite Stelle belegen. Dreißig Verse wendet Hessus für den Katalog der Höllenbewohner auf, das Aussetzen ${ }^{45}$ ihrer Strafen bei der Ankunft Christi bringt er auf immer neue Begriffe:

[...] Tormenta iacent; gemitusque dolentum

Nusquam exauditi, tristes siluere querelae.

(vv. 163f.)

[...]

Conticet omne forum. Silet omnis curia sontum.

«Die Qualen ruhten, und nirgends vernahm man das Stöhnen der Leidenden, die traurigen Klagen hörten auf. [...] Der ganze Platz schwieg, es schwiegen alle versammelten Sünder.>

Spangenberg hingegen, der in dichter Folge eine (teilweise erweiterte) Auswahl $^{46}$ aus Hessus' Katalog bietet, wirft neuerlich die Frage nach der

44 Für vergleichbare Wendungen vgl. Neuer Georges, Bd. 2, Sp. 3178, s. v. 〈multus〉. Zu diesen «brachylogical expression[s]» informativ auch Kortekaas (2007), S. 311. Der Ausdruck «Abbruchsformel > wird zwar oft zur Charakterisierung entsprechender rhetorischer Verfahren bei Pindar benutzt (zuerst Schadewaldt [1928], passim). Tatsächlich sind Abbruchsformeln außerhalb der Chorlyrik "weitaus seltener[]», Fuhrer (1992), S. 124, Anm. 460. Gleichwohl ist der Ausdruck für Pindar nicht reserviert, sondern wird auf funktional äquivalente Wendungen in der Epik übertragen (vgl. bspw. Kühlmann [1973], S. 152 u. 156).

45 Zum «holiday in hell» vgl. Vredeveld (2012), S. 35, Anm. 16 (das Zitat ebd.). Der Hinweis nach ebd., S. 472, Anm. 20.

46 Wenn man Spangenbergs Epitomisierung des ersten Katalogs mit derjenigen des zweiten vergleicht, so liegt ein wesentlicher Unterschied darin, dass sich das Unterweltspersonal in der Kurzfassung teilweise mit demjenigen in der Vorlage deckt, während Spangenberg nicht einen Patriarchen übergeht. Hier wie dort finden sich Charon, Megaera, Tisiphone, Allecto und die Parzen, hinzu kommen in der Bearbeitung Gorgonen und Harpyien, ausgespart sind Aeacus, Radamanthus, Minos, Tantalus, Ixion, Sisyphus und Prometheus. Den zweiten Katalog übernimmt Spangenberg hingegen so getreu, dass er in 
Zweckdienlichkeit vieler Worte auf und bündelt das Aussetzen der Höllenstrafen in einer knappen - wiederum asyndetischen - Aussage. Der Einsatz der Abbruchsformel wirkt an dieser Stelle umso raffinierter, da er mit genau jenem Moment in der Erzählung koinzidiert, da die in der Hölle gemarterten Seelen verstummen:

Gorgones Harpiaeque tremunt, pavet ipsa Megera,

Tisiphone, Alecto, perculsae luce molesta,

Ultrices Dirae, Furiae, Parcaeque sorores.

Et quid multa? Silent gemitus, tormenta, dolores.

(vv. 32-35)

¿Gorgonen und Harpyien zitterten, es ängstigten sich gar Megaera, Tisiphone, Allecto, die das lästige Licht überwältigte, die Rachegöttinen, Furien und die «Schwestern〉, die Parzen. Was bedarf es vieler Worte? Es schwiegen die Klagen, die Qualen, die Schmerzensschreie.>

In ihrer Selbstbezüglichkeit stellen die Abbruchsformeln das Stilideal der Erzählung allerdings nicht nur aus - sie dienen zugleich zu dessen Legitimierung. Die jeweiligen Fragen Et quid opus multis? und Et quid multa? involvieren die Leserschaft und lassen diese für gut befinden, was sich als Effekt der epitomisierenden Technik einstellt: ${ }^{47}$ die brevitas im Ausdruck, wohl aber auch das für Epitomai übliche Tempo der Erzählung, ihre velocitas. ${ }^{48}$ Den Beweis, dass es nicht vieler Worte bedarf, führt der Erzähler

Einzelfällen gar an den schmückenden Beiworten festhält (Joseph ist formosus, v. 43, Josua aber invictus, v. 45), an anderen Stellen ergänzt er eigene (so ist Moses sanctus und Aaron vitta insignis, v. 44). Einzelne Schlaglichter auf das Leben der alttestamentlichen Gestalten zu werfen, wie dies Hessus tut, vermag Spangenberg jedoch nicht, sodass der Triumphus Christi eine sehr viel gedrängtere Aufzählung der Patriarchen bietet: Sic pater Habramus, puer Isacus, atque Iacobus / Procedunt alacres [...]. (vv. 42f.) Dieses stärker enumerative Verfahren ist im katechetischen Zusammenhang wohl unter dem Aspekt der Memorabilität zu sehen.

47 Dass die Leserschaft «vom Epitomator gewissermaßen billigend in das verkürzende Verfahren mit einbezogen wird», beobachtet Reitz (2007), S. 347, für die Ilias Latina.

48 Dazu ebd., S. 338. Den Zusammenhang zwischen brevitas und velocitas erkennt bereits Quintilian in seiner Sallust-Diskussion; der Rhetoriker spricht von immortalis illa Sallustii velocitas (inst. X,1,102). In diesem Zusammenhang beachte man auch Kallendorf (1994), Sp. 55: «Der abgehackte Stil, der häufige Subjektwechsel und die Neigung zur Pa- 
dabei gleich selbst, denn Spangenbergs Katalog scheint tendenziell tautologisch - Megaera, Allecto und Tisiphone, Ultrices Dirae und Furiae lassen sich trennscharf jedenfalls nicht unterschieden. Eine Differenz zwischen den Ultrices Dirae und den Furiae sowie den Eumeniden beziehungsweise Erinyen (also Megaera, Allecto, Tisiphone) unterstellt zwar bereits der Vergil-Kommentator Servius (die Dirae lokalisiert er im Himmel, die Furiae auf Erden und die Eumeniden in der Unterwelt), allerdings nur, um den faktischen Sprachgebrauch der Dichter, die diese Namen vermischten, als entdifferenzierend zu erweisen..$^{49}$ Indem also der Erzähler das Katalogprinzip in der Performanz der Rede als ‘verbös〉 ausstellt, wirkt die Frage Et quid multa? unmittelbar plausibel. Obschon oder gerade weil die Abbruchsformeln einen Reflex auf die Epitomisierung darstellen, muss aber betont werden, dass dieselben nur für eine philologisch informierte Leserschaft die Funktion von Erzählerkommentaren, die auf die Hessus'sche Vorlage rekurrieren, übernehmen können - Spangenberg weist seinen Text nämlich nicht als Kurzfassung der Victoria Christi aus. Für die Wahrnehmung des zügigen Erzähltempos ist diese Information freilich nicht nötig. Dennoch ist der differenzierende Befund wichtig, dass an solchen Stellen, an denen eine Kurzfassung ihre eigenen Verfahren bespiegelt, die Frage durchaus nicht unwesentlich ist, für wen sich der betreffende Text überhaupt als Kurzfassung zu erkennen gibt.

Die auf Sparsamkeit angelegte Poetik des Triumphus Christi leitet auch Spangenbergs Bearbeitung der Monologe, die gekürzt oder gänzlich ausgeklammert werden. ${ }^{50}$ Getilgt ist die Ansprache des Psalmisten an Christus, worin David die sehnlich erwartete Erfüllung seiner prophetischen Worte

rataxe erzeugen den für Sallusts Texte typischen Eindruck von Geschwindigkeit (velocitas). Dies wird vor allem in den militärischen Berichten deutlich [...].»

49 Vgl. Serv. Aen. 4,609. Zur Identität von Dirae und Furiae Waser (1912), Sp. 313: «Dirae ist eine weitere selbständige Bezeichnung für die F[urien], vgl. Verg. Aen. IV 473 und 610 (beidemal Dirae ultrices).» Zur Identität von Dirae und Erinyen Wüst (1956), Sp. 87f.: «Dirae. Diese zwei Schwestern, Töchter der Nacht, Schwestern der E[rinys] Megaera, werden des öfteren völlig mit den E[rinyen] identifiziert[.]» Zur Identifizierung von Furiae und Erinyen (bzw. Eumeniden) Rapp (1886-1890), Sp. $1561 \mathrm{f}$.

50 Tatsächlich integriert Spangenberg nahezu wörtlich allein die ohnehin sparsamen Begrüßungsworte Adams an den Erlöser. 
kommentiert; in der Kurzfassung dient der Harfe spielende David allein als (hervorgehobener) Begleiter des Prophetenchors. Wo Spangenberg umfangreichere Redepartien aber reduziert oder einzelne Abschnitte aus diesen selegiert, sind verschiedene Prinzipien leitend. Ausschlaggebend kann die Beschleunigung des narrativen Fortgangs sein. Die erste, rund 30 Verse umfassende Ansprache des Höllenfürsten an die socii verkürzt der Epitomator auf ihre näherhin handlungsmotivierenden Inhalte. Das ausgeprägte agitatorische Moment des Vorlagentextes tritt dabei deutlich zurück:

¿O socii〉, exclamat, «iam tempus sumere tela,

Quandoquidem hic, sanie perfusus membra, propinquat,

Praedaturus opes nostras umbrasque animasque.

Scandite tecta alacres hostemque a limine telis

Arcete obiectis multa et compage serarum.

Regalem interea nos hic tutabimur armis,

Obicibus crebris, et duris vectibus aulam.?

(vv. 10-16)

¿O meine Gefährten〉, ruft er, ‘jetzt ist es Zeit, zu den Waffen zu greifen, da nämlich dieser, die Glieder mit blutigem Eiter übergossen, naht, um unseren Schatz, die Schatten und Seelen, zu plündern. Steigt eifrig die Dächer hoch und wehrt den Feind mit entgegengeworfenen Geschossen und einem großen Gefüge von Querriegeln vom Eingang ab. Derweil beschützen wir hier die königliche Halle mit Waffen, dichten Barrikaden und festen Türriegeln.>

II.

Am verknappenden Umgang mit längeren Redeabschnitten entdeckt sich endlich aber auch die reformatorische Kodierung der Kurzfassung. Entsprechende Akzentsetzungen lassen sich an der Bearbeitung des Prophetenchors feststellen, mit dem Hessus auf intradiegetischer Ebene das Hauptanliegen seines carmen heroicum einlöst: Christi Verherrlichung. In Distanz zur früheren Liebeselegik tretend, tut der Dichter im Widmungsgedicht für Eberbach sein Vorhaben kund, nunmehr paeana (v. 23), also feierliche Preislieder, anzustimmen. Diese Aufgabe tragen die Propheten mit, wenn sie begleitet von König David den Erlöser in einem Chorgesang verherrlichen. Die Propheten potenzieren damit die Stimme des Dichters in der Erzählung selbst. Derlei poetologische Implikationen sind für Spangenberg, der wortge- 
treu allein die exklamatorischen Apostrophen in seiner Kurzfassung aufgreift, nicht entscheidend. Wie ein direkter Vergleich des fraglichen Textausschnitts illustriert, nutzt Spangenberg den Chor vielmehr als Vehikel für eine zwar subtil eingeflochtene, aber doch deutlich vernehmbare rechtfertigungstheologische Botschaft - Christus ist, gut reformatorisch, die betont einzige Hoffnung auf Heil.51 Dieser Gedanke stellt gegenüber der Vorlage einen genuinen Zusatz dar:

Salve, magne Erebi Victor! Salve, inclyte Mortis

Infernae Domitor! Vitae o fortissime Vindex

Amissae $[\ldots]$.

(Victoria Christi, vv. 326-328)

¿Sei gegrüßt, gewaltiger Sieger über den Erebus! Sei gegrüßt, ruhmreicher Bändiger des höllischen Todes! O du stärkster Erretter des verlorengegangenen Lebens $[\ldots]$.

Salve, Herebi Victor! Domitor salve inclite Mortis, Destructor scelerum! Salve, o fortissime Vindex Amissae vitae! Salve, o Spes una salutis!

(Triumphus Christi, vv. 55-57)

¿Sei gegrüßt, Sieger über den Erebus! Sei gegrüßt, ruhmreicher Bändiger des Todes, Zerstörer der Sünden! Sei gegrüßt, o du stärkster Erretter des verlorengegangenen Lebens! Sei gegrüßt, o du einzige Hoffnung auf Heil!>

Dient die (quantitative) Reduktion der Vorlage hier zugleich einer (qualitativen, sinntragenden) Erweiterung, erweist sich die spezifisch reformatorische Tendenz $z^{52}$ der Kurzfassung deutlicher noch in explicatio und applicatio, mit denen sich Spangenberg von der Vorlage «emanzipiert). An dieser neu dazukommenden Partie ist zu ermessen, dass die Bearbeitung trotz ihrer

51 Dass es Spangenberg speziell darum zu tun ist, die Einzigkeit zu betonen, zeigt sich überdies daran, dass in Hessus' Epyllion zwar auch David von der spes salutis handelt (v. 305), die entsprechende Formulierung im Bezugstext also vorgeprägt scheint, dort aber der Zusatz una fehlt.

52 Die Nähe zur Reformation könnte sich auch in den folgenden Hexametern abzeichnen, die gänzlich ohne Entsprechung in Hessus' Vorlage sind: Aspice plasma tuum, sancte et venerande Creator, / Et post tot gemitus nos duc ad regna polorum (vv. $58 \mathrm{f}$.). Jedenfalls zitiert Spangenberg an dieser Stelle eine populäre, auch von Luther aufgegriffene Inschrift über dem Herrengrab. Vgl. Vredeveld (2012), S. 689, ad v. 58. 
temporeichen, handlungsorientierten Erzählweise durchaus keine Verflachung des Bezugstextes darstellt, sondern die descensus-Erzählung einer bestimmten Deutung zugeführt wird. Wie die Zwischenüberschrift Trophaeum Christi anzeigt, konzentriert sich die Exegese anschaulich um das Kreuz, das Christus im Evangelium Nicodemi, Rezension Lateinisch B, zum Zeichen seines Sieges in der Hölle aufstellt. ${ }^{53}$ Darin folgt Spangenberg dem apokryphen Text, darin geht er über Hessus hinaus:

\section{Trophaeum Christi}

Rex ergo noster Christus super omnia regnat.

Et veluti quondam belli statuere trophaea

Magnanimi Graium proceres regesque Latini,

Sic Christus statuit celebris victricia pugnae

Signa suae, signa aeternos mansura sub annos.

(vv. 81-85)

\section{Das Siegeszeichen Christi}

‘Als unser König herrscht Christus also über alles. Und wie einst die hochherzigen Prinzen der Griechen und die latinischen Könige Kriegstrophäen errichteten, so errichtete Christus Siegeszeichen seines gefeierten Kampfes, Zeichen, die für alle Ewigkeit bestehen.>

Am Beginn dieses Ausschnitts steht eine prägnante Schlussfolgerung, die den Kern der descensus-Erzählung in genau einem Hexameter resümiert: Rex ergo noster Christus super omnia regnat. Das Prinzip der abbreviatio wiederholt sich mithin im Text selbst - et quid opus multis? Was folgt, ist eine «philologische〉 Explikation des Trophaeum. Denn wohl überliefert das Evangelium Nicodemi die Errichtung des Kreuzes als Siegesmal, die Rückbindung dieser Praxis an ein antikes Triumphritual ist hingegen gelehrte Zutat, für die unterschiedliche Quellen infrage kommen. Möglich ist, dass Spangenberg seine antiquarische> Information aus einem Kommentar zum Evangelium Nicodemi bezog; denkbar ist aber auch, dass er die Auslegung einer bestimmten Stelle im paulinischen Kolosserbrief durch Philipp Melanchthon vor

Caput X. (XXVI.): Tunc omnes sancti dei rogaverunt dominum ut victoriae signum sanctae crucis relinqueret apud inferos, ne praevalerent ministri eius nequissimi aliquem retinere culpatum quem absolverit dominus. Et factum est ita, posuitque dominus crucem suam in medio inferni, quae est signum victoriae et usque in aeternum permanebit. Zitiert nach: Tischendorf (1876). 
Augen hatte. Letzteres lassen jedenfalls die in v. 85 genannten signa vermuten, die analog zu Beutewaffen vom triumphalen Kreuz hängen und gleich im Anschluss mit den Feinden Christi identifiziert werden (vv. 86-103): Pluto, der Tod, die Hölle, das schlechte Gewissen, der Zorn Gottes, die Welt und der im Kolosserbrief metaphorisch verstandene «Schuldbrief〉, den Christus ans Kreuz geheftet habe. ${ }^{54}$ Bemerkenswerterweise sieht auch Melanchthon in seinen Scholia in Epistulam Pauli ad Colossenses von 1527 einen figurativ gestifteten Zusammenhang zwischen der Idee des angehefteten Schuldbriefs und dem antiken Triumphritual:

Cum ait ‘affixum chirographum cruci`, alludit ad morem trophaeorum erigendorum et inde metaphoram sumpsit. Erat enim mos iis locis, ubi hostes superati erant, erigi trophaea, hoc est: columnas vel arcus, in quibus scribebant aut pingebant rem gestam. Sic Paulus ait «Christum affixisse chirographum cruci〉, id est: trophaeum erexisse, tamquam in quo scripserit aut pinxerit victoriam suam. Porro ea figura nihil aliud significat nisi Christum vicisse et eam victoriam omnibus gentibus palam fecisse per resurrectionem et per Spiritum sanctum. ${ }^{55}$

«Wenn [der Apostel] sagt, «der Schuldbrief wurde ans Kreuz geheftet», spielt er auf den Brauch an, Siegesmale zu errichten, und wählte von dort die Metapher. Es war nämlich gebräuchlich, an jenen Orten, wo die Feinde besiegt wurden, Siegesmale, also eine Säule oder einen Bogen, auf die sie die Kriegstaten schrieben oder malten, zu errichten. Auf diese Weise sagt Paulus, «Christus hat die Aufzeichnung ans Kreuz geheftet), das meint: dass er eine Säule errichtet hat, gleich, als ob er auf sie seinen Sieg geschrieben oder gemalt hätte. Ferner bezeichnet diese Wendung nichts anderes, als dass Christus gesiegt und diesen Sieg allen Völkern durch die Auferstehung und den Heiligen Geist bekanntgemacht hat.>

Obschon m. W. nicht bekannt ist, ob Spangenberg diesen Kommentar zur Kenntnis genommen hat, eine Anregung durch Melanchthon höchstens plausibel, aber nicht verifizierbar ist - die Parallele stimmt nachdenklich.56

54 Der Hinweis auf Col 2,14f. bei Vredeveld (2012), S. 505, Anm. 46.

55 Zitiert nach Stupperich (1963), S. 209-303, hier: S. 250, Z. 16-25. Die deutsche Übersetzung stammt von mir, O. G. Zu dieser Stelle auch Kuropka (2002), S. 62 u. 66. 56 Tatsächlich scheint mir die Möglichkeit eines Einflusses durch Melanchthon so abwegig nicht, immerhin hat Spangenberg mit der Margarita theologica (1540) eine Bearbeitung der Loci communes vorgelegt. 
Für die Interpretation wesentlicher als die (offene) Quellenfrage ist ohnehin die Funktion, die das suggestive Bild des Trophaeum Christi im Text übernimmt. Diese erklärt sich aus den Schlussversen: Der im Triumphkreuz sinnfällige Sieg über die Feinde soll der Leserschaft zur Erbauung gereichen. Die betreffende Passage stellt Spangenberg just unter den Titel des von ihm epitomisierten Kleinepos: Victoria Christi. Wir haben es also mit einer Art Binnen-abbreviatio zu tun: Spangenberg rundet die Kurzfassung mit einem Schluss ab, der nunmehr den aedifikatorischen Gehalt der descensus-Erzählung bilanziert. Auf ovidische Verse anspielend, ${ }^{57}$ gleicht er die Victoria Christi dem Sieg der fideles über die Anfechtungen der höllischen Feinde an ( vincere nostrum est [...] victoria nostra est, vv. 106f.):

\author{
Victoria Christi \\ Hos hominum Christus saevos absorbuit hostes, \\ Ut neque iam possint ultra damnare fideles. \\ His equidem tentare datum, sed vincere nostrum est. \\ Id quoque per Christum, cuius victoria nostra est, \\ Cum Patre, qui aeternum Sancto cum Flamine regnat.
}

(vv. 104-108)

\title{
Der Sieg Christi
}

〈Diese wilden Feinde der Menschen hat Christus verschlungen, auf dass sie die Gläubigen nie mehr verdammen können. Ihnen freilich ist es vergönnt, uns anzufechten, der Sieg aber ist unser. Auch dies ist uns durch Christus gegeben, dessen Sieg der unsrige ist, der mit dem Vater [und] dem Heiligen Geist herrscht.>

Worin liegt nun die protestantische Spezifik dieses Schlusses? Ausschlaggebend ist, dass Spangenberg den zuvor narrativierten Sieg Christi über die Höllenmächte tropologisch auf die Situation der Gläubigen in der tentatio bezieht. Eine damit vergleichbare Verknüpfung von descensus und Anfechtung sieht Luther, wenn er ausweislich der ersten Psalmenvorlesung in tentatio und deiectio eine sgeistliche Höllenfahrt erkennt. ${ }^{58}$ Lutherisch betrachtet, ist der Übergang von der descensus-Erzählung zur Anfechtungsproblematik also naheliegend. Aufhorchen lässt aber auch die Semantisierung der Anfechtungssituation als Kampfgeschehen: Die Glaubenden «in- 
gen` mit den hostes. Was Spangenberg damit beschwört beziehungsweise voraussetzt, ist die Figur des «christlichen Ritters», die sich im 16. Jahrhundert einen festen Platz in der reformatorischen Vorstellungswelt sichern konnte. Traditionsbildend wirkte Erasmus' von Rotterdam Enchiridion militis Christiani von 1503, bekannt ist der zehn Jahre später entstandene Kupferstich Albrecht Dürers, der einen Ritter mit Tod und Teufel konstelliert. ${ }^{59} \mathrm{Zu}$ Prominenz verhalf dem miles Christianus aber auch die Welt der Bühnen.60 Als Beispiel herausgegriffen sei Friedrich Dedekinds Christlicher Ritter (Erstdruck 1576), dem der Dramatiker den Apostel Paulus und die personifizierte Fides an die Seite stellt.61 Der Ritter besiegt so den Teufel und überwindet obendrein die altgläubige Lehre. Die mithin antikatholische Anlage des Bühnenstücks offenbart sich überdies in der Vermittlung der Rechtfertigungslehre.62

Vor dem Hintergrund der miles Christianus-Figur wird verständlich, weshalb Spangenberg eine Bearbeitung von Hessus' Victoria Christi überhaupt reizte: Das descensus-Epyllion lieferte ihm eine Textgrundlage, den Ritterschaftsgedanken nicht nur effektvoll einzukleiden, sondern außerdem mit dem Konzept der imitatio Christi zu verbinden - es ist der Stigis Domitor (v. 68) selbst, der bei Spangenberg zum nachahmbaren Muster des miles Christianus wird. Symptomatisch ist die Epitome mit ihrer Umsetzung der militia Christiana also zunächst unter einem diskursiven Gesichtspunkt. Bezeichnend ist sie aber auch im spangenbergschen Werkzusammenhang. Weitere zeitnahe Schriften des Nordhäuser Reformators umkreisen nämlich ebenfalls den Gedanken der christlichen Ritterschaft. So seine 1542 erschienene ars moriendi mit dem Titel Ain new Trostbüchlein, worin die militia im Zentrum einer lutherisch begründeten Anthropologie erscheint: Was ist des menschen leben? Die Antwort: Nichts anders / dann ain teglicher kampff vnd Ritterschaft hie auff erden / Job. $7 .^{63}$ Stärker ins Gewicht dürfte aber ein

Vgl. Kolb (2004), S. 69-72, und Schottroff (2012), S. 54, Anm. 15 (jeweils mit weiterführenden Literaturhinweisen).

60 Vgl. Goedeke (1865), S. 92-107, und, ergänzend, Rehm (1928), S. 149, Anm. 2.

61 Dazu Goedeke (1865), S. 93-102, und Müller (2012), Sp. 122 f.

62 Vgl. Müller (2012), Sp. $122 \mathrm{f}$.

63 Ain new Trost büchlin / Mit ainer Christlichen vnderrichtung / Wie sich ain Mensch berayten soll / zů ainem seligen sterben / inn Fragstuck verfasset / Durch Johan- 
Dokument fallen, das den miles Christianus bereits im Titel führt - Spangenbergs erbauliche Schrift Vom Christlichen Ritter, ${ }^{64}$ die in der Tat zu den herausragenden textuellen Beispielen des Ritterschaftsgedankens gehört.65 Fertiggestellt und zum ersten Mal in Druck gegangen war der Christliche Ritter bereits 1541, also nur zwei Jahre nach dem Erscheinen der Evangelia dominicalia, und ab 1542 wurde er öfter mit Spangenbergs Sterbetrost abgedruckt. ${ }^{66}$ Der im Triumphus Christi angelegte Gedanke der militia ist hier voll entfaltet: Nach Ausweis der Vorrede wird im Christlichen Ritter angezaigt / Was ain Christlicher Ritter sey / Warinne die Christliche Ritterschafft stee / Vnd was er für Waffen brauchen müß / damit er wider den Haubtfeind den Teüffel / Ritterlich müge fechten / auch den Sieg behalten. ${ }^{67}$ Die auf dem Epheserbrief aufruhenden Ausführungen zur 'Waffenrüstung〉 der Gläubigen (dazu gehören neben anderen: der 〈Helm des Heils〉, das 〈Schwert des Geistes`) werden ergänzt um eine Exegese der Exodus-Geschichte als eines alttestamentlichen Exempel[s] der Christlichen Ritterschafft. ${ }^{68}$

Im unmittelbaren Werkzusammenhang betrachtet, erscheint der Triumphus Christi also auch als Vorspiel zu Spangenbergs volkssprachlicher Auseinandersetzung mit der Figur des christlichen Ritters. Die Nähe zu lutherischen Reflexionshorizonten ist hierauf aber nicht beschränkt. Spangenbergs hostes, namentlich Mala conscientia und Ira Dei, beschreiben auch Aspekte von Luthers Höllenbegriff, für den das schlechte Gewissen, der Zorn Gottes, von zentraler Bedeutung sind:69 ein bose gewissen ist die Helle selbs,

nem Spangenberg / Prediger zů Northausen, Augsburg: Valentin Otmar, [1542] [VD 16 S 7873], Bl. A vir.

64 Dazu Kolb (2004).

65 So das Urteil von Schottroff (2012), S. 54, Anm. 15.

66 Vgl. Kolb (2004), S. 66, und Illg (2017), Sp. 68.

67 Da der Wittenberger Erstdruck von 1541 [VD 16 S 8064] nicht als Digitalisat vorliegt, zitierte ich Spangenbergs Christlichen Ritter hier nach dem in Anm. 59 genannten Druck; das Zitat hier Bl. D iiiir ${ }^{\mathrm{r}}-\mathrm{D}$ iiii ${ }^{\mathrm{v}}$.

68 Ebd., Bl. E viii".

69 Zu Luthers Höllenverständnis grundlegend Vogelsang (1932), S. 35. Vgl. hier und zu den im Folgenden angeführten Stellen außerdem Althaus (1962), S. 158, Jacob (1929), 
lesen wir in der 1533 gedruckten Verantwortung der aufgelegten Aufruhr. ${ }^{70}$ Vertiefen wird Luther diese Definition in der Genesisvorlesung, deren Druck jedoch in die Zeit nach Spangenbergs Text fällt: infernus, qui nihil aliud erit, quam ipsa conscientia mala. [...] Ea vero accendit flammas inferni et exuscitat horribiles cruciatus et erynnias in corde ${ }^{71}$ («die Hölle, die nichts anderes sein wird als das schlechte Gewissen selbst. [...] Es entzündet wirklich die Flammen der Hölle und erregt schreckliche Qualen und Erinyen im Herzen >). An anderer Stelle in derselben Vorlesung nennt er das Gewissen auch eine pessima et infernali[s] bestia («ein höchst schändliches und höllisches Untier〉) und kommentiert: Absque enim ea si esset, infernus non haberet ignem aut cruciatus ullos. Haec vero inflammat et roborat mortem et infernum, et universam creaturam armat contra nos («Wenn es [scil. das Gewissen, O. G] nämlich abginge, dann hätte die Hölle kein Feuer noch irgendwelche Folterwerkzeuge. In der Tat: Dieses entzündet und kräftigt Tod und Hölle und rüstet die gesamte Schöpfung gegen uns). ${ }^{72}$ In unserem Zusammenhang besonders interessant ist dann weiter das Zeugnis der 1532 gehaltenen Vorlesung über den zweiten Psalm - auch hier ist jedoch zu beachten, dass diese erst 1546 gedruckt wurde. Dort jedenfalls heißt es: Vexare nos potest mundus, peccatum, conscientia et diabolus, sed vincere ist $y h n$ verboten ( $($ Welt, Sünde, Gewissen und Teufel können uns martern, zu siegen aber ist ihnen verboten $).{ }^{73}$ Die gedankliche Nähe zu v. 106 bei Spangenberg: His tentare datum est, sed vincere nostrum est, ist offensichtlich. Um ein letztes Beispiel aus der Zeit vor den Evangelia dominicalia anzuführen, sei endlich auf den 1535 gedruckten Galaterbriefkommentar hingewiesen, worin Luther von den «zweien Teufeln` Sünde und Gewissen handelt. ${ }^{74}$ Um aber den Brückenschlag vom schlechten Gewissen zum Zorn Gottes zu illustrieren, empfiehlt sich zunächst neuerlich die Genesisvorlesung. Das Empfinden des Gewissens vergleicht Luther mit dem Verneh-

S. 26, mit Anm. 5, Ebeling (1985), S. 114, mit Anm. 17, Kittsteiner (1991), S. 116-120, Münkler (2011), S. 307-311, Kern (2014), S. 262.

70 WA $38,113,7$.

71 WA 44, 617, 29f.; $31 \mathrm{f}$.

72 WA 44, 546, 32-34.

73 WA 40 II, 265, $5 \mathrm{f}$.

74 WA $40 \mathrm{I}, 73,2$. 
men der Stimme des erzürnten Gottes, dessen Zorn wie Feuer brenne, wüte und töte ${ }^{75} \mathrm{im}$ Anschluss an die bereits angeführte Definition des infernus als mala conscientia in der Genesisvorlesung formuliert Luther denn auch konsequent: Ira Dei est infernus Diaboli et omnium damnatorum ${ }^{76}$ ( $(\mathrm{Der}$ Zorn Gottes ist die Hölle des Teufels und aller Verdammten`). Nicht nur aus Gründen der Chronologie zu würdigen ist schließlich die 1526 gedruckte Jona-Auslegung, worin Luther die Hölle ebenfalls mit der Erfahrung des Zorns Gottes gleichsetzt: eyn iglicher hat seyne helle mit sich, wo er ist, so lange er die letzte noten des tods und gotts zorn fulet. ${ }^{77}$ Bezeichnenderweise bemüht Luther dabei eine Bildsprache, die an einen descensus denken lässt: Es ist yhn [scil. den Sterbenden, O. G.] aber zu synn, als furen sie hynuntern ynn die helle, das ist, ynn Gottes zorn sincken sie, wie wol sie keynen ort wissen, da sie hyn faren. ${ }^{78}$

Die Jona-Auslegung dokumentiert aber nicht nur die Berührungspunkte der Spangenberg'schen Anfechtungsreihe mit Luthers Höllenverständnis, sondern macht umgekehrt auch eine - vermeintliche - Unschärfe sichtbar. Das letzte Zitat deutet es an: Luther denkt die Hölle nicht von vornherein als wirklichen Ort, sondern zunächst als (Gewissens-)Erfahrungsraum. ${ }^{79}$ Konkrete Formen nehme jene erst am Ende der Zeit an:

Was aber die helle sey fur dem jungsten tage, bin ich noch nicht alzu gewis. Denn das eyn sonderlicher ort sein solte, da die verdampten seelen itzt ynnen seyen, wie die maler malen und die bauch diener predigen, hallt ich fur nichts. ${ }^{80}$

Von dieser Überzeugung bleibt Luthers Höllenfahrtslehre ${ }^{81}$ nicht unberührt. Tatsächlich bricht der Reformator mit der überkommenen Auffassung des

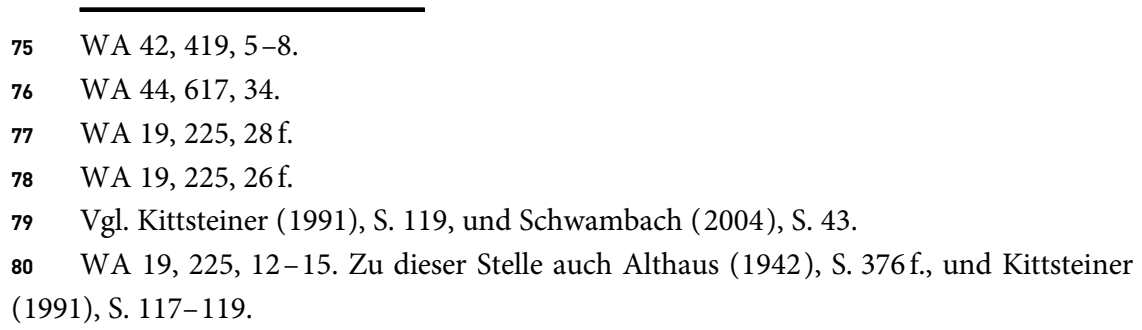

81 Dazu zusammenfassend Vogelsang (1941), S. 96-100, mit weiterführenden Literaturhinweisen auf Vogelsang (1932) auf S. 96, Anm. 3; anschließend daran (mit Differen- 
descensus als eines realen Siegeszugs und lehrt stattdessen eine «geistliche Höllenfahrt), die er in das Passionsgeschehen verlagert. ${ }^{82}$ Christus habe die Hölle als «Zorn Gottes im Gewissen» und als «Gottesverlassenheit» in Gethsemane und am Kreuz durchlebt. ${ }^{83}$ Die Überwindung der Hölle besteht in ihrem Erleiden. Diese Lehre, die sich bereits 1519 und $1521 \mathrm{im}$ Sterbesermon beziehungsweise in den Operationes in Psalmos greifen lässt, hat im vierten Kreuzeswort eine argumentativ gewichtige Grundlage: ${ }^{84}$ Eli, eli, lama asabthani, O meyn Gott, o meyn Gott, warum hastu mich vorlassen? ${ }^{85}$

Die entschieden (mythisierende> Umsetzung des descensus im Triumphus Christi scheint vor diesem Hintergrund erklärungsbedürftig. Nur einen Ansatz zur Lösung des Problems gibt die von der Forschung wiederholt herausgestellte Widersprüchlichkeit der lutherischen Höllenfahrtslehre. Die Paradoxie gründet darin, dass «Luthers eigenster Gedanke über die Höllenfahrt [...] ihre Beziehung auf Jesu Passion [ist]», ${ }^{86}$ er aufgrund des Glaubensbekenntnisses aber auch einen realen descensus in Anschlag bringt - die daraus entstehenden Probleme, etwa im Verhältnis zur gleichzeitigen Absage an die Idee eines konkreten Höllenorts vor dem Jüngsten Gericht, vermag der Reformator nicht zu klären. ${ }^{87}$ Noch verwickelter präsentiert sich die Lage aber deshalb, weil Luther für den realen descensus zwei inkommensurable Deutungen formuliert: Bevor er sich in der Jona-Auslegung gegen die Vorstellung einer lokalen Hölle aussprechen wird, entwickelt Luther in den

zierungsabsicht) die grundlegende Arbeit von Althaus (1942). Vgl. außerdem Bagchi (2008).

82 Zusammenfassend dazu Herzog (2006), S. 109 f.; vgl. für den übergreifenden Zusammenhang außerdem Herzogs grundlegende descensus-Studie (1997).

83 Althaus (1942), S. 371. Entsprechend Vogelsang (1941), S. 96 f.: «Luther versteht unter Hölle die qualvolle Erfahrung des Zornes Gottes im Gewissen, demgemäß unter Christi Höllenfahrt sein notvoll kämpfendes, inneres Erdulden und Überwinden der Erfahrung von Gottes Gericht, des Zweifels an der ewigen Erwählung und der Anfechtung zu Verzweiflung und Gotteshaß.»

84 Althaus (1942), S. $371 \mathrm{f}$.

85 Zitiert nach dem Sterbesermon WA 2, 690, $20 \mathrm{f}$.

86 Althaus (1942), S. 379.

87 Althaus (1942), S. 379. Zur Widersprüchlichkeit von Luthers descensus-Lehre auch Bagchi (2008). 
erwähnten Operationes in Psalmos auch den Gedanken einer realen Höllenfahrt der Seele Christi nach dem Kreuzestod, die er jedoch nicht als Siegeszug, sondern als Erleiden der Höllenstrafen verstanden wissen will. ${ }^{88}$ Daraus folgt: «Die Hölle und die Höllenfahrt ist ihm [scil. Christus] diesseits und jenseits des Todesaktes, denn diesseits und jenseits begegnet Jesus dem Zorne Gottes.» ${ }^{89}$ Gleichzeitig lassen sich Zeugnisse Luthers beibringen, die (merkwürdigerweise) die traditionelle Vorstellung des descensus als Triumphzug vermitteln. Der schlichte Hinweis auf das mithin konflikthafte Nebeneinander unterschiedlicher descensus-Auslegungen kann die Erzählung Spangenbergs, dem die Vorstellung einer «Höllenpassion ${ }^{90}$ offensichtlich fremd ist, also nur unzureichend begründen. Inwiefern die triumphale descensus-Narration in lutherischer Perspektive durchaus plausibel ist, lässt sich differenziert erst dann beantworten, wenn man nach den Bedingungen fragt, unter denen Luther die in seinen Schriften nur selten begegnende traditionelle Auffassung einer siegreichen Höllenfahrt profiliert. Erhellend ist in diesem Zusammenhang die 1533 gedruckte Torgauer Predigt, ${ }^{91}$ die den Glaubensartikel Nidder gefaren zur helle, am dritten tage widder aufferstanden von den todten zum Gegenstand hat.92 Denn dort begrüßt Luther, anders als seine Lehre von der geistlichen Höllenfahrt vermuten ließe, Wandgemälde, Osterspiele und Osterlieder, die den descensus kkonkretisierend als Siegeszug darstellen, inszenieren oder besingen. Weil Denken und Verstehen auf Bilder, auf «Anschaulichkeit`, angewiesen seien:

So ist fein und recht, das mans dem wort nach ansehe, wie mans malet, das er mit der fahn hinunter feret, die Helle pforten zu bricht und zustoret, und sollen die hohen unuerstendlichen gedancken anstehen lassen. Denn solch gemelde zeiget fein die krafft und nutz dieses Artikels, darumb er geschehen, gepredigt und gegleubt wird, wie Christus der Hellen gewalt zustoret, und dem Teuffel seine macht genomen habe, Wenn ich das habe, so habe ich den rechten kern und verstand da

Vgl. Althaus (1942), S. 373-375.

89 Ebd., S. 374.

90 Den Ausdruck hier und im Folgenden nach Herzog (2006), passim.

91 Zur Torgauer Predigt vgl. Vogelsang (1931).

92 WA $37,62,28 \mathrm{f}$. 
von und sol nicht weiter fragen noch klůgeln, wie es zu gangen odder mo̊glich sey $[\ldots] \cdot{ }^{93}$

Voraussetzungslos ist das Kriterium der Anschaulichkeit dabei mitnichten. Bereits im obigen Zitat klingt an, dass Luther den Glaubensartikel nicht scharff und subtil' ${ }^{94}$ auslegen möchte - er warnt gar vor unerlaubtem klügeln und meistern der vernunfft. ${ }^{95}$ Neben andern erklärt er deshalb auch die Frage, ob Christus per substantiam oder (bloß) per effectum in der Hölle war, für unlösbar, da sie die menschliche Geisteskraft übersteige. ${ }^{96}$ Vielmehr will Luther bey dem einfeltigsten verstand bleiben, das heißt: sich dem Glaubensartikel in der Weise annähern, wie mans kindern vnd einfeltigen furbilden mus. ${ }^{97}$ Begründet wird die überkommene triumphale Darstellung der Höllenfahrt also auch mit einem katechetischen Argument - und genau daraus bezieht Spangenbergs 〈Fürbildung〉 ihre Legitimität: Die intendierten Adressaten der Evangelia dominicalia, deren Vorrede an den jugendlichen Justus Jonas junior gerichtet ist, sind Lateinschüler.

III.

Der Begründungszusammenhang in der Torgauer Predigt dürfte dann auch erklären, weshalb der Triumphus Christi 1550 im Anhang von Spangenbergs Catechismus, et institutio Christianae religionis beigegeben wurde. ${ }^{98}$ Es handelt sich hierbei um dessen lateinische Übersetzung seiner 1541 gedruckten Schrift Der Gros Catechismus vnd Kinder Lere, die Luthers Katechismen für die hausväterliche Unterweisung aufbereitet. ${ }^{99}$ Gleichwohl ist der Wiederabdruck des Triumphus Christi symptomatisch. Anders als die Sonntags-

\footnotetext{
93 WA 37, 63, 27-34.

94 WA 37, 63, 14.

95 WA 37, 63, 35.

96 WA 37, 63, 14-18.

97 WA 37, 62, 34-37. Vgl. Herzog (2006), S. 125.

98 Zur sekundären Überlieferung vgl. Vredeveld (2012), S. $452 \mathrm{f}$.

99 Vgl. Illg (2017), Sp. 69. Zur Druckgeschichte der niederdeutschen sowie lateinischen Übersetzung von Spangenbergs Großem Katechismus vgl. Brüggemann / Brunken (1987), S. $1192 \mathrm{f}$.
} 
evangelien ist Spangenbergs descensus-Dichtung hier mit einem Druckbild ausgestattet, das den titelgebenden Sieg in die traditionelle Ikonographie des Christus victor ${ }^{100}$ übersetzt (vgl. Abb. 1). Gezeigt wird, wie Christus, mit der Osterfahne in der Linken, vor den niedergerissenen Höllentoren erscheint und seine Rechte nach den Verdammten ausstreckt. Die ihn umgebenden Strahlen dürften sich dem Zeugnis des Evangelium Nicodemi verdanken, wonach Christus die Hölle mit Licht geflutet habe. ${ }^{101}$

Vor dem Hintergrund der Torgauer Predigt erscheint diese Text-BildKomposition unverdächtig. Und doch ist es im Jahr 1550 bezeichnend, wenn Spangenbergs Triumphus Christi nicht nur erstmals dem Katechismus beigegeben, sondern noch dazu mit einer Illustration ergänzt wird. Es ist zu bedenken, dass Luthers widersprüchliche Lehre vom descensus als geistliche sowie infernale Höllenpassion und als realer Siegeszug weitreichende Folgen hatte: Je nachdem, welche Schrift des Reformators man rezipierte, wurde diese oder jene Lehre vertreten. ${ }^{102}$ Und so geschah es, dass die Höllenfahrt seit den 20er Jahren des 16. Jahrhunderts wiederholt zum Austragungsort (nicht nur) innerreformatorischer Kontroversen wurde. ${ }^{103}$ Als prominenteste dieser Kontroversen in die Dogmengeschichte eingegangen ist der äpinsche Streit zwischen 1548 und 1551. ${ }^{104}$ Der Hamburger Superintendent und Domlektor Johannes Äpinus argumentierte unter Rekurs auf Luthers zweite Psalmenvorlesung, dass der descensus ein für unsere Satisfaktion notwendiges Erleiden der Hölle meine, woraufhin seine Hamburger Kollegen, unter Berufung auf die Torgauer Predigt, sich für die traditionelle Lesart aussprachen. Da der Streit zu eskalieren drohte und zu Unruhen im Volk führte, ersuchte der Stadtradt die Wittenberger Theologen 1550 um ein Gutachten, worin Melanchthon den streitenden Parteien ein Schweigegebot auferlegte. Äpins Gegner jedoch polemisierten unbeirrt weiter, und erst als diese der Stadt verwiesen wurden, kehrte in Hamburg wieder Ruhe ein.

\footnotetext{
100 Dazu Schiller (1986), S. 32-41.

101 Vgl. Evangelium Nicodemi, Rezension Lateinisch A bzw. B, jeweils Caput II.

102 Vgl. Herzog (2006), S. $123 \mathrm{f}$.

103 Dazu grundlegend Vogelsang (1941). Einen guten Überblick gibt Herzog (2006).

104 Vgl. Vogelsang (1941), S. 107-119, außerdem Düfel (1995), S. 540, und Herzog (2006), S. 116 f.
} 


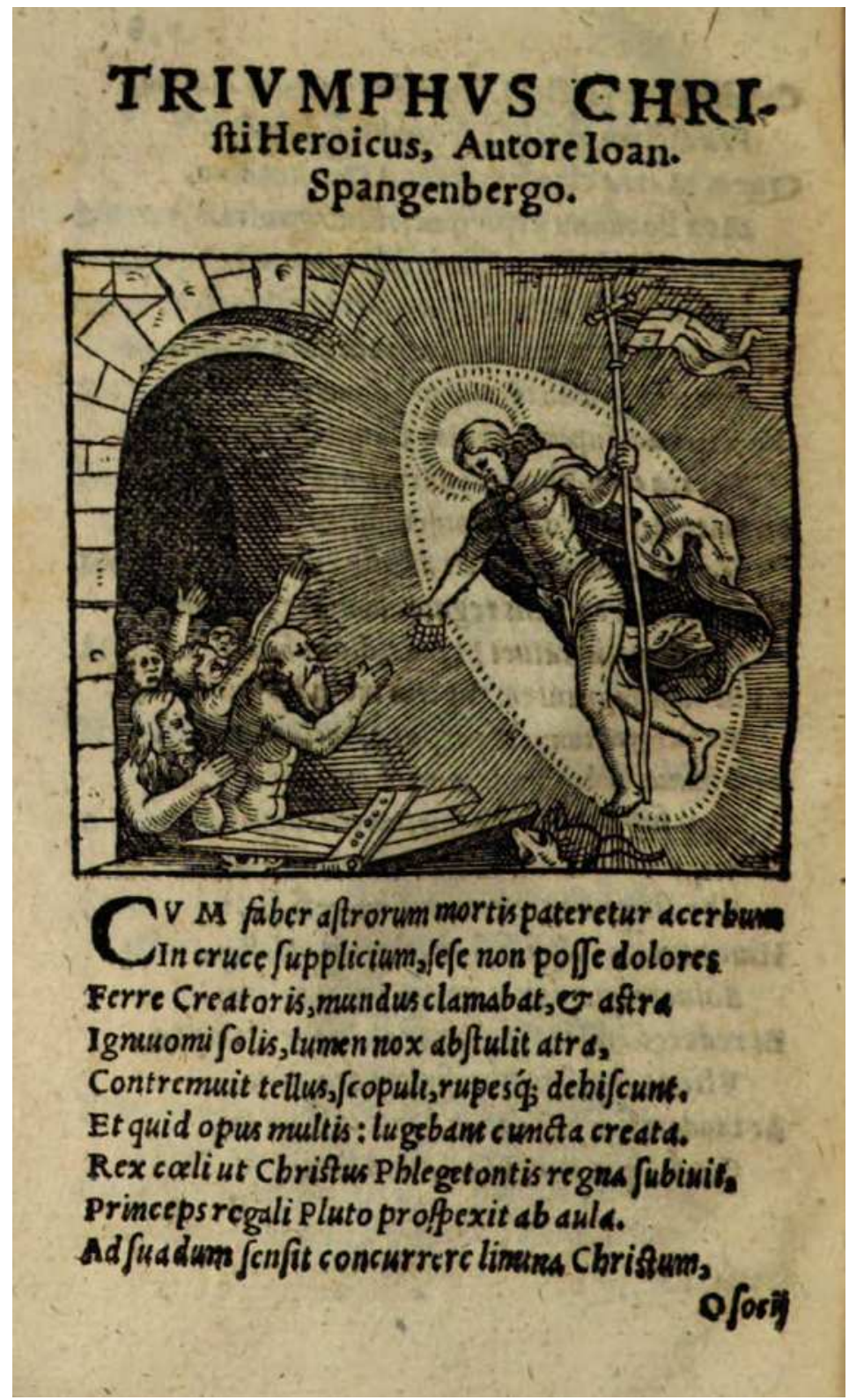

Abb. 1: Bayerische Staatsbibliothek München, Hom. 624\#Beibd.1, Bl. 148v, urn:nbn:de:bvb:12-bsb10179770-4. 
Da der äpinsche Streit zwischen 1548 und 1551 anzusetzen ist und über Hamburg hinaus Aufsehen erregte, muss es nachdenklich stimmen, wenn der Triumphus Christi just 1550 samt Bild mit dem spangenbergschen Katechismus abgedruckt wird. Die besondere Überlieferungslage der Epitome indiziert m. E. eine Funktionalisierung der Kurzfassung, die auf der katechetischen Ebene Klarheit bezüglich des strittigen Glaubensartikels schaffen sollte. Ein Indiz hierfür liefert die Tatsache, dass die lateinische Übersetzung von Spangenbergs Katechismus bereits 1544 in Druck ging, der Triumphus jedoch erst der Ausgabe von 1550 im Anhang beigegeben wurde. Elf Jahre nach ihrem erstmaligen Erscheinen in Spangenbergs Evangelia dominicalia von 1539 konnte die Kurzfassung eine Aktualität beanspruchen, die vor dem Hintergrund der Höllenfahrtkontroversen nachvollziehbar ist. Dass im Zuge dieser Kontroverse Druckbilder Einsatz fanden, welche die eine oder andere Position bestätigen oder widerlegen sollten, lehrt eine 1526 erschienene refutatio des franziskanischen Theologen Kaspar Schatzgeyer, ${ }^{105}$ die mit einem markanten Titelblatt aufwartet. Schatzgeyer richtet sich in der fraglichen Schrift gegen Anton Zimmermann, einen Hörer von Luthers zweiter Psalmenvorlesung, der entsprechend die Lehre eines Strafleidens Christi vertrat - das Titelblatt verleiht dem provokant Ausdruck: «Hier wird der Descensus-Christus nämlich nicht nur mit einer einzelnen Requisite des irdischen Sühneleidens Christi dargestellt (Dornenkrone), sondern der Unterweltaufenthalt erscheint insgesamt als eine eigene, von der Kreuzigung unterschiedene Station des satisfaktorischen Strafzusammenhangs.» ${ }^{106}$ Den umgekehrten Weg wählte Schatzgeyer in einer 1525 gedruckten Verteidigung des Purgatoriums:107 Dort bringt die Versoseite des Titelblatts die konforme descensus-Deutung mit einem Bild zur Darstellung, das demjenigen in

105 Verwerffung eines irrigen artickels das die seel Christi nach abschaidt vom leib in absteigung zu den hellen hab darinn geliden hellische pein. Mit erklerung der warhayt warumb Christus zů der hellenn gestigenn sey. Durch Gaspar Schatzger barfusser ordens, Landshut: Johann Weißenburger, 1526 [VD 16 S 2343].

106 Herzog (1997), S. 336.

107 Vom fegfeür oder volkommner Raynigung der außerwölten / Das durch die gnůgthůung Christi / das Fegfeüer nit außgelescht ist. Wiewol er durch sein leyden den weg zů der seligkait geraumbt / vnd die thür geôffnet hat / Durch Gasparn Schatzger Barfüeser ordens, München: Hans Schobser, 1525 [VD 16 S 2347]. 
Spangenbergs lateinischem Katechismus vergleichbar ist. Aus diesen Gründen halte ich dafür, dass Johann Michael Reu die theologische Brisanz des bei Spangenberg sowohl erzählten wie gedeuteten descensus unterschätzt, wenn er 1911 in seinen Quellen zur Geschichte des kirchlichen Unterrichts den Triumphus Christi und weitere «Zusätze[ ]» im Katechismus als «Füllstoff» abtut. ${ }^{108}$

Ist es aber zutreffend, dass der Wiederabdruck im Katechismus (auch) auf das Bedürfnis reagiert, das Verständnis eines problematisch gewordenen Glaubensartikels zu moderieren (nämlich im Sinne der Torgauer Predigt), muss gleichzeitig festgehalten werden, dass der Text selbst freilich komplexer als seine Indienstnahme ist. Wie wir gesehen haben, bleibt Spangenberg bei der suggestiven Anschaulichkeit der descensus-Mythe nicht stehen. Auch wenn die Epitome diesen Zusammenhang nicht expliziert: Die zuvor beobachtete Affinität von Höllenfahrt und Anfechtung wäre konzeptuell ohne Luthers Theologie einer geistlichen Höllenfahrt schwer vorstellbar: tentatio et deiectio est spiritualis descensus ad Inferos ${ }^{109}$ (‘Anfechtung und Verwerfung sind eine geistliche Höllenfahrt`). Dass aber die Konkretion der Erzählung und die Abstraktionsleistung der Schlusspartie nicht widersprüchlich werden, hängt daran, dass lutherische Höllentheologie in der Bearbeitung zwar präsent, es Spangenberg (mit Luther zu sprechen) aber nicht um eine scharff[e] und subtil[ []$^{110}$ Diskussion, sondern um aedificatio zu tun ist: Der siegrieche descensus Christi verheißt die Überwindung der höllischen Anfechtung - wie sich die Hölle im Mythos nun aber zu derjenigen der Gewissens- und Zorneserfahrung in der Anfechtung verhält, dem gegenüber bleibt der Text ebenso indifferent wie gegenüber der heiklen Frage, inwiefern der Gottessohn diese Erfahrungen teilte. Umgekehrt ermöglicht dieselbe Indifferenz jene Funktionalisierung, die für die Spangenberg'sche Katechismus-Schrift von $1550 \mathrm{zu}$ veranschlagen ist.

Darüber hinaus scheint mir die Aufnahme der Epitome in den Katechismus aufschlussreich für die Ausprägung der lutherischen Orthodoxie in der zweiten Jahrhunderthälfte. Auch wenn das Siegesmotiv in Luthers descensus- 
Theologie gegenüber der Höllenpassion deutlich zurücktritt - für die sich konsolidierende Orthodoxie ist Luthers Vorstellung eines die Höllenqualen leidenden Christus in Gänze irrelevant. Die Formula Concordiae wird sich nicht, wie es Äpinus tat, auf Luthers zweite Psalmenvorlesung, sondern auf die Torgauer Predigt berufen und den descensus Christi ad inferos entsprechend als ein triumphales Ereignis begreifen: «Die Höllenfahrt ist der erste Akt im Stande der Erhöhung.» ${ }^{111}$ Befördert wurde diese Lehre von Melanchthon, ${ }^{112}$ verbrieft wurde sie mit der Formula Concordiae 1577. Der (angenommene) kontroverstheologisch motivierte Wiederabdruck des Triumphus Christi gibt allerdings Grund zu der Annahme, dass die Entscheidung für diese Lehre, pointiert ausgedrückt, 1550 bereits gefallen war. Vielleicht erschöpft sich die dogmengeschichtliche Aussagekraft unseres Textes aber nicht in einer dokumentarischen Funktion, indem die descensus-Erzählung eine Interpretationstendenz also nur aufzeigte. Vielmehr, so meine ich, ist damit zu rechnen, dass Spangenbergs Dichtung an der Stabilisierung des späterhin orthodoxen Wissens Anteil hatte. Ihre breite Überlieferung spricht jedenfalls dafür: Als Schulbuch wurden die Evangelia dominicalia zwischen 1541 und 1548 sechsmal nachgedruckt, außerdem finden wir die Perikopenparaphrasen in den lateinischen Übersetzungen von Spangenbergs Epistelpostillen von 1545 und $1547,{ }^{113}$ und 1561 erschien sein Katechismus in zweiter Auflage. ${ }^{114}$

War Hessus' Victoria Christi Mutianus Rufus noch Anlass, einer Befreiung der christlichen Poesie aus dem Klammergriff der Scholastik das Wort zu reden, scheint die Bearbeitung demgegenüber in zweierlei Hinsicht an den theologischen Diskurs zurückgebunden: sowohl entstehungsgeschichtlich (Katechismusunterricht) wie rezeptionshistorisch (Kontroverstheologie). Darin gründet die analytische Ergiebigkeit des untersuchten Gegenstands: Der Triumphus Christi erlaubt einerseits die philologische Rekonstruktion von Kürzungsverfahren, andererseits das kontextsensible Studium von Moti-

111 Althaus (1942), S. 383.

112 Vgl. ebd.

113 Vgl. Vredeveld (2012), S. $452 \mathrm{f}$.

114 Das Druckbild mit dem Christus victor findet sich freilich auch in dieser zweiten Auflage. 
vation und Nutzung literarischer abbreviatio in der Frühen Neuzeit. Freilich wäre die Indienstnahme, mithin der historische Rezeptionsort des Textes, unter Absehung der Form kaum vorstellbar. Indem sich Spangenberg von verbositas distanziert, das Narrativ der Victoria Christi konzentriert und zuletzt um eine Auslegung ergänzt, ist der Triumphus Christi zur katechetischen Vermittlung eines nicht länger unproblematischen Glaubensartikels geradezu prädestiniert. Dabei griffe ein Urteil, wonach die Verkürzung der kleinepischen Vorlage notwendig eine Banalisierung impliziere, zu kurz. Naturgemäß finden die genuin epischen Techniken, die dem Epyllion seinen Reiz verleihen, keine oder nur in reduzierter Form Umsetzung in der Epitome. Indem der Erzähler die brevitas der Kurzfassung und ihre beschleunigenden Verfahren kommentiert, ist dem Triumphus Christi allerdings eine Ebene der Selbstbeobachtung eingezogen, auf der sich die Epitomisierung als bewusste, reflektierte Praxis präsentiert.

\section{Bibliographie}

\section{Primärliteratur}

Evangelia Apocrypha adhibitis plurimis codicibus Graecis et Latinis maximam partem nunc primum consultis atque ineditorum copia insignibus collegit atque recensuit Constantinus de Tischendorf. Editio altera ab ipso Tischendorfio recognita et locupletata, Lipsiae 1876.

Gillert, Karl: Der Briefwechsel des Conradus Mutianus, hg. von der Historischen Comission der Provinz Sachsen, 1. u. 2. Hälfte, Halle a.d. Saale 1890 (Geschichtsquellen der Provinz Sachsen 18).

Hessus, Helius Eobanus: Victoria Christi ab Inferis carmine heroico, in: The Poetic Works of Helius Eobanus Hessus. Volume 3. King of Poets, 1514-1517, hg., übers. und komm. v. Harry Vredeveld, Leiden / Boston 2012 (The Renaissance Society of America. Texts and Studies Series 1), S. 456-491.

Hieronymus: Biblia Sacra Vulgata. Lateinisch-deutsch. Bd. 5, hg. von Andreas Beriger, Widu-Wolfgang Ehlers und Michael Fieger, Berlin/ Boston 2018 (Sammlung Tusculum).

D. Martin Luthers Werke. Kritische Gesamtausgabe, Weimar 1883-1929.

Melanchthon, Philipp: Scholia in Epistulam Pauli ad Colossenses [1527], in: Robert Stupperich (Hg.): Melanchthons Werke in Auswahl, Gütersloh 1951-1975, Bd. 4 (1963), S. 209-303. 
Schatzgeyer, Kaspar: Verwerffung eines irrigen artickels das die seel Christi nach abschaidt vom leib in absteigung zu den hellen hab darinn geliden hellische pein. Mit erklerung der warhayt warumb Christus zù der hellenn gestigenn sey. Durch Gaspar Schatzger barfusser ordens, Landshut: Johann Weißenburger, 1526 [VD 16 S 2343].

Schatzgeyer, Kaspar: Vom fegfeür oder volkommner Raynigung der außerwòlten / Das durch die gnůgthůung Christi / das Fegfeüer nit außgelescht ist. Wiewol er durch sein leyden den weg zů der seligkait geraumbt / vnd die thür geơffnet hat / Durch Gasparn Schatzger Barfueeser ordens, München: Hans Schobser, 1525 [VD 16 S 2347].

Spangenberg, Johann: Triumphus Christi heroicus, in: The Poetic Works of Helius Eobanus Hessus. Volume 3. King of Poets, 1514-1517, hg., übers. und komm. v. Harry Vredeveld, Leiden / Boston 2012 (The Renaissance Society of America. Texts and Studies Series 1), S. 498-507.

Spangenberg, Johann: Ain new Trost büchlin / Mit ainer Christlichen vnderrichtung / Wie sich ain Mensch berayten soll / zů ainem seligen sterben / inn Fragstuck verfasset / Durch Johannem Spangenberg / Prediger zů Northausen, Augsburg: Valentin Otmar, [1542] [VD 16 S 7873].

\section{Forschungsliteratur}

Althaus, Paul: «Niedergefahren zur Hölle», in: Zeitschrift für Systematische Theologie 19 (1942), S. 365-384.

Der Neue Georges. Ausführliches lateinisch-deutsches Handwörterbuch, aus den Quellen zusammengetragen und mit besonderer Bezugnahme auf Synonymik und Antiquitäten unter Berücksichtigung der besten Hilfsmittel ausgearbeitet von Karl Ernst Georges, hg.v. Thomas Baier, bearb. v. Tobias Dänzer, 2 Bde., Darmstadt 2013.

Bagchi, David: Luther versus Luther? The Problem of Christ's Descent into Hell in the Long Sixteenth Century, in: Perichoresis 6 (2008), S. 175-200.

Baumbach, Manuel / Bär, Silvio: A Short Introduction to the Ancient Epyllion, in: Dies. (Hgg.): Brill's Companion to Greek and Latin Epyllion and Its Reception, Leiden 2012, S. ix-xxi.

Bernstein, Eckhard / Huber-Rebenich, Gerlinde: Art. Mutianus Rufus, Conradus, in: Killy Literaturlexikon Bd. 8 (2010), S. 472-474.

Beutel, Albrecht u. a.: Art. Predigt, in: HWRh Bd. 7 (2005), Sp. 45-96.

Brüggemann, Theodor / Brunken, Otto: Handbuch zur Kinder- und Jugendliteratur. Vom Beginn des Buchdrucks bis 1570, Stuttgart 1987.

Düfel, Hans: Art. Äpinus, Johannes (1499-1553), in: Horst Balz u. a. (Hgg.): Theologische Realenzyklopädie, Berlin / New York 1976-2004, Bd. 2 (1995), S. 535-544. 
Ebeling, Gerhard: Das Gewissen in Luthers Verständnis, in: Lutherstudien, Bd. 3, Tübingen 1985, S. 108-125.

Erren, Manfred: P. Vergilius Maro: Georgica, Bd. 2: Kommentar, Heidelberg 2003 (Wissenschaftliche Kommentare zu griechischen und lateinischen Schriftstellern).

Fuhrer, Therese: Die Auseinandersetzung mit den Chorlyrikern in den Epinikien des Kallimachos, Basel / Kassel 1992 (Schweizerische Beiträge zur Altertumswissenschaft $23)$.

Goedeke, Karl: Every-Man, Homulus und Hekastus. Ein Beitrag zur internationalen Literaturgeschichte, Hanover [sic] 1865.

Herzog, Markwart: Descensus ad inferos. Eine religionsphilosophische Untersuchung der Motive und Interpretationen mit besonderer Berücksichtigung der monographischen Literatur seit dem 16. Jahrhundert, Frankfurt a. M. 1997 (Frankfurter theologische Studien 53).

Herzog, Markwart: Strafleidenstheorie - Anthropologie - Kosmologie - Soteriologie. Kontroversen in der Höllenfahrttheologie der Reformation des 16. Jahrhunderts, in: ders. (Hg.): Höllen-Fahrten. Geschichte und Aktualität eines Mythos, Stuttgart 2006 (Irseer Dialoge 12), S. 109-127.

Herzog, Reinhart: Exegese - Erbauung - Delectatio. Beiträge zu einer christlichen Poetik der Spätantike, in: Walter Haug (Hg.): Formen und Funktionen der Allegorie. Symposion Wolfenbüttel 1978, Stuttgart 1979 (Germanistische Symposien, Berichtsbände III), S. 52-69.

Illg, Thomas: Art. Spangenberg, Johann, in: Frühe Neuzeit in Deutschland 1520-1620. Literaturwissenschaftliches Verfasserlexikon Bd. 6 (2017), Sp. 64-74.

Kallendorf, Craig: Art. Brevitas, in: HWRh Bd. 2 (1994), Sp. 53-60.

Kern, Udo: Dialektik der Vernunft bei Martin Luther, Berlin 2014 (Rostocker Theologische Studien 27).

Kittsteiner, Heinz D.: Die Entstehung des modernen Gewissens, Frankfurt a. M. / Leipzig 1991.

Kolb, Robert: Johann Spangenbergs Christlicher Ritter als Beispiel der frühlutherischen Erbauungsliteratur, in: Lutherische Theologie und Kirche 28 (2004), S. 57-80.

Korenjak, Martin: Short Mythological Epic in Neo-Latin Literature, in: Manuel Baumbach / Silvio Bär (Hgg.): Brill's Companion to Greek and Latin Epyllion and Its Reception, Leiden 2012, S. 519-536.

Korn, Uwe Maximilian / Werle, Dirk / Worms, Katharina: Das carmen heroicum in der frühen Neuzeit, in: Daphnis 46 (2018), S. 1-14.

Kortekaas, George A. A.: Commentary on the Historia Apollonii Regis Tyrii, Leiden 2007 (Mnemosyne 284).

Krummacher, Hans-Henrik: Der junge Gryphius und die Tradition. Studien zu den Perikopensonetten und Passionsliedern, München 1976. 
Kuropka, Nicole: Philipp Melanchthon: Wissenschaft und Gesellschaft. Ein Gelehrter im Dienst der Kirche (1526-1532), Tübingen 2002 (Spätmittelalter und Reformation, Neue Reihe 21).

Kühlmann, Wilhelm: Katalog und Erzählung. Studien zu Konstanz und Wandel einer literarischen Form in der antiken Epik, Freiburg 1973.

Kühlmann, Wilhelm: Wissen als Poesie. Ein Grundriss zu Formen und Funktionen der frühneuzeitlichen Lehrdichtung im deutschen Kulturraum des 16. und 17. Jahrhunderts, Berlin / Boston 2016 (Frühe Neuzeit 204).

Loehr, Johanna: Ovids Mehrfacherklärungen in der Tradition aitiologischen Dichtens, Stuttgart / Leipzig 1996 (Beiträge zur Altertumskunde 74).

Müller, Jan-Dirk: Art. Dedekind, Friedrich, in: Frühe Neuzeit in Deutschland 1520-1620. Literaturwissenschaftliches Verfasserlexikon Bd. 2 (2012), Sp. 119-128.

Münkler, Marina: Narrative Ambiguität. Die Faustbücher des 16. bis 18. Jahrhunderts, Göttingen 2011 (Historische Semantik 15).

Ohly, Friedrich: Typologie als Denkform der Geschichtsbetrachtung, in: Volker Bohn (Hg.): Typologie. Internationale Beiträge zur Poetik, Frankfurt a. M. 1988 (Poetik. Internationale Beiträge 2), S. 22-63.

Rapp, Adolf: Art. Furiae, in: Wilhelm Heinrich Roscher (Hg.): Ausführliches Lexikon der griechischen und römischen Mythologie, Leipzig 1886-1937, Bd. 1,2 (1886-1890), Sp. 1559-1564.

Rädle, Fidel: Art. Mutianus Rufus, Conradus, in: Deutscher Humanismus 1480-1520. Verfasserlexikon Bd. 2 (2013), Sp. 377-400.

Rehm, Walther: Der Todesgedanke in der deutschen Dichtung vom Mittelalter bis zur Romantik, Tübingen ${ }^{2} 1967$ (reprografischer Nachdruck der Ausgabe Halle an der Saale 1928).

Reitz, Christiane: Verkürzen und Erweitern - Literarische Techniken für eilige Leser? Die Ilias Latina als poetische Epitome, in: Hermes 135 (2007), S. 334-351.

Reu, Johann Michael: Quellen zur Geschichte des kirchlichen Unterrichts in der evangelischen Kirche Deutschlands zwischen 1530 und 1600. 1. Teil: Quellen zur Geschichte des Katechismus-Unterrichts. Bd. 2: Mitteldeutsche Katechismen. 1. Abteilung: Historisch-bibliographische Einleitung, Hildesheim/ New York 1976 (Nachdruck der Ausgabe Gütersloh 1911).

Roscher, Wilhelm Heinrich: Art. Mondgöttin, in: ders. (Hg.): Ausführliches Lexikon der griechischen und römischen Mythologie, Leipzig 1886-1937, Bd. 2,2 (1890-1897), Sp. 3119-3200.

Schadewaldt, Wolfgang: Der Aufbau des Pindarischen Epinikion, Halle 1928 (Schriften der Königsberger Gelehrten Gesellschaft, Geisteswiss. Kl., 5. Jahr, Heft 3), S. $255-$ 343.

Schiller, Gertrud: Ikonographie der christlichen Kunst. Bd. 3: Die Auferstehung und Erhöhung Christi, Gütersloh ${ }^{2} 1986$. 
Schmidt, Jochen: Hölderlins geschichtsphilosophische Hymnen Friedensfeier - Der Einzige - Patmos, Darmstadt 1990.

Schottroff, Luise: Die Bereitung zum Sterben. Studien zu den frühen reformatorischen Sterbebüchern, Göttingen 2012 (Refo500 Academic Studies 5).

Schwambach, Claus: Rechtfertigungsgeschehen und Rechtfertigungsprozess. Die Eschatologien von Martin Luther und Leonardo Boff im kritischen Gespräch, Göttingen 2004 (Forschungen zur systematischen und ökumenischen Theologie 101).

Schönhaar, Rainer: Art. Epos, in: HWRh Bd. 2 (1994), Sp. 1327-1347.

Stupperich, Robert: Art. Lang(e), Johannes, in: Neue Deutsche Biographie Bd. 13 (1982), S. 540-541.

Vogelsang, Erich: Luthers Torgauer Predigt von Jesu Christo vom Jahre 1532, in: LutherJahrbuch 13 (1931), S. 114-130.

Vogelsang, Erich: Der angefochtene Christus bei Luther, Berlin / Leipzig 1932 (Arbeiten zur Kirchengeschichte 21).

Vogelsang, Erich: Weltbild und Kreuzestheologie in den Höllenfahrtsstreitigkeiten der Reformationszeit, in: Archiv für Reformationsgeschichte 38 (1941), S. 90-132.

Vredeveld, Harry: A Case of Plagiarism Revisited: Eobanus Hessus'Victoria Christi ab inferis and Ps. Juvencus, Triumphus Christi heroicus, in: Dirk Sacré / Jan Papy (Hgg.): Syntagmatia: Essays on Neo-Latin Literature in Honor of Monique MundDopchie and Gilbert Tournoy, Louvain 2009 (Supplementa Humanistica Lovaniensia 26), S. 251-260.

Waldner, Katharina: Griechische und römische Aitiologie in Ovids Metamorphosen, in: Anton Bierl / Rebecca Lämmle / Katharina Wesselmann (Hgg.): Literatur und Religion 2. Wege zu einer mythisch-rituellen Poetik bei den Griechen, Berlin / New York 2007 (MythosEikonPoiesis 1/2), S. 203-237.

Waser, Ernst: Art. Furiae, in: Paulys Real-Encyclopädie der classischen Altertumswissenschaft Bd. 7 (1912), Sp. 308-314.

Wüst, Ernst: Art. Erinys, in: Paulys Real-Encyclopädie der classischen Altertumswissenschaft Suppl.-Bd. 8 (1956), Sp. 82-166. 
Fassungsdivergenz und Formen redaktioneller Kürzung 



\section{Bedingungen und Formen der Fassungenbildung im höfischen Roman}

von

Martin Baisch (Hamburg)

\section{Kriemhild in der Klage* $\mathrm{J}$}

Nû ist iu wol gesagt daz, wie Kriemhilt zen Hiunen saz.

als diu edel Helche ê.

doch tet ir zallen zîten wê, daz si dâ ellende hiez, wan si der jâmer niht enliez geruowen selten keinen tac, wan ir in dem herzen lac, wie si verlôs ir wünne.

ir aller naechstez künne

het ir ir lieben man benomen.

$(\text { vv. } 1-11)^{1}$

Der Beginn der Klage, wie man sie in der Berliner Klage-Handschrift J lesen kann und wie sie Joachim Bumke in seiner Edition als Fassungen-Text abdruckt, setzt <unvermittelt > ein. Die übrigen Fassungen des Textes rekapitulieren nach einem ausführlichen Prolog entsprechend dem Erzählprinzip 〈Was bisher geschah〉 die katastrophische Handlung des Nibelungenliedes, das der Text der Klage weiterführt, kommentiert oder 〈betrauert `. ${ }^{2}$ Im Mittelpunkt des ersten Teils der sogenannten Kurzfassung der Klage steht dagegen die Figur der Kriemhild, "wobei ihre Entlastung im Vergleich zu anderen Klage-Fassungen markanteres Profil gewinnt [...]». ${ }^{3}$ Wie kaum ein anderer Fassungen-Text der höfischen Epik verdient die ${ }^{\star} J$-Version der Klage

1 Der Text wird zitiert nach der synoptischen Ausgabe von Bumke (1999). Vgl. auch die Ausgaben von Bartsch (2000) u. Heinzle (2013).

2 Vgl. Koch (2011).

$3 \quad$ Frick (2018), S. 28. Vgl. auch Bumke (1996). 
den Begriff der Kurzfassung. ${ }^{4}$ In dieser Bearbeitung erweist sich die Streichung von Text nämlich als das zentrale Mittel der poetischen Gestaltung. ${ }^{5}$ Diese Version der Klage hat in der Forschung überraschenderweise erhebliche Wertschätzung erfahren - gerade weil sie sich durch brevitas auszeichnet und damit einen «kürzeren` (Erzähl-)Weg wählt:

Unter ästhetischen Gesichtspunkten ist an der ${ }^{\star}$ J-Klage nicht viel auszusetzen. Hier fehlt fast alles, worauf sich die negative Beurteilung bezieht, die die Klage in der Forschung gefunden hat. Es gibt kein langwieriges Resümee des Geschehens, kein sich wiederholendes Klage-Lamento von (für unseren Geschmack) schwer erträglicher Eintönigkeit, keine ausufernden Beschreibungen nebensächlicher Details der Botenreisen. Die ${ }^{\star}$ J-Klage bietet ein knapp erzähltes Nachspiel zum furchtbaren Ende des Nibelungenlieds. An dem Schmerz der drei Frauen wird das Schreckliche des Geschehenen greifbar. ${ }^{6}$

Allerdings lässt Joachim Bumkes Begründung die Frage aufkommen, nach welchen Maßstäben die Ästhetik der mittelalterlichen Epik hier bewertet wird (und damit die Frage nach der Alterität dieser Ästhetik!). ${ }^{7}$ In eins gesetzt scheint hier das Missfallen gegenwärtiger Rezeption an der Repetitivität vormodernen Erzählens, um eine Eigenart mittelalterlichen Erzählens zu benennen, und die rhetorisch geprägte Ästhetik der abbreviatio. Doch wie lässt sich das Phänomen der «Streichung〉 genauer bestimmen?

\section{Streichung und Vermehrung}

Es ist der Gedanke, daß «Streichungen〉, daß Löschungen von Zeichen im Text einer Kultur nicht zu einer Reduktion, sondern im Gegenteil zu einem weiteren Ausufern des Schreibstroms führen, zu einer Wucherung des eingelagerten Schichtensystems der Varianten. Man könnte vom paradoxen Gesetz einer Streichung als Vermehrung

$4 \quad$ Vgl. die Zusammenstellung bei Bumke (1996), S. 297.

$5 \quad$ Vgl. Kiehl (2008).

6 Bumke (1996), S. 289.

7 Vgl. hierzu den Sammelband von Gerok-Reiter u. a. (2019). Vgl. ebenso den Problemaufriss von Braun (2007). 
sprechen, eines Schnittes, der nicht zur Löschung, sondern zu weiterer `Ausdifferenzierung> von Bedeutungsnuancen führt. ${ }^{8}$

Gerhard Neumanns luzide Überlegungen sind im Kontext der textkritischen Versuche zu sehen, die Werke beziehungsweise Texte von Franz Kafka im Schreibprozess zu edieren: Zu Beginn der 1980er-Jahre blickten Philologen wie Neumann oder Wolf Kittler in Nachfolge der Frankfurter HölderlinAusgabe und ihrer herausragenden Neuerungen mit neuem Interesse auf die Handschriften des Prager Autors, in denen Textgenese und Schreibstrom, Vorgänge wie Kürzung und Streichung in den Manuskripten unmittelbar zur Anschauung kommen. ${ }^{9}$ Zweifelsohne sind die Reflexionen des Kafka-Editors mehr von einem poststrukturalistischen Text- und Kulturbegriff geprägt als von einem semiotischen, der zumindest die damalige germanistische Textkritik und Editionsphilologie prägte. ${ }^{10}$ Streichung und Kürzung von Text besitzen nach dieser Auffassung also gesetzmäßig Bedeutung generierende Potenz. Ähnliche Reflexionen finden sich auch bei Frank Bezner im Kontext eines Sammelbandes, der im Gefolge der Fassungen-Debatte im höfischen Roman nach den Formen und Funktionen von Phänomenen der Retextualität in der mittelalterlichen Literatur fragt:

[W]o hinzugefügt oder gekürzt wird, entsteht unweigerlich Differenz; und gerade diese Differenz wird metikulöser literaturwissenschaftlicher Analyse (und Theorie) zugänglich, lässt sich als eine Transformation von Gegebenem begreifen, die unweigerlich neuen, anderen Sinn erzeugt oder doch ein Gemeinsames neu ‘verhandelt ^: gleich, ob dies in Bezug auf ästhetische Figuren, Strukturen, Aporien erfolgt oder Probleme - etwa: die in einem Text deponierten oder repräsentierten Herrschaftsansprüche, Tabus, Wissensinhalte - betrifft. ${ }^{11}$

Vorsichtiger wird hier die Kürzung (und Hinzufügung) von Text als Phänomen beschrieben, das Differenz erzeugt, als Phänomen einer «Transformation von Gegebenem), wobei das Gegebene, das im Schreib- und

$8 \quad$ Neumann (1999), S. 421.

9 Vgl. Neumann (1982), Kittler / Neumann (1990), vgl. auch (zum Schreibprozess bei Robert Walser) Kammer (2013).

10 Vgl. Martens (2005).

11 Bezner (2005), S. 207. 
Arbeitsprozess bearbeitet wird, genauer benannt wird. Bezner betont zudem den im Grunde nicht auflösbaren Bezug zum Ausgangsmaterial, das den Status einer Verstehensfolie für das Neue besitzt und dennoch fortgesetzt überschritten wird. Dieser Gedanke führt unweigerlich auf den Zusammenhang von Bedeutungserzeugung und Emergenz. ${ }^{12}$

Eine überaus gelungene Zusammenfassung dieser in den letzten Jahren intensiv geführten Diskussion bietet für die Mittelalterphilologien Ursula Peters unter dem Stichwort «Retextualisierung〉:

Die lateinische wie volkssprachige Programmatik dieses spezifisch vormodernen Textverständnisses ist in den letzten Jahren in Arbeiten zur mittelalterlichen Poetik und Ästhetik in ihrem reichen Spektrum der Interaktion von Prä- und Re-Text zu einem zentralen Forschungsgegenstand geworden. Dies gilt auch für die literarischen Ausfaltungen der damit verbundenen Literaturpraxis der Retextualisierung, deren Variantenreichtum und Inszenierungsmöglichkeiten inzwischen auf den verschiedensten Ebenen - in literarhistorischen Fallstudien zu Einzelwerken, Literaturtypen wie ganzer Textcorpora - intensiv erarbeitet wird. Eine besondere Volte nimmt dabei die jüngere Forschungsdiskussion zum Romanerzählen, die das typenspezifische Charakteristikum des «Wiedererzählens〉 mit neueren Überlegungen zur Fiktionalität des Höfischen Romans verbindet und dadurch zu überzeugenden Einsichten in die spezifische Faktur dieses Literaturtyps kommt. ${ }^{13}$

\section{Der rhetorisch-poetische Ansatz}

Maßgeblich ist die Diskussion um die Textualität der höfischen Epik, ich habe es bereits erwähnt, in den vergangenen beiden Jahrzehnten durch die Fassungen-Diskussion der 1990er-Jahre geprägt worden. ${ }^{14}$ Von zentraler Bedeutung hierbei ist der Befund gewesen, dass die Bearbeitung der meist französischen und lateinischen Vorlagen mittels Erweiterung und Kürzung erfolgte. Verantwortlich für solchen Umgang mit Text sah man - zumindest nach den einschlägigen Aufsätzen von Franz Josef Worstbrock ${ }^{15}$ - mittelalterliche Poetiken wie die des Matthäus von Vendôme und Galfried von

Vgl. Iser (2013).

Vgl. Wortbrock (1985), S. 1-30; Worstbrock (1999). 
Vinsauf an, die, antike Konzepte und Postulate aufnehmend, diese für ihre je eigenen Zusammenhänge transformierten und kodifizierten, "was bereits geübter und anerkannter Standard literarischer Praxis und sprachlich-formaler Gestaltung in der Literatur ihrer Zeit ist». ${ }^{16}$ Wie man sich diese Praxis vorzustellen hat, beschreiben Marie-Sophie Masse und Stephanie Seidl im Kontext zu Untersuchungen zu deutschsprachigen Antikenromanen, die die beiden Philologinnen als «Texte dritter Stufe bezeichnen:

Mit der materia liefert die latinitas zugleich Anleitung zur tractatio materiae. Die volkssprachlichen Autoren, die sehr wahrscheinlich eine klerikale Ausbildung erfahren haben, sind mit lateinischen Dichtungstheorien vertraut, welche in den Schulen vermittelt und seit der zweiten Hälfte des 12. Jahrhunderts in den Artes Poeticae kodifiziert werden. Insofern erscheint es legitim, die ursprünglich auf die lateinische Stilistik abzielende Dichtungstheorie für die Untersuchung der volkssprachlichen Literatur heranzuziehen. ${ }^{17}$

Als «Regeln der Adaptation bezeichnet Silvia Schmitz in ihrer hier einschlägigen Habilitationsschrift das in den mittelalterlichen artes poeticae kodifizierte Wissen. ${ }^{18}$ Herangezogen werden von ihr vor allem die Ars versificatoria des Matthäus von Vendôme, die Poetria nova Galfrids von Vinsauf sowie die von Galfrid angefertigte Kurzfassung des Documentum de modo et arte dictandi et versificandi. In den Fokus der Untersuchungen von Schmitz kommen das Konzept der inventio und die mit ihr verbundenen Verfahren der abbreviatio und der dilatatio. ${ }^{19}$ In den artes poeticae werde das Ziel der topischen inventio, die prinzipielle Vielfalt der Argumente zu garantieren,

\footnotetext{
16 Henkel (2017), S. 28.

17 Seidl / Masse (2016), S. 12.

18 Schmitz (2007); vgl. hierzu Baisch (2010) u. Schmitz (2016).

19 Vgl. Linden (2017), S. 6: «In der amplificatio, der kunstvollen Erweiterung, kann ein Dichter, der einen vorgegebenen Stoff bearbeitet, seine eigene Könnerschaft ausweisen. Entsprechend viel Aufmerksamkeit erhält dieser Bereich in den mittelalterlichen Poetiken, die sich in ihren Anweisungen an die aktuelle Literatursituation anpassen. abbreviatio und dilalatio sind dabei zwei Kehrseiten derselben Medaille, nämlich zwei gegensätzliche Bewegungen in einer Beschäftigung mit einem Grundtext, die man auch über das Bild des Einfaltens und Ausfaltens begreifen kann.»
} 
eingeschränkt (durch Systematisierung, die proprietates-Lehre und die officia des genus demonstrativum), wie Schmitz in Bezug auf Matthäus zeigt.

Mittels eines subtilen Vergleichs zwischen Johannes von Garlandia, der seiner Parusiana Poetria ein eigenes inventio-Kapitel beigefügt hat, und Matthäus wird die inventio als hermeneutischer Akt - als ein Verfahren der Auslegung und Formung von materia - beschrieben, wobei die Autorin die Anpassung rhetorischer Praxis an die Bedürfnisse der Textdeutung in den Blick nimmt. Schließlich stellt Schmitz dar, dass Begriff und Konzept von inventio auch auf die geistige Durchdringung des Werkes abzielen können.

Die mittelalterliche Konzeptualisierung von abbreviatio und dilatatio wird zunächst von der minutio und amplificatio der antiken Rhetorik abgehoben. Denn wo in der antiken Rhetorik die gedankliche Steigerung des Ausdrucks und die Ausdehnung wie Abschwächung (beziehungsweise Konzentration) des Ausdrucks und Kürzung zusammengeführt werden, trete bei den mittelalterlichen Textbearbeitungstechniken «die qualitative Dimension zurück»:

Im Unterschied zu den antiken Techniken tritt bei der dilatatio und abbreviatio, wie sie in den artes poeticae begegnen, die qualitative Dimension zurück. Sie sind überwiegend auf die Erweiterung bzw. Raffung eines vorgegebenen Stoffes gerichtet. Gleichwohl muß insbesondere für die amplificatio und dilatatio festgehalten werden, daß eine zu scharfe Trennung der beiden Verfahren weder den antiken noch den mittelalterlichen Lehren gerecht wird. ${ }^{20}$

abbreviatio und dilatatio verdanken ihre Aufwertung in der mittelalterlichen Tradition den progymnasmata - «denn bei den rhetorischen Übungen im Paraphrasieren und Ausgestalten eines Sujets kommt dem Kürzen und Erweitern erhebliche Bedeutung zu» ${ }^{\mathbf{2 1}}$ - und der spätantiken Kommentartradition (etwa den Servius-Kommentaren). Über die Autorität Vergils erhalten die im Schulbetrieb eingeübten Verfahren des Kürzens und Erweiterns wesentliche Bedeutung als Arbeitsschritte der Adaptation. Doch bleibt das Bild, bedingt auch durch eine wenig einheitliche Terminologie und durch die 
kategoriale Unbestimmtheit der Begriffe in den Poetiken, so unscharf wie komplex:

Galfrid nennt acht Techniken, mit deren Hilfe eine materia erweitert werden kann: die «Häufung synonymer Aussagen», die Umschreibung (circuitio), den Vergleich (collatio), die Anrede (apostropha), die redende Personifikation (prosopopeia), den Exkurs (digressio), die Beschreibung (descriptio) und die santithetische[] Ausdrucksweise.${ }^{22}$

Als Techniken des Kürzens beschreibt Galfrid entsprechend sieben Verfahren der Textbearbeitung, zu denen etwa die Reduktion des Ausdrucks auf das Wesentliche (emphasis) oder die Vermeidung von Wiederholungen gehören. ${ }^{23}$ Doch behandle Galfrid die Techniken der abbreviatio in der Poetria nova nur knapp, wie Schmitz abschließend feststellt. Diese besitzt aber zweifellos dispositionelle Funktionen bei der Stoffanordnung und -gewichtung.

In einem wichtigen Beitrag hat Ludger Lieb Arbeiten wie jene von Schmitz wie auch von Worstbrock, der die Unterscheidung von materia und artificium in der Debatte stark gemacht hat, kritisiert und hinterfragt, ob «eine Anwendbarkeit des rhetorischen Modells der lateinischen Poetik auf narrative volkssprachliche Großformen sinnvoll sei». ${ }^{24}$ Die rhetorisch-poetischen Termini führen im Bereich der mittelalterlichen Großepik «kaum zu hinreichend sauberen Differenzierungen $»{ }^{25}$ Lieb kommt zu dem bedenkenswerten Schluss,

dass die Anwendung des rhetorisch-poetischen Konzepts auf einen höfischen Roman tendenziell Komplexität reduziert. Es verschleiert nämlich die komplexe Problemlage, insbesondere indem es suggeriert, man könne bei Epen und Romanen

22 Schmitz (2007), S. 269; vgl. auch Worstbrock (1999).

23 «Für die abbreviatio nennt er sieben Verfahren: die Reduzierung des Ausdrucks auf das Wesentliche (emphasis), den Gebrauch (kurzer) Satzglieder (articulus), den Ablativus absolutus (ablativus), die Vermeidung von Wiederholungen, die bloße Anspielung auf einen weitläufigen Gegenstand, die unverbundene Reihenfolge von Einzelwörtern und Wortgruppen und die Fusion mehrerer Aussagen zu einer.» Schmitz (2007), S. 269.

24 Lieb (2005), S. 357; vgl. auch Hasebrink (2009), Gollwitzer-Oh (2012), Köbele (2017).

$25 \quad$ Lieb (2005), S. 359 mit Anm. 10. 
das Artificium von der Materia so trennen wie etwa bei Fabeln. Statt historisch mit dilatatio und abbreviatio zu hantieren und gerade wegen der attraktiven dichotomischen Schlichtheit des Modells schnell an analytische Grenzen zu stoßen, könnte man vielmehr die wechselseitige Bedingtheit von Materia und Artificium hervorheben $[\ldots] .^{26}$

Einerseits insistiert Lieb also darauf, die Paradoxien der materia-Semantik ernster zu nehmen, als rhetorische Ansätze dies tun. Er konstatiert, dass aus Sammlungen von Dilationen und Abbreviaturen allein noch keine Interpretation zu gewinnen ist - zumindest keine methodisch transparente. Stärkere Aufmerksamkeit sollte auch die Frage erfahren nach dem Verhältnis von (antik-mittelalterlicher) 〈Theorie〉 und der Praxis, den Praktiken des Ab-/ Schreibens durch die mittelalterlichen Schreiber und Redaktoren. In den Zusammenhang unserer Fragestellung gehören aber auch Überlegungen zur Poetik von Kurzfassungen als Abbreviaturen komplexer Sachverhalte, narrativer Sujets oder Vorstellungen, wie sie von Nikolaus Henkel und Hans Jürgen Scheuer kürzlich entwickelt worden sind. ${ }^{27}$ Dieser Ansatz versteht das Phänomen der Kürzung als ein poetisches Verfahren der komplexen, auf Form wie Inhalt zielenden Verdichtung, das Spiele der Entschlüsselung zwischen Autor und Rezipient ermöglicht.

Freilich bleibt der Umstand, dass Theorie und Praxis auch in Hinblick auf die mittelalterliche Textproduktion je unterschiedliche Bedeutung und Reichweite besitzen, von Gewicht:

Die Artes poeticae und andere hochmittelalterliche poetologische Werke und Werkpassagen sind wichtige Indizien dieser literarischen Infrastruktur), machen diese aber [...] beileibe nicht allein aus. Jeder mittelalterliche Erzähler, der etwas länger eine bessere Schule besucht oder professionellen Kontakt mit einem fortgeschrittenen Schüler gehabt hatte, wußte z. B., daß eine Erzählung «kurz, klar und wahrscheinlich sein soll> (Rhetorica ad Herennium I,9,14: ut brevis, ut dilucida, ut veri similis sit). Erzähler, welche grob dagegen verstoßen, versuchen daher vielfach ernsthaft oder ironisch, sich zumindest nominell gegen entsprechende Vorwürfe zu 
verwahren, versprechen also etwa, der nötigen Kürze wegen etwas zu übergehen ehe sie dann doch meist schildern. ${ }^{28}$

\section{Bumkes Modell für die Beschreibung variierender Epenüberlieferung}

Für die Überlieferung der Nibelungenklage hat Joachim Bumke ein differenziertes «Modell für die Beschreibung variierender Epenüberlieferung ${ }^{29}$ entworfen, das den Versuch unternimmt, die «Variantenlizenz volksprachlicher Schriftlichkeit im 13. Jahrhundert» zu bestimmen und das von der Forschung, wenn ich richtig sehe, kaum diskutiert worden ist. ${ }^{30}$ Der vorrangig formalästhetische Beschreibungsversuch rückt die Quantifikation und stilistische Klassifikation der Varianten in den Mittelpunkt des philologischen Interesses. Damit favorisiert dieser Frageansatz die synchrone Struktur mittelalterlicher Überlieferung und vernachlässigt Fragen nach den Funktionen. Dem Verfahren entspricht Bumkes skeptische Forderung, zunächst kein «Frageprogramm für die Interpretation epischer Parallelfassungen zu entwickeln, solange die Überlieferungsfragen nicht geklärt sind und solange es keine kritischen Ausgaben gibt».31

Um der Varianz in der Überlieferung der höfischen Romane angemessen zu begegnen, entwirft Joachim Bumke damit ein Beschreibungsmodell, das «1. der Vielgestaltigkeit der zu beschreibenden Phänomene und 2. der Unbrauchbarkeit des herkömmlichen Begriffapparats» gerecht werden soll. ${ }^{32}$ Das Modell ist ein Versuch, eine Typologie von Varianz mittelalterlicher volksprachlicher Texte zu erarbeiten. Von großer Bedeutung ist es gerade deshalb, weil es die a priori wertende Begrifflichkeit traditioneller Textkritik überwindet und den Möglichkeitsraum von Textvarianz absteckt - wie er im 13. Jahrhundert aus der Schreibpraxis erwächst.

\footnotetext{
28 Knapp (2014), S. 231.

29 Vgl. Bumke (1996), S. 397-455.

30 Mit Ausnahme der einschlägigen Rezensionen von Strohschneider (1998), Haustein (1999), Stackmann (2001), Henkel (2001).

31 Bumke (1996), S. 88. Vgl. dagegen Müller (1998), S. 54.

32 Bumke (1996), S. 390.
} 
Unter dem Begriff der «epischen Variation» versteht Bumke «[a]lle Unterschiede zwischen verschiedenen Handschriften und verschiedenen Fassungen eines Epos [...], soweit sie sich nicht als Fehler einzelner Schreiber erklären lassen ». ${ }^{33}$ Damit deckt der Begriff eine Vielfalt von Phänomenen ab, die quantitativ und qualitativ stark differieren und die in den Texten z. T. ineinandergreifen. Bumkes Modell zielt darauf ab, «alle Variationsphänomene in ein Koordinatensystem» einzuordnen, «das 1. die Art der Variation (was und wie variiert wird) und 2. das Ausmaß der Variation (wie stark variiert wird) erkennen lassen soll». ${ }^{34}$

Um Varianz qualitativ beschreiben zu können, unterscheidet Bumke mit seinem Modell zwischen den Kategorien Textbestand, Textfolge und Textformulierung, die sich zu unterschiedlichen Varianztypen kombinieren. Das Kriterium der Quantität von Varianz wird auf den Ebenen Vers, Verspaar und größere Versgruppen untersucht. Morphologische und syntaktische Varianten werden im Beschreibungsmodell separat behandelt.

So zielt das Modell am Beispiel der Klage auf eine Darstellung der synchronen Struktur von Varianz und verzichtet auf eine Rückkoppelung mit dem komplementären Phänomen der Textkonstanz. Es verbleibt in der Innenordnung des untersuchten Textsystems, öffnet vorurteilsfrei den Blick auf die Vielfalt möglicher Erscheinungsformen von Varianz, kann und will diese aber nicht an funktionale Analyse rückbinden. Es stellt sich aber die Frage, ob ein solch formal und phänomenologisch orientierter Zugriff das Problem der Textvarianz mittelalterlicher Texte nicht verkürzt. Denn die Bestimmung differierender Typen von Varianz kann ohne thematisch-inhaltliche und kontextuell-funktionale Frageraster nicht auskommen.

Auch Nikolaus Henkel hat versucht, für Kürzungstechniken beziehungsweise -praktiken im Bereich der höfischen Epik ein Modell zu entwickeln. Dabei unterscheidet er vier Kürzungstypen, denen «formal gemein [ist], daß das Reimpaar als Grundelement vielfach erhalten bleibt». ${ }^{35}$ Kleineren Reduktionen um ein bis drei Reimpaare und Kürzungen von größeren Handlungsabschnitten von 10 bis 400 Versen, welche die beiden ersten Kürzungstypen

34 Ebd. S. 391.

35 Henkel (1992), S. 7. Vgl. auch Henkel (1993), S. 39-59. 
darstellen, schreibt Henkel die Tendenz zur brevitas zu. Er unterstellt diesen Kürzungen, dass sie den Erzählablauf nicht verändern, sondern seine «Fülligkeit» zurücknehmen. ${ }^{36}$ Der dritte Kürzungstyp bezeichnet die Verknappung beziehungsweise Streichung von Erzählerkommentaren und Exkursen: «Die Redaktoren entfernen hier Elemente des Erzählens, die der Kontaktaufnahme von Erzähler und Publikum, der Lenkung des Verständnisses und der Herstellung von Einvernehmen zwischen Autor/Erzähler und Publikum dienen.» ${ }^{37}$ Schließlich wird - der letzte Kürzungstyp - in der erzählten Handlung selbst Text gekürzt: «descriptiones von Personen, Tieren, Sachen, Bauwerken; Monologe, Dialoge, Gesprächs- und Beratungsszenen; Kampfschilderungen ${ }^{38}$

Aus den hier vorgelegten Überlegungen und Beobachtungen ergeben sich eine Reihe von Fragen:

1. Wie ist in textproduktiver Perspektive das Zusammenspiel von Umsetzung rhetorisch-poetischer Konzepte der abbreviatio und konkreter Arbeit am Text durch die Schreiber und Redaktoren an der Handschrift zu beschreiben und zu analysieren?

2. Welche Phänomene und Effekte werden durch die hier beschriebenen Formen der Verkürzung beziehungsweise Bearbeitung von Text erzeugt? Welche Textzustände entstehen dabei? Wie lassen sich diese bestimmen und kategorisieren? Erscheint das Erzählen handlungsorientierter, wie lässt sich dann das Verhältnis von Zeit und Erzählen bestimmen?

$\mathrm{Zu}$ denken wäre hier an hermeneutisch greifbare Neukonzeptionen, in denen neue Sinn- und Bedeutungsebenen aufscheinen. Mit Sicherheit lassen sich spezifische Arten von sprachlich-rhetorischer Prägnanz beobachten, ebenso drückt sich in den Bearbeitungsvorgängen ein besonderer Stilwillen aus. Schließlich sind (lokal begrenzte) Effekte von Schreibarbeit/-praxis wahrnehmbar, die durch «eine unmittelbar auf die Materialität der Texte bezogene Aufmerksamkeit» entstehen. ${ }^{39}$ Diesen Umstand hat auch Nikolaus

36 Henkel (1993), S. 49.

37 Henkel (1992), S. 8.

38 Henkel (1993), S. 50; Frick (2018) unterscheidet drei Typen redaktioneller Kürzung.

39 Gabler (2012), S. 319. 
Henkel in seiner Rezension von Bumkes Monographie zur Nibelungenklage hervorgehoben:

Eine Frage bleibt freilich auch jetzt noch unbeantwortet: die nach der Motivation eines Schreibers/Redaktors, die zu varianten Formulierungen geführt hat wie: Gunther der fürste riche - Gunter der künec riche oder daz mans in giht für ere daz mans in iach für ere. Hier wird eine Interpretation einsetzen müssen, die nicht auf umfassende Sinnstiftung ausgerichtet ist, sondern auf die Arbeitsprozesse, aus denen die Texte hervorgehen: The Making of the Text. ${ }^{40}$

3. Besitzt nicht auch die Varianz mittelalterlicher Textüberlieferung einen historischen Index? Auszugehen ist von einem sich wandelnden Umgang in der reproduktiven Textpraxis des Mittelalters.

Der Titel des Aufsatzes bezieht sich, wie im Folgenden zu zeigen ist, auf einen doppelten Vergleich: Die Fassung ${ }^{\star} J$ der Klage wird exemplarisch mit den anderen Fassungen des Werks verglichen, wie sie auch in Bezug gesetzt wird zu einer weiteren Kurzfassung aus dem Bereich des höfischen Roman: der im bebilderten Cgm 51 tradierten Bearbeitung $M$ von Gottfrieds von Straßburg Tristan beziehungsweise von Ulrichs von Türheim Fortsetzung. ${ }^{41}$ Im Fokus stehen dabei Überlegungen, die sich mit den stilistisch-rhetorischen wie konzeptuellen Parametern, nach denen die Transformationen von Kurzfassungen sich beschreiben lassen, beschäftigen.

\section{Kriemhild und Isolde}

Wie bereits Joachim Bumke, aber auch Julia Frick herausgestellt haben, sollten die Text kürzenden Praxen und ihre kulturellen Funktionen, die sich an den Überlieferungen der höfischen Epik im 12. und 13. Jahrhundert feststellen lassen, miteinander verglichen werden. Die Fassung S von Herborts Liet von Troie, die Fassung M von Gottfrieds Tristan und Ulrichs von Türheim Tristan-Fortsetzung, die Fassung $\mathrm{S}$ des Wilhelm von Orlens von Rudolf von Ems, die Kurzfassungen von Ulrichs von Etzenbach Alexander und des Friedrich von Schwaben sind hier zu nennen - wie eben auch die

41 Vgl. Baisch (2006). 
Fassung ${ }^{\star} J$ der Klage. Die Reduktion des Textbestandes in der Fassung ${ }^{\star} J$ der Klage, die sich gleichmäßig über den ganzen Text verteilt, ist im 13. Jahrhundert freilich ohne Parallele. ${ }^{42}$

Durch die starke Reduktion des Erzählten - die um 1300 enstandene Handschrift J der Klage überliefert 944 Verse, die Fassung ${ }^{*} \mathrm{~B}$ hingegen 4354 Verse - ist auf eine signifikante Weise eine eigene Fassung des Textes entstanden. Die Handlung dieser Kurzfassung, das belegten zuletzt die schon genannten Arbeiten von Bumke, Kiehl und Frick, ist auf die drei leidenden Frauen zentriert:

Im Mittelpunkt der ${ }^{\star} \mathrm{J}-\langle$ Klage $〉$ stehen die drei Frauen: Kriemhild, deren Schmerz über die Ermordung ihres ersten Mannes die Untergangshandlung auslöst, sowie Gotelind und Brünhild, die mit fassungslosem Schmerz auf die Nachricht vom Tod ihrer Ehemänner reagieren. Die inhaltliche Konzentrierung auf die drei Frauengestalten läßt erkennen, dass die ${ }^{\star} \mathrm{J}-\prec$ Klage nicht durch Nachlässigkeit oder Gedankenlosigkeit zustande gekommen ist, sondern daß hier ein planender Redaktor am Werk war, der eine bestimmte Vorstellung davon hatte, wie der Text aussehen sollte $[\ldots] .^{43}$

Durch die beobachtbare Raffung beziehungsweise Streichung von Handlungselementen werden in der Kurzfassung ${ }^{*} \mathrm{~J}$ zwei Aspekte der KlageFassungen ${ }^{\star} \mathrm{B}$ und ${ }^{\star} \mathrm{C}$ stärker profiliert: Die Forschung verweist zum einen auf die Entlastung Kriemhilds, "die sowohl im Nibelungenlied als auch in den anderen Klage-Fassungen, trotz des Bemühens um Vereindeutigung, letztlich eine ambivalente Figur bleibt».44 ${ }^{\star} J$ streicht die Schuldzuweisungen an Kriemhild für den Mord an Hagen: «Auch in Bechelaren, Passau und Worms sind Reden und Verhaltensweisen der Hinterbliebenen in ${ }^{\star}$ J gekürzt, die Kriemhild deutliche Vorwürfe machen.» ${ }^{45}$ Demgegenüber sind es die Burgunden, denen in ${ }^{\star} J$ die Schuld an Siegfrieds Tod zugesprochen wird. ${ }^{46}$

\footnotetext{
42 Vgl. Bumke (1996), S. 297.

43 Ebd. S. 284.

44 Frick (2018), S. 28.

45 Kiehl (2008), S. 180.

46 Ebd., S. 184: «Kriemhilds Leid gegenüber steht die große Schuld der Burgunden [...], die für die Trauer und Rache Kriemhilds verantwortlich sind. Ohne die vorhergehende Vorstellung der ehrenvollen, mächtigen und reichen Burgunden wie auch des klei-
} 
Zum anderen setzt die Kurzfassung ${ }^{\star} J$ einen Schwerpunkt auf «die Weiterführung bzw. de[n] Abschluss des Geschehens, in dem Trauer und Klage mit der Krönung von Gunthers und Brünhilds Sohn sowie mit Dietrichs und Hildebrands Heimkehr aufgehoben sind».47 Hervorzuheben ist schließlich wiederum in Anschluss an Joachim Bumkes Überlegungen zur Nibelungenklage -, dass der Redaktor die Fassung ${ }^{\star} J$ nicht nur erheblich gekürzt und die Kürzungsstellen gekonnt aufbereitet hat, «sondern daß er den ganzen Text mit einem eigenen Gestaltungs- und Formulierungswillen bearbeitet hat.»48

Die Figur der Isolde erfährt in der Münchner Tristan-Handschrift M von ihrem Auftreten im Roman bis zum Abbruch des Fragments besondere Aufmerksamkeit vonseiten des Redaktors des Skriptoriums um den Cgm 19 und 51. Diese reich bebilderte Handschrift, im zweiten Viertel des 13. Jahrhunderts entstanden, bietet bekanntermaßen Kurzfassungen der Werke von Gottfried und Ulrich. Die Protagonistin des Liebes- und Hofromans wird bei ihrem Auftritt in Weisefort durch eine exzeptionelle descriptio ausgezeichnet:

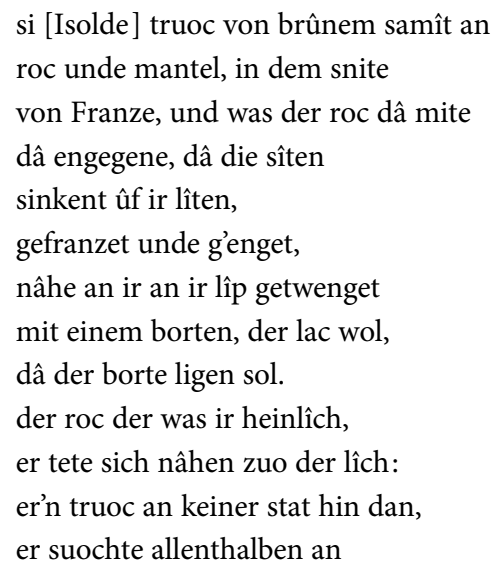

nen, relativierenden Moments von Siegfrieds übermuot als Ursache seines Todes verschiebt sich in ${ }^{*}[\ldots]$ das Gewicht auf den Gegensatz zwischen der unschuldigen, leidgebeugten Kriemhild, die aus Treue zu ihrem ersten Mann die Machtstellung am Hunnenhof zur Rache nutzt, und den Burgunden, die die Schuld an Siegfrieds Tod und dem daraus folgenden Unheil tragen.»

47 Frick (2018), S. 28.

48 Bumke (1996), S. 289. 
al von obene hin ze tal;

er nam den valt unde den val

under den vüezen alse vil

als iuwer iegelîcher wil.

der mantel was ze vlîze

mit hermîner wîze

innen al ûz gezieret,

bî zîlen geflottieret;

er'n was ze kurz noch ze lanc:

er swebete, dâ er nider sanc,

weder zer erden noch enbor. [...]

man sach ez innen und ûzen

und innerhalben lûzen

daz bilde, daz diu Minne

an lîbe und an dem sinne

sô schône hæte gedræt:

diu zwei, gedræt unde genæt,

diu'n vollebrâhten nie baz

ein lebende bilde danne daz.

gevedere schâchblicke

die vlugen dâ snêdicke

schâchende dar unde dan:

ich wæne, Îsôt vil manegen man

sîn selbes dâ beroubete.

(Gottfried von Straßburg, Tristan, vv. 10.900-10.961)

Bei den höfisch inszenierten Auftritten von Isolde und Tristan übernimmt der Bearbeiter der Münchner Tristan-Handschrift nicht die detaillierten Beschreibungen ihrer Gestalt und Kleidung, ihrer Haltung, Bewegung und Gestik. Besondere Bedeutung kommt dabei der Erscheinung Isoldes zu.49 Gottfrieds ausführliche Darstellung von Isoldes Erscheinen vor Gericht hat in der Forschung viel Aufmerksamkeit erfahren. Dabei haben die Interpreten - bei aller Differenz der Auffassungen - vor allem Gottfrieds herausragende Technik der descriptio hervorgehoben. Nach C. Stephen Jaeger, der Gott-

49 In M fehlen die Verse Tristan 10.901-10.989 (die Beschreibung des Auftritts Isoldes), 11.103-11.144 (die Darstellung von Tristans prachtvoller Ausstattung) und 11.20711.220 (die Reaktion des Hofes auf Tristans Auftritt). 
frieds Beschreibung von Isolde mit Darstellungsprinzipien der gotischen Plastik in Verbindung setzt, betont die Darstellung der Heldin den Faltenwurf ihrer so sorgfältig beschriebenen Kleider. Gottfrieds Hervorhebung der sich bewegenden Kleidung an Isoldes Körper repräsentiere, so Jaeger weiter, den gleitenden Blick des Betrachters der Figur. ${ }^{50}$ Die Wirkung Isoldes wird «im kollektiven räuberischen Blick» allererst erzeugt. ${ }^{51}$

Nach Christoph Huber stellt die Beschreibung Isoldes, die er in Frauenportraits des Alanus ab Insulis vorgebildet sieht, eine Überhöhung der Romanfigur dar, die in die Nähe zum Mittel der Personifikation gerückt werden kann. Der damit etablierte Zweitsinn einer allegorisierenden descriptio-Technik bewegt sich nach Huber spannungsgeladen zwischen den Polen höfischer Idealität und einer latenten Minnegefährlichkeit der Frauenfigur. ${ }^{52}$

Die im Cgm 51 fehlende Beschreibung Isoldes vor Gericht bewirkt das zeigen auch andere Textänderungen, die der Redaktor vornimmt - eine Desambiguisierung der Figur. Daraus folgt ebenso, dass Gottfrieds narrative Strategie ihrer an der lateinischen Tradition orientierten Dimension in der Textgestalt des Cgm 51 beraubt ist: Gottfrieds Erzählen, das hier mittels der Übernahme einer elaborierten descriptio-Technik eine Exkurs- und Kommentarebene einfügt, wird diese Möglichkeit der poetischen Sinnbildung und -vermittlung genommen.

Ein vom Typ ähnlicher Eingriff des Redaktors findet sich in der berühmten Gottesurteil-Episode: Die Beschreibung von Isoldes härenem Bußgewand vor Gericht wird im Text des Cgm 51 nicht ausgeführt:

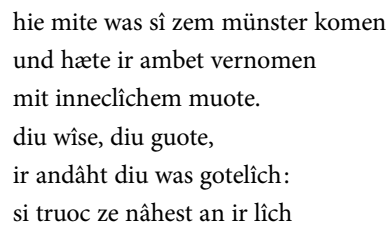

51 Brüggen (1993), S. 209. Ebenso als Objekt voyeuristischer Phantasien interpretiert Schultz (2006), S. 98, hier die Darstellung Isoldes; Müller (1995), S. 233, verweist auf die descriptio der Kriegerin Camilla in Heinrichs von Veldeke Eneasroman, in welcher der Körper dieser Jungfrau ebenfalls begehrlichen Blicken ausgesetzt ist.

52 Vgl. Huber (1988), S. 89. 


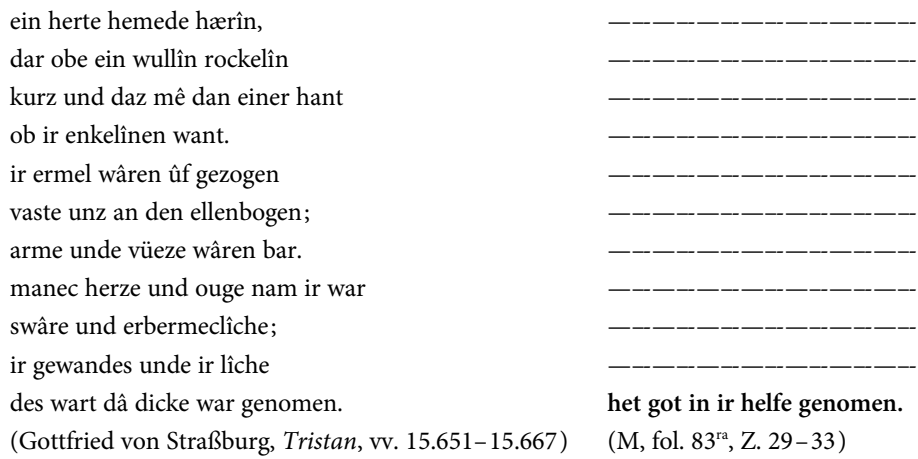

Das Gewand der Angeklagten, das Teile des Körpers Isoldes nicht bedeckt, übernimmt bei diesem öffentlichen Auftritt Isoldes bestimmte narrative Funktionen: Das Bußkleid, das alle Blicke auf sich zieht, zeigt beim Publikum enorme Wirkung. Dass der Redaktor der Münchner Handschrift der Büßerin in seiner Textfassung dieses Mittel der Manipulation vorenthält, bewirkt, dass die Inszenierung der Heldin an elaborierter Ausgestaltung verliert.

Die dabei entstehende Form des Erzählens ist raffend und beschleunigt den Fortgang der erzählten Handlung. Damit wird auch der Zusammenhang von Zeit und Erzählung in den Vordergrund gerückt. ${ }^{53}$ Das sich verändernde Verhältnis des Erzählprozesses zur Temporalität erhält im Cgm 51 an anderer Stelle eine noch größere Signifikanz: In keiner Episode des Gottfried'schen Tristan-Fragments sind die Veränderungen, die der Redaktor des Münchner Codex vornimmt, zu den Konzeptionen, die sich in den anderen Handschriften finden, größer als in der Darstellung beziehungsweise der Beschreibung der Minnegrotte. Der Redaktor kürzt zunächst in der Beschreibung des Grotteninneren die Verse Tristan 16.711-16.726. Damit fällt die Erwähnung des Gewölbes mit seinem edelsteingeschmückten Schlussstein, des grasgrünen Marmorbodens und des Kristallbettes weg. Diese Bestandteile des Grotteninterieurs werden in der später folgenden Allegorese im Hinblick auf die Eigenschaften der minne gedeutet. Der Text im Cgm 51 erwähnt explizit nur mehr von der Grotte, dass eine eherne Tür zu ihr führt und dass 
durch kleine Fenster Tageslicht in sie scheint. ${ }^{54}$ Erhalten bleiben also jene verknüpften Motive, die für die Ausgestaltung der folgenden narrativen Handlung wichtig sind: Die Liebenden müssen ja durch eine Tür, wollen sie in die Grotte gelangen, und Marke muss durch ein Fenster schauen, will er das Paar und das Schwert erblicken. Der sich daran anschließende Mittelteil der Minnegrotten-Episode ist in der Fassung der Münchner Tristan-Handschrift nicht überliefert. ${ }^{55}$ Die Allegorese der Grotte samt der sie umschließenden sogenannten 〈autobiographischen` Exkurse, welche die Erfahrungen des Erzählers in der Grotte präsentieren, sind im Text des Cgm 51 nicht erhalten. Damit hat der Redaktor die Erzählung vom Leben Tristans und Isoldes in der Minnegrotte de-allegorisiert und die Entmaterialisierung der Grotte - wie sie durch das Deutungsmuster der Allegorese bewirkt wird rückgängig gemacht.

\section{Schluss}

Die Poetik der abbreviatio und der brevitas findet in alternativen narrativen Konzepten ihre Entsprechung, in denen sich durchaus Differenzen in der ästhetischen und ethischen Auffassung der bearbeiteten Texte ausdrücken können. Als eine auffällige Bearbeitungstendenz, die sich in der Kurzfassung des Tristan im Cgm 51 zeigt, aber auch für weitere in dieser Werkstatt angefertigte Texte Geltung beanspruchen kann, hat sich der redigierende Umgang mit den Konzeptionen der weiblichen Figuren der höfischen

54 Erhalten sind auch die auf die Grotte bezogenen Adjektivattribute in den Versen Tristan 16.709f. Die Grotte ist in M auch einer Göttin geweiht; dass es die der Minne ist, muss man aus dem Kontext erschließen, was aber nicht schwerfällt. Gottfried hatte eigentlich eine Gravur mit der Widmung an die Göttin der Minne auf dem Kristallbett vorgesehen.

55 Es fehlen die Verse Tristan 16.905-17.142. «Das Ganze [sc. die Grottenepisode] ist (nach der Gliederung, nicht der Verszahl) als Zentralkomposition erkennbar mit den auktorialen Passagen und der allegorischen Auslegung der Grotte in der Mitte, wobei die Verbindung der Elemente vor allem durch das rondoartig nur leicht variierte Motiv vom schönen Naturort hergestellt wird.» Huber (2001), S. 99. Durch die Textkürzungen ist in der in $\mathrm{M}$ überlieferten Fassung die ästhetische Komposition der Episode aufgehoben. 
Erzähltexte erwiesen. ${ }^{56}$ In der Klage-Fassung ${ }^{\star} \mathrm{J}$ ist mit der Figur der Kriemhild auf eine vergleichbare Weise verfahren worden.

Die zu rekonstruierenden Interessen der Schreiber und Redaktoren belegen eine der Funktionen der literarischen Texte und - davon nicht zu trennen - ihrer Überlieferungen: Das tradierte Material wird insofern zum Medium anthropologischer Reflexion, als es sich «menschliche[n] Hervorbringungen» verdankt «und Teil von Handlungsvollzügen und Kommunikationssituationen" ist. ${ }^{57}$ In den Überlieferungszeugen entstehen dabei je unterschiedlich kohärente (Gegen-)Entwürfe zu den bearbeiteten Textwelten; es werden im Überlieferungsmaterial Aspekte von Problem- und Konfliktsituationen in den entworfenen Weltkonstruktionen mittels der untersuchten Bearbeitungstendenzen entfaltet und reflektiert. Momenthaft sind in den Texten dieser Handschriften jene Widersprüche rekonstruierbar, welche die Auslassungen und Reformulierungen in den ästhetischen Zeichenordnungen veranlassten. Mikrohistorisch werden derart die einzelnen Überlieferungsträger «im Schnittpunkt verschiedener Herstellungs- und Verwendungszusammenhänge» sichtbar, lassen sich aus der «Detailanalyse Modelle für die kommunikative Funktion der Texte gewinnen ", ${ }^{58}$ die zwischen ästhetischem Genuss, kritischer Reflexion, Wissensvermittlung und Lebensorientierung changieren. Bei der Diskussion um die Formen und Funktionen des rhetorisch-poetischen Prinzips der abbreviatio ist die Handschrift in ihrer Materialität eine unhintergehbare Größe - die Bezugsgröße kann nicht allein ein kritisch hergestellter Fassungen-Text sein.

\section{Bibliographie}

\section{Primärliterartur}

Gottfried von Straßburg. Tristan und Isold, hg.v. Walter Haug und Manfred Günter Scholz. Mit dem Text des Thomas hg., übers. und komm. v. Walter Haug, 2 Bde., Berlin 2011 (Bibliothek des Mittelalters 10-11 [= Bibliothek deutscher Klassiker 192]).

56 Vgl. Baisch (2006).

$57 \quad$ Kiening (2003), S. 41.

58 Ebd. 
Die Nibelungenklage. Mittelhochdeutscher Text nach der Ausgabe von Karl Bartsch. Einführung, neuhochdeutsche Übersetzung und Kommentar von Elisabeth Lienert, Paderborn 2000 (Schöninghs mediävistische Editionen 5).

Die Nibelungenklage. Synoptische Ausgabe aller vier Fassungen, hg.v. Joachim Bumke, Berlin 1999.

Das Nibelungenlied und die Klage. Nach der Handschrift 857 der Stiftsbibliothek St. Gallen. Mittelhochdeutscher Text, Übersetzung und Kommentar, hg.v. Joachim Heinzle, Frankfurt a. M. 2014 (Bibliothek des Mittelalters 12 [= Bibliothek deutscher Klassiker 196]).

\section{Forschungsliteratur}

Baisch, Martin: Textkritik als Herausforderung der Kulturwissenschaft. Tristan-Lektüren, Berlin / New York 2006 (Trends in Medieval Philology 9).

Baisch, Martin: Rezension zu: Silvia Schmitz: Die Poetik der Adaptation. Literarische inventio im Eneas Heinrichs von Veldeke, Tübingen 2007 (Hermaea. N. F. 113), in: ZfdPh 129 (2010), S. 455-459.

Baisch, Martin: Überlieferung und Ambiguität. Die Textualität des höfischen Romans nach der Fassungen-Debatte, in: Margreth Egidi / Markus Greulich / Marie-Sophie Masse (Hgg.): Hartmann von Aue 1230-1517. Kulturgeschichtliche Perspektiven der handschriftlichen Überlieferung, Stuttgart 2020, S. 327-341.

Bezner, Frank: Zwischen «Sinnlosigkeit» und 〈Sinnhaftigkeit〉. Figurationen der Retextualisierung in der mittellateinischen Literatur, in: Joachim Bumke / Ursula Peters (Hgg.): Retextualisierung in der mittelalterlichen Literatur, Berlin 2005 (ZfdPh 124, Sonderheft), S. 205-237.

Braun, Manuel: Kristallworte, Würfelworte. Probleme und Perspektiven eines Projekts 〈Ästhetik mittelalterlicher Literatur〉, in: Manuel Braun / Christopher Young (Hgg.): Das fremde Schöne. Dimensionen des Ästhetischen in der Literatur des Mittelalters, New York 2007, S. 1-40.

Brüggen, Elke: Kleidung und adliges Selbstverständnis. Literarische Interessenbildung am Beispiel der Kleidermotivik in der höfischen Epik des 12. und 13. Jahrhunderts, in: Joachim Heinzle (Hg.): Literarische Interessenbildung im Mittelalter. DFG-Symposion 1991, Stuttgart/ Weimar 1993 (Germanistische Symposien. Berichtsbände XIV), S. 200-215.

Bumke, Joachim: Die vier Fassungen der Nibelungenklage. Untersuchungen zur Überlieferungsgeschichte und Textkritik der höfischen Epik im 13. Jahrhundert, Berlin / New York 1996 (Quellen und Forschungen zur Literatur- und Kulturgeschichte 8 [242]). 
Chinca, Mark / Young, Christopher: Responsible Philology. Editing the Kaiserchronik in the Digital Age, in: Digital Philology. A Journal of Medieval Cultures 6 (2017), S. $288-329$.

Frick, Julia: abbreviatio. Zur historischen Signifikanz von Kürzungsfunktionen in der mittelhochdeutschen höfischen Epik des 13. Jahrhunderts. Eine Projektskizze, in: PBB 140 (2018), S. 23-50.

Frick, Julia: Reflexionen des Untergangs. Erzählen vom Ende in den Fassungen der Nibelungenklage, in: Julia Weitbrecht / Andreas Bihrer / Timo Felber (Hgg.): Die Zeit der letzten Dinge. Deutungsmuster und Erzählformen des Umgangs mit Vergänglichkeit in Mittelalter und Früher Neuzeit, Göttingen 2020 (Encomia Deutsch 6), S. 125-142.

Gabler, Hans Walter: Wider die Autorzentriertheit in der Edition, in: Jahrbuch des freien deutschen Hochstifts 2012, S. 316-348.

Geork-Reiter, Annette u. a. (Hgg.): Ästhetische Reflexionsfiguren in der Vormoderne, Heidelberg 2019 (GRM-Beiheft 88).

Gollwitzer-Oh, Kathrin: materia und artificium. Tradition und poetischer Möglichkeitssinn im Eneasroman Heinrichs von Veldeke, in: Hartwin Brandt u. a. (Hgg.): Erfahren, Erzählen, Erinnern. Narrative Konstruktionen von Gedächtnis und Generation in Antike und Mittelalter, Bamberg 2012 (Bamberger Historische Studien 9), S. 169-194.

Hasebrink, Burkhard: Die Ambivalenz des Erneuerns. Zur Aktualisierung des Tradierten im mittelalterlichen Erzählen, in: Ursula Peters / Rainer Warning (Hgg.): Fiktion und Fiktionalität in den Literaturen des Mittelalters. Jan-Dirk Müller zum 65. Geburtstag, München 2009, S. 205-217.

Haustein, Jens: Rezension zu: Joachim Bumke: Die vier Fassungen der Nibelungenklage. Untersuchungen zur Überlieferungsgeschichte und Textkritik der höfischen Epik im 13. Jahrhundert, Berlin / New York 1996 (Quellen und Forschungen zur Literaturund Kulturgeschichte 8 [242]), in: ZfdPh 118 (1999), S. 442-445.

Henkel, Nikolaus: Kurzfassungen höfischer Erzähltexte als editorische Herausforderung, in: editio 6 (1992), S. 1-11.

Henkel, Nikolaus: Kurzfassungen höfischer Erzähldichtung im 13./14. Jahrhundert. Überlegungen zum Verhältnis von Textgeschichte und literarischer Interessenbildung, in: Heinzle, Joachim (Hg.): Literarische Interessenbildung im Mittelalter, DFG-Symposion 1991, Stuttgart / Weimar 1993 (Germanistische Symposien 14), S. 39-59.

Henkel, Nikolaus: Rezension zu: Joachim Bumke: Die vier Fassungen der Nibelungenklage. Untersuchungen zur Überlieferungsgeschichte und Textkritik der höfischen Epik im 13. Jahrhundert, Berlin / New York 1996 (Quellen und Forschungen zur Literatur- und Kulturgeschichte 8 [242]); Die Nibelungenklage. Synoptische Ausgabe aller vier Fassungen, hg. v. Joachim Bumke, Berlin / New York 1999, in: PBB 123 (2001), S. 137-144. 
Henkel, Nikolaus: Reduktion als poetologisches Prinzip. Verdichtung von Erzählungen im lateinischen und deutschen Hochmittelalter, in: Franz-Josef Holznagel / Jan Cölln (Hgg.): Die Kunst der brevitas. Kleine literarische Formen des deutschsprachigen Mittelalters, Berlin 2017 (Wolfram-Studien XXIV), S. 27-58.

Huber, Christoph: Die Aufnahme und Verarbeitung des Alanus ab Insulis in mittelhochdeutschen Dichtungen. Untersuchungen zu Thomasin von Zerklaere, Gottfried von Strassburg, Frauenlob, Heinrich von Neustadt, Heinrich von St. Gallen, Heinrich von Mügeln und Johannes von Tepl, München 1988.

Huber, Christoph: Gottfried von Straßburg. Tristan, Berlin 2001 (Klassiker-Lektüren 3). Iser, Wolfgang: Emergenz. Nachgelassene und verstreut publizierte Essays, hg.v. Alexander Schmitz, Paderborn 2013.

Jaeger, C. Stephen: Medieval Humanism in Gottfried von Straßburg's Tristan and Isolde, Heidelberg 1977.

Kammer, Stephan: Figurationen und Gesten des Schreibens. Zur Ästhetik der Produktion in Robert Walsers Prosa der Berner Zeit, Tübingen 2003. - 2. Aufl. Berlin / New York 2013 (Hermaea. N. F. 10).

Kiehl, Christina: Zur inhaltlichen Gestaltung einer Kurzfassung. Eine verkürzte Nibelungen-Klage als Fortsetzung des Nibelungen-Liedes, Frankfurt a. M. 2008 (Hamburger Beiträge zur Germanistik 45).

Kiening, Christian: Gewalt und Heiligkeit, in: ders. (Hg.): Zwischen Körper und Schrift. Texte vor dem Zeitalter der Literatur, Frankfurt a. M. 2003, S. 35-55.

Kittler, Wolf / Neumann, Gerhard (Hgg.): Franz Kafka. Schriftverkehr, Freiburg 1990.

Knapp, Fritz Peter: Poetik, in: ders. (Hg.): Die Rezeption lateinischer Wissenschaft, Spiritualität, Bildung und Dichtung aus Frankreich, Berlin / Boston 2014 (Germania Litteraria Mediaevalis Francigena 1 [GLMF]), S. 217-242.

Köbele, Susanne: Registerwechsel. Wiedererzählen, bibelepisch (Der Saelden Hort, Die Erlösung, Lutwins Adam und Eva), in: Bruno Quast / Susanne Spreckelmeier (Hgg): Inkulturation. Strategien bibelepischen Schreibens in Mittelalter und Früher Neuzeit, Berlin / Boston 2017 (Literatur. Theorie. Geschichte 12), S. 167-202.

Koch, Elke: Die Vergemeinschaftung von Affekten in der Klage. Mit Untersuchungen zur Semantik von verklagen und klagen helfen, in: Johannes Keller / Florian Kragl / Klaus Zatloukal (Hgg.): Mittelalterliche Heldenepik - Literatur der Leidenschaften. Beiträge des 11. Pöchlarner Heldenliedgesprächs 07.- 10.04.2010, Wien 2011, S. 6182.

Lieb, Ludger: Die Potenz des Stoffes. Eine kleine Metaphysik des Wiedererzählens, in: Joachim Bumke / Ursula Peters (Hgg.): Retextualisierung in der mittelalterlichen Literatur, Berlin 2005 (ZfdPh 124, Sonderheft), S. 356-379.

Linden, Sandra: Exkurse im höfischen Roman, Wiesbaden 2017 (MTU 147). 
Martens, Gunther: Was ist ein Text? Ansätze zur Bestimmung eines Leitbegriffs der Textphilologie, in: Stephan Kammer / Roger Lüdeke (Hgg.): Texte zur Theorie des Textes, Stuttgart 2005, S. 94-115.

Masse, Marie-Sophie / Seidl, Stephanie: ‘Texte dritter Stufe〉. Eine Einleitung, in: dies. (Hgg.): 〈Texte dritter Stufe〉. Deutschsprachige Antikenromane in ihrem lateinischromanischen Kontext, Berlin 2016 (Kultur und Technik 31), S. 9-19.

Müller, Jan-Dirk: Spielregeln für den Untergang. Die Welt des Nibelungenliedes, Tübingen 1998.

Müller, Maria: Jungfräulichkeit in Versepen des 12. und 13. Jahrhunderts, München 1995 (Forschung zur Geschichte der älteren deutschen Literatur 17).

Neumann, Gerhard: Der verschleppte Prozeß. Literarisches Schaffen zwischen Schreibstrom und Werkidol, in: Poetica 14 (1982), S. 92-112.

Neumann, Gerhard: Schreiben und Edieren, in: Heinrich Bosse / Ursula Renner (Hgg.): Literaturwissenschaft. Einführung in ein Sprachspiel, Freiburg i. Br. 1999 (Rombach Reihe Grundkurs 3), S. 401-426.

Peters, Ursula: Philologie und Texthermeneutik. Aktuelle Forschungsperspektiven der Mediävistik, in: IASL 36 (2011), S. 251-282.

Scheuer, Hans-Jürgen: Faltungen. Brevitas, Allegorie und Exemplarität in mittelalterlichen Transformationen Ovids, in: Franz-Josef Holznagel / Jan Cölln (Hgg.): Die Kunst der brevitas. Kleine literarische Formen des deutschsprachigen Mittelalters, Berlin 2017 (Wolfram-Studien XXIV), S. 57-75.

Schmitz, Silvia: Die Poetik der Adaptation. Literarische inventio im Eneas Heinrichs von Veldeke, Tübingen 2007 (Hermaea. N. F. 113).

Schmitz, Silvia: Wenn eine Hindin nicht mehr «modern > ist. Heinrichs von Veldeke Eneas und der Verlust poetischer Komplexität «auf dritter Stufe`, in: Masse / Seidl (2016), S. 21-37.

Stackmann, Karl: Joachim Bumkes Ausgabe der Klage. Notizen zu einer bemerkenswerten Neuedition, in: ZfdPh 120 (2001), S. 381-393.

Strohschneider, Peter: Rezension zu: Joachim Bumke: Die vier Fassunngen der Nibelungenklage. Untersuchungen zur Überlieferungsgeschichte und Textkritik der höfischen Epik im 13. Jahrhundert, Berlin/ New York 1996, in: ZfdA 127 (1998), S. $102-117$.

Schultz, James: Bodies That Don't Matter. Heterosexuality before Heterosexuality in Gottfried's Tristan, in: Karma Lochrie / Peggy McCracken / James Schultz (Hgg.): Constructing Medieval Sexuality, Minneapolis 1997, S. 91-110.

Wortbrock, Franz Josef: Dilatatio materiae. Zur Poetik des Erec Hartmanns von Aue, in: Frühmittelalterliche Studien 19 (1985), S. 1-30.

Wortbrock, Franz Josef: Wiedererzählen und Übersetzen, in: Walter Haug (Hg.): Mittelalter und Frühe Neuzeit. Übergänge, Umbrüche und Neuansätze, Tübingen 1999 (Fortuna vitrea 16), S. 128-142. 



\section{Original und Kopie des Rappoltsteiner Parzifal Kürzungsverfahren in der Abschrift Roma, Biblioteca Casanatense, Ms. 1409}

von Michael Stolz (Bern) und Richard F. Fasching (Bern / Zürich)

I.

Der vorliegende Beitrag behandelt textliche Kürzungsverfahren anhand eines konkreten Fallbeispiels, das einen Bezug zwischen einer handschriftlichen Vorlage und der daraus erstellten (unmittelbaren) Abschrift aufweist. Es geht im Folgenden um das Verhältnis zwischen der als Rappoltsteiner Parzifal bekannten Handschrift Karlsruhe, Badische Landesbibliothek, Donaueschingen 97, und ihrer mutmaßlichen Abschrift in Ms. 1409 der Biblioteca Casanatense in Rom (ehemals Cod. Pal. germ. 317 aus dem Bestand der Bibliotheca Palatina ). ${ }^{1}$ Da der Karlsruher Codex immer wieder als «Original-

1 Die Teile I und III dieses Beitrags stammen vorwiegend von Michael Stolz, die Teile II und IV vorwiegend von Richard Fasching; Teil V wird von beiden Autoren verantwortet. Der Aufsatz basiert auf Forschungsresultaten des durch den Schweizerischen Nationalfonds geförderten und in Zusammenarbeit mit dem Berner Parzival-Projekt (http:// www.parzival.unibe.ch) durchgeführten Forschungsvorhabens «Original und Kopie des Rappoltsteiner Parzifal. Handschriftliche Überlieferung und Textgenese im 14. Jahrhundert. Im Rahmen des Vorhabens ist eine Digitaledition der beiden erwähnten Handschriften erstellt worden, die Abbildungen, Teiltranskriptionen und eine Einführung zu den beiden Überlieferungsträgern enthält; vgl. [http://www.parzival.unibe.ch/rapp/index. html\#/] sowie die gedruckte Version der Einführung, ergänzt durch eine Analyse der Abschreibevorgänge, in Fasching (2020). Die im vorliegenden Beitrag dargestellten Phänomene sind über die Digitaledition nachvollziehbar. Alle hier und im Folgenden zitierten Internetseiten wurden zuletzt am 29.2.2020 abgerufen. 
handschrift» bezeichnet worden ist, ${ }^{2}$ wird das Verhältnis beider Manuskripte terminologisch als jenes von «Original〉 und 〈Kopie〉 beschrieben. Die betreffenden Handschriften haben in der Erforschung zur Überlieferungsgeschichte von Wolframs Parzival Aufmerksamkeit erfahren, da sie diesen Text (beziehungsweise im Falle des Casanatensis Teile davon) zusammen mit Erweiterungen überliefern, bei denen es sich um die Übersetzungen altfranzösischer Conte du Graal-Fortsetzungen handelt. In der Parzival-Philologie werden beide Textzeugen unter den Siglen V (für den Karlsruher Codex) beziehungsweise $V^{\prime}$ (für die mutmaßliche Abschrift im Casanatense-Manuskript) geführt. ${ }^{3}$

Zuletzt hat sich Fabian Sietz im Rahmen seiner 2017 erschienenen Untersuchungen zu den Erzählstrategien im Rappoltsteiner Parzifal mit den Korrelationen beider Handschriften befasst. ${ }^{4} \mathrm{Er}$ ist dabei zu dem Schluss gelangt, dass sich im Bezug beider Textzeugen Verfahren der dilatatio materiae und der abbreviatio im Wechselverhältnis beobachten lassen: ${ }^{5} \mathrm{Im}$ Text der Karlsruher Handschrift erfährt Wolframs Parzival mittels der einbezogenen Conte du Graal-Fortsetzungen eine Ausweitung. In der mutmaßlichen Abschrift des Casanatense-Manuskripts lassen sich hingegen auffällige Kürzungsvorgänge beobachten: Der Textbestand der übersetzten Conte du Graal-Fortsetzungen wird hier, besonders gegen Ende der Handschrift, stark verdichtet. Von Wolframs Parzival liegen im Casanatensis zudem nur die beiden letzten, an die Conte du Graal-Fortsetzungen anschließenden Bücher 15 und 16 vor. Und es gibt Anzeichen dafür, dass in diesem Manuskript die in der Karlsruher Handschrift als erster Teil sehr wohl vorhandenen Bücher 1-14 von Wolframs Parzival gar nie abgeschrieben worden sind. Es dürfte sich also bei diesem Textausfall des Casanatensis nicht um einen Überlieferungsverlust handeln.

Vgl. beispielsweise Schorbach (1888), S. XI (im Vorwort der Erstedition des Rappoltsteiner Parzifal nach der Karlsruher Handschrift), und Bumke (1996), S. 23, Anm. 118.

3 Vgl. zu den Siglen der Parzival-Handschriften Klein (2011), S. 943-959.

4 Vgl. Sietz (2017), mit Ausführungen zum allgemeinen Forschungsstand auf S. 1423, zu den beiden Handschriften aus Karlsruhe und Rom auf S. 48-141.

5 Vgl. zusammenfassend ebd., S. 140. 
Die folgenden Ausführungen knüpfen an die Forschungsergebnisse von Fabian Sietz an, schlagen aber methodisch eine etwas andere Richtung ein: Während Sietz das Verhältnis der beiden Handschriften im Bezugsrahmen der Entstehung früher epischer Parallelfassungen beurteilt, ${ }^{6}$ wird in diesem Beitrag die Eigenart von in der Schriftlichkeit vorgenommenen Kopiervorgängen pointiert. Die Entstehungsbedingungen der beiden Textzeugen, die beide gegen Mitte des 14. Jahrhunderts angefertigt worden sind (der Codex Karlsruhe in den 1330er-Jahren, das Casanatense-Manuskript im zweiten Viertel des 14. Jahrhunderts), unterscheiden sich nämlich von denjenigen, wie sie etwa Joachim Bumke für die Ausprägung von autornahen Fassungen in der Zeit um und bald nach 1200 geltend gemacht hat. ${ }^{7}$ Die semi-oralen Produktions- und Rezeptionsbedingungen höfischer Epik, von denen Bumke bei seinem Fassungskonzept ausgeht, sind im 14. Jahrhundert keinesfalls mehr anzusetzen. Zumindest gilt das für die Karlsruher Handschrift, über deren komplexe Anfertigung in der Zusammenarbeit von Redaktoren, Schreibern, Übersetzern wir recht genau unterrichtet sind. Es gilt aber auch für das Casanatense-Manuskript, in dem sich gerade über den Bezug zur mutmaßlichen Vorlage Schreibprozesse erkennen lassen.

Das Verhältnis von 〈Original〉 und 〈Kopie〉 soll in diesem Bezugsrahmen als jenes einer 〈Transkription` gefasst werden. Dies geschieht unter Berücksichtigung eines jüngeren medientheoretischen Ansatzes, gemäß dem der Bezug von Vorlage und Kopie konsequent in einer skripturalen Begrifflichkeit entwickelt worden ist. So spricht Ludwig Jäger davon, dass eine Vorlage, die er 〈Prätext 〉 beziehungsweise 〈Präskript〉 nennt, erst über den Prozess der 〈Transkription〉 den Status eines 〈Originals〉 erhalten kann. ${ }^{8}$ Eigenschaften der Vorlage, die in eine Abschrift überführt werden, bezeichnet Jäger als

6 Vgl. ebd.

7 Vgl. Bumke (1996). Von Fassung spricht Bumke u. a., wenn zwischen zwei Versionen von Texten «kein Abhängigkeitsverhältnis im Sinne der klassischen Textkritik vorliegt, womit zugleich ausgeschlossen wird, daß die eine Version als Bearbeitung der anderen definiert werden kann» (ebd., S. 32).

8 Vgl. Jäger (2002), S. 30 - 35; Jäger verwendet anstelle von «Original` den Begriff der 〈Quelle(n)〉. Der Bezug auf den Begriff des 〈Originals` ist in seinem Schülerkreis im Kontext des Nominalkompositums 〈Originalkopie〉 erfolgt; vgl. Fehrmann u. a. (2004), Einleitung, S. 7-17, hier: S. 9-11; Weingart (2012), S. 206 f. 
〈Skript〉. Oft profiliert sich die Vorlage erst über diesen «Skript〉-Status. Die Wahrnehmung von Vorlage und Abschrift unterliegt dabei einem dynamischen Wechselverhältnis: Das 〈Präskript〉 wird erst in seiner Transformation in ein 〈Skript` als solches (als Vorlage) sichtbar. Überlegungen dieser Art waren Grundlage einer interdisziplinären Forschungsplattform zur Reproduzierbarkeit in den Künsten am Walter-Benjamin-Kolleg der Universität Bern. ${ }^{9}$ In diesem Umfeld ist auch das Verhältnis zwischen der Karlsruher Handschrift und ihrer Abschrift im Casanatense-Manuskript untersucht worden. Mit Blick auf das Verhältnis von «Original` und 〈Kopie` werden im Folgenden spezifische Kürzungsverfahren präsentiert, die der Codex Casanatensis gegenüber seiner Vorlage erkennen lässt.

II.

Codex Donaueschingen 97 der Badischen Landesbibliothek Karlsruhe (Hs. V) ist im Auftrag eines Herrn Ulrich von Rappoltstein in den Jahren 1331 bis 1336 in oder im Raum Straßburg entstanden. ${ }^{10}$ Angefertigt wurde die Handschrift von einer Reihe teilweise namentlich genannter Konzepteure, Kompilatoren, Dichter und Übersetzer, und es handelt sich bei diesem Codex tatsächlich um dasjenige Exemplar - wenn auch in Reinschrift -, das vom Auftraggeber in Bestellung gegeben worden ist. Die Handschrift enthält neben dem Parzival Wolframs von Eschenbach eine Kompilation aus Conte $d u$ Graal (Perceval)-Fortsetzungen in deutscher Übertragung sowie sieben Minneliedstrophen. Nach dem erwähnten Auftraggeber wird dieses Textkonvolut in der Forschung Rappoltsteiner Parzifal genannt; im Hinblick auf Notate in der Handschrift trägt der zweite Teil die Bezeichnung Nuwer Parzifal. ${ }^{11}$

9 Vgl. Rippl / Stolz (2019).

10 Vgl. zur Hs. Fasching (2020), S. 150-201.

11 Dies gemäß Einträgen zur Blattberechnung, in denen Der alte parzefal (d. h. Wolframs Parzival) vom nvwen abgegrenzt wird: So fint dez nvwen parzefales . Der | hie noch gefchriben ftot · vij · bletter $\mid v n($ de $)$ 3wei hvndert dirre bletter · (Karlsruhe, Badische Landesbibliothek, Donaueschingen 97, Bl. 115 ${ }^{\mathrm{va}}$ ). Der Abdruck erfolgt hier und in Anm. 15 diplomatisch, Abkürzungen werden in Klammern aufgelöst. Zitiert wird der Rappoltstei- 
Nur dieser zweite Teil findet sich, ergänzt durch die letzten beiden Bücher von Wolframs Parzival, in Ms. 1409 der Biblioteca Casanatense (Hs. V'). ${ }^{12}$ Diverse Anzeichen deuten darauf hin, dass der Codex Casanatensis mit hoher Wahrscheinlichkeit direkt von der heute in Karlsruhe aufbewahrten Handschrift abgeschrieben worden ist. ${ }^{13} \mathrm{Zu}$ nennen sind in diesem Zusammenhang auch kleinere paläographische Besonderheiten wie beispielsweise die Übernahme von unüblichen Spatien zwischen Buchstaben oder Verlesungen, die genau die Graphien von Hs. V als Vorlage voraussetzen. So wird ein großes Spatium zwischen den ersten beiden Buchstaben beim Verb betwungen auf Bl. $115^{\mathrm{vb}}$ von Hs. V falsch interpretiert und in Hs. $\mathrm{V}^{\prime}\left(\mathrm{Bl} . \mathrm{r}^{\mathrm{ra}}\right)$ das $b$ zum vorhergehenden Wort har gezählt, was zum Adjektiv harb (bitter) führt. Zudem wird das rubrizierte $M$ von Mere auf $\mathrm{Bl} .305^{\mathrm{rb}}$ von Hs. V in Hs. $\mathrm{V}^{\prime}\left(\mathrm{Bl} .173^{\text {ra }}\right)$ verlesen zu einem $H$, und im Epilog beginnt der Vers 116 in Hs. $\mathrm{V}^{\prime}\left(\mathrm{Bl} .180^{\mathrm{rb}}\right.$, 14. Zeile) wie auch in Hs. V (Bl. $318^{\mathrm{rb}}$, erste Zeile) mit einer Minuskel, obschon in der Umgebung sonst alle Versalien mit Majuskeln geschrieben werden.

Die Abschrift in Hs. V' ist Vers für Vers erfolgt. ${ }^{14}$ Dabei sind - ohne Zwischenstufen - während des Kopierprozesses zum Teil umfangreiche Kürzungen vorgenommen worden, was sich an einigen Stellen direkt nachweisen lässt. So entscheidet sich der Schreiber auf Bl. $144^{\mathrm{r}}$ beispielsweise,

ner Parzifal mit den Kürzeln NP (Nuwer Parzifal) bzw. Ep (Epilog des Nuwen Parzifal) und entsprechender Versnummer nach der in Anm. 1 erwähnten Digitaledition.

12 Vgl. zur Hs. Fasching (2020), S. 202-226; die Datierung folgt Schneider (2009), Textband, S. 141.

13 Vgl. die bereits bei Stolz (2010), S. 285-287, und Stolz (2012), S. 341-343, angeführten Indizien, sowie Fasching (2020), S. 202f. Bei der Abschrift haben die Kopisten von Hs. V' den niederalemannischen Schreibdialekt der Vorlage ihren eigenen schreibsprachlichen Gewohnheiten angeglichen und dadurch die Graphie verändert; dazu Fasching (2020), S. 233-237. Solche Schreibvarianten sind der Tatsache geschuldet, dass noch «keine graphematischen Normen existierten, die die Erwartung steuerten» (Schulze [2001], S. 68).

14 Dies zeigen Fehler in Hs. V', die nur beim direkten Textvergleich entstanden sein können, wie beispielsweise die durch einen Augensprung verursachte, nachträglich korrigierte Dittographie (Wiederholung der drei Verse NP 10.855-10.857 nach Vers NP 10.861) auf $\mathrm{Bl} .57^{\mathrm{vb}}$ (die entsprechende Stelle fehlt in Hs. V infolge Blattverlusts). Vgl. auch Fasching (2020), S. 237 f. 
einen ganzen Abschnitt von 32 Verspaaren (NP 29.526-29.589) auszulassen, nachdem er das erste Verspaar (NP 29.526-29.527) am Wechsel der Spalten $\mathrm{a} / \mathrm{b}$ bereits geschrieben hat. Die beiden überschüssigen Verse radiert er wieder aus und fährt mit dem neuen Absatz fort, der mit einer Lombarde beginnt. ${ }^{15}$

Im Gegensatz zur Vorlage V blieb die Herkunft der Kopie V' lange Zeit im Dunkeln. 2007 hat Matthias Miller als Erster bemerkt, dass der Codex spätestens ab 1581 bis 1623 zum Bestand der Heidelberger Palatina zählte, von wo er im Dreißigjährigen Krieg in die Biblioteca Apostolica Vaticana überführt wurde. ${ }^{16}$ Paläographische und kodikologische Untersuchungen haben nun ergeben, dass sowohl die erste Schreiberhand wie auch die Malerhand der Initialen auf dem ersten Blatt einem nordfränkischen Skriptorium zugewiesen werden können, ${ }^{17}$ das Karin Schneider aufgrund der dort kopierten Werke (Epenwerkstatt) genannt hat. ${ }^{18}$ Als Erzeugnisse dieser nordbairisch-fränkischen Schreibstube sind insgesamt sieben teilweise nur bruchstückhaft erhaltene Textzeugen aus dem zweiten Viertel des 14. Jahrhunderts bekannt. Sie überliefern Wolframs von Eschenbach Dichtungen mit deren Vorgeschichten und Fortsetzungen beziehungsweise Ausweitungen sowie - im Falle der Bruchstücke - weitere epische Texte. ${ }^{19}$ Es liegen folgende Handschriften bzw. Fragmente vor:

15 Die beiden Verse der letzten Zeile der ersten Spalte und der ersten Zeile der zweiten Spalte sind, obwohl sie - vermutlich weil eine Lombarde folgt - nicht mehr beschrieben wurden, nur noch unter UV-Licht lesbar (der Abdruck erfolgt diplomatisch, nicht entzifferbare Buchstaben werden durch : wiedergegeben): A: dem morgen fie :it enpitten |Balde ire ftraf3e fie riten. Vgl. auch Hs. V', Bl. 170 ${ }^{\text {va }}$, 2. Zeile von unten (NP 36.203), wo der Schreiber das Possessivpronomen siner aus der Vorlage übernimmt, sich dann jedoch für eine Kürzung entscheidet, das bereits geschriebe Wort streicht und mit einer eigenen Formulieren fortfährt; dazu auch unten, S. 360.

16 Vgl. Miller (2007a) u. Miller (2007b).

17 Vgl. Fasching (2018), S. 498-502.

18 Vgl. Schneider (2009), Textband, S. 121.

19 Vgl. Fasching (2018), S. 498-504. 
- Hs. Heidelberg, Universitätsbibliothek, Cod. Pal. germ. 364, mit Wolframs von Eschenbach Parzival $\left(\mathrm{Bl} .1^{\text {ra }}-111^{\text {ra }}\right)$ und dem anonym überlieferten Lohengrin (Bl. $\left.113^{\text {ra }}-151^{\mathrm{rb}}\right),{ }^{20}$

- Hs. Roma, Biblioteca Casanatense, Ms. 1409, mit dem Nuwen Parzifal,

- Hs. Heidelberg, Universitätsbibliothek, Cod. Pal. germ. 383, mit Albrechts Jüngerem Titurel, ${ }^{21}$

- Hs. Heidelberg, Universitätsbibliothek, Cod. Pal. germ. 404 (sogenannte Willehalm-Trilogie), mit Ulrichs von dem Türlin Arabel (Bl. $\left.1^{\mathrm{ra}}-45^{\mathrm{rb}}\right)$, Wolframs von Eschenbach Willehalm (Bl. $\left.45^{\mathrm{va}}-107^{\mathrm{vb}}\right)$ und Ulrichs von Türheim Rennewart (Bl. $\left.108^{\text {ra }}-271^{\text {ra }}\right),{ }^{22}$

- Fragment Staatsbibliothek zu Berlin - Preußischer Kulturbesitz, Ms. germ. fol. 923, Nr. 25, mit Rudolfs von Ems Willehalm von Orlens, ${ }^{23}$

- Fragment Köln, Universitätsbibliothek und Stadtbibliothek, Cod. 5 P 62, mit Heinrichs von dem Türlin Diu Crône, ${ }^{24}$

- Fragment Bruxelles, Koninklijke Bibliotheek van België / Bibliothèque royale de Belgique, Ms. IV 950,11, mit Konrads von Würzburg Trojanerkrieg. ${ }^{25}$

Die genannten Codices entsprechen sich in der Buchgröße und Texteinrichtung weitgehend. Nur Hs. $V^{\prime}$ weicht mit einer kleineren Blattgröße ab und übernimmt mit der Seiteneinrichtung auch die Buchblockgröße ihrer Vorlage $\mathrm{V}^{26}$

20 Vgl. zur Hs. [http://handschriftencensus.de/2678] (Digitalfaksimile und weiterführende Literatur).

21 Vgl. zur Hs. [http://handschriftencensus.de/2682] (Digitalfaksimile und weiterführende Literatur).

22 Vgl. zur Hs. [http://handschriftencensus.de/2684] (Digitalfaksimile und weiterführende Literatur).

23 Vgl. zum Fragment [http://handschriftencensus.de/2143] (Digitalfaksimile und weiterführende Literatur).

24 Vgl. zum Fragment [http://handschriftencensus.de/1861] (Abbildung Vorderseite und weiterführende Literatur).

25 Vgl. zum Fragment [http://handschriftencensus.de/2680] (weiterführende Literatur).

26 Vgl. dazu die Übersicht bei Fasching (2018), S. 503. 
Aufgrund paläographischer Vergleiche können insgesamt sieben in der 〈Epenwerkstatt` tätige Schreiberhände A bis G unterschieden werden. Sie sind in der folgenden Übersicht ausgewiesen. Wie sich deutlich zeigt, liegt der Hauptanteil bei Schreiber A, dem sogenannten «Epenschreiber`; von den anderen Schreibern stammen oftmals lediglich einzelne Passagen (nach den Blattangaben folgen bei kurzen Abschnitten die Zeilenangaben) oder die roten Überschriften (bezeichnet durch Ü):27

\begin{tabular}{|c|c|c|c|c|c|c|c|c|}
\hline & & $2 \mathbf{A}$ & $2 \mathrm{~B}$ & $\triangle \mathrm{C}$ & $\therefore \mathrm{D}$ & $\& \mathbf{E}$ & $\& F$ & $\mathscr{G}$ \\
\hline $\begin{array}{l}\text { Parzival } \\
\text { Lohengrin }\end{array}$ & $\begin{array}{l}\text { Cod. Pal. } \\
\text { germ. } 364\end{array}$ & $\begin{array}{l}\text { beide } \\
\text { Teile / Ü }\end{array}$ & & & & & & \\
\hline $\begin{array}{l}\text { Nuwer } \\
\text { Parzifal }\end{array}$ & Hs. $V^{\prime}$ & $\begin{array}{l}\text { bis } 48^{\text {vb }} / \\
\ddot{U} \\
\left(3^{\text {ra }}, 4^{\text {ra }},\right. \\
\left.6^{\text {ra }}, 8^{\text {vb }}\right)\end{array}$ & & & & & & $\begin{array}{l}\mathrm{ab} \\
49^{\text {ra }} / \ddot{U} \\
\left(\mathrm{ab} 11^{\text {va }}\right)\end{array}$ \\
\hline $\begin{array}{l}\text { Jüngerer } \\
\text { Titurel }\end{array}$ & $\begin{array}{l}\text { Cod. Pal. } \\
\text { germ. } 383\end{array}$ & $\begin{array}{l}\text { bis } 183^{\text {va }} / \\
\ddot{U} \\
\text { (Lage 1) }\end{array}$ & $\begin{array}{l}\ddot{U} \\
(\text { Lagen } \\
12-20)\end{array}$ & & & & & \\
\hline $\begin{array}{l}\text { Willehalm- } \\
\text { Trilogie }\end{array}$ & $\begin{array}{l}\text { Cod. Pal. } \\
\text { germ. } 404\end{array}$ & $\begin{array}{l}87^{\text {rb }}, \\
51-56 \\
\text { und ab } \\
186^{\text {ra }}, \\
13 \text { (m. } \\
\text { Unter- } \\
\text { brech- } \\
\text { ung) / Ü }\end{array}$ & $\begin{array}{l}\text { bis } 186^{\text {ra }} \text {, } \\
12(\mathrm{~m} . \\
\text { Unter- } \\
\text { brech- } \\
\text { ungen }) / \\
251^{\text {rb }}, \\
21-27 \text { / } \\
\ddot{U}\end{array}$ & $\begin{array}{l}\ddot{U} \\
\left(115^{\mathrm{va}} ;\right. \\
115^{\mathrm{vb}} ; \\
128^{\mathrm{ra}} ; \\
128^{\mathrm{rb}} ; \\
\left.136^{\mathrm{ra}}\right)\end{array}$ & $\begin{array}{l}88^{\text {ra }} \\
11-54\end{array}$ & $\begin{array}{l}8^{\mathrm{vb}}, \\
36-48 / \\
65^{\mathrm{rb}}, \\
1-10 / \\
180^{\mathrm{va}}, \\
15-30\end{array}$ & & \\
\hline $\begin{array}{l}\text { Willehalm } \\
\text { von Orlens }\end{array}$ & $\begin{array}{l}\text { Fragment } \\
\text { Berlin }\end{array}$ & $\begin{array}{l}\text { Erhal- } \\
\text { tenes }\end{array}$ & & & & & & \\
\hline Diu Crône & $\begin{array}{l}\text { Fragment } \\
\text { Köln }\end{array}$ & $\begin{array}{l}\text { Erhal- } \\
\text { tenes / Ü }\end{array}$ & & & & & & \\
\hline $\begin{array}{l}\text { Trojaner- } \\
\text { krieg }\end{array}$ & $\begin{array}{l}\text { Fragment } \\
\text { Brüssel }\end{array}$ & & & & & & $\begin{array}{l}\text { Erhal- } \\
\text { tenes / Ü }\end{array}$ & \\
\hline
\end{tabular}

27 Vgl. zur Unterscheidung und Charakterisierung der Schreiberhände Schnelbögl (1930), S. 5-12 (mit teilweise leicht abweichenden Zeilenangaben) u. 55-57 (zu den Überschriften); Fasching (2018), S. 499 f. 
Im Heidelberger Cod. Pal. germ. 383 übernimmt Schreiber B lediglich die Überschriften der Lagen 12 bis 20 und in Hs. V' wechseln die Schreiberhände nach der sechsten Lage; Schreiberhand A kann dort ab der siebten Lage nicht mehr nachgewiesen werden. Die häufigen Händewechsel im Heidelberger Cod. Pal. germ. 404 belegen jedoch, dass im Skriptorium auch mehrere Schreiber gleichzeitig tätig waren, um sich mitten im Schreibakt abzuwechseln und teilweise nur kurze Passagen zu übernehmen. In dieser Handschrift mit der Willehalm-Trilogie waren insgesamt fünf Schreiber tätig: Schreiber B kopiert zunächst bis Zeile 12 von $\mathrm{Bl} .186^{\text {ra }}$, wobei er dreimal für kurze Passagen von Schreiber E (Bll. $8^{\text {vb }}$, Z. $36-48 ; 65^{\text {rb }}$, Z. 1-10; $180^{\text {va }}$, Z. $15-29$ ) und auf Bl. $87^{\text {rb }}$ für die letzten sechs Verse der Spalte von Schreiber A abgelöst wird. Schreiber B fährt ab Bl. $87^{\text {va }}$ fort und wird erneut zweimal von anderen Schreibern abgelöst: Auf Bl. $88^{\text {ra }}$ setzt mitten in der von Schreiber B begonnenen 11. Zeile ein in der «Epenwerkstatt〉 sonst nicht nachweisbarer Schreiber D ein und kopiert den Abschnitt bis zur Überschrift (später von Schreiber A eingefügt) am Spaltenende zu Ende (weitere 43 Verse). Zudem stammen auf Bl. 180 va die Zeilen 15-30 von Schreiber E. Ab Zeile 13 von Bl. $186^{\text {ra }}$ stellt schließlich Schreiber A die Handschrift bis Bl. $217^{\text {ra }}$ fertig. Unterbrochen wird er lediglich auf Bl. 251 ${ }^{\mathrm{rb}}$ für die Zeilen 21-27 von Schreiber B, der die Beschriftung des Codex zunächst begonnen hatte. Auch die roten Überschriften im Cod. Pal. germ. 404 stammen von den drei Schreibern A, B und C, die sich in unregelmäßigen Abständen abtauschen.

Abgesehen von Hs. V ist keine der von den Schreibern der «Epenwerkstatt> benutzten Vorlagen bekannt. Bevor die Kürzungsverfahren in Hs. V' genauer darzustellen sind, soll versucht werden, den Usus der Schreibstube bezüglich der Kürzungen in den genannten Abschriften zu beschreiben. Im Vergleich mit verwandten Textzeugen lassen sich nämlich Vermutungen anstellen über den Textbestand der beiden vollständig erhaltenen Dichtungen Parzival (Cod. Pal. germ. 364) und Jüngerer Titurel (Cod. Pal. germ. 383). Keine nennenswerten Kürzungen lassen sich hingegen beim Lohengrin (Cod. Pal. germ. 364) ${ }^{28}$ sowie innerhalb der Willehalm-Trilogie (Cod. Pal.

28 Der von Hauptschreiber A kopierte Lohengrin auf Bl. $113^{\text {ra }}-151^{\text {rb }}$ (Sigle B) geht zusammen mit einer um 1470 in der Werkstatt Ludwigs Henfflin entstandenen Handschrift (Heidelberg, Universitätsbibliothek, Cod. Pal. germ. 345 [Sigle A]) auf eine gemeinsame, nicht belegte Vorstufe zurück; vgl. Rückert (1858), S. 204; Panzer (1894), S. 11, und Cra- 
germ. 404 $)^{29}$ finden. Für einen Vergleich ungeeignet sind außerdem die vorhandenen Bruchstücke, die mindestens Rudolfs von Ems Willehalm von Orlens (Berliner Fragment), ${ }^{30}$ Heinrichs von dem Türlin Diu Crône (Kölner Fragment) ${ }^{31}$ und Konrads von Würzburg Trojanerkrieg (Brüsseler Fragment $)^{32}$ enthalten haben. Für sie können keine verwandten Textzeugen ausgemacht werden.

Der Textbestand der Handschriften mit Wolframs Parzival (Cod. Pal. germ. 364) und dem Jüngeren Titurel (Cod. Pal. germ. 383) lässt sich nunmehr wie folgt einschätzen:

mer (1971), S. 17 f. Im Vergleich mit dem um 1470 geschriebenen Codex überliefert die von Hauptschreiber A kopierte Handschrift eine Strophe (Strophe 40) mehr. Mit einem Textbestand von 767 Strophen (=7.670 Verse) liegt sie der Edition von Thomas Cramer zugrunde; vgl. Cramer (1971), S. 15. Kürzungen lassen sich hier nicht beobachten.

29 Der auf 271 Blättern kopierten Willehalm-Trilogie zugrunde liegt (wie auch der Vorstufe der Vollhandschrift Staatsbibliothek zu Berlin - Preußischer Kulturbesitz, Ms. germ. fol. 1063, und eines Codex discissus) eine nicht belegte Fassung; vgl. Fasching (2018), S. 506, Anm. 59. Im Vergleich mit dem vollständigen Versbestand der Trilogie von rund 60.500 Versen $(14.000+10.000+36.500$ Verse) (vgl. Fasching [2018], S. 505) bringt die Handschrift aus der «Epenwerkstatt` lediglich um die 1.600 Verse weniger (berechnete Versbestände im Cod. Pal. germ. 404: Bl. $1^{\text {ra }}-271^{\text {ra }}$, zweispaltig, 56 Zeilen, Verse abgesetzt $=60.704$ Verse). Dies entspricht einer Kürzung von weniger als drei Prozent. Im Vergleich mit dem genannten Ms. germ. fol. 1063, der Abschrift einer Schwesterhandschrift mit einem berechneten Versbestand von 58.890 Versen (Bl. $1^{\mathrm{ra}}-151^{\mathrm{vc}}$, dreispaltig, 65 Zeilen, Verse abgesetzt $=58.890$ Verse), weist die Willehalm-Trilogie aus der $\prec$ Epenwerkstatt> sogar einen um rund 1.800 Versen leicht größeren Textbestand auf.

30 Das Fragment mit den Versen 14.681-14.904 kann keiner der bekannten Überlieferungszweige des Werkes von Rudolf von Ems zugeordnet werden; vgl. Zeidler (1894), S. 54 f. u. 56 (Stemma) (Sigle Cö).

31 Das Fragment umfasst die Verse 19.304-19.347, 19.359-19.403, 19.415-19.459 u. 19.471-19.516; vgl. den Paralleldruck in der Ausgabe Heinrich von dem Türlin (Ed. Ebenbauer / Kragl, 2005), S. 197-203.

32 Auch dieses Fragment, das die Verse 243-275, 299-330, 354-381, 388-390, 414$444,1.309-1.344,1.363-1.397,1.417-1.451$ u. 1.473-1.508 enthält, kann keinem der bekannten Textzeugen zugeordnet werden; vgl. Thoelen / Häberlein (2015), S. XV u. XVIII. 
Wolframs von Eschenbach Parzival: ${ }^{33}$ Der von Hauptschreiber A der 〈Epenwerkstatt` angefertigte Heidelberger Cod. Pal. germ. 364 mit Wolframs von Eschenbach Parzival (Sigle Z) weist gemessen am Versbestand der Fassung ${ }^{\star} \mathrm{G}$ mit lediglich 281 Fehlversen einen «fast lückenlos[en]» Text auf. ${ }^{34}$ Bei den grösseren Lücken sind viermal (L. 44,7-51,12) beziehungsweise einmal (L. 806,1-807,24) genau 54 Verse ausgespart; diese Regelmäßigkeit deutet darauf hin, dass bei der Kopie einer Vorlage, deren Seiten zweispaltig eingerichtet waren, versehentlich ein Blatt (mit 4 mal 54 Versen) beziehungsweise eine Spalte (mit 54 Versen) übersprungen worden sind. Laut Gesa Bonath gehen diese Auslassungen von insgesamt 270 Versen sowie alle anderen Lücken - mit Ausnahme von zwei Auslassungen - auf den Schreiber von Hs. Z zurück. ${ }^{35}$ In der Handschrift selbst finden sich freilich keine Hinweise darauf, dass erst Schreiber A die Kürzungen vorgenommen hat; möglicherweise fehlten die Verse bereits in der von ihm benutzten Vorlage. Denselben Versbestand wie Hs. Z lassen zwei ebenfalls dem 14. Jahrhundert zugehörige, fragmentarisch erhaltene Schwesterhandschriften erkennen. ${ }^{36}$ Abgesehen von der Überschrift vor L. 101,21, die nur Hs. Z

Der Versbestand ist auf der Datengrundlage des Berner Parzival-Projekts errechnet worden. Die Verszählung mit Kürzel $L$. und entsprechender Dreißiger- bzw. Zeilennummer folgt Lachmanns Parzival-Ausgabe (Ed. Lachmann / Knecht / Schirok, 2003).

34 Bonath (1971), S. 176. Es bestehen folgende Lücken L. 44,7-51,12 (Bl. $6^{\mathrm{vb}}$ ); L. 95,9f. $\left(B 1.12^{\text {va }}\right)$; L. 103,22 (Bl. 13 $\left.{ }^{\text {vb }}\right)$; L. 136,6 (Bl. 18 $\left.{ }^{\text {ra }}\right)$; L. 289,24f. (Bl. $\left.38^{\text {vb }}\right)$; L. 401,16 (Bl. $\left.54^{\text {ra }}\right)$; L. 494,27 f. (Bl. $66^{\text {va }}$ ); L. 522,23f. (zwischen Bl. $70^{\text {rb }}$ und 70 ${ }^{\text {va }}$ ); L. 806,1-807,24 (Bl. 180 $0^{\text {rb }}$ ); dazu Bonath, ebd. (ohne den in Hs. Z fehlenden Vers 401,16). Nicht von Schreiber A stammen laut Bonath die Auslassungen L. 95,9f. und L. 494,25f.

35 Vgl. ebd. Den Epenschreiber A charakterisiert Bonath, ebd., S. 175, gestützt auf die Beobachtungen von Röll (1964), S. 143 (zu Cod. Pal. germ. 383 mit Albrechts Jüngerem Titurel), wie folgt: «Der Schreiber [...] war offensichtlich ein sorgfältiger Kopist, der sich bemühte, den Text möglichst getreu wiederzugeben, ohne sich über den Sinn des Geschriebenen viel Gedanken zu machen.»

36 In die erste Hälfte des 14. Jahrhunderts datiert wird das Parzival-Fragment 58 (Freiburg i. Br., Universitätsbibliothek, Fragm.-Hs. Nr. 530 [Verse L. 1,3-2,8; L. 3,4-13; L. 4,12-21 und L. 4,27-6,2]). Der zweiten Hälfte bzw. dem dritten Viertel des 14. Jahrhunderts zugerechnet wird das Parzival-Fragment 48 (Nürnberg, Germanisches Nationalmuseum, Hs 17439 [Verse L. 639,5-641,4; L. 651,5-653,4 und L. 657,5-659,4]; München, Bayerische Staatsbibliothek, Cgm 5249/3e [Verse L. 90,7-15; L. 91,7-15; L. 100,7-102,6; 
enthält, sind im Codex der 〈Epenwerkstatt〉 alle 710 Verse der beiden Bruchstücke überliefert. ${ }^{37}$ Dieser Befund lässt darauf schließen, dass Hs. Z mit ihren Schwesterhandschriften einen gegenüber der nicht erhaltenen gemeinsamen Vorstufe stabilen Textbestand bewahrt hat.

Albrechts Jüngerer Titurel: Die Heidelberger Universitätsbibliothek besitzt mit dem Cod. Pal. germ. 383 eine weitere Handschrift des Hauptschreibers A. Die Fassung von Albrechts Jüngerem Titurel aus der «Epenwerkstatt` mit der Sigle B geht zusammen mit drei weiteren Handschriften ${ }^{38}$ auf eine gemeinsame Vorstufe zurück. ${ }^{39} \mathrm{Ab} \mathrm{Bl} .175^{\mathrm{va}}$, der ersten Versoseite der letzten neun beschriebenen Blätter, weist der Cod. Pal. germ. 383 bis Bl. $181^{\text {rb }}$ größere Lücken im Textbestand (42 Strophen) auf: Von mehreren Strophen hat Schreiber A lediglich Teilverse kopiert oder bereits Geschriebenes wieder radiert und für die fehlenden Verse Zeilen leer gelassen. ${ }^{40}$ Dass es sich hier

L. 745,13-747,12; L. 755,13-757,12; L. 797,5-799,4 und L. 803,9-805,8] und Staatsbibliothek zu Berlin - Preußischer Kulturbesitz, Ms. germ. fol. 923,41 [Verse L. 759,13761,12 und L. 775,1-776,30]). Vgl. zu beiden Bruchstücken [http://www.handschriften census.de/1727] und [http://www.handschriftencensus.de/1725] sowie Bonath / Lomnitzer (1989), S. 134 f., 142, und Rolle (2001), S. 145-149.

37 Die Versfolge ist lediglich bei zwei Verspaaren pro Fragment vertauscht: Fragment 58 bringt L. 1,24 vor L. 1,23 und Fragment 48 L. 658,16 vor L. 658,15.

38 Es sind dies die Sammelhandschrift Wien, Österreichische Nationalbibliothek, Cod. 2675 (1. V. 14. Jahrhundert, ostfrk.) (vgl. zur Hs. mit der Sigle A [http://hand schriftencensus.de/1270]), sowie Vorstufen der Handschriften Staatsbibliothek zu Berlin Preußischer Kulturbesitz, Ms. germ. fol. 470 (A. 15. Jahrhundert, südbair.), und London, British Library, MS Add. 30984 (15. Jahrhundert, md.). Vgl. zu den beiden letztgenannten Handschriften mit den Siglen D und E [http://handschriftencensus.de/4389] und [http:// handschriftencensus.de/3612].

39 Vgl. Zarncke (1876), S. 405 (mit Stemma). Eine detaillierte Untersuchung des Strophenbestands der Berliner und Londoner Handschrift bietet für den Bereich der Strophen 1-1225 Röll (1964), S. 143-148.

40 Teilweise oder ganz fehlen nach der Textausgabe Albrechts Jüngerer Titurel (Ed. Nyholm, 1992), S. 397-409, die Strophen 5978-5981; 5984-5992; 5994; 6001-6003; 6007-6010; 6012-6015; 6018; 6022-6025. Der Ausgabe des Jüngeren Titurel von Karl August Hahn aus dem Jahr 1842 liegt der Cod. Pal. germ. 383 zugrunde. Die fehlenden Stellen (hier ab Strophe 5899) wurden mit Lesarten des Cod. 2675 der Österreichischen 
um ursprünglich nicht geplante, unabsichtliche Kürzungen handelt, zeigt der Umstand, dass der Schreiber an einer Stelle mitten im letzten Wort der Zeile abbricht und an mehreren Stellen Raum für die fehlenden Verse frei gelassen worden ist. Dies lässt sich nur damit schlüssig erklären, dass die Vorlage korrupt war und der Schreiber die Möglichkeit für eine spätere Ergänzung der unverständlichen beziehungsweise verlorenen Verse nach einer anderen Vorlage schuf. Mit dem Verlust des Textes in der Vorlage sind die Gründe für den Ausfall der Verse in der Handschrift mit Albrechts Jüngerem Titurel folglich materieller Art.

Für die beiden untersuchten Handschriften aus der 〈Epenwerkstatt〉 lässt sich also festhalten, dass gegenüber deren Vorlagen keine auffälligen Kürzungstendenzen erkennbar sind. Bei korrupter Vorlage berücksichtigt Schreiber A den Textbestand seiner Vorlage sogar in der Einrichtung der Handschriftenseite und belässt Raum für die nicht kopierten Verse und Strophen. Der materialbedingte Ausfall von Versen ist somit nicht als absichtliche Kürzung im Sinne einer Textgestaltung (vgl. dazu unten, S. 365) zu verstehen und dürfte bei der Rezeption auch nicht als solche empfunden worden sein.

III.

Anders als die bereits behandelten vollständig erhaltenen Handschriften der 〈Epenwerkstatt` weist die Kopie des Nuwen Parzifal gegenüber dem Original einen deutlich geringeren Versumfang auf. Von den 37.000 Versen in Hs. V fehlen in Hs. V' rund 5.300 Verse, was einer Kürzung des Textbestandes von rund 14 Prozent gleichkommt. Die Tabelle in der 2017 erschienen Untersuchung von Fabian Sietz zu den Erzählstrategien im Rappoltsteiner Parzifal zeigt, dass die Kürzungen gegen Ende der Handschrift deutlich zunehmen. ${ }^{41}$

Nationalbibliothek in Wien ergänzt; vgl. Der jüngere Titurel (Ed. Hahn [1842]), dazu auch Wolf (1955), S. LIVf.

41 Vgl. dazu die graphische Darstellung bei Sietz (2017), S. 133, Abb. 13. Wir danken Fabian Sietz, der uns die Daten, welche der Darstellung zugrunde liegen, zur Verfügung gestellt hat. Auf ihnen basiert die erwähnte Schätzung von rund 5.300 Fehlversen in Hs. $\mathrm{V}^{\prime}$. 
Keine Änderungen des Textbestandes gegenüber der Vorlage V finden sich allerdings im ersten Teil von Hs. V', dessen erste Lagen von Hauptschreiber A der «Epenwerkstatt〉 stammen. Erst der ab Bl. 49 einsetzende Schreiber G beginnt ab etwa Bl. 160 seine Vorlage stetig zu kürzen. Auch dieser Befund bestätigt, dass die Kürzung der Vorlage kein Merkmal der 〈Epenwerkstatt` ist. Vielmehr beschränken sich die Kürzungstendenzen mit Schreiber G auf einen einzigen Kopisten, der im Skriptorium sonst nicht nachgewiesen werden kann.

Nikolaus Henkel hat mit Blick auf die höfische Epik des 13. und 14. Jahrhunderts vier Grundtypen redaktioneller Kürzungen ermittelt: kleinere Reduktionen um ein bis drei Reimpaare - die Kürzung größerer Handlungsabschnitte (10-400 Verse) - die Verknappung beziehungsweise Streichung von Passagen, die nicht Teil des Handlungsgangs sind - Kürzungen innerhalb der Handlung selbst. ${ }^{42}$ Die Typen sind am Erzählablauf orientiert, wobei der erste diesen «nicht eigentlich verändert〉 (vgl. unten, S. 365 f.); die verbleibenden drei Typen beziehen sich auf die Handlung, indem sie ganze Abschnitte, Teile außerhalb des Handlungsgangs oder aber innerhalb der Handlung eliminieren. Allerdings hat Henkel bei seiner Typologie einen «produktiv mitund weitergestaltende[n] Redaktor» im Blick und schließt zumindest den «einfachen Vorgang des Kopierens einer umfangreicheren Vorlage» gerade aus. ${ }^{43}$ Doch lassen sich verwandte Techniken auch im Verfahren des Schreibers $\mathrm{G}$ ausmachen. Wie Untersuchungen ergeben haben, kommt es dabei zu ersatzlosen Tilgungen, zur Zusammenfassung von Handlungskomponenten, was mitunter zu erläuternden Ergänzungen führen kann, sowie zu Kürzungen bei Aufzählungen und Beschreibungen. ${ }^{44}$

Mehrfach fasst der Kopist Passagen unterschiedlichen Umfangs in einem einzigen Vers oder Verspaar zusammen, indem er in der Vorlage weit auseinanderliegende Abschnitte verbindet und auf diese Weise den Anschluss zwischen den Versen herstellt. Durch die Kürzung verlorene Reimpaarbindungen 〈repariert〉 er mittels Umstellungen und Ergänzungen von einzelnen Wörtern, wobei die bezweckte Kohärenz von Inhalt und Form nicht immer

43 Ebd., S. 50.

44 Vgl. dazu Fasching (2020), Teil II, S. 255-267. 
gelingt; gelegentlich werden kurze Erläuterungen zur Klärung hinzugefügt. Aufzählungen und Beschreibungen, die sich in der Vorlage über mehrere Verse erstrecken, kondensiert der Schreiber wiederholt in einem einzigen Verspaar. Wenn Beschreibungen ersatzlos gestrichen werden, behält der Kopist angelagerte Verse mit Handlungskomponenten bei, indem er sie umformuliert oder verschiebt; auf diese Weise bleibt die narrative Logik leidlich gewahrt.

Die Kürzungstechniken in $\mathrm{Hs}$. $\mathrm{V}^{\prime}$ sollen nunmehr anhand zweier konkreter Beispiele beschrieben werden. Das Hauptaugenmerk liegt dabei auf dem Umgang des Kopisten mit dem vorgefundenen Textmaterial und den sich dabei gegenüber der Vorlage ergebenden inhaltlichen Konsequenzen. Zur Erleichterung des Verständnisses sind die Texte von V und $\mathrm{V}^{\prime}$ gegenüber der handschriftlichen Schreibweise im Folgenden normalisiert und interpungiert. ${ }^{45}$

Das erste Beispiel entstammt der dritten Conte du Graal-Fortsetzung und beinhaltet jene Szene, in welcher der Fischerkönig entdeckt, dass Parzival sein Neffe ist (NP 36.175-36.230 = Rappoltsteiner Parzifal [Ed. Schorbach (1888)], 839,10-840,28).46 Die daraufhin anerbotene Übertragung der Herrschaft lehnt Parzival mit dem Argument ab, dass er das Königsamt erst nach dem Tod seines Onkels übernehmen wolle. Diesen Abschnitt kopiert der Schreiber G nahezu wörtlich; auffällig ist jedoch die Reimvariante im Verspaar $36.177 \mathrm{f}$., welche zur Elimination des Syntagmas unde dunket mich reht führt (vielleicht angeregt durch den unreinen Reim mit iehet). Mit dem Verspaar NP 36.183 f. setzt dann eine der charakteristischen Kürzungen ein:

Hs. V, BL. $300^{\text {vb }}$

NP 36.175

NP 36.176

NP 36.177
Des entwúrtete Parzefal wolgemůt, er sprach: »lieber herre gůt, sit ir min o̊heim sint, des ir iehet,
Kopie: Hs. V', BL. 170

Dez antwurte Parzifal wolgemuet, er sprach: »lieber herre guet, sint ir min oheim sint, als ir iehent doch,

45 Groß- und Kleinschreibung wird vereinheitlicht, Abbreviaturen werden stillschweigend aufgelöst, Lombarden erscheinen in Fettdruck. - Handschriftengetreu synoptisch mit den entsprechenden Digitalisaten dargestellt sind die Transkriptionen in der eingangs genannten Digitaledition zugänglich.

46 Die mhd. Übersetzung in Hs. V folgt hier ihrer altfranzösischen Vorlage, der 28. Episode der Troisième Continuation; vgl. The Third Continuation (Ed. Roach [1983]), vv. 42.037-42.094. 


\section{Hs. V, BL. 300 vb}

NP 36.178

NP 36.179

NP 36.180

NP 36.181

NP 36.182

NP 36.183

NP 36.184

[NP 36.185- [..]

36.200]
Kopie: Hs. V', BL. 170

so verloube ich got sicher noch, daz nymer krone kumet uf daz houpt min, nach wil kein kunig sin, alle die wile man uch leben sicht, mich gelustet uwers landes nicht. aber min dienst zu aller zit bereit sol uch sin unverseit." [V': Kürzung um 16 Verse]

Ab Vers NP 36.183 legt Parzival ausführlich dar, dass er dem Fischerkönig in Notzeiten jederzeit behilflich sein werde. Anschließend zeigt sich die Hofgesellschaft erfreut darüber, dass Parzival Goondesert, den Bruder des Königs, gerächt hat und dass der Fischerkönig selbst genesen ist. Diesen in Hs. V insgesamt 18 Verse umfassenden Abschnitt (NP 36.183-36.200) verdichtet der Kopist von Hs. V' zu einem einzigen Verspaar, in dem Parzival seine Dienstbereitschaft erklärt (NP 36.183f.). Danach klärt der Fischerkönig die Hofgesellschaft über das Verwandtschaftsverhältnis auf und lässt Parzival des Nachts an seine Seite betten:

Hs. V, Bl. $300^{\text {vb }}$

NP 36.201

NP 36.202

NP 36.203

NP 36.204

NP 36.205

NP 36.206

NP 36.207

NP 36.208

NP 36.209 der kúnig seite menglichem mere, daz Parzefal sinre swester sun were. sinre ôheime tohter, die zwo megede zart, der beider froude harte gros wart. manigerhande froude wart do gemaht, [301 $\left.{ }^{\text {ra }}\right]$ sú hofiertent bitze mitternaht. do es slofendes zit wart, uf der stette der kúnig, der sin ôheim liep hette, bat in mit imme slofen gon.
Kopie: Hs. V', BL. 170

der kunig seite menliche mere, daz Parzifal siner swester sun were.

siner sie hatte freude und wunne zart.

$-$

-

do ez slaffens zit wart,

$\left[170^{\mathrm{vb}}\right]$ Anfortes hiez in mit ime gan.

Im Reimpaar NP 36.201f. folgt der Kopist wörtlich der Vorlage und übernimmt auch das erste Wort des folgenden Verses (NP 36.203), ehe er es spontan wieder streicht. Dieser Vorgang darf als weiteres Indiz dafür gelten, dass die Kürzungen gegenüber Hs. V direkt in Hs. $V^{\prime}$ - und nicht in einer Zwischenstufe - vorgenommen worden sind. Die nächsten drei Verspaare (NP 36.203-36.208), in denen von der Freude der beiden Töchter des 
Fischerkönigs und von der beginnenden Schlafenszeit berichtet wird, sind in Hs. V' zu einem einzigen Verspaar zusammengefasst (NP 36.203/7). Eine kürzende Manipulation am Ende von Vers NP 36.207 ermöglicht dabei die Aufrechterhaltung des Reims zart : wart. Inhaltlich wird der Text insofern verändert, als in Hs. V' nicht die Freude der Töchter, sondern (gemäß Vers NP 36.202) diejenige der Schwester des Fischerkönigs beschrieben wird, was das Verständnis der Stelle stört und einen inhaltlichen Bruch zur Folge hat. Wenn der König im nächsten Vers (NP 36.209) seinen Neffen dazu auffordert, mit ihm das Schlafgemach zu teilen, wird in Hs. V' vermutlich zur Harmonisierung mit Wolframs Parzival der dort begegnende Personenname Anfortes eingesetzt; das Verbum bat (lud ein `) ist durch das semantisch intensivere hiez (‘hieß), befahl`) ersetzt.

Anschließend folgt Hs. V' für die nächsten elf Verse (NP 36.21036.220) wiederum nahezu wörtlich der Vorlage: Parzival schläft, nachdem er zuerst nicht einwilligen wollte, sorglos an der Seite des Fischerkönigs; am nächsten Morgen verlangt er nach seiner beschädigten Rüstung, doch der König lässt ihm andere Waffen bringen. Die Beschreibung dieser Rüstung, die der Oheim selbst getragen hat, und die eindringliche Bitte an den Neffen, diese zu tragen, werden durch den Kopisten jedoch eliminiert (NP 36.22136.230):

Hs. V, Bl. $301^{\text {ra }}$

NP 36.210

NP 36.211

NP 36.212

NP 36.213

NP 36.214

NP 36.215

NP 36.216

NP 36.217

NP 36.218

NP 36.219

NP 36.220

[NP 36.221-

36.230 ]

NP 36.231

NP 36.232

NP 36.233 [...] $[\ldots]$
Parzefal enwolte des nút lon, do er sach, daz es sin wille was, do tet er gewillecliche das. sú sliefent die naht sunder sorgen. so balde uf gie der morgen, do stunt Parzefal uf unde tet sich an; sinen harnesch hiesch der kůne man. der es gehielt, der broht es dar, es waz aber zerzerret gar. der kúnig hies im andere wofen bringen, die worent rich an allen dingen

Parzefal wefente sich wol zeflis unde saz uf $\sin$ ros wis
Kopie : Hs. V', BL. 170 vo

Parzifal enwolte dez nit lan, da er sach, daz ez sin wille waz, do tet er williclichen daz. sie slieffen die nacht sunder sorgen. so balde uf ging der morgen, do stunt Parzifal uf und tet sich an; sinen harnesch hiesch der kune man. wer ez gehielt, der bracht ez dar. ez waz abir zurzerret gar. der kunig hiez ime ander wofen bringen, die worent rich an allen dingen. [V': Kürzung um zehn Verse]

Parzifal woffent sich wol zu fliez und sas uf sin ros wies [...] 
Das zweite Beispiel entstammt dem Epilog und enthält ein inszeniertes Gespräch, das die Personifikationen Minne und Milte über den Auftraggeber des Buchs Ulrich von Rappoltstein führen (Ep 117-150 = Rappoltsteiner Parzifal [Ed. Schorbach (1888)], 848,23-849,10).47 Dabei kündigt schließlich die Minne an, Ulrich einen Minnebrief zu schreiben und persönlich zu überbringen:

\section{Hs. V, BL. $318^{\text {rb }}$}

Ep 117 Do begunde die Milte iehen:

Ep 118 »die kost getar nieman gesehen,

Ep 119 wan alleine der herre min.

Ep 120 ich, Milte, bin sin eigin,

Ep 121 lip noch gưt er nút enspart.

Ep 122 wo men dient schónen frowen zart,

Ep 123 do tůt ers anderen herren vor.

Ep 124 Minne, du bist sin urbor,

Ep 125 du treist sin herze bi dir.«

Ep 126 die Minne sprach: »den nenne mir.»

Ep 127 »ich tůn dirn«, sprach die Milte,

Ep 128 »bekant bi sime schilte.

Ep 129 der ist so rich gevisieret,

Ep 130 daz in nieman úberzieret:

Ep 131 daz velt ist von finen berlin groz,

Ep 132 von Origent, wisser denne ein sloz.

Ep 133 dar uz gent drie schilte irn schin,

Ep 134 jeclicher ist ein robin,

Ep 135 gesliffen reine von Origent,

Ep 136 die rehte karfunkel schin gent;

Ep 137 fúr rot brinnent sú dar inne.«

Ep $138 \quad$ "nu weiz ich«, sprach die Minne,

Ep 139 "wer er ist, bi den wofen sin.

Ep 140 ich bin sin eigin unde er min;

Ep 141 wir sint beide ein lip,

Ep 142 anders denne man unde wib,

Ep 143 die zwo seln unde ein lip hant.

Ep 144 ez ist umbe unz frúntlicher gawant;

Ep 145 wir hant selen nuwen eine,

Ep $146 \quad$ lib unde sele ist gemeine.

Ep 147 er ist ich unde bin ich er,

Ep 148 wez er gert, dez selben ich ger.

\section{Kopie: Hs. V', Bl. $180^{\text {rb }}$}

Do begonde die Minne iehen: »die kost getar nyeman sehen, wan alleine der herre min.« »ich, Milte, bin sin eigin, lip noch guet er nit enspart. wo man dient frouwen zart, do tuet ers andern herren vor.»

$-$

die Minne sprach: »den nenne mir zwor.» »ich tun dir«, sprach die milte, »in bekant by sime schilte. der ist so rich gevisieret, daz in nyeman uber zieret: daz velt ist von vinen perlin gros, von Oriente, wiszer danne ein slos. dar uz gibent drie schilte iren schin, jeclicher ist ein rubin.«

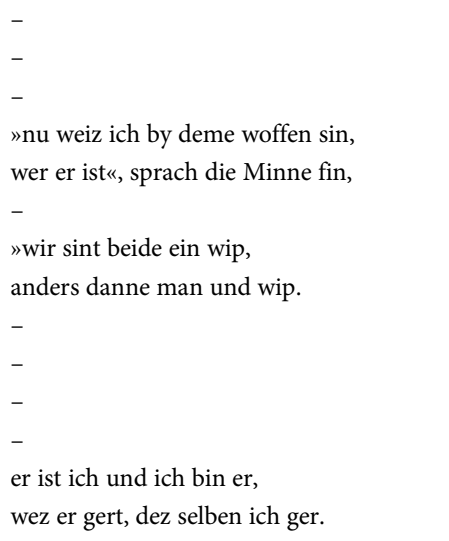


Hs. V, Bl. $318^{\text {rb }}$

Ep 149

Ep 150
Ich wil ein minnebriefelin

imme schriben unde selber botte sin."
Kopie: Hs. V', BL. 180

ich wil ein minne brifelin

ime schriben und selbe bote sin.«

Abgesehen von dem auffälligen Sprecherwechsel in Ep 117 weist auch dieser Abschnitt in Hs. V' gegenüber der Vorlage mehrere Kürzungen auf, die sich in ihrem Umfang zwischen einem Wort und zwei Verspaaren bewegen:

In Ep 122 wird das in Hs. V gut lesbare Adjektiv schönen, welches dort das Substantiv frowen ergänzt, getilgt, ohne dass dadurch das Textverständnis beeinträchtigt würde.

Mit Ep 124f. werden zwei Verse, in denen die Personifikation Minne sowie in einem Herzenstauschtopos deren Vereinigung mit dem Auftraggeber beschrieben werden, eliminiert. ${ }^{48}$ Grund dafür könnte neben der Thematik, die in Ep 140-146 nochmals gemieden wird (vgl. unten, S. 364), das für den Kopisten wohl schwer verständliche, selten belegte Nomen urbor sein, das einen Zinspflichtigen bezeichnet. Da die beiden auf diese Weise getilgten Verse je einem gesonderten, vorausgehenden beziehungsweise nachfolgenden Reimpaar entstammen, wird in Hs. V' bei Ep 126 das Adverb zwor als Reimwort zu vor in Ep 123 angefügt.

Mit dem Wegfall der Verse Ep 135-137 ist in Hs. V' die Beschreibung der Beschaffenheit der Rubine auf dem Schild des Auftraggebers ausgespart. Erhalten bleibt jedoch die Aussage der Minne, dass der Auftraggeber an seinem Wappen erkennbar sei: by deme woffen sin (in Hs. V' Ep 138). Der Kopist kreiert dabei aus den beiden in Hs. V jeweils dem vorausgehenden beziehungsweise nachfolgenden Reimpaar zugehörigen Versen Ep $138 \mathrm{f}$. ein neues Verspaar: Für Vers Ep 138 übernimmt er aus der Vorlage den ersten Teil von Vers Ep 138 (die direkte Rede der Minne) und kombiniert ihn mit dem zweiten Teil von Vers Ep 139 aus Hs. V. Für Vers Ep 139 bewahrt er wiederum den ersten Teil und schließt dann mit der in der Vorlage im vorausgehenden Vers Ep 138 vorhandenen Inquit-Formel ab, indem er zur

48 Vgl. zum Topos des Herzenstauschs den Forschungskommentar in: Lancelot und Ginover. Prosalancelot (Ed. Kluge / Steinhoff [1995]), Bd. 2, S. 965 f.; im Zusammenhang mit der Topik des «Einwohnens im Herzen〉 in Ep 329-332 spricht Strohschneider (2004), S. 547, mit Anm. 14, von «reziproken Immanenzbegriffen». 
Sprecherin Minne das nachgestellte Adjektiv oder das Adverb fin ergänzt und damit den Reim zum in Hs. $V^{\prime}$ vorausliegenden Vers herstellt.

Eliminiert werden in Hs. V' verschiedene Aussagen, die auf eine Einheit von Minne und Auftraggeber zielen: Dies betrifft den gegenüber der Vorlage getilgten Vers Ep 140 (Hs. V: Ich bin sin eigin und er min) sowie die Verspaare Ep 143-146, die in Hs. V eine Leib und Seele umfassende Gemeinschaft evozieren. ${ }^{49}$ Aufrechterhalten bleibt in Hs. V' nur die lapidare, an die beiden Verspaare anschließende Aussage: er ist ich und ich bin er (Vers Ep 147). Der in der Kopie hergestellte Text erweist sich damit insgesamt als deutlich einfacher gestaltet und lässt die vergleichsweise komplexe Machart der auf Motive des Herzenstauschs und der Leib-SeeleGemeinschaft rekurrierenden Version der Vorlage hervortreten.

IV.

Wie bereits oben ausgeführt, sind die Kürzungen erst in Hs. V' und nicht etwa in einer (verlorenen) Zwischenstufe erfolgt (vgl. S. 349 f., mit Anm. 15). Einige Kürzungen sind nachweislich spontan während des Kopierprozesses entstanden. So hat Schreiber G von Hs. V' die beiden Triumphlisten von Feirefiz (L. 770,1-30) und Parzival (L. 772,1-30) mit den besiegten Gegnern vor dem Abschreiben nicht gänzlich überblickt (Hs. V, Bl. $\left.307^{\mathrm{vb}}-308^{\text {ra }}\right)$. Erst im Zuge der Abschrift, nach der Übernahme einiger Verse aus der Vorlage, hat er sich für Kürzungen entschieden und die restlichen Verse übersprungen. In jeweils zwei neu formulierten Verspaaren hat er schließlich die Triumphlisten zusammengefasst (Hs. V', Bl. 174 ${ }^{\text {va-b }}$ ). Angesichts solcher Befunde sind die Voraussetzungen gegeben, im direkten Vergleich mit der Vorlage Kürzungsprozesse in situ am Material zu beobachten.

Im Anschluss an die von Nikolaus Henkel zusammengestellten «Typen redaktioneller Kürzungen» und die von Joachim Bumke erhobenen «Arten von Kürzungen ${ }^{50}$ können aufgrund der Beobachtungen zu Hs. V' zumindest

49 Vgl. im Kontext des Epilogs auch Emmerling (2003), S. 33 f. u. 43 f.; Strohschneider (2004), S. $545 \mathrm{f}$.

50 Vgl. Henkel (1993), S. 49 f., und Bumke (2010), S. 461-465. 
folgende Kategorien von Kürzungstechniken unterschieden werden, wobei eine eindeutige Abgrenzung nicht immer möglich ist:

〈absichtlich〉 versus 〈unabsichtlich〉

Von den «absichtlich〉 erfolgten Kürzung mit einem «Willen zur Textgestaltung $»^{51}$ lassen sich einige Fälle von «unabsichtlich», d. h. versehentlich oder ungeplant erfolgten Versauslassungen unterscheiden. Die Kürzungen in den beiden obgenannten Beispielen dürften alle absichtlich erfolgt sein, worauf die Veränderungen, die Schreiber $G$ beim Kürzen vorgenommen hat, hindeuten. Unabsichtliche Kürzungen wären demgegenüber Auslassungen infolge von Augenabirrungen (Augensprüngen) beim Kopieren oder - wie vermutlich bei den Überschriften von Hs. $V^{\prime}$ - aufgrund einer im Laufe der Abschrift nicht mehr verfügbaren Vorlage (vgl. dazu unten, S. 369).

〈Mit Veränderung〉 versus «ohne Veränderung〉

〈Mit Veränderung〉 ist die Kürzung erfolgt, wenn es im Umfeld der gekürzten Passagen zu Textumformulierungen in umgestalteten oder in zugedichteten Kittversen kommt, die als «Überleitungen und Verbindungen» der stehen gebliebenen Verse dienen. ${ }^{52}$ In denjenigen Fällen, in denen die Kürzung «ohne Veränderung〉 erfolgt, fehlen solche Verbindungsverse. In den beiden angeführten Beispielen hat Schreiber $G$ für Anschlüsse bei Kürzungen mehrmals Versbestandteile der Vorlage angepasst, neu kombiniert und damit den Text verändert. Der längere Abschnitt NP 36.183-36.200 ist in Hs. V' nicht einfach eliminiert, sondern er wird im Verspaar NP $36.183 \mathrm{f}$. verdichtet. Die Passage NP 36.203-36.208 wird in dem neu kreierten Verspaar NP 36.203/7 zusammengefasst, in dem Bestandteile aus den entsprechenden Versen der Vorlage übernommen und verändert sind. Ähnlich verfährt der Kopist auch im Abschnitt Ep 135-139, den er durch Übernahme und Neukombination von Versbestandteilen im Verspaar 138/139 zusammenfasst. In Ep 126 allerdings verändert Schreiber G lediglich ein Reimwort, um den Anschluss an einen Vers herzustellen, der aufgrund von Kürzung seinen 〈Reimpartner` verloren hat. Ohne textliche Veränderung in den Nachbarver- 
sen hat der Kopist hingegen die ebenfalls längere Passage NP 36.221-36.230 sowie die vier Verse Ep 143-146 gekürzt.

Die Kombination der erwähnten Kategorien ergibt im Hinblick auf die Produktion folgende beim Abschreibeprozess mögliche Spielarten von Kürzungstechniken:

- Absichtliche Kürzung ohne Veränderung

- Absichtliche Kürzung mit Veränderung

- Unabsichtliche Kürzung ohne Veränderung

- Unabsichtliche Kürzung mit Veränderung

Im Hinblick auf die Wahrnehmung bei der Rezeption erscheinen die Kürzungen außerdem immer entweder 〈bruchlos〉 oder «mit Bruch〉. 〈Bruchlos〉 ist die Kürzung dann, wenn sich das «Fehlen» von Versen nicht bemerken ${ }^{53}$ lässt, solange keine anderen Handschriften vergleichend beibezogen werden, wenn es also zu keinem «Verlust in der Aussagesubstanz» kommt. ${ }^{54}$ 〈Mit Bruch〉 hingegen erfolgt die Kürzung, wenn dadurch die Syntax oder der Inhalt gestört werden. ${ }^{55}$

Mit solchen Kürzungsverfahren kann ein Kopist bei der Abschrift seiner Vorlage in den Text eingreifen. Aus welchen Gründen dies geschieht, soll nun abschließend anhand von Hs. V' diskutiert werden. Dazu ist vorab der Umweg über eine etwa hundert Jahre ältere Schreibwerkstatt angezeigt.

Bereits um die Mitte des 13. Jahrhunderts wurde in einem im bairischen oder ostalemannischen Raum anzusetzenden, nicht genau lokalisierbaren Skriptorium um die Tristan-Handschrift Cgm 51 (Sigle M) und die ParzivalHandschrift Cgm 19 (Sigle G) «nicht nur in größerem Umfang deutsche Epik abgeschrieben, sondern auch kürzend redigiert». ${ }^{56}$ In unterschiedlichem Maß wurden die aus dem Skriptorium überlieferten Texte im Vergleich mit der Parallelüberlieferung hinsichtlich «Textbestand, Textfolge und Textfor-

55 Implizit ebd., S. 49, sowie Bumke (2010), S. 461 (mit Deutung als «Überlieferungsfehler»).

56 Klein (1992), S. 58. - Vgl. zum sogenannten G-Skriptorium und dessen Schreiber Schneider (1987), Textband, S. 150-154; Klein (1992), S. 39-53 u. 64-66; Baisch (2006), S. 99-353, und Baisch (2013). 
mulierungen ${ }^{57}$ verändert, wobei in der Tristan-Handschrift Cgm 51 am meisten gekürzt wurde. Nicht einig ist sich die Forschung über die den Kürzungen zugrunde liegenden Motivationen. ${ }^{58}$

Thomas Klein hat 1992 für die Tristan-Handschrift M mit einem stark gekürzten Textbestand konstatiert, dass der auffällig «sparsame Umgang mit dem Pergament» die Ursache «für die Textkürzungen im Cgm 51» gewesen sein könnte. ${ }^{59}$ Weiter hat Klein beobachtet, dass «der Wille zu kürzen erst während des Schreibens gewachsen zu sein [scheint] - vielleicht auch gefördert von dem Streben, schneller fertig zu werden oder aber Pergament $\mathrm{zu}$ sparen».60 Martin Baisch hingegen ist für den gesamten Cgm 51 zum Schluss gekommen, dass der Redaktor die Kürzungen nach einem Bearbeitungskonzept mit hermeneutischen Deutungen vorgenommen hat. ${ }^{61} \mathrm{Er}$ vermutet als Usus des gesamten Skriptoriums «eine formende Redaktion bei der Anfertigung von Handschriften $»{ }^{62}$

Im Vergleich mit der Tristan-Handschrift Cgm 51, in der die Texteingriffe ebenfalls erst in der Textmitte beginnen, ${ }^{63}$ hat Fabian Sietz für Hs. V' gefolgert: «Eine 〈Sparthese〉 zur Erklärung der Kürzungen, die Martin Baisch für den Cgm 51 zurückweist, ist aus denselben Gründen (sorgfältige und damit kostspielige Anlage der Handschrift und der Kürzungen) nicht plausibel.» ${ }^{64}$ Vielmehr konstatiert Sietz, dass «[d]ie hier getrennt auftretenden Techniken der dilatatio materiae und der abbreviatio [...] nicht als Gegenbewegungen, sondern als einander ergänzend zu verstehen» seien - dies

57 Baisch (2006), S. 109, und Baisch (2013), S. 676.

58 Klein (1992), S. 58; Baisch (2006), S. 109-132, und Baisch (2013), S. 676 f.

59 Vgl. Klein (1992), S. 37 f., Zit. S. 37. - Für seine Annahme, dass die Kürzungen im Cgm 51 und nicht etwa bereits in einer früheren Vorlage entstanden sind, kann Klein keine direkten Nachweise erbringen; vgl. ebd., S. 54, dazu auch Baisch (2006), S. 113 115.

60 Klein (1992), S. 61.

61 Vgl. Baisch (2005), S. 111.

62 Baisch (2013), S. 669-690, Zit. S. 676f., Zit. S. 677.

63 Vgl. Baisch (2005), S. $108 \mathrm{f}$.

64 Sietz (2017), S. 139. 
bestätige die Annahme der Forschung, "dass verschiedene Fassungen mittelalterlicher Werke bereits früh nach oder sogar parallel entstehen können».65

Mit einer gewissen Skepsis gegenüber der Anwendung von Bumkes Fassungsbegriff auf Hs. V' soll nun ebendiese ‘Sparthese` nochmals aufgegriffen werden, um nach den Gründen und Motivationen des Kopisten zu fragen, der Hs. V' gegenüber seiner Vorlage V um einen Bestand von rund 14 Prozent gekürzt hat.

Es drängt sich zunächst die Frage auf, ob mit diesen Kürzungen tatsächlich gespart werden konnte. Und wenn ja, woran? Wie sich gezeigt hat, war beim Kopiervorgang der Aufwand relativ groß, bei den Kürzungen die Textanschlüsse zu gewährleisten - zumindest, was die Reime anbelangt.66 Der Kopist hatte jedoch beim gesamten Kopiervorgang einen guten Überblick über den Textverlauf, auch wenn er offensichtlich nicht alles genau verstanden hat.

Hinsichtlich der Materialkosten konnten mit den Kürzungen immerhin 28 Blätter, also dreieinhalb Quaternionen, eingespart werden. ${ }^{67}$ Dass der Kostenfaktor bei der Herstellung von Hs. V' tatsächlich berücksichtigt wurde, deutet zumindest die Verwendung von Pergament minderer Qualität an. Im 13. und auch noch im 14. Jahrhundert wurde bei der Buchproduktion laut Jürgen Wolf solches Pergament gewählt, «[u]m die Kosten zu minimieren $»: 68$

Als die Mittel zu einem großen Teil aufgebraucht waren, ein Ende des Buchs aber noch in weiter Ferne lag, zog man im Skriptorium die Notbremse. Alle Kostenfaktoren wurden überprüft. Am Pergament bzw. an den Rohstoffen ließ sich am

65 Ebd., S. 140.

66 Vgl. dazu auch Stolz (2012), S. 338, Anm. 24.

67 Die fehlenden etwa 5.300 Verse hätten in Hs. V' - bei einer durchschnittlichen Zeilenanzahl von 47 Zeilen pro Spalte - 56 Seiten, also 28 Blätter, gefüllt und den Umfang von Hs. V' von 181 Blättern auf 209 Blätter erhöht. - Über die Kosten für die Handschriftenproduktion im 14. Jahrhundert ist wenig bekannt. Erhalten hat sich immerhin eine Auflistung der Kosten für den ersten Band eines zweibändigen Antiphonars aus dem Jahr 1373; vgl. Hust (2001) und Steinmann (2013), S. 551 (Nr. 615).

68 Wolf (2008), S. 127. 
einfachsten sparen, ohne das Buch in seiner sichtbaren Kostbarkeit vollständig zu diskreditieren. ${ }^{69}$

Ein zusätzlicher, ebenfalls materieller Grund für Kürzungen in Hs. V' könnte die zeitlich beschränkte Verfügbarkeit der Vorlage gewesen sein. ${ }^{70}$ Darauf weisen jedenfalls die von Schreiber $G$ angefertigten roten Überschriften hin: Beim Kopieren des Textes hat dieser meist die Anzahl der Zeilen ausgespart, welche die ausführlichen Überschriften in der Vorlage V einnehmen. Als Anweisung für die spätere Einfügung mit roter Tinte ist der Wortlaut der Überschriften von Hs. V teilweise stichwortartig in Gebrauchsschrift an den Rändern von Hs. V' vorgeschrieben worden. Die von Schreiber $G$ mit roter Farbe nachgetragenen Überschriften entsprechen allerdings weder in der Länge noch im Wortlaut denjenigen der Vorlage. Lediglich die wenigen Überschriften, die noch von Schreiber A von Hs. V' stammen, folgen genau Hs. V.71 Schreiber G hingegen hat die Überschriften vermutlich ad hoc erstellt, wobei es - wohl unabsichtlich - zu Kürzungen gegenüber den Formulierungen in der Vorlage gekommen ist, die nicht mehr zur Verfügung gestanden hat.

\section{V.}

Wie auch immer die Motivationen und Beweggründe für die Kürzungen zu deuten sind, lassen sich aus den angestellten Beobachtungen die folgenden Schlüsse ziehen: Die untersuchte Handschrift V' mit dem Nuwen Parzifal ist der seltene Beleg einer direkten Kopie, an der mit den Abschreibevorgängen auch Kürzungsprozesse fassbar sind. Die spezifische Anwendung von teilweise spontanen Kürzungsverfahren lassen den zweiten Schreiber (G) von Hs. $V^{\prime}$ nicht als Redaktor erkennen, dessen Intention es war, eine Kurzfassung im

70 Die Verwendung anderer Tinte sowie Textneuformulierungen lassen zumindest vermuten, dass bei der Überarbeitung der Abschrift die Vorlage nicht mehr vorhanden war; vgl. dazu Stolz (2012), S. 343.

71 Vgl. dazu Stolz (2012), S. 346-349, und Fasching (2020), S. 242 f. Beispiele für Anweisungen an den Rubrikator und Ausführungen von Überschriften in Hs. V' finden sich bei Stolz (2012), S. 353-356, und Fasching (2020), S. 244-251. 
Sinne des Fassungskonzepts von Joachim Bumke zu erstellen. Vielmehr erweist sich der Schreiber als guter Kopist des ihm vorliegenden Textes, der kompetent den Überblick über seine Vorlage behält und diese bei Bedarf während des Abschreibevorgangs bearbeitet und kürzt. Die im Akt der Abschrift entstandene Varianz konstituiert dabei keine neue 〈Fassung〉 des Textes, sondern «sie ergibt sich gewissermaßen als Begleiterscheinung einer sinngemäßen Textreproduktion».72 Mit Martin Baisch, der im Anschluss an den Text-Begriff von Konrad Ehlich und Peter Strohschneider «[a]lle schriftlichen Aufzeichnungen eines Textes [...] als prinzipiell gleichrangige kommunikative Handlungen» versteht, ${ }^{73}$ kann die durch die Kopie entstandene Varianz wie folgt beschrieben werden:

Textvarianz - auch jene in Wolframs Roman - ist die Folge einzelner Verstehensakte; in jedem dieser Rezeptionsakte können spezifische Sinndimensionen aktualisiert werden. Die Abschrift des vorgängigen Texts erweist sich so als komplexe Umschrift. ${ }^{74}$

Diese Aktualisierung von Sinndimensionen im Rezeptionsakt lässt sich abschließend nochmals mit dem Ansatz der Transkriptivität von Ludwig Jäger in Zusammenhang bringen. ${ }^{75}$ Wie das Skript durch die Transkription das Präskript erst sichtbar macht, verleiht erst die Abschrift der Vorlage den Status eines ‘Originals`. Unter dieser Perspektive bietet der Text von Hs. V' mit allen seinen Änderungen in Gestalt von Umformulierungen und Kürzungen nicht eine eigenständige ‘Fassung〉 des Nuwen Parzifal, sondern eine Umschrift, deren Eigenart Verstehensakte im Überlieferungsprozess nachvollziehen lässt. 


\section{Bibliographie}

\section{Primärliteratur}

Albrechts Jüngerer Titurel (Ed. Nyholm [1992]) = Albrechts Jüngerer Titurel Band III/2 (Strophe 5.418-6.327), nach den Grundsätzen von Werner Wolf kritisch hg.v. Kurt Nyholm, Berlin 1992 (DTMA 77).

Der jüngere Titurel (Ed. Hahn [1842]) = Der jüngere Titurel, hg.v. K[arl] A[ugust] Hahn, Quedlinburg / Leipzig 1842 (Bibliothek der gesammten deutschen NationalLiteratur von der ältesten bis auf die neuere Zeit 24).

The Third Continuation (Ed. Roach [1983]) = The Third Continuation by Manessier, hg.v. William Roach, Philadelphia 1983 (The Continuations of the Old French Perceval of Chretien de Troyes 5).

Heinrich von dem Türlin (Ed. Ebenbauer / Kragl [2005]) = Heinrich von dem Türlin, Die Krone (Verse 12282-30042). Nach der Handschrift Cod. Pal. germ. 374 der Universitätsbibliothek Heidelberg nach Vorarbeiten von Fritz Peter Knapp und Klaus Zatloukal hg.v. Alfred Ebenbauer / Florian Kragl, Tübingen 2005 (ATB 118). Lancelot und Ginover. Prosalancelot (Ed. Kluge/ Steinhoff [1995]) = Lancelot und Ginover. Prosalancelot. Nach der Heidelberger Handschrift Cod. Pal. germ. 147 hg.v. Reinhold Kluge, ergänzt durch die Handschrift Ms. allem. 8017-8020 der Bibliothèque de l'Arsenal Paris. Übers., komm. und hg.v. Hans-Hugo Steinhoff, Frankfurt a. M. 1995 (Bibliothek des Mittelalters 15 [= Bibliothek deutscher Klassiker 123]).

Rappoltsteiner Parzifal (Ed. Schorbach [1888]) = Parzifal von Claus Wisse und Philipp Colin (1331-1336). Eine Ergänzung der Dichtung Wolframs von Eschenbach. Zum ersten Male hg.v. Karl Schorbach, Straßburg / London 1888 (Elsässische Litteraturdenkmäler aus dem XIV-XVII. Jahrhundert 5) [Neudruck Berlin / New York 1974 und (Berlin / Boston 2010)].

Wolfram von Eschenbach, Parzival (Ed. Lachmann / Knecht / Schirok [2003]) = Wolfram von Eschenbach, Parzival. Studienausgabe. 2. Auflage. Mittelhochdeutscher Text nach der sechsten Ausgabe von Karl Lachmann, Übersetzung von Peter Knecht. Mit Einführungen zum Text der Lachmannschen Ausgabe und in Probleme der Parzival-Interpretation von Bernd Schirok, Berlin / New York 2003 (de Gruyter Texte).

\section{Forschungsliteratur}

Baisch, Martin: Parzivals einfache Probe. Zur kulturellen Funktion von Varianz am Beispiel der Handschriftengruppe um den Cgm 19, in: Wiesinger, Peter (Hg.): Akten des X. Internationalen Germanistenkongresses Wien 2000. ¿Zeitenwende - 
Die Germanistik auf dem Weg vom 20. ins 21. Jahrhundert), Bern u. a. 2002 (Mediävistik und Kulturwissenschaften 5. Jahrbuch für Internationale Germanistik. Reihe A. Kongreßberichte 57), S. 243-248.

Baisch, Martin: Die Bedeutung der Varianz. Zu den auktorialen Selbstentwürfen im Parzival Wolframs von Eschenbach, in: Arthur Groos / Hans-Jochen Schiewer (Hgg.): Kulturen des Manuskriptzeitalters. Ergebnisse der Amerikanisch-Deutschen Arbeitstagung an der Georg-August-Universität Göttingen vom 17. bis 20. Oktober 2002, Göttingen 2004 (Transatlantische Studien zu Mittelalter und Früher Neuzeit Transatlantic Studies on Medieval and Early Modern Literature and Culture 1), S. 11-39.

Baisch, Martin: abbreviatio im Spannungsfeld von Textkritik und Hermeneutik. Zur Kurzfassung der höfischen Erzähltexte Gottfrieds von Straßburg und Ulrichs von Türheim im cgm 51, in: Elizabeth Andersen / Manfred Eikelmann / Anne Simon (Hgg.): Texttyp und Textproduktion in der deutschen Literatur des Mittelalters, Berlin / New York 2005 (Trends in Medieval Philology 7), S. 101-120.

Baisch, Martin: Textkritik als Problem der Kulturwissenschaft. Tristan-Lektüren, Berlin / New York 2006 (Trends in Medieval Philology 9).

Baisch, Martin: Das Skriptorium des Cgm 51, in: Martin Schubert (Hg.): Schreiborte des deutschen Mittelalters. Skriptorien - Werke - Mäzene, Berlin / Boston 2013, S. 669-690.

Bonath, Gesa: Untersuchungen zur Überlieferung des Parzival Wolframs von Eschenbach. Bd. 2, Lübeck / Hamburg 1971 (Germanische Studien 239).

Bonath, Gesa / Lomnitzer, Helmut: Verzeichnis der Fragment-Überlieferung von Wolframs Parzival, in: Kurt Gärtner / Joachim Heinzle (Hgg.): Studien zu Wolfram von Eschenbach. Festschrift für Werner Schröder zum 75. Geburtstag, Tübingen 1989, S. 87-149.

Bumke, Joachim: Die vier Fassungen der Nibelungenklage. Untersuchungen zur Überlieferungsgeschichte und Textkritik der höfischen Epik im 13. Jahrhundert, Berlin / New York 1996 (Quellen und Forschungen zur Literatur- und Kulturgeschichte 8 [242]).

Bumke, Joachim: Zur Textkritik des Parzival. Der Textbestand in den Handschriften D und G, in: ZfdA 139 (2010), S. 453-485.

Cramer, Thomas: Lohengrin. Edition und Untersuchungen, München 1971.

Emmerling, Sonja: Geld und Liebe. Zum Epilog des Rappoltsteiner Parzifal, in: Horst Brunner / Werner Williams-Krapp (Hgg.): Forschungen zur deutschen Literatur des Spätmittelalters. Festschrift für Johannes Janota, Tübingen 2003, S. 31-49.

Fasching, Richard F.: Neue Erkenntnisse zum Nuwen Parzifal und zu einer Epenwerkstatt des 14. Jahrhunderts, in: ZfdA 147 (2018), S. 491-509.

Fasching, Richard F.: Original und Kopie des Rappoltsteiner Parzifal. Handschriftliche Überlieferung und Textgenese im 14. Jahrhundert, in: Michael Stolz Parzival im 
Manuskript. Profile der Parzival-Überlieferung am Beispiel von fünf Handschriften des 13. bis 15. Jahrhunderts. Mit einem Beitrag von Richard F. Fasching, Basel 2020, S. $145-271$.

Fehrmann, Gisela u. a. (Hgg.): Originalkopie. Praktiken des Sekundären, Köln 2004 (Mediologie 11).

Henkel, Nikolaus: Kurzfassungen höfischer Erzähldichtung im 13./ 14. Jahrhundert. Überlegungen zum Verhältnis von Textgeschichte und literarischer Interessenbildung, in: Joachim Heinzle (Hg.): Literarische Interessenbildung im Mittelalter. DFG-Symposion 1991, Stuttgart / Weimar 1993 (Germanistische Symposien. Berichtsbände 14), S. 39-59.

Hust, Christoph: Bemerkungen zu einer Abrechnung über die Herstellung und Ausstattung eines Antiphonars des 14. Jahrhunderts, in: Gutenberg-Jahrbuch 2001, S. $60-$ 66.

Jäger, Ludwig: Transkriptivität. Zur medialen Logik der kulturellen Semantik, in: Ludwig Jäger / Georg Stanitzek (Hgg.): Transkribieren. Medien / Lektüre, München 2002, S. 19-41. [Zusammenfassung einzelner Abschnitte unter demselben Titel in: Transkriptionen. Newsletter des Kulturwissenschaftlichen Forschungskollegs «Medien und kulturelle Kommunikation> SFB / FK 4272 (2003), S. 2-6; wieder abgedruckt in: Transkriptionen. Newsletter des Kulturwissenschaftlichen Forschungskollegs 〈Medien und kulturelle Kommunikation`SFB / FK 42710 (2008), Sondernummer: Rückblick, S. 8-12.]

Klein, Thomas: Die Parzivalhandschrift Cgm 19 und ihr Umkreis, in: Joachim Heinzle / L. Peter Johnson / Gisela Vollmann-Profe (Hgg.): Probleme der Parzival-Philologie. Marburger Kolloquium 1990, Berlin 1992 (Wolfram-Studien XII), S. 32-66.

Klein, Klaus: Beschreibendes Verzeichnis der Handschriften (Wolfram und WolframFortsetzer), in: Joachim Heinzle (Hg.): Wolfram von Eschenbach. Ein Handbuch, Bd. 2, Berlin / Boston 2011, S. 941-1002.

Miller, Matthias: Der welsch parcefall, perment, reimen, bretter, braun leder. Zum Rappolsteiner [sic] Parzifal aus der Bibliotheca Palatina, in: ZfdA 136 (2007), S. 307-311 [= Miller (2007a)].

Miller, Matthias: Rom, Biblioteca Casanatense, Mss. 1409 (olim Cod. Pal. germ. 317), in: Matthias Miller / Karin Zimmermann (Bearbeiter): Die Codices Palatini germanici in der Universitätsbibliothek Heidelberg (Cod. Pal. germ. 304-495), Wiesbaden 2007 (Kataloge der Universitätsbibliothek Heidelberg 8), S.69-71 [= Miller (2007b)].

Panzer, Friedrich: Lohengrinstudien, Halle a. S. 1894.

Rippl, Gabriele / Stolz, Michael (Hgg.): Original und Kopie. Techniken und Ästhetiken der re-/produktiven Abweichung, in: Kulturwissenschaftliche Zeitschrift 4, Heft 3 (2019). 
Röll, Walter: Studien zu Text und Überlieferung des sogenannten Jüngeren Titurel, Heidelberg 1964 (Germanische Bibliothek. 3. Reihe: Untersuchungen und Einzeldarstellungen).

Rolle, Sabine: Bruchstücke. Untersuchungen zur überlieferungsgeschichtlichen Einordnung einiger Fragmente von Wolframs Parzival, Erlangen/ Jena 2001 (Erlanger Studien 123), S. 145-149.

Rückert, Heinrich: Lesarten, in: Heinr[ich] Rückert (Hg.): Lohengrin. Zum erstenmale kritisch hg. und mit Anmerkungen versehen, Quedlinburg / Leipzig 1858 (Bibliothek der gesammten deutschen National-Literatur von der ältesten bis auf die neuere Zeit 36), S. 204-223.

Schneider, Karin: Gotische Schriften in deutscher Sprache. I. Vom späten 12. Jahrhundert bis um 1300. Text- und Tafelband, Wiesbaden 1987.

Schneider, Karin: Gotische Schriften in deutscher Sprache. II. Die oberdeutschen Schriften von 1300 bis 1350. Text- und Tafelband, Wiesbaden 2009.

Schnelbögl, Fritz: Die Heidelberger Handschriften 364 (Parzival $G^{\kappa}$ und Lohengrin A), 383 und 404, in: PBB 54 (1930), S. 1-64.

Schorbach, Karl: Einleitung, in: Parzifal von Claus Wisse und Philipp Colin (1331-1336). Eine Ergänzung der Dichtung Wolframs von Eschenbach. Zum ersten Male hg.v. Karl Schorbach, Straßburg / London 1888 (Elsässische Litteraturdenkmäler aus dem XIV-XVII. Jahrhundert 5), S. VII-XLIV [Neudruck Berlin / New York 1974 und Berlin / Boston 2010].

Schulze, Ursula: Varianz und Identität in rechtssprachlichen und dichterischen Texten, in: Ursula Peters (Hg.): Text und Kultur. Mittelalterliche Literatur 1150-1450, Stuttgart / Weimar 2001 (Germanistische Symposien Berichtsbände 23), S. 47-71.

Sietz, Fabian: Erzählstrategien im Rappoltsteiner Parzifal. Zyklizität als Kohärenzprinzip, Heidelberg 2017 (Studien zur historischen Poetik 25).

Steinmann, Martin: Handschriften im Mittelalter. Eine Quellensammlung, Basel 2013.

Stolz, Michael: Copying processes. Genetische und philologische Perspektiven, in: Martin Schubert (Hg.): Materialität in der Editionswissenschaft, Tübingen 2010 (Beihefte zu editio 32), S. 275-291.

Stolz, Michael: Die Abschrift als Schreibszene. Der Nuwe Parzifal in der Handschrift Rom, Biblioteca Casanatense, Mss. 1409, in: Eckart Conrad Lutz, in Verbindung mit Susanne Köbele / Klaus Ridder (Hgg.): Finden - Gestalten - Vermitteln. Schreibprozesse und ihre Brechungen in der mittelalterlichen Überlieferung, Berlin 2012 (Wolfram-Studien XXII), S. 331-356.

Strohschneider, Peter: Literarische Ligaturen. Philipp Colin über Paradoxien höfischer Kunstaufträge im Mittelalter, in: Joachim Fischer / Hans Joas (Hgg.): Kunst, Macht und Institution. Studien zur Philosophischen Anthropologie, soziologischen Theorie und Kultursoziologie der Moderne. Festschrift für Karl-Siegbert Rehberg, Frankfurt a. M. / New York 2004, S. 537-556. 
Thoelen, Heinz / Häberlein, Bianca: Einleitung, in: Konrad von Würzburg Trojanerkrieg und die anonym überlieferte Fortsetzung. Kritische Ausgabe von dens., Wiesbaden 2015 (Wissensliteratur im Mittelalter 51), S. IX-XXI.

Weingart, Brigitte: Originalkopie, in: Christina Bartz u. a. (Hgg.): Handbuch der Mediologie, Paderborn 2012, S. 203-208.

Wolf, Jürgen: Buch und Text. Literatur- und kulturhistorische Untersuchungen zur volkssprachigen Schriftlichkeit im 12. und 13. Jahrhundert, Tübingen 2008 (Hermea. Germanistische Forschungen N. F. 115).

Wolf, Werner: Einleitung, in: ders. (Hg.): Albrechts von Scharfenberg Jüngerer Titurel. Band 1 (Strophe 1-1957). Nach den ältesten und besten Handschriften kritisch hg., Berlin 1955 (DTMA 45), S. IX-CXXXVII.

Zarncke, Friedrich: Der Graltempel. Vorstudie zu einer Ausgabe des jüngern Titurel, in: Abhandlungen der philologisch-historischen Classe der Königl. Sächsischen Gesellschaft der Wissenschaften 7/5 (1876), S. 375-553.

Zeidler, Victor: Untersuchung des Verhältnisses der Handschriften von Rudolfs v. Ems Wilhelm von Orlens, in: Achtzehnter Jahresbericht der Deutschen Staatsrealschule in Karolinenthal 1894, Prag 1894, S. 3-56. 



\section{So vil unnútzer wort man list!}

\section{Kürzung und Zusammenfassung in der Heidelberger und der Dresdener Virginal}

von

Cordula Kropik (Basel)

Wer sich die Problematik der Länge und Kürze von Erzähltexten exemplarisch vor Augen führen will, findet in den Fassungen des aventiurehaften Dietrichepos Virginal ein eindrückliches Studienobjekt. Als Extrempunkte auf einer hypothetischen Skala zwischen den Polen fallen insbesondere die Heidelberger $\left(\mathrm{H}, \mathrm{V}_{10}\right)$ und die Dresdener Virginal ins Auge (Dresdener Heldenbuch: D, $\left.\mathrm{V}_{11}\right){ }^{1}$ Das im dreizehnzeiligen Bernerton verfertigte Epos ist in der zuerst genannten Fassung mit nicht weniger als 1.097 Strophen, in der zweiten hingegen mit lediglich 130 Strophen überliefert. Es enthält im Dresdener Heldenbuch also nur 11,85 Prozent des Textbestands der Heidelberger Virginal beziehungsweise ist um ganze 88,15 Prozent kürzer. ${ }^{2}$ Wie sich diese Diskrepanz auf die poetische Faktur sowie, damit zusammenhängend, auf den Lektüreeindruck der Texte auswirkt, lässt sich unmittelbar einer Forschung entnehmen, deren Urteil einhellig lautet, dass die Heidelberger

1 Die beiden Textfassungen repräsentieren zugleich zwei Versionen des Epos, die in jeweils einer Handschrift vollständig überliefert sind: Die Heidelberger Virginal $(\mathrm{H})$ im cpg 324 der UB Heidelberg $\left(\mathrm{V}_{10}\right.$, um 1440) und die Dresdener Virginal (D) im Mscr. M 201 der SLUB Dresden $\left(\mathrm{V}_{11}, 1472\right)$. Hinzu kommt als dritte Version die in Linhart Scheubels Heldenbuch (ÖNB Wien, Cod. 15478, Handschrift $V_{12}$, um 1480/90) überlieferte Wiener Virginal (W): Sie stellt, da sie einen H- mit einem D-Text kombiniert, eine eigenständige Mischversion dar. Außerdem sind zehn Fragmente überliefert $\left(V_{1}-V_{9}, V_{13}\right)$, die durchweg zu $\mathrm{H}$ gehören, lediglich zwei davon weisen darüber hinaus auch Bezüge zu W auf. Überlieferung und Versionenbildung dokumentieren Heinzle (1978), S. 34-37 u. 329-334; Heinzle (1999), S. 135-137; Lienert (2017), Bd. 1, S. 3-28.

2 Die Wiener Virginal hingegen zählt in $\mathrm{V}_{12} 866$ Strophen (fünf davon sind nicht erhalten, aber in der Handschrift bezeugt). Vgl. dazu Lienert (2017), Bd. 1, S. 28-30. 
Virginal «ermüdend zu lesen» sei, ${ }^{3}$ während die Kurzfassung des Dresdener Heldenbuchs «dunkel und verworren» wirke. ${ }^{4}$ Dass man zumindest hinsichtlich der Länge auch schon im Mittelalter ähnlicher Ansicht sein konnte, beweist zudem der Redaktor des Dresdener Heldenbuchs selbst, der am Ende seiner Fassung mit unverkennbarer Befriedigung seinen Kürzungserfolg kundtut und im Zuge dessen kritisch kommentiert:

Ein ent hat disses tichtes art.

Got geb uns dort sein wune!

des altenn vir hundert und echte ist:

dis hie hundert und dreissigke sein:

So vil unnútzer wort man list!

$\left(\mathrm{V}_{11} 130,9-13\right)^{5}$

Die Dialektik der abbreviatio liegt an dieser Stelle offen zutage. Langweilige Länge und unverständliche Kürze stehen einander diametral gegenüber, und dazwischen tut sich abgrundtief die Frage nach dem rechten Maß der Worte auf. Hinzu kommt, dass sich die Situation im vorliegenden Fall insofern noch um einiges schwieriger gestaltet, als die Vorlage des Dresdener Heldenbuchs, die gegenüber der Heidelberger Virginal eine eigenständige Textversion darstellte, nicht erhalten ist. Weil so die Vergleichsgrundlage fehlt, ${ }^{6}$ ist kaum begründet nachzuvollziehen, weshalb dem Dresdener Redaktor auch seine - mit 408 Strophen (vir hundert und echte) nur gut ein Drittel der Länge der Heidelberger Virginal umfassende - Vorlage noch zu lang erscheinen konnte. Vor allem aber ist es unter diesen Bedingungen nahezu unmöglich, die Fassung des Dresdener Heldenbuchs hinsichtlich von Länge

3 Stein (1982/1983), S. 61.

4 Grimm (2009), S. 257. Ich zitiere diese beiden Textstellen, weil sie den in der Forschung immer wieder formulierten Gesamteindruck besonders bündig formulieren.

$5 \quad$ Ich zitiere alle Fassungen der Virginal nach der Ausgabe von Lienert (2017).

6 Das gilt, obwohl sich die Wiener Virginal in der Tendenz eher zu D stellt - und insofern bis zu einem gewissen Grad eine Vorstellung davon vermitteln kann, wie die ungekürzte Version D ausgesehen haben mag. Denn von den an D orientierten W-Passagen direkt auf die Vorlage der Virginal-Fassung des Dresdener Heldenbuchs zu schließen, ist selbstverständlich nur sehr bedingt möglich (vgl. dazu Lienert [2017], Bd. 1, S. 2327). Dass der vergleichende Blick auf die Wiener Virginal trotzdem wenigstens punktuell aufschlussreich sein kann, wird sich im übernächsten Abschnitt zeigen. 
und Kürze in ein sinnvolles Verhältnis zur Heidelberger Virginal zu setzen. Denn zwar ist klar, dass hier ein und dieselbe 〈Geschichte - das meint: eine Erzählung mit einem gewissen Grundbestand an Handlung, Motiven und Formulierungen - zweimal ganz unterschiedlich dargeboten wird, nämlich einmal besonders lang und einmal besonders kurz. Und klar ist auch, dass Verfahren von Erweiterung und Reduktion im damit einhergehenden Prozess des Um- und Wiedererzählens eine Rolle gespielt haben müssen. Wo und wie sie konkret zum Einsatz kamen, ist aber mangels eines gemeinsamen Referenzpunktes nicht mehr zu ermitteln.

Für eine Untersuchung zum Phänomen der abbreviatio ist das eine unkomfortable Ausgangslage - eine Ausgangslage, die für die traditionell mündlichkeitsnahe und unfeste Gattung der Heldendichtung freilich erwartbar ist und die dafür sorgt, dass diese im Rahmen des vorliegenden Sammelbandes generell einen schwierigen Gegenstand darstellt.7 Um einen heldenepischen Text auf Konzepte und Techniken der abbreviatio zu untersuchen, bedarf es deshalb ganz besonderer Gründe - und solche Gründe sind im Fall der Virginal dadurch gegeben, dass die Dresdener und die Heidelberger Fassung unabhängig voneinander Formen des Kürzens und Zusammenfassens realisieren, wie sie unterschiedlicher kaum sein könnten. An diese Prämisse anschließend geht es mir im Folgenden keineswegs um einen direkten - und als solchen wenig erkenntnisversprechenden - Vergleich der Texte. Stattdessen nehme ich die Heidelberger und die Dresdener Virginal einzeln in Bezug auf Kürzungen und Zusammenfassungen in den Blick, die sie auf verschiedenen Ebenen prägen und die nur in je spezifischen methodischen Zugängen erfasst werden können. Dabei wird sich herausstellen, dass die jeweils auftretenden Formen der abbreviatio sowohl in ihren konzeptuellen Grundlagen als auch in ihrer Zielrichtung grundlegend divergieren, was wiederum weitreichende Rückschlüsse auf unterschiedliche Kontexte von Mündlichkeit und Schriftlichkeit, auf differierende Wissens- und Erwartungshorizonte und nicht zuletzt auf verschiedene (angestrebte) Rezeptionsmodi zulässt. Einen gemeinsamen Fluchtpunkt haben die dergestalt getrennten Untersuchungen gleichwohl, und dieser führt auf die Frage nach dem rechten Maß der Worte zurück. Beide Virginal-Fassungen zeichnen sich

$7 \quad$ Vgl. dazu die grundlegende Studie von Heinzle (1978), hier bes. S. 56 f. 
nämlich dadurch aus, dass ihre abbreviationes das Verständnis sinnhaften Erzählens in besonderer Weise herausfordern und im Zuge dessen vor allem die Kategorien des «Nützlichen〉 und «Überschüssigen〉 auf den Prüfstand stellen. Die daraus resultierenden Fragen stehen im Zentrum meiner Untersuchung: Woraus ergibt sich, welche Worte für die Erzählung jeweils «nützlich〉 sind und welche nicht? Wer bestimmt es nach welchen Kriterien, und: Sind die Erwartungen, die wir selbst an einen sinnvoll gestalteten Erzähltext haben, bei der Beantwortung dieser Frage unbedingt hilfreich?

\section{Zur Heidelberger Virginal: abbreviatio als Element einer rhetorischen Narratologie}

Ich beginne meine Überlegungen bei der bereits recht früh im 14. Jahrhundert bezeugten und damit nicht nur längsten, sondern wohl auch ältesten Version, der Heidelberger Virginal. ${ }^{8}$ Indem ich diese auf das Thema der abbreviatio beziehe, begebe ich mich zumindest scheinbar in einen Widerspruch zur gesamten Forschung. Was ich als Verkürzung beschreiben möchte, erscheint dort nämlich durchweg unter dem Schlagwort der Erweiterung, oder genauer: der aus- und zerdehnenden «Rekapitulation», welche in weiten Partien der Virginal, so Hugo Kuhn, «als sinnlose Manier wuchert». ${ }^{9}$ Warum amplificatio und abbreviatio hier praktisch in eins fallen, ist indes leicht zu begründen: Am Anfang des Textes, in Strophe 7, wird der junge Dietrich von Bern in einem Kreis von Damen in Verlegenheit gebracht, weil er nicht von offentúre zu erzählen vermag $\left(\mathrm{V}_{10} 7,12\right) .^{10}$ Die restlichen 1.090 Strophen handeln, kurz gesagt, davon, wie er so lange mit Aventiure traktiert wird und man so lange davon erzählt (und schreibt), bis er es kann. Im Zuge dieser programmatisch durchgeführten «Erziehung zum Erzählen`"1

8 Die Fragmente $V_{1}-V_{4}$ und $V_{13}$ datieren in die erste Hälfte des 14. Jahrhunderts und repräsentieren den Textbestand des cpg 324 zumindest so weit, dass man ihn im Wesentlichen in dieser Zeit verorten darf.

$9 \quad$ Kuhn $\left({ }^{2} 1969\right)$, S. 224.

10 Die Belege in diesem Abschnitt beziehen sich durchweg auf $\mathrm{V}_{10}$ (im Folgenden ohne Sigle).

11 Dass Dietrichs Erziehung, um die es in der Virginal vornehmlich geht, als eine Erziehung zum Erzählen verstanden werden muss, deutet schon Stein an (1982/1983), 
werden Dietrichs eigentlich überschaubare Abenteuer - er rettet eine von Heiden bedrohte Jungfrau, kämpft gegen Drachen, wird durch Riesen gefangen genommen und von ihnen befreit und kämpft dann noch einmal gegen Riesen und Drachen ${ }^{12}$ - von verschiedenen Figuren und über mehrere Handlungsstränge verteilt wieder und wieder erzählt. Das erzeugt den Eindruck von dilatierender Weitschweifigkeit, obwohl die Rekapitulationen im Einzelnen durchweg verkürzende Zusammenfassungen des Erzählten darstellen.

Die ältere Forschung wusste dies nicht anders zu deuten denn als Unfähigkeit und Vergesslichkeit eines Erzählers (beziehungsweise Dichters), der offenbar des simplen Rückverweises nicht mächtig sei und der sich beim Wiederholen zudem permanent in Ungereimtheiten und Widersprüche verwickle. $^{13}$ Die jüngere Forschung ist zwar mehrheitlich zur Einsicht gelangt, dass die repetitiven Passagen das Erzählen thematisieren und so ein spezifisches Sinnangebot unterbreiten oder doch jedenfalls das Verständnis des Textes erleichtern. Worauf dieses Angebot zielt, beziehungsweise welches Verständnis erleichtert werden soll, wird von ihr allerdings ganz unterschiedlich wahrgenommen. So hat man die rekapitulierenden Berichte und Briefe als erzähltechnisches «Mittel d[ ]er Synchronisation ${ }^{14}$ sowie, in völlig ande-

S. 77 f., im Anschluss daran arbeitet besonders Reuvekamp-Felber (2003) die Ausbildung kommunikativer Kompetenz als wesentlichen Aspekt des narrativ entfalteten Erziehungsprogramms heraus. Daneben lernt Dietrich auch anderes, insbesondere ritterliches Verhalten im Kampf wie gegenüber Frauen und richtiges Herrschaftshandeln (vgl. dazu mit Verweis auf ältere Forschung Gillespie [1987]; Kropik [2003/2004]). Die Verbindung von beidem steht augenscheinlich in engstem Bezug zu einem arthurischen Verständnis von Aventiure, in dem Geschehen und Geschichte, Handeln und Erzählen untrennbar zusammengehören. Vgl. dazu Kerth (2003/2004), S. 148f.; Kerth (2008), S. 155-179; Kragl (2013), bes. S. 365 f.; Knäpper (2016), S. 38-41.

12 Ich verzichte auf einen umfassenden Abriss der Handlung und gehe im Folgenden nur auf die Passagen näher ein, die für meine Argumentation notwendig sind. Eine ausführliche Zusammenfassung mit Hinweis auf alle Berichte und Briefe findet sich bei Störmer-Caysa 2002, S. 9-11.

13 Vgl. bes. von Kraus 1908; Kuhn $\left({ }^{2} 1969\right)$, S. 224-226.

14 Stein (1982/1983), S. 77. Stein weist zudem auf einige inhaltliche Funktionen hin, die in der anschließenden Forschung aufgenommen und weiter begründet werden: die narrative Rahmenbildung, die Thematisierung der Erzählsituation in ihrer gesellschaftli- 
rer Akzentuierung, als Rezeptionshilfe im Zusammenhang mündlicher Aufführung vor einem "womöglich [...] teilweise wechselnde[n] Publikum» verstanden. ${ }^{15}$ Man hat die Erzählungen der Figuren als Diskussionsmedium von «Wissens- und Kommunikationsdefiziten» gedeutet, deren Beseitigung entweder Dietrichs Erfolg als Fürst ermögliche ${ }^{16}$ oder das ihm im Gegenteil kommunikative Insuffizienz bescheinige. ${ }^{17}$ Und schließlich hat man das Nebeneinander von (arthurisch) aventiurehaftem Erzählen und historisierendem Bemühen um Wahrhaftigkeit als «Schieflage» beschrieben, die heldenepisches Erzählen in einen "prekäre[n] Zwiespalt» treibe. ${ }^{18}$ Angesichts dieser verwirrenden und durchaus kontroversen Deutungsvielfalt kann es wenig verwundern, dass die Sinnhaftigkeit der Erzählwiederholungen der Heidelberger Virginal zuletzt wieder in Abrede gestellt wurde ${ }^{19}$ - ganz abgesehen davon, dass das Befremden über die Art des Erzählens allen interpretierenden Bemühungen zum Trotz nicht abzunehmen scheint: Auch und gerade in den avanciertesten Deutungsversuchen ist bis in die jüngste Zeit hinein von «Wiederholung um des Wiederholens willen ${ }^{20}$ und von «[e]rzähllogisch völlig unsinnig[en]» und «entbehrlich[en] [...] Zusammenfassungen ${ }^{21}$ die Rede; zudem wird man nicht müde, hier besonders viele «Erzählfehler»22, darunter vor allem inhaltliche Widersprüche, inkohä-

chen und artistischen Funktion, die figurengebundene Perspektivierung der vorangehenden Handlung sowie, damit zusammenhängend, die Charakterisierung der Figuren (ebd., S. $77 \mathrm{f}$.$) .$

15 Störmer-Caysa (2002), bes. S. 14-19, hier: S. 19. Dieser Vorschlag geht zwar ebenfalls von einer Art der Synchronisation (von Wissensständen) aus, zielt damit aber nicht auf die innere Koordination des Erzählens, sondern auf die Pragmatik des Vortrags. Kritisch dazu bes. Reuvekamp-Felber (2003), S. 73.

16 Reuvekamp-Felber (2003), hier: S. 63.

17 Philipowski (2008), bes. S. 341.

18 Kragl (2013), S. 323-373; 367-373; hier: S. 372.

19 Zimmermann (2017), bes. S. 111.

$20 \quad \operatorname{Kragl}$ (2013), S. 360.

21 Störmer-Caysa (2003), S. 18.

22 Ebd., S. 19. 
rente Figurenzeichnungen und narrative Unklarheiten infolge mangelnder Unterscheidung von Erzählebenen, zu konstatieren. ${ }^{23}$

All diese Abwertungen, das sei betont, sind absolut nachvollziehbar: Wohl jeder Leser und jede Leserin, der / die moderne zumal, würde sie sofort unterschreiben. Über ihre Angemessenheit ist damit freilich noch nicht alles gesagt, und zwar unter anderem deshalb nicht, weil sich der Befund anders darstellt, wenn man die Wiederholungen statt als Erweiterungen der Erzählung als abbreviationes der Handlung begreift, oder genauer: als eine Reihe von abbreviationes, die nach einem bestimmten Prinzip vorgenommen und über einen Text verteilt werden, der nicht zuletzt mit Blick auf sie komponiert und narrativ geformt ist. Der Effekt einer dergestalt veränderten Betrachtungsweise besteht vornehmlich darin, dass sich der Fokus der Untersuchung verschiebt, wobei an die Stelle von Problemen, die in der Systematik moderner Narratologie virulent erscheinen - wie etwa solchen des Verhältnisses von Erzählinstanzen sowie der Kohärenz und Konsistenz von Erzählebenen -, nun Fragen treten, die in den Kontext mittelalterlicher Poetik hineinführen. Konkret richtet sich der Blick im vorliegenden Fall auf Verfahren der stofflichen Disposition im Zusammenhang eines Verständnisses von «Erzählen〉, das wesentlich von der rhetorischen narratio-Lehre geprägt ist. Ich beschränke mich darauf, dieses Verfahren exemplarisch aufzuzeigen, und wähle dafür ein Beispiel, das mir besonders beweiskräftig scheint - einen Teil der im Verlauf der Handlung wenigstens fünf Mal rekapitulierten Ereignisse um Dietrichs ersten Drachenkampf, konkret: die Rettung des Ritters Rentwin aus dem Maul eines Drachen. ${ }^{24}$

Um die narrativen Eigenheiten zu verdeutlichen und das Geschehen einzuordnen, beginne ich mit einem kurzen Blick auf die Ereignisse am Anfang des Textes.

23 Vgl. etwa ebd., S. 17; Kragl (2013), S. 331-347; 363-365; Zimmermann (2017), bes. S. $95-99$.

24 Meine Untersuchung berücksichtigt die narrativ ausformulierten Berichte des Geschehens in den Erzählungen 1. Rentwins (179-181), 2. Bibuncs (282-290), 3. Dietrichs (410f.), 4. Hildebrands (602f.) und 5. Dietrichs (1017). Nicht einbezogen ist jene Passage, in der Bibunc direkt im Anschluss an seinen Bericht von Rentwins Abenteuer noch einmal Rentwins Bericht dieses Abenteuers schildert (297), sowie eine nochmalige (sehr kurze) Rekapitulation Rentwins in Str. 901. 
Die aus mehreren raumzeitlich koordinierten Strängen bestehende Handlung geht so, dass Dietrich durch sein Versagen im Aventiuregespräch (s. o.) dazu veranlasst wird, auf die mere (2,5) von der Bedrohung der Königin Virginal durch einen mordlustigen Heiden zu reagieren, und beschließt, die Bedrängte zu befreien. Gemeinsam mit seinem Lehrer Hildebrand reitet er in den Tiroler Gebirgswald - wo er sich sogleich wieder von ihm trennt: Während Hildebrand dem Hilferuf einer vom Heiden bedrohten Gefolgsfrau der Virginal folgt und den Übeltäter besiegt, stößt Dietrich, auf die Rückkehr seines Gefährten wartend, auf das heidnische Gefolge und reibt es vollkommen auf. Danach treffen Dietrich, Hildebrand und die Jungfrau zusammen, und letztere lädt ihre Retter an den Hof Virginals ein. Sie reitet voraus, um Rapport zu erstatten und die Ankunft vorzubereiten. Während dies ausführlich (123-142) erzählt wird, bleiben die Helden (wiederum wartend) im Wald zurück und geraten in den Drachenkampf, um den es hier vornehmlich geht.

Da die Erzählung der Jungfrau an den Hof folgt und erst mit dem Zwergenboten Bibunc, den Virginal zu den Helden aussendet, zum Ort des Geschehens zurückkehrt, beginnt die Schilderung des Drachenkampfes in Strophe 143,7 medias in res und zieht sich dann über gut 33 Strophen hin (bis 176).

In diesen wird zunächst kurz (144-146) von Dietrichs Kampf gegen einen riesigen feuerspeienden Drachen erzählt. Danach geht es um den - erneut an anderer Stelle kämpfenden - Hildebrand: Dieser ist dabei, ein Drachennest auszuheben, als ein alter Drache herbeieilt, der einen hilferufenden Ritter im Maul trägt und ihn fallen lässt, als er angegriffen wird (147-149). Nachdem Hildebrand den Drachen erlegt hat (150f.), sucht und weckt er den ohnmächtigen Ritter $(152,1-153,3)$ und redet lange mit ihm $(153,4-$ 167,13). Im Zuge dessen nennt dieser seinen Namen, Rentwin (157,1), und den seiner Eltern, Helfferich von Lune (155,9f.) und Portalaphin (156,1), welche Hildebrand als seine Nichte identifiziert (158f.). Danach lädt Rentwin den Onkel auf seine Burg Arona ein; der lehnt das Angebot jedoch mit Verweis auf den noch immer drachenkämpfenden Dietrich ab (160f.). Rentwin beschließt, Hildebrand zu begleiten (162). Da sein Pferd, wie Hildebrand jetzt mitteilt, von Drachen gefressen wurde (163,3-6), sitzt er bei diesem auf (164). Die nächsten Strophen (168-176) berichten, wie die Helden Dietrich im Kampf mit einem Drachen finden, sich jedoch zunächst damit begnügen, ihm zuzusehen. Erst als sein Schwert bricht und Dietrich beginnt, dem Drachen in Ermangelung eines Besseren Steine ins Maul zu werfen (174,5-9), will Hildebrand eingreifen, was Dietrich jedoch ablehnt (175,7-13). Stattdessen nimmt er Rentwins Schwert und tötet den Drachen (176). 
Wie seltsam die Schilderung tatsächlich wirkt, kann dieser Abriss nur in Ansätzen vermitteln. Das Merkwürdigste ist nicht einmal die verschlungene, gespaltene und wieder zusammengeführte, vielfach springende Handlungsdarstellung selbst. Vielleicht noch verblüffender ist vielmehr der Aufwand an schriftliterarisch avancierter Erzählkunst, mit dem alles arrangiert und ausgebreitet wird. Der Verfasser der Heidelberger Virginal scheint eine geradezu maliziöse Freude daran zu haben, die Handlung zu unterbrechen, um Botengänge, Reden, Dialoge und Berichte dazwischenzuschieben. Zudem gefällt er sich offenbar darin, Passagen mit interessanten Ereignissen, wie z. B. Hildebrands Drachenkampf, lapidar abzutun (147-151) und sich dafür in schier endlosen Gesprächen (z. B. Hildebrands mit Rentwin: 153-167) und (Reise-)Beschreibungen zu ergehen. Damit in Zusammenhang steht der Ansatz einer Perspektivierung, die die Darstellung auf den Erlebnishorizont einer handelnden Figur beschränkt. Wenn die Erzählung der geretteten Jungfrau an den Hof der Virginal folgt (123), so entsteht etwa der Eindruck, als nähmen «die Boten [...] die Zuhörer gleichsam mit». ${ }^{25}$ Doch damit noch nicht genug: Da die RezipientInnen ganze 18 Strophen bei Virginal verharren und im Zuge dessen durch ihre Zeltstadt geleitet sowie in ihren Hofstaat eingeführt werden (124-142), verbindet sich ihr Eindruck des «Mitgenommen-Werdens` fast unweigerlich mit dem Gefühl, sich bei Virginal gleichsam $\mathrm{zu}$ vertrödeln und inzwischen einen wesentlichen Teil des Hauptgeschehens - nämlich den Anfang des Drachenkampfes, in den sie darum später mitten hineinplatzen - zu verpassen. Ob der Effekt damit korrekt beschrieben und gezielt erzeugt ist, sei dahingestellt; festzuhalten ist jedoch, dass er sich, wenn

25 Störmer-Caysa (2003), S. 11. In narratologischer Terminologie ist von einem Raumfilter zu sprechen, dessen fokalisierende Wirkung dadurch verstärkt wird, dass die Erzählung den Figuren nicht nur folgt, sondern auch ihre Wahrnehmungen wiedergibt (z. B. $124,1 ; 143,6)$. Eine interne Fokalisierung liegt gleichwohl nicht vor: zum einen, weil die «mitnehmende` Figur wechselt und z. T. nicht identifizierbar ist, zum anderen, weil der narrative Fokus sich auch unabhängig (weiter-)bewegen kann. So lässt er etwa in der vorliegenden Passage Bibunc im Wald zurück, während er weiter zu den Drachenkämpfern voranschreitet (Bibunc selbst kommt erst nach Abschluss der Kämpfe an und betrachtet in Str. $218 \mathrm{f}$. staunend die toten Tiere). Die Wirkung des Erzählens ließe sich mithin als eine Art Kameratechnik beschreiben, wobei sich die Kamera zwar in der erzählten Welt befindet, den Figuren aber nur partiell folgt. 
Motivationen fehlen und wichtige Informationen stückchenweise nachgetragen werden, bestätigt und verstärkt. So kann man etwa den Umstand, dass der Ritter in Strophe 147 ohne jegliche Vorbereitung oder Einführung aus dem Maul des Drachen herausruft, damit erklären, dass die Zuhörer und Zuhörerinnen hier von Hildebrand «mitgenommen` und von den Ereignissen darum genauso überrascht werden wie dieser selbst. Aus demselben Grund scheint auch plausibel, weshalb die Vorgeschichte von Rentwins DrachenBredouille an dieser Stelle dunkel bleibt - denn dieser bleibt die Antwort auf Hildebrands dahingehende Frage schuldig. ${ }^{26}$ Und so erklärt sich ebenfalls, dass wir nicht verstehen, warum Dietrich Hildebrands Schwert ablehnt (176,1-5): Dessen kindlich-trotzige Reaktion ist uns genauso unverständlich wie (vermutlich) seinem Waffenmeister.

In der Forschung wurde gelegentlich vermutet, dass der Verfasser der Heidelberger Virginal die Handlung absichtlich verkompliziere, um Kommunikationssituationen zu zerdehnen und so einen Informationsbedarf herzustellen, der durch die Berichte bewältigt werde. ${ }^{27}$ Vor dem Hintergrund meiner letzten Beobachtung liegt es nahe, noch einen Schritt weiter zu gehen und zu behaupten: Nicht nur die künstliche Dehnung der Handlung, sondern auch ihre in Ansätzen perspektivische Darstellung ist darauf angelegt, ein Defizit zu erzeugen, das in den Erzählungen der Figuren behoben wird. In diesem Sinne wäre davon auszugehen, dass die Ereignisse absichtlich so geschildert werden, wie sie sich einem «mitgenommenen` Berichterstatter darbieten würden - nämlich unübersichtlich, ungeordnet und lang -, damit die Figuren sie anschließend verdeutlichend, ordnend und kürzend so weit verdichten können, dass sie als Erzählung genießbar werden. ${ }^{28}$ Der wohl prominenteste Parallelfall für ein solches Vorgehen ist die (darin auf das Nibelungenlied reagierende) Klage, wo bekanntlich ebenfalls ein Bote, nämlich Etzels spilman Swämmel, dafür verantwortlich ist, verschiedene Berichte

Er sagt nur, dass der Drache in ligen vor der steines want gefunden habe $(154,4)$. Dass er geschlafen habe (oder sich schlafend gestellt, um dem Drachen aufzulauern, wie Lienert [2017], Bd. 1, im Kommentar zur Stelle [S. 105] vermutet), behauptet erst Hildebrand Str. 157,12 f., vgl. Anm. 32.

27 So bes. Philipowski (2008), S. 334-336.

28 Das entspricht in etwa der narratologischen Vorstellung der Transformation von Geschehen in Geschichte. Vgl. etwa Schmid ( $\left.{ }^{3} 2014\right)$, S. $223 \mathrm{f}$. 
der Ereignisse um den Burgundenuntergang zu sammeln, zu ordnen und als verbürgte Botschaft zu verbreiten. ${ }^{29}$ Den Erzählungen der Heidelberger Virginal geht die staatstragende Ernsthaftigkeit, mit der die ungeheuren Vorgänge des Untergangsgeschehens in der Klage in «legitimitätsstiftende historia» überführt werden ${ }^{30}$ zwar gänzlich ab. Gerade weil sie die Thematisierung des Erzählens stattdessen mit ihrem sehr viel 〈leichteren` Erziehungsprogramm verbinden, gewinnen sie jedoch die Freiheit eines vergleichsweise spielerischen und bis zu einem gewissen Grad vielleicht sogar amüsanten Umgangs mit der Materie. In diesem Licht sind die Rekapitulationen insgesamt, darunter auch die des Drachenkampfes, als eine vielstimmige Reaktion auf Dietrichs anfängliches Versagen als Erzähler zu verstehen: Wenn die Figuren das Aventiuregeschehen mehrfach, und zwar in immer wieder anderer Weise, zu Geschichten umgestalten, dann formulieren sie damit so etwas wie eine praktische Erzähllehre - eine Erzähllehre, die die Chancen und Möglichkeiten des Erzählens in weitem Umfang auslotet und in der das Kürzen und Zusammenfassen augenscheinlich eine wichtige Funktion hat.

Der Bezug zur rhetorischen narratio liegt an dieser Stelle insofern ohnehin nahe, als jede Form von Erzähllehre in der rhetorisch verfassten Poetik des Mittelalters nur hier ihren Platz haben kann. Ihre besondere Relevanz für die Erzählungen der Heidelberger Virginal zeigt sich spätestens beim genaueren Blick auf den Text. So zeichnen sich die Rekapitulationen der Rettung Rentwins dadurch aus, dass sie die Ereignisse verschiedenen Figuren in den Mund legen und dabei in Situationen stehen, in denen jeweils ein ganz bestimmtes (und wiederum je differentes) Ziel angestrebt und erreicht werden soll: Wenn hier so etwas wie eine «Narratologie` entworfen wird, dann ist das darum schon im Ansatz keine, die das Erzählen systematisieren oder gar theoretisch konzeptualisieren soll, sondern eine auf spezifische Wirkungskalküle gerichtete, rhetorische. ${ }^{31}$

29 Dazu bes. Müller (1996), zu dieser Deutung im Zusammenhang von Nibelungenlied und Klage auch Kropik (2008), bes. S. 148-152.

$30 \quad$ Müller (1996), S. 95.

31 Sie ist also auf das persuadere gerichtet, das die Rhetorik definiert (vgl. Lausberg [2008], \$33) und auch die narratio bestimmt (vgl. ebd., \$293). 
Worauf es dabei im Wesentlichen ankommt, lässt der erste Bericht besonders nachdrücklich deutlich werden. Das gilt umso mehr, als er modernen Lesern und Leserinnen leicht störend erscheinen kann, weil er alles, was sie schon wissen, noch einmal wiederholt - und zwar ohne nennenswerte Pause direkt im Anschluss an das berichtete Geschehen.

In Strophe 176 tötet Dietrich den letzten Drachen; gleich danach eilt, herbeigerufen durch den Lärm des Kampfes, schon Rentwins Vater Helferich in Begleitung seiner Gefolgsleute herbei und verlangt nach einer Erklärung des Geschehens (177f.). Daraufhin berichtet Rentwin, beginnend mit einer Wahrheitsbeteuerung $(179,13)$, wie er auf der Suche nach Drachen ausgeritten, dann aber im Wald eingeschlafen sei. Er erzählt weiter, dass der Drache ihn darum wehrlos vorgefunden, halb verschlungen und - nach seinem Pferd davongetragen habe (180). Dabei sei er auf Hildebrand gestoßen, welcher seinem Hilferuf gefolgt sei und ihn gerettet habe (181). Schließlich erfahren wir nochmals, wie er gemeinsam mit Hildebrand auf einem Pferd reitend just in dem Moment zu Dietrich kam, als diesem das Schwert brach (182).

Inhaltlich bietet der Bericht - abgesehen vom Detail, dass Rentwin (wie Ortnit) im Wald eingeschlafen sei $^{32}$ - also keine neuen Informationen. Ihn als «leere Wiederholung ' zu bezeichnen, wäre dennoch verfehlt, denn es ist unschwer zu erkennen, welchem Reglement der Erzähler folgt: Rentwin beantwortet die Frage seines Vaters $\{[w]$ as ist hie der mere? $(178,3)$, indem er die Ereignisse erfasst, chronologisch ordnet, nachvollziehbar verknüpft und glaubhaft vermittelt, wobei er den Inhalt der dreißig vorangehenden Strophen, die all diese Merkmale nicht aufwiesen, in drei Strophen zusammenfasst. ${ }^{33}$ Nimmt man noch hinzu, dass er damit auf eine etwas brenzlige Situation reagiert, da der Vater anfangs nicht weiß, wer ihn angegriffen hat, und seine Racheabsicht leicht gegen Dietrich und Hildebrand wenden

32 Kragl ordnet ihn deshalb in die Kategorie der «Wiederholung mit neuen Details» ein ([2013], 356 f.). Streng genommen geht der Nachtrag freilich auf Hildebrand zurück, der Rentwin schon zuvor belehrt hatte: 〈Legent sloffen iu veste fúr den walt und tragent dem wilden wurme has.> (157,12 f.), vgl. Anm. 26.

33 Ordo naturalis sowie narratio probabilis und brevis dienen der perspicuitas und wirken zugleich credibilis. Vgl. Lausberg (2008), § 315-325. 
könnte, ${ }^{34}$ dann ist klar: Rentwins Bericht ist lehrbuchhaft rhetorisch verfasst. Er erzählt mit einem bestimmten persuasiven Ziel, das, wie er selbst expliziert, darin besteht, den Vater dazu zu bringen, seine Begleiter als Gäste $\mathrm{zu}$ behandeln und ehrenvoll zu empfangen. ${ }^{35}$ Redezweck und -situation, Sprecher und Adressat steuern also Inhalt, Anlage sowie natürlich Länge und Kürze des Berichteten. Das Ergebnis fällt aus wie gewünscht: Helferich versteht, dankt den Rettern und nimmt sie hocherfreut bei sich auf.

Rentwin illustriert mithin auf engstem Raum, was einen instruktiven Bericht ausmacht, wobei er die rhetorischen virtutes von brevitas, perspicuitas und verisimilitas vorbildlich realisiert. Ob er damit geradezu das Modell setzt, wage ich nicht zu entscheiden; der Blick auf drei der vier anderen Berichte zeigt aber, dass sie ähnlich angelegt sind. Ihre im Detail differierende Gestalt lässt sich jeweils aus dem situativen Kontext erklären, in dem sie stehen.

So wird die Geschichte vom Ritter im Drachenmaul in ihrer vierten und fünften Rekapitulation wohl deshalb noch kürzer abgehandelt als von Rentwin, weil sie dort jeweils nur eine Episode in einem größeren Ganzen darstellt und insofern weniger bedeutsam ist: Der vierte Bericht folgt, als Hildebrand nach einigen Wendungen, die zu Dietrichs Gefangenschaft in der Burg Muter führten, allein nach Bern reist, um Hilfe zu holen. Dass sein Auftritt Besorgnis auslöst, ist da nur allzu verständlich und wird breit illustriert (595-599). Hildebrand beantwortet die Frage nach dem Verbleib des Berners, indem er der etwas peinlichen Gefangennahme (604,12f.) einen Bericht der erfolgreichen Heiden- (600f.) und Drachenkämpfe (602f.) vorangehen lässt. Er bemüht sich also insgesamt um eine positive Darstellung des Unternehmens und beruhigt die Gemüter damit immerhin so weit, dass er den Aufruf zur Teilnahme an der Befreiung Dietrichs ungestört vorbringen kann. - Ganz sachlich gehalten ist hingegen der fünfte Bericht, in dem Dietrich am Schluss das gesamte Geschehen noch einmal resümiert (1.014,4$1.024,4)$ und dadurch nicht zuletzt beweist, dass er des Erzählens nun mächtig ist: Das Rentwin-Abenteuer wird konsequenterweise zu einer oventure $(1.017,3)$ unter vielen, die entsprechend in einer Strophe abgehandelt werden kann (1.017).

34 〈Mag ichs an dem gerechen niht / der úch do hat verhouwen, / dar an mir hertzeleit geschicht.> (178,7-9). Gegen wen sich die Äußerung richtet, wird zwar nicht gesagt; dass Dietrich und Hildebrand hier in Verdacht stehen, ist aber eine naheliegende Vermutung. Rentwin bestätigt sie durch die Forderung in der nächsten Strophe (vgl. Anm. 35): Scheinbar meint er, seine Begleiter in Schutz nehmen zu müssen.

35 〈Here und lieber vatter min, / enpfohent wol die geste. / Dar an lit hoher eren vil, / als ich úch underwisen wil.> (179,2-5). 
Der dritte Bericht ist mit zwei Strophen «Ritterrettung〉 ebenfalls sehr kurz, diesmal allerdings deshalb, weil Dietrich aus einer dezidiert subjektiven Perspektive vor allem von seinen eigenen Erlebnissen berichtet und daher über Rentwin weniger zu sagen hat. So erfahren wir jetzt zwar, was nach dem Abschied der Jungfrau im Wald geschah (407), und wir erfahren auch sehr viel über die angest und not seiner eigenen Drachenkämpfe (412,1); das Rentwin-Abenteuer aber bleibt in seiner Schilderung vergleichsweise blass (410f.). Interessant ist an dieser Stelle ein anderes Detail: Wenn Dietrich behauptet, die Befreiung Rentwins mit [s]inen ougen gesehen zu haben $(410,11)$, dann lügt er offensichtlich - und tut im Sinne der narrativen Rhetorik eventuell gleichwohl das Richtige: Hier kommt zumindest der Verdacht auf, dass der beglaubigende Gestus und die mit ihm einhergehende verisimilitas für ein 〈gutes〉, d. h. erfolgreich-überzeugendes Erzählen mehr gelten als das Streben nach Wahrheit und die Genauigkeit des Berichts. ${ }^{36}$

Von diesen vier dergestalt recht homogen verfassten Rekapitulationen von Rentwins Rettung hebt sich die zweite in mehrfacher Hinsicht ab und erlaubt es, den bisher benannten Aspekten noch einige hinzuzufügen. Auffällig ist zunächst, dass hier anders als in den anderen Berichten kein unmittelbar Beteiligter spricht, sondern einer, der die Ereignisse nur aus den Erzählungen anderer kennt - wir haben es also quasi mit einer Erzählung auf zweiter Stufe zu tun. Immerhin hat sich der Botenzwerg Bibunc in der Nähe der Ereignisse befunden; ${ }^{\mathbf{3 7}}$ vor allem aber ist er ein Meister im Fach der narratio. Schon zuvor hatte er in Arona eine Probe seines Könnens gegeben (229232), und hier kann er nun reichlich nachlegen: Sein Bericht umfasst insgesamt nicht weniger als dreißig Strophen. Bibunc erzählt von seiner Reise nach Arona, von seiner Ankunft, seinem Empfang und davon, wie er den Brief erhielt, der kurz zuvor (258-267) verlesen worden ist (270,7-280,13). Wenn er danach zur Geschichte Rentwins übergeht, so ist das in diesem Zusammenhang nicht nur insofern bemerkenswert, als er diese mit neun Strophen deutlich länger fasst als alle Figuren vor und nach ihm. Mindestens ebenso beachtlich ist, dass er mit ihm zumindest unmittelbar keinen (prag-

36 Da es Dietrichs erster Erzählversuch ist, könnte man auch behaupten, er schieße über das Ziel hinaus. Immerhin wird sein Lapsus nicht sanktioniert: Seine (freilich etwas naive) Zuhörerin glaubt ihm jedes Wort.

37 Auf seinem Weg von Jeraspunt zum Kampfplatz ist er in Hörweite, als die Erzählung zu Dietrich springt. ([...] bitz er kam an die stat, / do er horte den Berner striten, 143,5 f.). 
matischen) Zweck verfolgt und insofern nicht auf den Bereich der (informierenden beziehungsweise überzeugenden) 〈Belehrung〉 (docere), sondern auf den der Unterhaltung, also des delectare zielt. Das vielleicht deutlichste Indiz dafür ist, dass Bibunc seinen Auftrag an dieser Stelle schon erfüllt hat: Er hat den Brief übergeben, narrativ authentifiziert und ist von der Königin ausdrücklich für seine Arbeit gelobt worden ( $(D u$ hast geworben, als $d u$ solt. / Min hertze ist dir mit truwen holt.〉, 281,4f.). Wenn sie jetzt noch fragt: ‘was dút sú do czú Arone?? (181,8), dann verlangt sie etwas anderes als zuvor: eine unterhaltsame Geschichte.

Die Königin ist also schlicht neu- oder auch: aventiuregierig, und Bibunc geht darauf ein, indem er flugs die Geschichte von Rentwins Rettung erzählt. Weshalb er sich unter all den Abenteuern, die in Arona umgehen (vgl. 295,9-13), für dieses entscheidet, ist nicht schwer zu erraten: Hier bietet sich der Stoff, der für den ambitionierten Erzähler am meisten hergibt. In diesem Kontext ist nicht nur die relative Länge des Berichts zu verstehen, sondern auch seine vergleichsweise ausgeprägte Artifizialität. Bibunc schmückt seine Erzählung mit wörtlicher Rede, deskriptiven Passagen sowie motivierenden (und beschönigenden) (Zahlen-)Angaben; ${ }^{38}$ vor allem aber verleiht er ihr durch die Verknüpfung zweier Handlungsstränge eine fast schon literarisch anmutende Komplexität. Letzteres ist an dieser Stelle besonders interessant, weil die narrative Komplexitätssteigerung einen weiteren rhetorischen Effekt zeitigt: Der Erzählung des Zwergs wohnt ein Moment der Affekterregung inne, das zugleich die Sympathie seiner Zuhörerin lenkt und ihre Aufmerksamkeit fesselt.

38 Er beginnt mit einer lobenden Charakterisierung Rentwins (als captatio benevolentiae: 281,11-283,1) und behauptet weiter, Rentwin sei heimlich $(283,4)$ ausgeritten (wovon vorher nicht die Rede war) sowie zwene dage und zwo nacht unterwegs gewesen $(283,7)$, bevor er eingeschlafen sei (Rentwin selbst spricht dagegen von einem Tag und einer Nacht [180,1]). Eindrucksvoll ausgebaut ist der dramatische Dialog zwischen Rentwin und Hildebrand (sermocinatio: 287); in wörtlicher Rede gegeben ist außerdem Helferichs Entschluss, dem Lärm zu folgen (292,5-8). Pathetische Wirkung hat die Apostrophe: Wo wart ie hertze me so fro, / als er her Hiltebranden sach? (286,12f.). Es handelt sich - ebenso wie bei den gleich noch zu ergänzenden - durchweg um Mittel der Evidenzerzeugung, welche ihrerseits zum ornatus gehören, vgl. Lausberg (2008), $\$ 810-825$, bes. $\$ 810$. 
Ausgangspunkt ist ein narrativer Kniff, der es Bibunc ermöglicht, das Geschehen um Rentwin auf der einen und das um Hildebrand auf der anderen Seite in eine chronologische Abfolge zu bringen. Ganz ähnlich wie der Erzähler der Heidelberger Virginal selbst bedient er sich dafür eines 〈Boten〉, der seine Zuhörerin 〈mitnimmt»:39 Bibunc berichtet zunächst, wie Rentwin in Hoffnung auf ritterliche Bewährung ausgeritten, dann aber $[o] b$ einem burnen eingeschlafen sei (283,12, Rentwin-Handlung). Mithilfe des Drachen, der Rentwins Pferd packt und es zu sinen jungen bringt (284,6), überbrückt er sodann die räumliche Distanz zu Hildebrand. Während der die Drachenbrut erlegt (284,9-285,2, Hildebrand-Handlung), gelangt Bibuncs Erzählung mit dem alten Drachen wieder zurück zu Rentwin (285,3-10) - und expediert diesen im Drachenmaul zu Hildebrand, um ihn in bewährter Weise retten zu lassen (285,11-286,13, Zusammenführung der Handlungsstränge). Was in dieser Weise als ein erzähltechnisches Hilfsmittel erscheint, gewinnt affekterregende Qualität, weil Bibunc den Drachen über seine vermittelnde Funktion hinaus zur fokalen Figur macht. Rhetorisch gesehen fällt seine Darstellungsweise in den Bereich der evidentia: Indem er den Vorgang detailreich ausmalt, zieht er seine Hörerin auch in dessen 'Akteur hinein..$^{0}$ Im Zuge dessen verfolgt er nicht nur den Weg des Drachen (von eines burnen flus [...] uff zü berge, 285,7f.), sondern benennt auch seine Motivation (er wolte me bejagen, 284,8) und die Intentionalität seines Verhaltens (Der alte kam geloffen, / do er daz ros hette genomen. / Do kunde er wol hien wider komen. / Er volgete siner slóffen, 285,3-6). Resultat dieser fictio personae ist, ${ }^{41}$ dass das Verhalten des Drachen den Rezipienten genauso nachvollziehbar erscheint wie das Rentwins und Hildebrands. Aus diesem Grund entfaltet sich in Bibuncs Erzählung parallel zur schon bekannten Ritterrettung ein veritables Familiendrama: Wenn Bibunc berichtet, wie der vom Drachen gepackte Rentwin nach studen oder este[ $n]$ greift $(286,8)$ und Hildebrand um Hilfe anfleht, dann führt er uns dessen Verzweiflung ebenso eindringlich vor Augen wie Hildebrands Sorge um ihn, als er vom Drachen $z u^{o}$ einer wende geworfen wird $(288,8)$. Andererseits steht uns aber auch der Schock des Drachen lebhaft vor Augen, als er des Gemetzels gewahr wird, das Hildebrand in seinem Nest angerichtet hat (289,1-4), und wir verstehen, weshalb er daraufhin in zorn [...] erbrant besonders heftig auf Hildebrand losgeht $(289,5)$.

Dass Bibunc hier Verständnis, ja Mitgefühl für den Drachen weckt, ist vielleicht bis $\mathrm{zu}$ einem gewissen Grad befremdlich, hat aber einen guten

39 Vgl. dazu nochmals Störmer-Caysa (2003), S. 11, und meine Erläuterung in Anm. 25.

40 Lausberg (2008), $\$ 810$. Zu den hier aufscheinenden Parallelen von rhetorischen und narratologischen Kategorien Hübner (2010).

41 Vgl. Lausberg (2008), § 826-829. 
Sinn: Indem er das Handeln des Untiers plausibilisiert und seine Gerissenheit nicht minder eindrücklich zeigt als die grausige Fürsorge gegenüber seinen Jungen, baut er es zu einem Antagonisten auf, dessen Überwindung ausnehmend schwierig und darum ganz besonders verdienstvoll ist. Wo der epische Erzähler 15 von 21 Strophen auf die Schilderung eines langweiligen Gesprächs verwendet hatte und wo die anderen Figuren hauptsächlich informative Abrisse des Geschehens geben, da entfaltet Bibunc mithin in neun Strophen eine Erzählung, die nicht nur Anfang, Mitte und Ende hat, sondern auch einen Spannungsbogen, der seine Hörerin mitzureißen vermag, und eine Bewertung, die sich von selbst erschließt. ${ }^{42}$

Obwohl es Bibunc vordergründig zweifellos darum geht, seiner Herrin kunstvolle Unterhaltung zu bieten, wird an dieser Stelle deutlich, dass auch sein Bericht nicht frei von utilitas ist. Wenngleich es kaum nötig ist, Virginal nochmals von der ritterlichen Exzellenz ihrer Befreier zu überzeugen, so kann es doch jedenfalls nicht schaden, ihr diese erneut vor Augen zu halten: Immerhin ist es die Aufgabe der Damen, den Rittern für ihre Heldentaten zu danken ${ }^{43}$ - und Bibunc lässt damit nicht zuletzt uns, den Hörern und Hörerinnen der Heidelberger Virginal, verständlich werden, was eine gute Aventiure-Erzählung leistet.

Ob und inwiefern diese Qualität auch die Heidelberger Virginal selbst kennzeichnet, kann man natürlich mit einigem Recht fragen. Und gewiss darf man auch darauf hinweisen, dass sich aus meinen Beobachtungen eine Reihe neuer Ungereimtheiten und Widersprüche ergibt. So will sich etwa nicht recht erschließen, wie sich das Erziehungsziel «Dietrich soll lernen, von Aventiure zu erzählen` zum Umstand verhält, dass er bei den meisten Berichten gar nicht zugegen ist, und zugegebenermaßen werden persuasive Ausrichtung und rhetorische Anlage der Rekapitulationen gegen Ende des Textes hin verschwommener. Gleichwohl gilt, dass sich ein guter Teil der von der Forschung vermerkten «Fehler» vor dem Hintergrund einer rhetorischen Perspektivierung verflüchtigt, vor allem aber rückt der Maßstab, vor

42 Entsprechend fällt Virginals Reaktion aus: Sie ist ob der spektakulären Geschichte zunächst höchst verwundert (295,2-6) und fragt nach Bibuncs Quelle. Nachdem er ihr von der in Arona gepflegten gewonheit berichtet hat, alle virtage [...] von oventúre $\mathrm{zu}$ sagen (295,7-300, zit. 295,9-12), zeigt sie sich höchst erfreut (301,1-7).

43 Vgl. etwa $110,8-13 ; 197,10-13 ; 312,11-13 ; 996,10-13$ u. ö. 
dessen Hintergrund die zusammenfassenden Rekapitulationen erst als Fehler erscheinen, ins Licht des Zweifels. Denn, so frage ich noch einmal: Nach welchen Kriterien urteilen wir über die Qualität von Verteilung und Frequenz der narrativ gegebenen Information? Und: Sollte die rhetorische Narratologie, die der Verfasser der Heidelberger Virginal augenscheinlich vor uns ausbreitet, bei der Urteilsfindung nicht wenigstens berücksichtigt werden?

\section{Die Dresdener Virginal: abbreviatio als Übergang in konzeptuelle Mündlichkeit}

Ich wende den Blick von hier aus der Virginal-Fassung des Dresdener Heldenbuchs zu und stelle fest: Obgleich sich die Konfiguration der abbreviatio hier vollkommen anders darstellt, bleiben die Fragen im Prinzip dieselben. In diesem Fall haben wir es mit einer Forschung zu tun, die keinen Zweifel daran zu hegen scheint, dass der Redaktor des späten 15. Jahrhun$\operatorname{derts}^{44}$ an seiner Kürzungsaufgabe gescheitert ist. Wenn sie den Text überhaupt einmal erwähnt, dann als Zeugen einer Version (D), die in ihrem Bestand mit der Heidelberger Virginal verglichen und in der vorliegenden Bearbeitung klar abgewertet wird. Die Handlung werde durch die Kürzung zu einer bloßen «Rumpferzählung», welche Motivationen und Begründungen ebenso vermissen lasse wie die für die Parallelfassung typische thematische Reflexion. ${ }^{45}$ Zudem führe mangelnde Sorgfalt zu neuen Fehlern: Rentwin wird mit Helferich verwechselt, Helden werden vergessen oder erstehen von den Toten wieder auf, Generationenfolgen und Verwandtschaftsverhältnisse geraten durcheinander u. v. m. ${ }^{46}$ Der Lektüreeindruck bestätigt all diese Beobachtungen in vollem Umfang, und doch regen sich erneut Bedenken:

44 Zur Datierung und Geschichte der Handschrift bes. Lienert (2017), Bd. 1, S. 17-20; Kofler (2006), S. 9-22; 49-56.

45 Grimm (2009), S. 245; vgl. ebd., S. 257f.; Kerth (2003/2004), S. 150; Kragl (2013), S. 381 .

46 Vgl. dazu die Aufstellung bei Kofler (2006), S. 39-41. Vergleichende Überblicke über die Handlungsverläufe finden sich bei Heinzle (1978), S. 34-37, und Lienert (2017), Bd. 1, S. 23-28. 
Liegt der Verfasser der Dresdener Fassung mit seiner Einschätzung, alle «unnützen Worte〉 gestrichen zu haben $\left(\mathrm{V}_{11} 130,13\right)$, wirklich derart daneben? Wo schießt er über sein Ziel hinaus? Welche Worte wären also doch zusätzlich(?) - nötig gewesen, um den Text verständlich zu machen? Oder ist er gerade noch verständlich genug? Und wenn ja: inwiefern - und für wen?

Ich versuche mich einer Antwort anzunähern, indem ich das abbreviierende Verfahren der Dresdener Virginal charakterisiere und $\mathrm{zu}$ dem der Heidelberger Fassung ins Verhältnis setze. Der Vergleich auf dieser Ebene der wie gesagt kein Vergleich der Texte ist -, ist im vorliegenden Zusammenhang schon allein deshalb interessant, weil er zeigt, wie unterschiedlich Phänomene des Kürzens und Zusammenfassens ein und denselben epischen (Kern-)Text prägen können. Dabei spielen offenbar die spezifischen Bedingungen von Mündlichkeit und Schriftlichkeit die entscheidende Rolle. Die Kürzung des Dresdener Heldenbuchs differiert nämlich nicht nur darin von der Heidelberger Virginal, dass sie eine zugrunde liegende (D-Lang-)Version insgesamt erfasst und umformt, wohingegen der Vorgang des Kürzens dort als integraler Bestandteil des (H-)Textes thematisiert und vorgeführt worden war. Vielmehr ist dieser Vorgang in der Heidelberger Virginal auch literarisch markiert, denn er realisiert sich, wie gezeigt, in einer komplexen schriftliterarischen Komposition. Als solcher steht er auf der Basis schriftkulturell vermittelten, rhetorischen Wissens und wird mit einiger Sicherheit auch nur der sehr genauen Lektüre (oder gegebenenfalls Mehrfachlektüre) des Textes verständlich. Bei der Dresdener Virginal hingegen deutet schon beim ersten Hinsehen alles in den Bereich des Mündlichen.

Besonders wichtig für diese Einschätzung ist die Kontextualisierung im Rahmen des Dresdener Heldenbuchs. Dieses zeichnet sich nicht allein dadurch aus, dass es, ähnlich wie das etwa zeitgleich entstandene Heldenbuch des Lienhard Scheubel und der Heldenbuch-Druck, ausschließlich Heldenepen in Strophen verzeichnet und im Zuge dessen sogar den Laurin, der sonst stets in Reimpaaren steht, in strophischer Form präsentiert. ${ }^{47}$ Noch

47 Vgl. Kornrumpf (1984), die auch die Vermutung formuliert, dass der Laurin «vielleicht eigens für die Dresdener Sammlung in die Heunenweise umgeformt worden» ist (ebd., S. 327). Zum Textbestand und zu den Bearbeitungstendenzen der Handschrift bes. auch Kofler (2006), S. 26-50. 
weit mehr als die anderen Heldenbücher ist es vielmehr auch für einen mündlichen beziehungsweise sogar gesanglichen Vortrag 48 konzipiert: Immer wieder ist vom singen, sagen und horen, dezidiert nicht jedoch vom lesen die Rede. So vermerkt z. B. die erste Strophe des Ortnit (k):49 Das wir abent und morgen do von zu singen haben! $(1,4) ; 50$ am Anfang des Meerwunder fordert ein Ich das Publikum auf: Nun hort und schweigt $z u$ disser stunt! $(1,1)$; und in der zweiten Strophe des Sigenot $\left(\mathrm{S}_{6}\right)$ heißt es: Ir herschaft, wolt ir hie betagen, obenteuer will ich euch sagen $\left(2,1 \mathrm{f}\right.$.). ${ }^{51}$ Hinzu kommt, dass der Vorgang des Kürzens programmatisch mit den Erfordernissen des Vortrags in Verbindung gebracht wird. Besonders klar kommt dies in der Schlussstrophe des Wolfdietrich (k) zum Ausdruck, die in unverkennbarer Parallele zur Dresdener Virginal (Str. 130, s. o.) formuliert:

Wolfdietrich in altem dichte hat sibenn hundert lied. manck unnútz wort vernichte: oft gmelt man als aus schid! drew hundert drei und dreissigk liet hat er hie behent, das man auf einem sitzen dick múg hórn an fanck und ent.

(Wolfdietrich k 334)

Der dritte Kürzungshinweis innerhalb der Handschrift, welcher sich am Ende des Ortnit findet, bietet zwar nichts vergleichbar Programmatisches, doch ist ihm mit der Anrede des Publikums (ir) und der Benennung der akustischen Rezeptionsform (hort) die tatsächliche Bestimmung für den mündlichen Vortrag umso deutlicher eingeschrieben:

48 Kornrumpf ([1984], S. 327) verweist in dem Zusammenhang auch darauf, dass die Aufzeichnungsweise der Strophen der der zeitgenössischen Liederhandschriften entspricht.

49 Ich zitiere alle Texte des Dresdener Heldenbuchs außer die Virginal nach der Ausgabe von Kofler (2006).

50 Der Ortnit-Eingang markiert zugleich den Anfang der Handschrift. Analog heißt es am Ende, in der letzten Strophe des Jüngeren Hildebrandslieds (D): des las wir auch dar von / und singen do von nit mere [...] (29,3f.). In der Vorlage des Ortnit (Fassung A) heißt es dagegen singen unde / oder lesen: vgl. Kornrumpf (1984), S. 329; Kofler (2006), S. $28 \mathrm{f}$. Ein singender Vortrag wird im Dresdener Heldenbuch auch im Eingang des Laurin beschworen: als ich euch singen will $(1,2)$.

51 Vgl. auch Ortnit k 297 (s. u.), Meerwunder 2,1; Wunderer 215,1 sowie Herzog Ernst $\mathrm{G}^{\mathrm{b}} 1,3$ und 55,1 . 
Und wie ir wurd ein mane, das hórt ir ytzunt nicht!

do von wir itzunt lane: hie hat ein ent das ticht.

got sent uns seinen fride. Wolfdittrich kórt hie drauff.

zwei hundert sibn und neúntzig lide: in so vil hór ich auf.

(Ortnit k 297)

Und schließlich wird der Bezug zwischen Kürze und Vortragsmündlichkeit noch ein weiteres Mal hergestellt: interessanterweise im Laurin, der (trotz seiner strophischen Umgestaltung) nicht $\mathrm{zu}$ den gekürzten Texten der Handschrift gehört. ${ }^{52}$ Seine Formulierung ist nicht zuletzt deshalb aufschlussreich, weil sie die 〈Kürze des Vortrags〉 in einen dezidierten Gegensatz zur 〈Länge der Schrift〉 stellt:

$\mathrm{Zu}$ singen und zu sagen das wer so manigfal

wie Signit wurd derslagen: er und sein gesellen al.

solt man das als durch grynden, das wurd doch als zu lanck,

als mans in der schrift thut finden: das wurd zu vil in gesanck!

(Laurin $\mathrm{L}_{11} 290$ )

Unabhängig von der Frage, wie man sich die Herstellung des Dresdener Heldenbuchs genau zu denken hat und wie viele Bearbeiter daran beteiligt waren, ist somit festzuhalten, dass Kürze hier textübergreifend geradezu als Bedingung für das Gelingen eines mündlichen (Gesangs-)Vortrags apostrophiert wird..$^{53}$ Insofern liegt es nahe, auch die Kürzungen selbst als mündlichkeitsnah anzusprechen - und zumindest im Fall der Virginal spricht einiges dafür, dass es sich tatsächlich so verhält.

Ein genauerer Blick auf den Text zeigt zunächst den bemerkenswerten Befund, dass der Redaktor der Dresdener Fassung von der «Abbreviationslehre> der Heidelberger Virginal keinerlei Kenntnis zu haben scheint und auch darüber hinaus fast alle gängigen schriftliterarischen Kürzungsformen

Vgl. Kornrumpf (1984), S. 329. Anders als die gekürzten Texte, deren Schreiber anonym bleibt, ist der Laurin vom Hauptschreiber und (anzunehmenden) Koordinator der Handschrift, Kaspar von der Roen, signiert.

53 Kofler geht davon aus, dass es sich bei den von Kaspar von der Roen signierten Texten durchweg um bereits vorhandene Bearbeitungen handelt, während die kürzenden Bearbeitungen auf den zweiten, anonymen Schreiber selbst zurückgehen ([2006], S. 12 u. 49 f.). Grimm hält dafür, dass «keiner der an der Handschrift beteiligten Schreiber sich als Redaktor betätigt» habe ([2009], S. 104; vgl. auch S. 243-246). Da das Ideal der Kürze auch im Laurin formuliert wird, steht es offenbar über den dadurch definierten Grenzen. 
seiner Zeit ignoriert. Damit einher geht ein Textverständnis, das in einer für die Kategorie des «Unnützen〉 höchst aufschlussreichen Weise auf inhaltliche Akzentuierung oder Gewichtung verzichtet. Anders als es sicherlich nahegelegen hätte, spart der Bearbeiter also keineswegs descriptiones, Exkurse und Handlungsverwicklungen aus, von denen auch seine (D-)Vorlage nicht frei gewesen zu sein scheint, und es ist auch umgekehrt nicht zu erkennen, dass er handlungsrelevante Ereignisse, spannende Episoden u. Ä. von der Kürzung ausnehmen oder gar sinnstiftend beziehungsweise (um-)wertend in die Darstellung eingreifen würde. ${ }^{54}$ Anstatt in seinem Material (wie es die intradiegetischen Erzähler der Heidelberger Virginal durchweg tun) Wichtiges von Unwichtigem zu trennen und mit Blick auf eine angestrebte Wirkung neu anzuordnen, folgt er seiner Vorlage offenbar bis ins Detail. Vor allem im ersten Teil der Handlung bis hin zu den Drachenkämpfen, in denen die Fassungen weitgehend parallel verlaufen, ist es geradezu frappierend, mit welcher Akribie alle Erzählstränge, Botengänge, Berichte, Reden, Gespräche, Rüstungs-, Kampf,- Reise- und Festbeschreibungen reproduziert werden. ${ }^{55}$ Wenn der Text der Dresdener Fassung im Ergebnis sehr viel kürzer ist, so bedeutet das mithin in der Tat vor allem, dass hier «dasselbe mit weniger Worten> gesagt wird.

Wie der Bearbeiter dies bewerkstelligt, kann in Ermangelung der Vorlage, auf die er sich bezieht, zwar nicht mehr genau ermittelt werden, doch wird Wesentliches im Vergleich der Fassungen zumindest erkennbar. Da sich seine Reduktion auf die Mikroebene - die 〈Worte〉 - konzentriert und relativ gleichmäßig verfährt, ist der Blick auf eine einzige exemplarische Stelle hier bereits höchst aufschlussreich. Der Anfang der Drachenkämpfe ist insofern ein besonders gutes Beispiel, als er an die Beobachtungen des letzten Abschnitts anschließt und zudem eine Passage betrifft, in der die Gegenüberstellung durch die Hinzunahme der dritten überlieferten Textfassung, der Wiener Virginal $\left(\mathrm{V}_{12}\right)$, überprüft werden kann. ${ }^{56}$ Diese zeichnet sich dadurch aus, dass sie eine D- und eine H-Fassung kontaminiert, wobei sie sich im Einzelnen eher zu D stellt und der verlorenen Vorlage der Dresdener Virginal

54 Vgl. dazu die Darstellung typischer Kürzungsverfahren in höfischer Erzähldichtung des 13. und 14. Jahrhunderts bei Henkel (1993).

55 Vgl. dazu die Aufzählung bei Kragl (2013), S. $380 \mathrm{f}$.

$56 \mathrm{Zu}$ dieser Fassung Anm 1. 
so einen Schritt näherkommt. ${ }^{57}$ Dies gilt auch für die vorliegende Stelle und lässt gerade dadurch die radikale Andersartigkeit der kürzenden Bearbeitung aufscheinen.

Hält man zunächst die Schilderung der beiden Langfassungen gegeneinander, so bietet sich das typische Bild einer schriftliterarischen Bearbeitung. Welche Fassung als die ursprünglichere zu gelten hat, fällt im vorliegenden Zusammenhang wenig ins Gewicht. Festzuhalten ist, dass Dietrichs Drachenkampf in beiden Fällen weitgehend identisch geschildert wird. Die Passagen differieren nur in einigen Lesarten sowie durch die ausführlichere Beschreibung des Drachen in der Wiener Virginal. Dass sie auf ein und denselben Text zurückgehen, der im Wortlaut mehr oder weniger genau abgeschrieben wurde, kann keinem Zweifel unterliegen:

Heidelberger Virginal $\left(\mathrm{V}_{10}\right)$, Str. 144-146

In ir oren hal ir beider sturm.

Her Dietherich hat einen wurm

mit slegen vir gefasset,

der was wol zwenzig ellen lang

(ein hitze ime us dem munde trang,

die der von Berne hassete),

gros und ungevige gar

(vroud[.] mahte er túre),

umbe das hóbet kuppfer var.

Zů sehende ungehúre

was eime iegelichen man,

das der von Bernen ringe wag.

Er lieff in zo̊rneclichen an.

Er ahtete wenig, das sin lip

veile wart durch schöne wip

und durch werde frówen,

gegen den er danckes sich verwag.

Do von ime groß schade geschach.

Uff bergen und in ouwen

er vor dem wilden wurme gie.

Sus werte sich der werde:
Wiener Virginal $\left(\mathrm{V}_{12}\right)$, Str. 262-265

Die herren hetten baid ein sturm:

Her Ditrich, der het einen wúrm mit schleg fúr sich gefasset, der waz wol dreissig elen lanck. die den von Perne hasset. Er was geschaffen fraischlich gar, sein freud macht er im tewre. Sein kopff, der was im kupffer far.

10 Czu sehen ungeheure, so was der wurm iglichem man, das der von Pern geringe wag und lieff in ritterlichen an.

Er achtet wenig, das sein leip da faill waz durch die schónen weip und durch die schón junckfrawen, czu den er danckes sich versach.

5 Dar durch dem held gar wee geschach in pergen und in awen.

Der grosse wúrm her gen im kroch und tet im also drangen.

Eyn langen schwancz er nach im czoch,

10 wol siben claffter | lange. 
Ein fúr er us dem munde lie.

Wo das draff die erde,

do selwete es blůmen und gras

der túrren heiden gar glich,

das e gelppfer varwe was.

Er treip in umbe hin und wider.

Recht als ein walt viele nider, sine starcken slege erhullent, die der Berner uff in treip (an einer stat er niht bleip), in daz gebúrge erschullen.

Sin ros stunt verre dort hien dan, gebunden zù eime aste.

Das wolt der wurm genomen han.

Es werte sich so vaste,

untze im der Berner kam en zit.

Er halff dem ros, das es genas,

do von drůg es in dannen sit.
Hin nach dem Perner er in schwang.

Er schlug in auff des schilldes rant,

das er von gold so laut erclang.

Der Perner sprach: «Wưrrm, las dein wedell!»

Er schlug in auff sein hurnein schedell,

und das daß rotte feure

im aus dem willden horne schein.

5 Erczurnet waz der würm unrein,

er paret ungeheure.

Den wallt er vor im nider stis, sprang nach dem fursten werde.

Ein hicz er auß den oren lies,

10 und wo si traff die erde,

da sengt es blümlein und das gras.

Der durren heid ward es geleich,

das doch von mancher farbe was.

Der würm in treib, er schlug hin wider, recht als ein wallt da ging der nider.

Die starcken schleg erschullen, die er da auff den wúrme treib.

5 An keyner stat er nirgen bleib.

Die perg und tal erhullen.

Sein roß, das stúnd da auff eim plan, gepunden an eim aste.

Das wollt der würm gefangen han.

10 Da wert es sich so faste,

pis der von Pern kam bey der czeit.

Dem roß halff er auß grosser not,

dar von trug es in dannen seit.

Die einstrophige Zusammenfassung des Dresdener Heldenbuchs zeigt demgegenüber ein deutlich abweichendes Profil. Offenbar basiert sie zwar ebenfalls auf einem Text, der dem der beiden anderen Fassungen sehr ähnlich gewesen sein muss - nur die Formulierungen in $\mathrm{V}_{11}$ 48,3, 9 und 10, gegebenenfalls auch in 48,6-8, deuten auf eine größere Nähe $z u V_{12}-$; sie verfährt damit aber völlig anders: 


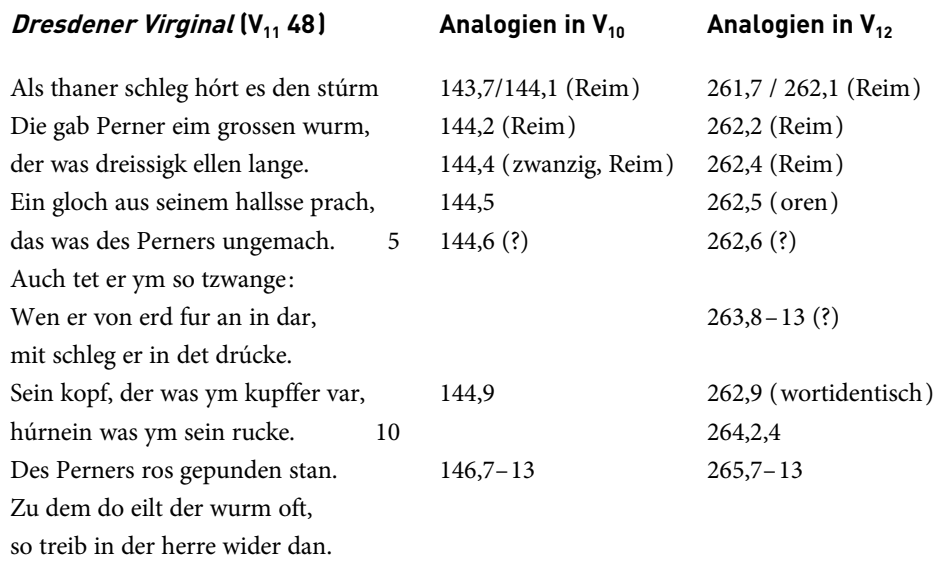

Hier stimmt nur ein einziger Vers $\left(\mathrm{V}_{11} 48,9\right)$ wörtlich mit einer anderen Fassung überein $\left(\mathrm{V}_{12}\right.$ 262,9). Alle anderen Parallelen sind demgegenüber bloß mehr oder weniger stark an deren Wortlaut angelehnt, wobei sie sich über alle vier Strophen der (wohl näher verwandten) Wiener Fassung verteilen. So folgen die Verse 1-5 der $V_{11}$-Strophe ziemlich weitgehend $V_{12}$ 262,1-6; die Verse 6-8 in $\mathrm{V}_{11}$ scheinen die Kampfbeschreibung in $\mathrm{V}_{12} 263$,8$13 \mathrm{zu}$ spiegeln, deren viermaliger -ang/-ange(n)-Reim (drangen, schwange, lang, erclang) hier zudem in Vers 6 (tzwange) ein Echo findet. Vers 9 greift in wörtlicher Übernahme auf $\mathrm{V}_{12}$ 262,9 zurück, Vers 10 der $\mathrm{V}_{11}$-Strophe rekurriert auf die Beschreibung des hornbewehrten Drachen in $V_{12}$ 264, 2 und 4, und die Verse $V_{11}$ 48,11-13 fassen den zweiten Teil von $V_{12} 265$ zusammen.

Versucht man, den Befund zu deuten, so bietet sich zweifellos jene Form der freien Nachdichtung als die plausibelste Annahme an, die Harald Haferland in seinen Beobachtungen zur Virginal-Fassung des Dresdener Heldenbuchs treffend so beschrieben hat:

Der Wortlaut erscheint durchgängig eingeschmolzen und neugefaßt, und es sind nur wenige Formulierungen [...] stehengeblieben, wie dies in der Regel bei Ersetzung einzelner Strophen in memoriellen Fassungen der Fall ist. Da dies aber für den gesamten Text gilt und nicht hier und da einmal eine Gedächtnislücke über 
wenigen Resten durch einen neuen Wortlaut geschlossen wird, hat der Bearbeiter anscheinend an einer Schriftvorlage entlang gänzlich neu gedichtet. ${ }^{58}$

In diesem Sinne ist davon auszugehen, dass der Bearbeiter jeweils einige Strophen der Vorlage gründlich gelesen und diese dann aus dem Gedächtnis in eigenen Worten zusammengefasst hat. Dabei scheint er freilich zumindest im vorliegenden Beispiel weniger den Text memoriert, als sich einen aus Bildern, Klängen und Ereignissen zusammengesetzten Gesamteindruck vor Augen gestellt zu haben, welchen er dann in einer Art imaginativer Schau in seinen prägnanten Bestandteilen - hier insbesondere das bedrohliche Aussehen des Drachen und sein Angriff auf Ross und Reiter - reproduziert und unter Verwendung der dominanten -urm- und -ang-Klänge zu einer neuen Strophe verarbeitet hat. Das mag man als «Inhaltsangabe» bezeichnen, ${ }^{59}$ doch ist es insofern mehr als das, als es über den bloßen Inhalt hinaus gerade solche Details bewahrt, die die Sinne ansprechen, Spannung erzeugen und das Geschehen anschaulich werden lassen.

Was bei der Lektüre des Textes nur bedingt funktioniert, dürfte also im Gesangsvortrag durchaus die gewünschte Wirkung gehabt haben. Wenn man davon ausgeht, dass hörende Rezipienten und Rezipientinnen weniger auf lückenlose Abläufe, Begründungen und Reflexionen achten, dafür mehr Wert auf sinnliche Eindrücklichkeit legen und eher dazu neigen, Darstellungslücken aus alltagsweltlichem oder literarischem Schemawissen zu füllen, ${ }^{60}$ dann streicht der Bearbeiter des Dresdener Heldenbuchs demnach tatsächlich nur die - für seine Zwecke - «unnützen〉 Worte. Er lässt in Struktur und Anlage des Textes alles, wie es ist, beschränkt sich jedoch auf jenen Teil der Darstellung, der genügt, um seinem Publikum Dietrichs Abenteuer eindrücklich-anschaulich zu vermitteln. Im Zuge dessen tilgt er alles, was den Gesangsvortrag lang und langweilig machen würde, und passt nicht zuletzt den Wortlaut selbst ans mündliche Register des Frühneuhochdeutschen an. Was uns beim ersten Hinsehen leicht als ungeschicktes Herumformulieren eines schlechten Nachdichters erscheinen kann, erweist

58 Haferland (2004), S. $313 \mathrm{f}$.

59 Vgl. Kragl (2013), S. 380.

60 In diesen Punkten unterscheidet sich die Rezeption nicht wesentlich von der mündlichen Reproduktion von Heldendichtung: vgl. Haferland (2004), bes. S. 302-305. 
sich so als Modifikation im Sinne des neuen Mediums: Der Bearbeiter der Dresdener Virginal zielt mit ihr geradewegs auf das Verständnis des Publikums und konnte im Vortragskontext wohl auch mit einigem Recht darauf rechnen.

\section{Fazit}

Am Ende meiner Überlegungen steht somit vor allem die Einsicht, dass über Sinn und Verständlichkeit einer abbreviatio nur in dem Kontext geurteilt werden kann, in dem sie jeweils vorgenommen wird. Das klingt banal und versteht sich auch in der Tat von selbst, muss aber, wie am Beispiel der beiden Virginal-Versionen unschwer zu sehen ist, trotzdem immer wieder in Erinnerung gerufen werden. Es mag mithin nicht überflüssig sein, als Ergebnis meiner Beobachtungen noch einmal explizit hervorzuheben, dass es das rechte Maß der Worte als solches nicht gibt; dass es vielmehr von Umständen abhängt, von denen ich hier einige genannt habe: von konzeptueller Mündlichkeit und Schriftlichkeit, von verschiedenen und sich wandelnden Produktions- und Rezeptionsbedingungen, von Ansätzen der literarischen Selbstreflexion sowie nicht zuletzt von generischen und fassungsspezifischen Wirkungsintentionen. Kurz gesagt: Welche Worte unnütz sind und welche nicht, ist immer nur von Fall zu Fall zu entscheiden.

\section{Bibliographie}

\section{Primärliteratur}

Das Dresdener Heldenbuch und die Bruchstücke der Berlin-Wolfenbütteler Heldenbuchs, hg.v. Walter Kofler, Stuttgart 2006.

Virginal, Goldemar, hg.v. Elisabeth Lienert / Elisa Pontini / Katrin Schumacher, Teilband

I: Einleitung, Heidelberger Virginal, Teilband II: Wiener Virginal, Teilband III:

Dresdener Virginal, Goldemar, Verzeichnisse, Berlin/ Boston 2017 (Texte und Studien zur mittelhochdeutschen Heldenepik 10/1-3). 


\section{Forschungsliteratur}

Gillespie, George T.: Hildebrants Minnelehre. Zur Virginal h, in: Jeffrey Ashcroft / Dietrich Huschenbett / William Henry Jackson (Hgg.): Liebe in der Literatur des deutschen Mittelalters. St-Andrews-Colloquium 1985, Tübingen 1987, S. 61-79.

Grimm, Ghislaine: Heldendichtung im Spätmittelalter. Überlieferungsgeschichtliche Studien zu den skriptographischen, typographischen und ikonographischen Erscheinungsformen des Rosengarten zu Worms, Wiesbaden 2009 (Imagines Medii Aevi 22).

Haferland, Harald: Mündlichkeit, Gedächtnis und Medialität. Heldendichtung im deutschen Mittelalter, Göttingen 2004.

Heinzle, Joachim: Mittelhochdeutsche Dietrichepik. Untersuchungen zur Tradierungsweise, Überlieferungskritik und Gattungsgeschichte später Heldendichtung, München 1978 (MTU 62).

Heinzle, Joachim: Einführung in die mittelhochdeutsche Dietrichepik, Berlin / New York 1999 (de Gruyter Studienbuch).

Henkel, Nikolaus: Kurzfassungen in höfischer Erzähldichtung im 13./14. Jahrhundert. Überlegungen zum Verhältnis von Textgeschichte und literarischer Interessenbildung, in: Joachim Heinzle (Hg.): Literarische Interessenbildung im Mittelalter. DFG-Symposion 1991, Stuttgart 1993 (Germanistische Symposien-Berichtsbände 14), S. 39-59.

Hübner, Gert: Evidentia. Erzählformen und ihre Funktionen, in: Harald Haferland / Matthias Meyer (Hgg.), Historische Narratologie - mediävistische Perspektiven, Berlin / New York 2010 (Trends in Medieval Philology 19), S. 119-148.

Kerth, Sonja: Helden en mouvance. Zur Fassungsproblematik der Virginal, in: Jahrbuch der Oswald von Wolkenstein-Gesellschaft 14 (2003/2004), S. 141-157.

Kerth, Sonja: Gattungsinterferenzen in der späten Heldendichtung, Wiesbaden 2008 (Imagines Medii Aevi 21).

Knäpper, Titus: Arthurische Erzähltradition in den Fassungen der Virginal. Zur Intergenerik aventürehafter Dietrichepik, in: Cora Dietl / Christoph Schanze / Friedrich Wolfzettel (Hgg.): Gattungsinterferenzen. Der Artusroman im Dialog, Berlin / Boston 2016 (Schriften der internationalen Artusgesellschaft 11), S. 33-56.

Kofler, Walter: Dresdner Heldenbuch. Handschriftenbeschreibung, Abschriften, Textmerkmale, Produktionsbedingungen, in: Walter Kofler (Hg.): Das Dresdener Heldenbuch und die Bruchstücke der Berlin-Wolfenbütteler Heldenbuchs, Stuttgart 2006, S. 9-56.

Kornrumpf, Gisela: Strophik im Zeitalter der Prosa. Deutsche Heldendichtung im ausgehenden Mittelalter, in: Ludger Grenzmann / Karl Stackmann (Hgg.): Literatur und Laienbildung im Spätmittelalter und in der Reformationszeit. Symposion 
Wolfenbüttel 1981, Stuttgart 1984 (Germanistische Symposien. Berichtbände 5), S. 316-340.

Kragl, Florian: Heldenzeit. Interpretationen zur Dietrichepik des 13. bis 16. Jahrhunderts, Heidelberg 2013 (Studien zur historischen Poetik 12).

Kraus, Carl von: Virginal und Dietrichs Ausfahrt, in: ZfdA 50 (1908), S. 1-123.

Kropik, Cordula: Dietrich von Bern zwischen Minnelehre und Fürstenerziehung. Zur Interpretation der Virginal h, in: Jahrbuch der Oswald von Wolkenstein-Gesellschaft 14 (2003/2004), S. 159-173.

Kropik, Cordula: Reflexionen des Geschichtlichen. Studien zur Konstituierung mittelhochdeutscher Heldendichtung, Heidelberg 2008 (Jenaer Germanistische Studien 24).

Kuhn, Hugo: Virginal, in: ders.: Dichtung und Welt im Mittelalter (Kleine Schriften 1), Stuttgart 1969, S. 220-248; 281-297.

Lausberg, Heinrich: Handbuch der literarischen Rhetorik. Eine Grundlegung der Literaturwissenschaft, Stuttgart ${ }^{4} 2008$.

Lienert, Elisabeth: Einleitung, in: Virginal, Goldemar, hg.v. Elisabeth Lienert / Elisa Pontini / Katrin Schumacher, Teilband I: Einleitung, Heidelberger Virginal, Berlin / Boston 2017, S. 3 - 36.

Müller, Jan-Dirk: Der Spielmann erzählt. Oder: Wie denkt man sich das Entstehen eines Epos? In: Harald Haferland / Michael Mecklenburg (Hgg.): Erzählungen in Erzählungen. Phänomene der Narration in Mittelalter und Früher Neuzeit, München 1996 (Forschungen zur Geschichte der älteren deutschen Literatur 19), S. 85-98.

Philipowski, Katharina: Sprechen, Schreiben und Lieben in der Virginal. Die Heidelberger Fassung als Beispiel literarischer Metakommunikation, in: Euphorion 102 (2008), S. 331-362.

Reuvekamp-Felber, Timo: Briefe als Kommunikations- und Strukturelemente in der Virginal. Reflexionen mittelalterlicher Schriftkultur in der Dietrichepik, in: PBB 125 (2003), S. 57-81.

Schmid, Wolf: Elemente der Narratologie, 3., erweiterte Auflage, Berlin / Boston 2014.

Stein, Peter K.: Virginal. Voraussetzungen und Umrisse eines Versuchs, in: Jahrbuch der Oswald von Wolkenstein-Gesellschaft 2 (1982/1983), S. 61-88.

Störmer-Caysa, Uta: Die Architektur eines Vorlesebuches. Über Boten, Briefe und Zusammenfassungen in der Heidelberger Virginal, in: ZfG N. F. 12 (2002), S. 7-24. Zimmermann, Julia: Vervielfältigungen des Erzählens in der Heidelberger Virginal, in: Anne-Katrin Federow / Kay Malcher / Marina Münkler (Hgg.): Brüchige Helden Brüchiges Erzählen. Mittelhochdeutsche Heldenepik aus narratologischer Sicht, Berlin / Boston 2017 (Studien und Texte zur mittelhochdeutschen Heldenepik 11), S. $93-113$. 



\section{abbreviatio als Beschleunigung \\ Einige Beobachtungen zu Redaktionen und Überlieferungsvarianz in der Versnovellistik}

von

Sandra Linden (Tübingen)

\section{I. abbreviatio und dilatatio in der Versnovellistik}

abbreviatio und dilatatio, wie sie die mittelalterlichen lateinischen Poetiken als zwei Möglichkeiten der Bearbeitung einer materia lehren, ${ }^{1}$ lassen sich als literarische Verfahren auch auf die Gattung der Versnovellistik anwenden. In der Gattung Märe ist der Gedanke, dass man eine Erzählung kürzer oder länger fassen und dass ein und dasselbe Erzählmuster in verschiedenen Formen auserzählt werden kann, durchaus gängig. Der Beitrag geht von der einfachen und gerade in der Editionsarbeit oftmals akuten Frage aus, wie man unterschiedlich lange Redaktionen in der Versnovellistik bewerten und in ihrer literarischen Strategie mit den Kategorien von Kürzung oder Erweiterung erfassen kann. Kann man aus der Beobachtung einer quantitativen Textvarianz in der Gattung Märe auf Strategien eines Redaktors schließen und diese in ihrer Motivation und Logik nachvollziehen?

Dass in der je neuen, auch quantitativ varianten Wiederholung einer Erzählung ein ästhetischer Reiz zu liegen scheint, zeigt bereits eine Durchsicht der gängigen Motivindizes des internationalen Erzählens, die zu den einzelnen Erzählmustern eine Fülle von Belegen verzeichnen. ${ }^{2}$ Dabei ist die literarische Beschäftigung mit einem Erzählstoff oder einem Erzählmuster

1 Dass beide Verfahren komplementär zueinander angelegt sind, findet sich sehr pointiert im Documentum des Galfred von Vinsauf, ed. Faral, S. 271 (2,1): Sunt enim artificia duo, quorum alterum est dilatandi et reliquum abreviandi materiam. «Es gibt nämlich zwei Bearbeitungstechniken, von denen die eine das Erweitern und die andere das Kürzen des Stoffes ist.>

2 Vgl. Aarne / Thompson (1964), Thompson (1955-1958) und Tubach (1969). 
nicht immer nur von der dilatatio, der Ausweitung hin zum Schmuckvollen und Komplizierten bestimmt. Gerade in der Versnovellistik kann sich ein Autor auch durch ein knappes und prägnantes Erzählen profilieren. ${ }^{3}$ Es geht im zeitlichen Verlauf der Entwicklung eines Erzählmusters weder von der Kürze zur Länge noch umgekehrt, sondern Kurz- und Langfassung liegen gleichzeitig vor und dokumentieren, dass kurzes und langes Erzählen gleichermaßen Relevanz hat.

Dass ein Märe in der Überlieferung in ganz unterschiedlichen Aggregatzuständen vorliegen kann, bei denen man nur schwer ein Besser oder Schlechter, ein Früher oder Später unterscheiden kann, hat schon Hanns Fischer betont:

Mären werden nämlich vielfach nicht $[\ldots]$ als tote Fossilien überliefert, sondern unterliegen einer tradition vivante, die infolge sich überlagernder Degenerationsund Regenerations- (zum Teil aber auch redaktioneller Erweiterungs- und Kürzungs-)Vorgänge ein stark oszillierendes Textbild hervorbringt, das im Nachhinein nicht mehr zuverlässig aufzulösen ist. Wieviel Verse besaß das Original eines Märes, dessen durch die Überlieferung vertretene drei Fassungen mit 84, 136 und 216 Versen aufwarten?4

Gerade in der Gattung Märe ist es evident, dass die Kurzfassungen nicht minderwertig im Sinne eines Ersatzprodukts für den Volltext sind, sondern dass sie einen produktiven Umgang mit literarischem Material dokumentieren, bei dem mehrere Fassungen gleichzeitig gelten und je nach Sammlungsinteresse für den Redaktor unterschiedlich attraktiv sein können. So gibt es die Erzählung Der betrogene Blinde in einem Bîspel aus dem StrickerUmkreis mit einem Umfang von 28 Versen, dann im 14. Jahrhundert eine Umarbeitung des Bîspels, die in drei zentralen Märenhandschriften 101 Verse zählt, daneben in der Liedersaal-Handschrift eine Redaktion mit 72

3 Zum Prägnanzbegriff in der Versnovellistik vgl. den Sammelband von Dimpel / Wagner (2019), insbesondere die Einleitung, in der auf S. 5-7 mit Wahrnehmung, Figurengestaltung, Zeit- und Raumstrukturierung, Kombinatorik von Handlungselementen, Figuren, Dingen usw. sowie Sinnkonstitution, aber auch Irritation der Sinnbildung wichtige Anwendungsfelder der Prägnanz als eines spezifisch literarischen Darstellungsmittels differenziert werden.

4 Fischer (1983), S. 19 f. 
Versen, die den Bestand der Märenredaktion kürzt und sich dann wiederum dem Charakter des Bispels annähert. ${ }^{5}$ Man hat es also vielfach mit einer komplexen Gemengelage zu tun, bei der ein klares «Vorher-Nachher〉 auf der Basis der Überlieferung kaum bestimmbar ist.

Anders als bei der brevitas, der Kürze als leitendem Prinzip in der Komposition, geht es bei der abbreviatio darum, ein Längeres in ein Kürzeres zu überführen, d. h., ein längerer Bezugstext wird einer kürzenden Bearbeitung unterzogen. Dass es sich dabei oft nicht um eine rein mechanische Tätigkeit handelt, hat Nikolaus Henkel betont, der das spielerische und intellektuell herausfordernde Element der abbreviatio über das Modell eines intellektuellen Kontrakts〉 fasst: ${ }^{6}$ Nur wer den Tristanroman kennt, kann literarischen Genuss aus den verkürzten Tristan-Erwähnungen im Minnesang ziehen. Für die Versnovellistik stellt sich nun angesichts der Überlieferung sehr akut die Frage, wie man mit dem Bezugstext umgehen soll: Die Gattung zeigt ein deutliches Interesse an kürzenden Bearbeitungen, und zwar an konzeptionellen, nicht nur rein quantitativen technischen Kürzungen. Ein Modell der abbreviatio, bei der das Publikum den ausführlichen Bezugstext kennt und ästhetische Freude aus der raffinierten Kürzung bezieht, führt in der Gattung Märe allerdings zunächst nicht weiter. Die Kürzung als poetisches Prinzip lässt sich schwer fassen, weil der längere Text $^{7}$ zwar dem Redaktor, nicht aber dem Publikum vorliegt, sodass nicht die Kürzung rezipiert wird, sondern nur der kurze und prägnante Text, d. h., es ist verstärkt auf das Verhältnis von rhetorischer Produktionsnorm und Rezeptionsästhetik zu achten. Nach der Analyse der Beispiele, in denen das Problemfeld fokussiert und geprüft wird, ob und wie sich dennoch Strategien der abbreviatio ausmachen lassen, ist auf diese Frage nochmals zurückzukommen.

$5 \quad$ Vgl. Ziegeler (1985), S. 225-231.

6 Vgl. Henkel (2017), der die Thematik am Beispiel des Schneekinds erläutert. Für einen etwas breiteren Fokus, der auch großepische Werke einschließt, vgl. Henkel (1993). 7 Die ältere Forschung hat Kurzformen im Bereich der Verserzählung gern mit einer Niederschrift aus dem Gedächtnis innerhalb einer oralen Kultur erklärt, vgl. etwa Schröder (1970), S. X. Die Gegenüberstellung in der Synopse zeigt jedoch aufgrund der z. T. wörtlichen Übereinstimmungen zwischen den Handschriften, dass es sich in vielen Fällen wohl eher um ein schriftsprachliches Arbeiten am Text handelt. 


\section{I.1. Kürzung oder Erweiterung? Thomas von Kandelberg und Der schwangere Müller}

Die Erzählung Thomas von Kandelberg 8 ist in drei auf das erste Viertel des 14. Jahrhunderts datierbaren Handschriften $\mathrm{H}, \mathrm{K}$ und $\mathrm{W}^{9}$ mit je 340 bis 350 Versen überliefert; die jüngere Papierhandschrift $\mathrm{m}$, die im dritten Viertel des 15. Jahrhunderts im Elsass entstanden ist, bietet lediglich 188 Verse. 9

Es handelt sich um ein Marienmirakel, das Bezug auf Thomas Becket, den Erzbischof von Canterbury, in seiner Jugendzeit nimmt. Die Handlung nimmt ihren Ausgang im höfischen Minnediskurs: Einer von zwölf Schülern verpflichtet alle anderen darauf, dass sie binnen einer Woche ein Geschenk ihrer Minnedame erhalten. Den Sieg erringt derjenige, der die schönste Gabe erhält. Ein Schüler, der sich nicht im höfischen Minnedienst engagiert, sondern die Gottesmutter verehrt, bekommt auf sein bittendes Gebet hin von Maria ein wunderbares Kleinod geschenkt, das alle anderen Geschenke übertrifft und die spätere klerikale Karriere des Erzbischofs andeutet.

In der Passage der Wettvereinbarung laufen beide Redaktionen zunächst parallel. ${ }^{10}$ In der längeren Redaktion $\mathrm{HKW}^{9}$ klagt der Schüler dann über die unvermeidliche Blamage, dass er als einziger kein Geschenk vorweisen kann, und auch der Erzähler kommentiert die Verzweiflung der Figur mit dem Vergleich, dass die Klage sogar einen harten Stein zum Erweichen bringen könnte $\left(\mathrm{HKW}^{9}\right.$, vv. 110-112). Es wird beschrieben, wie der Schüler die Woche ganz kläglich zubringt und am Ende den Entschluss fasst, Maria um ein Kleinod zu bitten (HKW ${ }^{9}$, vv. 134-142). In der Kurzfassung m hingegen sind die Gedanken des Schülers deutlich kürzer ausgeführt. Es gibt keine langen Verzweiflungsklagen, sondern er sucht sofort Trost bei Gott: er

8 Sämtliche Texte werden im Folgenden zitiert nach DVN (2020), hier Bd. 1, Nr. 21. Das Märe Thomas von Kandelberg ist zweispaltig ediert, nämlich mit der Redaktion $\mathrm{HKW}^{9}$ (Leithandschrift: $\mathrm{H}$ ) und dem Text von Handschrift $\mathrm{m}$.

9 Vgl. H: Heidelberg, Universitätsbibliothek, Cpg 341, Nr. 31, Bl. 62 $2^{\text {rb }}-64^{\text {va }}$ [350 Verse], K: Cologny, Fondation Martin Bodmer, Cod. Bodmer 72, Nr. 37, Bl. $76^{\mathrm{vb}}-78^{\mathrm{vb}}$ [348 Verse], $\mathrm{W}^{9}$ : Wien, Österreichische Nationalbibliothek, Cod. 2677, Nr. 33, Bl. $27^{\mathrm{vb}}-30^{\mathrm{ra}}$ [340 Verse] und m: München, Bayerische Staatsbibliothek, Cgm 714, Nr. 24, Bl. 206 ${ }^{\text {r }}$ $209^{v}$ [188 Verse]. Die Datierungen der Handschriften beziehen sich grundsätzlich auf die Angaben in DVN (2020) oder im Handschriftencensus.

10 Vgl. in Handschrift $\mathrm{H}$ ab v. 95 und in Handschrift $\mathrm{m}$ ab v. 53. 
sprach: «eye, vil lieber herre got, / gib mir selber deinen rot! [...]> (m, vv. 59 f.). Das folgende Reimpaar berichtet, wie die Wochenfrist verstreicht, ein weiteres, wie die Messe gesungen wird. Die Entscheidung des Schülers, vor dem Marienbildnis um eine Gabe zu bitten ( $m$, vv. 68-72), steht in der Kurzfassung unmittelbar nach der Bitte um göttlichen Ratschlag. Der Protagonist der Kurzfassung verzweifelt nicht, sondern betet, und dann fügt sich das Problem relativ schnell. Hier und auch in anderen Passagen ergibt sich der Eindruck, dass «Reflexionen, Figurenreden oder Beschreibungen von Emotionen ${ }^{11}$ herausgekürzt werden. Dieser Befund fügt sich gut zum Programm der Handschriften, denn die Langfassung steht in der Handschrift $\mathrm{H}$ in einer Gruppe von vier Marienmirakeln, während die Kurzfassung in Handschrift $m$ anders eingeordnet ist: Zwar zeigt sich hier mit den benachbarten Texten Die heiligen Farben, Die Geburt Christi des Regensburgers und Der Wirt der Seele ebenfalls eine Gruppe geistlicher Texte, allerdings wird in allen die Minnethematik in geistlicher Wendung verhandelt, sodass diese Stücke zu einer vorangehenden Gruppe von Erzählungen über die weltliche Minne in Bezug treten. Auf Thomas von Kandelberg folgen in Handschrift $m$ zwei Schwankmären, nämlich Die zwei Beichten B und Der Mönch als Liebesbote, die sich aber durch die komische Anwendung des Beichtsakraments auf den Ehebruchskonflikt beziehungsweise durch den Mönch als naive Vermittlerfigur im weltlichen Minnearrangement mit den vorangehenden geistlichen Erzählungen verbinden. Dahm-Kruse, die für den Cgm 714 einen sehr selbstbewussten Redaktor ansetzt, hat in der Handschrift die Tendenz zu prägnanter Kürze und einer gezielten Arbeit an der Pointe nachgewiesen. ${ }^{12}$ Je nach Sammlungskonzept variiert die Sinnbildung der Erzählung: Handschrift $\mathrm{H}$ bietet mit Thomas von Kandelberg eine breite Reflexion über die Wundertaten der Gottesmutter, Handschrift m konzentriert sich auf die Exemplarik, dass zwei Normsysteme, nämlich weltliche und geistliche Minne, gegeneinander gestellt werden und ein Problemfall zu lösen ist. In diesem pointierten Aufeinandertreffen von geistlichem und

11 Eichenberger (2015) bietet auf S. 228-233 ein Kapitel zum Thema «jüngere (Kurz-) Fassungen älterer Erzählungen»; zu Thomas von Kandelberg vgl. S. 231-233.

12 Vgl. Dahm-Kruse (2018), die für den Cgm 714 ein «hohes Maß an Schreiberautonomie» (S. 159) ansetzt. 
weltlichem Wert- und Denksystem fügt sich Thomas von Kandelberg gut in das Spektrum der benachbarten Erzählungen in Handschrift m ein.

Man kann die Handschrift $m$ in ihrem Überlieferungskontext stringent als Kürzung lesen, dennoch gehen die Meinungen der Forschung auseinander: Scholl plädiert in seiner textgeschichtlichen Detailuntersuchung dagegen, dass die ältere lange Fassung die Vorlage der jüngeren kurzen Fassung ist, ${ }^{13}$ Eichenberger plädiert dafür und weist die Kürze als zentrales Qualitätskriterium geistlichen Erzählens aus, betont aber zugleich, dass sich die Eigenschaft der Kürze häufig nicht einfach quantitativ fassen lässt. ${ }^{14}$

Wenn eine jüngere Handschrift im Überlieferungsspektrum deutlich kürzer ist als die älteren, neigt man instinktiv dazu, eine Kürzung anzunehmen. Doch gibt die Chronologie der Handschriften natürlich keinen absoluten Aufschluss über die Reihenfolge der Abhängigkeiten, denn die jüngere Handschrift mit der Kurzfassung kann von einer nicht überlieferten älteren, ebenfalls kurzen Vorlage abstammen. Und so läge vielleicht gar kein Fall von abbreviatio, sondern umgekehrt von dilatatio vor, wenn man sich die längere Redaktion von der kürzeren Vorlage ausgehend denkt. Zu bedenken sind zudem Kürzungen, die nicht auf die poetische Form des Textes zielen, sondern die der Materialität der Handschrift in ihrer Lagenaufteilung oder dem generellen Streben nach einer Verbesserung des Ausgangstextes etwa durch das Tilgen von Redundanzen geschuldet sind. Die Funktionen der Redaktortätigkeit, die auf der Textebene den Eindruck einer Kürzung ergeben, sind vielfältig. Auch zufällige Fehler beim Abschreiben sind in das Kalkül zu integrieren: So zeigt Handschrift $\mathrm{W}^{9}$ gegenüber den beiden anderen Handschriften der Redaktion vermeintlich eine planvolle Kürzung. In Handschrift $\mathrm{W}^{9}$ fehlt nämlich die Bitte Marias an Christus, dass sie die Büchse für Thomas erhalten möchte, sodass Marias Rolle als Fürsprecherin reduziert ist. Was wie ein durchdachter konzeptioneller Eingriff aussieht, ist tatsächlich aber durch einen Augensprung verursacht und somit ein rein

13 Scholl (1928), S. 10.

14 Vgl. Anm. 11. Vgl. auch Eichenberger (2017). In Anwendung des von Burghart Wachinger geprägten Begriffs des inneren Volumens kommt sie zu der Feststellung: «Die Eigenschaft der Kürze lässt sich dabei keineswegs auf den absoluten Umfang reduzieren, sondern betrifft verschiedene Facetten der Texte, sowohl die Komplexität der erzählten Handlung als auch die Elaboriertheit der erzählerischen Umsetzung» (S. 175). 
mechanischer Abschreibfehler: Der Schreiber springt beim Reimwort buchselin in v. 187 zum identischen Reimwort in v. 194, was die beschriebenen inhaltlichen Konsequenzen hat.

Noch weniger eindeutig stellen sich die Bezüge im Märe Der schwangere Müller ${ }^{15}$ dar, das den Themenbereich erotischer Naivität behandelt: Der unerfahrene Müller bezahlt ein Mädchen für die Einweisung in Liebesdinge, verschläft aber die erste Nacht und bekommt in der zweiten so viel Honig von ihr zu essen, dass er die darauf folgenden Bauchschmerzen für eine Schwangerschaft hält. Die anderen Figuren gehen auf seine Sicht der Dinge ein, treffen Geburtsvorbereitungen und präsentieren dem Müller dann zwei junge Schwalben als Kinder, die zu seiner großen Bestürzung sofort davonfliegen.

Das Märe ist in einer Kurzfassung von 204 Versen in den Handschriften w und i überliefert, während die Handschriften $k$ und d eine Langfassung mit rund 260 Versen bieten. ${ }^{16}$ Die Chronologie der Handschriften liefert keine sicheren Hinweise auf ein Vorher und Nachher der Texte: Der Wiener Codex 2885 (w) als ältester Zeuge wurde am 4. Juli 1393 in Innsbruck fertiggestellt, die w nahestehende illustrierte Handschrift $i$ ist in ihrem ersten Teil auf den 3. September 1456 datiert. Die Handschrift k ist 1430-1435 entstanden, die Fertigstellung von Handschrift $d$ ist vom Schreiber Peter Grieninger für den 8. Juli 1447 verzeichnet. Der Hauptunterschied zwischen den beiden Redaktionen ist, dass der Müller in der Kurzfassung bereits in der Nacht Anzeichen der Schwangerschaft spürt, sodass das Mädchen direkt die falschen Hebammen herbeiruft. In der Langfassung geht der Müller erst am nächsten Morgen im Gespräch mit dem Knecht Albrecht von einer Schwangerschaft aus, woraufhin der Knecht die Täuschungshandlung einleitet.

Vgl. DVN (2020), Bd. 3, Nr. 93, bearbeitet von Sandra Linden / Uta Dehnert. Es handelt sich um eine zweispaltige Edition der beiden Redaktionen wi (mit Leithandschrift w) und $\mathrm{kd}$ (mit Leithandschrift k).

16 w: Wien, Österreichische Nationalbibliothek, Cod. 2885, Bl. 137 ${ }^{\text {rb }}-139^{\text {ra }}$ [204 Verse]; i: Innsbruck, Tiroler Landesmuseum Ferdinandeum, Cod. FB 32001, Bl. $67^{\text {ra }}-68^{\text {ra }}$ [204 Verse]; k: Karlsruhe, Landesbibliothek, Cod. K 408, Bl. $11^{\mathrm{vb}}-13^{\mathrm{vb}}$ [259 Verse]; d: Dresden, Landesbibliothek, Msc. M 68(d), Bl. 17 $7^{\mathrm{va}}-19^{\text {ra }}$ [262 Verse]. 
Die längere Redaktion kd beschreibt, wie sich der Müller mit Honig füttern lässt, und zwar reichlich, weil er denkt, dass es sich um die Minne handelt, die er erlernen möchte:

trawt mein gespiel,

sage an, hastu der mynne icht vil?

sye ist so lustsam vnd so gut.

(kd, vv. 163-165)

Das Bauernmädchen gibt ihm, was er verlangt, streicht ihm immer mehr Honig in den Mund, biz er den hafen gar / jn der eynigen nacht verzert (kd, vv. 174f.). Der Müller geht am nächsten Morgen nach Hause zu seinem Knecht Albrecht und merkt nun die Folgen des Honigkonsums: da begond ez ym jn dem leibe krymmen. / er schrey mit iamers stymme (kd, vv. $179 \mathrm{f}$.). Woher das Bauchweh kommt, weiß er auch: jch weiß, daz ich recht swanger byn worden (kd, v. 182).

Der kurze Text in der Redaktion wi ist im Vergleich deutlich unmotivierter, denn er lässt das Bauchweh als logische Folge des Honigkonsums aus. Hier kommt der Gedanke der Schwangerschaft (wi, v. 128) unvermittelt direkt im Anschluss daran, dass der Müller die Minne-Honigspeise als gut und angenehm empfindet. Der Knecht Albrecht, der die Begegnung mit dem Mädchen zu Beginn arrangiert hat und die wichtigste Bezugsperson des Müllers ist, kommt in der Kurzfassung nicht noch einmal vor.

Falls hier die Langfassung gekürzt worden ist, dann nicht besonders gut, weil die mögliche Kürzung deutlich auf Kosten der Handlungslogik geht. Vielleicht erfolgt die Bearbeitung aber auch in die andere Richtung und führt als dilatatio von der Kurz- zur Langfassung? Vielleicht ist der Redaktor der Version, die durch $\mathrm{k}$ und $\mathrm{d}$ repräsentiert wird, ein umsichtiger Erweiterer, der die schlecht integrierte Schwangerschaft besser motiviert und die Erzählung dort enden lässt, wo sie auch begonnen hat, nämlich bei Knecht Albrecht? Diese Annahme erscheint zwar in Betrachtung der oben beschriebenen Passage durchaus reizvoll, fügt sich aber nicht zu anderen Textpassagen: So beschreibt die Redaktion wi, dass der Müller still wie ein Klotz auf dem Bett liege (Hs. w, v. 47). An der entsprechenden Stelle in Handschrift k heißt es, dass der Müller, als sie sich ins Bett legen, still liegt, nicht von der 
Stelle kommt und wie ein Block liegt, der still liegt. ${ }^{17}$ Als Erweiterung wären die Redundanzen ohne Sinn und ziemlich ungelenk. Im Vergleich beider Stellen kommt man eher zu der Vermutung, dass die mehrfache Erwähnung, dass der Müller still liegt, durch eine Kürzung getilgt wurde, um die semantisch wenig wertvolle Wiederholung zu vermeiden. Somit lässt sich weder wi für sämtliche Passagen des Textes stringent als Kürzung der Redaktion kd lesen noch umgekehrt; aus den vorhandenen Überlieferungszeugen lassen sich keine sicheren direkten Zusammenhänge erschließen.

Nach diesem Ausgangstableau der Uneindeutigkeit folgen zwei Beispiele, anhand derer versucht werden soll, Strategien der abbreviatio aufzuspüren, diese aber nicht nur von einer konkreten überlieferten Textfassung her zu denken, sondern auf eine imaginäre Standarderzählung zu beziehen.

\section{I.2. Arbeit am Gerüst der List. Volrat: Die alte Mutter}

Volrats Alte Mutter ${ }^{18}$ ist in einer Langfassung mit 424 Versen in Handschrift $\mathrm{H}$ und einer deutlich kürzeren Fassung mit 244 Versen überliefert, die durch die Handschriften w und i repräsentiert ist. ${ }^{19}$

In der Langfassung will eine blinde alte Freifrau aus Schwaben ihren Sohn wegen seiner vermeintlichen Verschwendungssucht beim Kaiser anklagen. Der Sohn geht zusammen mit seiner Mutter zum Kaiser, ahnt aber schon deren Vorhaben und greift daher zu einer List: Als beide am Hof ankommen, bittet er sie, im Gedränge gut achtzugeben, dass sie sich nicht verlieren. Zu diesem Zweck gibt er ihr einen Ärmel in die Hand, den sie festhalten soll. Die blinde Frau meint, den Ärmel ihres Sohnes zu halten, tatsächlich handelt es sich aber um den Ärmel eines fremden Ritters, der nun

17 Vgl. Redaktion kd, vv. 53-55: da sye zusamen kwamen an daz bette, / er lack stille vnd kwam nit von stett / alz ein bloch, daz da stille leit.

18 Vgl. DVN (2020), Bd. 1/2, Nr. 52, bearbeitet von Uta Dehnert; es handelt sich um eine zweispaltige Edition mit Handschrift $\mathrm{H}$ und der Redaktion wi (Leithandschrift: $\mathrm{w}$ ). 19 H: Heidelberg, Universitätsbibliothek, Cpg 341, Bl. $369^{\text {vab }} ; 358^{\text {ra }}-360^{\text {rb }}$ [424 Verse], w: Wien, Österreichische Nationalbibliothek, Cod. 2885, Bl. $47^{\mathrm{vb}}-50^{\mathrm{ra}}$ [244 Verse] und i: Innsbruck, Tiroler Landesmuseum Ferdinandeum, Hs. FB 32001, Bl. $31^{\text {ra }}-32^{\text {rb }}$ [244 Verse]. $\mathrm{Zu}$ erwähnen ist noch das Fragment $\mathrm{E}^{2}$ : Erfurt, Domarchiv, Deutsche Fragmente 5, Bl. $2^{\text {ra }}$ mit 29 Versen. 
mit der Mutter vor den Kaiser tritt und sich sehr darüber wundert, warum die alte Frau ihn anklagt und für ihren Sohn hält. Nach einigem Hin und Her ist man sich einig, dass der fremde Ritter zu Unrecht seine Mutter verleugnet, weil er sich der Anklage entziehen will. Auch der Einwand des Ritters, dass seine Mutter schon lange tot sei, wird nicht beachtet. Der Kaiser befiehlt, dass er seine Mutter mit nach Hause nehmen und fortan besser ehren soll. Auf dem Rückweg begegnen ihnen einige Leute, die die Mutter erkennen und die Geschichte aufklären.

Vergleicht man die Kurzfassung, die durch die Handschriften w und i repräsentiert wird, zeigt sich das Bemühen, die in $\mathrm{H}$ ausführlich und auch etwas redundant verhandelte Beschuldigung der Verschwendung kürzer zu fassen und die List deutlicher herauszuarbeiten.

Laut Handschrift $\mathrm{H}$ gibt der Sohn der Mutter die Erlaubnis, vor dem Kaiser frei zu sprechen, was die Mutter mit dem Satz: sun, daz si getan (H, v. 135 ) bestätigt. In der Kurzfassung wi fehlt die Passage über die freie Rede, sodass die Mutter mit dem identischen Satz bestätigt, dass sie sich eng an ihren Sohn halten wird, damit sie im Gedränge nicht verloren geht. In der Langversion folgt die direkte Rede des fremden Ritters, dass er mit einem Anliegen vor den Kaiser gehen will. Der Sohn hört dies, bringt seine Mutter zum Ritter, nimmt dessen Ärmel und gibt ihn seiner Mutter in die Hand:

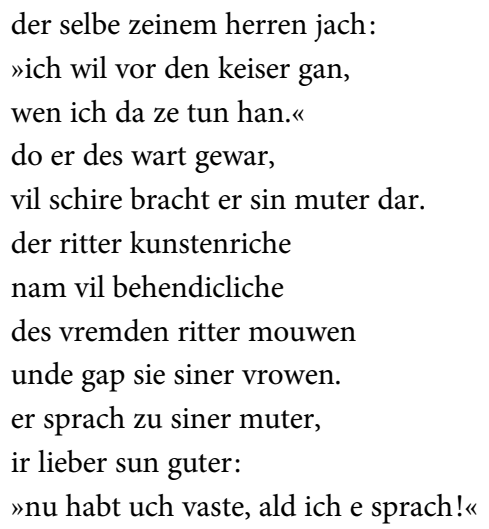
(H, vv. $140-151)$

In der Redaktion wi wird die Absicht des fremden Ritters indirekt wiedergegeben, dann packt der Ritter einfach zu und hängt die Mutter an: 
er wolt auch fur den kaiser gan

vnd wolt sein sache hören lan.

der ritter künstereiche

der nam behendikleiche

dez selben ritters muder.

er gab ez seiner muter.

»nu halt mich, alz ich ee sprach!«

(H, vv. 113-119)

Der Redaktor der Kurzfassung macht noch ein Wortspiel mit dem Reim, weil er den Ärmel nicht wie in $\mathrm{H}$ als mouwe bezeichnet, sondern den Begriff muoder wählt und so muder auf muter reimen kann (wi, vv. $117 \mathrm{f}$.). Die Kurzfassung wi hat in der Passage allerdings ein zusätzliches Verspaar, in dem beschrieben wird, wie sorgfältig die Mutter sich am Ärmel festhält und den Ritter in Richtung des Kaisers lenkt.

do si komen an daz gedreng,

wie fast si an im hieng,

daz er ir nicht engieng.

si nam in pey den ellenpogen

vnd wolt für den chaiser zogen [...].

(wi, vv. 122-126)

Handschrift $\mathrm{H}$ berichtet nur, dass die Mutter dem Ritter folgt, allerdings gleich zweifach:

die vrowe volgte vaste nach.

durch die leute was ir enge.

do sie quam in daz gedrenge,

sie begonde im vaste volgen $[\ldots]$.

(H, vv. 154-157)

Im detaillierten Vergleich zeigt sich, dass die kürzere Fassung den Trick, die Mutter an den fremden Ärmel zu hängen, deutlicher herausstellt und als dynamischen Handlungsablauf zur Darstellung bringt.

Das Gespräch vor dem Kaiser ist in der Redaktion wi wesentlich kürzer als in H. In der Langfassung wechselt die Rede mehrfach zwischen Mutter, Sohn und Kaiser: Der Ritter überlegt ausführlich, ob eine Auferstehung seiner verstorbenen Mutter vor dem Jüngsten Tag möglich sei. Aber selbst wenn die alte Frau seine auferstandene Mutter sei, könne er sich nicht vorstellen, dass sie ihn so beschuldigen würde. Schließlich lenkt er ein, um 
den Kaiser nicht zu verärgern, und nimmt die 〈Auferstandene〉 mit sich heim.

In der Kurzfassung wi widerspricht der Ritter zwei Mal in ansteigender Intensität der Anklage, schaut sich dann nach Bekannten um, die ihm in seiner Lage helfen könnten. Als diese sich im Scherz vor ihm verbergen, erinnert der Kaplan daran, dass man Vater und Mutter ehren solle, worauf der Kaiser dem Ritter befiehlt, sich besser um die Mutter zu kümmern. Der Ritter vermutet nun, dass wohl alles mit dem Teufel zugehe, und fügt sich in sein Schicksal.

Nach der Anklagerede der Mutter kommt die Redaktion wi mit gut 40 Versen aus, während die Langfassung das Gespräch vor dem Kaiser in 200 Versen erzählt (H, vv. 185-383, wi, vv. 154-199). Die Kurzfassung belässt es vor dem Kaiser bei der Verwechslungsgeschichte und bringt die Pointe über das Wunder der Auferstehung der verstorbenen Mutter erst ganz am Ende der Erzählung, nämlich als Rede des Ritters gegenüber den Leuten, die er auf dem Heimweg trifft. Die Pointe wird so bis zum Ende aufgespart, während sie in $\mathrm{H}$ schon in der Rede des Ritters vor dem Kaiser entfaltet wird, aber keine Reaktion erfährt und am Schluss auf dem Heimweg nur einmal wiederholt werden kann. In der Langfassung ist die Pointe an dieser Stelle durch die vorherige diskursive Entfaltung des Gedankens verschenkt und hat kaum noch Effekt. Was der Ritter den Leuten auf dem Heimweg sagt, ist in beiden Fassungen fast identisch:

der sine muter hat begraben,
die vindet er ze hove erhaben,
und vor drizic jaren anderswa,
der vindet sie ze hove alda.
sehet, ich fure mine alhie.
ich gesach si bi drizic jaren nie.

(H, vv. 403-408 [zit.], wi, vv. 217-222)

In der Redaktion wi ist dies eine spitzfindige Äußerung mit Überraschungseffekt für das interne und externe Publikum, in Handschrift $\mathrm{H}$ ist es nur eine Wiederholung des bereits Erörterten. In $\mathrm{H}$ ist der fremde Ritter Opfer der fremden List, in wi kann er sich mit der geschickten Rede über die vermeintliche Auferstehung selbst zum Listigen emanzipieren. Das direkte Aufeinanderfolgen zweier Listen, nämlich der des Sohns und der des 
fremden Ritters, kommt in der Redaktion wi auch durch die narrative Kürze und die dadurch erhöhte Erzählgeschwindigkeit besser zur Geltung.

Der Kommentar des Erzählers macht dann in der Kurzfassung das Verhalten des Ritters zu einem kalkulierten Schauspiel, indem er dessen Rede als gemeleiche[ ] sag (wi, v. 234) betitelt und die Figur damit zum Erzähler von Geschichten emanzipiert. Durch die Wortwahl werden Erzähler und Figur parallel gesetzt, denn im Prolog hatte der Erzähler sein Werk ebenfalls als ein gemeliches $(\mathrm{H}) /$ gamelleichs (i) beziehungsweise gemechleichs (w) mere (v. 3) angekündigt. In der Redaktion wi wird also durch die Wiederaufnahme des Signalworts vom Beginn eine Metaebene in die Geschichte eingezogen, die ihr zusätzliche Komplexität verleiht, indem reflektiert wird, dass eine unterhaltsame und gut gesetzte Rede in der Erzählung ebenso entfaltet werden kann wie in der Figurenrede, dass Ritter und Erzähler beide geschickte Wortkünstler sind, die auf einen Unterhaltungseffekt abzielen.

Das Märe Die alte Mutter zeigt, dass die kürzere Erzählung nicht automatisch einfacher ist, dass es nicht nur um ein Kondensat des längeren Textes geht. Vielmehr ergibt sich im detaillierten Vergleich von Kurz- und Langfassung der Eindruck, dass die kürzere Redaktion aus dem vorhandenen Erzählmaterial das herausfiltert, was nötig ist, um die Listhandlung möglichst prägnant hervortreten zu lassen, etwa wenn das Anhängen der Mutter an den Ärmel deutlicher betont wird.

Dieser Befund passt auch zum allgemeinen Programm der Handschrift w: Die Konzentration auf das Listhandeln ist ein grundlegendes Charakteristikum dieser Handschrift, die mit schwankhaft-komischen Erzählungen eine Atmosphäre der Geselligkeit und guter Unterhaltung anvisiert, dabei nur wenige lehrhafte Texte überliefert. Zahlreiche Erzählungen thematisieren Verwicklungen in der Minne - ein Sujet, das die Erzählung von der Alten Mutter gerade nicht bedient. Aber dennoch ergibt sich eine nachvollziehbare Gemeinsamkeit mit den anderen Texten der Sammlung, nämlich indem in der direkten Nachbarschaft des Stücks im Rahmen von Geschichten über erotische Naivität mehrfach von Verwechslungen zwischen wörtlicher und übertragener Sprache erzählt wird (z. B. Das Gänslein, Tor Hunor oder auch Der Minne Porten). Und über dieses Spiel mit der geschickten und innerhalb der List genau gesetzten Rede fügt sich die Alte Mutter dann doch recht gut ins Textspektrum der Handschrift ein. 
Um die narrative Strategie, mit der das kurze, prägnante Erzählen hier arbeitet, besser herauszustellen, kann man eine imaginäre Normalstufe des Auserzählens ansetzen, die nachvollziehbar und in angemessenem Tempo voranschreitet und die Figuren in ihrem Handeln und in ihren Reden plausibel entfaltet. Diese Normalstufe ist bewusst als Hilfskonstruktion zu denken, die nur einen ungefähren Bezugspunkt auf einer Skala des «Länger oder Kürzer > abgibt und sich primär aus den Erzählkonventionen der Gattung speist, somit also ein subjektives Empfinden der Rezipierenden über Länge und Kürze einkalkuliert. Von dieser Normalstufe aus, die auf den Plot konzentriert ist, kann sich ebenso ein flächiges und breit beschreibendes Erzählen wie ein verdichtetes, eiliges Erzählen ausbilden. Die Redaktion wi zeigt abweichend von dieser Normalstufe des Auserzählens ein abbreviatioKonzept, wie man es in der Versnovellistik mehrfach antreffen kann: Das vorhandene Material wird auf das Konstrukt der List hin geordnet, das Wesentliche vom Unwesentlichen getrennt. Auf ein flächiges, szenisch ausladendes Erzählen mit ausführlichen Dialogen und Beschreibungen wird verzichtet zugunsten der überraschenden Pointe, die ihren Effekt ganz wesentlich auch durch Geschwindigkeit erzielt.

Den ordnenden Zugriff, in dem vorhandenes Erzählmaterial zur besseren Herausstellung der List bearbeitet wird, erinnert an narrative Strategien, wie Wolfram sie im Bogengleichnis des Parzival beschreibt, wo er die poetologische Strategie entwirft, dass der Erzähler manchmal Dinge, die im natürlichen ordo der Handlung an der Reihe wären, im Erzählen zunächst verschweigt und erst später herausgibt, um den literarischen Effekt zu erhöhen. ${ }^{20}$ Auch in der Redaktionstätigkeit im Märe kann man diese Strategie, Erzählinhalte um des Effekts willen für später aufzubewahren, beobachten: In der Langfassung wird der Auferstehungsgedanke im Gespräch langsam vorbereitet und verständlich ausgeführt, erlangt in der Akzeptanz der auferstandenen Mutter durch den Ritter sogar einen gewissen Witz, ist als Pointe am Ende aber verspielt. Die Kurzfassung hingegen tilgt vorherige Erwähnungen des Gedankens und spart ihn bis zum Ende auf. Der Redaktor der Kurzfassung nimmt hier durch die extreme Kürze des Ge- 
sprächs vor dem Kaiser sogar einige Härten in Kauf, nämlich dass nicht nachvollziehbar ist, warum der Ritter die falsche Mutter mit so wenig Gegenwehr akzeptiert. Doch dafür kann er den Überraschungseffekt mit der wundersamen Auferstehung am Ende besser platzieren und offenbart so plötzlich, dass der Ritter eben doch kein Opfer ist, sondern auch ein Listiger, sogar ein listiger Erzähler.

\section{I.3. Geschwindigkeit und Wortwitz. Heinrich von Pforzen: Der Pfaffe in der Reuse}

Der Pfaffe in der Reuse ${ }^{21}$ von Heinrich von Pforzen ist mit acht Handschriften breit überliefert. ${ }^{22}$ Die kurze Version der Erzählung mit 286 bis 288 Versen findet sich in den Handschriften $\mathrm{m}^{1}, \mathrm{~m}^{3}$ und $\mathrm{s}^{6}$, die Langfassung in den Handschriften $\mathrm{k}$ und 1 mit 390 beziehungsweise 428 Versen. Die Forschung geht davon aus, dass Kurz- und Langfassung auf eine gemeinsame Vorlage ${ }^{\star} \mathrm{klm}$ zurückgehen. ${ }^{23}$ Der weitgehend gemeinsame Versbestand in $\mathrm{m}^{1}, \mathrm{~m}^{3}$ und $\mathrm{s}^{6}$ lässt sogar den Schluss zu, dass alle drei Handschriften auf eine gemeinsame Kurzfassung der Vorlage ${ }^{\star}$ klm zurückgehen.

21 Vgl. DVN (2020), Bd. 4, Nr. 160, bearbeitet von Gudrun Felder. Es handelt sich um eine vierspaltige Edition mit den beiden Langfassungen $\mathrm{k}$ und 1 in je eigener Spalte, der Kurzfassung $\mathrm{m}^{1}, \mathrm{~m}^{3}, \mathrm{~s}^{6}$ und der Redaktion $\mathrm{b}^{2}, \mathrm{c}, \mathrm{n}^{1}$ und $\mathrm{x}$, die zwischen 351 und 400 Versen schwankt und eine eigene Darstellung in der Edition erfährt, weil Niewöhner (1967) $\mathrm{b}^{2}$ als Leithandschrift bietet.

22 Vgl. k: Karlsruhe, Badische Landesbibliothek, Karlsruhe 408, Bl. 40 $0^{\text {va }}-43^{\text {ra }}$ [390 Verse]; 1: Karlsruhe, Badische Landesbibliothek, Donaueschingen 104, Nr. 202, Bl. $205^{\text {va }}-208^{\text {ra }}$ [428 Verse]; $\mathrm{m}^{3}$ : München, Bayerische Staatsbibliothek, Cgm 379, Bl. 22 $2^{\mathrm{r}}-27^{\mathrm{r}}$ [ 286 Verse ]; $b^{2}$ : Berlin, Staatsbibliothek Preußischer Kulturbesitz, Ms. germ. qu. 1107, Bl. 70 $-77^{\mathrm{v}}$ (neue Foliierung), [400 Verse]; $\mathrm{m}^{1}$ : München, Bayerische Staatsbibliothek, Cgm 270, Bl. $60^{\mathrm{r}}-64^{\mathrm{v}}$ [288 Verse]; $\mathrm{s}^{6}$ : Salzburg, Stiftsbibliothek St. Peter, Cod. b IV 3, Bl. $26^{\mathrm{v}}-32^{\mathrm{v}}$ [287 Verse]; n': Nürnberg, Germanisches Nationalmuseum, Hs. 5339a, Bl. 247 ${ }^{\mathrm{v}}-256^{\mathrm{r}}$ [351 Verse]; c: Chur, Staatsarchiv, Cod. B 1, Bl. $75^{\mathrm{v}}-82^{\mathrm{r}}$ [ 382 Verse]; x: Abschrift eines unbekannten Fragments durch Bernhard Joseph Docen, München, Staatsbibliothek, Docenia C 53, Bl. $1^{\text {ra }}-1^{\text {va }}[62$ Verse $]$.

23 Vgl. Wollenweber (1976), S. 165. Diese Annahme wird im allgemeinen Kommentar der DVN-Edition nochmals bestätigt und mit mehreren Belegstellen versehen. 
Das Märe bedient thematisch die beliebte Kategorie des Listhandelns im Ehebruch: Eine Fischersfrau betrügt ihren Mann mit dem Pfaffen und schädigt dabei auch den Burgherrn, weil sie mit dem Pfaffen während der Abwesenheit des Ehemanns die gefangenen Fische verspeist und der Fischer so seine Abgaben nicht ordentlich leisten kann. Der Burgherr, der alles durchschaut, erklärt dem ahnungslosen Fischer, dass die Fische wohl das Wasser verlassen hätten und er seine Reusen an drei anderen Stellen auslegen solle, nämlich bei ihm zu Hause, im Hag und im Wald. Dann möge er bringen, was er dort fange. Der Fischer wundert sich zwar über die Anweisungen seines Herrn, gehorcht aber und hängt eine der Reusen über der Feuerstelle auf. Als er früher nach Hause kommt, ist der Pfaffe gerade beim Liebesstelldichein mit der Frau des Fischers und wird nackt in der Reuse über dem Feuer versteckt. Er leidet unter dem Rauch, und seine weiße Haut wird ganz schwarz. Als der Fischer am nächsten Morgen den ungewöhnlichen Fang entdeckt, bittet der Pfaffe verzweifelt um Gnade, bietet auch Bestechungsgeld, aber der zornige Fischer lässt sich auf keinen Handel ein. Er sammelt noch Hasen und Rebhühner aus den beiden anderen Reusen ein und bringt dann den gesamten Fang zum Burgherrn. Dieser ist zufrieden, das Ehepaar wird versöhnt und der Pfaffe des Landes verwiesen.

Vergleicht man Lang- und Kurzfassung, so fällt auf, dass die Redaktionen in den ersten 260 Versen relativ parallel laufen. Dann aber wird in der Redaktion $\mathrm{m}^{1} \mathrm{~m}^{3} \mathrm{~s}^{6}$ radikal gekürzt, was die Erzählgeschwindigkeit steigert und den Text an Dynamik gewinnen lässt. So werden nicht einfach Schritt für Schritt Längen aus dem Text herausgenommen, sondern die Kürzung greift erst ganz am Ende, nämlich nach der Entdeckung, als die Frau des Fischers sich heimlich aus dem Haus stiehlt und die Bühne für den Konflikt zwischen Fischer und Pfaffen frei macht (k, v. 266; 1, v. 270; $\mathrm{m}^{1} \mathrm{~m}^{3} \mathrm{~s}^{6}$, v. 264). Während $\mathrm{k}$ noch 120 Verse und 1 sogar noch 160 Verse lang erzählt, kommt die Kurzversion mit nur 24 Versen zu einem schnellen Ende.

In der Langfassung $\mathrm{k}$ reagiert der Fischer mit einer ausführlichen Scheltrede auf den Kleriker, dass er wie ein Dachs oder Otter die Fische aus der Reuse weggefressen habe:

kunnet ir in rewsen suchen

fysch, ir vil vaiger dahs?

beyde, frauwen und lachs, 
dez hastu phaff lotter

heymlich geßen alz eyn otter

auß der rewsen in dem pach!

(k, vv. 280-285, vgl. l, vv. 290-295)

Die Kurzredaktion beschränkt sich auf die Handlung: Mit je einem Verspaar wirft der Fischer die Reuse mitsamt dem Pfaffen auf seinen Karren und holt zwei Hasen aus der zweiten Reuse, die Rebhühner in der dritten Reuse bekommen zwei Verspaare. Das Gespräch mit dem Pfaffen, der den zornigen Fischer um Gnade bittet, fehlt, ebenso dessen Beschämung. Stattdessen geht es ganz zügig zur Burg: und eilet zu der purg geswind $\left(\mathrm{m}^{1} \mathrm{~m}^{3} \mathrm{~s}^{6}\right.$, v. 273), wo dann der Burgherr spricht. Während der Burgherr in der Langfassung nur unspezifisch die Folgsamkeit des Fischers lobt und ihm sein Lehen in Eigengut verwandelt (k, vv. 328-339), fällt der Burgherr in der Kurzfassung durch seinen Wortwitz auf: du prachtest mir etwan ain seltzams uischlin! $\left(\mathrm{m}^{1} \mathrm{~m}^{3} \mathrm{~s}^{6}, \mathrm{v} .278\right)$. Er tut so, als sei der Pfaffe ein Fisch und als habe er ihn erst auf den zweiten Blick erkannt:

«ist das vnser caplan?

wie ist er dann also gethan?

haut er gestift ain andern orden, ist er uischers průder worden? [...]»

$\left(\mathrm{m}^{1} \mathrm{~m}^{3} \mathrm{~s}^{6}, \mathrm{vv} .281-284\right)$

In gespielter Verwunderung erkennt der Burgherr den Pfaffen und übt sich in spitzfindiger Rede. In der interessierten Frage, ob er nackt in der Reuse vielleicht einen neuen Orden gegründet habe, klingen anregungsreich die biblischen Menschenfischer aus der Rede Christi an Petrus und Andreas nach. ${ }^{24}$ In der Langfassung ist das Erkennen des Kaplans nicht Rede des Burgherrn, sondern die seiner Frau, was zwar die Peinlichkeit für den Pfaffen erhöht, aber das eigentlich konzise Figurenschema auch unnötig verwässert. ${ }^{25}$ Die vollständige Nachgeschichte, d. h., was mit dem Pfaffen geschieht, ob sich das Ehepaar versöhnt usw., ist für die Kurzfassung irrelevant, vielmehr

24 Vgl. Mt 4,19.

25 Die Edition nimmt zwischen v. 280 und 281 mit Blick auf die Langfassung, in der die betreffenden Verse Rede der Burgherrin sind, einen Sprecherwechsel an, doch setzt v. 281 in $\mathrm{m}^{1} \mathrm{~m}^{3} \mathrm{~s}^{6}$ logisch die Rede des Burgherrn fort, zumal eine Inquit-Formel fehlt und die Burgherrin in der Kurzfassung gar nicht erwähnt wird. 
bildet die Rede des Burgherrn hier ein prägnantes Schlusswort, auf das nur noch vier Verse Epimythion folgen.

In der Redaktion $\mathrm{m}^{1} \mathrm{~m}^{3} \mathrm{~s}^{6}$ lässt sich eine extreme Beschleunigung zum Ende hin beobachten, der Wortwitz des Burgherrn braucht Kürze, um zu wirken. Nach der detaillierten, in gemächlichem Tempo voranschreitenden Exposition nimmt die Erzählgeschwindigkeit in der Kurzfassung deutlich zu, sodass zum Ende hin eine Art Sogwirkung der immer schneller aufeinanderfolgenden Ereignisse entsteht. Doch ist das nicht nur eine Geschwindigkeit um ihrer selbst willen, sondern die Kurzfassung arbeitet auch an der Konsistenz der Figurenzeichnung: Die List, dass man in einer Reuse nicht nur Fische, sondern auch Ehebrecher fangen kann, geht ursprünglich vom Burgherrn aus. In der Langfassung bekommt dann aber der Fischer, der eigentlich nur ausführendes Organ ist, etwa durch den Tiervergleich mit dem Otter auch noch ein gewisses sprachspielerisches Potential zugesprochen. Die Kurzfassung hingegen belässt den Wortwitz konsequent bei dem, der die List eingeführt hat, nämlich beim Burgherrn. $\mathrm{Zu}$ ihm passt die raffinierte, doppeldeutige Rede besser als zum Fischer oder zur Burgherrin, und es ist effektvoller, wenn nur einer die listige Rede führt und sie als prägnantes Merkmal der Figur heraussticht, als wenn sich alle Figuren ein bisschen und somit weniger auffällig darin üben.

Die Langversion bietet eher ein flächiges Erzählen, das das Schicksal aller Figuren sorgfältig weiterdenkt und bis zum Ende nachverfolgt, dabei deutlich zu epischer Breite tendiert. Die Burgherrin wird zur Fürsprecherin des Pfaffen, dieser wird wieder bekleidet, verliert aber sein Amt und wird des Landes verwiesen. Die Fischersfrau, die schon längst die Bühne verlassen hatte, wird noch einmal herbeigeholt, damit das Ehepaar versöhnt werden kann.

Der Redaktor der Kurzfassung hingegen richtet alle Energie darauf, einen pointierten Schluss zu gestalten. Hier geht es vor allem um das Listhandeln und den sprachlichen Witz des Überlegenen. So entsteht durch die Kürzungen ein stark verdichtetes Erzählen, in dem die Szenen mit wenigen Worten umrissen und eng aneinandergestellt werden. Diese Verdichtung ist hier mit dem extrem schnellen Schluss auch zeitlich zu sehen: Die Kürzungen fordern ein schnelleres Reagieren des Publikums, die Erzählung jagt genauso schnell zur Pointe wie der Fischer mit seiner Beute zur Burg und setzt so die Sogwirkung der Ereignisse gut ins Narrativ. 


\section{Auf der Jagd nach der besten Erzählung. abbreviatio als ein Verfahren narrativer Beschleunigung}

Wie bereits zu Beginn des Beitrags erläutert, steht die abbreviatio immer in Bezug zu einem breiter ausgefalteten Text, auf den sie sich bezieht. Ästhetische Freude ergibt sich für das Publikum daraus, dass es in der Rezeption der Kurzform die Vollform gedanklich ergänzt, denn nur mit einem Referenztext kann man die geschickte Kürzung als literarische Leistung goutieren. Doch ist für die Versnovellistik fraglich, wo man diesen Bezugstext ansetzen soll. Wenn ein Redaktor kürzend in eine längere, ihm schriftlich vorliegende Form eingreift, bleibt dem Publikum diese längere Form verborgen und dürfte nur in seltenen Fällen bekannt sein. ${ }^{26}$

Bekannt ist vielmehr ein Gattungswissen, d. h. ein Wissen darüber, wie im Märe erzählt wird, welche Situationen dargestellt werden, welche Figuren vorkommen, wie ein Listhandeln literarisch entwickelt wird usw. Die These des Beitrags zielt darauf, dass die abbreviatio ihre ästhetische Wirkung nicht über den Vergleich mit einem konkreten längeren Ausgangstext und einer daraus resultierenden Freude des Publikums über die gute Kurzform erzielt. Vielmehr geht es darum, dass das Publikum ein gattungsspezifisches Wissen über das Märe abruft, ein Wissen darüber, wie Figuren in diesem Genre handeln, wie Konflikte üblicherweise entfaltet werden usw. In der gekürzten Fassung muss nicht lange erörtert werden, warum Ehefrau und Pfaffe ein Liebesverhältnis eingehen, weil der Rezipient dieses Handlungsmuster aus anderen Mären kennt. $\mathrm{Zu}$ diesem Gattungswissen gehört auch ein Gefühl für eine angemessene Länge, in der ein Erzählmuster entfaltet wird, für die zuvor beschriebene Normalstufe der Ausführlichkeit.

Die Beispiele sollten zeigen, dass die Strategien der abbreviatio im Märe oftmals darauf setzen, dass der Rezipient Dinge aus der Bezugsmatrix der Gattung eigenständig ergänzen kann. In der Konsequenz wird paradoxerweise genau das, was für die Gattung typisch und erwartbar ist, verzichtbar. Der ¿intellektuelle Kontrakt〉 der abbreviatio würde dann nicht auf den längeren

26 Vgl. etwa die Überlieferungszusammenhänge, die Dahm-Kruse (2018) für Konrads von Würzburg Herzmäre darlegt; hier könnte man angesichts der Bekanntheit der Erzählung vom gegessenen Herzen eine Vertrautheit des Publikums mit dem spezifischen Erzählmuster und weiteren Ausführungen voraussetzen. 
einzelnen Märentext zielen, sondern auf ein Wissen über ein literarisches Kontinuum, auf ein Wissen darüber, wie ein Märe funktioniert und wie ein Erzählmuster in einer quantitativ neutralen Normalstufe, die zwischen prägnanter Kürze und ausladender narrativer Breite steht, erzählt werden kann. Die Kürzungen zielen darauf, das Spektakuläre, das Besondere der je einzelnen Erzählung besser hervortreten zu lassen, indem das, was in der Gattung gängig und mehrfach in ähnlichen Erzählungen reproduziert ist, nicht breit auserzählt werden muss, sondern verkürzt über ein Stichwort aufgerufen werden kann. ${ }^{27}$

Gerade die Perspektive auf das Kontinuum der vielen Texte lässt die Redaktoren der Sammelhandschriften an dem je Spezifischen des Einzeltextes arbeiten, an dem, was den einen Text von den vielen anderen in der Sammlung absetzt. Den Umgang mit Besitz als Konfliktpotential zwischen den Generationen findet man in mehreren Erzählungen, aber nur in einem einzigen Märe wird die Mutter von ihrem Sohn an den falschen Ärmel gehängt. Es geht den Redaktoren darum, im Textkontinuum der Gattung Elemente der Signifikanz aufzuspüren und diese zu isolieren, indem sie das Nichtprägnante tilgen. Die herausgekürzten Elemente wurden also vielleicht gar nicht als störende Längen empfunden, sie waren lediglich als Material bei der Arbeit an der Singularität des einzelnen Märes im Wege.

abbreviatio als «sinnstiftende[] Tätigkeit des Verdichtens ${ }^{28}$ meint somit eine Fokussierung auf das Prägnante und Wesentliche, das in der Versnovellistik vor der Folie nicht einer einzigen Vorlage, sondern zahlreicher Bezugstexte zu verstehen ist. Das prägnante Detail ist es, das die Aufnahme eines Textes in die Märenhandschrift rechtfertigt, die ja immer ein Sammlungskontext aus vielen Texten ist. ${ }^{29}$ Die Heidelberger Märenhand-

27 Dass die abbreviatio dann auch wieder statt Einfachheit des Sinns eine Mehrdeutigkeit erzeugt, die zur obscuritas tendiert, weil das Publikum nicht mehr genügend Informationen erhält, um Zusammenhänge sicher herstellen zu können, sieht bereits Galfred von Vinsauf, vgl. dazu Waltenberger (2019), vor allem S. 31-34.

28 Vgl. Frick, in diesem Band, S. 14.

29 Wie sehr die Sammlung die Sinnbildung des Einzeltextes beeinflusst, hat DahmKruse (2018), S. 12, treffend formuliert: «Jede Sammlung fügt den Einzeltext in den übergeordneten Sinnhorizont ihrer Gesamtkonzeption ein und beeinflusst, indem sie je neue, individuelle Lektürezusammenhänge gestaltet, dessen Rezeption.» 
schrift cpg $341(\mathrm{H})$ sammelt 224 Texte, die Karlsruher Handschrift k hat 202 Texte, die Wiener Märenhandschrift w 68 Texte, die Liedersaalhandschrift 1 261 Texte. Um für die Aufnahme in eine solche Sammelhandschrift attraktiv zu sein, muss ein Märe einerseits einem allgemeinen Sammlungsschema entsprechen, andererseits aber durch eine spezifische Besonderheit hervortreten, denn nur dann kann es die Sammlung erweitern und bereichern. In einer solchen Pluralität avanciert die Kürzung zu einem probaten Mittel, um das prägnante Detail deutlicher hervorzuheben. In diesem Sinne wäre abbreviatio in der Gattung Märe also auch Arbeit an der Diversität im Sammlungskontext.

Die Beispiele haben auch gezeigt, dass die abbreviatio in der Versnovellistik als ein literarisches Verfahren genutzt wird, das in engem Zusammenhang mit der Geschwindigkeit einer Erzählung steht. Dieser Aspekt soll abschließend mit einem Seitenblick auf Alexander und Anteloie, ${ }^{30}$ einer Erzählung in der Alexandertradition, noch einmal hervorgehoben werden. Die Erzählung begegnet in drei Handschriften als Teil der AlexanderErzählung in der Weltchronik Heinrichs von München, ist aber auch separat als Märe überliefert, wo mit den Handschriften B und $\mathrm{d}^{5}$ wiederum Langund Kurzfassung nebeneinanderstehen. ${ }^{31}$ Die Kurzfassung kündigt anders als die lange Version an: Deme selbigen koninge riche
geschach gar wundirliche
eine gar selczene mere;
ab uch das zcu horin lip were,

30 Vgl. DVN (2020), Bd. 2, Nr. 67, bearbeitet von Henrike Schwab. Die Edition erfolgt in drei Spalten mit der Langfassung B, der Kurzfassung $\mathrm{d}^{5}$ und den Weltchronik-Handschriften $\mathrm{M}^{16}, \mathrm{M}^{15}$ und $\mathrm{w}^{14}$ (Leithandschrift $\mathrm{M}^{16}$ ).

31 Vgl. B: Berlin, Staatsbibliothek Preußischer Kulturbesitz, Ms. germ. qu. 663 [c], Nr. 1, Bl. $1^{\text {ra }}-2^{\text {vb }}$ [152 überlieferte Verse; Fragment $=$ Langfassung $]$ und $d^{5}$ : Dresden, Sächsische Landesbibliothek, Mscr. Dresd. M. 42, Nr. 2, Bl. $86^{\text {va }}-90^{\text {va }}$ [486 Verse $=$ Kurzfassung] sowie die drei Weltchronik-Handschriften: $\mathrm{M}^{16}$ : München, Bayerische Staatsbibliothek, Cgm 7377 [a], Nr. 1, Bl. 204 ${ }^{\text {va }}-206^{\text {rb }}$ [504 Verse]; $M^{15}$ : München, Bayerische Staatsbibliothek, Cgm 7330, Nr. 1, Bl. $186^{\text {rb }}-188^{\text {ra }}$ [438 Verse]; ${ }^{14}$ : Wien, Österreichische Nationalbibliothek, Cod. 12470, Nr. 1, Bl. $330^{\text {rb }}-332^{\text {rb }}$ [ 355 Verse]. 
die welde ich uch zcu dute sagin

vnd korczlichin obir jagin.

$\left(d^{5}, \text { vv. } 33-38\right)^{32}$

Die Formulierung korczlichin obir jagin zielt wohl auf ein schnelles und zusammenfassendes Berichten, auf eine Erzählweise, die nicht viel Zeit des Publikums in Anspruch nimmt und eine erhöhte Geschwindigkeit beim Erzähler voraussetzt. ${ }^{33}$

Als poetologische Strategie lässt sich das durchaus mit Konzepten der narrativen Großform Roman zu dieser Zeit vergleichen, denn der Roman im 14. Jahrhundert praktiziert ja schon lange nicht mehr das schrittweise Mitgehen im Strukturmodell, sondern hat sich durchaus dynamischere Konzepte des Erzählens erarbeitet. Eines der Modelle, das seinen Ausgang schon bei Wolframs Parzival nimmt, sieht den Erzähler im Austausch mit der personifizierten Aventiure, die ihn an die Orte des zu erzählenden Geschehens führt und ihn somit die oftmals stark raumgreifende Bewegung des Protagonisten direkt nachvollziehen lässt. Im Wilhelm von Österreich etwa begegnet ein temporeiches Konzept, bei dem der Erzähler der Aventiure nachjagt und sich im Erzählen beeilen muss, mit ihr Schritt halten zu können. ${ }^{34}$ Das Erzählte wird hier nicht mit ruhigem Kalkül und souveränem Überblick über das Ganze entworfen, sondern in hastiger Eile «erjagt〉. Der Erzähler betont immer wieder, dass er eilen muss, um nichts zu verpassen, ${ }^{35}$ und demonstriert, dass gutes Erzählen sich eben auch durch ein hohes Tempo und entsprechende Dynamik auszeichnet.

Vielleicht kann man dieses Bild des Jagens, das Roman und Märe hier gemeinsam für eine poetologische Aussage nutzen, auch hilfreich für das Verständnis der abbreviatio im Märe verwenden: Neben der Arbeit an der

Die Langfassung in Handschrift B kündigt lediglich in einer wenig aufmerksamkeitsträchtigen Formel den Bericht an, vgl. B, vv. 60-63: ab uch daz liep were / und gerne horen woldet, / wie schiere daz ich solde / uch berichten, waz ich meine.

33 Vgl. Grimm (1854-1961), Bd. 23,330, wo unter dem Lemma überjagen die Bedeutungen ‘hetzen, zu schnell treiben` und «durch Geschwindigkeit einholen` verzeichnet sind.

34 Vgl. Linden (2017), S. 499-501.

35 Vgl. Johann von Würzburg: Wilhelm von Österreich, z. B. vv. 7.276-7.279: ich wil der Minne geverte jagen / furbaz mit dem getiht, / da von ichz gerne riht / nach der Aventüre gir. 
Prägnanz des Erzählgerüsts und der Pointiertheit der List scheint die abbreviatio auch eine Freude an einer erhöhten Erzählgeschwindigkeit umzusetzen. Nicht Kürze als Textphänomen in einem schriftliterarischen Kalkül, sondern Geschwindigkeit als ein Phänomen eines auch mündlich vorgetragenen Erzählens, und zwar explizit die wechselnde Geschwindigkeit in Form der Beschleunigung, ist somit ein Kennzeichen der abbreviatio in der Versnovellistik. Die abbreviatio lässt sich hier als ein narratives Verfahren fassen, das an der Zeit ansetzt, das eine Dynamisierung und Beschleunigung der Handlungsabläufe bewirkt und sich mit der rhetorischen Kategorie der velocitas verbindet, die zwar primär auf Sprechgeschwindigkeit und Beweglichkeit im Wortwechsel zielt, ${ }^{36}$ aber etwa bei Quintilian in Bezug auf die Geschichtsschreibung Sallusts auch als Geschwindigkeit im narrativen Ablauf begegnet. ${ }^{37}$ Neben der intellektuellen Freude, die das Publikum aus der Pointiertheit der List bezieht, ergibt sich eine ästhetische Freude aus der Beschleunigung im Erzählen, dem - mitunter auch ganz unvermittelten Wechsel der Geschwindigkeit im Präsentieren und Erschließen der Ereignisse. Die abbreviatio zeigt sich somit als eine Möglichkeit für den Autor / Redaktor, die narrative Vermittlung als spezifische Leistung auszuweisen, die ein ästhetisches Werturteil erhalten kann. Die durch abbreviatio erzielten Beschleunigungseffekte sind ein kalkuliert eingesetztes Verfahren in der Versnovellistik, das das Publikum in seiner literarischen Versiertheit herausfordert, ihm aber, wenn es mit dem Tempo des Erzählers denn Schritt halten konnte, wohl auch ein besonderes Vergnügen bereitet hat.

\section{Bibliographie}

\section{Primärliteratur}

$[$ DVN $]=$ Deutsche Versnovellistik des 13. bis 15. Jahrhunderts, 6 Bde., hg.v. Klaus Ridder / Hans-Joachim Ziegeler, Basel / Berlin 2020.

36 Vgl. Quintilian: Institutio oratoria VI,4 (8), wo er die velocitas neben der mobilitas und einem animus praesens et acer zum rednerischen ingenium rechnet.

37 Vgl. Quintilian: Institutio oratoria X,1 (102). 
Galfred von Vinsauf / Anonymus: Documentum de modo et arte dictandi et versificandi (kurze Version), in: Les arts poétiques du XIIe et du XIIIe siècle, hg.v. Edmund Faral, Paris ${ }^{2} 1962$, S. $262-320$.

Johann von Würzburg: Wilhelm von Österreich, aus der Gothaer Handschrift hg.v. Ernst Regel, Dublin / Zürich 1970, Nachdruck der Ausgabe: Berlin 1906 (DTM 3).

Kleinere Dichtungen Konrads von Würzburg. Der Welt Lohn - Das Herzmaere Heinrich von Kempten, hg.v. Edward Schröder, mit einem Nachwort von Ludwig Wolff, Berlin 1970, Nachdruck der Ausgabe: Berlin 1924.

Neues Gesamtabenteuer. Das ist Fr. H. von der Hagens Gesamtabenteuer in neuer Auswahl. Die Sammlung der mittelhochdeutschen Mären und Schwänke des 13. und 14. Jahrhunderts, Bd. 1, hg.v. Heinrich Niewöhner. 2. Aufl. hg.v. Werner Simon, Dublin / Zürich 1967.

Marcus Fabius Quintilianus: [Institutio oratoria.] Ausbildung des Redners. 12 Bücher, hg. und übers. v. Helmut Rahn, 2 Bde. 2., durchges. Aufl., Darmstadt 1988 (Texte zur Forschung 3).

\section{Forschungsliteratur:}

Aarne, Antti / Thompson, Stith: The Types of the Folktale. A Classification and Bibliography, Helsinki ${ }^{2} 1964$.

Dahm-Kruse, Margit: Versnovellen im Kontext. Formen der Retextualisierung in kleinepischen Sammelhandschriften, Tübingen 2018 (Bibliotheca Germanica 68).

Dimpel, Friedrich Michael / Wagner, Silvan (Hgg.): Prägnantes Erzählen, Oldenburg 2019 (Brevitas 1 - BmE Sonderheft).

Eichenberger, Nicole: Geistliches Erzählen. Zur deutschsprachigen religiösen Kleinepik des Mittelalters, Berlin u. a. 2015 (Hermaea 136).

Eichenberger, Nicole: Variationen eines Themas. Zur Korrelation von Umfang und literarisch-konzeptioneller Gestaltung bei stoffverwandten geistlichen Verserzählungen, in: Franz-Josef Holznagel / Jan Cölln (Hgg.): Die Kunst der brevitas. Kleine literarische Formen des deutschsprachigen Mittelalters, Berlin 2017 (WolframStudien XXIV), S. 155-175.

Fischer, Hanns: Studien zur deutschen Märendichtung, 2., durchgesehene und erweiterte Aufl., besorgt von Johannes Janota, Tübingen 1983.

Grimm, Jacob und Wilhelm: Deutsches Wörterbuch. 16 Bde. in 32 Teilbänden, Leipzig 1854-1961.

Henkel, Nikolaus: Kurzfassungen höfischer Erzähldichtung im 13./14. Jahrhundert. Überlegungen zum Verhältnis von Textgeschichte und literarischer Interessenbildung, in: Joachim Heinzle (Hg.): Literarische Interessenbildung im Mittelalter. DFG-Symposion 1991, Stuttgart / Weimar 1993 (Germanistische Symposien. Berichtsbände 14), S. 39-59. 
Henkel, Nikolaus: Reduktion als poetologisches Prinzip. Verdichtung von Erzählungen im lateinischen und deutschen Hochmittelalter, in: Franz-Josef Holznagel / Jan Cölln (Hgg.): Die Kunst der brevitas. Kleine literarische Formen des deutschsprachigen Mittelalters, Berlin 2017 (Wolfram-Studien XXIV), S. 27-55.

Linden, Sandra: Exkurse im höfischen Roman, Wiesbaden 2017 (MTU 147).

Scholl, Richard: Thomas von Kandelberg. Eine mittelhochdeutsche Marienlegende, Leipzig 1928.

Thompson, Stith: Motif-Index of Folk-Literature. 6 Bde., 2. Aufl., Kopenhagen 19551958.

Tubach, Frederic C.: Index Exemplorum. A Handbook of Medieval Religious Tales, Helsinki 1969.

Wagner, Silvan / Dimpel, Friedrich Michael: Prägnante Kleinepik, in: Dimpel / Wagner (2019), S. 1-13.

Waltenberger, Michael: 〈Bedeutungsschwangerschaften〉. Überlegungen zu Prägnanz und Pointierung mit Lessing und Galfred von Vinsauf, in: Dimpel / Wagner (2019), S. 21-43.

Wollenweber, Klaus Wilhelm: Zwei Mären des Spätmittelalters in Parallelausgaben mit Kommentar. I: Die treue Magd, II: Der Pfaffe in der Reuse. 2 Bde., Indiana 1976. Ziegeler, Hans-Joachim: Erzählen im Spätmittelalter. Mären im Kontext von Minnereden, Bispeln und Romanen, München 1985 (MTU 87). 



\section{In der Kürze liegt die Würze}

\section{Kürzungsphänomene in lateinischen und deutschen Fleischpfanderzählungen des (Spät-)Mittelalters}

von

Pia Selmayr (Zürich)

\section{Fleischpfanderzählungen}

Shylock, der Antagonist in Shakespeares berühmtem Drama The Merchant of Venice (entstanden zwischen 1596 und 1598, 1. Quartoausgabe von 1600), ${ }^{1}$ legt den Zins für die monetäre Leihgabe an Bassanios Freund Antonio folgendermaßen fest:

Go with me to a notary, seal me there

Your single bond, and, in a merry sport, If you repay me not on such a day

In such a place, such sum or sums as are

Express'd in the condition, let the forfeit

Be nominated for an equal pound

Of your fair flesh, to be cut off and taken

In what part of your body pleaseth me. ${ }^{2}$

1 Die Genrezuordnung des Merchant of Venice ist in der Forschung umstritten, da eine «starke gegenseitige Abhängigkeit von Aufführungspraxis und literarischer Kritik» festzustellen ist, so Puschmann-Nalenz (2015), S. 249. «Die makroskopische Untersuchung der Struktur von Szene, Akt und Gesamtaufbau und die mikroskopische Analyse der zentralen Begriffe und Leitbilder müssen kombiniert werden, um eine Feststellung der Aussagen des Dramas zu ermöglichen» (ebd. S. 253). Siehe dazu auch die Gattungsdiskussion bei Scherrer (2016), S. 229 f., die «Drama in diesem Fall synonym mit dem Terminus «Schauspiel $>$ verwendet.

2 Shakespeare, I.3, 138-146. «Diese Freundlichkeit will ich zeigen, geht mit mir zum Notar, besiegelt mit mir dort Eure einfache Verpflichtung, und in listigem Spaß, wenn Ihr mir nicht an dem und dem Tag, an dem und dem Ort die Summe oder Summen, die festgehalten sind in der Bedingung, zurückzahlt, lasst als Buße genau ein Pfund von Eu- 
Was hier so lapidar von Shylock formuliert wird, ist ein notariell und rechtsverbindlicher Vertrag. Antonio sieht keine Gefahr im Zur-VerfügungHalten seines Körpers, da er in Kürze die Rückkehr zweier Handelsschiffe erwartet und so rechtzeitig vor dem Fristende seine Schulden, die er für seinen besten Freund aufgenommen hat, begleichen will. ${ }^{3}$ Auch Shylock spielt ironisch-süffisant seine drastische Forderung herunter, ein Pfund Menschenfleisch sei schließlich lange nicht so schätzenswert und gewinnbringend wie Fleisch von Hammeln, Rindern oder Ziegen. ${ }^{4}$ Der hier geschlossene Vertrag stellt für Antonio eine Verpflichtung dar, für Shylock spiegelt er einen Anspruch wider und offenbart zudem seinen schwelenden Hass gegen Antonio. ${ }^{5}$ Die wahre Dramatik tritt wenig später zutage, wenn die Handelsschiffe eben nicht in den Hafen zurückkehren und die Frist zur Rückzahlung verpasst wird. Die im Zitat noch zeitlich und monetär ungenau gehaltene Fleischverpfändung droht an Antonio tatsächlich vollzogen zu werden. Portia, die Angebetete Bassanios, tritt bei der Gerichtsverhandlung als Rechtsgelehrter auf und kann durch juristisches Wissen und der Forderung nach mercy, «dem christlichen Begriff von Vergebung und Barmherzigkeit», ${ }^{6}$ einen Freispruch für Antonio erreichen. Anhand dieser Episode werden im Spiel von Schein und Sein unterschiedliche Formen von Geltung und Gültigkeit im Merchant of Venice verhandelt und ausgestellt.

Das hier angewendete Motiv des Fleischpfands ist schon lange vor Shakespeares Umsetzung bekannt, ${ }^{7}$ weit verbreitet und in eine umfassende narrative Tradition eingebettet:

rem schönen Fleisch festgelegt sein, das herausgeschnitten und weggenommen werden soll von dem Teil Eures Körpers, der mir beliebt.) Übersetzung ebd., S. 40-42.

3 Vgl. ebd. I.3, 151-154.

4 Ebd. I.3, 160-162: A pound of man's flesh taken from a man, / Is not so estimable, profitable neither / As flesh of muttons, beefs, or goats.

5 Vgl. ebd., I.3, 36-47, u. S. 222 (Anmerkungen).

6 Puschmann-Nalenz (2015), S. 247.

7 In der Forschung geht man davon aus, dass als Vorlage für Shakespeares Merchant die erste Geschichte des vierten Tages in der italienischen Novellensammlung Il Pecorone (spätes 14. Jahrhundert, gedruckt 1558) des Ser Giovanni Fiorentino angesehen werden kann, «die zwar in englischer Übersetzung noch nicht publiziert vorlag, von der Shakespeare aber vermutlich Kenntnis hatte»(Wolpers [1996], S. $151 \mathrm{f}$.). Ein Vergleich von 
Die zentrale Episode handelt von einem Vertrag, der den Gläubiger einer ausgeliehenen Geldsumme dazu berechtigt, bei Überschreitung des Rückzahlungstermins dem Schuldner einen genau festgelegten Teil aus dessen Fleisch herauszuschneiden. Der Schuldner versäumt schemagemäß die Rückzahlung und wird vor einen Richter gezogen. ${ }^{8}$

In der Gerichtsverhandlung kann die Vollstreckung des Pfands durch geschickte Kommunikation und Finesse in der Rechtsauslegung verhindert und die unverhältnismäßige Forderung vollends zurückgewiesen werden.

In der vorliegenden Untersuchung sollen nun jene lateinischen und deutschen Versionen im Fokus stehen, die die Verbindung des Fleischpfandmotivs mit einer crossdressing-Episode und einer Freierprobe verbinden. Die gescheiterten Werbungsversuche gründen auf einem Schlafzauber, der damit zum «Ausgangspunkt für den Weg ins Verderben und der mittelbare Anlass für den verhängnisvollen Vertrag wird».?

In literarischer Form begegnet die Fleischpfanderzählung erstmals um 1223 in der Creditor-Geschichte im Dolopathos des Johannes de Alta Silva, einer frühen Version der Sieben weisen Meister. Sechs der insgesamt acht Binnenerzählungen aus dem lateinischen Dolopathos-Roman haben Eingang in eine deutsche Sammelhandschrift aus der ersten Hälfte des 15. Jahrhun-

Shakespeares Merchant und Kaiser Lucius' Tochter findet sich bei Grubmüller (1996), S. 102-105. Für eine Interpretation des Motivs «Fleischpfand im Merchant unter sprechakttheoretischer Perspektive siehe Scherrer (2016), S. 229-267.

$8 \quad$ Lixfeld (1984), Sp. 1257. Siehe zur detaillierten Untersuchung Schamschula (1984), die sechs Untergruppen von Fleischpfanderzählungen je nach Ausgestaltung und Einbettung des Motivs unterscheidet und drei Ursprungstheorien (Beeinflussung durch die Lehre des Buddhismus, Parallelen zum Talmund und das Fleischpfand als Teil der Rechtsgeschichte) aufführt. Zur Rechtsgeschichte des Motivs ausführlich Diederichsen (1996), zum germanischen Schuldrecht von Bloh (2001), S. 84. Zusammenfassend zu Ursprung und Herkunft des Motivs Grubmüller (1996), S. 99-102; Bildhauer (2006), S. 155-161 (v. a. zur Bedeutung von Blut), und Scherrer (2016), S. 33-37; analog zu Shakespeares Merchant of Venice Weigel (1996), S. $122 \mathrm{f}$.

$9 \quad$ Grubmüller (1996), S. 99. 
derts gefunden, ${ }^{10}$ darunter auch die Fleischpfanderzählung, im Weiteren als Leipziger Prosafassung betitelt. Die Creditor-Erzählung liegt auch der Version zugrunde, «die um 1300 im englischen oder süddeutschen Raum in die Gesta Romanorum übernommen wurde», ${ }^{11}$ und zwar sowohl in die lateinischen Fassungen wie auch in ihre zeitgenössischen deutschen Übersetzungen. ${ }^{12}$ Diese Version hat «nicht nur aufgrund der enormen Verbreitung der Gesta Romanorum Wirkung ausgeübt, sie wurde auch gelegentlich als Einzeltext übersetzt und bearbeitet», ${ }^{13}$ wie in der versnovellistischen Erzählung Kaiser Lucius' Tochter, entstanden im 15. Jahrhundert. ${ }^{14}$ In jeweils unterschiedlicher textueller Einbettung, Ausführung und Prägnanz wird in den CreditorVersionen eine Aushandlung von Liebe und Begehren, Recht und Gerechtigkeit, Ökonomie, Kommunikation und Wissen vorangetrieben.

Die vielfachen Erscheinungsformen der Fleischpfanderzählung zeigen Gestaltungsmöglichkeiten desselben Motivs und können als eigenständige Textfassungen mit konzeptionellen Verbindungen wahrgenommen werden, die im Modus der Retextualisierung Produkte unterschiedlich umfassender Überarbeitung sind und in der Folge auch fortwährend wiedererzählt, umerzählt und neuerzählt werden. ${ }^{15}$ Der Typus «Fleischpfand〉 gibt den primären Bezugspunkt vor, ist aber nicht einfach ein gegebener «Bedeutung bestimmender Kontext», sondern basiert auf der Zusammenschau «vielfältigen Materials wie auf der Grenzziehung zwischen dem noch und dem nicht

10 Es handelt sich um die Handschrift 1279 aus der Universitätsbibliothek Leipzig, fol. 236 ${ }^{\mathrm{r}}-286^{\mathrm{r}}$, siehe Mackert (2012), S. 222 f., und Losert (2008), S. 139-142. Pensel (1998), S. 174, geht fälschlicherweise von sieben Erzählungen aus.

11 Kiening (2019), S. 310.

12 Grubmüller (1996), S. 99. Vgl. dazu auch Weiske (1992), S. 121 (Nr. 168).

13 Kiening (2019), S. $310 \mathrm{f}$.

14 Eine präzise Schematisierung des Handlungsgangs der Gesta-Texte, die die auf Symmetrien und Homologien gegründete Handlungskonstruktion visualisiert, findet sich ebd., S. $311 \mathrm{f}$.

15 Vgl. zu Retextualisierungsvorgängen basierend auf der Technik der abbreviatio Frick (2018), S. 25, und in Bezug auf Märentexte Fischer (1966), S. XII. Zum Phänomen des Wiedererzählens grundlegend Worstbrock (1999), Bumke / Peters (2005), Hasebrink (2009) sowie neuerdings Zacke u. a. (2020). 
mehr Zugehörigen». ${ }^{16}$ Die Verfahren am Text, die u. a. sowohl durch Kürzungen wie auch durch Erweiterungen gekennzeichnet sein können, sind als sinnstiftende Vorgänge zu verstehen und weisen die jeweilige Version als kulturelles Produkt aus. ${ }^{17}$ Es zeigt sich an den unterschiedlichen Versionen eine Dynamik und wechselseitige Bedingtheit von Innovation und Tradition, die den Erzählkern immer wieder aufs Neue durch formale wie auch inhaltliche und konzeptionelle Eingriffe variieren und Akzentsetzungen vornehmen. ${ }^{18}$

Der besondere Reiz besteht darin, dass es sich bei den hier behandelten Versionen nicht um gleichzeitige Lang- und Kurzfassungen einer Geschichte handelt, sondern um jeweils kurze Erzähltexte exemplarischen Charakters, die auf «einen überschüssigen rhetorischen Ornat, auf psychologische Ausgestaltung ebenso wie auf komplexere kausale Motivationen» verzichten. ${ }^{19}$ Es stellen sich also die Fragen: Inwiefern und wo können Kürzungsphänomene festgestellt werden und wie verändern, verlagern oder entfalten sie die jeweilige Sinnkonstitution und ästhetische Struktur der Texte? Kommt es dadurch zu einer Aktivierung, Aktualisierung oder Akzentuierung von Wissen und Wissensordnungen? Und ganz konkret: Wie verhalten sich die volkssprachigen zu den lateinischen Versionen?

16 Kiening (2007), S. 78. "Ein Motiv ist nicht, sondern es wird qua Wiederholung», Geulen (1992), S. 38 (Hervorhebung im Original). Demnach, so Reichlin (2009), S. 29 in Anlehnung an Eva Geulen, handelt es sich bei einem Motiv weder um eine starre Einheit noch kann es vollständig in einer Erzählung aufgehen.

17 Kiening (2007), S. 79: «In all jenen Fällen, [... in denen ein Text durch Beziehungen auf andere Texte und Diskurse zum faszinierenden kulturellen Produkt wird, ist die Beziehungsstiftung keine willkürliche, kommt sie vielmehr aus der genauen Kenntnis zeitgenössischer Bezugshorizonte und der ertragreichen Auswahl präziser Referenzpunkte», was wiederum zur Sinnstiftung beiträgt. Sinn liegt dem Wiederzählen zum einen vor und wird zum anderen von diesem stets selbst hergestellt, so Köbele (2017), S. 168.

18 Vgl. Frick (2018), S. 24-26.

$19 \quad$ Kiening (2019), S. 308. 


\section{Die Creditor-Erzählung im Dolopathos und ihre Retextualisierung in der Leipziger Prosafassung aus dem 15. Jahrhundert}

Das Erstlingswerk des Mönches Johannes aus der Zisterzienserabtei Alta Silva (später Haute-Seille), zum Bistum Nancy gehörend, das er in seiner Praefatiuncula an den Bischof Bertrand von Metz (auf dem Bischofsstuhl 1179-1212) gerichtet hat, ist einer der frühesten Zeugen für die [...] Geschichte der Sieben weisen Meister. Der Verfasser bezeichnet es als «opusculum de rege et septem sapientibus〉 und behauptet, sich auf die mündliche Überlieferung (non ut uisa, sed ut audita 107,29) zu stützen. ${ }^{20}$

Die Creditor-Erzählung im Dolopathos ist eingebettet in eine Rahmenhandlung: Lucinius, der Sohn des fiktiven Herrschers Dolopathos in Sizilien, soll aufgrund der verleumderischen Anklage seiner Stiefmutter und auf Befehl seines eigenen Vaters verbrannt werden. Da der Sohn vor seiner Rückkehr in die Heimat ein Schweigegelübde bei seinem Lehrer Virgil abgelegt hat (vgl. Dolopathos, S. 21, 24-28), kann er sich nicht selbst gegen die falschen Anschuldigungen zur Wehr setzen. Vor der Vollstreckung des Urteils findet eine Woche lang jeden Tag ein weiser Meister aus Rom seinen Weg an den Hof und bittet darum, eine Geschichte erzählen zu dürfen. ${ }^{21}$ Dadurch wird die Hinrichtung so lange hinausgezögert, bis Virgil am letzten Tag alle Missverständnisse und falschen Beschuldigungen aufklären kann und die Stiefmutter rechtskräftig verurteilt wird.

Der Rahmen geht nicht in der Funktion auf, dem Erzählen von Geschichten einen Anlass zu bieten, sondern er bildet vielmehr eine eigene Geschichte, deren Fortgang wiederum von den instrumentellen Binnenerzäh-

Hilka (1913), S. VII. Eine genaue Diskussion der Unterscheidung und Auflistung der östlichen und westlichen Textgruppe der Sieben weisen Meister findet sich bei Steinmetz (2000), S. 7-15. Ebd., S. 13, wird auch auf das Mündlichkeitspostulat Johannes' eingegangen: Steinmetz hält fest, dass «gerade die letzten Worte darauf [hindeuten], daß Johannes im Bewußtsein der Fiktionalität seiner Geschichte mit ihrer vorgeblichen Faktizität spielt». Vgl. dazu auch Lundt (2002), S. 75 f. Siehe bezüglich der Widmung an Bischof Bertrand (Bertram) von Metz genauer ebd., S. 78, und Redzich (2010), S. 209.

21 Die sieben Geschichten lauten: Canis, Gaza, Senex, Creditor, Viduae filius, Latronis filii und Cygni. 
lungen mitbestimmt wird. ${ }^{22}$ Die sieben Geschichten, die formal und inhaltlich Gemeinsamkeiten mit exemplum und casus aufweisen, thematisieren aus verschiedenen Perspektiven die Bewährung der Weisheit, die positiven und negativen Aspekte von Listhandeln sowie die Bedingungen menschlicher Urteilsfähigkeit, zwischen Recht und Unrecht zu entscheiden. ${ }^{23}$ Die Deutung der Lehren aus den Geschichten ist explizit offen gehalten und beleuchtet Fragen des Zusammenlebens einer Gesellschaft, deren rechtliche und soziale Ordnungsprinzipien fragwürdig geworden sind. ${ }^{24}$

Der Erzählung des vierten weisen Meisters liegt das Motiv vom Pfund Fleisch zugrunde. ${ }^{25}$ Ein mächtiger nobilis lässt seine Tochter, die als einziger Nachkomme sein Erbe antreten wird, eine besonders gute Bildung in den artes liberales zukommen, die sie vor Übergriffen nach seinem Tod bewahren soll. Aufgrund ihrer scientia und subtilitas ist sie zudem fähig, eigenständig magische Kenntnisse zu erlernen (Dolopathos, S. 63, 12-14). Nach dem Tod ihres Vaters kann sie sich vor Heiratsangeboten kaum retten, möchte aber nur denjenigen erhören, der ihr an sapientia ebenbürtig ist. Der erste Teil der Erzählung rückt nun die Freierprobe der jungen Frau ins Zentrum. Jeder Bewerber muss 100 Mark bezahlen, und wenn er es schafft, den Beischlaf mit ihr zu vollziehen, werde sie ihn zum Mann nehmen. Was die Werber jedoch nicht wissen: Unter ihrem Bett befindet sich ein magischer Gegenstand, der den Liebeshungrigen vor Vollzug des Liebesakts in einen tiefen Schlaf

22 Vgl. Gerdes (1992), Sp. 1175, und Haug (1991), S. 275 f. Kiening (2008), S. 332: «Doch besteht textlogisch die Pointe der Sieben weisen Meister nicht zuletzt darin, Erzählen sowohl in seiner Vielheit wie seiner Wirksamkeit zu entfalten und beides, Vielheit wie Wirksamkeit, in paradoxer Steigerung aufeinander zu beziehen. Die Erzählsammlung institutionalisiert, was auch für die Einzelerzählung gilt: Wiedererzählen in einem sowohl situationsbezogenen wie verallgemeinerten Kontext.»

23 Redzich (2010), S. 207 f., und Lundt (2007), Sp. 656. «Das didaktische Anliegen der Weisen richtet sich primär an den Herrscher und seine Fähigkeit zur discretio guter und schlechter Ratschläge. In den meisten Fällen erschöpfen sich die Geschichten jedoch keineswegs in ihrer kasuistischen Verweisfunktion, [...] konkrete Deutungsangebote [bleiben] im Dolopathos auf der Figurenebene. Die Weisen liefern knappe Bilanzen ihrer Geschichten und deuten deren Zusammenhang mit dem konkreten Rechtsfall an, jedoch ohne spezifisch geistliche moralisationes einzuschließen.» Redzich (2010), S. 213.

24 Vgl. Lundt (2002), S. 85 u. S. 162.

25 Historia quarti sapientis: Creditor, Dolopathos, S. 63-68. 
versetzt. Indem sich die filia als öffentlich käuflich ausstellt, übertritt sie zum einen das gesellschaftliche Moralsystem und hält zum anderen zugleich den Verehrern einen Spiegel vor, die genau das von ihr verlangen: Partizipation an ihrem Geld und ihrer Körperlichkeit:26 Sicque illa multos spolians pecuniis infinitum sibi congregauit thesaurum et aliorum dampnis lucrum suum augmentauit (Dolopathos, S. 64, 8-10). ${ }^{27}$ Ein iuvenis nobilis lässt sich von seinem Versagen in der ersten Nacht nicht entmutigen und leiht sich weitere 100 Mark von einem reichen Bürger, der (weil ihn ebendieser am Bein verstümmelte) auf Rache sinnt. Bei nicht fristgerechter Rückgabe der Schuld verlangt er das Aufwiegen des Geldes mit einem gleich schweren Stück Fleisch des jungen Mannes. Dieser akzeptiert die Leihbedingungen, kehrt zu seiner Angebeteten zurück, entfernt beim Kissenaufschütteln zufällig den magischen Gegenstand und kann so die Nacht ungetrübt mit ihr verbringen. Aus der anfangs erzwungenen Gemeinschaft entsteht eine tiefe Zuneigung, die den jungen Mann die Frist der Rückzahlung vergessen lässt (vgl. Dolopathos, S. 65, 8-14).

Der zweite Teil der Erzählung fokussiert die Gerichtsverhandlung. Der verstümmelte Bürger fordert sein Pfand von dem jungen Mann, der aber von einem eloquenten Rechtsgelehrten, der eigentlich seine Gebliebte ist, verteidigt wird. Durch Anwendung ihrer subtilitas, ihrer intellektuellen Meisterschaft, stimmt sie dem Vollzug der Schuldeneintreibung unter den Vorbehalten $\mathrm{zu}$, dass das Gewicht des Fleisches exakt dem Gewicht des Geldes entsprechen müsse und kein Blut bei der Vollstreckung fließen darf. ${ }^{28}$ Der

Vgl. Lundt (2002), S. $176 f$.

27 Indem sie auf diese Weise viele Männer ihres Geldes beraubte, häufte sie für sich einen unendlich großen Schatz an und vergrößerte ihr (eigenes) Vermögen durch die Verluste anderer (Übers. hier wie sonst von der Verf.).

28 Dolopathos, S. 66, 12-16: Abscide, ait loripedi, quocumque uolueris ferramento marcarum tuarum pondus. Verum si plus aut minus iusto pondere ad quantitatem cuspidis accus inde tuleris uel si una sanguinis gutta infecerit linteum, cum sanguis substantia sit iuuenis, scias te continuo mille mortibus perimendum. «Sie sagte zu dem Verkrüppelten: «Schneidet das Gewicht eines Pfunds [Fleisch] mit einem beliebigen Instrument ab. Falls Ihr aber auch nur ein Haar mehr oder weniger als das gebührende Gewicht herausschneiden solltet oder nur ein Tropfen Blut das Tuch beflecken sollte - denn Blut ist Substanz des jungen Mannes -, so wisst, dass Ihr unverzüglich tausend Tode sterbt.> 
Einheit «Fleisch und Geld s setzt der Rechtsgelehrte die Einheit «Fleisch und Blut〉 entgegen; erstere ist durch unterschiedliche Qualitäten gekennzeichnet und unabhängig voneinander existent, zweitere jedoch, so macht es die Frau deutlich, ist nicht austausch- und handelbar, sondern existiert nur gemeinsam. ${ }^{29}$

Der reiche Bürger lässt daraufhin seine Forderungen fallen und tritt dem jungen Mann als Wiedergutmachung 1000 Mark ab. Im Zentrum stehen bei der Gerichtsverhandlung die Grenzen der Gültigkeit des Vertrags, sowohl in seinem Wortlaut wie auch in seiner rechtsverbindlichen Auslegung, ${ }^{30}$ und die Grenzen körperlicher Unversehrbarkeit und ökonomischer (In)Kommensurabilität.

Die Creditor-Erzählung aus dem Dolopathos findet sich im 15. Jahrhundert in einer Leipziger Handschrift in ostmitteldeutscher Schreibsprache wieder. ${ }^{31}$ Die Reihenfolge der sechs übernommenen Geschichten wurde verändert und die Rahmenhandlung ist im Zuge der volkssprachigen Adaptation weggefallen. Neu hinzugefügt wurde stattdessen jeweils eine Rahmung von «einleitenden und moralisierend zusammenfassenden Reimpaarstrophen»,32 die jede Erzählung formal als abgeschlossene Einheit sichtbar machen. Da sie nicht mehr aufeinander aufbauend, sondern zu Einzelexempeln reduziert wiedergegeben werden, zeigen sie sich als Produkte umfassender Überarbeitung. Indem nun auch die Fleischpfanderzählung nicht mehr Teil eines großen, zusammenhängenden Erzählkomplexes ist, sondern als

29 Vgl. Lundt (2002), S. 180, und Bildhauer (2006), S. 157 f. Der Körper fungiert hier als Medium, das das geltende Gesetz präsent hält, so von Bloh (2001), S. 75.

30 Vgl. Grubmüller (1996), S. 99.

31 Der Codex, der «ein seltenes Dokument poetisch-erzählender Textproduktion im ostmitteldeutschen Sprachgebiet darstellt», ist im Quartformat gestaltet und enthält auf 322 Blatt eine umfangreiche Sammlung unterschiedlicher Vers- und Prosatexte, siehe Mackert (2012), S. 221. Unter anderem finden sich in der Handschrift 1279 der Leipziger Äsop, der Leipziger Apollonius, zwei Contempus-Mundi-Dichtungen, eine volkssprachige Fassung der Crescentia-Legende und der Griseldis-Novelle, vgl. Pensel (1998), S. 173 175, Mackert (2012), S. 221-223, und Scherrer (2016), S. 193. Beim Prosateil der Leipziger Handschrift handelt es sich mit hoher Wahrscheinlichkeit, so Mackert (2012), S. 237, um eine «Urschrift〉, also um einen unmittelbaren und ohne weitere Zwischenstufen vollzogenen Übertragungsvorgang der lateinischen Quelle.

32 Pensel (1998), S. 174. 
eigenständige Fassung vorgestellt wird, verändern sich ihre Wirkung und Funktion. Es kommt durch die Ausgliederung aus dem größeren Erzählkomplex zu einer Pointierung des zuvor ausführlichen Narrativs.

Die Nähe von Recht und Unrecht wird im Dolopathos auf zwei Ebenen, zum einen der übergeordneten Geschichte um Lucinius und zum anderen auf der Ebene der Binnenerzählung fruchtbar gemacht. Das exemplum wird direkt auf das Zentralmotiv der Rahmenhandlung bezogen und schließt mit den folgenden Worten:

Quis hac, o rex, subtilitate iuuenem liberari posse speraret? Vides quod fere sub eodem puncto mors et uita, liberatio et dampnatio fuerit. Te quoque hoc exemplo monitum esse uolens rogo quatinus mei causa, immo tui quoque commodi gratia filio usque in crastinum prolonges uitam. Iterimque [sic] Romanas relegas leges, inuenturus profecto cum dampnatione salutem filii contineri. (Dolopathos, S. 66, 24-26)

〈Wer dürfte wohl erhoffen, mein König, dass der Jüngling durch dieses Raffinement befreit werden könnte? Ihr seht, dass Leben und Tod, Freiheit und Verurteilung beinahe an derselben Stelle liegen (dürften). Weil ich möchte, dass auch Ihr von diesem Beispiel geleitet werdet, bitte ich Euch um meinetwillen, mehr noch: um der Güte auch Eures Herzens willen, Euren Sohn bis morgen leben zu lassen. In der Zwischenzeit sollt Ihr noch einmal das Römische Recht konsultieren. Sicherlich werdet Ihr feststellen, dass es mit der Verurteilung auch die Freisprechung für Euren Sohn beinhaltet.>

Der weise Meister wünscht, dass Lucinius' Vater sich von diesem Beispiel in seiner Urteilsfindung leiten lasse und es zudem zum Anlass nehme, um noch einmal das Römische Recht zu konsultieren. ${ }^{33}$ Zwischen Schuld und Unschuld, wie sie in der Binnenerzählung vorgeführt werden, ist nicht einfach $\mathrm{zu}$ entscheiden, sondern sie hängen von der Verhältnismäßigkeit ihrer Anwendung ab. Die Übertragungsleistung wird hier vom vierten weisen Meister erbracht und auf Lucinius' Rechtsfall angewendet.

In der volkssprachigen Fassung fehlen diese Sätze zugunsten einer erzählerischen Straffung. Da es in der Leipziger Prosafassung keinen überge- 
ordneten Referenzrahmen mehr gibt, wird auch die didaktisch-ethische Tendenz der in Versform verfassten moralisatio am Ende erschwert.

Wer dysse mere wyl rech vornemen,

Der darff sich fromer frowen nicht schemen.

Es yfs hüyre alze uff ert [lies: vert],

Frome frowen synt lobes wert;

Bofse wyeb sich balde melden.

Das sollen dy fromen nicht enkelden;

Gyb yczlicher wafs sy angehöert,

So blybestdu von en umbethöert.

(Leipziger Prosafassung, S. 148)

Die Verse, die keine Entsprechung im Dolopathos haben, stehen thematisch eher unverbunden zum Rest der Erzählung beziehungsweise lassen sich nur teilweise auf deren ersten Teil rund um die Gerichtsverhandlung beziehen. Der Hinweis auf die bofsen wyeb, die sich balde offenbaren werden, markiert einen Bruch zur Prosaerzählung und eröffnet ein gänzlich neues Thema. Die moralisatio wirkt als explizite Hinzufügung und eher schwach motivierte, allgemeingültige Weisheit jenseits der Erzählung. Sie kann aber mit dem Wissen des Rezipienten in einem «intellektuellen Kontrakt» ${ }^{34}$ auf die Ursprungserzählung rückgeführt werden, in der die schlechten Frauen, allen voran Lucinius' Schwiegermutter, enttarnt werden sollen; ${ }^{35}$ dadurch fungiert die moralisatio als Scharnierstelle zwischen Retextualisierung und Reproduktion und offenbart die Bindung an einen «vorgängigen` Sinnhorizont.

34 Die Begrifflichkeit ist übernommen von Henkel (2017), S. 55: «Verbinden lässt sich dieses Material durch die Vorstellung vom intellektuellen Kontrakt zwischen der Abbreviatur einerseits und dem zu eigener Deutungs- und Erschließungsleistung aufgeforderten Leser bzw. Betrachter andererseits. Kommt er zustande, findet die Abbreviatur und mit ihr die Kunst der brevitas ihr Ziel, kommt er nicht zustande, steht der Rezipient draußen vor der Tür der Erkenntnis.»

35 Als Lucinius an den Hof seines Vaters zurückkehrt, versucht ihn seine Schwiegermutter zu verführen; ihr Stiefsohn geht darauf aber nicht ein und weist sie ab. Aus gekränktem Stolz bezichtigt sie ihn daraufhin der Vergewaltigung, weshalb es in der Folge zu Lucinius' Verurteilung zum Tode kommt. Immer wieder mischt sich die Schwiegermutter auch in die Verteidigungen der weisen Meister ein und drängt auf die Vollstreckung der Strafe. 
Die Creditor-Erzählung wird im Dolopathos mit den Bedenken des vierten weisen Meisters eingeführt, dass das Recht durch die Gelehrten des König Dolopathos falsch ausgelegt wurde (puto principes tuos circa leges male intellectas errasse, Dolopathos, S. 62, 28) und es doch eigentlich mehr um das Leben als um die Bestrafung des Sohnes gehen solle; unmittelbar daran schließt der Beginn der Binnenerzählung an: Fuit quondam nobilis uir et potens, castellum munitissimum aliasque multas possessiones habens (Dolopathos, S. 63, 5 f.; «Es war einmal ein edler und mächtiger Mann, der über eine sehr gut befestigte Burg und viele Besitztümer verfügte`). Dieser Beginn ist in der Prosaversion des 15. Jahrhunderts in Form eines in Versen gehaltenen Vorspanns ebenfalls vorhanden, enthält aber eine kleine und nicht unwichtige Hinzufügung. So heißt es:

Eyn edeler herre, alze ich lafs [Hervorhebung der Verf.]

Uff eyner schönen borg sals,

Eyn alder herre wolgemut

Richtum und geldes hatte he genug

(Leipziger Prosafassung, S. 143)

Ist die Erzählerrolle im Dolopathos deutlich mit dem weisen Meister besetzt, ist sie hier unspezifisch. Das Ich bezieht sein Wissen nicht aus einer mündlichen Überlieferung, sondern aus der Schrift: alze ich lajs. Der Modus des schriftlichen Wiedererzählens wird dadurch betont und die Gültigkeit der Erzählabsicht aktualisiert. Durch Vorspann und moralisatio entwickelt das Exempel eine eigene Wirkungsstrategie, die unabhängig von seiner Vorlage rezipiert werden kann, ihre Anspielungen aber erst in einer Rückbindung an diese offenbart.

Inhaltlich sind die Leipziger Prosafassung und die Creditor-Erzählung im Dolopathos fast identisch gestaltet, nur an einigen Stellen lassen sich Abweichungen feststellen, die einen anderen Sinn entfalten. So sind beispielsweise Erkrankung und Tod des Vaters in der volkssprachigen Version stark gekürzt. Im Dolopathos wird ausführlich erklärt, dass der nobilis infolge eines starken Fiebers darniederliegt, sein nahendes Ende wahrnimmt und in einem 
Testament alles Hab und Gut an seine Tochter überschreibt. ${ }^{36}$ Die Prosaübertragung rafft diesen Abschnitt zusammen: Dor noch starb yr vater gar schyre und stetigete sy czu eynem rechten erben des landes und czu eyner forstynne des richs (Leipziger Prosafassung, S. 144), und setzt zugleich mit der Herrschaft der Tochter ein. Durch die Kürzung tritt die Frauenhandlung schneller und auch expliziter ins Zentrum. Das Aufsetzen des Testaments als letzter Willensakt des Vaters wird zurückgedrängt, sodass sich in der volkssprachigen Version keine zwei rechtsverbindlichen Dokumente mehr finden, deren Geltung unterschiedlich bewertet wird. ${ }^{37}$

Das intellektuelle Geschick der Tochter wird in beiden Versionen betont und ausgestellt. So wird darauf hingewiesen, dass sie prudentis animi (Dolopathos, S. 63, 24) beziehungsweise wyjse und klug (Leipziger Prosafassung, S. 144) ist und allen Verehrern durch die Freierprobe auf geschickte Weise absagt, um keinen Groll gegen sich zu entfachen, was wiederum ihr Erbe gefährden könnte. Auch der enorme ökonomische Gewinn und damit ihr wirtschaftlich vorteilhaftes Handeln werden hervorgehoben. ${ }^{38}$ Die ethische Komponente des vermeintlichen Zur-Verfügung-Stellens ihres Körpers wird dem monetären Gewinn untergeordnet. Bei der Darstellung der Weisheit sind jedoch unterschiedliche Akzentsetzungen zu erkennen, wenn es beispielsweise um den Grund für die gute Bildung der Tochter geht. So heißt es im Dolopathos, dass sapientia wichtig für sie sei, um die Macht über ihren Besitz zu erhalten, da sie aufgrund der muliebris infirmitas nicht dazu fähig

36 Dolopathos, S. 63, 14-18: Contigit autem post hec patrem eius febre acuta correptum in lectum decidere. Qui infirmitatem se euadere non posse intelligens filiam ex testamento omnium bonorum suorum designauit heredem sicque ordinatis rebus suis defunctus est. ¿Es ereignete sich aber, dass ihr Vater danach, von einem heftigen Fieber ergriffen, im Bett darniederlag. Weil er verstand, dass er sich davon nicht mehr erholen würde, setzte er seine Tochter in einem Testament als Erbin all seiner Güter ein; und so, nachdem er seinen Nachlass geregelt hatte, starb er.)

37 Im Dolopathos wird das Testament von allen Werbern als rechtsverbindlich akzeptiert und die Tochter als Erbin und Herrscherin anerkannt; der Schuldvertrag des Liebhabers mit dem Bürger jedoch wird in seiner Rechtsauffassung von der Frau in Zweifel gezogen und kann durch den Hinweis auf das Talionsgesetz ausgehebelt werden.

38 Vgl. Dolopathos, S. 64, 8-10, und Leipziger Prosafassung, S. 144f: Alzo samelte dy jungfrowe vyl geldes und grofs gut und richtum. 
sei, sich physisch zur Wehr zu setzen und überhaupt Waffen zu tragen beziehungsweise damit umzugehen. ${ }^{39}$ Die intellektuelle Ausbildung wird von ihrem Vater zu einem eindeutigen Zweck bestimmt, nämlich dem Schutz des Erbes zu dienen. ${ }^{40}$ Er geht davon aus, dass sich seine Tochter als Alleinerbin gegen Angriffe unterschiedlicher Art zu Wehr setzen muss. Das erlernte Wissen soll dort von Nutzen sein, wo körperliche Stärke fehlt. Die volkssprachige Version hingegen verknappt den Grund für die gute Ausbildung zur schlichten Schicklichkeit: daz sich frowen wol czemete (Leipziger Prosafassung, S. 144); das vorvechten mit dem swerte (ebd.) sei nicht angemessen. Aus dem vorausschauenden, auf die Zukunft bezogenen Handeln des Vaters wird durch die Verknappung in der Leipziger Prosafassung eine simple Einhaltung geschlechtsspezifischer Ordnungsvorstellungen.

Als Kürzung nicht-handlungslogischer Elemente kann die Streichung der ausführlichen Gewaltandrohung gegenüber dem Gläubiger angesehen werden: ${ }^{41}$ Die Frau droht ihm im Dolopathos nicht nur mit thusent thöde wie in der Prosafassung, sondern zudem damit, ihn und seine ganze Familie an bestia[e] et au[es] zu verfüttern; zudem werde sein ganzes Vermögen konfisziert. ${ }^{42}$ Die Steigerung der Gewalt soll den grausamen Fleischpfand überbieten und die Unverhältnismäßigkeit ins Bild setzen. Die Kürzung hat keine handlungslogische Konsequenz, sowohl im einen wie auch im anderen Fall zieht der Gläubiger seine Forderung zurück. Es zeigt sich aber, dass die Prosafassung durch die Gewaltreduktion die reine Überzeugungskraft der juristischen Rede ins Zentrum stellt - den rechtsverbindlichen Worten müssen keine überbordenden Drohungen mehr folgen.

Aspekte der Zeitlichkeit sind in der Übertragung auf die volkssprachige Version gestrafft, so heißt es im Dolopathos (S. 64, 17f.), dass der Werber erst noch versucht, es sich auf dem Bett gemütlich zu machen, und dort dann

39 Dolopathos, S. 63, $11 \mathrm{f.:}[$ [...] quod posse armis aut uiribus ei muliebris infirmitas denegarat.

$40 \quad$ Lundt (2002), S. 176.

41 Frick (2018), S. 30: «Die Kürzung solcher Elemente im Modus der abbreviatio mag vielleicht zunächst als Komplexitätsreduktion erscheinen, erweist sich jedoch bei genauerem Hinsehen als schöpferisches Moment, indem neuer Sinn hergestellt bzw. der vorgefundene umgedeutet wird.»

42 Vgl. Dolopathos, S. 66, $17 \mathrm{f}$. 
unversehens vom Schlaf überrascht wird; in der Leipziger Prosafassung kommt der jung edel man gar nicht dazu, sich einzurichten, da er enstlief balde veste (S. 145). Die schnelle Wirksamkeit des Schlafzaubers wird dadurch besonders betont: Sobald der Werber das Bett berührt, gibt er sich dem Schlaf anheim. Nicht die Schnelligkeit, sondern die Dauer von Bemühungen fällt an einer anderen Stelle weg. So heißt es in der lateinischen Version, dass der König, dem der Fall zugetragen wird, mehrere Tage darauf verwendet, den Gläubiger zu überreden, die Vollstreckung der Strafe für den doppelten Geldwert auszusetzen und den Schuldner freizulassen. ${ }^{43}$ Die hartnäckigen Bemühungen des Königs fehlen in der Leipziger Prosafassung, stattdessen wird nach der Ablehnung der doppelten Auszahlung direkt der Gerichtstag festgelegt. Hier wie auch an anderer Stelle fällt auf, dass dem König in der lateinischen Fassung eine aktivere Rolle in der Verhandlung um Schuld und Unschuld zukommt. ${ }^{44}$ In seinen Anstrengungen, die Strafe für den Schuldner abzuschwächen, tritt sein Verständnis von Gerechtigkeit zutage, für dessen Umsetzung ihm aber die rechtliche Grundlage fehlt. Das umsichtige Verhalten des Königs kann im Dolopathos auf die Rahmenhandlung übertragen werden, in der sich Lucinius' Vater eben nicht für seinen Sohn einsetzt und die Anschuldigungen gegen diesen unterhinterfragt unterstützt. Die Prosafassung hingegen drängt die Königshandlung in den Hintergrund, um der Interaktion und Kommunikation mit der Frau mehr Raum zu geben. So erscheint sie nicht plötzlich und unmotiviert vor Gericht wie im Dolopathos, sondern ihr Handeln ist als Reaktion auf die Erzählung ihres Mannes von der ausweglosen Situation und der Festlegung des Gerichtstags zu sehen.

43

Dolopathos, S. 65, 26-28: Rogabat ergo rex loripedem quatinus iuueni parcens duplicem reciperet pecuniam. Quod cum illo negante diebus multis efficere conaretur. «Der König fragte also den Verkrüppelten, ob er den doppelten Geldbetrag annehmen und den Jüngling dafür verschonen würde. Weil dieser ablehnte, verbrachte der König mehrere Tage damit, ihn zu überzeugen.>

44 So ist es im Dolopathos der Vorschlag des Königs, dem Gläubiger den doppelten Betrag als Auszahlung anzubieten, in der Prosafassung geht diese Idee auf den jungen Mann zurück, der König wiederholt den Vorschlag nur noch einmal. Vgl. Leipziger Prosafassung, S. 147. 
Neben den genannten Kürzungsphänomenen, die sich zum einen auf die Herauslösung aus dem größeren Erzählzusammenhang und zum anderen auf nicht-handlungstragende sowie inhaltliche Kürzungen beziehen, verfügt die Prosafassung über diverse kleinere Hinzufügungen, die zur Präzisierung der Geschehnisse und zur Schärfung der Erzähllogik beitragen. Um den Rahmen nicht $\mathrm{zu}$ sprengen, seien hier nur wenige Beispiele genannt: So besteht der magische Schlafzauber nicht mehr nur aus einer penna, sondern aus einem Konglomerat von Schrift, Briefen und veddern von den wylden ruchen lüten (Leipziger Prosafassung, S. 145). ${ }^{45}$ Zwischen der Zusammenkunft von Gläubiger und Schuldner vor dem König und dem Tag des Urteilsspruchs gibt es in der Prosafassung die Möglichkeit für den jungen Mann, zu seiner Frau zurückzukehren und seine Angelegenheiten zu klären (vgl. Leipziger Prosafassung, S. 147); auch die Rückkehr in die Heimat nach dem Freispruch wird ausführlicher geschildert, indem der Mann vor seiner Frau die Argumentationsstruktur des angeblichen Rechtsgelehrten wortgetreu wiederholt. Die behendikeyt der Frau wird dadurch noch einmal überdeutlich vorgeführt; unaufgelöst bleibt auf der Figurenebene jedoch, wer sich tatsächlich hinter dem Rechtsgelehrten verbirgt. ${ }^{46}$

Die vorgenommenen Abbreviationen im volkssprachigen Text strukturieren den Inhalt auf neue Weise und lassen die Creditor-Erzählung in der Leipziger Prosafassung als formal eigenständig erscheinen. Die Bearbeitung der vorgegebenen Materie aktiviert und fokussiert die Handlung rund um die Königstochter und führt zu einer Neuauslegung der Figurendarstellung, indem Abhängigkeitsverhältnisse der lateinischen Version zurückgedrängt und die angemessene, weibliche Klugheit stärker ausgestellt werden. durchlässige "Grenze zwischen Natürlichem und Kultiviertem». Anders dazu Losert (2008), S. $141 \mathrm{f}$, die an dieser Stelle von einem «offensichtliche[n] Übersetzungsproblem» ausgeht.

46 Auch in der Creditor-Erzählung des Dolopathos wird die Maskerade nicht aufgelöst. 


\section{Das Fleischpfand in den Gesta Romanorum und in Kaiser Lucius' Tochter}

Die Gesta Romanorum gelten als «beliebteste Exempelsammlung des Mittelalters», die kein spezifisches Ordnungsschema aufweist und der in der überwiegenden Mehrzahl der Textzeugen eine geistliche Deutung beigegeben ist, welche die Einzeltexte in ihrer Funktion als Illustrationsmaterial definiert. ${ }^{47}$ Im Gegensatz zum Dolopathos, bei dem konkrete Deutungsangebote immer auf der Figurenebene bleiben, werden in den Gesta Romanorum die Erzählvorgänge durch ein fixiertes Deutungsschema zu Bildern einer geistlichen Wahrheit ausgeformt. ${ }^{48}$ Die Version der Creditor-Erzählung findet sich in der ältesten Handschrift unter der Nummer 168 mit dem Titel De Lucii filia et milite ${ }^{49}$ sowie in zeitgenössischen deutschen Fassungen des GestaTextes. ${ }^{50}$ Die als Einzeltext überlieferte, mittelhochdeutsche Verserzählung

47 Weiske (1992), S. 1.

48 Redzich (2010), S. 213. Die lateinische Überlieferung der rund 250 Handschriften und 40 Drucke kann man im weitesten Sinne als «variabel` in Umfang, Gestaltung und Kapitelfolge beschreiben beziehungsweise als «im höchsten Grade unfest tradiert», so Weiske (1992), S. 3. Die Textcorpora enthalten bis zu knapp 240 Exempel, im Mittelpunkt steht der sensus allegoricus oder mysticus der Geschichten, vgl. Gerdes (1981), Sp. 25 f., und Losert (2008), S. 142-154. Siehe zur genauen Aufarbeitung der Überlieferungsgeschichte sowohl die Handschriften wie auch Einzeltexte und Dubletten betreffend Weiske (1992).

49 Die Ausgabe der ältesten Handschrift aus dem Jahre 1342 ist von Wilhelm Dick herausgegeben, im Folgenden zitiert mit der Sigle GR Dick. Da Dick die moralisationes weglässt, ist auch die auf Frühdrucken basierende Ausgabe von Hermann Oesterley zu beachten, der die Creditor-Erzählung unter der Nummer 195 führt; im Folgenden zitiert mit der Sigle GR Oesterley. Beide Editionen entsprechen der kontinentalen Fassung der Gesta Romanorum.

50 Unter den bekannten 48 Handschriften und acht Drucken der volkssprachigen Übertragung ist die Creditor-Erzählung in drei Fassungen enthalten. Da sich diese - abgesehen von dialektalen Eigenheiten und kleineren sprachlichen Eingriffen - nicht voneinander unterscheiden, kann man davon ausgehen, dass sie der gleichen Fassung angehören. Vgl. Losert (2008), S. 149-154. 
Kaiser Lucius' Tochter geht darauf zurück und weicht nur in wenigen Details von ihrer Vorlage ab. ${ }^{51}$

Ich beschränke mich im Folgenden auf explizite und handlungstragende Kürzungen. Eine der Abweichungen zwischen dem lateinischen und mittelhochdeutschen Text betrifft den in diesen Versionen neu hinzugekommenen philosophus, dessen Rat der verzweifelte miles beziehungsweise ritter einholt, um nicht noch einmal die erhoffte und inzwischen schon mehrfach teuer bezahlte Liebesnacht mit der Königstochter zu verschlafen. ${ }^{52}$ Der maister lobesan (KLT, v. 172) erklärt ihm, dass es sich bei der Schlaftrunkenheit um einen Zauber handelt, hervorgerufen durch eine carta. Im lateinischen GestaText ergänzt der philosophus, dass er sich mit dem Schlafbrief unter dem Bett bestens auskenne, denn er sei schließlich auch dessen Urheber: De hoc sum expertus quia cartam ordinaui (GR Dick, S. 143). In Kaiser Lucius' Tochter findet sich diese zusätzliche Information nicht, dort ist der philosophus generell der Wissende, der zur richtigen Zeit am richtigen Ort den passenden Ratschlag geben kann. Indem er als Urheber des Schlafbriefs ausgespart wird, zeigt sich der philosophus damit «noch deutlicher als derjenige, der einerseits dem Geschehen eine signifikante Wendung gibt, andererseits sichtbar macht, dass der Ritter nicht selbst in der Lage ist, sich aus seiner misslichen Situation zu befreien $» .^{53}$

Der mittelhochdeutsche Text verzichtet zudem auf die reductio, die dem lateinischen Gesta-Text beigegeben ist. ${ }^{54}$ Nach Christian Kiening bietet die

51 Vgl. Kiening (2019), S. 310 f., und Schallenberg (2012), S. 277. Die Verserzählung ist nur einmal überliefert, in der heute nicht mehr fassbaren Handschrift des Berufsschreibers Matthias von Günzburg aus dem 15. Jahrhundert. Der Text ist im Folgenden mit der Sigle KLT zitiert. Der einzig vorhandenen Fassung liegt eine Abschrift von Friedrich Heinrich von Hagen zugrunde, vgl. Schallenberg (2012), S. 277, und KLT (1966), S. 530 f. (Anmerkungen).

52 GR Dick, S. 143: Perrexit ad quendam phylosophum, bzw. KLT, vv. 171-174: er gieng zustond zu ainem man. / der was ain maister lobesan, / der natürlichen kunst gelert. I sins rauts er do begert.

$53 \quad$ Kiening (2019), S. $313 \mathrm{f}$.

54 Das Epimythion der mittelhochdeutschen Verserzählung besteht aus einer knappen, allgemeinen Segensformel, die unverbunden zur Geschichte steht, und der Selbstnennung des Autors: Des helf uns der raine tegen, / das wir gottes frid pflegen / und wir sin gnad 
reductio «eine moraltheologische Lesart an, doch wird man sie kaum als eine konzeptionell mit der narratio ganz abgestimmte Deutung verstehen dürfen». ${ }^{55}$ Thema der Auslegung ist die christliche Heilslehre in ihrem Zusammenhang von Heilsgeschichte und individuellem Heilsweg der einzelnen Seele, wie es typisch ist für die Gesta Romanorum. ${ }^{56}$ So wird der Kaiser gleichgesetzt mit dominus noster Ihesus Cristus, der Kaufmann als dyabolus offenbart, der die Schrift für Schmerzen nutzt, der Weise als mundi verita[s] und die Tochter als menschliche Seele, anima, ausgedeutet, die fortwährend von der fleischlichen Begierde, also dem Ritter, in Versuchung geführt wird. ${ }^{57}$ Die reductio vereindeutigt die einfachen Wertungen, die schon im Text angelegt sind, wodurch z. B. das Verhalten des Freiers mit seiner bloßen Begierde erklärbar und sein Handeln im Nachhinein noch einmal motiviert wird. Die allegorischen Verweisstrukturen sind aber punktuell und bewegen sich dann doch so weit von der Handlung der Erzählung weg, dass sie in ihrer didaktischen Funktion vor allem als unabhängige Abstraktion ihre Wirkung entfalten. Die Weglassung der reductio sowohl in den deutschen Gesta wie auch in Kaiser Lucius' Tochter ist als bewusster Eingriff in der Überlieferung zu verstehen, die als eine Rückführung und Konzentration auf den Kern der Erzählung gesehen werden kann.

\section{Fleisch ist nicht gleich Fleisch - die Fassungen im Vergleich}

Zwischen den Dolopathos- und den Gesta-Versionen finden signifikante Kürzungen statt, die sinnverändernd wirken und eine neue Ebene der Interpretation eröffnen, teilweise aber auch Handlungsmotivationen verschleiern und sich als Produkte umfassender Bearbeitung präsentieren. ${ }^{58}$

erwerben / und in sinem frid ersterben, / so wirt unser selen raut. / M. v. G. das geschrieben haut, KLT, V. 617-622.

$55 \quad$ Kiening (2019), S. 314.

56 Siehe Weiske (1991), S. 188.

57 GR Oesterley, S. $607 \mathrm{f}$.

58 Mit dem Ausdruck ‘Gesta-Versionen` meine ich hier sowohl die lateinische wie auch deutsche Version der Creditor-Erzählung in den Gesta Romanorum wie auch die in 
Die spezifische Bildung der namenlosen Tochter findet sich in keiner Gesta-Version wieder; weder ihre Ausbildung in den septem artes liberales noch in der swartczen kunst werden erwähnt. ${ }^{59}$ Die Beschreibung ihrer Klugheit wird zugunsten der Betonung von äußerster Schönheit und großer Vaterliebe getilgt: qui habebat filiam pulcherrimam, quam multum dilexit (GR Dick, S. 142). Kaiser Lucius' Tochter ergänzt den puren Schönheitsaspekt noch im Sinne der Kalokagathia:

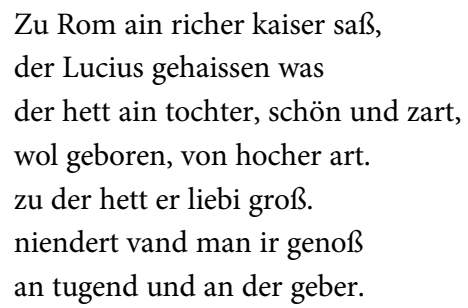

(KLT, vv. 1-7)

So ist die Kaisertochter nicht nur in ästhetischen, sondern auch in ethischen Aspekten herausragend. Sie entspricht demnach dem aus Minnesang und Epik bekannten Topos der Schönsten, der keine gleichkommen kann.

Die Kürzung des Bildungsaspekts zugunsten der Schönheit hat aber unmittelbare Auswirkungen auf die Darstellung des Schlafzaubers. Erscheint dieser im Dolopathos und der Leipziger Prosafassung durch List und Kunst der Tochter selbst herbeigeführt und explizit zur Abwehr der Bewerber angewendet, ist er in den Varianten der Gesta-Texte schlicht vorhanden. Es handelt sich dabei auch nicht um eine penna oder ein magisches Konglomerat aus Feder, Schrift und Brief, sondern um eine carta (GR Dick, S. 143) beziehungsweise um ain klains brieflin (KLT, v. 212), das sich zwischen golters und lilach, zwischen Decke und Leintuch, befindet und den Werber, sobald er das Bett berührt, in Tiefschlaf versetzt: quicumque intrat lectum, statim oppressus sit sompno (GR Dick, S. 143). Aus der selbstständig han-

Verwandtschaft damit stehende, mittelhochdeutsche Verserzählung Kaiser Lucius' Tochter.

59 Eine Ausnahme bildet die Kapitelüberschrift der deutschen Gesta Romanorum, im Druck bei Johannes Schobser 1489 in Augsburg erschienen, siehe Losert (2008), S. 192, Anm. 371. Dort heißt es auf Bl. 13 ${ }^{\text {aa }}$ : Von der tochter Lucij des keisers die mit jr weißheit den ritter ernò ret. 
delnden Tochter, die ihr Erbe durch den Schlafzauber bewahren will, bis sie den richtigen, d. h. ihr in Klugheit ebenbürtigen Mann gefunden hat, wird in diesem Fall eine schlichte Anwenderin, die nur ihr Vermögen vermehren will. Der ökonomische Aspekt sowie der Tauschhandel «Geld gegen Minne` werden verstärkt in den Fokus gerückt.60 Durch diese Verknappung ergibt sich noch eine weitere Sinnrichtung: Dem Schuldbrief wird der magische Schlafbrief beigegeben, dessen genauer Inhalt aber in keiner Fassung offenbart wird. Der Text im Text bleibt als Leerstelle offen. ${ }^{61}$ Der Freier wird zweimal durch ein Schriftstück, und zwar durch ein magisch aufgeladenes und durch ein rechtsverbindliches und mit Blut verbürgtes, in Bedrängnis gebracht, wodurch sich paradigmatische Verbindungslinien innerhalb des Narrativs ergeben.62 Dabei wird er einmal zum aktiv Handelnden, der das magische Schriftstück selbsttätig entfernt und so seine Handlungsmacht zurückgewinnt, ${ }^{63}$ ein andermal, nämlich bei der Gerichtsverhandlung, zum passiv verhandelten Objekt.

Die Kürzung der Bildungsbeschreibung in den Gesta-Fassungen wirkt sich auch auf die Darstellung der Tochter in der Gerichtsverhandlung aus, indem der Ursprung ihres juristischen Wissens im Dunklen bleibt. Hinzu kommt, dass sie in den Dolopathos-Fassungen nicht nur Männerkleidung anlegt, sondern ihre magischen Künste nutzt, um ihre Stimme und ihre

60 Siehe dazu Kiening (2019), S. 310; Scherrer (2016), S. 148, 155 f. u. 162 f., außerdem Schallenberg (2012), S. 282-284, und Schallenberg (2006), S. 100-106.

61 Scherrer (2016), S. 163.

62 Nach Kiening (2019), S. 314, wird durch Schlafbrief und Schuldbrief eine Beziehung zwischen Liebes- und Geldhandel gestiftet. «Kann der Brief unter dem Kopfkissen einfach entfernt werden, ist der mit Blut geschriebene Schuldbrief, durch den sich der Ritter dem Bürger verpflichtet, nicht so einfach zu beseitigen.» Siehe zur Interpretation der Blutschrift im Vertrag Scherrer (2016), S. 169 f.

63 In der Dolopathos-Handlung wird der magische Gegenstand zufällig entfernt: Der Liebhaber schüttelt Decke und Kissen auf, damit er beim zweiten Versuch nicht allzu gemütlich liegt, und befördert dabei die sogenannte czöberye (Leipziger Prosafassung, S. 145) aus dem Bett. Der Freier handelt ohne konkretes Wissen, die Überwindung des Zaubers wird als kontingent ausgestellt. Dies ist insofern konsequent, als die Einzige, die Wissen über den magischen Gegenstand hat, die Dame selbst ist, die ja eben den Beischlaf mit allen Mitteln verhindern will. 
Gesichtszüge zu verändern. ${ }^{64} \mathrm{Im}$ lateinischen Text der Gesta Romanorum muss sie jedoch zu weiteren Mitteln greifen: Sie schneidet ihre Haare, wechselt in Männerkleidung, rüstet sich wie ein Mann und reitet auf männliche Art zum Gericht. ${ }^{65}$ Die Veränderungen werden tatsächlich und nicht nur scheinbar an ihrem Körper vorgenommen. Es handelt sich dabei um eine Transformation, nicht nur um eine Täuschung.

Eine weitere Kürzung betrifft den Tod des Vaters: Dieser erfreut sich in den Gesta-Fassungen bester Gesundheit. In den volkssprachigen und lateinischen Gesta Romanorum wird er nur einmal zu Anfang erwähnt, in der mittelhochdeutschen Verserzählung ein zweites Mal am Ende. Er tritt weder handelnd noch sprechend in Erscheinung und dient lediglich als Orientierungsmarker für die Herkunft der Tochter. Ohne Umschweife kann so der Fokus auf die Tochter und die Werbungshandlung gelenkt werden. Damit wird aber nicht nur die Geschichte modifiziert, sondern auch die Motivation für den abgewiesenen Beischlaf gekürzt. Als Konsequenz der Kürzung rund um das Zustandekommen der Freierprobe steht im Gegenzug die Erweiterung um eine dreimalige Wiederholung des Beischlafs:

Die Dreizahl der Versuche (gegenüber zweien im Dolopathos) unterstreicht nicht nur das Moment der Wiederholung, sie erlaubt auch eine gesteigerte Verdeutlichung dessen, was auf dem Spiel steht - hat er beim ersten Mal einfach tausend Mark verloren, so beim zweiten auch noch seine Güter [...], beim dritten Mal drohen ihm armut, schand und laster (KLT $200 \mathrm{f}$.). ${ }^{66}$

Kaiser Lucius' Tochter will den Ritter für alle Ewigkeit verspotten: des mustu von mir spot und schal / fürbaß ewenklichen hon (KLT, vv. 60 f.). Die Privatheit der Kemenate soll durch Spott und Hohn nach außen getragen werden. Die Kategorien Innen und Außen, Zweisamkeit und Öffentlichkeit, Integrität und Bloßstellung werden aufgerufen und steigern die Not des Liebhabers ins Existentielle: Nicht nur sein Besitz, sondern auch sein Ruf

64 Leipziger Prosafassung, S. 147: Under den geschichten kleytte sich syne frowe yn mannes kleydere, yn rytterlich gewant, und gebruchte manlicher stymme adder sprache ufs der lere der swartczen kunst. Ähnlich Dolopathos, S. 65, 28-30.

65 GR Dick, S. 144: Statim crines capitis sui precisit ad modum viri, vestes mulieris mutauit et sicut vir se per omnia parauit ascendensque dextrarium ad iudicium equitauit.

66 Kiening (2019), S. $314 \mathrm{f}$. 
sind gefährdet. Der einzige Ausweg scheint der Vollzug des Beischlafs zu sein. Die Gewinnung von êre ist hier diametral angelegt:67 Der Ritter erringt diese durch den Beischlaf, die Tochter verliert sie eben dadurch, was sich an ihrer starken Gegenwehr zeigt. ${ }^{68}$ Tausch und Täuschung, zwei in Mären häufig vorkommende Motive, werden so in verstärktem Maße kombiniert und an Körper und Geld gekoppelt. ${ }^{69}$

Ebenfalls gekürzt wird die Begründung für die feindselige Haltung des reichen Bürgers gegenüber seinem Schuldner. Im Dolopathos und der Leipziger Prosafassung gibt es einen eindeutigen Grund für sein erbarmungsloses Verhalten und seine Rachelust:

Nicht verne von ym wante eyner syner börgere, deme hatte ${ }^{\star}$ he* vor yn czorne eyn beyn abgehowen; der selbige hatte vyl geldes. Czu dem gyng der edele man und borgete von ym hundert marg goldes. Do gedachte der börger an dy gewalt dy er ym gethaen hatte do he ym synen furs abe schlugte.

(Leipziger Prosafassung, S. 145) 70 $^{70}$

Gleiches soll hier mit Gleichem vergolten, Körper gegen Körper eingesetzt werden. Für die Verstümmelung erhofft sich der reiche Bürger nun die Entschädigung, indem er über die Art der körperlichen Versehrtheit des Ritters bestimmen kann. Die Streichung dieser Passage in den Gesta-Versionen lässt das Verhalten des Gläubigers auf der Figurenebene willkürlicher und blutrünstiger wirken. Die nicht gewährte Gnade bei der Gerichtsverhandlung erscheint unmotiviert und unterstreicht die Grausamkeit seiner Forderung. Als ihm die Frau nun in der Rolle des Rechtsgelehrten androht,

\footnotetext{
67 Ebd., S. 315.

68 Voller Schrecken bittet die Frau den Ritter, das gesamte Geld zu nehmen und dafür auf die gemeinsame Nacht zu verzichten: O domine, decepta sum: totam peccuniam, quam michi dedisti, tibi reddam, et me illesam permittas abire! (GR Dick, S. 143). Da der Ritter nicht auf ihr Angebot eingeht, will sie das Geld sogar verdoppeln: tibi peccuniam duplicabo (ebd.). Ähnlich KLT, vv. 254-265. Der Ritter schlägt alles aus: gebest du mir dins vatters rich / und sin gewalt ganz und gar, / ich mecht dich nit geweren zwar / des du begerst an mich hier (KLT, vv. 268-271, identisch GR Dick, S. 143). Siehe zur Interpretation dieser Stelle Scherrer (2016), S. 164-166.
}

69 Reichlin (2009), S. 162.

70 Identisch Dolopathos, S. 64, 24-28. 
sollte er bei seiner Schuldeneintreibung Blut vergießen, müsse ihn dasselbe Schicksal ereilen (vgl. KLT, vv. 490-501; GR Dicke, S. 144), zieht der Bürger seine Forderung aber nicht, wie im Dolopathos und in der Leipziger Prosafassung, zurück. ${ }^{71}$ Vielmehr beharrt er darauf, in diesem Fall zumindest die ursprünglich angebotene Summe zu erhalten:

sit den mären also ist,

so haißt mir geben das gelt min,

ich main die tusend guldin,

die ich im gelichen hon,

so will in nun ledig lon

des andren zuspruchs ganz und gar

(KLT, vv. 502-507)

Er wird so zum Sinnbild für Geiz und Gier. Die Aspekte von Wertverlust und Wertsteigerung werden durch die fehlende Begründung für das Verhalten des reichen Bürgers in ihrer gewaltsamen Radikalität offengelegt und verweisen dabei umso mehr auf die Inkommensurabilität des Getauschten.72

Im Dolopathos und der Leipziger Prosafassung fokussiert sich die Handlung auf die weibliche Protagonistin. Durch die vornehmlich inhaltlichen Kürzungen in den Gesta-Fassungen, die wiederum vor allem im zweiten Erzählabschnitt Erweiterungen aufgrund eines Kohärenzbedürfnisses hervorrufen, kommt es zu einer ausgewogenen Figurendarstellung von Frau und Ritter. Die aufgezeigten Kürzungen betreffen vor allem Erklärungen für unbarmherzige und geldsüchtige Handlungsmotivationen der Figuren, wodurch das immense Gewaltpotential in den einzelnen Episoden stärker ausgestellt und in den Mittelpunkt gerückt wird.

71 Dolopathos, S. 66, 19-23, und Leipziger Prosafassung, S. 148.

72 Kiening (2019), S. 313: «Auch braucht der das Geld verleihende Bürger oder Kaufmann keinen Grund mehr, um auf eine rigorose Durchsetzung seines Rechtsanspruchs zu dringen; er verkörpert einfach per se diesen Anspruch; er repräsentiert, wenn man so sagen will, das strukturelle Übel, das den Ritter und das Paar gefährdet.» 


\section{Organisationsformen von Wissen}

Abbreviationen können auch in generell kürzeren Erzählformen wie dem Typus «Fleischpfand als Gestaltungsprinzip eingesetzt werden und zu Neuordnung, Pointierungen und Akzentsetzungen dienen. Da in diesen Formen des Erzählens grundsätzlich auf ausführliche inhaltliche, psychologische und rhetorische Ausschmückungen verzichten wird, sind Kürzungen hier zugleich mit einer Umorganisation von Wissen und einer Verlagerung beziehungsweise einem Spiel von Sinnkonstitutionen verbunden; sie zeigen sich dabei nicht nur auf der Ebene der histoire, sondern auch auf der Ebene des discours und verbinden Formen der Rezeption mit textueller Reproduktion. ${ }^{73}$ In den vorliegenden Fällen ist zu beachten, ob es sich um eine Herauslösung aus einem größeren Erzählkomplex handelt (wie beim Dolopathos) oder aus einer Exempelsammlung (wie den Gesta Romanorum) beziehungsweise um die Überlieferung als Einzeltext (wie Kaiser Lucius' Tochter). Gerade im Fall des Dolopathos lassen sich in der verkürzten Leipziger Prosafassung noch Reflexe der ausgesparten Rahmenerzählung finden. Es geht dabei weniger um Abhängigkeitsverhältnisse als vielmehr um das Changieren zwischen Bekanntem und Neuem, das immer auch den intellektuellen Kontrakt) miteinschließen und anregen kann. Allen Versionen gemeinsam ist die Komponente der Gemachtheit, d.h. der nicht zufälligen Kürzung von Handlungsteilen, wodurch aktives und passives Figurenhandeln hervorgehoben und Zeitlichkeit als Strukturgerüst wegfallen können. Die Kürzungen sind teilweise auch an Erweiterungen gebunden, die nicht nur Motivationslücken zu schließen versuchen, sondern neue Motivationen hinzufügen, um vorhandene Konstellationen und auch Kippfiguren $\mathrm{zu}$ verdeutlichen, wie beispielsweise die Aspekte von Geiz, Gewalt und Ökonomie.

73 Vgl. zu dieser Feststellung in Bezug auf Abbreviationen in der höfischen Epik am Beispiel der Nibelungenklage Frick (2018), S. 48. 


\section{Bibliographie}

\section{Primärliteratur}

Dolopathos $=$ Historia septem sapientium II. Johannis de Alta Silva Dolopathos sive De rege et septem sapientibus, nach den festländischen Handschriften kritisch hg.v. Alfons Hilka, Heidelberg 1913 (Sammlung mittellateinischer Texte 5).

GR Dick = Die Gesta Romanorum, nach der Innsbrucker Handschrift vom Jahre 1342 und vier Münchner Handschriften, hg.v. Wilhelm Dick, Erlangen / Leipzig 1890 (Erlanger Beiträge zur englischen Philologie 7).

GR Oesterley = Gesta Romanorum, hg.v. Hermann Oesterley, Berlin 1872.

$\mathrm{KLT}=\mathrm{Diß}$ ist von Kaiser Lucius tochter wie mit listen yr er enthielt vnd si doch ain ritter erwarb mit listen, in: Die deutsche Märendichtung des 15. Jahrhunderts, hg.v. Hanns Fischer, München 1966 (MTU 12), S. 71-88.

Leipziger Prosafassung = Märchen und Sagen, in: Altdeutsche Blätter, Bd. 1, hg.v. Moritz Haupt, Leipzig 1836, S. $143-149$.

Shakespeare, William: The Merchant of Venice. Der Kaufmann von Venedig. Englisch / Deutsch, übers., komm. u. hg.v. Barbara Puschmann-Nalenz, Stuttgart 2015 (RUB 9800).

\section{Forschungsliteratur}

Bildhauer, Bettina: If you prick us do we not bleed? Making the body in Mären, in: Mark Chinca / Timo Reuvekamp-Felber / Christopher Young (Hgg.): Mittelalterliche Novellistik im europäischen Kontext. Kulturwissenschaftliche Perspektiven, Berlin 2006 (Beiheft zur ZfdPh 13), S. 148-169.

von Bloh, Ute: Die Sexualität, das Recht und der Körper. Kontrollierte Anarchie in vier mittelalterlichen Mären, in: Ulrike Gaebel / Erika Kartschoke (Hgg.): Böse Frauen Gute Frauen. Darstellungskonventionen in Texten und Bildern des Mittelalters und der Frühen Neuzeit, Trier 2001 (LIR 28), S. 75-88.

Bumke, Joachim / Peters, Ursula (Hgg.): Retextualierung in der mittelalterlichen Literatur, Berlin 2005 (ZfdPh 124, Sonderheft).

Diederichsen, Uwe: Das Fleischpfand, in: Ulrich Mölk (Hg.): Literatur und Recht. Literarische Rechtsfälle von der Antike bis in die Gegenwart, Göttingen 1996, S. $138-149$.

Fischer, Hanns: Einleitung, in: ders. (Hg.): Die deutsche Märendichtung des 15. Jahrhunderts, München 1966 (MTU 12), S. IX-XXVI.

Frick, Julia: abbreviatio. Zur historischen Signifikanz von Kürzungsfunktionen in der mittelhochdeutschen Epik des 13. Jahrhunderts. Eine Projektskizze, in: PBB 140 (2018), S. 23-50. 
Gerdes, Udo: Art. Gesta Romanorum, in: ${ }^{2}$ VL Bd. 3 (1981), Sp. 25-34.

Gerdes, Udo: Art. Sieben weise Meister, in: ${ }^{2}$ VL Bd. 8 (1992), Sp. 1174-1189.

Geulen, Eva: Worthörig wider Willen. Darstellungsproblematik und Sprachreflexion in der Prosa Adalbert Stifters, München 1992 (Cursus 7).

Grubmüller, Klaus: Kaiser Lucius' Tochter. Zur Vorgeschichte von Shakespeares Kaufmann von Venedig, in: Ulrich Mölk (Hg.): Literatur und Recht. Literarische Rechtsfälle von der Antike bis in die Gegenwart, Göttingen 1996, S. 94-137.

Hasebrink, Burkhard: Die Ambivalenz des Erneuerns. Zur Aktualisierung des Tradierten im mittelalterlichen Erzählen, in: Ursula Peters / Rainer Warning (Hgg.): Fiktion und Fiktionalität in den Literaturen des Mittelalters. Jan-Dirk Müller zum 65. Geburtstag, München 2009, S. 205-217.

Haug, Walter: Exempelsammlungen im narrativen Rahmen. Vom Pañcatantra zum Dekameron, in: ders. / Burghart Wachinger (Hgg.): Exempel und Exempelsammlungen, Tübingen 1991 (Fortuna vitrea 2), S. 265-288.

Henkel, Nikolaus: Reduktion als poetologisches Prinzip. Verdichtung von Erzählungen im lateinischen und deutschen Hochmittelalter, in: Franz-Josef Holznagel / Jan Cölln (Hgg.): Die Kunst der brevitas. Kleine literarische Formen des deutschsprachigen Mittelalters, Berlin 2017 (Wolfram-Studien XXIV), S. 27-55.

Hilka, Alfons: Einleitung, in: Historia septem sapientium II. Johannis de Alta Silva Dolopathos sive De rege et septem sapientibus, nach den festländischen Handschriften kritisch hg.v. dems., Heidelberg 1913 (Sammlung mittellateinischer Texte 5), S. VII-XIV.

Kiening, Christian: Versuchte Frauen. Narrative Muster und kulturelle Konfigurationen, in: Jan-Dirk Müller (Hg.): Text und Kontext. Fallstudien und theoretische Begründungen einer kulturwissenschaftlich angeleiteten Mediävistik, München 2007, S. 7798.

Kiening, Christian: Verletzende Worte - verstümmelte Körper. Zur doppelten Logik spätmittelalterlicher Kurzerzählungen, in: ZfdPh 127 (2008), S. 321-335.

Kiening, Christian: Ästhetik der Struktur. Experimentalanordnungen mittelalterlicher Kurzerzählungen (Fleischpfand, Halbe Birne), in: Annette Gerok-Reiter u. a. (Hgg.): Ästhetische Reflexionsfiguren in der Vormoderne, Heidelberg 2019 (GermanischRomanische Monatsschrift. Beihefte 88), S. 303-328.

Köbele, Susanne: Registerwechsel. Wiedererzählen, bibelepisch (Der Saelden Hort, Die Erlösung, Lutwins Adam und Eva), in: Bruno Quast/ Susanne Spreckelmeier (Hgg.): Inkulturation. Literarische Strategien bibelepischen Schreibens in Mittelalter und Früher Neuzeit, Berlin / Boston 2017 (Literatur - Theorie - Geschichte 12), S. 167-202.

Lixfeld, Hannjost: Art. Fleischpfand, in: Enzyklopädie des Märchens. Bd. 4 (1984), Sp. 12561262. 
Losert, Kerstin: Überschreitung der Geschlechtergrenzen? Zum Motiv der Frau in Männerkleidern im Dolopathos des Johannes de Alta Silva und anderen literarischen Texten des Mittelalters, Bern 2008 (Lateinische Sprache und Literatur des Mittelalters 43 ).

Lundt, Bea: Weiser und Weib. Weisheit und Geschlecht am Beispiel der Erzähltradition von den Sieben weisen Meistern (12.-15. Jahrhundert), München 2002.

Lundt, Bea: Art. Sieben weise Meister, in: Enzyklopädie des Märchens Bd. 12 (2012), Sp. 656-660.

Mackert, Christoph: Die Leipziger Textsammlung Ms 1279 und die Schriftproduktion eines Leipziger Augustinerchorherren im mittleren 15. Jahrhundert, in: Eckhart Conrad Lutz (Hg.): Finden - Gestalten - Vermitteln. Schreibprozesse und ihre Brechungen in der mittelalterlichen Überlieferung, Berlin 2012 (Wolfram-Studien XXII), S. 219-263.

Pensel, Franzjosef: Verzeichnis der deutschen mittelalterlichen Handschriften in der Universitätsbibliothek Leipzig, zum Druck gebracht von Irene Stahl, Berlin 1998 (DTM 70,3).

Puschmann-Nalenz, Barbara: Nachwort, in: Shakespeare, William: The Merchant of Venice. Der Kaufmann von Venedig. Englisch / Deutsch, übersetzt, kommentiert und hg.v. ders., Stuttgart 2015 (RUB 9800), S. 249-282.

Redzich, Carola: Der Dolopathos des Johannes de Alta Silva. Zur Legitimation des Erzählens von Geschichte(n), in: Regula Forster / Romy Günthart (Hgg.): Didaktisches Erzählen. Formen literarischer Belehrung in Orient und Okzident, Frankfurt a. M. u. a. 2010, S. 207-226.

Reichlin, Susanne: Ökonomien des Begehrens, Ökonomien des Erzählens. Zur poetologischen Dimension des Tauschens in Mären, Göttingen 2009 (Historische Semantik 12).

Schallenberg, Andrea: Gabe, Geld und Gender. Ein Beitrag zur Poetik der Geschlechterdifferenz in der mittelhochdeutschen Verserzählung, in: Mark Chinca / Timo Reuvekamp-Felber / Christopher Young (Hgg.): Mittelalterliche Novellistik im europäischen Kontext. Kulturwissenschaftliche Perspektiven, Berlin 2006 (Beiheft zur ZfdPh 13), S. 76-107.

Schallenberg, Andrea: Spiel mit Grenzen. Zur Geschlechterdifferenz in mittelhochdeutschen Verserzählungen, Berlin 2012 (Deutsche Literatur. Studien und Quellen 7).

Schamschula, Eleonore: Das Fleischpfand. Mot. J 1161.2 in Volkserzählung und Literatur, in: Fabula. Zeitschrift für Erzählforschung 25 (1984), S. 277-295.

Scherrer, Christine: Heikle Versprechen. Bürgschaft und Fleischpfand in der Literatur, Bern u. a. 2016 (Deutsche Literatur von ihren Anfängen bis 1700 51).

Steinmetz, Ralf-Henning: Exempel und Auslegung. Studien zu den Sieben weisen Meistern, Freiburg / Schweiz 2000 (Scrinium Friburgense 14). 
Weigel, Sigrid: 〈Shylock〉 und «Das Motiv der Kästchenwahl〉. Die Differenz von Gabe, Tausch und Konversion im Kaufmann von Venedig, in: Hartmut Böhme / Klaus R. Scherpe (Hgg.): Literatur und Kulturwissenschaften. Positionen, Theorien, Modelle, Reinbek b. H. 1996 (Rowohlts Enzyklopädie 575), S. 112-133.

Weiske, Brigitte: Die Gesta Romanorum und das Solsequium Hugos von Trimberg, in: Walter Haug / Burghart Wachinger (Hgg.): Exempel und Exempelsammlungen, Tübingen 1991 (Fortuna vitrea 2), S. 173-207.

Weiske, Brigitte: Gesta Romanorum. Bd. 1: Untersuchungen zu Konzeption und Überlieferung, Tübingen 1992 (Fortuna vitrea 3).

Wolpers, Theodor: Shakespeares The Merchant of Venice. Literarische Aspekte und dargestellte Gerechtigkeit, in: Ulrich Mölk (Hg.): Literatur und Recht. Literarische Rechtsfälle von der Antike bis in die Gegenwart, Göttingen 1996, S. 150-185.

Worstbrock, Franz Josef: Wiedererzählen und Übersetzen, in: Walter Haug (Hg.): Mittelalter und Frühe Neuzeit. Übergänge, Umbrüche und Neuansätze, Tübingen 1999 (Fortuna vitrea 16), S. 128-142.

Zacke, Birgit u. a. (Hgg.): Text und Textur. WeiterDichten und AndersErzählen im Mittelalter, Oldenburg 2020 (BmE Themenheft 5). 



\section{Beiträgerinnen und Beiträger}

Prof. Dr. Martin Baisch, Universität Hamburg, Fakultät für Geisteswissenschaften, Fachbereich Sprache, Literatur, Medien I, Institut für Germanistik, Überseering 35, Postfach \#15, D-22297 Hamburg, E-Mail: martin.baisch@uni-hamburg.de

Prof. Dr. Ricarda Bauschke, Heinrich-Heine-Universität Düsseldorf, Institut für Germanistik, Abteilung III: Deutsche Sprache und Literatur des Mittelalters, Universitätsstraße 1/Geb. 24.54.00.82, D-40225 Düsseldorf, E-Mail: bauschke@hhu.de

Dr. Richard Fasching, Universität Zürich, Deutsches Seminar, Schönberggasse 9, CH8001 Zürich, E-Mail: richard.fasching@ds.uzh.ch

Dr. Julia Frick, Universität Zürich, Deutsches Seminar, Schönberggasse 9, CH-8001 Zürich, E-Mail: julia.frick@ds.uzh.ch

MA Oliver Grütter, Universität Zürich, Deutsches Seminar, Schönberggasse 9, CH-8001 Zürich, E-Mail: oliver.gruetter@ds.uzh.ch

Prof. Dr. Thomas Haye, Georg-August-Universität Göttingen, Zentrum für Mittelalterund Frühneuzeitforschung, Abt. für Lateinische Philologie des Mittelalters und der Frühen Neuzeit, Humboldtallee 19, D-37073 Göttingen,

E-Mail: thomas.haye@phil.uni-goettingen.de

Prof. Dr. Susanne Köbele, Universität Zürich, Deutsches Seminar, Schönberggasse 9, CH8001 Zürich, E-Mail: susanne.koebele@ds.uzh.ch

Prof. Dr. Cordula Kropik, Universität Basel, Deutsches Seminar, Nadelberg 4, CH-4051 Basel, E-Mail: cordula.kropik@unibas.ch

apl. Prof. Dr. Sandra Linden, Eberhard-Karls-Universität Tübingen, Deutsches Seminar, Wilhelmstraße 50, D-72074 Tübingen, E-Mail: sandra.linden@uni-tuebingen.de

Prof. Dr. Christiane Reitz, Konstanzer Str. 5, D-10707 Berlin, E-Mail: christiane.reitz@uni-rostock.de

Prof. Dr. Hans Jürgen Scheuer, Humboldt-Universität zu Berlin, Institut für deutsche Literatur, Unter den Linden 6, D-10099 Berlin, E-Mail: scheuerh@hu-berlin.de

Dr. Raphael Schwitter, Rheinische Friedrich-Wilhelms-Universität Bonn, Institut für Klassische und Romanische Philologie, Abteilung für Griechische und Lateinische Philologie, Am Hof 1e, D-53113 Bonn, E-Mail: raphael.schwitter@uni-bonn.de

Dr. Pia Selmayr, Universität Zürich, Deutsches Seminar, Schönberggasse 9, CH-8001 Zürich, E-Mail: pia.selmayr@ds.uzh.ch 
Prof. Dr. Michael Stolz, Universität Bern, Institut für Germanistik, Länggassstrasse 49, CH-3000 Bern 9, E-Mail: michael.stolz@germ.unibe.ch

Prof. Dr. Almut Suerbaum, University of Oxford, Faculty of Medieval and Modern Languages, Somerville College, GB-Oxford, OX2 6HD,

E-Mail: almut.suerbaum@some.ox.ac.uk

Prof. Dr. Richard Trachsler, Universität Zürich, Romanisches Seminar, Zürichbergstrasse 8, CH-8032 Zürich, E-Mail: richard.trachsler@uzh.ch

Prof. Dr. Jörg Wesche, Georg-August-Universität Göttingen, Seminar für Deutsche Philologie, Käte-Hamburger-Weg 3, D-37073 Göttingen,

E-Mail: joerg.wesche@uni-goettingen.de 


\section{Verzeichnis der Autoren und Werke}

Acta diurna 191, 198

Acta Sanctorum 230, 240, $243 \mathrm{f}$.

Adenet le Roi

$$
\text { - Cleomadés 69,77f. }
$$

Aelian

$$
\text { - Varia Historia } 48
$$

Aelius Donatus 20

- Commentum Adelphoe Terenti 130

Albert von Stade

- Troilus 191, 202

Albrecht von Scharfenberg

- Jüngerer Titurel 351-357

Alexander und Anteloie 427

Alte Mutter 415, 419

Ambraser Heldenbuch $\quad 88,96 \mathrm{f}$.

Andreas Gryphius $30,165,167,170,173$, $176 \mathrm{f}$.,

- Carolus Stuardus 174, 178

- Catharina von Georgien 166, 174

- Die geliebte Dornrose 171, 175

- Horribilicribrifax 166

- Leo Armenius 164, 166, $168 \mathrm{f}$.

- Majuma 174

- Papinian 163

- Piastus 174

- Verlibtes Gespente $171 \mathrm{f}$.

Anseïs de Carthage 71

Apuleius

- Apologia 45
Aquila Romanus 131

- De figuris sententiarum et elocutionis $128 \mathrm{f}$.

Archilochos 153

Aristoteles

- Rhetorica 128

Auctor ad Herennium 18f., 128, 328

Ausonius 48, 135

- Caesares 150

- Eclogae $150 \mathrm{f}$.

- Epitaphia heroum qui bello Troico interfuerunt 150

- Mosella 151

- Ordo urbium nobilium 150

- Parentalia 150

- Periochae Homeri 50

Baebius Italicus

- Ilias Latina 28, 46-48, 50-56, 60, 190 f., 194, 295

Baudri von Bourgueil 191, 202

Belle Hélène de Constantinople 69, $73 \mathrm{f}$., 79

Benoît de Ste-Maure $\quad 185,197$

- Roman de Troie 183, 191, 200, 202, 205

Bernard von dem Geist (Bernardus Geystensis) 203

- Palpanista 202

Bertrand du Guesclin 72

Boccaccio 230, 236

- Decamerone 229 
Caesarius von Heisterbach 253

- Dialogus Miraculorum 249

Calpurnius Siculus

- Carmina Einsidlensia 57

Catull 153, 155

- Carmina 152

Carmina Burana 197, 203

Carmina Latina Epigraphica 146-148

Celtis, Konrad 291

Chrétien de Troyes 20

- Cligès 73,78

- Conte du Graal 346,348, 359

Cicero 17-20

- Brutus 49

- De inventione 16

- In Catilinam 129

- In Verrem 128

- Partitiones oratoriae 128

- Pro L. Flacco 126

Clara Hätzlerin

- Liederbuch der Clara Hätzlerin 219

Claudian $261 \mathrm{f}$., 281

Codex Salmasianus 143

Cycle des Lorrains 69

Dante

- Divina Commedia 287

Dares Phrygius 196,201-203

- Acta diurna belli Troiani 191, 198

- De excidio Troiae historia 190

De Lucii filia et milite 451

De sublimitate 128

Dedekind, Friedrich

- Christlicher Ritter 302-304

Dictys Cretensis

- Ephemeridos belli Troiani libri 190

Dietrich Schernberg 237

- Schön spiel von Frau Jutten 236
Dietrich von Apolda 242, 253

- Vita des Heiligen Dominikus 240, 243

- Vita S. Elyzabeth 240

(Pseudo-)Dionysius Areopagita 224

Dracontius

- De laudibus Die 133

Dresdener Heldenbuch 377f., 394-397, 400-402

Dürer, Albrecht 302

Eberhard der Deutsche

- Laborintus 19,214

Eberhard von Cersne

- Der Minne Regel 94

Meister Eckhart 217f., 221-225

Epikur 49

Erasmus von Rotterdam

- Enchiridion militis Christiani 302

Eugippius

- Vita et translatio sancti Severini 248, 250

Evangelium Nicodemi 281,299f., 309

Evrard de Conty 67

Excidium Troiae 190

Fioretti di San Francesco 235

Floriant et Florette 79

Florus 49

Formula Concordiae 313

Frechulf von Lisieux

- Historia Daretis Frigii de origine Francorum 189

Das Gänslein 419

Galfried von Vinsauf (Geoffroi de Vinsauf) 22, 193, 216, 225, 407, 426

- Documentum de modo et arte dictandi et versificandi 325

- Poetria nova 19, 21, 192, 216, 224, 325, 327 
Galien le Restoré 69

Die Geburt Christi 411

Gérard de Nevers 79

Gesta Romanorum 436, 449, 451 f., 457

Gilles de Chin 79

Giovanni Fiorentino 434

- Il Pecorone 434

Giovanni Mario Filelfo 265, 268-270,

274-276

- Amyris 262

- Cosmias 262, 264, 267

- De voluminum suorum numero 261

- Dentraretos 262

- Felsineis 262

- Herculeia 262

- Laurentias 32,261-264,266f., $271,277 \mathrm{f}$.

- Martias 262

- Minerva 262

Godefroi de Bouillon 74

Goethe, Johann Wolfgang

- Faust 163

Gottfried von Reims 191, 202

Gottfried von Straßburg 334f., 337

- Tristan 20, 33, 126, $334 \mathrm{f} ., 337 \mathrm{f}$., 366 f., 409

Granum sinapis 222

Guillaume de Palerme 70

Guillaume Leroy 77

Hadamar von Laber

- Die Jagd 94, 118

Hartmann von Aue 20, 97, 105, 117

- Erec $78 \mathrm{f}$.

- Klage 29,85-91, 93-96, 98, $100 \mathrm{f} ., 104,106-108,110-116$, 118

Die heiligen Farben 411

Heinrich von München

- Weltchronik 427
Heinrich von Pforzen

- Der Pfaffe in der Reuse 421

Heinrich von Veldeke

- Eneasroman 20,185, 336

Helius Eobanus Hessus 282, 286, 292,

294 f., 299

- Victoria Christi ab inferis 32, 281, 283-285, 287-291, 293, 295-299, 301-303, 305, 307, 309, $311,313 \mathrm{f}$.

Herbort von Fritzlar 24f., 196, 204, 206,

214,224

- Liet von Troye 31, 183-189, $192-195,197-200,202,205,332$

Hesiod 153

Hildebert von Lavardin 191, 204

- De humano semine 203

Hildebrandslied 396

Historia Daretis Frigii 189, 191

Hölderlin, Friedrich 323

Homer 47, 49, 150, 190

- Illias 29, 48, 50-56, 58-60, 64, $183,191,263$

- Odyssee 46, 263

Horaz 20, 153, 194, 216

- Ars poetica 11,215

- Epistulae 131

- Saturae 131

Hrotsvit von Gandersheim

- Passio Sancti Dionisii egregii martyris 291

Hugo Primas von Orléans 191, 202

Hyginius 197

Ich solt mich leren lossen 222

Ilias Latina, vgl. Baebius Italicus

Iulius Rufinianus

- De schematibus lexeos 129

Jacobus de Voragine

- Legenda Aurea 239, 243, 248

Jean de Mailly 
- Abbreviatio in gestis et miraculis sanctorum 239

Jean Wauquelin 69, 74

Johann von Konstanz 113

- Der werden Minne Lehre 94

Johannes de Alta Silva

- Dolopathos 435, 438-448, 451457

Johannes Tauler $217 \mathrm{f}$, , 223, 225

Johannes von Garlandia

- Parusiana Poetria 326

Joseph Iscanus 191

- Frigii Daretis Ylias 190, 202

Kafka, Franz 323

Kaiser Lucius' Tochter 435f., 449-452, 454,457

Keller, Gottfried 230, 232

- Sieben Legenden 229

Konrad von Würzburg 233

- Herzmäre 427

- Trojanerkrieg 191,353f., 354

Kosegarten, Ludwig Gotthard 229

Lamprecht von Regensburg $253 \mathrm{f}$.

- Sanct Francisken Leben 250252

Laurin 395-397

Legenda sancti dominici vulgariter 242

Leipziger Prosafassung 436-438, 442$448,452-457$

Livius

- Ab urbe condita 49

Livius Andronicus

- Odusia 46

Lohengrin 351-353

Lucan 153

- Iliacon 50

Lukrez

- De rerum natura 131

Luther, Martin 32, 229, 281, 284, 299,

302-304
- Galaterbrief-Kommentar 305

- Operationes in Psalmos $306 \mathrm{f}$.

- Sterbesermon $306 \mathrm{f}$.

- Torgauer Predigt 307-309,312f.

Macrobius

- Saturnalia 132

Martial

- Carmina 49, 152

Martin von Troppau 236

Matthäus von Vendôme (Matthieu de

Vendôme) 19, 193, 326

- Ars versificatoria 21, 192, 325

Maximianus 204

Mechthild von Magdeburg

- Das Fließende Licht der Gottheit 217

Melanchthon, Philipp 299f., 309, 313

- Scholia in Epistulam Pauli ad Colossenses 300

Menander 153

Der Minne Porten 419

Minneburg 118

Der Mönch als Liebesbote 411

Mutianus Rufus $281 \mathrm{f}$., 314

Naevius

- Bellum Punicum 130

Nibelungenklage 25, 33, 321, 332-334, $339,387,457$

Nibelungenlied $321 \mathrm{f}$., 333, 387

Odo von Magdeburg

- Ernestus 277

Ortnit $388,396 \mathrm{f}$.

Ovid $49,57,150,187,191,196,261,281$, 289,301

- Amores 143, 203, 275

- Ars amatorial 197, 203

- Epistulae 149

- Fasti 130, 149

- Heroides 143, 204 
- Metamorphoseon libri 138, 144f., 197, 288

- Remedia amoris 143

Pamphilus de Amore 204

Pamphilus und Gliscerium 204

Pascal, Blaise

- Les Provinciales 9

Petron

- Satyricon 47

- Cena Trimalchionis 58

Petrus Sanctonensis 191, 202

- Viribus arte minis 203

Pentadius

- De Narcisso 143-145

Pergama flere volo 191, $197 \mathrm{f}$., $202 \mathrm{f}$.

Philippe de Vigneulles 72

- Geste des Lorrains 73

Philochoros 49

Pierre Durand

- Guillaume de Palerme 70

Pindar 153, 294

Plautus 204, 276

- Amphitruo 130

- Captivi 129

- Persa 129

Plinius

- Epistulae 132

Priscian

- Praeexercitamina 126

Quintilian 19, 93, 193, 238

- Institutio oratoria $10 \mathrm{f} ., 128 \mathrm{f}$., 296, 431

Raimundus Lullus

- Breviculum 12

Rappoltsteiner Parzifal 34, $345 \mathrm{f}$., $348 \mathrm{f}$., 352, 357, 359-363, $369 \mathrm{f}$.

Reine Berte 79

Rhetorica ad Herennium, vgl. Auctor ad

Herrenium

Richard sans Peur 80
Ried, Hans $\quad 88,97$

Rudolf von Ems

- Wilhelm von Orlens 332, 351, 354

Schatzgeyer, Kaspar 311

Schiller, Friedrich

- Die Räuber 163

Der schwangere Müller 410, 413

Sedulius 133

- Carmen paschale 132

Seneca 132

- Apocolocyntosis 57

- Epistulae 129

- Medea 137

- Phoenissae 131, 137

Servius

- Vergil-Kommentar (Servii Grammatici qui feruntur In Vergilii carmina commentarii) 47, 296, 326

Shakespeare, William

- The Merchant of Venice 433435

Sidonius Apollinaris $\quad 146,151,156$

- Carmina 134-139, 141f., 152155

- Epistulae 136, 143, 149

Die Sieben weisen Meister 435, $438 \mathrm{f}$.

Simon Aurea Capra

- Ylias $191 \mathrm{f} ., 195,197,202 \mathrm{f} ., 205$

Spangenberg, Johann $\quad 281,283$ f., 290 -

309, 311-314

- Ain new Trostbüchlein 302

- Catechismus, et institutio Christianae religionis 308

- Evangelia dominicalia 283, $303 \mathrm{f}$., 308, 311, 313

- Margarita theologica 300 
- Triumphus Christi 32, $283 \mathrm{f}$., 290-292, 295f., 298, 303, 306, 308 f., 311-314

- Vom Christlichen Ritter $303 \mathrm{f}$.

Statius 153,187

- Achilleis 197

- Silvae 50,131

- Thebais 131, 263, $276 \mathrm{f}$.

Stesichoros 153

Stricker

- Der betrogene Blinde 410

- Die Frauenehre 94, 118

Sueton

- Divus Iulius 129

Sulpicius Apollinaris 49, 276, 276

Sulpicius Severus 235, 249, 255

- Vita Sancti Martini 244, 247

Tabulae Iliacae 29, 47, 60

Terenz 49, 276

- Andria 129

Theseus de Cologne 71

Theophrast 49

Theopomp 49

Thomas von Celano (Tommaso da

Celano) 250

- Vita prima di S. Francesco d'Assisi 251

Thomas von Kandelberg 410-412

Tibull

- Carmina 149

Tor Hunor 419

(Pseudo-)Turpin 74

Ugolino Verino

- Carlias 277
Ulrich von Etzenbach

- Alexander 332

- Friedrich von Schwaben

332

Ulrich von dem Türlin

- Arabel 351

- Diu Crône 351 f., 354

Ulrich von Liechtenstein

- Frauenbuch 113

- Frauendienst 94

Ulrich von Türheim

- Rennewart 351

- Tristan-Fortsetzung 332

Usener, Hermann

- Legenden der Pelagia 232f., 236, 281, 289

Vergil 47, 49, 57, 142, 153, 191, 261, $264 \mathrm{f}$.

- Aeneis 59, 130, 263, $276 \mathrm{f}$.

- Georgica 151, 293

Vitalis von Blois

- Geta 204

Virginal 34, 377-380, 382, 385-387,

392-396, 398, 401, 403

Von dem überschalle (Über die Übertöne) 219 f., 222 f., 225

Walther von Châtillon

- Alexandreis 202, 277

Der Wirt der Seele 411

Wolfdietrich 396

Wolfram von Eschenbach 188,372

- Parzival 346, 348f., 351-355, 359, 361, 366, 420, 428

- Willehalm 351-354

Die zwei Beichten B 411 



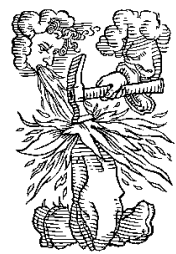

Das Signet des Schwabe Verlags ist die Druckermarke der 1488 in Basel gegründeten Offizin Petri, des Ursprungs des heutigen Verlagshauses. Das Signet verweist auf die Anfänge des Buchdrucks und stammt aus dem Umkreis von Hans Holbein. Es illustriert die Bibelstelle Jeremia 23,29:

«Ist mein Wort nicht wie Feuer, spricht der Herr, und wie ein Hammer, der Felsen zerschmeisst?» 


\section{abbreviatio}

Historische Perspektiven auf ein rhetorisch-poetisches Prinzip Julia Frick / Oliver Grütter (Hg.)

Dieser Band versteht das literarische Verfahren der abbreviatio als einen bewussten Vorgang der Reduktion und als eine sinnstiftende Tätigkeit des Verdichtens umfangreicherer Bezugstexte. Er führt interdisziplinäre sowie komparatistische Perspektiven auf das rhetorisch-poetische Prinzip der Kürzung zusammen und arbeitet so über einzelne Textsorten hinausgehend Formen und Funktionen heraus.

Anhand der Analyse antiker, mittelalterlicher und frühneuzeitlicher Texte profilieren die Beiträge systematische und historische Aspekte der literarischen Kürzung im Spannungsfeld von Latinität und Volkssprache.

\section{Die Herausgeberin und der Herausgeber}

Julia Frick arbeitet in der Abteilung Ältere deutsche Literaturwissenschaft an der Universität Zürich. Ihre Forschungsschwerpunkte liegen im Bereich der lateinisch-deutschen Bilingualität in Mittelalter und Früher Neuzeit, der höfischen Epik, der Intermedialität der Druckgraphik in der Frühen Neuzeit sowie der historischen Poetik. Oliver Grütter arbeitet in der Abteilung für Ältere deutsche Literaturwissenschaft an der Universität Zürich. Zu seinen Forschungsschwerpunkten gehören die neulateinische Dichtung im deutschen Sprachraum, Literatur im konfessionellen Zusammenhang, Modelle literarischer Selbstsorge sowie Friedrich Hölderlin.

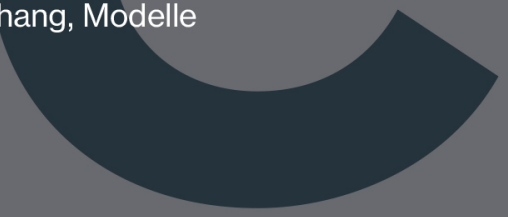

\section{SCHWABE VERLAG}

www.schwabe.ch

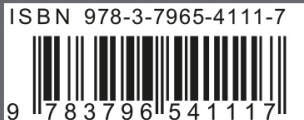

